\title{
Intentional Design: Reaching the Most Excluded Girls in the Poorest Communities-A Guide for Practitioners and Advocates
}

Judith Bruce

Population Council

Sophie Soares

Population Council

Follow this and additional works at: https://knowledgecommons.popcouncil.org/departments_sbsr-pgy How does access to this work benefit you? Let us know!

\section{Recommended Citation}

Bruce, Judith and Sophie Soares. 2021. "Intentional Design: Reaching the Most Excluded Girls in the Poorest Communities-A Guide for Practitioners and Advocates." New York: Population Council. 
The Adolescent Girls Community of Practice, established by the Population Council in 2013, helps strengthen the capacity of different actors to design, implement, and evaluate effective, scalable programs that build the health, social, economic, and cognitive assets of adolescent girls. We work with institutions that range from large multilateral and bilateral organizations and governments to small communitybased organizations and national networks.

The Population Council confronts critical health and development issues-from stopping the spread of HIV to improving reproductive health and ensuring that young people lead full and productive lives. Through biomedical, social science, and public health research in 50 countries, we work with our partners to deliver solutions that lead to more effective policies, programs, and technologies that improve lives around the world. Established in 1952 and headquartered in New York, the Council is a nongovernmental, nonprofit organization governed by an international board of trustees.

The Population Council is committed to expanding programming on the ground for girls, anchored in evidence, in partnership with community practitioners, and with the needs of specific segments of girls at the center. For more information on evidence-based approaches to adolescent programming and an overview and links to tools and videos, please visit: popcouncil.org/girl-centeredprogram-resources.

\section{NoVo Foundation}

create. change.

This publication is made possible by funding from the NoVo Foundation.

(c) 2021 The Population Council, Inc.

Suggested citation: Judith Bruce and Sophie Soares. 2021. Intentional Design: Reaching the Most Excluded Girls in the Poorest Communities: A Guide for Practitioners and Advocates. New York: Population Council. 


\section{CONTENTS}

Abbreviations and Acronyms $\quad 3$

Acknowledgments: Foundational Partnerships 4

Preface: Investing in Adolescent Girls $\quad 8$

Chapter 1 Optimizing Investment in the Most Excluded Girls in Their Home Communities 14

Chapter 2 Using Key Data to Identify Regions with High Concentrations of Off-Track Girls

Chapter 3 Finding the Walkable Community and Laying the Basis for Program Scale-Up and Creating Clusters of Change

Chapter 4 Identifying the Full "Universe" of Girls in a Walkable Community and Dividing Them into Meaningful Segments for Girl-Centered Programming Using the Girl Roster ${ }^{\mathrm{TM}}$

Chapter 5 Segmentation and Planning: How to Use Girl Roster Results to Identify Key Segments of Girls and Make Overarching Program Decisions

Chapter 6 Probing Deeper into Community Resources and Linking Them Intentionally to Segments of Girls

Chapter 7 A Review of the Tools to Support the Basic Model for an Intentional Design Approach

Chapter 8 Intentional Design in Action: Reaching Indigenous Adolescent Girls in Guatemala

Chapter 9 The Practitioner Experience: Intentional Design on the Ground

1 IMAGEN: Shifting Native American Youth Programming to a Gender Focus through Intentional Design Methods

2 Intentional Design as a Catalyst for Change in Belize Migration Zones and Later Yucatán, Mexico

3 An Assessment of Plan International El Salvador's GAD (Gender and Development) Programming-Using Evidence for Redirection after the Initial Implementation

4 A Network of Intentional Design Adopters Working for Adolescent Girls' Futures in Post-Earthquake Haiti and Beyond

5 Fine-Tuning the Batonga Foundation's Approach to Reaching Girls: Mapping, Targeting, and Training Benin's Future Leaders 
6 Implementing Intentional Design Tools in CSAGE (Community Spaces for Adolescent Girls Empowerment), Northern Nigeria, to Build a New Program and Assess Coverage of an Ongoing Program

7 Implementing the Girl Roster and Community Resource Scan in Sierra Leone: The Foundation of the Sierra Leone Adolescent Girls Network

8 Intentional Design in Homa Bay, Kenya, in the Context of the DREAMS

Partnership

9 Global Communities' Use of Intentional Design to Implement the DREAMS Program-Getting the Correct Value for Money in Highly HIV-Affected Settings in Kenya

10 Lessons from DREAMS Interventions in Matutuíne and Namaacha, Mozambique

11 Investing in Girls in Northern Mozambique

13 Turning a School into the Center of a Movement Using Intentional Design Tools: The SEGA Girls School, Tanzania

14 Intentional Design Builds Up and Coordinates an Existing Community of Practice in Mwanza, Tanzania

15 The Girl Power Project (Just Like My Child Foundation) Moves Forward with Intentional Design to Intensify Regional Impact, Central Uganda

16 Implementation of the Girl Roster in Ezbet Khairallah, Egypt

17 Beginning with the Girl Roster Results from West Bekaa, Lebanon, to Reach the Unreached Girls

18 Proactive Engagement with the Intentional Design and I'm Here Approaches to Ensure Programming Responds to the Needs of the Most Vulnerable Adolescents in Gaziantep, Turkey

19 Implementation of the Girl Roster in Dompu and Sikka, Indonesia

20 The Influence of an Intentional Design Approach on WomenStrong International's Work with Women and Girls in Haiti and Washington, DC

Appendix I Glossary

Appendix II How to Conduct the Community Resource Scan

Appendix III DHS Estimates of the Proportion of the Population in Rural and 


\section{ABBREVIATIONS AND ACRONYMS}

\begin{tabular}{|c|c|}
\hline AGYW & Adolescent Girls and Young Women \\
\hline AIDS & Acquired Immunodeficiency Syndrome \\
\hline AO & Abriendo Oportunidades \\
\hline ASERTTM & Ascertaining Sexual Relationship Types \\
\hline CEDAW & Convention on the Elimination of All Forms of Discrimination Against Women \\
\hline COCODE & Consejo Comunitario de Desarrollo \\
\hline DEMI & Office for the Defense of Indigenous Women \\
\hline DHS & Demographic and Health Survey \\
\hline DRC & Danish Refugee Council \\
\hline DREAMS & Determined, Resilient, Empowered, AIDS-free, Mentored, and Safe \\
\hline FGM & Female Genital Mutilation \\
\hline GiE & Girls in Emergencies Collaborative \\
\hline GPS & Global Positioning System \\
\hline HAGN & Haitian Adolescent Girls Network \\
\hline HIV & Human Immunodeficiency Virus \\
\hline IDP & Internally Displaced Person \\
\hline IMAGEN & Indigenous Adolescent Girls' Empowerment Network \\
\hline INGO & International Nongovernmental Organization \\
\hline IT & Information Technology \\
\hline MEL & Monitoring, Evaluation, and Learning \\
\hline MICS & Multiple Indicator Cluster Survey \\
\hline NGO & Nongovernmental Organization \\
\hline OVC & Orphans and Vulnerable Children \\
\hline PEPFAR & U.S. President's Emergency Plan for AIDS Relief \\
\hline SDGs & Sustainable Development Goals \\
\hline SRH & Sexual and Reproductive Health \\
\hline STI & Sexually Transmitted Infection \\
\hline UN & United Nations \\
\hline UNFPA & United Nations Population Fund \\
\hline UNTF & United Nations Trust Fund to End Violence Against Women \\
\hline WHO & World Health Organization \\
\hline WRC & Women's Refugee Commission \\
\hline
\end{tabular}




\section{Foundational Partnerships}

Many people have been central to the efforts of developing the Intentional Design approach, the Girl Roster, and related tools to provide an evidentiary base from which practitioners can work to reach at-risk adolescent girls. These acknowledgments are not merely recognition of individuals' contributions over these last years but the strongest underscoring that none of this work could have gone forward without the efforts of gifted and dedicated thought partners, technical experts, and moral supporters.

Before acknowledging the individuals who made this work possible, we especially wish to thank the NoVo Foundation and its committed staff for their recognition and deep appreciation of this work. Their co-creation of and passionate engagement in the Adolescent Girls Community of Practice has been vital to our impact on the lives of the most excluded, youngest adolescents on the ground.

My very special thanks to Sophie Soares, my coauthor and partner for the last three years in bringing this publication to fruition. The Population Council's Guatemala teamAngel del Valle and Alejandra Colom in particular-was the first to use Roster-like tools to map communities and include girls in identifying safe and unsafe spaces. Annabel Erulkar employed a house-to-house approach in establishing her benchmark, and now world-famous, programs of Biruh Tesfa and Berhane Hewan in Ethiopia. Andrew Karlyn (serving in Nigeria at the time we started developing these tools) and, later, Craig Savel, Vira David-Rivera, Dana Smiles, Sophie Soares, Omar Robles, and Sarah Blake provided dedicated, consistent, and imaginative support to the technological aspects that make the Girl Roster what it is now. Andrew led the first experiments with Satvika Chalasani on using information technology (IT) devices to create unique numbers and identification cards for girls. Andrew also saw the potential of a Roster-like informationcollection approach and demonstrated it as early as 2007. Craig has been dedicated to this project, from first inception to development of Output Tables and related mapping tools, to the much desired in-progress Girl Roster app. This has required moving through different mechanical and technological possibilities with fervor.

Other important tools, such as the Building Assets Toolkit ${ }^{\oplus}$, benefited from strong and early support from colleagues such as Jennifer Sebstad and Veronica Torres, as the Toolkit and specifically financial literacy and other economic skills became central content in our programs. To the Toolkit production team, Sarah Engebretsen and Kimberly Glazer, I owe my thanks for their creativity and endurance.

Foundational to Intentional Design were the coauthors of The Uncharted Passage: Girls' Adolescence in the Developing World, Barbara Mensch and Margaret E. Greene. 
Cynthia Lloyd, as former Director of Social Science Research at the Population Council, was a constant support in making large datasets, such as the Demographic and Health Surveys (DHS), accessible and useful; this was most evident in the Adolescent Experience In-Depth guides, whose data are part of the foundation of this guide. Also instrumental in that project was Adam Weiner in assisting in the development of tables and commentary that allowed easy access to key data for practitioners and policymakers alike.

The Intentional Design approach has benefited greatly from a wealth of insights from field innovators: the Guatemalan team, particularly Angel and Alejandra; Karen Austrian, who, in all the work she does, provides a methodical baseline outlining the circumstances of girls and their communities before she plans programs; Annabel Erulkar's outstanding toolkit From Research, to Program Design, to Implementation Programming for Rural Girls in Ethiopia represents the gold standard of using collected information that is strong qualitatively but can be quantified; Kelly Hallman, who was early to recognize that the most-at-risk were systematically missed by youth services and who has given intense attention to the microeconomic aspects and role of friendship networks and sexual coercion; the late Marie Assaad, my beloved mentor, and Yousriya Loza-Sawiris provided visionary guidance in establishing the benchmark adolescent girl-centered work among the garbage-collection workers of Mokkatam in Cairo; Barbara L. Ibrahim and Ragui Assaad, former directors of the Council's West African and North Asian work, provided support for our work in Upper Egypt at a time when examples of Intentional Design and systematic investments in excluded girls in the region were both rare and essential. Nadia Zibani's passion for girls and ability to see them and make them be seen contributed both to our mission and our learning; Shireen Jejeebhoy, in her tenure, and K.G. Santhya, both in India, partnering closely with Nicole Haberland, designed programs that not only observed Intentional Design principles but anchored themselves in the realities of India's efforts to create a denser network of entitlements and control of community resources, employing a rigorous but compassionate approach to their work, both inspiring and instructive to the rest of us; and Sajeda Amin cares about how systems for change can be built and how they perform, and was an early supporter of our livelihoods work.

The Council was never alone in this effort. Particularly as we approached the development of practitioner-focused tools, it was vital that we worked outside and far beyond our own field network. Omar Robles, while at the Women's Refugee Commission (WRC), brought the Roster's possibilities to light on many occasions and highlighted the tool's ability to assist with some of the most remote and difficult challenges, and Dale Buscher of WRC provided critical support for the Council-WRC action learning partnership; Audrey Anderson, while in her capacity of directing the Because I Am a Girl program at Plan International, led the introduction of the Roster in various settings and thoughtful analyses of Roster results that have been exemplary in explaining the tool's usefulness to practitioners. Chernor Bah, a long-term collaborator and former Associate at the Council during several pivotal years, and a founder of Purposeful Productions, advocated for the Roster and supported its initial fielding in Sierra Leone. In the challenging days post-Ebola epidemic, Sarah Blake, Nadia Assad, Arnold Williams, and Salma Babu worked to make Intentional Design the framework of the Sierra Leone Adolescent Girls Network and the application of the learning tools a 
systematic foundation. The latter work was supported by partners at the United Nations Population Fund (UNFPA), specifically the Global Programme to Accelerate Action to End Child Marriage program.

The Intentional Design approach and tools, including the Roster, were given a huge boost under Miriam Temin's leadership of the Council's DREAMS Partnership. Miriam worked closely with Sophie Soares and Craig Heck to introduce the tools to DREAMS partners, an ideal project as the issue at hand was the exclusion of girls from decades of human immunodeficiency virus (HIV) investment. Craig Heck and Katharine McCarthy were also integral in conducting analyses of DHS estimates of boy and girl populations in 54 countries (see Appendix III). Audrey Anderson and Dana Smiles went to Kenya early in the DREAMS Partnership to orient partners ${ }^{1}$ on the use of the tools, and later were instrumental in acquainting these partners with their potential. Emmanuel Charles and the Population Council's partners in Haiti worked closely with the Haitian Adolescent Girls Network (HAGN), ${ }^{2}$ particularly the Network's Director Myriam Narcisse-an enormous supporter of Intentional Design-to use systematic tools to assess and scale programs and ensured that a high proportion of member sites were rostered and results analyzed and used thoughtfully; as of 2019, we began to see the full potential of results used to form a business plan for girls in the country.

Eva Roca, Sarah Engebretsen, and Liz McGrory, first as Council staff and then as close collaborators and consultants at the ready, provided moral and technical support and substantive insight to the Intentional Design process; Eva, in east and southern Africa, and Sarah in francophone West Africa, adapted Intentional Design to challenging onthe-ground circumstances with flexibility and insight. Liz was an intrepid early editor of the guidance on rostering. They, along with our institutional partners, have provided a strong core. Colleagues and consultants Ann Wahinya and Veronica Torres similarly have participated in a high proportion of significant field applications, especially in subSaharan Africa. Martha Brady had her critical eye on the on-the-ground stories found in this guide in its earlier drafts and I appreciate her vision for their potential.

We doubly thank Audrey Anderson, Sarah Blake, Nicole Haberland, Kelly Hallman, and Miriam Temin, as well as Samantha Berg, Susan Blaustein, Jessica DeMulder, Stephanie Psaki, and Corinne White for their thoughtful peer review of the chapters of this guide, Their willingness and enormous effort under various pressures has made this guide not only possible but also comprehensible.

We owe a very special recognition to those who are at the heart of the Intentional Design process. It is their efforts that assure that real girls get real things in real places. The on-the-ground experiences shared throughout this guide and most prominently in Chapter 9 reflect only a small percentage of those who daily "see" the girls and make them actionable. These practitioners are special heroes. Below are the names of the authors of the on-the-ground experiences included in the guide. Please know, all of you listed here, how grateful we are.

1 Kenyan partners included: AFYA Jijini, APHIAplus Western, Global Communities, Henry Jackson Foundation, HOPE Worldwide, IMC, IRDO, and LVCT Health.

2 HAGN members who implemented the Roster include: AMURTEL, CFTA, Fondation Ti David, Fondation Toya, FORHAD, Haiti Outreach Pwoje Espwa (H.O.P.E.), ODAPCUH, OFEMAB-LH, ORFREFKAD, Profamil, SOLFAKDEV, and Timoun Gosen. 


$\begin{array}{llll}\text { Alexia Abrego } & \text { Rose-Marie Chierici } & \text { Allen Kakakawa } & \text { Altunay Özatay } \\ \text { Agnes Achom } & \text { Tessa Davis } & \text { Audrey Kanyesigye } & \text { Daniel Perlman } \\ \text { Judith Akware } & \text { Xenia de Velasco } & \text { LeToy Lunderman } & \text { Lisa Polen } \\ \text { Cristina Alcada } & \text { Angel del Valle } & \text { Aimee Lyons } & \text { Omar Robles } \\ \text { Kátia Almeida } & \text { Wencesclas Djokpe } & \text { Alexandra Machado } & \text { Janet Routzen } \\ \text { Audrey Anderson } & \text { Pauline Dolan } & \text { Carlos Ernesto Martinez } & \text { Karen Scriven } \\ \text { Maritza Avalos } & \text { Shirley Eng } & \text { Stephanie Martinez } & \text { Yesenia Segovia } \\ \text { Ana Avillez } & \text { Sarah Engebretsen } & \text { Annette McFarland } & \text { Revocatus Sono } \\ \text { Yvenique Bathard } & \text { Rachelle Fleurimond } & \text { Habiba Mohammed } & \text { Belmiro Sousa } \\ \text { Susan Blaustein } & \text { Made George } & \text { Rima Mourtada } & \text { Matt Streng } \\ \text { Emile Bove } & \text { Kelly Hallman } & \text { Clementina Mwambene } & \text { Gisela Turcios } \\ \text { Laura Brazee } & \text { Donnie Hampton } & \text { Janet Nakiggude } & \text { Thony Voltaire } \\ \text { Lynda Brown } & \text { Sarah Hewitt } & \text { Myriam Narcisse } & \text { Amie Wells } \\ \text { Dale Buscher } & \text { Caitlin Hone } & \text { Margareth Nhancale } & \text { Emy Yanni } \\ \text { David Cao } & \text { Amy lbold } & \text { Joy Ochai } & \text { Marzalena Zaini }\end{array}$

My thanks to Thoai Ngo and Ann Blanc as both supervisors and colleagues. Their support of the Community of Practice has been unfailing and essential. In the final stages of preparation for publication, under difficult COVID-19 conditions, Samantha Berg, Lisa Polen, and Grace Saul provided indefatigable support.

This guide's publication would not be possible without the deep commitment of Joyce Altman (editor), and James DeGroat and Ebonye Gussine Wilkins (graphic designers). Their excellence in their respective crafts as well as their synchronicity as key members of the Council's publishing team facilitated this guide's successful production; we are indebted to them for their undertaking of this comprehensive document.

For the past several years, this work has been carried out effectively and devotedly by Sophie Soares, who has supported rostering and related tools in numerous countries, including Benin, The Gambia, Ghana, Haiti, India, Kenya, Lebanon (particularly in the Syrian diaspora), Malawi, Mozambique, South Africa, Tanzania, Uganda, and more.

The individuals mentioned here work beautifully in a team-supporting each other, supporting the practitioners, and always holding the girls at the center. We thank those who we may have forgotten, who helped us daily and across the 41 countries where this approach has been applied, in one form or another, and the Population Council's Community of Practice-the brave and committed partners who were the earliest innovators. 


\section{Investing in Adolescent Girls}

The notion of Intentional Design arose early in discussions about how best to invest in adolescent girls. The Population Council's original monograph on this subject, The Uncharted Passage: Girls' Adolescence in the Developing World (Mensch, Bruce, and Greene 1998), identified numerous gaps in knowledge about girls, especially those who were most disadvantaged and at-risk, and few dedicated policies or programs on the ground. The Council drove interest in revealing the diversity of girls and meeting the full breadth of adolescent girls' social, economic, and health needs by convening practitioner-focused learning and working seminars, exemplified by the first-ever international meeting on adolescent girls' livelihoods ("Essential Questions, Essential Tools"), in Cairo in 1999.

We see our mission-now and then-as delivering scientific methods and a solid evidence base to those advocating for concrete investment in the most challenging places for the most-at-risk populations of girls.

Assessments of global development consistently confirm the inadequacies of conventionally configured youth programs in reaching the most-at-risk adolescent girls in the poorest communities (Bruce and Hallman 2008; Erulkar 2014; McCarthy, Brady, and Hallman 2016). These girls should be, but generally are not, treated as a distinct and heterogeneous group that requires a range of services anchored in evidence and contextualized to their lived experience. The assessments have called attention not only to the longstanding health and human rights effects of their exclusion, but also to the intergenerational economic and social consequences that result from excluding these girls, the majority of whom will be responsible not only for their own financial needs but also those of younger and older family members (Clark and Hamplová 2013; Clark and Brauner-Otto 2015). ${ }^{3}$

The failure of standard development approaches to reach or even negligibly engage younger, poorer, and more socially isolated girls is reflected in still high, though declining, child marriage rates, shocking levels of poverty-driven sexual exchanges and coercion among adolescent girls (Hallman, Kelvin, et al. 2016), and disease differentials between young females and males. For example, in 2016, new HIV infections among young women aged 15-24 were 44 percent higher than men their age. In eastern and southern Africa, young women make up 26 percent of new HIV infections despite only accounting for 10 percent of the population (UNAIDS 2017). These alarming conditions and disparities, persisting over decades, challenge organizations to design and scale onthe-ground programs to reach the girls who are most disadvantaged.

${ }^{3}$ Analyses were originally commissioned by the Population Council. 
In recent years, increasing faith has been put in social marketing and access to the internet to close the access gap. The results are mixed. While compelling documentaries, social media messaging, and stunning photographs illuminating girls' realities are welcomed, the "talk" remains way ahead of the "walk" (Bruce 2014). Though the messaging is directed at the "leadership elite," it does not reliably result in evidence-anchored action or confer on the girls at most risk (and usually offline and out of sight) the information and power to claim their rights. Further, to the extent that such media glamorizes and homogenizes girls by employing overly generalized categories ("youth" or "the girl"), they may hide crucial distinctions among girls and reinforce the invisibility of the most-at-risk.

The poorest girls typically also have the most limited access to social media. Having access to mobile phones or social media can confer a pathway to services and better information for adolescents. However, it can also raise exposure to sexual imagery, online solicitation, and trafficking. Finally, mediasavvy campaigning for girls, uncoupled from quantification of their current coverage by existing services, may foster the impression that there is much more programmatic action on the ground than is really there.

Customary program design procedures and planning and evaluation frameworks often unintentionally conceal and marginalize especially younger girls' experience. This may begin with challenges in having the wrong problem statement; for example, promoting girls making informed reproductive health choices without acknowledging or addressing layers of power that inhibit effective choice. Programs may be relabeled as "gender-sensitive" or "girl-centered" but retain benchmarks for success that promote false social constructs and reflect donor preferences for high numbers. Some family planning programs continue to use "couple years of protection" to gauge coverage among adolescent populations-when the majority of girls are not in couples, at least formally, or, to the extent that they are "couples," are not making consented decisions about having sex and may or may not have limited control over their own fertility and disease protection. As another example, HIV infection certainly is a negative, but its common and unmeasured precursor is nonconsensual sex, including child marriage, which has historically received less attention because the world is attuned to the disease aspect rather than how girls' poverty drives sexual and disease exposure inside and outside of marriage.

Systematic information within the cultural context is a vital antidote to unconscious biases, ambivalence about gender equity, and the convenience of "business as usual." Practitioners-even with new resources-may subtly redirect resources intended for adolescent girls because of their inexperience with and fear of working directly with the most-at-risk girls; they may also have discomfort challenging traditional family structures. It's often difficult to keep these young females as the primary subject of programs. When interventions are proposed that would give especially younger girls more control of resources, including a space of their own, some program designers give more weight to the preferences of gatekeepers-men and boys in the community (including community leaders, husbands, male siblings/peers, and many others) who exert power over these girls. For example, we may find disproportionate support for expanding married mens' clubs in a program's design in geographic areas where there is no dedicated female space and a striking need to engage and invest in 


\section{The most excluded girls in the poorest communities-at a critical inflection point in their lives-must be our first "clients."}

married girls, out-of-school girls, girls living apart from parents, and very young first-time mothers. The most excluded girls in the poorest communities-at a critical inflection point in their lives-must be our first "clients."

Without Intentional Design, combined with commensurate levels of investment, small and large adolescent girl programs alike will fail to make a difference proportionate to their effort. Prevention at scale to support the most excluded girls in the poorest communities is essential to reverse the current regime of "planned poverty" (Bruce 2016). There is no branding shortcut. Critical thinking about where and in whom to invest combined with evidence-informed execution are the bedrocks of lasting change.

Optimistic that both formal and unconscious biases can be overcome, the Population Council hopes to support the field as a whole as it adopts systematic information-gathering and analysis tools, intentional recruitment plans, and wellcrafted, tested, and appropriate content and program models.

Through its multiple partnerships in more than 40 countries, including the Indigenous Adolescent Girls' Empowerment Network (IMAGEN) and Girls in Emergencies (GiE) Collaborative, the Population Council's Adolescent Girls' Community of Practice has supported the development of learning tools. These include the Girl Roster ${ }^{\mathrm{TM}}$, the Community Resource Scan, the Building Assets Toolkit $^{\oplus}$, the Coverage Exercise, and the Ascertaining Sexual Relationship Types [ASERT] tool to assist our partners in their journey. We are certain that broadly engaged learning partnerships will result in real girls getting real things in real places.

Progress for the most-at-risk girls requires persistence and accountability, purposeful investment, and imagination. Intentional program design fosters seeing the full "universe" of girls as well as the range of available resources within the girls' walkable communities. Both the girls and the communities are joint subjects for transformative change, as pandemics and social justice movements confirm the necessity of well-managed and resourcerich communities that work for everyone and make a difference at the household level and to the members within it.

Without a dedicated learning process, practitioners may not know how many girls are in a community, or assume that those who participate represent the most in need, or believe they have reached a larger portion of the population than they actually have. Program staff, evaluators, and donors may assume that service use accurately reflects demand; without looking beyond immediate participation, they cannot gauge the elasticity of demand including whether 


\section{Prevention at scale to support the most excluded girls in the poorest communities}

\section{is essential to reverse the current regime of \\ "planned poverty."}

more or different hours or a higher frequency of program activities would broaden and intensify participation. Further, also invisible is how to expand and improve outcomes for those currently participating and those who might join. They may conclude that the content covers core needs, whereas-in most places-standard content for young females is biased toward imparting little more than health information and a sprinkling of life skills, offered as a course, rather than through a regularly available girls-only space.

Many programs under stressful demand are purely reactive, rather than preventive, providing too little too late; crisis-centered care may reinforce the notion among both providers and girls that girls are to blame for their own problems rather than that the problems are a product of structural and addressable inequalities around them. Learning tools must focus attention "upstream" where exclusion begins (e.g., falling behind in school), not simply on pathologized outcomes (e.g., married at 16), and illuminate the local drivers of poor health, social isolation, and economic exclusion.

Demand-led programs may attract relatively well-off girls (often referred to as elite capture), because of the way in which their services are organized-by hours, staffing, content, and locations that subtly favor those girls. All girls have rights and needs, but even in the poorest communities we must see and prioritize the capture of the most socially and economically marginalized. If we do not begin with those excluded girls, we rarely get to them.

Intentional Design: Reaching the Most Excluded Girls in the Poorest Communities provides an evidence-based approach that generates a cycle of information collection and analysis and disaggregation of girls into specific geographic areas (subnational districts, walkable communities) and likesituated populations (segments). This information guides segment-specific planning, including segment-specific targets, engagement strategies, mentoring structures, meeting venues, and program content. Learning is sequential and stepwise, each collection of evidence or insight building up from the preceding one; it is not unidirectional and is it always possible to go back and refine previous steps taken or use what was gained from one step to inform others. The approach promotes fairness-particularly amid sudden threats like climate and health emergencies, which can exacerbate inequalities. Systematic information about the diversity of girls' realities is fundamental to meaningful evaluation and the defining of value for money metrics. 


\title{
By drawing in practitioners and mentors
}

\author{
from the community as core girl advocates, \\ maximizing their quantitative information, \\ and creating space for their insights about \\ the needs and promise of key segments of \\ girls, we can craft and scale programs that \\ reach enough girls with enough things early \\ enough to make a difference.
}

Rigorous results regarding impact cannot be obtained without authenticating dialogue, trusted relationships with local partners (government and nongovernment), and a building of their capacity on their terms from beginning to end.

Evaluations must gauge the degree to which programs build the assets and voice of the most disadvantaged, increase their safe access to a relevant array of services and opportunities, and expand (and permanentize) young female pathways for civic engagement. Effective efforts operate at two levels:

- improving the human stock (Sen 2000)-building the health, social, economic, and cognitive assets of excluded segments of girls;

- changing the shape and scope of communities' governance and delivery structures, ensuring that there are regular and safe meeting spaces, a local supportive cadre of mentors (slightly older females who can advocate for and support girl participants), and community resources mobilized and improved for the benefit of the girls (Bruce 2015).

The tools used in the sequential learning approach, presented in this guide, include the Girl Roster developed by the Population Council and its partners, ${ }^{4}$ which has been tested and refined through field applications in Africa, Asia, Central America, and the Middle East in both peaceful and conflict settings. The Girl Roster's Overview Output Table and other Output Tables allow girls to be "envisioned" and, when used in combination with the Community Resource Scan, can see where populations of girls are situated in relation to one other (geographically) as well as to key resources. The Coverage Exercise estimates how well a program is being accessed by different target groups-that is, what the program's reach is among its target and other beneficiaries. These tools

\footnotetext{
4 The Women's Refugee Commission and operational organizations of the Girls in Emergencies Collaborative have adapted the tool for deployment in a range of humanitarian contexts, including emergency settings.
} 
can all be used in concert with other tools, such as the Building Assets Toolkit, which helps define program content, and the ASERT tool, which reveals the often surprising and disturbing range of sexual contacts girls must engage in for economic survival, access to core services, and emotional support.

This guide-and the materials contained within it-is designed to place as much power as possible in the hands of conscientious local practitioners while keeping the experiences of excluded girls at the center. By drawing in practitioners and mentors from the community as core girl advocates, maximizing their quantitative information, and creating space for their insights about the needs and promise of key segments of girls, we can craft and scale programs that reach enough girls with enough things early enough to make a difference.

The materials are offered with humility in the spirit of a perpetual "first draft" to be improved upon by the users - a series of catalysts to learning and on-theground change.

Judith Bruce

Senior Associate and Policy Analyst, Population Council 


\section{Optimizing Investment in the Most Excluded Girls in Their Home Communities}

\section{LEARNING OBJECTIVES}

- Gain an overview of the approach to steps and decision-making to ensure the highest return on investment with respect to the most excluded girls in the poorest communities.

- Explore content summary of Chapters 2 through 9.

\author{
Investing in girls-especially the most excluded \\ girls in the poorest communities-improves \\ health, lowers fertility, increases levels of \\ education and skills, creates a basis for decent \\ livelihoods and stronger local economies, and \\ introduces sustainable environmental practices \\ in the home, community, and in overall \\ resource management. Prioritized attention \\ to the rising generation of girls is foundational \\ both to justice and poverty alleviation. Not \\ only are a high and likely increasing proportion \\ of females bearing-solely or substantially- \\ the economic support of families, but their \\ responsibility for meeting the caregiving \\ and material needs of older and younger \\ dependents begins at a young age. While \\ international discourse suggests that girls are \\ key constituents for health and development, \\ efforts on the ground remain far too thin, and \\ successful approaches are too rarely scaled. \\ Development practice has been slow to \\ apply the same scientific-intensive methods \\ for designing investments in adolescent
}

girls that have been applied in other areas. Practitioners have not had ready access to systematic information as a basis for program design and evaluation. We-the Adolescent Girls Community of Practice and its partners who are trying to build capacity on the ground-promote basic due diligence in girl programming. Data-anchored strategic plans allow cost and value for money projections and can be used to mobilize political will for national efforts going beyond piecemeal and tiny "boutique" or "marquee" programs.

Many early "girl programs" were put in place as an add-on to existing activities without a concerted process of identifying hotspots that have the highest concentrations of atrisk girls. The advocacy power of aspirational images of girls is amplified by the validation of place-specific numbers-telling a governor of a subnational region, "Did you know there are 7,000 girls aged 10-14 who are living apart from both parents and are out of school in your district?" to move him or her from 


\section{We seek to replace "Too little, too late" with "Enough girls with enough things early enough to make a difference"-reaching those at the highest risk of the}

worst outcomes at the youngest ages.

empathy to an accountable plan. Locale-specific information galvanizes the iconic "community." Community members, including the power elite, are living in resource-poor situations along with the more gravely affected girls but lack tools to "see" them. Overwhelmed program staff have few nimble, user-friendly tools to assist decision-making and may wait for and trust external experts more than themselves. Without an evidence base and support from investors (governments or nongovernmental organizations [NGOs]), the local community may react to the latest problem by employing casual, demand-led recruitment. A reliance on this "If you build it, they will come" mentality without sufficient information, analysis, and follow-through will result in multiple program failures. Even marquee programs may reach far too few girls within a catchment area (e.g., 25 girls in a community of 500 girls), or reach the wrong girls, or reach the right girls but too late. We seek to replace "Too little, too late" with "Enough girls with enough things early enough to make a difference"-reaching those at the highest risk of the worst outcomes at the youngest ages.

\section{Seeing the Full Universe of Girls Including the Most-At-Risk}

All girls deserve to have their needs met and their rights upheld and protected, but resources are not unlimited. Thus, subnational regions and, within them, the poorest communities with the highest proportion of at-risk girls (such as out-of-school or married girls), must be prioritized for investment. In such places, programs intended to reach those most in need are often ill-served by the terms "vulnerable" or "disadvantaged," because girls' statuses change rapidly and these terms can be subjective and imprecise. The terminology may inadvertently stigmatize girls, suggesting subtly that they are at fault rather than that the system has failed them. A focus on girls' suffering, though understandable, may inadvertently define girls as "victims," and may not gain momentum because it is difficult to lead change or investment with negatives.

Many of the learning and engagement activities proposed in this guide both avert bad outcomes and, as importantly, create conditions for good, sustainable results. Definitions common to the global development field for "the most vulnerable" often emanate from outside the affected community. These external definitions may identify a small subset of the girls who are at exceptional risk at a specific time and ignore a more local definition and the volatility of girls' well-being. Vulnerability analyses are often costly and, therefore, conducted as oneoffs, whereas girls' vulnerability is not static. Recognizing this, low-cost learning tools in the hands of local practitioners allow for more contextualized and sustainable responses.

In poor communities, even those (particularly the youngest) who are currently on-track (defined as being in school, at grade for age, living with at least one parent, unmarried, and without children if you are under exact age 18) may be at risk a few years later. Collected evidence indicates a tremendous volatility in the conditions of girls and the importance of investing early (McCarthy, Brady, and Hallman 2016), so we must find ways to reach a wider diversity of girls earlier. Program tools create a base of more objective information from which difficult decisions about targeting can be made. 
BOX 1. SEGMENTS OF GIRLS TYPICALLY

\section{DEFINED AS OFF-TRACK}

- School-age girls who are not in school or are significantly behind grade for age.

- Extremely isolated girls aged 8-15 (with an emphasis on those aged 10-14) living apart from parents and/or not in school.

- Girls who have been married under age 18 (or the legal age of marriage in a particular setting).

- Married or unmarried girls under age 18 who have borne children.

\section{Defining Girls Who Are Off-Track}

We use the more neutral term off-track to define segments of girls who are missing out on basic rights and services in their walkable community. Girls are identified as being offtrack by using objective, basic, minimum criteria set by national governments and implemented by subnational authorities, and typically framed by international laws and conventions. Though there is some variation (local standards may mandate eight rather than ten years of schooling), girls are considered off-track according to educational attainment, legal age of marriage and consent, and the expectation of parental support, common across various legal and social settings (see Box 1).

\section{Locating Girls within Their Walkable Communities as a Basic Strategy to Attain Rights and Services}

Through formal commitments made by national and international bodies, girls are entitled to a range of rights and services codified in local and international policies, such as the United Nations (UN) Convention on the Rights of the Child, Convention on the Elimination of All Forms of Discrimination Against Women (CEDAW), the Sustainable Development Goals (SDGs), and the African Union's Maputo Protocol. However, these protective covenants

\section{are effectively "mottos" without local accountability and companion investment}

plans. Central government bodies, leaders, and courts may define rights and protections-such as the legal age of marriage, or the entitlement of ten years of education, but these rights and protections remain largely theoretical unless they are upheld locally and girls are able to claim them within their walkable communities, which is typically a radius of 3-4 kilometers (2-2.5 miles).

For most of us, the location, hours, and so forth of a service are determinant of its access; the geographic aspect is especially important for young girls. In many communities, if you cannot "safely" walk to it, it is, in effect, out of reach. Proximity is not the only determining factor, because there are also social barriers that restrict girls' safe access. Different segments of girls may have different degrees of access (e.g., the school-going girl can go places the domestic worker cannot, and vice versa). Age is also salient as puberty limits the space in which girls can move securely (Hallman et al. 2015). In general, entitlements such as basic education, health care, skills training, a formal savings mechanism, and judicial protection must be physically nearby and "friendly"-these are the minimum conditions of accessibility.

\section{Meaningful realization of entitlements requires} not only physical proximity but also social

support. Girls may be aware of a service that's being offered but not feel entitled to it; they may not identify with the kind of girls who are portrayed as using it ("It's not for a girl like me"). They may internalize a sense that they do not deserve things and encounter adults or others who actively discourage them and intimidate their social participation. Factors that limit girls' access include concerns for their safety, expectations that they dedicate their time to work in and for the home, and isolation from school and public resources such as playing fields, community centers, and health services (see Figure 1) (Amin and Huq 2008; Wamoyi 2011; Hallman et al. 2015). Exclusion results from an interplay of household-level poverty and environmental and 


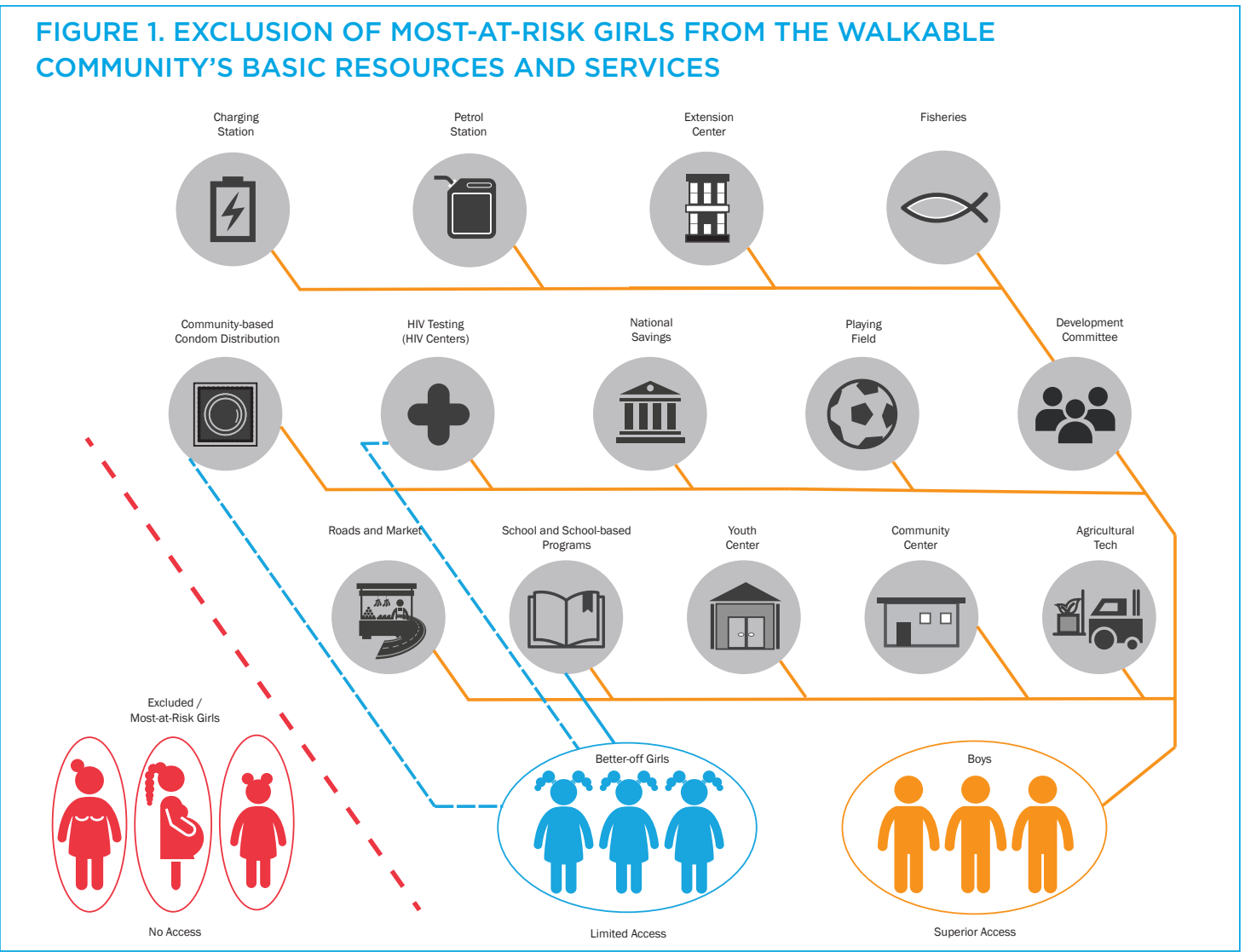

economic shocks (Erulkar and Matheka 2007). This interplay often turns girls into community "credit cards," increasing controls over girls' mobility, the deployment of their labor to mediate scarcities-for example, to gather water in a far-off place, to go to the market and "find" food (without specifying the means), to look after younger children when the mother has to work. These factors may intensify the pressure to withdraw a girl from school or to marry her off suddenly for family economic gain, all of which simultaneously heighten risk and reduce opportunity (Atkinson and Bruce 2015; Bruce 2016).

Restrictions on girls are often presented as something that is "protecting" them; even female genital mutilation (FGM) is portrayed as a "protection" of a girl's decency (and that of the family) and a precondition for a "reputable" marriage. Protection of girls must be reconfigured as safe access to services and opportunities, as conferring skills needed for rightful control of one's sexuality and marital life, and preparation for the uptake of decent livelihoods and the control of the fruits of one's own labor. Protection should not be used to justify exclusion or understate the assets girls require and deserve to claim their rights. Those who work on behalf of girls must promote expansion of female voice early and the availability of girl-only spaces in which girl peers can acquire skills, learn, grow, play, and lead; they have a dual duty to democratize communities such that girls have equitable access to services, entitlements, and facilities (Bruce 2016).

\section{Overview of Chapter Content}

This guide provides practical tools for the program community to learn about girls and their settings. Using the Intentional Design tools helps segment the full universe of girls into meaningful subpopulations and craft 
programs that offer them spaces of their own (community-based, girls-only safe spaces) as well as specific mechanisms to connect to the resources in their immediate environment.

\section{Chapter 2 Using Key Data to Identify Regions with High Concentrations of Off-Track Girls}

A critical first step is to use data to identify the most disadvantaged subnational districts where investment in girls is likely to create impact. Selecting where to work is both a practical and ethical decision greatly assisted by secondary data sources that capture subnational-level patterns in girls' schooling, marriage, childbearing, living arrangements, savings behaviors, experiences of violence, access to water and electric grids, degrees of financial inclusion (at least at the household level), subnational food security, and other descriptive variables. These data can reveal the so-called hotspot locations where off-track girls are concentrated (Amin et al. 2013; Engebretsen 2013; Erulkar 2013).

Chapter 3 Finding the Walkable Community and Laying the Basis for Program Scale-Up and Creating Clusters of Change

After identifying disadvantaged subnational districts, the next step is to use "community mapping" to establish the physical boundaries of walkable communities or catchment areas. These boundaries are often defined by administrative designation, but also by ethnicity, language, basic physical features, and landmarks. Then, within the boundaries of the walkable communities, households are mapped with respect to number and type of girls within them. A Community Resource Scan can be used for community mapping, locating the full range of facilities, spaces, services, opportunities, and resources in a community, and gauging which ones are utilized by different segments of girls. (Chapter 6 and Appendix II provide details on how to conduct a Community Resource Scan.)

Chapter 4 Identifying the Full "Universe" of Girls in a Walkable Community and Dividing Them into Meaningful Segments for GirlCentered Programming Using the Girl Roster ${ }^{\mathrm{TM}}$
Once the community has been identified and the community mapping and Community Resource Scan have been completed, the Girl Roster can help identify the full universe of girls in the area and break them into meaningful segments. The Roster consists of: 1) a household questionnaire that provides a snapshot of how many girls are in the catchment area and their basic characteristics, and 2 ) a rapid analysis mechanism that delineates categories of girls by age, schooling, marital and childbearing status, and living arrangements. This information is sorted into Output Tables that provide key information in easy, readable displays. Program staff typically go door-to-door to administer the Girl Roster questionnaire, gathering information from the heads of household on girls within a defined geographic area. The information allows program staff to see how many girls fall into each category (e.g., the number of girls aged 10-12 who are out of school and living with one parent). This helps reveal the pool of off-track girls that may be reached by programs and services, and also the on-track girls who might serve as mentors. Moving around the community also provides an opportunity to identify locations where programs can potentially be held. Information, both quantitative and qualitative, provides a basis for decisions regarding which segments of girls to work with and where, mentoring structures, and appropriate program content and length for each segment.

\section{Chapter 5 Segmentation and Planning: How to Use Girl Roster Results to Identify Key Segments of Girls and Make Overarching Program Decisions}

Once Girl Roster information is collected, it must be analyzed to see where different segments of girls live in relation to one another. (For example, are out-of-school girls clustered in one part of the community?) Maps connected to the Roster's Output Tables allow visualization of concentrations of girls in different segments in relation to one another and key features of the community, such as a river or a facility. The Girl Roster often determines whether girls are participating in specific programs, so skewing 
(better-off or older girls getting the greater share of resources in programs) may also be revealed. Examples are provided of Output Tables and maps generated by the Roster that can assist in initial programming decisions. Often, program staff discoveries from Roster results indicate that the number of girls in a particular segment is larger than anticipated, and the moment when an appreciable proportion of girls go off-track (not in school, married, have children) happens earlier. These are important factors that affect the structure of programs.

\section{Chapter 6 Probing Deeper into Community Resources and Linking Them Intentionally to Segments of Girls}

Connecting girls to resources begins with seeing the girls in the target community who have similar lived experiences. The main features of an area (river, roads) can establish the physical boundaries of a community, but a detailed assessment from girls in different social categories about access to available resources is essential. The investigation into what the community looks like from the girls' perspective sparks the imagination of program staff. They begin to see how they can make more direct and productive connections, such as how an abandoned school would make an excellent girls' club space. If needed, program staff can use a series of slightly more sophisticated tools. The Community Resource Scan allows for a more detailed inventory of services, spaces, and facilities. The Coverage Exercise can be used to determine by age, gender, and schooling status who is benefiting from a program, enabling program staff to look at which services are being provided to whom, where they are being provided, and whether program beneficiaries are repeat participants. This allows for corrections in program design if the intended beneficiaries are not being reached, programs are underutilized, or services are not appropriate for the girls receiving them. Advances in translating the Girl Roster's Overview Output Table into maps allows for rapid visualization, seeing, for example, the households in which girls aged 10-12 are out of school in contrast to those aged 15-17. These social categories can be presented on a map, thus they can be seen in relation to key community features, resources, facilities, and services.

\section{Chapter 7 A Review of the Tools to Support the Basic Model for an Intentional Design Approach}

The Population Council and its partners in the Community of Practice ${ }^{5}$ promote a sequential learning approach. Not all groups will follow all of these steps or exactly this sequence, but the steps are provided as a useful model. The sequence is as follows:

1. Identify the places with the highest concentrations of girls.

2. See the full universe of girls.

3. Segment the universe of girls into likesituated groups for intervention.

4. Prioritize and locate the most excluded segments in affected communities, both in relation to each other and to community physical features and facilities.

5. Intentionally recruit priority segments.

6. Secure a regular, safe community space in which girls can meet, mindful of seasonal stressors and risk scenarios.

7. Build indigenous social support-mentors to recruit girls and deliver programs, and provide support, a local safety net, and links to resources.

8. Build meaningful content keyed to girls' real lives that establishes positive, achievable metrics.

\footnotetext{
5 Since 2013, the Population Council has received vital support from the NoVo Foundation to help expand and maintain a Community of Practice-individuals and organizations, especially those operating in contexts of poverty, seasonal scarcity, conflicts, and emergencies. More than 1,000 individuals and 100 organizations from 38 countries have been engaged in a substantial way; the majority of these countries rank in the lower fourth of the UN's Human Development Index. We support our partners and learn from them in service of an Intentional Design process that sequentially asks: where in the world resources should be invested, which parts of the country, and in which communities; which segments of girls are at the highest risk of worst outcomes at the youngest ages; what content is vital to girls, particularly in the transition from late childhood to early adolescence; what is the best way to deliver health, cognitive, social, and economic assets; and how do we define meaningful metrics of change.
} 
9. Design programmatic on-ramps assuring girls' access to public/private resources in their walkable communities.

10. Pull it all together in systematic, persegment planning, and offer a sound basis for future evaluation and measurement of program outcomes.

\section{Chapter 8 Intentional Design In Action: Reaching Indigenous Adolescent Girls in Guatemala}

The spirit of Intentional Design is exemplified by this case study from the Population Council's Guatemala office, which illuminates the power of the local voice and the centrality of local leaders, practitioners, and mentors in crafting and securing change. Population Council staff tackled the question of how to reach excluded Mayan populations. In deciding where to work, they were initially struck by the high proportion of the adolescent population that was indigenous in Guatemala and the lack of programs to reach them. An initial Coverage Exercise revealed that the prime beneficiaries of youth-serving programs were urban males over the age of 20 years, and occasionally married girls seeking work; only 250 excluded girls were being reached. With continuous community engagement, many of the sequential learning principles and tools were put into action to reach excluded rural Mayan girls. A core focus was the development of a mentoring network that could advocate for girls, deliver programs to them, and bring transformational change to girls in the Highlands communities. This has been challenging because the Guatemalan program-Abriendo Oportunidades (AO)-has unfolded (in 2018 reaching 12,000 girls) in areas with high levels of criminal activity. AO has explored girls' definitions of security and safety and grappled with contrasts in girls' experiences and those of the community. The program has innovated an approach to community engagement, support, and protection of girls. Its lessons and approaches have been used to inform programs throughout Central America.
Chapter 9 The Practitioner Experience: Intentional Design on the Ground

Once the key steps of Intentional Design are understood, practitioner engagement is enhanced by instructive and inspirational firsthand on-the-ground reports. The 20 reports

presented reflect how practitioners have used the tools described in this guide, the adaptations they've made in their contexts, and their initial insights. These reports allow the reader to hear directly from a wide array of actors working across numerous geographic settings, in different language/cultural zones, and operating under different stressorsconflict, health emergencies, climate change. These reports, which include some of the earliest experiences and some of the most recent, are organized by region. Feedback from our partners has been essential to the evolution of our work. 


\section{Using Key Data to Identify Regions with High Concentrations of Off-Track Girls}

\section{LEARNING OBJECTIVES}

- Learn how to use readily available data to identify subnational districts in which girls at the highest risks are concentrated.

- Learn how to use preliminary statistics on population size (for different districts) in combination with information on adolescents' age, schooling, living arrangements, and marital and child-bearing status to make initial projections of numbers of individuals in need and/or to be reached.

\section{When designing interventions that focus on bringing resources to girls, it is important to understand that we are working at two levels; the first is building up the human stock, which is the social, economic, health, and cognitive assets of the girls themselves, and the second is helping to make communities more hospitable to girls by providing equitable access to core resources and facilities (see Figure 14, Chapter 7, "The Full Vision: Working at Two Levels"). We want to support those at risk, especially adolescent girls, so that they can be safe, happy, and productive beings "Who they are, where they are" (Atkinson and Bruce 2015).}

To determine the best way to build communities that create more equitable access to offtrack girls, it's essential to first identify the subnational districts in which they live, and then to understand the context in which they can safely access resources in their communities and avoid danger to their well-being. That context, especially for younger girls, is the walkable community-the place where they live. By knowing what these girls consider their walkable community you have not only sorted out where they live but also where you will work and deliver resources to them.

Deciding where to work-that is, making distinct selections of walkable communities-is a twostep process. The first step is looking for and identifying the subnational regions where youpractitioners and advocates for excluded girlsfind the highest concentrations of off-track girls (school-age girls who are not in school or significantly behind grade for age; extremely isolated girls aged 8-15 living apart from parents and/or not in school; girls who have been married under age 18 [or the legal age of marriage]; married or unmarried girls under age 18 who have borne children). The second step is disaggregating the selected subnational regions 
into those very walkable communities (see Chapter 3).

In 2016, the UN established 17 sustainable development goals that were to be integrated into national and regional policies and strategies, but just as important, recognizing the vast internal diversity in country, at subnational levels as well. This emphasis highlights the importance of focusing on local geographies where the most acute conditions of scarcity, inequity, and high disease prevalence exist (hotspots). It is in these subnational areas where organizations would do well to concentrate their resources. However, even though it's essential for organizations to work in regions where their investments can make the most difference, analysis of the conditions of adolescent girls is rarely reflected in programmatic decisions and has generally not "led" organizations' decisions about where to work. Intentional Design stresses making strategic, deliberate decisions about where to work-in areas that have the highest concentrations of populations you wish to reach. In this chapter, we discuss how data from different sources can guide you in finding subnational regions where off-track girls are more likely to be reached.

\section{Key Data Sources to Guide Subnational Region Selection}

Representative surveys such as Demographic and Health Surveys (DHS) and Multiple Indicator Cluster Surveys (MICS) include data on various indicators that are useful in selecting appropriate subnational regions; with additional analysis of its raw data, practitioners can also make selections of smaller and highly affected communities within those regions. These locations are often referred to as "program communities" and in some cases as "catchment areas," because they describe the area in which a given organization or service initiative is geographically concentrated.
Demographic, social, health, and economic data help us identify subnational hotspots where a particular condition of interest is more prevalent. For example, by looking at the relevant data, we can see that HIV prevalence in Homa Bay, Kenya, is 27.1 percent, while in Garissa, Kenya, it is 2.6 percent, providing reason to situate a program on HIV mitigation, prevention, and treatment for girls in Homa Bay, which has ten times the HIV prevalence among girls as Garissa (UNAIDS 2014). To build an effective program, once a subregion has been selected, additional contextual information will help us plot a strategy and characterize the challenges facing the population to be served. For example, the process for identifying a subnational hotspot may combine data on where HIV prevalence is highest among girls with data on schooling status, financial inclusion, local access to electrical grids, and experience or normative acceptance of violence.

Another useful source of information when selecting appropriate subnational regions is the Population Council's Adolescent Experience InDepth guides. ${ }^{6}$ Presented in graphs, tables, and maps, the data in these guides show geographic variation in basic social, economic, and health indicators for individuals in a specific age range, such as their living arrangements, school enrollment, and age at marriage. Variation in key indicators (with the possible exception of rainfall) suggest the potential for intervention; girls' conditions are often portrayed as cultural or natural and thus immutable to change yet the existence of variation across a country indicates that some conditions could be zeroed out with targeted effort. Data on variation guides practitioners on where to prioritize efforts, such as where child marriage, school leaving, and/or acceptance of violence are higher.

In doing an analysis, it is desirable to use a variety of data sources to get a fuller picture of the context. For example, in a 2016 baseline study in two districts in Liberia that

\footnotetext{
6 The Adolescent Experience In-Depth guides, also known as the Adolescent Data Guides, draw principally on data from the Demographic and Health Surveys to provide decision-makers at all levels-from governments to advocacy organizations-with synthesized evidence on the situation of adolescent girls and boys and young women aged 10-24. The Population Council's Girl Innovation, Research and Learning (GIRL) Center has amassed and is always updating its Adolescent Data Hub to assist practitioners working with adolescents and young people in lowto middle-income countries.
} 
FIGURE 2. MAP USED TO SELECT ETHIOPIAN HOTSPOTS, 2005

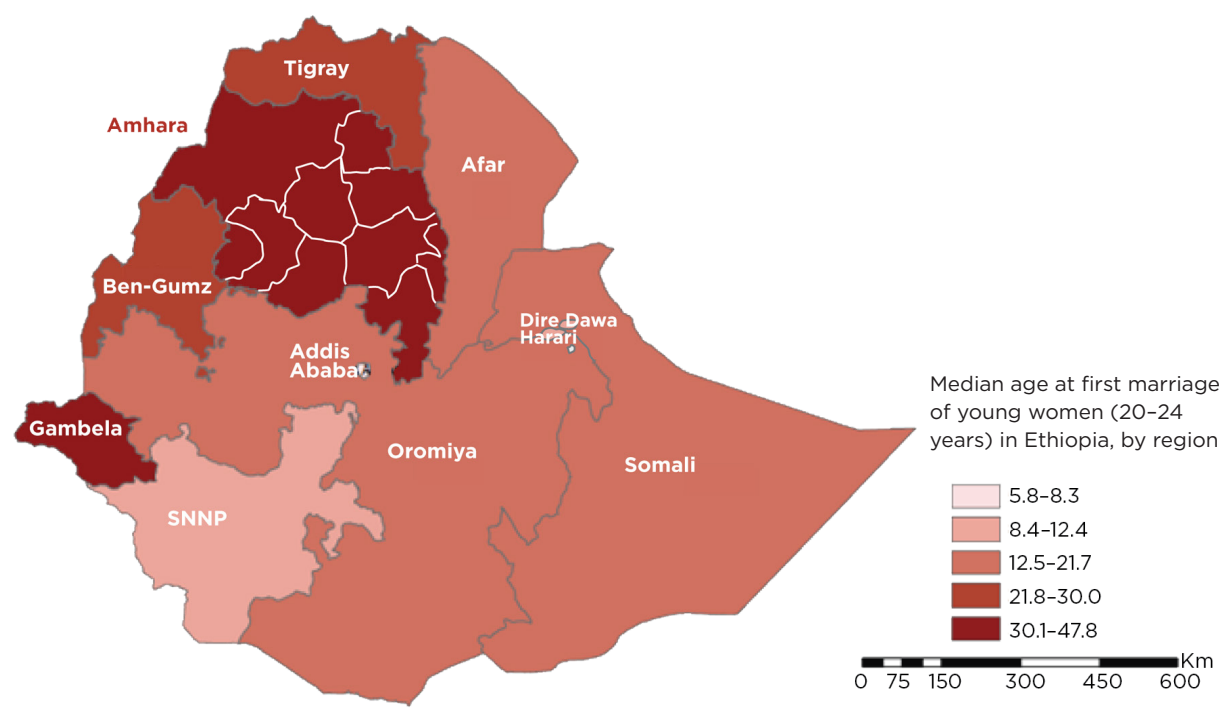

"The Adolescent Experience In-Depth: Using Data to Identify and Reach the Most Vulnerable Young People: Ethiopia 2005." New York: Population Council, 2009. Also see Footnote 9.

were especially affected by Ebola, research established that more than 10 percent of 12-year-old girls had experienced sexual coercion and/or exchanges of sex for gifts/ money (Hallman, Kelvin, et al. 2016). The pattern of sexual coercion, or other significant challenges to girls, can vary not only at the subnational level but also across different populations and types of communities (e.g., urban, rural, peri-urban, and recently displaced). These data, when layered, allow us to prioritize the communities in which we want to work. For example, program staff might select a place to work where a high proportion of girls are married under exact age 15 and polygamy and acceptance of violence in the general population is higher.

Though all girls have rights and needs, we need to use data to select the subnational districts where the greatest need exists. In the early 2000s, the Population Council determined to focus its efforts on the Amhara region of Ethiopia where 42 percent of the girls at that time were married under exact age 15 and an
HIV epidemic was unfolding (see Figure 2) (Population Council 2009). This provided an evidentiary basis for establishing four segmentspecific programs that, over the next ten years, went to scale in Amhara. These programs reduced the levels of child marriage and adolescent pregnancy, increased contraceptive use, and addressed young female adolescents' HIV risk (Erulkar 2014). We believe the initial selection of Amhara increased impact and yielded higher value for money-defined as the most advantageous combination of cost, quality, and sustainability for the program staff-helping us find the off-track girls who would benefit the most from program investments.

The approach of focusing on hotspot areas has been exemplified by the DREAMS partnership, ${ }^{7}$ a collaborative initiative sponsored by the U.S. President's Emergency Plan for AIDS Relief (PEPFAR) and established to reduce HIV infection among adolescent girls and young women in vulnerable countries.

\footnotetext{
7 The DREAMS partnership aims to reduce HIV infections among adolescent girls and young women (AGYW) in ten sub-Saharan African countries. The ten DREAMS countries-Kenya, Lesotho, Malawi, Mozambique, South Africa, Swaziland, Tanzania, Uganda, Zambia, and Zimbabwe-accounted for more than half of all new HIV infections incurred among AGYW globally in 2015. The partnership's goal is to help girls develop into Determined, Resilient, Empowered, AIDS-free, Mentored, and Safe women.
} 
Because the HIV epidemic has persistently and sometimes increasingly affected young females in sub-Saharan Africa-a 3-to-1 female-to-male prevalence in young ages across the continent, an 8-to-1 female-to-male ratio in some highly affected places-DREAMS sought to find key hotspots for intensified investment where a number of conditions were present. These included high overall HIV prevalence and also a particularly skewed ratio of young female to male infection.

Girls' schooling level is another differentiating factor. Apart from the obvious value of being schooled, education influences girls' health status, social participation, and readiness to pursue decent livelihoods (Lloyd 2009; Psaki 2016; Mensch et al. 2019). For example, a research brief produced by the Population Council's GIRL Center found a correlation between females' schooling and improvements in HIV status, child mortality, and other health measures (Psaki et al. 2019). Thus, relative schooling attainment levels by geographic area may guide the selection of program areas. The table in Box 2 shows the proportion of girls and boys aged 15-19 years by their education status in Sierra Leone.

\section{Projecting the Number of Girls to Reach in Different Categories}

At the outset of your program, it is useful to estimate about how many girls are in each segment in each region, so that you can begin to estimate the current coverage-that

\section{BOX 2. USING DATA TO IDENTIFY THE DIFFERENTIAL SCHOOLING ENROLLMENT AND ACHIEVEMENT OF MALES AND FEMALES BY REGION}

Although subnational district-level data is collected in official DHS surveys, and datasets are available by request (without charge), these surveys often include only national figures for indicators concerning adolescent girls. To make relevant data on adolescents accessible to policymakers and others who make decisions related to adolescents, the Population Council and UNFPA compiled a series of more than 50 Adolescent Experience In-Depth guides: http://www.popcouncil.org/research/the-adolescent-experience-indepth-using-data-to-identify-and-reach-th. These guides draw principally on data from the DHS to provide decision-makers at all levels-including governments, nongovernmental organizations, and advocacy groupswith evidence on the situation of girls, boys, and young women aged 10-24 years. They can be used as a first step in deciding where to work-noting the contrasting school enrollment for females by region and femaleto-male differentials.

School enrollment among 15-19-year-olds, Sierra Leone (DHS 2008)

Females (\%)

Males (\%)

\begin{tabular}{lllllllll}
\hline Region & $\begin{array}{l}\text { Not in } \\
\text { school }\end{array}$ & $\begin{array}{l}\text { Attending } \\
\text { primary }\end{array}$ & $\begin{array}{l}\text { Attending } \\
\text { secondary }\end{array}$ & $\begin{array}{l}\text { Attending } \\
\text { higher }\end{array}$ & $\begin{array}{l}\text { Not in } \\
\text { school }\end{array}$ & $\begin{array}{l}\text { Attending } \\
\text { primary }\end{array}$ & $\begin{array}{l}\text { Attending } \\
\text { secondary }\end{array}$ & $\begin{array}{l}\text { Attending } \\
\text { higher }\end{array}$ \\
\hline Eastern & 51.3 & 17.5 & 31.2 & 0.1 & 34.7 & 27.3 & 37.5 & 0.5 \\
Northern & 58.1 & 13.7 & 28.0 & 0.2 & 34.3 & 19.5 & 45.9 & 0.4 \\
Southern & 60.2 & 13.6 & 25.7 & 0.4 & 38.3 & 24.2 & 37.5 & 0.0 \\
Western & 31.5 & 8.6 & 59.6 & 0.4 & 18.8 & 8.3 & 71.9 & 1.1 \\
Urban & 28.5 & 11.4 & 59.5 & 0.6 & 16.0 & 10.9 & 72.3 & 0.8 \\
Rural & 70.1 & 14.9 & 15.1 & 0.0 & 45.1 & 26.1 & 28.5 & 0.2 \\
National & 51.4 & 13.3 & 35.1 & 0.3 & 31.5 & 19.0 & 49.0 & 0.5 \\
\hline
\end{tabular}

Data from the Sierra Leone data guide, shows that in the Western region of the country $31.5 \%$ of females aged 15-19 are not in school, while $\mathbf{6 0 \%}$ of females in the Southern region are not in school. In contrast, $\mathbf{3 8 \%}$ of males are not in school in the Southern region, illustrating the priority for girl programming in Southern Sierra Leone. 
is, the extent to which a specific segment of the population participates in programs, entitlements, or services-and the scaling challenge (see Chapter 6).

In many underserved places, there will be a single program to track or one organization or government agency may provide most services and may want to know who they are or are not reaching. Calculating cost effectiveness requires a clear understanding of who is being covered by a program; Intentional Design seeks to reduce the cost of reaching the most excluded girls in the poorest communities by promoting a better match between expenditure and need. The fairest programs are also the most costefficient.
So, as you begin this thinking process, how many girls might need to be considered? There are a few rules of thumb. In general, about 9.2 percent of the poorest countries' populations (United Nations 2017) will be girls between the ages of 10 and 17 (the official World Health Organization [WHO] definition of adolescents). In other words, if you are in a community of 10,000 people, 920 is a rough estimate of the adolescent girl population.

\section{BOX 3. COMBINING DHS AND NATIONAL DATA TO ESTIMATE THE SIZE OF THE POPULATION OF GIRLS BY AGE AND KEY CHARACTERISTICS}

Simple calculations using national-level data can help you estimate how many girls of a certain age live in your program community. For example, in a rural community in Mozambique it is estimated that 7.9 percent of the population will be girls aged 10-14 (according to the 2015 DHS) (MISAU, INE, and ICF 2018).

To estimate the total number of 10-14-yearold girls in rural community $X$ with a total population of 7,000 , you may perform the following calculation:

- The proportion of girls aged 10-14 in rural areas is equal to $2.1+1.3+1.7+1.3+1.5$ or $7.9 \%$.

- $\quad$ Total population of $7,000 \times .079=553$ girls aged 10-14.

- If your program aims to reach all girls aged 10-14 in the community, you now know to target and recruit over 500 girls.

- This same calculation method can be used to determine how many girls of a specific age (e.g., all 10-year-olds) or age cohort (10-12, 13-14, 15-17) live in your program communities. See Appendix III for the DHS national, rural, and urban estimates by country.
DHS Estimates: Mozambique 2015

\begin{tabular}{cccc} 
Girl's age & National (\%) & Urban (\%) & Rural (\%) \\
\hline 6 & 1.8 & 1.8 & 1.8 \\
7 & 1.8 & 1.6 & 1.9 \\
8 & 1.8 & 1.5 & 2.0 \\
9 & 1.6 & 1.5 & 1.6 \\
10 & 1.9 & 1.5 & 2.1 \\
11 & 1.3 & 1.3 & 1.3 \\
12 & 1.6 & 1.4 & 1.7 \\
13 & 1.4 & 1.4 & 1.3 \\
14 & 1.5 & 1.6 & 1.5 \\
15 & 0.9 & 1.2 & 0.7 \\
16 & 1.0 & 1.2 & 0.9 \\
17 & 0.8 & 0.9 & 0.7 \\
18 & 1.2 & 1.2 & 1.2 \\
19 & 1.1 & 1.4 & 1.0 \\
\hline TOTAL & 33,038 & 14,900 & 18,138 \\
& & &
\end{tabular}

This analysis combined with Girl Roster information (see Chapter 4) provides an idea of how many girls need to be reached by your program to achieve effective saturation. 
BOX 4. A MODEST PROPOSAL: THE 12-YEAR-OLD CHECK-IN

As a young girl enters adolescence, she is at a critical point in time for protective health interventions. A 12-year-old check-in provides a scheduled and uniform way to ensure that girls most vulnerable to unhealthy outcomes receive the care they need and may have missed in childhood. This could be an important platform for girls themselves and for global health in general. The Population Council has developed a promising idea in the spirit of "leaving no girl behind."

As with early-childhood health schedules, donors and national health ministries can codify an age-benchmarked check-in wherein adolescent girls, in a rolling fashion across a district or country, are reliably contacted at this propitious moment. This social gateway can be used to find out where girls are on basic health indicators and the social conditions that underlie health outcomes (see "Check-in Wellness Components"). Screening can be conducted for universal health concerns such as vision and hearing, but also for detection of country-specific health priorities such as malaria, sickle-cell anemia, and HIV. Gaps in immunization can be corrected, and the HPV vaccine and other more sophisticated health technologies can also be made available, where appropriate.

Girls might be offered information about the core rights framing their health and development, such as minimum age for legal marriage, ages of consent for sexual relations, voting, working, and opening a savings account. This moment can also be used to inform parents and their children about their rights before child marriage, unsafe migration, FGM, and other genderlinked practices set in. An inventory of girls' status can be conducted in terms of their living arrangements (e.g., with two parents, with one parent, with no parents, in a foster home, or as a domestic worker) and schooling level, and plans can be conducted to connect them to appropriate services as needed. Ambitious programs might provide key assets, such as IDs and the opening of entry-level small savings accounts (possibly in
Check-in Wellness Components

\begin{tabular}{ll} 
Health & Social \\
\hline - Physical exam & - Counseling \\
- Immunizations review & - Life-skills building \\
and catch-up & - Educational \\
- Nutrition/growth & assessment and \\
check-up & support \\
- Sexual and & - Peer and social \\
reproductive health & support screening \\
information and & and improvement \\
services & - Drugs/alcohol/ \\
- HPV vaccine (when & smoking screening \\
available) & and support for \\
- HIV/AIDS prevention & addiction prevention \\
information & - Family wellness and \\
- Violence screening & social support \\
and support & Citizenship and \\
- Mental health & social participation \\
screening and & skill building and \\
support & motivation \\
- Injury screening and & \\
prevention & \\
\hline
\end{tabular}

partnership with the private sector). Additionally, the check-in could provide a safe venue for adolescents to be confidentially queried about sensitive topics. Such a check-in lends itself to effective implementation through many avenues and features.

The 12-year-old check-in can provide an opportunity to find the information on adolescent girls that is often hidden by aggregated numbers. Health and demographic data can be collected and tracked, and allow for a longitudinal assessment of women's health, pooling a subset of girls at critical ages.

\section{For more discussion of age-specific programming, see Chapter 5.}

Note: This proposal originated with Judith Bruce in "The Diverse Universe of Adolescents, and the Girls and Boys Left Behind: A Note on Research, Program, and Policy Priorities," a background paper to Public Choices, Private Decisions: Sexual and Reproductive Health and the Millennium Development Goals. Additional applications with respect to Guatemala and sub-Saharan Africa were elaborated by former Population Council colleagues Jennifer Catino and Martha Brady. This box is based on the background note "Poor Adolescent Girls-Still Lost Between Childhood and Adulthood-The Case for a 12-Year-Old Check-In" for a presentation entitled “Making Critical and Timely Investments in Adolescent Girls' Health: Why and How" prepared by Judith Bruce for the G-8 International Parliamentarians' Conference: Strategic Investments in Times of Crisis-The Rewards of Making Women's Health a Priority.

Source: Temin and Levine 2009

8 Amin and colleagues (1998) early study of garment workers in Bangladesh assesses how in order to create a change in norms, a certain density of out-of-the-norm activity must occur for it to become normalized. In this study, a certain density of girls going into garment work had an influence on girls' norms in the workforce. Population Council researcher Sajeda Amin observed that age of marriage was highest where there was highest saturation of girls going into garment work (suggesting that the community had come to shift the norm and attain a certain level of acceptance and even interest in girls being educated and working before they marry). In equally poor communities, with few or no girls going into garment work, the marriage age remained low. 
Projecting the Number of Girls you Need to Reach at a Key Age

Early in the program design process, an excellent source-if available-for projecting the number of girls you may reach is DHS surveys combined with census data. DHS

surveys include the percentage of the population of girls of a specific age, presented separately for urban and rural areas (see Appendix III). The surveys can help estimate how many girls of a specific age live in a given community. For example, if a DHS table shows that 1.2 percent of the country's rural population is 12-year-old girls, you can estimate that in a rural village of 2,000, there will be around 24 12-year-old girls. In a subnational district of 200,000 people, there will be 2,400 12-year-old girls (see Box 3 for another example).

The government of Rwanda, inspired by the Population Council's proposal for a national campaign to reach girls early enough to prevent the worst outcomes initiated a year-long program to support girls in early adolescence (see Box 4). Originally entitled the "12-Year-Old Check In," this initiative shifted to focus on girls age 11 after an analysis of need. Specifically, data showed that the rate of school dropout increased for girls at age 11. Using Rwandan census data, it is estimated that there were about 120,000 girls across the country, with desired target numbers projected in each of the 30 districts in which the program was to be implemented.

\section{Using these data to plan a program in a specific subdistrict can combine numeric projections with information on the proportion of girls who are on-track and off-track, to generate numeric and saturation targets. As an exercise, let us explore how to use population}

information to forecast program options. In a 2,000-person community, where about 15 percent of the population is girls aged 7-17, we can estimate there are $\mathbf{3 0 0}$ girls in that age range. Let's suppose another data point indicates that only 10 percent will complete ten years of schooling by age 18 . So potentially 90 percent of the 300, or 270 girls, will be likely program prospects. Similarly, we can use such calculations to identify the pool of potential program mentors. In an urban population of 4,000, where 17 percent (680) are girls 10-17 years old, if half of these urban-based girls complete 10 years of schooling, then perhaps 340 girls would have an education level that would make them potential mentors. While these are preliminary estimates to guide thinking, these numbers are crucial advocacy tools to focus policymakers and local government on an investment plan and assist program managers in targeting and prototyping programs amenable to long-term and sustainable scaling.

The estimates of girl population size are the initial benchmarks used by programs when considering how many individuals they need to reach, and a basis from which to project levels of meaningful coverage or saturation for tipping-point change (Amin et al. 1998; Erulkar and Muthengi-Karei 2012).8, 9

Reaching just a few girls may be helpful to those individual girls, but may also render them the exception in the community. If there are too few girls practicing innovative behaviors, the community may find that these girls are being incentivized to leave because suddenly they are outperforming and even violating community standards (Bandiera et al. 2013). But when many girls are seen doing "new things"-completing school, delaying marriage, saving money-and

\footnotetext{
9 In Amhara, Ethiopia, the Population Council's Berhane Hewan program was initiated at a time when half the girls were married under the age of 15; intensive community engagement and participation of girls resulted in 80 percent of the eligible girls participating in the program. This high saturation of participation is credited with shifting the "marriage market" and leading to a delay in marriage of two years. It became normalized and accepted for girls to be in the program and families were incentivized to keep girls in school, so girls were valued as a group, in contrast to scholarship programs that may single out a girl (who usually leaves the community). Where typical girls' lives are affected, there is a much higher chance of normative change, versus when one or two are selected for exceptional investment and their experiences are seen as unusual, and their marriage partners are more likely outside the community. Bottom line, saturation programming is more likely to change norms, such as child marriage, than programming that reaches relatively few girls.
} 
these are girls with whom the most excluded segments of the population identify, norms shift and change at the community level is promoted.

These projections help contextualize the potential impact of new initiatives. It is important to know how many more girls in given categories will need support, not just for immediate planning purposes but for creating prototype programs that can be scaled. For example, during a workshop with an international nongovernmental organization (INGO) in the Middle East, the organization knew that its programs reached 300 girls in an Internally Displaced Persons (IDP) camp. However, the organization did not have a denominator; they did not know what proportion of the refugee girls in a very stressful IDP camp these 300 girls represented. A more in-depth estimate was developed using demographic data. These data suggested that 12 percent of the camp's population consisted of girls between the ages of 10 and 18. With a total population of 90,000 , it was then possible to determine that 10,800 girls in this age range were living in the camp. It was clear that reaching 300 girls was just a beginning. In this way, the simple but concrete data provided the information that the program organizers needed and served as a basis for systematic planning to reach more girls.

\section{Projections of numbers might be undertaken alongside consideration of the population density of your program area and the desirable level of saturation. For example, reaching 200 girls who live within a one-mile radius of each other may have far more impact than reaching $\mathbf{2 0 0}$ girls across a ten-mile radius.} The scattering of participation often reflects a selective bias to better-off girls, such as those who have time to travel. It is often sobering to know, as was learned in Haiti in 2017, that in a densely packed community of 30,000 people there were 2,400 adolescent girls and that a benchmark program that was generally well regarded was only reaching 208 of those girls, which is 8 percent (not enough and given the available budget and tremendous need, a major underutilization of resources). (See Practitioner Report 4, Chapter 9.)

In the next chapter, we explore the concept of the walkable community and the importance of sustainability and scale-up. 


\section{Finding the Walkable Community and Laying the Basis for Program Scale-Up and Creating Clusters of Change}

\section{LEARNING OBJECTIVES}

- Review the theory of change underpinning the focus on girls' walkable communities.

- Understand the potential degree of variation of walkable communities within subnational districts.

- See the full "universe" of girls in walkable communities.

- Learn how to select communities that are representative of your programming area and offer strong prototypes for eventual scale-up.

- Appreciate why it is important to learn how different segments of girls experience the same community.

\section{PRACTICAL STEPS}

- Learn practical/mechanical measures for charting the boundaries of walkable communities.

\section{Defining the Walkable Community and the Site of Accountable, Measurable Change}

A girls' opportunity to grow up safely and flourish is largely defined by the resources available within her home and community and the ability to access them and benefit from them. Girls often face economic, social, or geographic challenges that limit their access within the community. If a girl cannot reach a service or facility comfortably she will likely not benefit from it.

\begin{abstract}
We define the area in which a girl can theoretically safely walk to access community services, facilities, and opportunities as her walkable community. It is in this geographic domain that programs are best anchored. Whether they are safe or not remains to be seen. In Box 5 are examples of potential walkable communities. It is within these community boundaries that key services, facilities, and opportunities should be anchored; services are generally within a 3-4 kilometer (2-2.5 mile) radius.
\end{abstract}


Communities have many different shapes. A walkable community might be a neighborhood in an urban area or a cluster of rural villages. And within those differently shaped and sized communities is another community-the one experienced by girls in different segments (girls grouped by socioeconomic and other characteristics, such as age, schooling, marital status, occupation). Walkable community size and shape varies whether you are working in an urban or rural area, a refugee camp or major town, or by geographic or social features that define the area.

Defining the walkable community is a useful first step in designing programs for girls in any region. However, what is considered a walkable community will vary by context. In some urban settings with dense populations, a girl's community may be far smaller than 3-4 kilometers (2-2.5 miles) and be defined instead by the location of physical boundaries, such as a large road or railroad track, or by the location of a social institution such as a school.

In rural areas, geographic features such as rivers or mountains may bound girls' experience, so even though a predefined administrative district may include both sides of a river, thoughtful observations suggest that girls on one side of the river might have a different walkable community than those on the other. A girl's walkable community may align with her village, but often administrative boundaries do not align; many administrative units harbor substantial internal variation and must be broken down into multiple walkable communities, mindful of those contrasting levels of risk. Box 6 and 7 provide real-life examples.

\section{Why It Is Important to Learn How Different Segments of Girls Experience Their Community}

Access to the walkable community crucially varies not simply by geography, as measured by kilometers or miles, but by social identity. A 14-year-old female domestic worker, for example, living in the wealthy part of town sees the community drastically differently than her
BOX 5. EXAMPLES OF WALKABLE

\section{COMMUNITIES}

- A small, well-defined rural village (3-4 kilometers [2-2.5 miles]; might vary by context).

- A low-income housing complex.

- A small displaced-persons' camp.

- A subdivision of a larger community that is divided by a river (Community $A$ is on one side, Community $B$ is on the other).

- A community set in a mountainous geographic location, with a separate community established at the base of the mountain.

- A subdivision of a large, densely populated informal settlement.

housemate, a school-going girl and daughter of the household. There might be yet another perspective-that of a girl in a poorer family, living far from school and struggling with both the costs and social distance of traveling to and from home and finding time to study. Additionally, a "differently abled" girl (with physical and/or mental/cognitive limitations) may experience other impediments (see Box 8).

Girls' social category fundamentally defines what they can access safely and comfortably (see Box 9). The poorest 40 percent of girls, however defined, can be expected to have the least access to community services and facilities. Their experience, skills, and resource levels are rarely explicitly considered in the placement of services and facilities, neither for recruitment purposes nor considerations of cost. Their experiences are invisible to those higher up in the social hierarchy, including both advantaged men and women and girls not like them. Thus, those likely to be influential in program design-community leaders (who tend to be older and male), teachers (who know and may have a strong bias to inschool populations), health providers (who are accustomed to dealing in poor health outcomes rather than in prevention)-often do not see the girls who are in most-at-risk categories, except after the worst outcomes (pregnant, HIV-infected, etc.). 


\section{BOX 6. ZEROING IN ON A CORE COMMUNITY}

WITHIN AN AFFECTED DISTRICT: A STORY

In Tripoli, Lebanon, a program was established in the largest district where Syrian refugee girls in need were concentrated. Program decisions (including site of services) were assessed in light of geographic and social distance for participants. The Danish Refugee Council (DRC) collaborated with the Women's Refugee Commission (WRC) to help prevent child marriage among vulnerable girls in this community through WRC's 'I'm Here" approach, which uses a series of key steps and complementary tools to improve program inclusion and combat "elite capture." The first measure was to identify the crisis-affected walkable community. Using Google Earth, WRC was able to identify the borders of the program catchment area, Haret El Tanak, noting that the concentration of Syrian families within this community was at the center of the bordered area.

Once the walkable community was defined, the program venue was moved so that it was central to the core Syrian girl refugee area, maximizing the possibility of finding local mentors, of concentrating resources, and most important of reaching a higher proportion of girls with less program effort, that is, "Higher value for money" (Robles et al. 2015). (Acknowledgment: Danish Refugee Council [Rana Raoun], and UNICEF Lebanon [Nisrine Tawily]).

\section{BOX 7. IMPORTANT CONTRAST BETWEEN TWO NEARBY COMMUNITIES IN A HIGH-HIV-PREVALENCE ZONE: A STORY FROM KENYA}

Partners in Kenya who were eager to work on the HIV crisis among girls used the Girl Roster to map 50,000 individuals rapidly over a few weeks (see Chapter 4). Initially, they did not put in the geographic positioning information or break down their records by community, meaning that they still had information at a higher level of organization that allowed them to plan for girls in walking distance. When that information was disaggregated by communities, a striking fact emerged: girls in all of these communities were likely highly disadvantaged. In Ward A, of girls aged 15-17, 10 percent were out of school; in an adjacent community, Ward B, 25 percent of girls aged 15-17-a 2.5 times higher proportion-were out of school.

\section{WARD A}

Age segment Out of school (\%) Never went to school (\%) Married/has a child (\%) Lives with neither parent (\%)

\begin{tabular}{lcccc}
\hline $10-14$ & 2 & 0 & 0 & 14 \\
$15-17$ & 10 & 0 & 10 & 14 \\
$18-19$ & - & 0 & 42 & - \\
$20-24$ & - & 0 & 85 & -
\end{tabular}

\section{WARD B}

Age segment

Out of school (\%) Never went to school (\%)

Married/has a child (\%)

Lives with neither parent (\%)

\begin{tabular}{lccc}
\hline $10-14$ & 1 & 0 & 0 \\
$15-17$ & 25 & 4 & 8 \\
$18-19$ & - & 11 & 44 \\
$20-24$ & - & 18 & 81
\end{tabular}

This information allowed the implementer to make an initial decision of where to begin their pilot work; in Ward $\mathrm{B}$, it is observed that girls aged 15-17 years of age are 2.5 times more likely to be out of school. At this critical age, a lack of schooling, and other foundations of social isolation, can be precursors to social exploitation and its associated HIV risks. In this case, Community B was chosen as the pilot location. $-=$ Not applicable. 


\section{BOX 8. A WORD ON THE TERM “WALKABLE”: CONSIDERING THE NEEDS OF THE DIFFERENTLY}

ABLED

The Population Council's Community of Practice adopted the word "walkable," as in the "walkable community," to help program staff, donors, and other practitioners distinguish between the most general location, likely the narrowest administrative unit of a country (village, ward, city, town) from a place that is experienced as the community the girls feel they belong in and in which you must focus your program. "Walkable" is intended to communicate the scale at which the Council encourages its partners to work. While a community is often a place that is home to hundreds of thousands of people, a "walkable community" is more likely smaller, with a range of 3-4 kilometers (2-2.5 miles), which is, for most, within "mobile" range.

However, sometimes an appreciable portion of people and girls in the walkable community are not mobile in the sense of the definition of "moves freely and easily," and so while "walkable" might encourage the Council's partners to focus on the level at which they should be delivering services and building better access to existing resources, the word is not meant to exclude clients who are not mobile.

Globally, more than one billion people are "differently abled," and in low- and middle-income countries girls and young women are estimated to comprise three-quarters of persons with disabilities. Poverty, discrimination, and stigma only compound their exclusion and lack of access to basic entitlements. Limits to a girls' mobility in the community may be physical-that is, girls may have physical limitations and not have the ability to walk somewhere. It is possible they may be psychosocial, intellectual, or mental as well, making a girl impaired in both her social and material environment. Communities that are walkable by adult males may still not be walkable by girls, even those who are not differently abled.

An Intentional Design approach renders these girls visible and also provides steps that can practically ensure accessibility to those whose contact with the community and its resources is further encroached upon by such limitations. Even addressing the layers of meaning of "walkable" in your own communities is an activity of Intentional Design-seeing and overcoming barriers to girls' participation, whether these barriers are physical or social in origin.

Finally, puberty is a critical moment of inflection, limiting girls to the public sphere (Hallman et al. 2015); at this age they face pressures to focus on caregiving and vital, productive, home-based tasks while avoiding threats to their safety, reputation, and in some settings, marriageability. When girls are discouraged from moving around their community, they may simultaneously lose out on educational opportunities and effectively "disappear" from the view of community members. In the process, girls often become "invisible" to those outside their households, including program staff and practitioners (see Box 9.)

Within selected geographic boundaries, all individuals have theoretical access to services, fixed facilities, social venues and entertainment, and economic-transaction gathering places. In reality, a sense of being welcome and safe varies dramatically by one's gender, social class, and age. Once initial information has been collected on the girls within those geographic boundaries, and segments of girls have been identified and their geography visualized, you may find that like-situated girls live in clusters in specific neighborhoods (see Figure 3). Whether geographically concentrated or not, it will be useful to gather the perceptions of the community among different segments of girls. How do they navigate within it? Describe its boundaries? What are the hours during which they have safe access to different parts of the community (Baldwin 2011; Hallman et al. 2015; Erulkar 2018)?

Designing for Scale: Defining a Set of Similar Walkable Communities
It may seem contradictory, but while your exploratory work is just beginning in a few walkable communities, it is wise to 
BOX 9. COMPARISON OF GIRLS’ AND BOYS’ ACCESS TO THEIR COMMUNITY
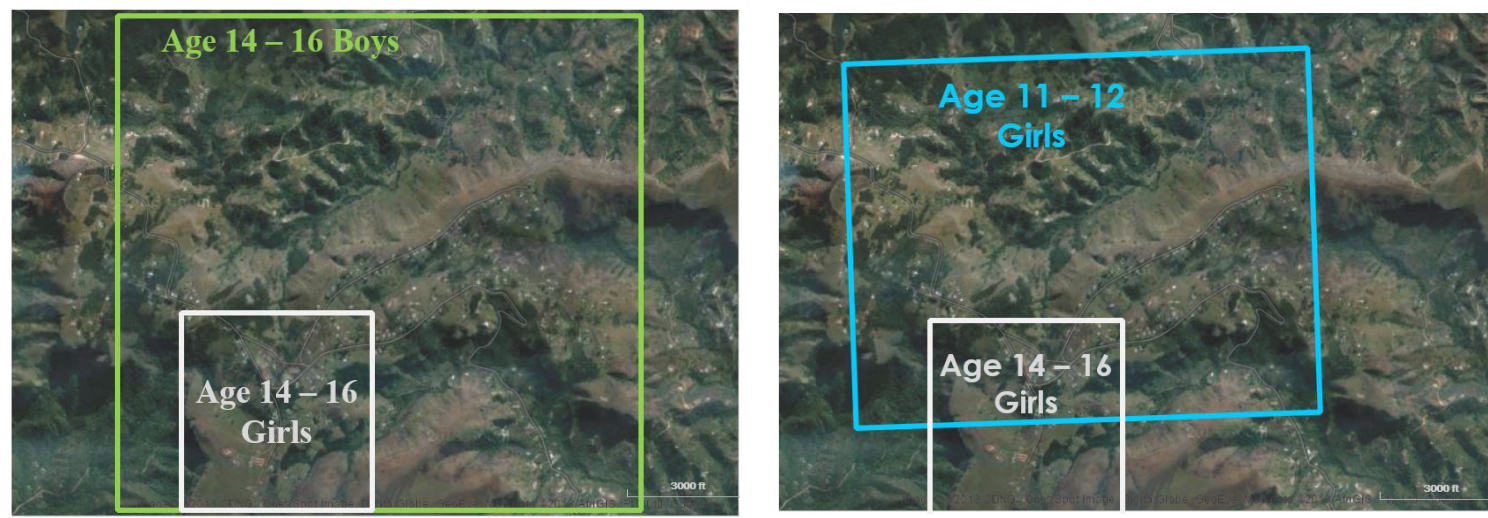

Hallman and colleagues (2015) queried girls and boys aged 10 and 15 in 2006 in rural and urban areas about where they were able to go within their communities. Contrasts were seen both in the amount of space they could comfortably inhabit and the areas. There was a reduction that almost cut in half the community access girls reported between pre-puberty and mid-adolescence (right image). The contrast between boys' and girls' access became more extreme with age, with girls aged 14-16 having access to approximately one-sixth of the male space (left image). This space is then multiplied by hours of access, with girls feeling safe approximately 8 hours a day, at best, and boys feeling safe for 16 hours, resulting in the exclusion factor rising. Girls have effectively one-twelfth the access to the community as boys. These are the kinds of problems Intentional Design seeks to solve: How do we expand the space that different segments of girls find safe and comfortable, and increase the resources within that space?

\section{simultaneously think ahead to sustainability}

and scale. Though programs that work are often founded on similar principles (bringing girls of similar types together regularly), it's also important to select as test communities those that are "typical" of disadvantaged places, not outliers, when laying the foundations for sustainable scale. From the beginning, our first test communities offer an illuminating contrast among them and serve as prototypes for scaling plans: how do we reach and scale programs for girls aged 8-15 in domestic service who typically live apart from parents and work in more urban areas? How do we engage 10-14-year-old girls in rural communities where schooling is typically curtailed by age 14 and forced/child marriages are common by age 15? Features of a program that works in a densely packed urban area in the north of the country will likely differ some from those of a program that works in a southern, agricultural area characterized by larger distances and less population density.
Once you have selected the subnational region where you would like to focus, begin work in a few walkable communities that are typical in size and resource base, and thus are part of a "set" of like-situated communities, neighborhoods, villages, or clusters of villages. Selecting a place with "typical" levels of disadvantage increases the possibilities that the lessons learned are applicable to a wider set of sites. (See Box 10 for the process in Nigeria and Guatemala.). If you are working with poor rural communities, these communities should not be the most extremely disadvantaged.

\section{Scaling Out from Representative Walkable Communities}

Program experiences and exercises from "typical" poorer settings will attract more policy attention and be more applicable and useful when the time comes to scale up. In addition to using secondary data sources, such as 


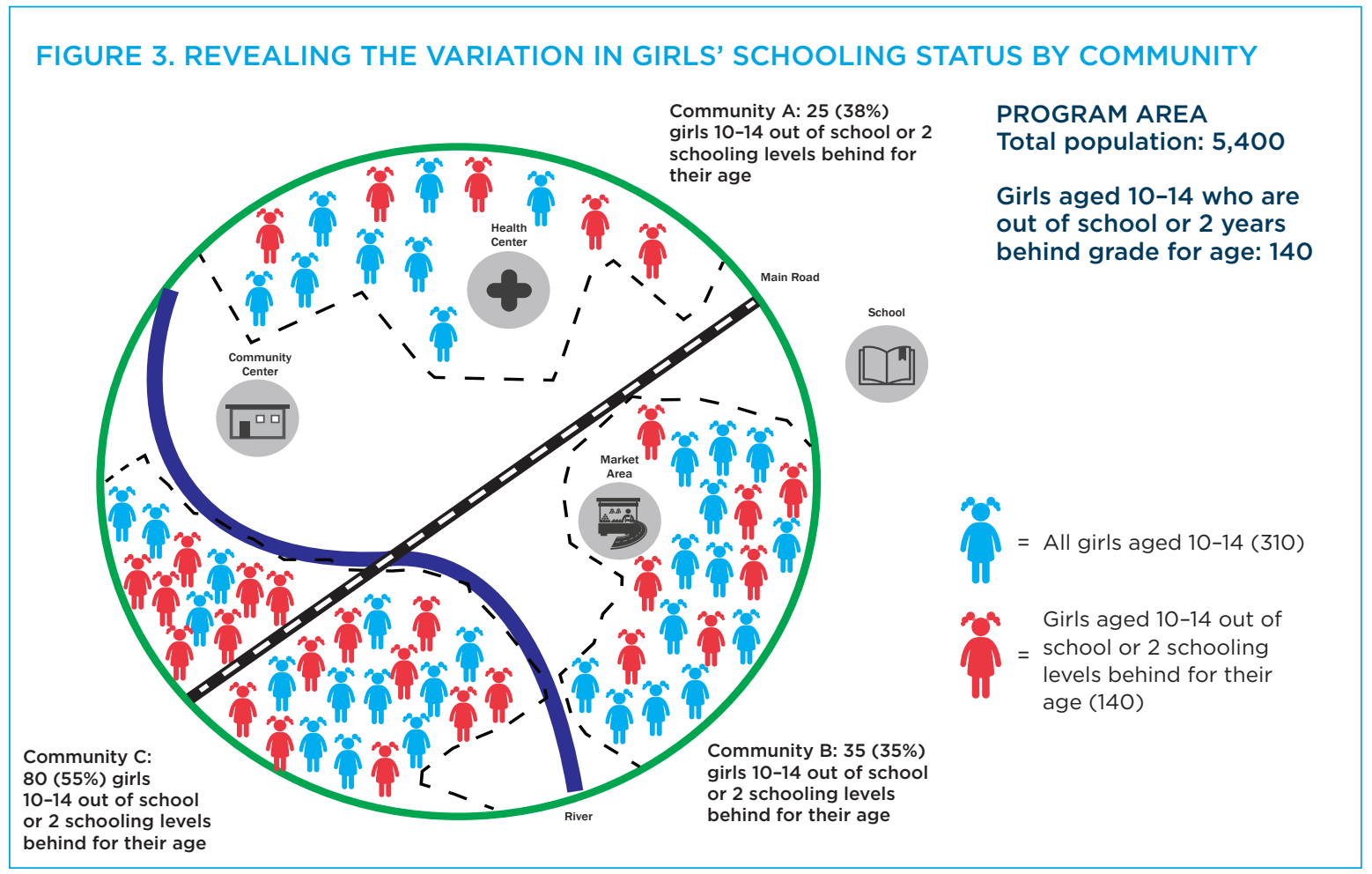

representative surveys, to estimate geographic size and population density, it is important to set clear criteria for the selection of pilot sites with respect to minimum levels of resources and infrastructure (see Box 10). A systematic approach, which identifies such communities within a range, enables program staff to make the case for expansion. Once a program is successfully designed and implemented in a test walkable community, reaching the desired proportion of girls in key categories, the program can be scaled up to nearby walkable communities. Well-selected pilot communities provide a hub from which to scale out a cluster of program communities anchored by a team of program staff and local mentors, and to project coverage of a new and neglected area.

Figure 4 presents a strategy that several programs have used. The programs find clusters of "typical" villages and begin in the center core (green) area, which has some promising features, such as a willing community leader. Having prototyped the work in the core area, the program can more easily reach the adjacent areas (first blue, then pink), which is called spider-scaling (Kohl and Cooley 2005). The Guatemala Highlands and Nigeria (see Box 10) are exemplary cases of using exactly this strategy to reach clusters of villages at one time, initiated in the core of the cluster.

\section{Setting the Boundaries of the Walkable Communities in Which You Will Roster Girls}

It is important to define and map the boundaries of your walkable community and very basic key features (some that might even be visible in a topographic map service such as Google Maps). Perhaps the community is an administrative unit, and perhaps you have defined a neighborhood. Rapid accounting of key geographic and social features of your prospective sites will help you visualize the defined area in which your program will be situated and the community to which it will be accountable.

This is not a complete inventory of community resources, which comes down the line when you 
have a fuller picture of the girls. At a later point, after having set the boundaries and rostered the girls, you can use the Community Resource Scan to locate venues for program delivery, locate existing resources to which girls will be connected, identify gaps in resources to fill, and identify safe and unsafe spaces for girls in the community (see Chapter 6).

As you prepare to work in your selected initial communities, familiarize yourself with the geography and determine its walkability. This learning process is often productively undertaken by program staff, accompanied by community leaders, potential girl beneficiaries, and mentors. As programs generate momentum, staff and community residents familiar with the process might join the first walk as a form of support and training. This offers an illuminating moment in which "invisible" girls are "seen." Clearly, a strategy to give access to key resources to excluded girls is beginning to emerge with this very first exercise.

\section{Visualizing Tools/Maps}

You can use paper maps of the area, or an online tool such as Google Earth or Google Maps to orient yourself within the community in advance of carrying out the mapping exercise. In rural settings, a satellite image from Google
BOX 10. SELECTING PILOT COMMUNITIES:

\section{CRITERIA USED IN NIGERIA AND}

\section{GUATEMALA}

Let us consider an example of a typical community selected for scaling. One organization in Northern Nigeria noted that there were few very small villages and one large city in the area where they worked, and most communities consisted of between 2,500 and 3,000 households. On further investigation, they found that most communities had only minimal access to health and education services. Therefore, when planning initial mapping, they chose a group of typical communities that were within this range in terms of population size and had limited resources available.

A program in rural Guatemala worked in communities that ranged in size between 500 and 1,500 people, and program staff observed that conditions between small and large communities varied in important ways. The program also imposed additional criteria: a typical community was defined as including a road, a community development committee, and a school.

In both settings, program staff looked for typical individual communities and at the same time noted how to cluster them, thereby establishing the groundwork for potential scaling and thus influencing a broader range of communities. In Guatemala, these clusters have helped foster a broader movement where communities look to others for lessons and examples of effective practices that they then use to improve their own efforts to support girls (see Chapter 8).

FIGURE 4. SPIDER-SCALING TO MAXIMIZE COVERAGE

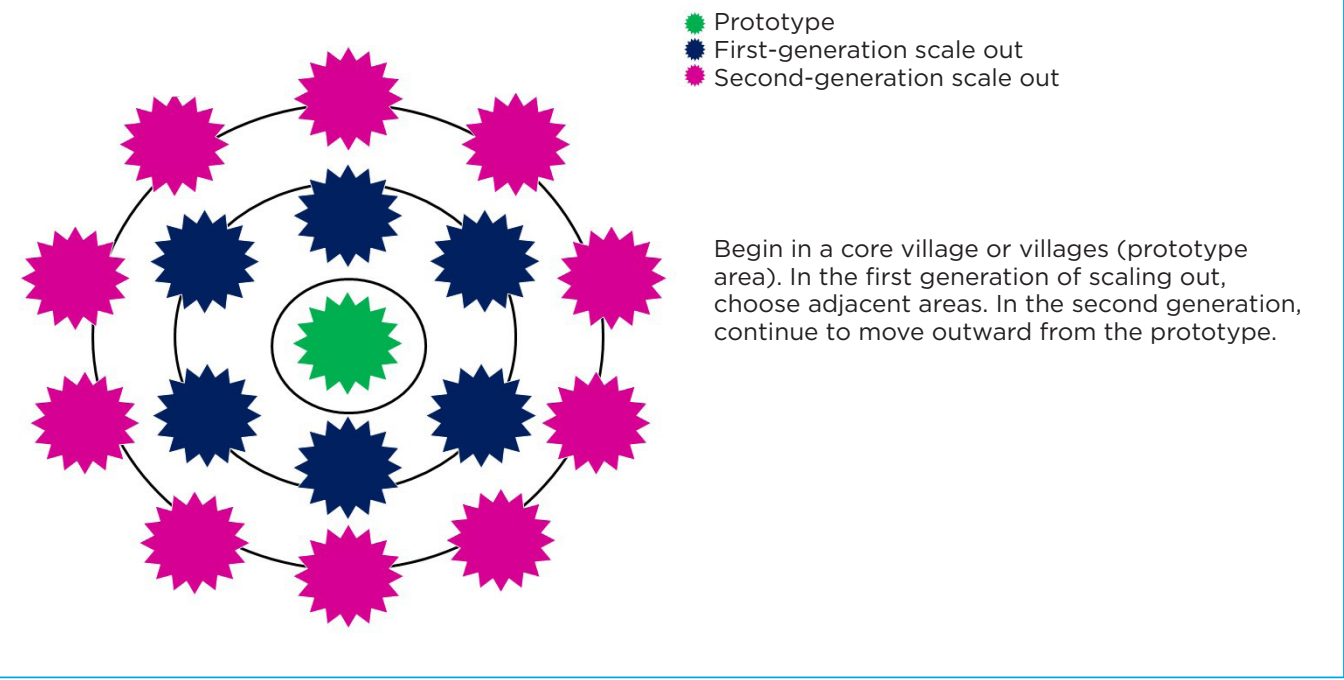


Earth may be the most accurate depiction you can find of a community's geography given that many communities are not officially defined and/or do not have an administrative map. In urban areas, it may be easier to use a road map. Whether the program site is a subsection of a larger neighborhood, such as a community within an urban area or large informal settlement, it represents the "territory" within which the girl program will be accountable. It is often more challenging to define the walkable community in a densely populated urban area than in rural areas.

Nairobi's Greater Kibera is often called the largest slum in Africa. This informal settlement, which includes about 1.3 million people, clearly must be broken down into smaller programmatic units. To define a more manageable area, a program area was carved out by residents familiar with the community who walked its boundaries and uploaded its Global Positioning System (GPS) points. This subsection was additionally broken down into 13 walkable communities. In Figure 5, the Google Earth map shows the subsection of Kibera that was the focal point of program efforts.

The Google Earth map in Figure 6 displays the boundary around a rural village in Sierra Leone, a relatively contained and isolated walkable community. Other such small communities are located nearby. Under the current program strategy of the Sierra Leone Adolescent Girls Network, though each community is mapped separately, some resources, such as a common meeting place and mentoring support, can be shared across proximate small communities, a seedling to the spider-scaling strategy.

If your site does not have official boundaries, you will have to create boundaries for yourself by establishing GPS points. To do so, you may need to walk the site's presumed perimeter with an Android phone and an application that allows you to define a boundary. It is valuable and often inevitable that you include key community features on the map because they tell you clearly where you are.

Having defined the boundaries of your walkable community, you are now ready to take the next crucial step-seeing and enumerating the full universe of girls, and breaking them into significant social segments.
FIGURE 5. KIBERA SUBSECTION IN NAIROBI, KENYA

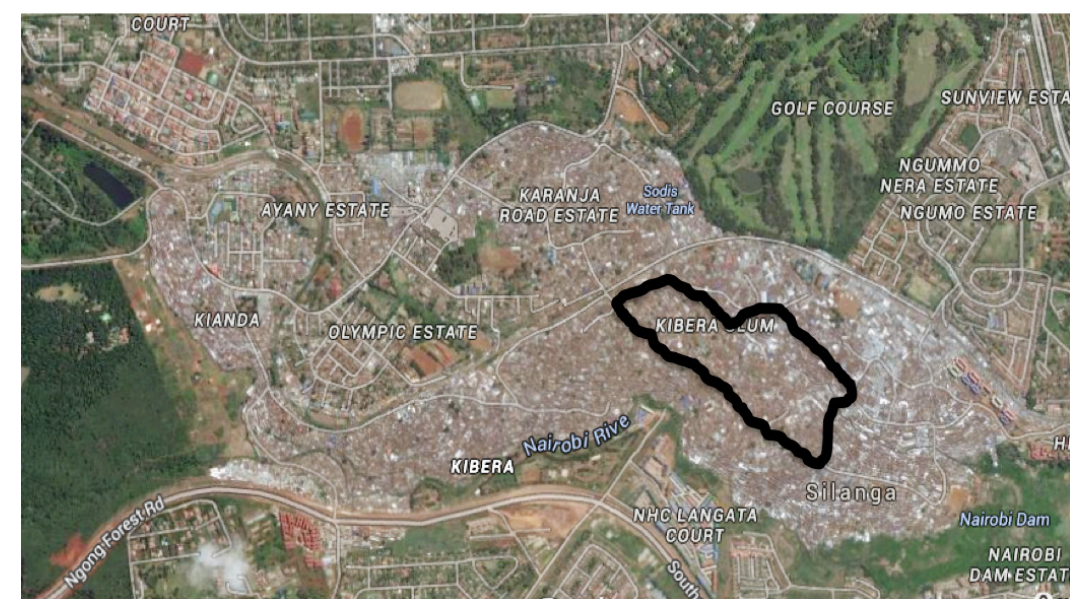

FIGURE 6. SMALL RURAL VILLAGE IN SIERRA LEONE

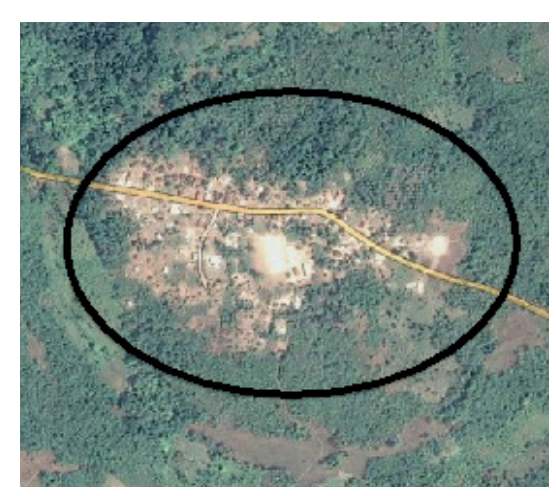




\section{Identifying the Full "Universe" of} Girls in a Walkable Community and Dividing Them into Meaningful Segments for Girl-Centered Programming Using the Girl Roster ${ }^{\mathrm{TM}}$

\section{LEARNING OBJECTIVES}

- Learn why it is important to identify the full universe of girls in your walkable community.

- Learn why dividing girls into meaningful segments is an important step for girlcentered programming.

- Learn about the Girl Roster, and how the information it collects can help you:

-See the full universe of girls and divide them into segments.

-Acquaint program staff with "invisible girls" and foster an empathetic curiosity about their conditions, needs, and potential.

-Estimate the size and location of off-track and on-track girls by age.

-Provide initial insights on social and geographic access to different community resources.

-Determine first projections of who is participating in programs and who is excluded.

- Plan how you can implement the Girl Roster.

- Understand how the Girl Roster can help inform your program design and recruit participants. 
Once you have defined your walkable community and conducted a scan of its key features, the next step is to carry out the Girl Roster exercise, visiting all households to gather basic information about the girls and young women who reside there (see Box 11). This process allows you to: 1) provisionally estimate how many girls who live in your walkable community can be reached through your program; 2) identify their basic demographic profiles (age, schooling, marital and childbearing status, and living arrangements); 3) get a meaningful sense of numbers that need to be reached per segment; and 4) rethink program design elements to best suit these girls' needs.

The Girl Roster supports the broader principle of democratizing communities' investment and promotes the prioritization of the most-off-track segments of girls-those least able to access resources and opportunities. While this seems straightforward, most conventional youthserving programs (including some designed specifically to serve girls) do not reach off-track girls. What's more, without a community-level understanding of girls' demographics, program staff may not even be aware of who they are missing. Even where programs plan to work in high-need sites, with high concentrations of off-track girls, this does not mean that those girls will show up for a program; recruitment strategies are rarely tailored to reach girls who are already marginalized and/or excluded from common community activities. For example, if you are working in a community with many girls aged 14-16 who are in domestic service (girls who are off-track), but you only recruit through schools, you will not find these girls. As a result, a program in a poor neighborhood may only reach girls who are already at some advantage, leaving domestic workers behind.

Information gathered from conducting the Girl Roster helps identify the size and location of different segments of girls (by age, schooling, marital and childbearing status, and living arrangements), including the girls who are most in need and likely to benefit from a program and matching the aspirations of your operational plan. For example, if you are implementing a program that is attempting to mitigate the risk factors girls married under the age of 18 might

\section{BOX 11. FUNCTIONS OF THE}

GIRL ROSTER

The Girl Roster is:

- User-friendly/practitioner-led

- $\quad$ Requires limited training and is easy to implement

- Contains only nonsensitive questions

- Lays the foundation for overarching programmatic decisions

- An opening into the learning process of intentionally designing programs for girls

The Girl Roster is NOT:

- A research tool

- Meant for asking sensitive questions

- Meant for deciding which individuals receive specific benefits such as a cash transfer

face-e.g., isolated or limited freedom, early pregnancy, sexually transmitted infections (STIS) and HIV/AIDS, and violence-the Girl Roster can help identify potential participants and where they are located in relation to each other and to the nominally "helpful" resources.

The Girl Roster can also guide appropriate staffing by providing answers to such questions as: "Are there potential mentors?" and "Where do they live in relation to girls at most risk?"

Additionally, the Girl Roster allows a glimpse of the age at which it is necessary to intervene to prevent unwanted outcomes (like school leaving or pregnancy). In viewing the results of the Roster, one can get a general sense of the age at which it is necessary to intervene to prevent the worst outcomes that could lead a girl offtrack.

The information derived from the Girl Roster exercise also supports program implementers in evolving an evidence-based theory of change. For example, the Girl Roster can indicate how many girls aged 10-14 in the community are out of school and living apart from their parents and begin the conversation about how many girls in this segment must be reached with the program. This is considered the required saturation to make a difference. When seeking 


\section{The Girl Roster reveals the heterogeneity of girl populations, and appreciation of their heterogeneity is key to intentionally designing a girls' program.}

to affect community norms, it may become clear that an initial plan of reaching 25 girls, out of 500 at risk, will not be enough to alter pervasive acceptance of child marriage or high levels of sexual exchange for gifts and money among poor, uneducated girls.

The Girl Roster has been applied in rural, periurban, and urban areas, conflict zones, refugee camps, informal settlements, and affordable housing complexes (see Box 12). It has been implemented in 43 countries $^{10}$ and translated into 21 languages. In every context, the profile of girls has been different and program staff have learned something new (and often surprising) about the girls in their walkable communities. For example, an organization in Haiti was very surprised to learn how many girls aged 6-9 in their community were out of school, in a country where elementary education between ages 6 and 11 is compulsory. After learning that school dropout begins earlier than expected in this community, the organization redirected its programming to include segments of girls aged 6-9 who are out of school, as opposed to only focusing on older girls.

\section{Dividing the Universe of Girls into Meaningful Segments for Program Planning}

Girls and young women, even those living in the same community, are a diverse group. Some have similar experiences and situations, such as being 15 years old, living with both parents, and being in school, while others are quite different-already married at 15, out of school, and living with a husband. Although these girls share the same age, they are socially distinct; their lives contrast in many ways, including

\section{BOX 12. "I'M HERE": MAKING ADOLESCENT GIRLS VISIBLE IN A CRISIS}

As part of its efforts to foster better responses to crisis-affected adolescent girls' needs, the Women's Refugee Commission (WRC) has led the introduction of the Girl Roster in humanitarian contexts. The Girl Roster is part of the "I'm Here" approach, a series of steps and complementary field tools that equip practitioners to see, understand, respond to, and be accountable for addressing the distinct needs of those adolescent girls and boys who are too often overlooked in humanitarian responses. WRC developed two optional modules that can be included with the Roster: the "Boy Matrix," which gathers and displays sociodemographic information on boys, and "Inclusion Now," which supports disability inclusion in adolescent-serving humanitarian programming. Find resources at womensrefugeecommission.org/ research-resources/.

their daily pressures, the places where they feel comfortable, and the services they can access safely. Thus, a peer group is not simply individuals who share an age and gender but individuals who also have meaningful connections to one another through a shared lived experience.

Programming for peers allows for sound recruitment plans, mentoring arrangements, and content development. This tailoring of material per segment creates more comfort for participants, which is often reflected in higher attendance and retention in programs. In short, the most effective programming is not simply girl-centered, it is peer-girl centered.

10 This includes settings where WRC has supported partners in using the Roster and l'm Here approach (Robles et al. 2015.) 
FIGURE 7. ADOLESCENT GIRLS, MARRIED "WOMEN," AND MARRIED GIRLS ARE DISTINCT POPULATIONS FOR PROGRAMMING PURPOSES

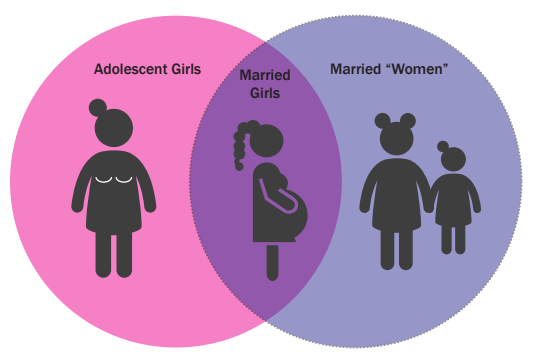

Married girls have their age in common with adolescent girls, but not their marital status. Married girls have their marital status in common with married women, but not their age. Therefore, married girls are their own segment.

Married girls are an interesting case in point. In policy documents they seem to be categorized as "married" women, but on the ground they are behaviorally distinct and treated differently than even slightly older females. By social status they are women, but by age they are adolescents. In general, married adolescents (under exact age 20) are less likely to participate in programs for married women than those over 20-often, by then, with several children. Married girls may also not be considered appropriate peers for unmarried and presumably not sexually active adolescent girls. The Girl Roster, in fostering household-level inquiry, helps us to find younger, married girls often carrying starkly elevated disease and reproductive risks (see Figure 7). In 2020, Roster findings on over 9,000 Syrian refugee adolescent girls in both urban camps and rural settlements found about 10 percent of those 13-17 years old were already married, many with children, and only negligibly attending reproductive health, financial inclusion, and education activities in the area (see Chapter 9, Practitioner Report 17).

Demand-led recruitment-that is, initially accepting all who might wish to attend a program-may mix populations of girls, such as those who are in school and those who are out of school. This approach may be ineffective because girls who are out of school may not socially relate to those who are in school. The daily realities of out-of-school girls and inschool girls do not align. Out-of-school girls, for instance, might have lower literacy skills but higher numeracy skills, resulting from being active in the marketplace. Also, mentors might have an unconscious bias to gear program sessions toward those who are more like them, such as the in-school girls, rather than effectively working with younger, less literate girls who are less socially anchored. It is also possible that the lack of access to the proper pedagogical tools to create more targeted session content limits mentors from working effectively with less literate girls. Intentional peer-oriented program design must reflect the distinct needs of different segments of girls, and adjust to meet their priorities.

The Girl Roster lays the foundation for establishing different segments of girls, planning programs that meet their specific needs, and establishing connections to existing community services and resources. In these programs, girls meet regularly with peers in safe female-only settings. A program, for example, might treat a health service space as a safe space for married women who commonly access it, allowing them to link up with each other and introducing them to other resources, such as banks and other financial institutions. Out-of-school girls will need nonformal education and social support, which they gain through regular meetings at accessible places. Such girls are often less socially connected, may be new to the community or a migrant, or may be living apart from parents. They might especially need a "program ID" that would help them establish some standing and rights in the community. As an example, for the Population Council's successful Biruh Tesfa (Bright Future) program, which had, as of 2018 , reached 61,000 at-risk, out-of-school girls aged 8-20 in urban Ethiopia, girls were provided with program IDs that had been stamped by kebele chiefs and allowed for group introduction visits to the local health center. These chiefs are effectively the mayors of urban centers.

The Girl Roster is used to gather basic, nonsensitive information about the girls in a 


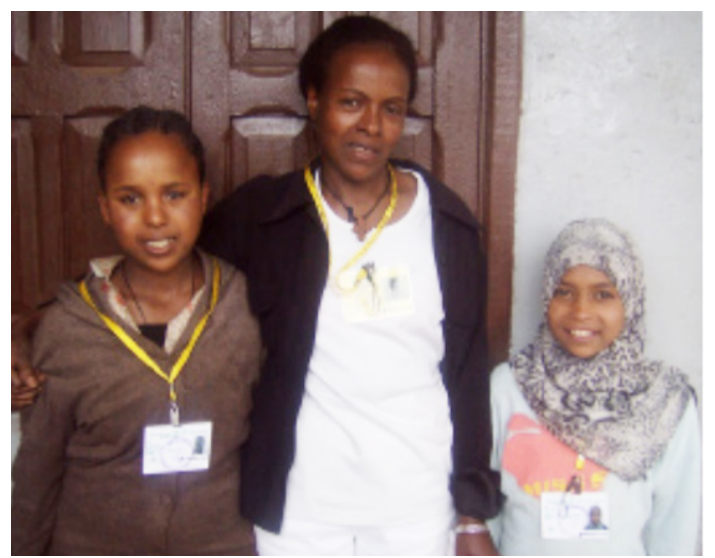

Girl participants of the Biruh Tesfa program in Ethiopia wearing program IDs. The program mainly serves girls aged 8-15 living apart from parents and not in school. (Photo: Zeleman Productions.)

particular household from a knowledgeable adult member. As staff become more experienced, the average completion time for in-person Girl Roster questionnaires generally decreases from 15-20 to 7-10 minutes. The Girl Roster produces information about the on-theground reality, household by household, of the real girls who live in a program communitynot about girls in general. It is not a survey or research tool, but those who do research or more rigorous information collection certainly appreciate its value (see Box 13).

The information generated by the Girl Roster can guide program staff who are assessing existing efforts or initiating new efforts to refine their approach based on better-anchored estimates. Finding out about all the girls in a community allows program staff to both count and categorize the most-at-risk girls and also identify those who may serve as program mentors in the community.

The Girl Roster typically relies on open-source (freely available) software programs to collect basic information, and is designed as a mobilebased application. It can be conducted using paper instead of an Android phone in contexts where mobile devices are not accessible or might be considered intrusive.

The information as reported is uploaded and, using web-based platforms, is sorted into readable Output Tables, usually displayed

\section{BOX 13. BASIC PRINCIPLES OF THE GIRL} ROSTER

\section{Brief household visits}

A single interview should take no more than 7-10 minutes to complete. This increases the number of households that may be visited in a day and ensures that participating in an interview does not cause undue inconvenience to respondents.

\section{Nonsensitive questions}

Basic demographic information about girls and their households is sufficient to plan a program and design recruitment strategies. Information about more sensitive matters, such as girls' experiences of sexual and gender-based violence may be addressed once girls are enrolled in a program. However, any potentially sensitive information, including current pregnancy, HIV status, and experiences of violence, is not appropriate for the Girl Roster exercise. Not only is the addition of such information beyond the scope of the tool, but it would also require ethical approval.

\section{Actionable information}

Because the Girl Roster is a program tool, not a research or evaluation instrument, it should incorporate only the minimum amount of information needed to guide basic decisions for program design.

through Google Sheets. The tables can be sorted by disaggregated information for each walkable community, or aggregated up for the entirety of the rostered district. So, for example, if you selected four walkable communities to roster that comprise a portion of a larger district, we encourage you to look at the information at the walkable community level for those four areas, as we have explained the important value of community-level information (see Chapter 3). The option is also available to compile the information, so that each Output Table is populated by the information from all four communities.

These rapidly generated, easy-to-read Output Tables highlight off-track girls and neatly groups them into segments. The Output Tables can be specialized in certain circumstances, such as when there is an unusual schooling pattern and 
the type of school attended makes a difference (e.g., religious, public, private, vocational) in understanding girls' social networks and educational status. The Output Tables provide totals for different age cohorts (for example, the number of girls aged 6-9) and social categories (such as the number of girls in a given age group who are married). Girl Roster information can be gathered and analyzed quickly, often within 24 hours.

The Girl Roster is distinct from a survey that might be conducted to reach a select sample. It is best completed in an area where a high level of disadvantage exists among girls, with many living in challenging households in underresourced communities. The goal of the Girl Roster is to reveal invisible populations, and it is designed to provide a fast estimation and actionable information.

\section{The Girl Roster Collects Information and Divides Girls into Actionable Social and Demographic Segments}

The concepts of on-track and off-track are based on national and global guidelines for girls' rights, laid out by governments, local governing bodies, and international covenants. These commitments include: having a minimum number of years of schooling (and the latest age to start school), and allowing consented marriage at a legal age. When a girl's profile suggests that she is out of school when she is of school-going age or is under age 18 and is married or has a child, she is considered to be off-track, referring not to her failure but to society's failure to protect her and ensure her rights to a safe and supported childhood. As such, the Girl Roster questionnaire asks about girls' age, schooling, marital and childbearing status, and living arrangements. Living arrangements give a sense of how many adults-especially parents-are nearby to support a girl socially and economically. (See Box 14 for additional details on indicators and how they relate to a girl being on-track or offtrack.)

\section{The goal of the Girl Roster is to reveal invisible populations, and it is designed to provide a fast estimation and actionable information.}

\author{
The Girl Roster Is Designed to Be \\ Applicable to a Range of Settings and \\ Program Goals
}

As a rapid learning tool, the Girl Roster keeps direct questions to a minimum, limited to the essentials. Questions about household wealth or relative economic status are not included, as these may be sensitive and difficult to gauge. Furthermore, the wealth of a household is not the wealth of a girl, and a poor girl in a wealthy household (such as a domestic servant) may indeed be especially disadvantaged. Sometimes, however, there is information that can be observed and recorded, which a given organization might find important. For instance, if roof type is an indicator of deep poverty or a special health risk, staff might record whether a given home has a tin or thatched roof-but this

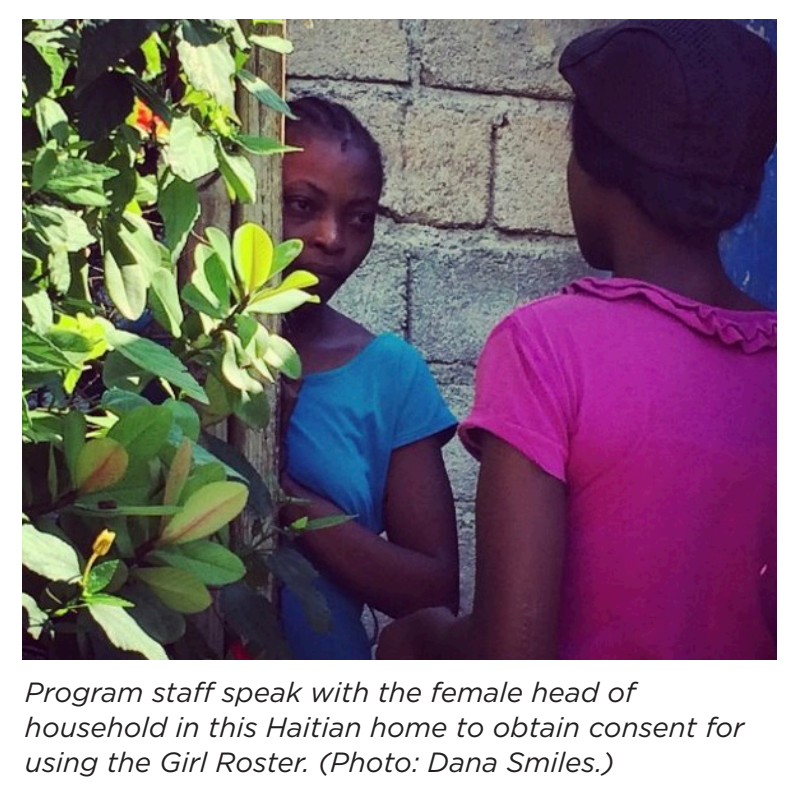


observation is not incorporated in the formal questioning.

Girl Roster results can be mapped using GPS tracking. When program planners use the output of the Girl Roster, they can discern whether girls of a particular type are concentrated in a certain geographic area. Out-of-school girls, for instance, may be more concentrated in densely populated parts of the community, or on the outskirts. By crossreferencing the location of social groups with the location of different facilities, it helps us understand accessibility; for example, married girls concentrated in Neighborhood A may have more restrictions on their movement than their unmarried, school-going peers who might be concentrated in Neighborhoods $B$ and $C$. Therefore, programs might select neighborhoods where many married girls live, or organize existing activities in areas they frequent (Tuesday market days, for example). When maps indicating where different groups of girls live are compared to resources available in their communities (see Community Resource Scan, Chapter 6), program staff can identify places where girls are near resources, and also challenges that may be faced, such as long distances to a mobile phone charging station or a savings bank. (See Figure 8 for an illustration of how girl segments may be socially and geographically anchored in their communities.)

\section{BOX 14. THE INTERSECTION OF GIRLS' RIGHTS AND EVIDENCE ON HEALTH AND OTHER OUTCOMES: THE FOUNDATION OF ON-TRACK/OFF-TRACK IDENTIFICATION}

\section{SCHOOLING}

In most countries, girls (and boys) are expected to be in school by age 6 and to stay through at least age 14, with a growing number of policies specifying that school-going should continue through age 16 or 17. The Girl Roster asks whether girls aged 6-24 are in school. If a girl of school-going age (however defined in a particular country) is not in school, she is off-track in relation to government commitments. Such girls may be a priority segment for programmatic intervention. If she is in school but behind the appropriate schooling level for her age by two or more years, she is off-track.

\section{MARRIAGE}

Under the almost universally ratified Convention on the Rights of the Child, and recodified in most national laws, any marriage involving a girl or boy under age 18 is child marriage. Child marriage is often linked to school attainment: married girls often are forced to leave school while girls who have dropped out of school may be forced to marry. Girls who are married as children may also have large age differences from spouses, creating steep power imbalances, and they may face restrictions on their movement, and pressures to become pregnant that they are unprepared to manage.

\section{CHILDBEARING}

In most circumstances, girls who have children are married, and married girls have children soon after marriage. However, there may be some circumstances in which girls have children outside of marriage. While communities may regard young married mothers with respect and stigmatize young unmarried mothers, both groups face barriers to developing critical health, social, and economic assets. Young mothers and their children often need dedicated help and social support.

\section{LIVING ARRANGEMENTS}

Adult protection and care is critical to any child or adolescent. Girls' prospects are heavily conditioned by their living arrangements. Girls who live with both their parents are more likely to have both economic and social support. While living with one parent is also protective, girls who live with one parent or guardian may face greater demands on their time than girls who live with two parents or a guardian. Those girls living with neither a parent nor a guardian may lack the basic support they need to continue schooling. Therefore, the Girl Roster records whether the girl is living with both parents, one parent, or neither parent, and in cases where lack of any sort of guardianship indicates vulnerability, living with a guardian as well. In the basic Output Table, girls are sorted into categories based on whether they are married and, if unmarried, whether they live with both, one, or neither parent. 
FIGURE 8. ANCHORING EACH PRIORITY SEGMENT OF GIRLS IN THEIR OWN PEER PLATFORM

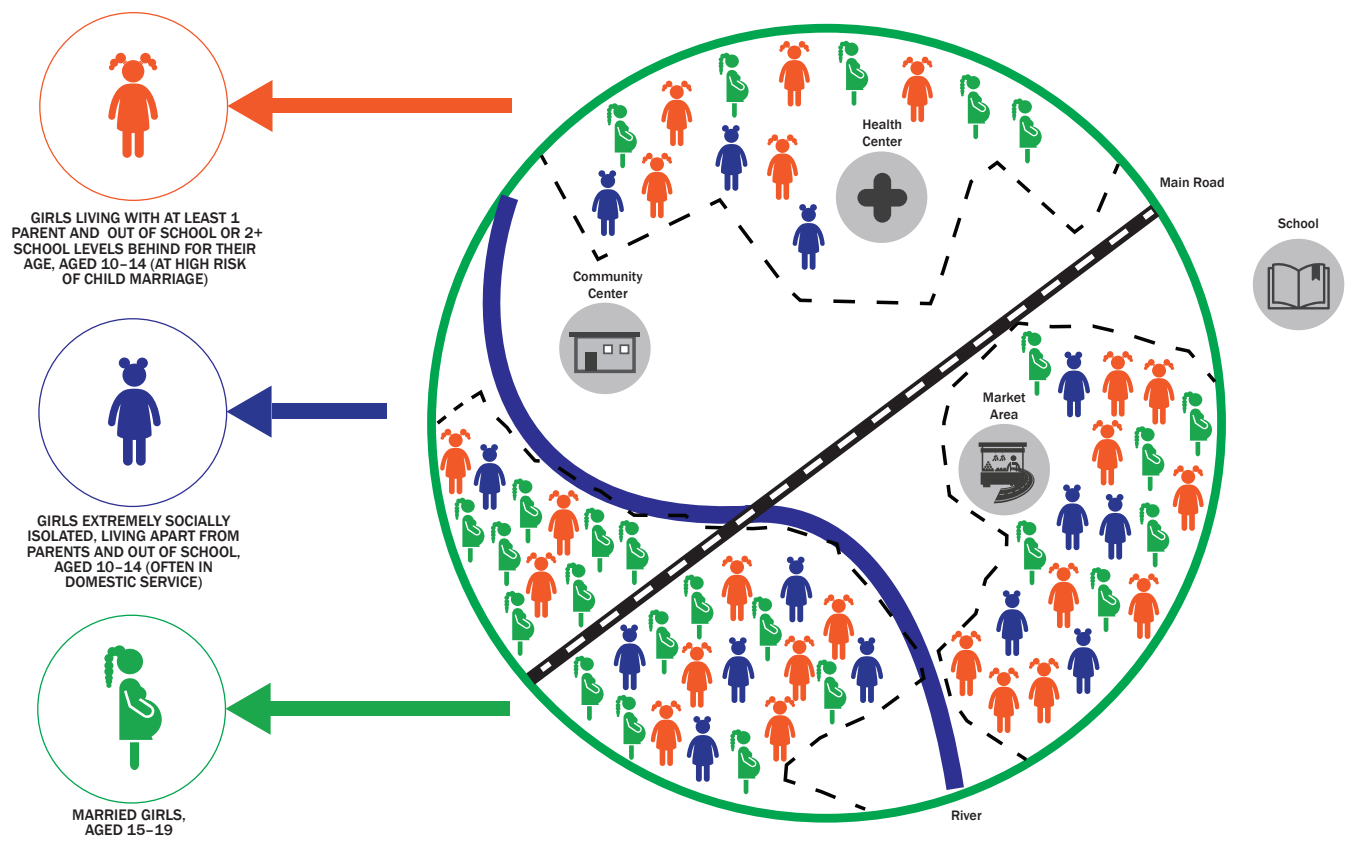

A simple program-participation question or short sequence of questions can be added to the Girl Roster if you want to know more about whether an existing program is reaching the community. For example, you might include the question "Is this girl a participant in Program A?" In communities where an organization has already established a program for girls, the Girl Roster can serve as an early warning that key segments of girls are being overlooked. If, for example, there are large numbers of out-ofschool girls aged 10-12 in a community, but they are not participating in a program designed to reach the "most vulnerable," this should prompt program staff to take action. For example, they may seek to determine whether this is because the girls do not know about the program. Or, for example, is it because the meetings are at a time of day or week they cannot attend? Do their parents or caregivers need extra encouragement or information about the program-and can consultations help provide information they need to support girls to return to school?

\section{Customization of the Girl Roster Questionnaire}

Although the Girl Roster is applicable to a range of settings and program goals, the question-and-answer choices may be adapted slightly as long as the questionnaire remains brief, nonsensitive, and generates actionable information. For example, in settings where there is a dramatic difference in the quality or nature of schooling, an additional question can be asked about the type of school attended (academic, or religious-only instruction). This can be a valuable question when, for example, girls are attending a religious school with little or no academic content and their reading or writing skills are not being developed, and a program that requires participants' literacy unintentionally excludes them. In this case, classifying them as "in school" does not help in understanding their status, livelihood prospects, and so forth. Counting them as "out of school," however, can also be inaccurate.

In Sierra Leone, the question "How many people live in a household?" was modified because both polygamy and sharing of housing structures are common. Therefore, the question 
was revised to: "How many people eat out of the same pot?" because this follows the local understanding of a household as centering around a woman and her cooking pot. Similarly, in The Gambia, polygamous families reside in compounds, and a household consists of a mother and the children attached to her, thus in a compound with four wives, four interviews were conducted.

\section{Ethical Considerations When Using GPS to Implement the Girl Roster}

When implementing the Girl Roster questionnaire, all normal ethical considerations must be observed including initial consent to be interviewed. These considerations are especially vital when considering the GPS coordinates that the Girl Roster records. The Girl Roster takes GPS coordinates for each household. The inclusion of GPS coordinates is immensely valuable as it allows program staff to generate maps that illuminate girls' geographic anchoring in the community by segment, but the GPS must be managed in a way that does not put girls at risk. It is vital to review all benefits and procedures and review questionnaires for any content that is inappropriate to the context or interferes with trust. For example, when necessary, program staff can disable the GPS feature.

Contact information for the girls or interviewees, if requested by the sponsoring organization, should be collected separately from the Girl Roster and be optional. We know that many groups take responsibility for getting consent for contact information because they wish to contact a household to follow up about programming. If contact information is requested, it is the responsibility of the organization to keep it safe and secure.

\section{Using Android Phones to Implement the Girl Roster}

The Girl Roster can be completed using a mobile application optimized for use on Android mobile phones or tablets. Using this application on these devices simplifies the process of adapting the questionnaire,

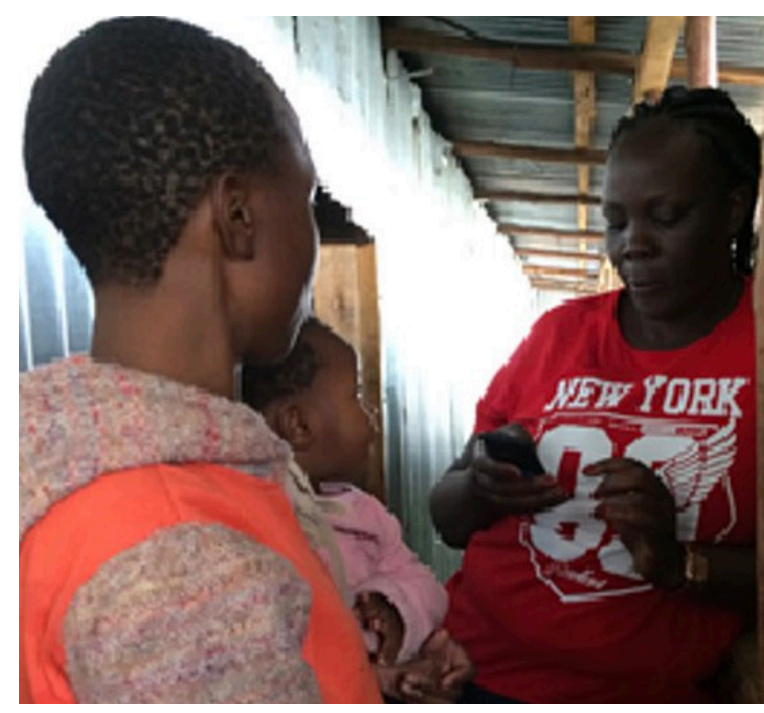

Implementation of the Girl Roster in Nairobi, Kenya. (Photo: Dana Smiles.)

recording responses, collecting and managing information, and enabling program staff to collect the geographic location of households. An initial investment into Android phones or tablets saves time and money in the long run, and helps prevent errors. However, if using phones/tablets to collect information is not feasible or is beyond your budget (suitable Android phones/tablets can cost at minimum US\$100 each), you can achieve similar results with traditional pen and paper.

When using Android phones/tablets, the basic questionnaire is created in an Excel-like template. Once the questionnaire has been completed, it is uploaded-and results are stored-in a secure online platform. For details on how to access the Girl Roster questionnaire, contact the Population Council at girlroster@ popcouncil.org. Up-to-date technical details on how to prepare and implement the Girl Roster can also be obtained.

By using Android phones/tablets, information is collected digitally and received almost instantly. No manual data entry is required as with paper surveys. Using the mobile application, skip patterns are automatically generated; a skip pattern is a question or series of questions associated with a conditional response, meaning that if a question does not pertain to some girls, it will automatically be skipped by the questionnaire, reducing the risk of user error. So, for example, if the girl never attended 
school, the questionnaire will skip any additional questions about her schooling experience.

Geographic location (i.e., GPS coordinates) can be collected as part of the exercise, which makes it possible to see where girls live in relation to each other and to resources, and where potential mentors live. This information can inform discussions about where to locate program activities, and areas to avoid, such as those that are far from girls' homes or require crossing roads.

\section{Adapting and Translating the Girl Roster Questionnaire}

Before implementing the Girl Roster, review the questionnaire and conduct practice interviews with individuals from the community you are working in, or similar to one in which you will be working. By conducting practice interviews, program staff can better anticipate any positive responses or doubts from community members in using the tool. Needed revisions might be revealed during this process, particularly on how a question needs to be phrased in translation or in more appropriate local terms. While the questionnaire currently exists in 21 languages, to some extent it must always be adapted. The questionnaire should be assessed considering the following:

- Is the language clear, accurate, and representative of what is being asked?

- Are you satisfied with both the questions and the answer choices?

- Are program staff who will ask questions and record information comfortable with the procedures and information being asked?

- Is it understood that participation by households is private and voluntary, and that answers are not cross-checked (that is, verified by more rigorous research)?

- Have program staff thoroughly reviewed and practiced the questionnaire?

\section{The Field Experience}

Before going into the field, there is always enthusiasm and expectation about the results;

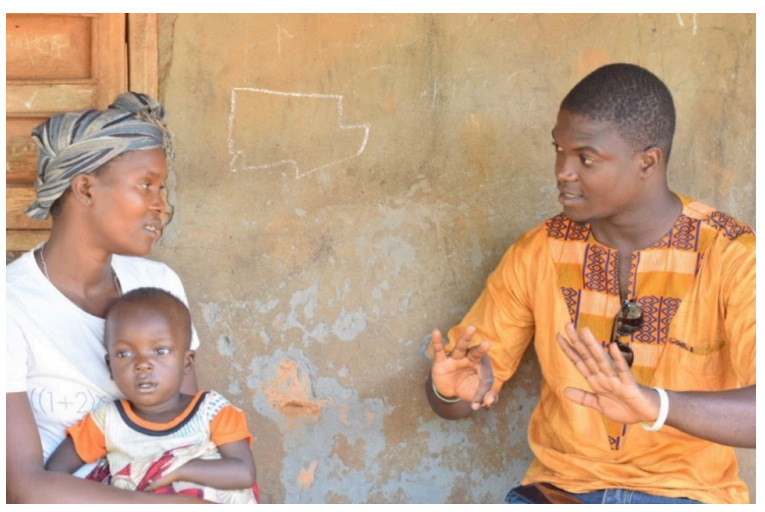

Introduction of the Girl Roster to the female head of household in Freetown, Sierra Leone. (Photo: Sierra Leone Adolescent Girls Network.)

however, Girl Roster results can really surprise program staff, as we have often observed from our partners. A worthwhile exercise before using the Roster for the first time-and one we have encouraged among our partners in many settings-is to ask program staff to note what they assume the Roster results will show. The types of reflections you might elicit are: What do you think is the total population size of girls in the community? What is the proportion in versus out of school? How many girls do you anticipate are married/have children? You can note your assumptions, implement the Roster, and then compare the realities the Roster results present in contrast to what you expected.

For example, in The Gambia a group of implementing organizations were tasked to roster a community where many community members lived in large compounds composed of polygamous families. Because The Gambia is a small and closely knit country, many program staff expressed a deep familiarity with this community and as such seemed certain of what the Roster results would show them. Although, as expected, their assumptions were in line with many of the results, one result stood out to them afterward-the total population of girls far exceeded what they had expected, and this, they quickly identified, was because many girls in the community were hidden in these compounds, deeply isolated from the rest of the community. This little exercise in testing assumptions out, therefore, proved an eye- 
opening one that informed their path forward as they continued to roster.

When the Girl Roster implementation is underway, a community of 100-300 households, with approximately 5-7 teams of rosterers can take only 2-3 hours to completely roster. All households within the walkable community should be approached. While the refusal rate is usually very low, sometimes no adult is at home to answer questions, and some households may not give consent. Noting even "not at home" is a useful category. For example, in one part of a settlement near Dar es Salaam, Tanzania, migrant men lived in small households and sometimes in groups, and were absent during the day and weekends. Program staff could see that this was valuable to know as the area was full of bars as well as single men, and so not an ideal site for a girls' program to meet.

The length of time and cost it takes to complete the Girl Roster for your program depends on the size and population density of your walkable community, the number of trained people you have conducting it, and the number of phones/tablets. Programs engage their staff, community members, and even young women (age 18 and up) who are current or potential mentors, to conduct the Girl Roster. We refer to those who implement the tool as rosterers, and recommend that they work in pairs. One pair with one phone might complete 6 questionnaires in one hour, and 30 questionnaires in one five-hour workday. If ten pairs are in the field, comprised of those from one organization or several, or including local community members, then 300 households can be interviewed in one day even if that is a training day. A densely populated walkable community of 1,000 households could thus be completed by ten pairs in three to four days.

It is preferable that Girl Roster questions are answered by an adult female who is in charge of the household and likely has deep knowledge of the girls who live there. Subjects include: age, schooling, marriage and childbearing status, living arrangements, and, if desired, program participation. If there is no woman available to be interviewed, you can speak with any adult who is available and willing to answer the questions. The girls who are the subject of the roster are not directly interviewed. However, if a young woman under 25 self-identifies as the "most knowledgeable" woman in the household, it is acceptable to interview her. In cases where there may be child-headed households, it is important to check local policies regarding conducting interviews with minors who head households in your setting before designing guidance for rosterers. In some places, a child under 18 who is living on her/his own, married, and/or caring for younger children may be considered an adult and can be interviewed. Obtaining consent from participants (heads of household) before conducting the Girl Roster questionnaire is always required (see Box 15 for more details on unsuitable respondents).

\section{Key Girl Roster Questions}

The Girl Roster questionnaire begins by asking the rosterer to record basic details, including

\section{BOX 15. UNSUITABLE GIRL ROSTER RESPONDENTS}

When conducting the Girl Roster exercise, it is preferable to speak to the female member of the home who knows the most about the people living there. Typically, that is the eldest woman. If neither she nor the most knowledgeable man of the household is available, you might encounter others who are willing to provide responses, namely girls under the age of 18. As capacity-building partners, the Population Council generally advises against implementing the Roster with an interviewee under the age of 16 , although each organization is welcome to determine for itself whether it is acceptable to interview an underage respondent or not.

In those instances where you must decline to roster a household because the respondent is unsuitable, the Council suggests you politely extricate yourself from rostering and select "No" to consent question "Does this person consent to participate?" The Roster will then prompt you to select the reason why consent was not given, and here you might select that it was a "Child-Headed Household." 
date, rosterer ID (a number assigned to the individual or team of rosterers), and location. The Roster then lists basic questions about the girls, household makeup, and other observations. While every question is subject to adaptation, the following sections detail the most standard template. The questionnaire prompts the rosterer to identify the location and sublocation of implementation. This is an important and context-specific question, helping program staff think about what constitutes a truly walkable community from a girl's perspective-and a meaningful catchment area for their program (see Box 16). Following these questions, which set the scene for rostering, the questionnaire prompts the rosterer to make introductions, obtain consent, and identify the person with whom they are speaking. For more information on this,

BOX 16. HOW TO DECIPHER WHAT THE WALKABLE COMMUNITY IS: TWO EXAMPLES FROM THE GAMBIA AND MOZAMBIQUE

The small country of The Gambia is divided into five administrative regions which, because of their small size, were used as the "locations" for a Girl Roster implementation conducted in November 2017. These five regions are further made up of administratively designated communities that became the "sublocations" of the Girl Roster implementation. Sometimes it is difficult to go by administrative designations because they are too vague or too large. For example, in Nampula, Mozambique, using the steps to identify the walkable community, it was determined that the location for the purposes of the questionnaire was the bairro, the smallest official administrative designation. Since it was not walkable (because of its large size), the practitioners identified sublocations using local descriptors (e.g., "the area before the river," "the area after the river") and each was assigned a walkable community name for the purpose of rostering. The point of this process is to assure that the information is aggregated in ways that reflects girls' experiences and access using the boundaries they perceive as their community. contact the Population Council at girlroster@ popcouncil.org.

\section{Household information}

First come the household information questions. The objective is to allow the respondent to systematically count the total number of people living in the home to make sure no girls are overlooked in the information collected. The number of girls living in the household is identified, which is the population you are interested in for your program.

- "How many people live here in this household most of the time?" is phrased in a general way, but you should decide on a standard definition that is appropriate for your context. In some places, "living in a household" may include asking who eats from the same pot, as in Sierra Leone, or who sleeps in a home at least four nights a week. This question seeks numbers that are as inclusive as possible, including people such as the respondent herself, household help, babies, and long-term visitors.

- Asking "How many of the people who live here are adults age $\mathbf{2 5}$ or over?" also helps the respondent count and visualize all individuals living in the household to ultimately get the correct number of girls.

- Although girl-centered programs focus on girls, we ask about the boys to avoid the misconception that boys' needs are not also worth considering: “How many boys and young men ages 0 to 24 live here?"

- For the next question-“'How many girls and young women ages 0 to 24 live here?"-it is important to probe to ensure that the respondent is accounting for all the girls in the household, including household help or girls with disabilities who are often left out and who would greatly benefit from attending a program.

\section{Information about girls}

This following section, about the girls in the household, is to be repeated as many times as necessary to ask questions about each girl 0 to 24 years living in that home, starting with the oldest (this is merely to help the interviewee keep his/her thoughts organized). 
- The first question asks for her age-"How old is she?" If the exact age is unknown, it is okay to fill in the approximate age. It is better to categorize girls close enough to their age (at least in the appropriate age cohort or stage) than not to collect age information at all. Having a good estimate of girls' ages will be very useful in segmenting the girls and planning programs accordingly.

- The next three questions ask about a girl's schooling status. First, "Has she ever gone to school?" If the answer is "yes," then the next two questions are "Is she currently attending school?" and "What is the highest level she completed?" These questions will help you segment the girls according to their schooling status. Girls who have never been to school will likely need specific programming to meet their needs in terms of literacy and other factors, while girls who are currently enrolled in school and girls who are behind schooling level for age may need different programming. Please note that the question about highest level completed is an example of where context-specific adaptation is essential-the answer choices for this question must reflect the schooling system of the country (e.g., P1, P2, P3; S1, S2, S3; 3 rd grade, 4th grade). In some communities, girls who are behind grade for age for more than three years may be able to gather with girls who have never gone to school, in girls-only spaces.

- The next question asks about childbearing status. By default, this question is only asked if the girl is above age 12, but the default setting can be changed if it is relatively common for girls in your community to bear children below age 12 and it is nonsensitive to ask. If the response to the question "Does she have any children?" is yes, the subsequent question will be, "How many children?" and you will enter the number. The childbearing question is also asked before any questions about marital status. This is because having a child is not a condition of being married but can happen outside the confines of a marriage. Here is another moment for adaptation.
When reviewing the questionnaire for implementation in Syrian refugee camps in Lebanon and Jordan, the team noted that it was culturally insensitive and indelicate to ask such a question before confirming if a girl was married or not. Therefore, for the questionnaire, this question appeared after, not before, questions about marriage.

- The next question asks "What is her marital status?" Typical answer responses are: single, married, or living with partner, married but not living with partner, and "other." By default, this question is only asked if the girl is above age 12. When modifying the questionnaire, this can be changed if child marriage below age 12 is common in your program community and you want to get a picture of how common it might be. Answer choices can be added such as engaged, divorced, or widowed if these categories are meaningful in your community and will be held distinct from the standard choices. For example, in some settings, girls who are engaged may experience similar situations and risks as married girls (e.g., limited control of resources, early pregnancy), but a parent responding to the question may not consider engaged girls as married. Therefore, it may be accurate to say that an engaged girl is "single, never married." However, grouping engaged girls with unmarried girls in a program in this setting may present a challenge, since the two groups do not share similar living circumstances and have different needs and priorities. It is therefore better to gather this additional information and distinguish with a choice of "engaged" in order to consider tailoring the programming to ensure that engaged girls can take part, either in a group of their own or with married girls.

- The next question asks about the girl's living arrangements-"Does her mother or father live here?" (See Box 17 for additional details on why these demographic indicators have been chosen for the Girl Roster.)

In the standard questionnaire, these questions about the girls-from age to living arrangements-are repeated for each girl until 


\section{BOX 17. ADJUSTING THE}

\section{QUESTIONNAIRE}

If there is further nonsensitive girl-level information that is essential for your program, you may insert additional questions at the end of the sequence of questions on each girl. In settings where programs are prepared to deliver disabilityinclusive programming, this may include a sequence of questions on disability (such as WRC's Inclusion Now module); or if the program is operating in a setting where girls are either highly mobile or many people have recently arrived, you may decide to ask a question about how long a girl has lived in the community. You might also include a question on whether the girl has been a participant in one of your programs or another program in the area: "Has she ever participated in [name of the program]?" The Girl Roster Output Tables (see Chapter 5) can then show you the proportion of girls by age and demographic characteristics that are enrolled in your program or another program. You may learn, for example, that you have enrolled 60 percent of the community's in-school girls aged 10-14 but have only reached 5 percent of girls who are out of school at this age. You can then redirect your recruitment strategies to focus on reaching out-of-school girls to enroll in your program.

you have asked about all of them, ending with the youngest and last girl residing in that household. At this point, you will have reached the end of the questionnaire and you will wrap up the rostering of this home. You will be prompted to note any other observations you made about the home or girls while you say your goodbyes to the interviewee and thank him/her for his/her participation. In the notes section of the questionnaire, you can add additional relevant information or observations that are of concern (see Box 17).

\section{GPS locator}

- After speaking with a respondent, the Girl Roster will prompt you to record the GPS location of the house: "[To the rosterer] Without asking further questions, make a note if you observed or heard anything of concern about the girls." Sometimes a community's security concerns-such as in a humanitarian setting-and/or other issues prohibit the use of GPS, in which case this step can be skipped. The safety and comfort of the girls and their families and the consent of the respondents should always be the priority. The GPS locator does not create 100 percent specific or accurate coordinates; it is meant to help you create a Girl Roster map that can give a picture of where homes are located in relation to other resources, and may help identify whether there are any areas where girls of particular segments are geographically concentrated in your program catchment area. The GPS is incredibly useful to you.

\section{Additional factors for off-track status and} other concerns

Once the GPS location of the house has been recorded, you will have two more opportunities to note any observations you made. First it will say "Did you observe any issues that might need specific follow-up?" with a series of choices. This is an opening to note such things as whether a girl appears to be pregnant, or any household member is particularly ill or in need of immediate care. You might also note girls who have physical and learning disabilities in order to actively recruit them into programs. You can select as many of these options as you want and later analyze and quantify how many observations of particular issues occurred, or immediately alert program staff or service providers to the issue and person in need of intervention.

Finally, one more time, the questionnaire will ask you if there are any other notes you would like to make. This question is open-ended and allows you to make any additional observations you might have. These last two questions should not be asked directly as they are too sensitive, but respondents may volunteer information, or you may make direct observations. As mentioned before, there are instances where consent will not be given. Even if you do not receive consent, these personal observation questions will still appear, allowing you to gather qualitative information even though no rostering of that specific household is taking place. 


\section{Segmentation and Planning: How to Use Girl Roster Results to Identify Key Segments of Girls and Make Overarching Program Decisions}

\section{LEARNING OBJECTIVES}

- Learn to use Roster results to understand heterogeneity among girls and define priority segments.

- $\quad$ Estimate the numbers of girls in different segments to start the decision-making process.

- Identify the age at which there are increases in girls going off-track.

- Assess fit between current program reach and actual population.

- Define areas for program redirection and innovation.

\section{Gaining Insights from the Girl Roster Overview Output Table}

Once the Girl Roster has been implemented, several Output Tables are generated to provide a rapid snapshot of girls' characteristics in your program community. The Overview Output Table (see Table 1) is the primary table and it displays and summarizes the collected information-girls' ages and other sociodemographic characteristics. The Overview Output Table assigns each girl to a single segment according to characteristics that are most likely to reflect exclusion from basic entitlements and/or mark a division that carries critical programming implications. This basic information can challenge assumptions about community-level sociodemographics, and inform programming decisions, such as helping set community-level recruitment targets for girls, determining how many groups to form, and setting mentor-selection criteria.

Let's break Table 1 down into its various parts, starting with the leftmost column (in blue).

- The table first sorts girls by age, allowing program staff to consider how to focus program content and program design around key age subsets of girls. The selection of the age groups shown in the table is based on research and qualitative reporting of cohorts' similar lived experience. The age groups of 10-12 and 13-14 are differentiated rather than clumped together because of the high life transitions that occur during these ages. In the table, girls aged 18-19 and 20-24 are separated from girls 17 years and under 
by a purple bar to distinguish the older subset of girls from the younger. If you recall, we define off-track girls as those who are 6-17 years old who meet any one of a number of conditions (e.g., out of school, married, etc.), therefore the separation of the under-18 from the 18 and over is meant to help distinguish the typically most neglected populations-younger adolescents-from the seemingly less neglected.

- Looking then to the topmost row-marital status (in violet)-girls are being grouped by whether they are unmarried or married. We do not typically ask the marital status of girls 12 and younger, so it is only adolescent girls and young women ages 13 and older who will fall in the column of married, if at all. Marital status is prioritized in the table because married girls tend to be more socially isolated, less able to access basic resources, and harder for programs to reach. Married girls with children (in yellow) are also likely to have very different experiences, concerns, and interests than their married peers who have not yet had a child. Likewise, unmarried girls who have a child may face both discriminatory treatment and social exclusion that heighten their vulnerabilities while reducing their prospects for participating in programs, making them a distinct group from either married girls or in-school, childless girls.

- Under the unmarried row, you will see two schooling status columns next-in-school (in green) and out-of-school (in pink). All unmarried girls are grouped first according to schooling status, which represents a critical entitlement, and then by parental accompaniment, a critical but often overlooked source of social connectedness and access to economic and interpersonal support. Even for girls who are in school, living apart from parents often reflects the presence of challenges in their lives, including heightened pressure to generate income or contribute to household chores, leaving them less likely to come to a program than peers who live with at least one parent.

The Overview Output Table provides a way to test your initial assumptions. Implementers are often surprised by the number of girls already out of school between the ages of 6 and 9 , or the proportion of girls overall in the community who are out of school, or the proportion of girls who have children. For instance, an organization

\begin{tabular}{|c|c|c|c|c|c|c|c|c|c|c|}
\hline \multicolumn{11}{|c|}{ TABLE 1. GIRL ROSTER OVERVIEW OUTPUT TABLE } \\
\hline \multicolumn{8}{|c|}{ UNMARRIED } & \multicolumn{2}{|c|}{ MARRIED } & \multirow[b]{3}{*}{ TOTALS } \\
\hline & \multicolumn{3}{|c|}{ IN SCHOOL-NO CHILDREN } & \multicolumn{3}{|c|}{$\begin{array}{c}\text { OUT OF SCHOOL-NO } \\
\text { CHILDREN }\end{array}$} & \multirow[t]{2}{*}{$\begin{array}{l}\text { HAS A } \\
\text { CHILD }\end{array}$} & \multirow[b]{2}{*}{ Has a child } & \multirow[b]{2}{*}{$\begin{array}{l}\text { Does not have a } \\
\text { child }\end{array}$} & \\
\hline $\begin{array}{l}\text { Age } \\
\text { group }\end{array}$ & $\begin{array}{c}\text { Living } \\
\text { with both } \\
\text { parents }\end{array}$ & $\begin{array}{l}\text { Living } \\
\text { with one } \\
\text { parent }\end{array}$ & $\begin{array}{c}\text { Living } \\
\text { with } \\
\text { neither } \\
\text { parent }\end{array}$ & $\begin{array}{c}\text { Living } \\
\text { with both } \\
\text { parents }\end{array}$ & $\begin{array}{l}\text { Living } \\
\text { with one } \\
\text { parent }\end{array}$ & $\begin{array}{c}\text { Living } \\
\text { with } \\
\text { neither } \\
\text { parent }\end{array}$ & & & & \\
\hline $6-9$ & & & & & & & - & - & - & \\
\hline $10-12$ & & & & & & & - & - & - & \\
\hline $13-14$ & & & & & & & & & & \\
\hline $15-17$ & & & & & & & & & & \\
\hline $18-19$ & & & & & & & & & & \\
\hline $20-24$ & & & & & & & & & & \\
\hline Totals & & & & & & & & & & \\
\hline
\end{tabular}


in Haiti observed that a higher proportion of girls 6-9 years old were out school than anticipated-approximately 12 percent (see Table 2 for an example of an Overview Output Table with results).

\section{Learning More About the Schooling Status of Married and Unmarried Mothers}

Where the initial Overview Output Table includes the most basic descriptors of girls' status, additional tables provide further detail on either all girls, or key segments. The first example of an additional table is the ChildrenOnly table (see Table 3).

While having a child marks a dramatic change in the life of a girl or young woman, mothers who are younger, unmarried, and out of school are likely to have distinct needs and face distinct barriers to participating in programs when compared with those who are older and married. Likewise, while many girls may leave or be forced out of school due to a pregnancy, this is not always the case. Table 3 shows how girls' marital, schooling, and childbearing status intersect. The table captures only those girls who have children, among whom you can see those who are unmarried or married, in school or out of school.

\section{Using On-/Off-Track Output Tables to Identify Patterns in Girls' Loss of Entitlements}

The Overview Output Table allows you to gain a basic understanding of what proportion of girls in each age cohort are on-track or off-track according to specific categories (e.g., marriage, having a child, or leaving school before age 18). From the Overview Output Table alone, you can see patterns in the absolute numbers and proportions of girls who are off-track according to various criteria. In the youngest age ranges, before age 14, off-track tends to mean being out of school and/or living apart from parents. By age 15-17, a rising proportion of girls are likely to be off-track because they drop out of school; some might be married or have children.

In addition to the information captured in the Overview Output Table, the Girl Roster On-/ Off-Track Output Tables (Tables 4, 5, and 6) show the proportions of girls who fall into one or more off-track categories by age. In Table 4,

TABLE 2. GIRL ROSTER OVERVIEW OUTPUT TABLE FROM URBAN, HIV-AFFECTED COMMUNITY, HAITI

\begin{tabular}{|c|c|c|c|c|c|c|c|c|c|c|}
\hline \multicolumn{8}{|c|}{ UNMARRIED } & \multicolumn{2}{|c|}{ MARRIED } & \multirow[b]{3}{*}{ TOTALS } \\
\hline & \multicolumn{3}{|c|}{ IN SCHOOL-NO CHILDREN } & \multicolumn{3}{|c|}{$\begin{array}{l}\text { OUT OF SCHOOL- } \\
\text { NO CHILDREN }\end{array}$} & \multirow[t]{2}{*}{$\begin{array}{l}\text { HAS A } \\
\text { CHILD }\end{array}$} & \multirow[b]{2}{*}{ Has a child } & \multirow[b]{2}{*}{$\begin{array}{c}\text { Does not have a } \\
\text { child }\end{array}$} & \\
\hline $\begin{array}{l}\text { Age } \\
\text { group }\end{array}$ & $\begin{array}{c}\text { Living } \\
\text { with both } \\
\text { parents }\end{array}$ & $\begin{array}{c}\text { Living } \\
\text { with one } \\
\text { parent }\end{array}$ & $\begin{array}{l}\text { Living } \\
\text { with } \\
\text { neither } \\
\text { parent }\end{array}$ & $\begin{array}{c}\text { Living } \\
\text { with both } \\
\text { parents }\end{array}$ & $\begin{array}{l}\text { Living } \\
\text { with one } \\
\text { parent }\end{array}$ & $\begin{array}{l}\text { Living } \\
\text { with } \\
\text { neither } \\
\text { parent }\end{array}$ & & & & \\
\hline $6-9$ & 270 & 98 & 27 & 30 & 19 & 5 & - & - & - & 449 \\
\hline $10-12$ & 206 & 87 & 36 & 15 & 13 & 9 & - & - & - & 366 \\
\hline $13-14$ & 152 & 60 & 24 & 14 & 5 & 12 & 0 & 0 & 2 & 269 \\
\hline $15-17$ & 220 & 109 & 74 & 14 & 11 & 15 & 4 & 6 & 7 & 460 \\
\hline $18-19$ & 121 & 61 & 52 & 19 & 22 & 19 & 53 & 35 & 15 & 397 \\
\hline $20-24$ & 125 & 55 & 52 & 23 & 21 & 24 & 66 & 61 & 17 & 444 \\
\hline Totals & 1,094 & 470 & 265 & 115 & 91 & 84 & 123 & 102 & 41 & 2,385 \\
\hline
\end{tabular}

- $=$ Not applicable. 


\begin{tabular}{|c|c|c|c|c|c|}
\hline \multicolumn{7}{|c|}{ Table 3. Girl Roster: Children-Only } & \multirow{2}{*}{ TOTALS } \\
\hline Age group & In School & Out of School & In School & Out of School & \\
\hline $13-14$ & & & & & \\
\hline $15-17$ & & & & & \\
\hline \multicolumn{7}{|c|}{} & & & & \\
\hline $18-19$ & & & & & \\
\hline $20-24$ & & & & & \\
\hline Totals & & & & & \\
\hline
\end{tabular}

you have the most basic definition of off-track girls: age 6-17 years and meeting a minimum of one of these categories: out of school, or living with no parent, or married, or have a child. In Table 5, the second sort of off-track girls, we add a layer-girls who are living with only one parent. And finally, in Table 6, we add a dimension to their schooling status-girls who are in school but behind grade for age (by $2+$ years). While the Overview Output Table can guide you in calculating proportions of off-track girls by your own definitions, the On-/Off-Track Output Tables lay out those proportions for you. For example, in a program community in rural Gambia (see Table 7), program staff noted a large proportion of off-track girlsapproximately one out of every three girls aged 6-9 were considered off-track by category 1 , meaning that they were out of school and/ or living with neither parent. With this in mind, program staff realized that their earlier assumption-that younger girls were getting the support they needed-was inaccurate, and decided to focus on a younger cohort of girls than they had initially planned.

You can use the On-/Off-Track Output Tables to identify ages where there may be a relative shift toward increasing proportions of girls going off-track. In many settings, there are notable changes in early and middle adolescence, shifting from very few girls classified as offtrack in the 10-12-year-old group to large proportions of girls in the 15-17-year-old age bracket falling into at least one off-track category. These numbers can suggest how early you may need to engage girls if you are seeking to address, for example, child marriage or school-leaving. Table 7 is an example of an On-/ Off-Track Output Table Category 1 with results from rural Gambia. Here you can see a jump from the age cohort 13-14 to 15-17.

\section{Using the Girl Roster to Determine Which Girls Are Participating in Ongoing Programs}

The Girl Roster can help identify which segments of girls are participating in an ongoing program or benefiting from preexisting activities in a community. Roster results may reveal that program utilization is low by those most in need, such as younger, out-of-school, or married girls. Thus the results can guide programs to refocus recruitment strategies, content, or activities to better meet the needs and interests of those groups. If included in the Roster questionnaire (as noted in Chapter 4, program participation information is not part of the standard questionnaire), programparticipation information collected for each girl can be added to the Overview Output Table using a modified format.

Table 8 is an example of exactly this-an Overview Output Table with Program Participation. As can be seen, the framework of the Overview Output Table remains the same (notice the same column and row titles) but each cell contains two numbers-the numerator to the left, the denominator to the right, separated by a slash ("/"). 


\begin{tabular}{|l|l|l|l|l|l|l|l|l|}
\hline \multicolumn{7}{|c|}{ Table 4. On-/Off-Track Output Table } \\
\hline & OFF-TRACK & ON-TRACK & TOTALS & & OFF-TRACK (\%) & ON-TRACK (\%) & TOTALS (\%) \\
\hline AGE GROUP & & & & AGE GROUP & & & \\
\hline $6-9$ & & & & $6-9$ & & & \\
\hline $10-12$ & & & & $10-12$ & & & \\
\hline $13-14$ & & & & $13-14$ & & & \\
\hline $15-17$ & & & & $15-17$ & & & \\
\hline Totals & & & & & & & \\
\hline
\end{tabular}

\begin{tabular}{|l|l|l|l||l|l|l|l|}
\hline \multicolumn{7}{|c|}{ Table 5. On-/Off-Track Output Table } \\
OR \\
& OFF-TRACK & ON-TRACK & TOTALS & & OFF-TRACK (\%) & ON-TRACK (\%) & TOTALS (\%) \\
\hline AGE GROUP & & & & AGE GROUP & & & \\
\hline $6-9$ & & & & $6-9$ & & & \\
\hline $10-12$ & & & & $10-12$ & & & \\
\hline $13-14$ & & & & $13-14$ & & & \\
\hline $15-17$ & & & & $15-17$ & & & \\
\hline Totals & & & & & & & \\
\hline
\end{tabular}

\begin{tabular}{|l|l|l|l|l|l|l|l|l|}
\hline \multicolumn{7}{|c|}{ Table 6. On-/Off-Track Output Table } \\
Category 3 of Off-Track Girls 6-17 who are out of school OR behind grade for age (2+ years) OR living with no parent \\
OR living with one parent OR married OR have a child \\
\hline & OFF-TRACK & ON-TRACK & TOTALS & & OFF-TRACK (\%) & ON-TRACK (\%) & TOTALS (\%) \\
\hline AGE GROUP & & & & AGE GROUP & & & \\
\hline $6-9$ & & & & $6-9$ & & & \\
\hline $10-12$ & & & & $10-12$ & & & \\
\hline $13-14$ & & & & $13-14$ & & & \\
\hline $15-17$ & & & & $15-17$ & & & \\
\hline Totals & & & & & & & & \\
\hline
\end{tabular}

\begin{tabular}{|c|c|c|c|c|c|c|c|}
\hline \multicolumn{8}{|c|}{$\begin{array}{l}\text { Table 7. On-/Off-Track Output Table-Category 1, Rural Gambia } \\
\text { Girls who are out of school OR living with no parent OR married OR have a child }\end{array}$} \\
\hline & OFF-TRACK & ON-TRACK & TOTALS & & OFF-TRACK (\%) & ON-TRACK (\%) & TOTALS (\%) \\
\hline AGE GROUP & & & & AGE GROUP & & & \\
\hline $6-9$ & 113 & 244 & 357 & $6-9$ & $32 \%$ & $68 \%$ & $100 \%$ \\
\hline $10-12$ & 78 & 170 & 248 & $10-12$ & $31 \%$ & $69 \%$ & $100 \%$ \\
\hline $13-14$ & 55 & 109 & 164 & $13-14$ & $34 \%$ & $66 \%$ & $100 \%$ \\
\hline $15-17$ & 102 & 95 & 197 & $15-17$ & $52 \%$ & $48 \%$ & $100 \%$ \\
\hline Totals & 348 & 618 & 966 & & & & \\
\hline
\end{tabular}




\begin{tabular}{|c|c|c|c|c|c|c|c|c|c|c|}
\hline \multicolumn{8}{|c|}{ UNMARRIED } & \multicolumn{2}{|c|}{ MARRIED } & \multirow[b]{3}{*}{ TOTALS } \\
\hline & \multicolumn{3}{|c|}{ IN SCHOOL-NO CHILDREN } & \multicolumn{3}{|c|}{$\begin{array}{c}\text { OUT OF SCHOOL-NO } \\
\text { CHILDREN }\end{array}$} & \multirow[t]{2}{*}{$\begin{array}{l}\text { HAS A } \\
\text { CHILD }\end{array}$} & \multirow[b]{2}{*}{ Has a child } & \multirow[b]{2}{*}{$\begin{array}{c}\text { Does not have a } \\
\text { child }\end{array}$} & \\
\hline $\begin{array}{l}\text { Age } \\
\text { group }\end{array}$ & $\begin{array}{c}\text { Living with } \\
\text { both } \\
\text { parents }\end{array}$ & $\begin{array}{c}\text { Living } \\
\text { with one } \\
\text { parent }\end{array}$ & $\begin{array}{l}\text { Living } \\
\text { with } \\
\text { neither } \\
\text { parent }\end{array}$ & $\begin{array}{l}\text { Living } \\
\text { with } \\
\text { both } \\
\text { parents } \\
\end{array}$ & $\begin{array}{c}\text { Living } \\
\text { with one } \\
\text { parent }\end{array}$ & $\begin{array}{l}\text { Living } \\
\text { with } \\
\text { neither } \\
\text { parent } \\
\end{array}$ & & & & \\
\hline $6-9$ & $0 / 270$ & $0 / 98$ & $0 / 27$ & $0 / 30$ & $0 / 19$ & $0 / 5$ & - & - & - & $0 / 449$ \\
\hline $10-12$ & $23 / 206$ & $11 / 87$ & $3 / 36$ & $0 / 15$ & $3 / 13$ & $8 / 9$ & - & - & - & $48 / 366$ \\
\hline $13-14$ & $13 / 152$ & $8 / 60$ & $4 / 24$ & $3 / 14$ & $2 / 5$ & $5 / 12$ & $0 / 0$ & $0 / 0$ & $0 / 2$ & $35 / 269$ \\
\hline $15-17$ & $40 / 220$ & $15 / 109$ & $9 / 74$ & $4 / 14$ & $1 / 11$ & $3 / 15$ & $0 / 4$ & $0 / 6$ & $0 / 7$ & $72 / 460$ \\
\hline $18-19$ & $11 / 121$ & $3 / 61$ & $4 / 52$ & $1 / 19$ & $2 / 22$ & $0 / 19$ & $2 / 53$ & $0 / 35$ & $0 / 15$ & $23 / 397$ \\
\hline 20-24 & $13 / 125$ & $4 / 55$ & $4 / 52$ & $2 / 23$ & $0 / 21$ & $1 / 24$ & $2 / 66$ & $0 / 61$ & $0 / 17$ & $26 / 444$ \\
\hline Totals & $100 / 1,094$ & $41 / 470$ & $24 / 265$ & $10 / 115$ & $8 / 91$ & $17 / 84$ & $4 / 123$ & $0 / 102$ & $0 / 41$ & $204 / 2,385$ \\
\hline
\end{tabular}

In this example of an Overview Output Table with Program Participation-this one coming from an HIV-affected community in Haiti where a partners' program was already being implemented-the denominator is the total number of girls in that specific segment while the numerator is the number of girls out of that total who are participating in the existing program the Roster inquired about. For example, as you can see, there are a total of 206 girls aged 10-12 who are unmarried, in school, and living with both parents in the community rostered. Out of those 206 girls, 23 are participating in the program.

Roster findings can inform the development of more in-depth assessments or consultations with girls or adult community members. The results may help identify, for example, which segments of girls to involve, and what information to collect from them-such as whether they know about the program-and to determine their interests in program content, what times they are available for club activities, and broader questions of whether a given program will meet their needs.

In the example shown in Table 8, the organization doing the rostering asked heads of household whether the girls were participating in their current program, which we call the "Blue
Program," intended to target girls particularly vulnerable to HIV. The organization observed that very low proportions of out-of-school girls or girls with children, and no married girls, were attending, even though their program had identified these as critical groups to include.

After collecting information on current participation levels, programs may decide to collect information directly from members of underrepresented groups. For example, further investigation may reveal that while relatively well-off girls join programs, these girls may also drop out at higher rates because they have other opportunities. On the other hand, the girls who most need the program may not know about it or may feel less inclined to register and participate even if they are aware. They may feel intimidated by the more advantaged and confident girls and so may be more likely to drop out of the program. Lower participation or higher dropout by off-track girls may reflect a higher opportunity cost for their participation. On the other hand, in contexts with few opportunities, younger off-track girls may so need the program that once recruited their attendance is high (Erulkar 2014). Obtaining this kind of information can be a valuable step in prioritizing the needs of those girls who might otherwise be overlooked in the initial stage of programming and who are more likely to drop 
out if they do make it into a program. This is critical because, if dropout is skewed toward those girls who are more socially isolated and have fewer ties to services or support, they may retreat into invisibility, only "appearing" to service providers again when they have an urgent need, such as pregnancy or HIV testing.

\section{Customizing Outputs for Program Needs and Context-Specific Concerns}

It is possible to create specialized displays of Roster information that either place greater emphasis on components that are not typically included in the basic outputs or that reflect additional questions that are included in the questionnaire to meet a program's distinct needs. It is important to balance the interest in in-depth community-level details on girls' profiles with the value of a rapid snapshot to guide informed, rapid decision-making in program design. In most cases, the basic outputs are sufficient for providing the kind of picture needed to inform design of program goals and activities, set target populations, or set criteria for mentor recruitment. A few specialized outputs may also be of use, as follows.

\section{Schooling Policy and Locating "Off-Track"} Out-of-School Girls: If local policies set the age to begin school at 7, instead of 6 , it may be appropriate to adjust the display to only include information on girls aged 7 or older in the Overview Output Table. Or, if policy mandates that school attendance is compulsory until age 16, a program for out-of-school girls would likely have different goals and program strategies for those under 16 versus those 17 and older. In this case, the table may be adjusted so that 17-year-olds are grouped with older girls to determine what program strategies are needed for each group. Where they fit a program aim or need, additional specialized outputs may also be developed to show girls who are off-track because they are lagging in terms of grade for age, or among out-of-school girls, to gain an understanding of relative school attainment.
BOX 18. USING THE ROSTER TO CREATE MAPS

Because the Roster includes a GPS function, it is possible to generate maps that map locations of households against the geographic features of a community, and identify clusters of households where girls live. This can help determine, for example, whether households with an adolescent girl are clustered in one part of a community and not another. It can also inform choices such as where to locate a girls' club so that it is in walking distance for many girls, or identify an area of a community where door-to-door recruitment will be feasible.

\section{Marriage, Schooling, and Married Girls'} Programming: The Roster's Overview Output Table prioritizes marriage because this marks a dramatic difference in girls' relative social isolation and programmatic needs, rather than, for example, schooling or living with a parent. However, if you are working on a program that involves school-based programming and/or married girls and it is common for married girls to also attend school, it may be appropriate to develop a separate output displaying only married girls, and grouping them by age and marital status. Likewise, where response choices are modified to include options on engagement or widowhood, separate output displays can be developed to illustrate how many girls fall into any of these categories, or how many belong to each of these distinct subgroups.

\section{Programming for Tailored or Inclusive}

Programming: Where additional questions, such as those on disability or duration of residency in a community are included in the questionnaire, these may also be incorporated into a specialized output to demonstrate either what proportion of all girls fall into a given category, or to include additional details, such as school attendance or marital status for this group alone. (See Box 18 and 19.) 


\section{Using Roster Results to Inform Discussions about Strategy}

The Transition from Primary to Secondary School: The Girl Roster's standard age brackets (6-9; 10-12; 13-14; 15-17) for the Overview and On-/Off-Track tables emphasize common ages when girls transition between primary and secondary school. The age at which a girl transfers from primary to secondary school, whether 6th or 8th grade, can be very consequential. The direct costs of schooling, such as school fees, uniforms, and books, and the indirect costs, such as transportation and/or travel time, may increase as a girl moves from one school to another (SolerHampejsek et al. 2018). In addition to cost and the distance of the school itself, placement exams may influence families' decisions about girls' schooling because preparing for exams may require additional tutoring or lessons that carry further monetary and opportunity costs for girls and their families. Therefore, you may want to consider what ages fall before and after major exams and schooling transitions in both interpreting the Roster outputs and considering program recruitment, since it may be difficult

\section{BOX 19. REVISITING THE ROSTER TO RESPOND TO CHANGES IN CONTEXT}

In a setting with either long-term programming or high migration, it may be useful to conduct a new round of rostering. For example, if a school is built or new policy is introduced to ease the cost burden of education, an ongoing program may use the Roster to test the assumption that this immediately leads to universal enrollment, and use the results to either shift program content to support newly returned girls, or focus more resources on the girls who remain out of school despite the change.

to recruit and retain girls during preparation for exams. Figure 9 was created by an organization conducting the Girl Roster in Benin, and gives a different sort of graphic representation of Girl Roster information. The information was collected in 21 Benin villages and shows a pattern by which school enrollment drops off at 12-14 years of age (green line)-during the transition from primary to secondary schoolbut marriage (blue line) and childbearing (yellow line) increases. By this analysis, the implementing organization knew that they

\section{FIGURE 9. GIRL ROSTER INFORMATION ON SCHOOL ENROLLMENT, MARRIAGE, AND}

CHILDBEARING FOR GIRLS AGED 12-24 IN 21 BENIN VILLAGES

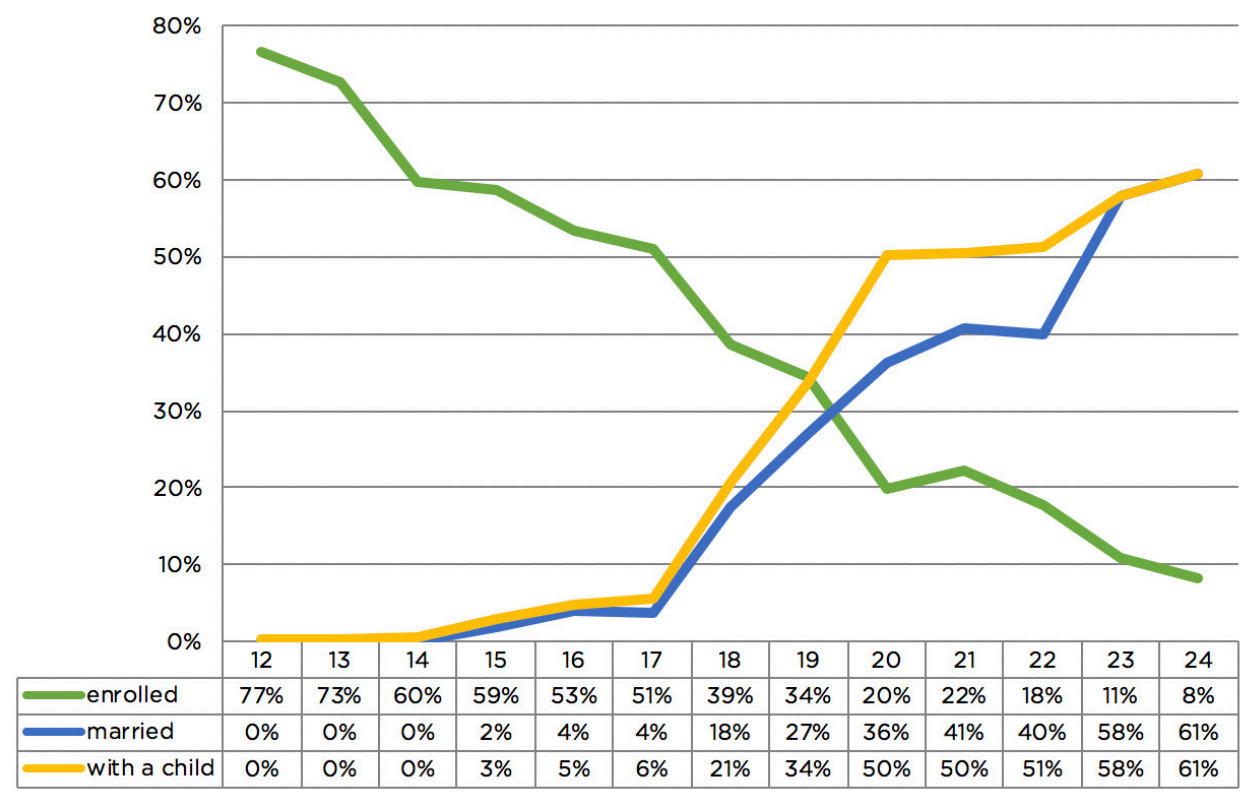

School enrollment drops off at 12-14 years of age, whereas marriage and childbearing increase. This figure was created using Girl Roster information collected in 2016.

Source: Figure prepared by Angel del Valle using Girl Roster data collected from 1,080 households in Benin, in 2016. 


\begin{tabular}{|c|c|c|c|c|c|c|c|}
\hline \multicolumn{7}{|c|}{ Table 9. Modified Overview Output Table-Nine- and ten-year-old unmarried girls only, rural Haiti (example) } \\
\hline \multirow{2}{*}{ Age group } & \multicolumn{7}{|c|}{ UNMARRIED } \\
\cline { 2 - 8 } & \multicolumn{2}{|c|}{ IN SCHOOL-NO CHILDREN } & \multicolumn{2}{c|}{ OUT OF SCHOOL-NO CHILDREN } & \multirow{2}{*}{ TOTALS } \\
\cline { 2 - 8 } & $\begin{array}{c}\text { Living with } \\
\text { both parents }\end{array}$ & $\begin{array}{c}\text { Living with } \\
\text { one parent }\end{array}$ & $\begin{array}{c}\text { Living with } \\
\text { neither parent }\end{array}$ & $\begin{array}{c}\text { Living with } \\
\text { both parents }\end{array}$ & $\begin{array}{c}\text { Living with } \\
\text { one parent }\end{array}$ & $\begin{array}{c}\text { Living with } \\
\text { neither parent }\end{array}$ & \\
\hline 9 & 74 & 19 & 8 & 2 & 6 & 3 & 112 \\
\hline 10 & 71 & 31 & 7 & 7 & 6 & 3 & 125 \\
\hline \multirow{2}{*}{ Totals } & 145 & 50 & 15 & 9 & 12 & 6 & 237 \\
\hline
\end{tabular}

wanted to reach girls at a younger age, before this transition happens, so as to mitigate the risk of school dropout, child marriage, and adolescent pregnancy.

Age-Specific Programming: In communities where there are very large numbers of girls and/or clear transitional points in their lives, if large proportions of girls are either leaving communities for secondary school or dropping out of school at age 15, you may want to generate more specific information about girls in the years before this transition and tailor programming to a narrow age cohort. (See Chapter 2, Box 4, "A Modest Proposal: The 12-Year-Old Check-In.") In such settings, it may be useful to adjust the Overview Output Table to narrow age brackets or to customize displays to focus on a narrower subset of ages. (An example of this method of using Output results can be seen with an organization from Haiti, see Table 9.)

Identifying a key age has another benefit, as the number of girls who have needs may be too large to reach and program targeting may be difficult to implement because it prioritizes one girl over the other in ways the community may not understand. By defining a specific age at which all girls will be served, a program can scale but also appear fair. As a matter of both reaching greater numbers and program simplicity, if the Overview Output Table shows that a high number of girls are leaving school by age 10, they might decide to create a program to reach all girls at age 9 in order to increase school retention and graduation to secondary school, as in Table 9. Though sorting by singular ages is not the purpose of the Rosterespecially as respondents might not always know the exact age of the girl in question-this is an appealing analysis to undertake to increase donor or government buy-in and support for a program's scale-up.

\section{Examples of How Girl Roster Output Tables Were Used to Make Program Decisions}

The following four examples illustrate the value of the Girl Roster, demonstrate how program staff can learn about the girls living in their program community, and quantify the number of girls in different categories. Combining the Roster with community mapping allows for classification both socially and geographically so one sees these girls in relation to one other and to community resources. As you will see, each example gives context to the community and organization, and shows results for a Girl Roster implementation in the Output Tables. What follows is an interpretation of those results-general observations, implications for program decisions-and what actions should be considered and/or taken. 


\section{GIRL ROSTER INTERPRETATION, EXAMPLE 1: ISOLATED RURAL COMMUNITY IN SIERRA LEONE}

An organization in Sierra Leone, West Africa, implemented the Girl Roster to lay the foundation for girls' clubs as a base for delivering a range of content, including health, life skills, and financial literacy. The Girl Roster was conducted to assist in decisions about recruitment of participants and mentors, to select locations for girls' clubs, to estimate the number of girls in each club, and to make initial decisions about content. The Overview Output Table was generated for the program community (see Table 10), with the girls first sorted by marital status. Schooling and living arrangement status for married girls is not provided, although this information is captured in the information collection and can be accessed elsewhere. At the time the Girl Roster was conducted, girls aged 10-12 and 13-14 were grouped together in a segment.

\begin{tabular}{|c|c|c|c|c|c|c|c|c|c|}
\hline \multicolumn{7}{|c|}{ UNMARRIED } & \multicolumn{2}{|c|}{ MARRIED } & \multirow[b]{3}{*}{ TOTALS } \\
\hline & \multicolumn{3}{|c|}{ IN SCHOOL-NO CHILDREN } & \multicolumn{3}{|c|}{ OUT OF SCHOOL-NO CHILDREN } & \multirow[b]{2}{*}{ Has a child } & \multirow[b]{2}{*}{$\begin{array}{c}\text { Does not have a } \\
\text { child }\end{array}$} & \\
\hline $\begin{array}{l}\text { Age } \\
\text { group }\end{array}$ & $\begin{array}{c}\text { Living } \\
\text { with both } \\
\text { parents }\end{array}$ & $\begin{array}{c}\text { Living } \\
\text { with one } \\
\text { parent }\end{array}$ & $\begin{array}{l}\text { Living } \\
\text { with } \\
\text { neither } \\
\text { parent }\end{array}$ & $\begin{array}{l}\text { Living with } \\
\text { both parents }\end{array}$ & $\begin{array}{l}\text { Living with } \\
\text { one parent }\end{array}$ & $\begin{array}{c}\text { Living with } \\
\text { neither } \\
\text { parent }\end{array}$ & & & \\
\hline $6-9$ & 40 & 25 & 0 & 5 & 10 & 2 & - & - & 82 \\
\hline $10-14$ & 40 & 25 & 6 & 18 & 16 & 6 & 2 & 5 & 118 \\
\hline $15-17$ & 10 & 15 & 4 & 10 & 14 & 10 & 10 & 5 & 78 \\
\hline $18-24$ & 4 & 8 & 0 & 5 & 4 & 8 & 16 & 10 & 55 \\
\hline Totals & 94 & 73 & 10 & 38 & 44 & 26 & 28 & 20 & 333 \\
\hline
\end{tabular}

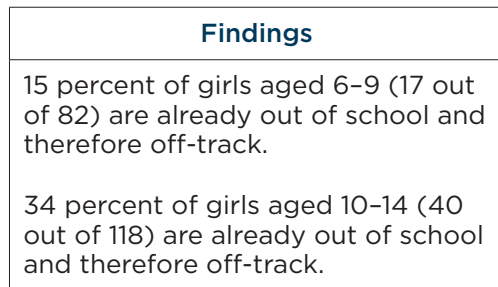

35 of the 82 girls aged $6-9$ are living with one parent (43 percent) and two are living with neither parent, while 41 of the 111 girls aged 10-14 are living with one parent and 12 are living with neither parent.

There appears to be a transition between age groups 6-9 and 10-14 with an almost doubling of girls who are off-track through marriage or being out of school.

Of girls aged 15-17, more than 45 are married and/or out of school, and 10 have children.

\section{Wit}

With so many girls out of school at early ages, program staff decided that the program should place greater emphasis on encouraging girls to enroll in school than they had initially anticipated and to tailor program content to meet their needs.

Program content would need to be tailored for young girls who are very likely unable to read, including relevant visuals and interactive games, and focus on issues key to their segment such as basic reading and writing skills, and financial literacy.

Girls who are not living with both parents, particularly those who are living with neither parent, warrant intentional recruitment strategies to get them into the program.

There needs to be additional inquiry into why the transition is so abrupt and, as a foundation for redesign, determining which age or ages should receive increased attention with what content.

Program staff need to: review whether these girls are geographically concentrated; conduct more qualitative interviews; take note that about 20 percent less than expected have children; and explore whether the same program can serve girls with and without children.

GPS data indicated that out-ofschool girls were concentrated in the southern part of the community. The program staff noted that this is where households often consist of women alone with their children.
Given this concentration of poverty and family type (single mothers), program staff considered how best to gain their trust and the potential value of locating programs as close to them as possible. The process of recruitment would likely have to take place after market hours as so many of the single mothers had heavy out-of-home work schedules.

\section{Program decisions considered and/or taken}

The program staff will visit every girl aged 6-9 and 10-14 who is out of school with the goal of helping them begin or return to school. At the same time, the program staff will invite the girls to join a girls' group that can foster other kinds of learning such as financial literacy and can support their school learning by offering a place to study and practice their skills.

Program staff conducted special home visits to learn more about the girls' circumstances and living arrangements, to ensure that the girls and their families understood that the program is for them, and to intentionally recruit the girls in need of key services.

Program staff will increase the recruitment of 9and 10-year-old girls and adjust program content to suit age and literacy level. They will explore whether and how these girls can be mainstreamed back into primary school.

Program staff decided to establish one girls group for those married, whether or not they had children, in a location where the majority were concentrated.

Household visits before the program starts sensitizes the community and gains the trust of often younger single mothers to allow their girls to participate. Two girls' groups of 20-25 each will be established for the younger out-of-school girls. 


\section{GIRL ROSTER INTERPRETATION, EXAMPLE 2: POST-CONFLICT RESETTLEMENT COMMUNITY IN THE MIDDLE EAST}

An INGO in the Middle East region has been providing services in humanitarian settings focusing on education for primary-schoolaged children. However, program staff have been concerned that girls in communities affected by the conflict are not attending programs intended for their benefit, including schooling. This community is economically fragile-many fathers are deceased or living outside the resettlement. There is high food insecurity and very little access to health care resulting in high levels of maternal and child mortality and morbidity. The delivery of health programming after the Girl Roster was completed has taken place in the schools. Information was provided about vaccinations and other health services, and meals were offered. That meant that if a girl did not attend school she would miss health and nutrition resources, as would her families, and poor families counted on a supplementary meal for their children. At the same time, the schools have had trouble keeping up with the wide range of services they are expected to deliver. The program staff, alarmed by high levels of maternal and child mortality and morbidity, were not able to do more than refer girls for childhood immunizations. The Girl Roster generated the results shown in Table 11.

Table 11. Girl Roster Overview Output Table from post-conflict resettlement community in the Middle East

\begin{tabular}{|c|c|c|c|c|c|c|c|c|c|}
\hline \multicolumn{7}{|c|}{ UNMARRIED } & \multicolumn{2}{|c|}{ MARRIED } & \multirow[b]{3}{*}{ TOTALS } \\
\hline & \multicolumn{3}{|c|}{ IN SCHOOL-NO CHILDREN } & \multicolumn{3}{|c|}{ OUT OF SCHOOL-NO CHILDREN } & \multirow[b]{2}{*}{ Has a child } & \multirow[b]{2}{*}{$\begin{array}{c}\text { Does not have a } \\
\text { child }\end{array}$} & \\
\hline $\begin{array}{c}\text { Age } \\
\text { group }\end{array}$ & $\begin{array}{c}\text { Living } \\
\text { with both } \\
\text { parents }\end{array}$ & \begin{tabular}{|c} 
Living \\
with one \\
parent
\end{tabular} & $\begin{array}{l}\text { Living } \\
\text { with } \\
\text { neither } \\
\text { parent }\end{array}$ & $\begin{array}{c}\text { Living with } \\
\text { both parents }\end{array}$ & $\begin{array}{l}\text { Living with } \\
\text { one parent }\end{array}$ & $\begin{array}{c}\text { Living with } \\
\text { neither } \\
\text { parent }\end{array}$ & & & \\
\hline $6-9$ & 55 & 10 & 0 & 50 & 20 & 0 & - & - & 135 \\
\hline $10-14$ & 60 & 10 & 4 & 32 & 9 & 2 & 5 & 9 & 131 \\
\hline $15-17$ & 15 & 5 & 2 & 23 & 2 & 5 & 12 & 8 & 72 \\
\hline $18-24$ & 5 & 2 & 0 & 11 & 10 & 5 & 21 & 10 & 64 \\
\hline Totals & 135 & 27 & 6 & 116 & 41 & 12 & 38 & 27 & 402 \\
\hline
\end{tabular}

- $=$ Not applicable.

\section{Findings \\ Of 338 girls aged $6-17$ in 278 \\ households, 143 are out of school. \\ It's likely that some of the girls aged \\ 6-17 who are married are also out \\ of school, of whom 17 have children. \\ These off-track girls are \\ concentrated in one particular part of the community.}

More than half of the girls aged 6-9 are out of school, as are a large proportion of the 10-14-year-olds. Thus, a very large population of girls is out of school and missing out on the chance for an education, as well as the other services delivered through schools.

34 girls out of 203 aged 10-17 were already married and/

or had children. Among those, approximately half were married but did not have children.

A higher than expected proportion of girls who are married do not have children.
Though the number of girls is high, given the level of exclusion, it is best that they not be in groups that are too large (20-30 per group is too large). Some of the girls live at a considerable distance from the nearest school. Married out-of-school girls have likely very different needs and social position than younger unmarried girls.

Considering the young ages of all the married girls, it is likely that this group has had little education. Given how many girls aged 10-17 are married, the program staff also decided to focus on supporting this group. Recognizing that married girls have distinct needs and limitations that their unmarried peers do not, staff determined that it is vital to design a distinct programmatic approach for this segment, and to place them in a separate group (or groups). Most of the girls with children are living with their husbands, but qualitative observations indicate they might be responsible for supporting themselves, and it is unclear how they do that. The possibility of sexual exchange, if necessary, to support themselves and their children brings with it additional risks.

Given the level of high child mortality, some of these girls might have experienced the death of a child. Also, it is likely that many of these married girls without children will become pregnant soon. Firsttime mothers need special support and many girls may not be getting that from male family members.

This problem in a post-conflict setting needs specific programming. The existent services are limited to immunization for children. Health-service providers have limited contact with girls unless the girls have children.

\section{Program decisions considered and/or taken}

A non-school-based delivery platform is needed. Health, reading, and writing skills, content and financial literacy, and enterprise development will be provided through community-based girls' groups. The program will be located where the outof-school girls, including those that are married, can easily access it. For the married girls, health needs and continuing study will likely have to be combined, and as most also have children, meeting venues where they can bring their children will be essential.

In places where there are high concentrations of younger, out-of-school girls, groups of 14-20 will be formed initially to support their introduction back to school.

Basic education is a priority for this group, so sessions for married girls will include a strong emphasis on literacy, numeracy, and other skills, and may be led by existing teachers. To encourage married girls who are parenting to take part, program staff will make sure that they understand that they can bring their children with them. If teachers are involved in leading sessions, the organization will also explore whether there could be sessions at the school for married girls after hours, and if so, if married girls would feel comfortable with sessions at this location.

Program staff will interview young married girls, both with and without children (to learn more about their vulnerabilities) and design appropriate interventions at appropriate times (when the married girls are free), being cognizant that these girls may have exceptionally low social power. 


\section{GIRL ROSTER INTERPRETATION, EXAMPLE 3: PERI-URBAN PROGRAM COMMUNITY IN EAST AFRICA}

In East Africa, an NGO implemented the Girl Roster in a peri-urban, densely populated setting. Many people displaced by a conflict in a neighboring country had recently arrived in the area. The program's goals were to keep girls aged 6-14 in school, and to discourage child marriage. Its focus was on the girls' transition from primary to middle school. Notably, in this poor peri-urban area, public services-such as schools and health centers-are relatively geographically accessible, and every school has a nurse. In this East African setting, school is structured so that girls make a transition to middle school in early adolescence. Therefore, the Overview Output Table had be modified to include narrower age cohorts (specifically, they asked to divide ages 10-14 into 10-12 and 13-14) to account for potential differences among girls' experiences in their program community.

As part of their work on child marriage, the organization also wanted to understand the situation of older adolescents (aged 15-17 and 18-19). If many of these girls have children, it is likely that they were married under the legal age of 18 and also missed out on educational and economic opportunities. In addition (although not shown in the Overview Output Table), program staff were asked to note the primary language of the household to gain a better sense of how recent displacement, language barriers, and other differences may relate to girls' schooling, living arrangements, and marital and childbearing status. Notably, the Girl Roster does not include direct questions about displacement or migration status because this is a sensitive question.

Making notes that may indicate which households recently arrived versus families with a long-standing presence in the community provides basic information that can be incorporated into the analysis of the Girl Roster information to give a preliminary sketch of the number of girls who were recently displaced and who would require distinct programming. If it is necessary to have more information before implementing a program, further details about the displaced girls may be gathered in follow-up home visits, focus group discussions, or other participatory exercises. The NGO conducted the Girl Roster and generated an Overview Output Table (see Table 12).

\begin{tabular}{|c|c|c|c|c|c|c|c|c|c|}
\hline \multicolumn{7}{|c|}{ UNMARRIED } & \multicolumn{2}{|c|}{ MARRIED } & \multirow[b]{3}{*}{ TOTALS } \\
\hline & \multicolumn{3}{|c|}{ IN SCHOOL-NO CHILDREN } & \multicolumn{3}{|c|}{ OUT OF SCHOOL-NO CHILDREN } & \multirow[b]{2}{*}{ Has a child } & \multirow[b]{2}{*}{\begin{tabular}{|c|}
$\begin{array}{c}\text { Does not have a } \\
\text { child }\end{array}$ \\
\end{tabular}} & \\
\hline $\begin{array}{c}\text { Age } \\
\text { group }\end{array}$ & $\begin{array}{c}\text { Living } \\
\text { with both } \\
\text { parents }\end{array}$ & $\begin{array}{c}\text { Living } \\
\text { with one } \\
\text { parent }\end{array}$ & $\begin{array}{c}\text { Living } \\
\text { with } \\
\text { neither } \\
\text { parent }\end{array}$ & $\begin{array}{l}\text { Living with } \\
\text { both parents }\end{array}$ & $\begin{array}{l}\text { Living with } \\
\text { one parent }\end{array}$ & $\begin{array}{l}\text { Living with } \\
\text { neither } \\
\text { parent }\end{array}$ & & & \\
\hline $6-9$ & 369 & 22 & 13 & 45 & 3 & 15 & - & - & 467 \\
\hline $10-12$ & 139 & 10 & 8 & 7 & 2 & 22 & - & - & 188 \\
\hline $13-14$ & 207 & 21 & 6 & 40 & 1 & 27 & 0 & 3 & 305 \\
\hline $15-17$ & 117 & 11 & 12 & 27 & 4 & 10 & 35 & 18 & 234 \\
\hline $18-19$ & 39 & 5 & 3 & 19 & 1 & 2 & 32 & 16 & 117 \\
\hline $20-24$ & 42 & 6 & 5 & 22 & 7 & 5 & 136 & 27 & 250 \\
\hline Totals & 913 & 75 & 47 & 160 & 18 & 81 & 203 & 64 & 1,561 \\
\hline
\end{tabular}

$-=$ Not applicable. 


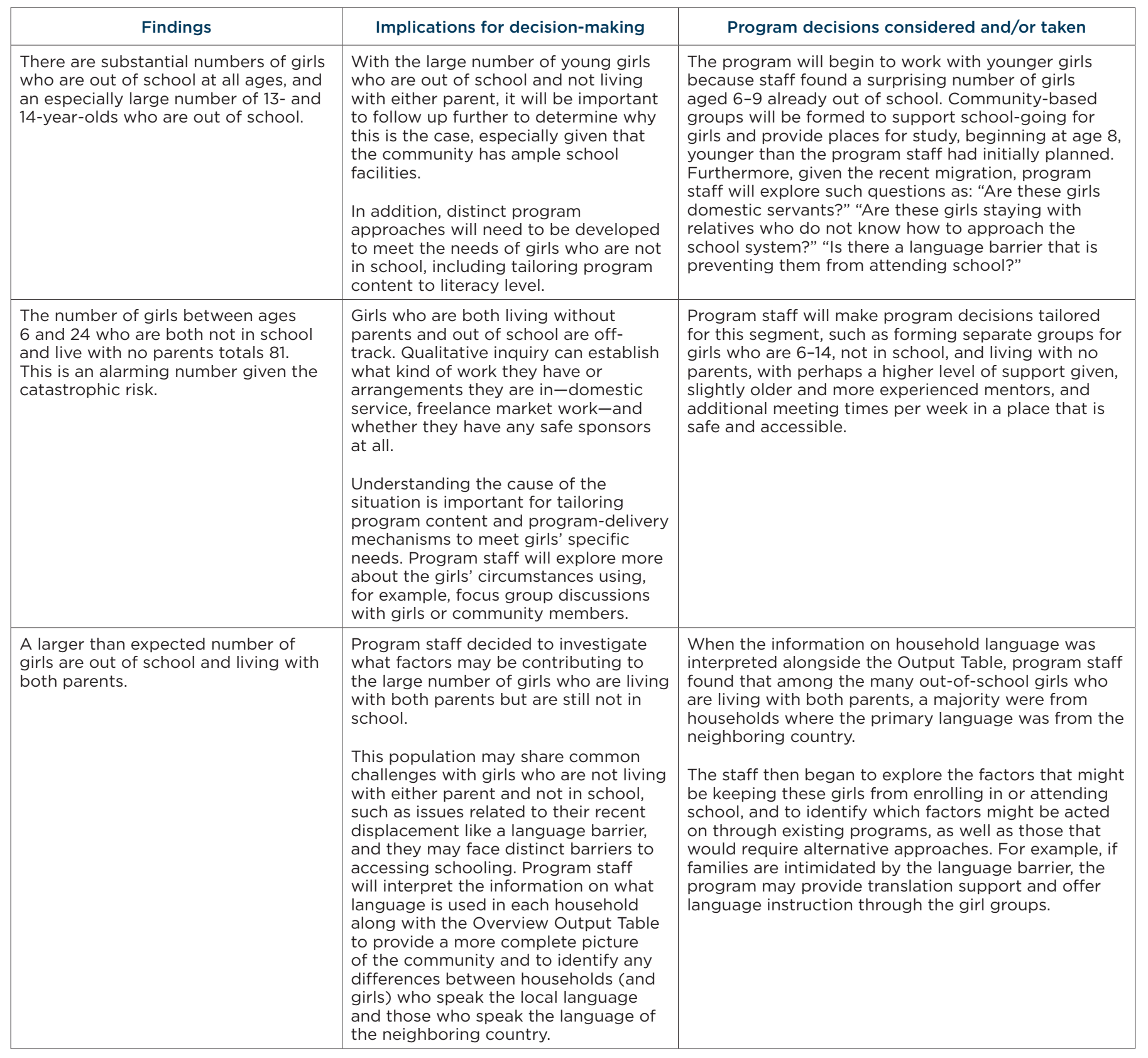




\section{GIRL ROSTER INTERPRETATION, EXAMPLE 4: DETERMINING INITIAL PROGRAM PARTICIPATION IN RURAL NIGER COMMUNITY}

A large relief organization in Niger, West Africa, wanted to expand its program to add nutrition content to a curriculum that primarily addressed reproductive health, because the high prevalence of anemia in girls was found to be a major problem related to both their reproductive and general health. The organization had a special interest in recruiting and enrolling girls in mid-adolescence, aged 14-17, as this is the common age of sexual initiation.

Initially, program participation was based on referrals from the village leaders and the program was advertised through schools. A question was added to the Girl Roster asking whether the girl had formerly participated in this program, to help determine who the program was or was not reaching. Table 13 shows which girls were participating in the organization's reproductive health information program.

\begin{tabular}{|c|c|c|c|c|c|c|c|c|c|}
\hline \multicolumn{7}{|c|}{ UNMARRIED } & \multicolumn{2}{|c|}{ MARRIED } & \multirow[b]{3}{*}{ TOTALS } \\
\hline & \multicolumn{3}{|c|}{ IN SCHOOL-NO CHILDREN } & \multicolumn{3}{|c|}{ OUT OF SCHOOL-NO CHILDREN } & \multirow[b]{2}{*}{ Has a child } & \multirow[b]{2}{*}{$\begin{array}{c}\text { Does not have a } \\
\text { child }\end{array}$} & \\
\hline $\begin{array}{c}\text { Age } \\
\text { group }\end{array}$ & $\begin{array}{c}\text { Living } \\
\text { with both } \\
\text { parents }\end{array}$ & $\begin{array}{c}\text { Living } \\
\text { with one } \\
\text { parent }\end{array}$ & $\begin{array}{l}\text { Living } \\
\text { with } \\
\text { neither } \\
\text { parent } \\
\end{array}$ & $\begin{array}{c}\text { Living with } \\
\text { both parents }\end{array}$ & $\begin{array}{l}\text { Living with } \\
\text { one parent }\end{array}$ & $\begin{array}{c}\text { Living with } \\
\text { neither } \\
\text { parent }\end{array}$ & & & \\
\hline $6-9$ & $4 / 18$ & $4 / 26$ & $1 / 2$ & $0 / 0$ & $0 / 0$ & $0 / 0$ & - & - & $9 / 46$ \\
\hline $10-14$ & $14 / 18$ & $26 / 72$ & $0 / 0$ & $5 / 15$ & $1 / 10$ & $0 / 12$ & - & - & $46 / 127$ \\
\hline $15-17$ & $8 / 10$ & $10 / 20$ & $0 / 10$ & $2 / 12$ & $2 / 14$ & $0 / 13$ & $0 / 3$ & $\mathrm{O} / \mathrm{O}$ & $22 / 82$ \\
\hline $18-19$ & $6 / 10$ & $2 / 8$ & $0 / 4$ & $0 / 0$ & $6 / 26$ & $0 / 2$ & $0 / 6$ & $2 / 10$ & $16 / 66$ \\
\hline Totals & $32 / 56$ & $42 / 126$ & $1 / 16$ & $7 / 27$ & $9 / 50$ & $0 / 27$ & $0 / 9$ & $2 / 10$ & $93 / 321$ \\
\hline
\end{tabular}

\begin{tabular}{|c|c|c|}
\hline Findings & Implications for decision-making & $\begin{array}{c}\text { Program decisions considered } \\
\text { and/or taken }\end{array}$ \\
\hline $\begin{array}{l}\text { Among unmarried girls aged } 10-14 \text { and } 15-17 \text { in this } \\
\text { program community, many are in school, with } 71 \\
\text { percent of girls } 10-14 \text { in school and } 49 \text { percent of } \\
\text { girls } 15-17 \text { in school. } \\
\text { However, this still means that } 3710-14 \text {-year-old girls } \\
\text { are out of school and } 3915-17-y e a r-o l d \text { girls are out } \\
\text { of school. } \\
\text { Girls who are living with both parents and are in } \\
\text { school are much more likely to participate in the } \\
\text { program at all ages ( } 57 \text { percent) than those in } \\
\text { school living with one or neither parent ( } 31 \text { percent) } \\
\text { and have substantially more access to the program } \\
\text { compared with all girls who are out of school. } \\
\text { Results among the } 15-17-y e a r-o l d \text { girls are striking: } \\
8 \text { of the } 10 \text { girls in school living with both parents } \\
\text { are in the program; } 10 \text { of the } 20 \text { in school with } \\
\text { one or no parent are in the program; and of the } \\
\text { large proportion of girls } 15-17 \text { out of school and/or } \\
\text { married ( } 42 \text { ), only } 4 \text {, less than } 10 \text { percent, are in the } \\
\text { program. }\end{array}$ & $\begin{array}{l}\text { In response to the surprisingly high } \\
\text { proportion of girls who are out of } \\
\text { school in their program community, } \\
\text { program staff needed strategies for } \\
\text { recruiting out-of-school girls. } \\
\text { Focusing on these girls was also } \\
\text { justified by the low number of out- } \\
\text { of-school girls who were currently } \\
\text { attending their program and who could } \\
\text { greatly benefit from services. } \\
\text { In this case, some girls were clustered } \\
\text { near each other, so this helps with } \\
\text { recruitment. }\end{array}$ & $\begin{array}{l}\text { Program staff implemented } \\
\text { community-based, intentional } \\
\text { recruitment strategies (including } \\
\text { house-to-house recruitment) that } \\
\text { went beyond seeking referrals } \\
\text { through village leaders and the } \\
\text { school system to target the most } \\
\text { excluded and isolated girls and to } \\
\text { reach the high proportion of girls } \\
\text { who were out of school. }\end{array}$ \\
\hline
\end{tabular}




\section{Probing Deeper into Community Resources and Linking Them Intentionally to Segments of Girls}

\section{LEARNING OBJECTIVES}

- Learn about the potential contribution of the Community Resource Scan and the Coverage Exercise to program decision-making.

- Learn how to implement a Community Resource Scan and "grade" the accessibility of programs to different segments of girls.

- Assess whether more formal Coverage Exercises can help increase policy commitment and program targeting.

- Bring the results of the Girl Roster together with the Community Resource Scan to define positive actions to increase girls' access to vital community resources.

- Learn how to estimate current coverage of girl segments in subnational districts by combining DHS, census information, and organizations' self-reports.

In Intentional Design, we work at two levels. We build girls' health, social, cognitive, and economic assets (typically within a dedicated girls-only space), and we increase knowledge and use of community resources among different segments of girls. In this chapter, we address the second of these two interlinked efforts.

Although potentially useful resources may be available, some proportion of girls at risk may not have adequate access to them for the following reasons:

- the girls' location in relation to the resources;

- lack of active recruitment by the program;
- $\quad$ staff that is unprepared to deal with excluded adolescent girls or is perceived by girls to be too different from them;

- lack of female staff available to create social connection and a sense of safety;

- $\quad$ perception by girls that current program beneficiaries are too different from them;

- content offered is narrow, irrelevant, or stigmatizing.

The learning tools described here have a double relevance for program staff and practitioners. First, they can be used to convince skeptical but well-intentioned program staff that girls in need are underserved. Second, by helping program staff visualize the girls, count their numbers, 
The learning tools described here have a double relevance for program staff and practitioners. First, they can be used to convince skeptical but well-intentioned program staff that girls in need are underserved. Second, by helping program staff visualize the girls, count their numbers, note their locations, and acknowledge potential exclusion factors, they can be encouraged to redirect program resources to capture a higher proportion of girls in need by intentional recruitment, more active referral links (like vouchers), or adjusting program schedules.

note their locations, and acknowledge potential exclusion factors, they can be encouraged to redirect program resources to capture a higher proportion of girls in need by intentional recruitment, more active referral links (like vouchers), or adjusting program schedules. For instance, sessions or days can be dedicated specifically to girls of a certain type or age, and opportunity visits can be organized for girls to visit an unfamiliar or previously unsafe facility or program. All of this cannot be achieved, however, without much dialogue and it is important to note that these tools are intended to prompt discourse and decision-making, not merely to just collect information.

In this chapter we focus on two tools: the Community Resource Scan (as a complement to the Girl Roster), and the Coverage Exercise. We begin with the Community Resource Scan, an inventory of facilities, services, and resources in the walkable community. The results of the Community Resource Scan and the Girl Roster (see Chapters 3 and 4) can be used in tandem by organizations to plan better access for girls to key resources in the community, and to address resource gaps that might exist.

The Community Resource Scan is more elaborate than the initial noting of geographic boundaries and features of the program community that can be done very basically before or during implementation of the Girl Roster, and might even be necessary to map the community for rostering purposes. The Community Resource Scan is typically completed after the Roster exercise, and generates a more rigorous inventory of resources, which are often graded for accessibility.

In conducting a Community Resource Scan, we take several steps:

1. Inventory the resources ("investment") already on the ground from which girls can benefit more equitably;

2. Provisionally "grade," based on basic community knowledge, girls' current access to (or participation in) resources.

3. Identify potential meeting places for different segments of girls;

4. Gain awareness about the safety and accessibility of current sites and chart potential opportunities for using them.

The technical process by which the Community Resource Scan is undertaken is described in Appendix II. To increase access to community resources thoughtfully, program staff must consider the specific program community boundaries to be covered and establish broad community commitment to reach the girls. This commitment can include formal contracts through which community leaders publicly agree to provide space and support for girls and their mentors." The learning process and community commitment helps convert basic 
national entitlements and policies into on-theground resources where "Real girls get real things in real places."

The Community Resource Scan can include facilities, programs, public spaces, commercial enterprises, venues through which formal services and entitlements are delivered, playing fields, banks or other financial institutions, religious facilities, mobile-phone-charging kiosks, schools, agricultural training or technology programs, local or national government meeting spaces, female-specific spaces (e.g., watercollection points, markets, beauty parlors, women's baths), or any place people do or could gather. The Community Resource Scan draws on individual and collective judgment in the community to decide whether a given resource is girl-friendly or not and grade it as such. The locations or facilities are graded on the following general scale:

1. Due to cultural and/or social restrictions, girls are likely not found here.

2. This place could serve girls, but it is unlikely to be currently doing so.

3. This facility is female-centered and mostly utilized by adult unmarried and married females.

4. There is some age criteria-youth, adolescents, children-but there is no dedicated, age-graded, girls-only time.

5. Girls are definitely found here and have a safe space and time at this location.

Conducting the Community Resource Scan creates a moment to "re-see" the features of the community through girls' eyes and project the potential of a community to serve girls without, in many cases, much additional investment. Just as certain segments of girls become a priority once they are "seen" and quantified, the inventory of community resources fosters the same re-envisioning of the potential of existing community investments.
This activity is not intended to link all girls to all resources but rather to promote more effective deployment of what is already found in the community to priority segments of girls. For example, in urban centers in Ethiopia where migrant girls are often initially coerced into domestic employment and later sadly trafficked, IDs are a "right" of all citizens. These girls rarely have them. Under the Population Council's Biruh Tesfa (Bright Future) program, a large population of migrant adolescent girls-a group often unacknowledged as legitimate community residents and stigmatized, and one without official citizenship-were given program IDs stamped by kebele chiefs. These same girls became regular users of health-screening posts, using vouchers (though services are free, the vouchers served as a "passport" of sorts) and their IDs to validate their access (Erulkar 2014).

\section{Identify Places Where Girls Can Gather}

If the Girl Roster has been implemented in advance of the Community Resource Scan, sometimes that initial walkabout can spark conversation about which spaces are suitable for specific subgroups of girls to meet. The Scan can deepen understanding, then, of those spaces and provide even more thorough assessment of safety. Girl meeting places can be established in a great variety of locations: in schools, in lean-to sheds, even around a tree, provided there is both safety and aural privacy and the spaces are regularly available (see Box 20).

Existing facilities can be repurposed to create a private girls-only space. For example, in an effort to replace the more public space originally chosen for girl-centered activities in a small community of Sierra Leone, those conducting the Girl Roster searched for an alternative. While conducting an initial Community Resource Scan, armed with the knowledge of where girls at risk lived because

11 In the Population Council's Abriendo Oportunidades program in Guatemala, community contracts are designed after initial discussions and the first rostering and community assessment is undertaken. These agreements (see Chapter 8 ) are bringing together the interests and engagements of as many as 50 clustered villages to review their written obligation, for example to protect the space (often during afterschool time) and ensure the safety of mentors moving around the community, in case of issues of violence. In Guatemala, these agreements are monitored annually and communities are "recertified" as having kept their commitments. In Sierra Leone, community contracts were employed in a slightly different way to not only make explicit community leaders, school officials, and sponsoring organizations' commitment to the girls' clubs but also to protect new technologies as the girls' property and underscore the importance of the physical security of the girls' spaces. 


\section{BOX 20. POTENTIAL PLACES WHERE GIRLS CAN MEET REGULARLY AND PRIVATELY}

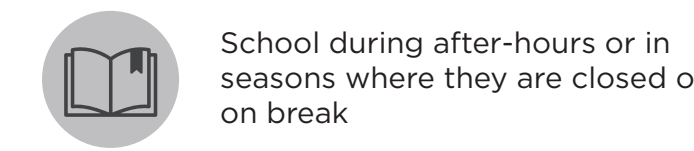

School during the school day with dedicated meeting space not supervised by teaching staff

Extra room adjacent to home of village leader

Health center with dedicated separate space

Community center

Youth center

Tree-shaded area with a floor mat the fields, visual barriers were established so that girls could practice and play their sports unseen. Further, the games were staffed by female monitors and were accessible to both girls and their parents (Hermes 2009; Selim et al. 2013).

Although adolescent girls' health and risk conditions are often cited as a rationale for empowerment and youth programs, without an evidence base and complementary planning these programs often fail girls. Even when girls are "eligible" for programs or services, they may be subtly discouraged from going there-they may be harassed, made to feel unwelcome by staff, made to feel unsafe, or their reputation questioned, or the services may not offer what is most useful to girls (Erulkar and Mensch 1997). Girl Roster results, for example in one case in Sierra Leone, revealed that in-school girls living with both parents were seven times more likely to be in a supportive program than those who were out of school and had a child. Though the community was very small, the Roster information alerted organizers of the program's unintended shortfalls. Thus, targeting community resources increases the value for money and measurably expands the female space.

\section{Gaining Insights About How Different Segments of Girls Experience Their Community and Its Resources}

The Community Resource Scan can spur dialogues about access that are enlightening to all stakeholders. The girls who experience inclusion do not always understand the experience of the girls who are excluded; the excluded in many instances do not even know resources exist. Explicit discussion about how girls can access the basics is illuminating for program staff, current and prospective mentors, and village leaders. It is also through this exercise that girls' voices can be heard as they share personal insights.

The experience of "living while girl," girls' perception of safety, and difficulty in gaining access are often shocking revelations to 


\section{Conducting the Community Resource Scan creates a moment}

\section{to "re-see" the features of the community through girls" eyes and project the potential of a community to serve girls}

without, in many cases, much additional investment.

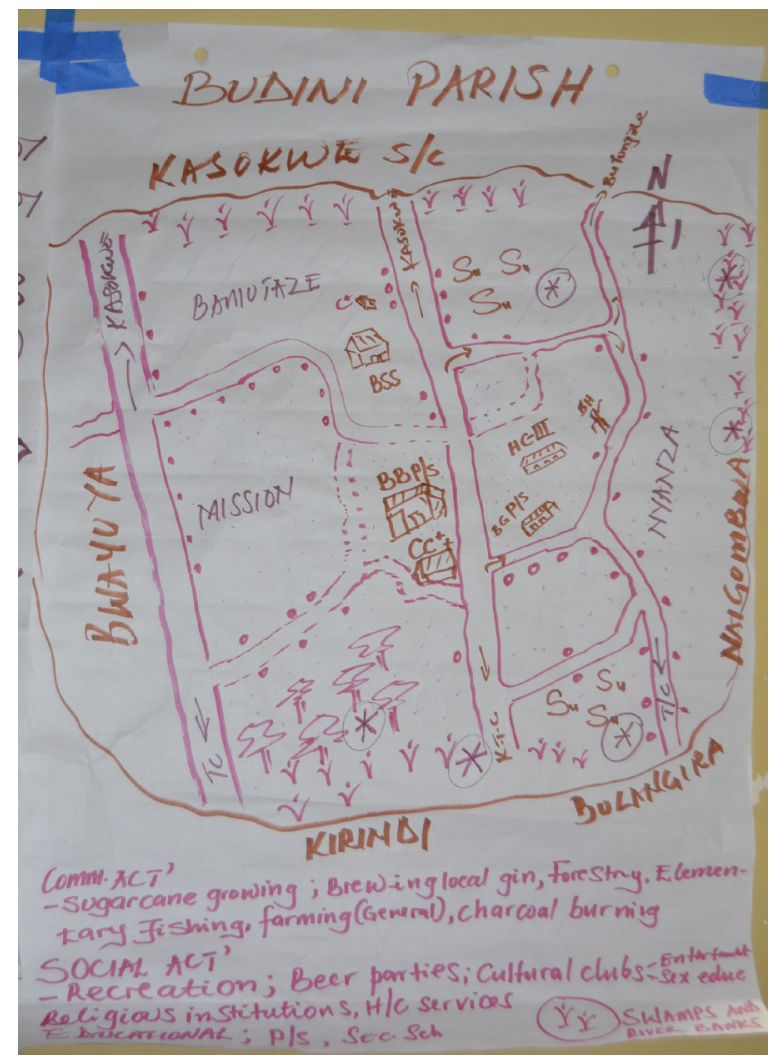

Crude map of a local community in eastern Uganda drawn by program staff who work there. As pictured, the map outlines community facilities. (Photo: Sophie Soares.)

others who have more social power. Simple visuals drawn by the girls, which can be done as a complement to or separate from the Community Resource Scan (see photo of eastern Uganda), show the community as they experience it.

As a complement to the visuals that the Resource Scan creates, the Girl Roster information-collection process and Output Tables can provide other illuminating surprises such as the actual size of the population segment of concern (for instance, the number of out-of-school girls aged 10-14 may be much larger than anticipated). Insights from the Roster foster constructive dialogue. The number of girls in need is specified and their participation is gauged. The degree of exclusion is quantified and visualized and the skewing to the better-off is highlighted.

\section{Knowledge of Girls' Distinctive Experience Catalyzes a Search for Solutions}

The Girl Roster information can offer an initial estimate of coverage. Although the information is not cross-checked and does not include how often a girl attended or the quality of her experience, it is a useful "first line" assessment and often the first time anyone has even examined the question. This information can be presented in a way that is highly understandable by program staff. And when Girl Roster information is presented within each cell of the Overview Output Table, it can show the number of girls who were reported by respondents to be participating in a given program (see Chapter 5, Table 8). This allows program staff to have a provisional view of the degrees of access between the most excluded girl segments and the most advantaged.

One of the earliest examples of using the Girl Roster to see skewed coverage was in South Sudan in 2011. Conscientious and concerned managers of a displaced persons camp estimated the proportion of girls out of school at 10 percent but learned through Roster results that it was closer to 45 percent. The managers were troubled to learn this as they were delivering various forms of support through the schools; this revelation helped them change their policy and deliver more support through community-based centers (Women's Refugee Commission 2014). 
A larger-scale example is provided by the experience of a large NGO operating in multiple sites in a small West African country. The NGO had more than 100 sites with dedicated safe spaces for girls, and through nominally open self-recruitment the highest proportion of participants became girls 16-19 years old; the program was designed around the needs of the older girls, including those with children. Analysis of the Roster results, combined with rigorous discussion of how early the girls needed to have livelihood skills (if they were to have a say in marriage and sexual and reproductive health, as well as prepare for a long future of providing for themselves) resulted in a change in operational guidelines for the organization. The alteration was to prioritize the recruitment of younger girls into their own clubs at specific hours separate from the older girls. Following the Roster, interviews with young and older girls confirmed that they much preferred to be with girls their own age.

\section{When a Formal Coverage Exercise Can Add Value}

Collaborating programs may wish to have more rigorous information about whom they are reaching and deploy a more formal set of assessments that we call Coverage Exercises. A Coverage Exercise collects data on individuals benefiting from a program's service; these include age, gender, schooling, culture/language (if acceptable to ask), living arrangements, work status, and marital status. The Coverage Exercise offers program staff a more formal and systematic look at which services they are providing, to whom and where exactly they are being provided, and whether program beneficiaries are repeat customers or not. This is a "supply side"

analysis tool that shows what is being provided. It helps determine whether services offered are reaching intended beneficiaries (allowing corrections in program design as needed), and whether services are appropriate for the people receiving them.

Program staff may opt to use this tool because they have specific targets of coverage. For example, one well-known organization wanted to make sure that at least 80 percent of their young clients were "the poorest," but the program data suggested that the overlap was closer to 15 percent as unmarried girls and school-going girls were the primary beneficiaries.

Coverage Exercises can also lay the foundation for a consortium of organizations to collaborate in achieving coordinated, quality coverage, using information on their current reach to cocreate a targeted coverage plan. For example, a consortium of 16 organizations working in rural Tanzania fostered dialogue about their reach in an attempt to share and benefit from each other's resources so coverage could be expanded.

Even provisionally convinced managers may want to have more exact information to address skepticism among colleagues. The Coverage Exercise is a basic monitoring and evaluation tool that is simple to use and low cost to implement. Understanding whether programs are reaching intended beneficiaries or not helps implementers and donors focus their activities and funding to reach those who are most in need, or (for our purposes) off-track. Results of the Coverage Exercise hold providers accountable and ensure that services and resources intended for girls are reaching the intended segments. This can be an important step in supporting deepened intentionality and in facilitating community and leader buy-in to new program efforts to meet the needs of the underserved, particularly off-track girls.

Policy analysts at the Population Council developed the Coverage Exercise to offer youth-serving programs (youth centers, youthfriendly services, community- and schoolbased peer education) a simple field tool for practitioners that recognizes the diversity of adolescent populations and lives. A Coverage Exercise can be used to monitor and evaluate a single program or network of services in a local area, or it can be used to learn who is being reached by a number of co-located programs on a much larger, even national scale. The methodology varies depending on your resources and objective. 
TABLE 14. RESULTS OF COVERAGE EXERCISE IN SEVEN COUNTRIES: GENDER AND AGE OF BENEFICIARIES SERVED

\begin{tabular}{|c|c|c|c|c|c|c|}
\hline \\
\hline Country & $\begin{array}{c}\text { Number of } \\
\text { beneficiaries } \\
\text { served (number } \\
\text { of contacts) }\end{array}$ & $\begin{array}{l}\text { Males } \\
\text { (\%) }\end{array}$ & $\begin{array}{c}\text { Females } \\
(\%)\end{array}$ & $\begin{array}{c}10-14 \text { years } \\
(\%)\end{array}$ & $\begin{array}{c}\text { 15-19 years } \\
(\%)\end{array}$ & $20+$ years $(\%)$ \\
\hline Belize & 3,550 & - & - & $\begin{array}{c}\text { Males: } 32.3 \\
\text { Females: } 18.6\end{array}$ & $\begin{array}{c}\text { Males: } 33.9 \\
\text { Females: } 30.8\end{array}$ & $\begin{array}{c}\text { Males: } 33.8 \\
\text { Females: } 50.7\end{array}$ \\
\hline Burkina Faso & $\begin{array}{c}6,218 \\
(6,860)\end{array}$ & 56 & 44 & 7 & 30 & 63 \\
\hline Ethiopia & $\begin{array}{c}10,866 \\
(10,873)\end{array}$ & 58 & 42 & 22 & 45 & 33 \\
\hline Guatemala & $\begin{array}{c}- \\
(12,920)\end{array}$ & 47 & 53 & 37 & 54 & 9 \\
\hline $\begin{array}{c}\text { Guinea- } \\
\text { Bissau }\end{array}$ & $\begin{array}{c}7,625 \\
(8,167)\end{array}$ & 57 & 43 & 7 & 37 & 56 \\
\hline Malawi & $\begin{array}{c}15,471 \\
(19,666) \\
\end{array}$ & 54 & 46 & 18 & 31 & 50 \\
\hline Mauritania & $\begin{array}{c}5,452 \\
(8,115)\end{array}$ & 83 & 17 & 28 & 42 & 25 \\
\hline
\end{tabular}

Note: For country-specific references, see "Results of Previous Coverage Exercises," below.

The Coverage Exercise has been used to assess both utilization levels and the age, gender, and social characteristics of beneficiaries; it is also used to differentiate repetitive users from one-time users. It can profile the social and demographic characteristics of those using a particular part of a program. For example, who comes for the remedial, after-school, and reinforcing literacy classes that a program offers versus who comes for the HIV testing. Often girls seek a community service offered by a program for very different reasons than boys. They are rarely there for play or asset-building; they are often there because something has gone wrong or they are worried (e.g., forced sex acts, a broken condom, or a violent episode).

\section{Results of Previous Coverage Exercises}

The Population Council and its on-the-ground partners have conducted Coverage Exercises in Belize, Burkina Faso, Ethiopia, Guatemala, Guinea-Bissau, Malawi, and Mauritania (see Table 14) (Mekbib, Erulkar, and Belete 2005; National Youth Council of Malawi and UNFPA 2010; Weiner 2011; Joint UN Programme of Adolescent Girls 2012; Lardoux and N'Bouke 2013). The findings have been shared with a wide range of stakeholders both to inform them about common issues in youth-service provision and to facilitate discussion of youth-oriented policies and programs. The results from the different contexts (presented in Table 14) overwhelmingly show that conventional youth programs engage in elite capture and do not reach adolescent girls most in need. Those who receive the most youth services are at lesser risk and have greater social assets (e.g., in-school or older boys, unmarried males who are urbanborn and living in two-parent households, older adolescents, and youth aged 20-24+).

Those who are at greatest risk and are the least socially anchored receive a negligible share of youth-serving resources. They include out-of-school (younger) girls, married girls, migrants, those who are from rural origins living apart from parents, and the youngest adolescents (aged 10-14 years). In Ethiopia, for example, only one in five beneficiaries (22 percent) of peer education and youth-center programs were out of school, despite the low overall enrollment.

In slum areas of Addis Ababa, Ethiopia, an inventory of youth programs (youth centers and peer-education programs) showed that programs reach the more advantaged in-school population, while most Ethiopian adolescents are out of school. It also showed that older boys and men dominated the program; 45 percent of 


\begin{tabular}{|c|c|c|c|c|c|c|c|c|c|}
\hline \multicolumn{10}{|c|}{$\begin{array}{l}\text { TABLE 15. ASSESSMENT OF USERS OF A CONVENTIONALLY CONFIGURED YOUTH } \\
\text { PROGRAM IN UGANDA, NORTHERN REGION, BY GENDER AND AGE }\end{array}$} \\
\hline \multicolumn{5}{|c|}{ Female users (\%) } & \multicolumn{5}{|c|}{ Male users (\%) } \\
\hline Under 10 & $10-14$ & $15-19$ & Over 19 & Total & Under 10 & $10-14$ & $15-19$ & Over 19 & Total \\
\hline 2 & 10 & 17 & 9 & 38 & 3 & 11 & 21 & 27 & 62 \\
\hline
\end{tabular}

contacts were boys aged 15 and older, and 1 out of 5 were men aged 20 or older. Only 3 percent of female contacts were married, even though most girls in Ethiopia marry during adolescence and most sexually active girls are married. These findings were corroborated by populationbased surveys among 1,000 adolescents aged 10-19 years, where they were asked about utilization of youth centers and peer educators in the previous year. The population-based surveys additionally showed that girls who work long hours and are isolated are less likely to access and benefit from programs (Mekbib, Erulkar, and Belete 2005).

In North Africa, in a country with extremely high levels of child marriage and childbearing among young adolescents, the government invested in youth centers in an effort to solve this problem. A Coverage Exercise was conducted, and it was found that 20 percent of the youth centers had never been visited by a girl or young woman, and at 80 percent of the centers females were never more than 10 percent of the visitors (Lardoux, Ekeibed, and Bossou 2006). In an East African country, youth centers were found to be a potentially dangerous place for girls; studies reaching as far back as 20 years ago show these youth centers to be frequent enclaves for older males with staff that were not only inattentive to girls but had openly discriminatory attitudes toward them (Erulkar and Mensch 1997).

A survey of adolescent-serving organizations in Uganda reveals that in the northern region where girls have among the worst indicators, the most common users of adolescent programs are males over the age of 19 (that is, nonadolescent males). It reveals that females comprised 38 percent of overall program beneficiaries (see Table 15) (Amin et al. 2013). In analyzing such statistics, it is important to cross-reference age and gender and other defining characteristics such as schooling and distinguish between visits and unique users.

Unless girls are being counted individually and not by visit, the overall figure of only 38 percent of beneficiaries being female may reflect even more bias. In this example, it's possible that older girls are repeat customers while younger girls rarely attend (as there are no separate times or services for younger females). If programs do not have age- and genderstratified sessions-and most do not-younger boys may also be discouraged (Kalibala and Elson 2010). Using Evidence of Differential Access to
Increase Fairness and Value for Money

Many youth services are underutilized. In a review of youth centers in a Central East African country, the beautifully organized centers (four different meeting rooms, a large play area) received an average of only 2,000 visits a year. Looking at the facilities, it was clear that several groups could have met simultaneously, with a much higher visit count. Review of the attendance log showed that although a few girls visited, there were mainly boys and they appear to have been repeat visitors. That insight led to the suggestion of doing a formal Coverage Exercise, which confirmed that very few of the younger, poor, adolescent girls were using the available space. 
Apart from levels of participation, it is vital to know who is being exposed to beneficial program content. Coverage Exercises can reveal differences in program curriculum topics and services delivered by age and gender. An analysis of peer programs in francophone West Africa, for example, found that girls in Burkina Faso and Guinea-Bissau were more likely to come once or twice and receive education on family planning, as well as on family and social problems; conversely, boys participated in sports and discussions on HIV/AIDS, STIs, condoms, and drugs. Younger children were more likely to learn about children's rights and hygiene/sanitation, while older adolescents received information on drugs and HIV/AIDS (Lardoux and N'Bouke 2013). In a program in northern Liberia, many more older adolescent males than females were participating in the afternoon sessions of the tutorial program (in one session, 44 boys and 1 girl attended). The girls were more likely to visit the health unit with fears of being pregnant or having contracted STIs. The males were building assets and enjoying themselves, whereas the females were managing and trying to prevent crises.

In general, we recommend that program staff consider stratifying program sessions by age, gender, and perhaps social category (e.g., the usually highly neglected females in domestic service). And, further, when the information permits, we recommend prioritizing populations especially in need, and increasing their frequency and ease of participation. Whereas boys can attend programs and play basketball with relative safety on a Friday night, girls, especially in humanitarian settings, have little freedom to socialize or move outside their immediate home areas after dark.

In addition, because of the burden of chores and lack of safety, girls may not be allowed to attend, or be attracted to, evening sessions, but would welcome tailored afternoon sessions with female mentors.

\section{How the Coverage Exercise Functions} at Different Levels

Individual service-delivery organizations may deploy simple Coverage Exercises, implemented by their staff, at the same time they provide services-to know who they are reaching. Four organizations in Liberia (before a more ambitious Coverage Exercise was undertaken) sought to find out who walked through their doors over the course of several weeks. Using fairly simple color coding of cards assigned to specific age groups and genders, program staff pasted up the cards on a wall each time someone in that age group and gender category came into the program space (Weiner 2011).

The impact was immediate and staff who collected the information could see at the end of the day how selective the program participation was and noted not only differences by age and gender but also by regularity of attendance. Some of those most in need rarely showed up with a problem and never came back, while others-more often males with greater social freedom-visited two or three times a week.

Groups of organizations conducting contemporaneous Coverage Exercises can use the information as a basis for planning for a common clientele and can rationalize use of program resources to extend their reach to girls in the program catchment area. There may be substantial variation among them, such as in Ethiopia where there were only a few organizations seeing a high proportion of adolescent girls and other organizations that had a high proportion of males over the age of 25 (Mekbib, Erulkar, and Belete 2005). By cooperating with one another to attract and serve the underserved groups, these organizations can set up a division of labor. They can extend service hours and expand afternoon slots, some can operate on Saturdays and others on Sundays, and they can make efforts to attract excluded girls. In many settings, married girls have absolutely nowhere 
to go, so having facilities close to them is important; again, cooperation and transparent sharing of results among providers of different services could facilitate access for young females who have the most limited geographic range.

Policy planners and donors may wish to assess the value-for-money of their investment. As sexual and reproductive health ( $\mathrm{SRH}$ ) activities were promoted in Ethiopia, it was assumed that at-risk girls could be reached through "youth" programs (e.g., school-based reproductive health programs, youth-friendly services, youth centers, peer programs) as a primary vehicle (commonly embracing those up to age 35). Coverage Exercises revealed the negligible access of the most-at-risk populationsyounger, female, out-of-school, married, and so forth. In high-HIV-burden countries over the last decades, despite a steady and increasing investment, the female-to-male new HIV infection rate has remained persistently high (eight times as many females 15-24 years infected as males the same age in sub-Saharan Africa). The Coverage Exercise can, therefore, greatly assist the targeting of scarce resources to those most in need (see Box 21).

\section{Bringing the Results of the Girl Roster Together with the Community Resource Scan}

The Community Resource Scan, together with Girl Roster results, provides a detailed and geographically anchored vision of where rostered girls reside in relation to community resources. Depending on the level of detail an organization desires, the Scan can also include an initial grading of access to facilities; that, in turn, can be prompted by findings from the Girl Roster ${ }^{12}$ that show the persistent underrepresentation of an at-risk group. The Roster can reveal the presence and location of a large number of out-of-school girls living

BOX 21. TYPES OF COVERAGE EXERCISE AND THEIR PURPOSE

\begin{tabular}{|l|l|}
\hline Type of exercise & \multicolumn{1}{|c|}{ Purpose } \\
\hline $\begin{array}{l}\text { Snapshot in time of one } \\
\text { program }\end{array}$ & $\begin{array}{l}\text { This is for the provider who would like quick results of a single } \\
\text { program. }\end{array}$ \\
\hline $\begin{array}{l}\text { Ongoing monitoring of one } \\
\text { program }\end{array}$ & $\begin{array}{l}\text { In this case, the Coverage Exercise is integrated into the program's } \\
\text { monitoring plan, including repeating the exercise at key moments } \\
\text { (for example, once a year) to see if the profile of users has changed } \\
\text { in the desired direction. }\end{array}$ \\
\hline $\begin{array}{l}\text { Snapshot of coverage of } \\
\text { one organization's multiple } \\
\text { programs }\end{array}$ & $\begin{array}{l}\text { An organization with a number of different outlets across the } \\
\text { country may decide that it wants to find out who is being reached at } \\
\text { its different locations, and data are being collected around the same } \\
\text { point in time. (Note: It is important to check on the seasonality, and } \\
\text { aim to do the exercise during "typical" circumstances; e.g., not at a } \\
\text { busy time of year.) This can be repeated a year later, for example, or } \\
\text { in different seasons. }\end{array}$ \\
\hline $\begin{array}{l}\text { Planning coverage of programs } \\
\text { in the defined catchment } \\
\text { region by coordinating among } \\
\text { programs }\end{array}$ & $\begin{array}{l}\text { This method of Coverage Exercise helps you see who, among a group } \\
\text { of organizations, is reaching particular segments of girls differently } \\
\text { and better than others. It can help this set of organizations plan } \\
\text { intentionally how to coordinate efforts not only by geographic area } \\
\text { but also by the specialty or intention of the organization to best } \\
\text { serve the girl segments. }\end{array}$ \\
\hline $\begin{array}{l}\text { Representative evaluation of } \\
\text { coverage in a defined region }\end{array}$ & $\begin{array}{l}\text { This helps you generalize your results from your sample of programs } \\
\text { to the larger population of all adolescent-serving programs. }\end{array}$ \\
\hline
\end{tabular}

12 This will entirely depend on the order in which you employ these tools; typically, we advise that the Roster be employed first, as it can help familiarize you with a new community in a way that then informs the Community Resource Scan; others might choose to use the tools simultaneously, as some partners have sent staff out to do the Roster while utilizing one to two team members to do the Scan during the same visit to the community. 


\section{FIGURE 10. RESULTS OF A COMMUNITY RESOURCE SCAN IN A REMOTE BORDER TOWN IN HAITI}

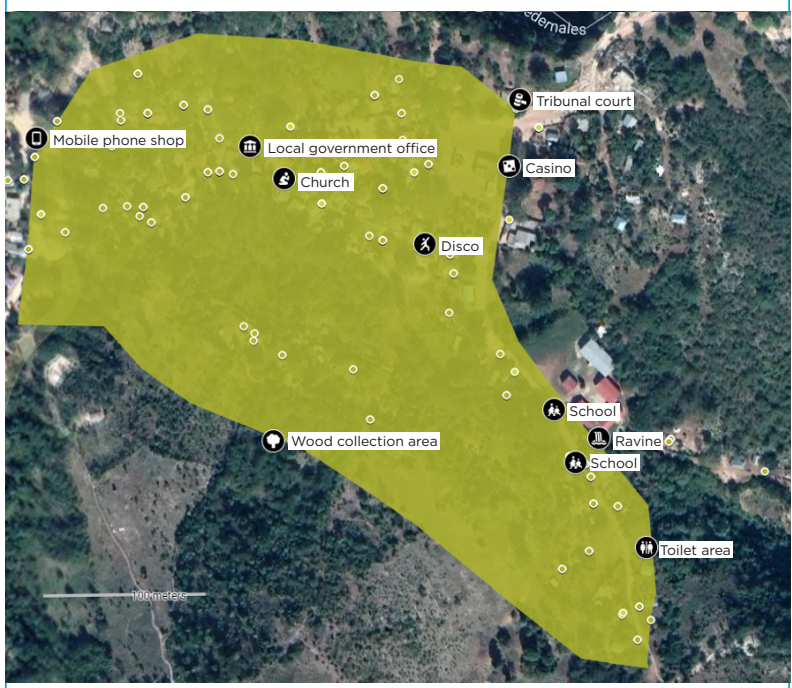

As can be seen here, both the boundaries of the walkable community and a variety of resources and facilities have been mapped, including a church, mobile phone shop, toilet area, wood collection area, disco, etc. (Map analysis: Eva Roca.)

with one or no parents. The Scan (see example in Figure 10) can be combined visually with the GPS information from the Girl Roster (see example in Figure 11), or an otherwise crude map locating girl segments in the areas in which they cluster, potentially allowing practitioners to see excluded segments and where they are in relation to key resources. In Figure 11, for example, we can see where concentrations of 10-14 year olds out of school and in school are living. In Figure 12 (an overlay of Figure 10 and 11 ), you can see that though there are out-ofschool girls 10-14 years old throughout the community, they are especially concentrated in the northern area of this border town in Haiti, farther away from the main road.

The Girl Roster, complemented by the Community Resource Scan, deepens girls' visibility and lays the foundation for a sustainable community-wide plan that gives girls access to new resources, leading to:

- The creation of segment-specific, community-based girl platforms wherein social, economic, health, and cognitive assets can be built and opportunity visits to community service sites can be conducted;
FIGURE 11. RESULTS FROM THE GIRL ROSTER IN A REMOTE BORDER TOWN IN HAITI

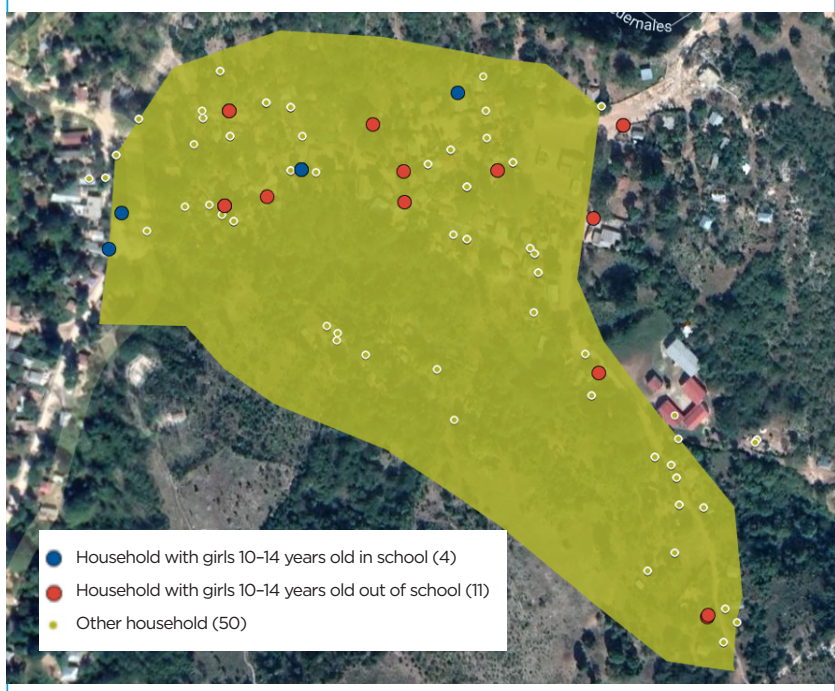

Significant portions of girls aged 10-14 are out of school. (Map analysis: Eva Roca.)

FIGURE 12. OVERLAYING RESULTS OF THE GIRL ROSTER AND THE COMMUNITY RESOURCE SCAN IN HAITI

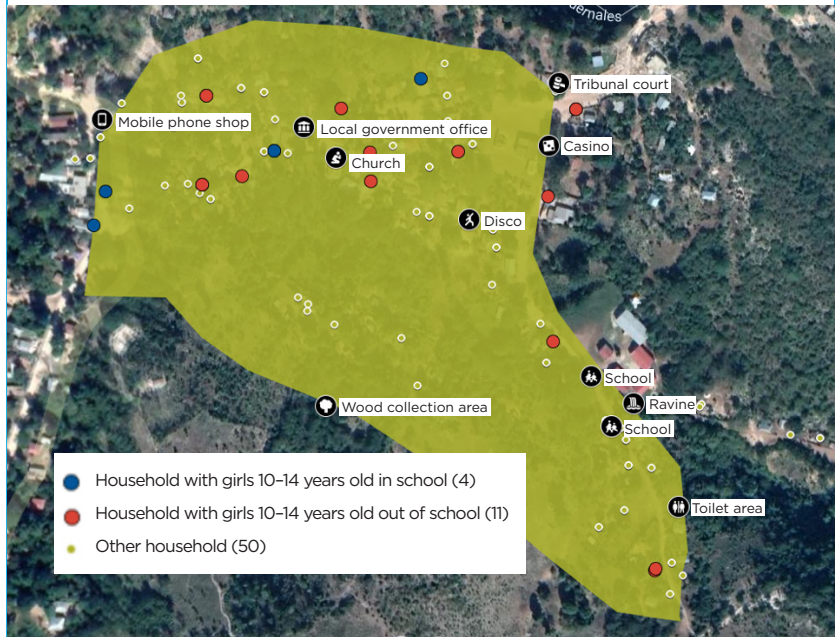

The overlay shows where girls live in relation to places in their community-both potential resources and places to be avoided. (Map analysis: Eva Roca.) 
BOX 22. USING THE INVENTORY OF COMMUNITY RESOURCES TO PLAN HOW BEST TO ENGAGE GIRL SEGMENTS AND GIVE THEM FULL ACCESS

\begin{tabular}{|c|c|c|c|}
\hline Girl segment & Core needs & $\begin{array}{l}\text { Community resources } \\
\text { from which girl } \\
\text { segment can now } \\
\text { benefit }\end{array}$ & Potential sources of support \\
\hline $\begin{array}{l}\text { Girls } 10-14 \text { years old } \\
\text { living apart from } \\
\text { parents and not in } \\
\text { school }\end{array}$ & $\begin{array}{l}\text { Protection } \\
\text { Basic social support } \\
\text { Reentry into } \\
\text { schooling } \\
\text { Livelihoods training }\end{array}$ & $\begin{array}{l}\text { None (are not in } \\
\text { school, not safe in } \\
\text { the market, do not } \\
\text { use the playing field, } \\
\text { are not welcome in } \\
\text { financial services } \\
\text { facilities for the poor, } \\
\text { do not feel they have } \\
\text { the credentials to get } \\
\text { health services) }\end{array}$ & $\begin{array}{l}\text { Multipurpose girl platforms where } \\
\text { vouchers and IDs are provided to } \\
\text { encourage visits to health services and } \\
\text { banking outlets } \\
\text { Weekly place where girls can meet with } \\
\text { other girls like them } \\
\text { Regular, nonformal, second-chance } \\
\text { schooling (in school after hours or at } \\
\text { community center during hours in which } \\
\text { segment of girls is not working) } \\
\text { Community center as site for auxiliary } \\
\text { food-security program during scarcity } \\
\text { seasons }\end{array}$ \\
\hline $\begin{array}{l}\text { Migrant adolescent } \\
\text { girls in domestic } \\
\text { service }\end{array}$ & $\begin{array}{l}\text { Social support from } \\
\text { extreme social } \\
\text { isolation } \\
\text { Financial literacy and } \\
\text { space for savings } \\
\text { Protection from } \\
\text { sexual exploitation } \\
\text { Life skills, including } \\
\text { access to health, } \\
\text { hygiene, and sexual/ } \\
\text { reproductive health } \\
\text { services } \\
\text { Literacy }\end{array}$ & $\begin{array}{l}\text { None (except funeral } \\
\text { societies-where } \\
\text { girls get a savings } \\
\text { mechanism that is } \\
\text { nominally organized } \\
\text { to save for their own } \\
\text { funeral) }\end{array}$ & $\begin{array}{l}\text { Multipurpose platforms that guide } \\
\text { girls through establishment of savings } \\
\text { accounts and address other financial } \\
\text { literacy needs } \\
\text { Accompanied/facilitated visits to local } \\
\text { service providers } \\
\text { Option of literacy courses }\end{array}$ \\
\hline $\begin{array}{l}\text { Married girls 10-24 } \\
\text { years of age }\end{array}$ & $\begin{array}{l}\text { Health or family } \\
\text { planning services } \\
\text { Financial literacy and } \\
\text { space for savings, } \\
\text { including financial } \\
\text { autonomy } \\
\text { Completion of } \\
\text { schooling }\end{array}$ & $\begin{array}{l}\text { Prenatal visits } \\
\text { (majority of girls make } \\
\text { one prenatal visit) } \\
\text { No second-chance } \\
\text { schooling programs }\end{array}$ & $\begin{array}{l}\text { Establishment of health worker visiting } \\
\text { married girls' clubs one time } \\
\text { Financial literacy activities integrated } \\
\text { into married girls' clubs } \\
\text { For those interested, nonformal } \\
\text { schooling that fosters literacy } \\
\text { Transition back into school-based } \\
\text { programs }\end{array}$ \\
\hline
\end{tabular}


BOX 23. ESTIMATING COVERAGE OF GIRLS 10-14 YEARS OLD LIVING APART FROM PARENTS IN CABO DELGADO, MOZAMBIQUE (TOTAL IN NEED = 45,000)

Potential coverage of three organizations

\begin{tabular}{|l|l|}
\hline Organization description & Number of girls reached \\
\hline $\begin{array}{l}\text { Organization A } \\
\text { - Distributes health information only to disadvantaged girls }\end{array}$ & 1,000 per year \\
\hline $\begin{array}{l}\text { Organization B } \\
\text { - Conducts radio broadcasts } \\
\text { Decision to do so did not take into account who had access } \\
\text { to radios or were influenced by them } \\
\text { Prevailing information from people within the area is that } \\
\text { very few have radio access, and especially those out of } \\
\text { school were not in reach of such broadcasts }\end{array}$ & $\begin{array}{l}\text { (Potential here but not targeted } \\
\text { to broadcast) }\end{array}$ \\
\hline $\begin{array}{l}\text { Organization C } \\
\text { Provides Orphans and Vulnerable Children (OVC) } \\
\text { programming to 6,700 male and female orphans-70\% boys, } \\
\text { 30\% girls-reaching an estimated 2,000 per year }\end{array}$ & 2,000 per year \\
\hline Estimated coverage & \\
\hline
\end{tabular}

- The establishment of a location in which to aggregate the demand for existing services and make active links, such as by inviting visits from health workers, building savings programs, or giving girls "passports" detailing services available in the community;

- The crafting of actual plans, per existing resources and facilities, for specific segments of girls to get the services and entitlements they need with minimal social, emotional, and economic costs.

This mapping of the girls and community resources, and subsequent dialogue, lays the foundation for new plans. In Box 22 are illustrative girl segments, core needs, community resources, and a comment on what actions might be prioritized to ensure that girls' most pivotal needs are met.

\section{Estimating Coverage in Subnational Districts}

Estimating coverage in hotspot subnational districts is a vital part of advocacy for more resources from bilateral and multilateral donors, national governments, and local authorities.

Typically, when a problem such as the persistently high ratio of HIV infection among young adolescent girls in relation to young adolescent boys is discussed, policy audiences may be deceived by one or two programs with the right labels and believe that their job, including funding support, is "done." To counter this tendency, systematic information and enumeration is vital.

An Adolescent Girls Community of Practice partner, Girl Move Foundation ${ }^{13}$ in northern Mozambique, first did a review of the country and identified hotspots in the North where girls were at a very high level of risk for a number of

13 Girl Move Foundation, or Fundação Girl Move, was founded in 2013 as a nonprofit organization working to improve the lives of girls through education and the development of life skills. The foundation of its work is that girls are the principal agents of change. For more information, visit girlmove.org. 
outcomes, including HIV. Girl Move Foundation and the Adolescent Girls Community of Practice convened a meeting of 16 organizations working in the region, following a wider national workshop and combining population projections of different segments of girls.

In the northernmost Cabo Delgado Province, for example, it was estimated-combining DHS and other census data-that 45,000 girls aged 10-14 years were living apart from their parents and out of school. It was noted that there were three organizations working in that area (see Box 23). The organizations were interviewed about their reach to adolescent girls, and combined it was estimated, most optimistically, that Organization A was reaching 1,000 of these girls per year; Organization B, though it had potential in terms of its capacity, had no specific audience and was not reliably reaching any of the girls; and Organization C was focusing on a population overlapped with these girls, meaning of the 6,000 users their program reached per year, only 2,000 may have been these girls. Hence, of the 45,000 who were in need, perhaps 3,000 were reached between these three organizations, leaving 42,000 unreached. This information argues for strengthening the targeting of resources to the out-of-school girls and building the capacity of the network of organizations in the region.

\section{Summary}

The Intentional Design process is like putting together a puzzle, circling back to see where the holes are, reconsidering your placement, and trying again. In other words, it is not only cyclical but ongoing; there are always opportunities to return to previous steps and make adjustments. There will always be more action possibilities than you can practically pursue.

There is no real wrong answer except no answer, and you will do periodic reevaluation. On an optimistic note, once excluded girls have established strong identities and peer relationships, and have started to use facilities and services, service providers become familiar with the girls and their different needs. At this point, there is usually no going back-you have set in motion a virtuous cycle of meaningful community engagement and have laid the foundation for a community that can work for everybody. 


\section{A Review of the Tools to Support the Basic Model for an Intentional Design Approach}

\section{LEARNING OBJECTIVES}

- Learn about the programmatic decisions after communities with high concentrations of at-risk girls are selected, their resources mapped, and the full "universe" of girls is seen and segmented.

Throughout the guide, we have alluded to a basic programmatic approach (Basic Model) for visualizing the full universe of girls and developing evidence-based plans to reach different segments of girls, especially those that are most neglected and at highest risk. This Basic Model has been deployed and tested in more than 41 countries, as of 2019. We view practitioners as our central constituency, and this guide provides an overview of the learning and interpretive tools available from the Population Council that lay the foundation for program design that has two clear objectives:

- To deliver health, social, economic, and cognitive assets through girls-only spaces;

- To assure specific segments of girls access to vital facilities, resources, and entitlements already in the community.

These tools are not only meant for the initial design of the program, but to course-correct already implemented programs, assist in the expansion or scale-up of an existent program, and monitor and evaluate the implementation process and impact.
Box 24 contains a list of the ten core steps of the Intentional Design method. Steps 1-4 have been discussed in previous chapters. We concentrate here on steps 5-10, which are presented as sequential, segmentspecific programmatic decisions made after communities with high concentrations of at-risk girls are selected, their resources mapped, and the full universe of girls seen and segmented.

On the ground, as you will see in the practitioner reports in Chapter 9, the precise sequence of the steps is flexible. The sequence, and the interpretation of Girl Roster and Community Resource Scan results, are informed by practitioners' sense of possibilities and political realities. This process typically results in a program with dedicated girlsonly spaces and selective engagement of communities, supportive mentoring structures, and plans to intensify girls' access to existing programs, entitlements, and participation in governance structures, amplifying girls' voices in governance decisions. In Box 25 (Bruce 2015), the Population Council schematized the typical interventional model. 
Our review of Steps 5 through 10 includes an explanation of why the particular steps are important, central observations reflecting what we have learned through workshop and on-the-ground applications, and a listing of resources. Throughout this chapter, sections are color coded to provide information relevant for specific steps.

\section{BOX 24. THE BASIC MODEL FOR REACHING DIFFERENT SEGMENTS OF GIRLS USING AN INTENTIONAL DESIGN APPROACH}

1 Identify the places with the highest concentrations of off-track girls.

2 See the full universe of girls.

3 Segment the universe of girls into likesituated groups for intervention.

Prioritize and locate the most excluded

4 segments in affected communities, both in relation to each other and community physical features and facilities.

5 Intentionally recruit priority segments.

Secure a regular, safe community

6 space in which girls can meet, mindful of seasonal stressors and risk scenarios.

Build indigenous social support-

7 mentors to recruit girls, deliver programs, and provide support, a local safety net, and links to resources.

Build meaningful content keyed

8 to girls' real lives that establishes positive, achievable metrics.

\begin{tabular}{|c|l}
\hline $\mathbf{9}$ & $\begin{array}{l}\text { Design programmatic on-ramps- } \\
\text { assuring girls' access to public/ } \\
\text { private resources in their walkable } \\
\text { communities. }\end{array}$ \\
\hline 10 & $\begin{array}{l}\text { Pull it all together in systematic, } \\
\text { per-segment planning, and offer a } \\
\text { sound basis for future evaluation and } \\
\text { measurement of program outcomes. }\end{array}$
\end{tabular}

Practitioners and policymakers of both genders, who are devoted to the well-being of their communities may feel they have a sense of girls' lives. This feeling may be strongest among female practitioners who have worked with women and believe they are fully informed about their lives. The application of the Population Council's tools is meant to create moments of reflection, which enable people with decision-making power to question and revisit assumptions. Over time, conditions for girls change, and their experiences are often invisible. A consistent use of tools and sensitization exercises can make girls visible and actionable.

\section{Sensitization Workshop Exercise}

A useful starting point is to ask practitioners to identify with a particular segment of girls and think through their problems to highlight the heterogeneity of their experiences and tease out the scenarios of risk. Often when people enter the workshop room, they find themselves assigned to a table with a segment identified, such as "14-year-old migrant girl living in distant but unknown cousin's family, in domestic work with unregulated hours for a salary at the discretion of the employer" or "second wife, 15 years old, of a richer, better-off farmer." Then, as various questions about the girls' needs emerge, we ask each group to think about the specific segment in the context in which they are working. You can ask "What are the unique needs of this segment?" which highlights the internal heterogeneity even among the most excluded girls. What are the highest seasons or scenarios of risk? To what degree do you believe that such girls have access at all or adequately to the programs that are meant to reduce HIV infection, promote schooling, deter child marriage, and build the skills required to pursue safe, decent livelihoods?

These exercises are typically very rewarding because they stretch participants' empathy and allow them to think more about the differential 


\section{BOX 25. COMMENTARY: INVESTING IN THE POOREST GIRLS IN THE POOREST COMMUNITIES EARLY ENOUGH TO MAKE A DIFFERENCE}

The Population Council and its partners have applied a targeted, evidence-based approach to adolescent girl programming in over 20 countries, prioritizing neglected and exceptionally at-risk adolescent girls (Bruce and Hallman 2008), including:

- Girls aged 10-14 years, behind in grade level for age, or not in school in places where child marriage and/or HIV infection are common (Clark, Bruce, and Dude 2006; Bruce, Temin, and Hallman 2012);

- Girls, often migrants, aged 8-15 years, living apart from their parents and not in school (Temin et al. 2013); and

- Girls aged 10-24 years, married as children, many of whom also have children (Erulkar and Muthengi 2009).

This approach uses community-based spaces (platforms) where marginalized girls can build protective health, social, economic, and cognitive assets as the foundation for agency, self-esteem, and the ability to claim their human rights and decent livelihoods.

Girls are grouped by age, and school-going and marital status, and have at least weekly access to girlsonly spaces that typically offer 40 or more sessions over the course of a year. Local mentors (young women aged 18-30 years) facilitate meetings, offer social support, and impart communication, leadership, and context-specific practical skills.

Programs include intensive community engagement and aim for "tipping point" participation (i.e., 30-80 percent of eligible girls/households should be engaged to promote normative changes). Strategic planning-including mapping concentrations of girls at risk (Population Council 2013), rapid assessment and programming tools (Mensch, Bruce, and Greene 1998; Austrian and Ghati 2010; Erulkar 2011; Population Council 2011; Austrian et al. 2012), and operations research-facilitates expansion once the returns on girl-centered investments are demonstrated. Currently, over 35,000 girls are in Population Council randomized controlled trials, and over 500,000 have participated in closely tracked programs, which will enable longitudinal assessment of costs and benefits.

The scaling strategy functions at two levels-creation of permanent girl spaces and substantially increasing girls' demand for and access to underutilized services and facilities such as schools, playing fields, and banking services. Several programs show the potential of this approach for enabling access to underused or mistargeted health services in particular. For example, while contraceptive prevalence among adolescent married girls is 35 percent in Amhara, Ethiopia, prevalence among those participating in clubs supported by the Population Council and the Ministry of Women, Children, and Youth Affairs is typically 71-74 percent. A program for more than 60,000 extremely socially isolated girls in Ethiopian cities with high HIV prevalence yielded measurable increases in demand for HIV testing (Erulkar et al. 2013). Health vouchers in Ethiopia, especially for girls in domestic service and those with disabilities (Erulkar and Muthengi 2009; Erulkar and Tamrat 2014), reversed the typical pattern of youth programs in which better off, older, and male populations receive disproportionate benefits.

Most platforms provide age-appropriate financial literacy, recognizing that economic capability is vital to empowerment (Population Council 2005). For example, an adolescent girl who is financially literate and is saving can more easily recognize and take action on her HIV risk (Hallman, Stoner, et al. 2013). A program piloted in Uganda and Kenya, now expanding in Kenya and to Zambia, offered girls aged 10-19 years access to financial literacy groups and incubator savings accounts. Initial research comparing girls who only had savings with girls who were both saving and participating in groups suggests that group membership increased girls' ability to manage sexual threats (Austrian and Muthengi 2014).

Although much remains to be learned, certain program premises are clear: work with girls should begin a year or two before puberty (Chong, Hallman, and Brady 2006); community-based platforms must engage girls individually and in a purposeful movement to capture more resources; and information must be accompanied by investment in girls' social capital and preparation for decent livelihoods, recognizing that they will solely or substantially support themselves and their children in the future (Clark and Hamplová 2013).

Source: Bruce 2015. 
structures of constraint girls are living in, which, in turn, challenges previous assumptions and leads to more realistic program planning. This early and dedicated attention to identifying specific segments' perspectives as a foundation for subsequent decision-making is fundamental Intentional Design practice. At the end of this chapter, we will review the Segment Planning Worksheet (see Step 10, Box 31), which anchors decision-making around not an individual "girl" or a monolithic groups of "girls" but specific segments, which is a more reliable way to assure the evolution of meaningful content, appropriate staffing, and the greatest value for money.

\section{STEP 5: Intentional Recruitment of Priority Segments of Girls}

Recruitment strategies must be properly tailored to ensure that the desired segments are reached and recruited into the program. If a recruitment strategy is inappropriate for the segment-such as using the radio to advertise a program where your target segment does not have access to a radio-then it will be ineffective. The Recruitment Strategy Worksheet (see a simplified version in Box 26) helps program staff match segments to the methods of recruitment that are best suited for them. Do the girls read and write? If so, perhaps a flyer posted in spaces where they frequent and would feel comfortable reading the advertisement-such as a salon, school, or marketplace, depending on the segment-would work. Completing this worksheet is useful for program debate and exchange. For practitioners who might have become accustomed to a singular approach to recruitment, here we are promoting an intentionally diversified approach.

Typically, an on-demand recruitment strategy (meaning welcoming whomever shows up into a program) or reliance on word of mouth and broadcasting the program will fail to reach excluded, younger female populations. And often, excluded female younger populations are heterogeneous. For example, in Haiti in the first 2010 post-earthquake gathering of organizations responding to the crisis, the girls in domestic service were identified in high need of health and other services. Because they did not venture far from the homes where they worked, were isolated, had little access to media, and had limited ability to read and write, a house-to-house approach was required to advise them of available services and programs. Similarly, in Ethiopia, married girls in baseline assessments were shown to have the fewest friends and opportunities to socialize and were out of reach of any media, thus they were also recruited door-to-door and some effort was made to promote the program through marketplace advertisements.

\section{STEP 6: Establishing Your Program Venue-Secure a Regular, Safe Community Space in Which to Meet}

To reach socially isolated girls, programs often create segment-specific safe spaces that are available at least once a week and provide at least an hour of programmatic time (net of travel time to and from, and allotting time for settling in at the beginning of the session). The Council recommends a minimum operation of one year, which allows girls enough programmatic exposure to establish in their own minds the legitimacy of regular social connection among girls. It also allows enough time for parents and the community to accept that girls meeting together is both desirable and normal, and to recognize that girls have a right to a safe, private, and secure place with their peers where they can learn, play, and grow. Further, it allows for programming through a full year's cycle of risks; for example, school breaks and festivals are often very threatening periods for girls. Similarly, rainy or dry seasons, any moment of scarcity, increases pressure on girls' time and labor and raises the risk of sexual exploitation. A year-long program assures some recognition and coping with these threat points to girls. The Population Council's tools and exercises can facilitate your consideration of: safety and risk scenarios; timing, frequency and duration of program activities; and the available venues' appropriateness for specific segments.

The safety of potential program spaces has 


\begin{tabular}{|c|c|c|c|c|c|c|c|c|c|}
\hline $\begin{array}{l}\text { SEGMENT 1: } \\
\text { e.g., 10-14-year- } \\
\text { old girls, living } \\
\text { apart from } \\
\text { parents, not in } \\
\text { school } \\
\text { SETTING: } \\
\end{array}$ & \multicolumn{3}{|c|}{$\begin{array}{l}\text { ACCESS } \\
\text { Is this a person/place accessible to } \\
\text { this segment of girls? }\end{array}$} & \multirow[t]{2}{*}{\begin{tabular}{|l|} 
PLEASE \\
DISCUSS \\
Is this an \\
effective \\
recruitment \\
strategy to \\
reach this \\
segment of \\
girls? Consider: \\
Why/why not?
\end{tabular}} & \multirow[t]{2}{*}{\begin{tabular}{|l} 
SEGMENT 2: \\
e.g., 15-17- \\
year-old girls, \\
married and \\
with children \\
SETTING: \\
$\begin{array}{l}\text { RECRUITMENT } \\
\text { STRATEGIES }\end{array}$ \\
\end{tabular}} & \multicolumn{3}{|c|}{$\begin{array}{l}\text { ACCESS } \\
\text { Is this a person/place accessible to } \\
\text { this segment of girls? }\end{array}$} & \multirow[t]{2}{*}{$\begin{array}{l}\text { PLEASE } \\
\text { DISCUSS } \\
\text { Is this an } \\
\text { effective } \\
\text { recruitment } \\
\text { strategy to } \\
\text { reach this } \\
\text { segment of } \\
\text { girls? Consider: } \\
\text { Why/why not? }\end{array}$} \\
\hline $\begin{array}{l}\text { RECRUITMENT } \\
\text { STRATEGIES }\end{array}$ & $\begin{array}{c}\text { Very } \\
\text { Accessible }\end{array}$ & $\begin{array}{l}\text { Somewhat } \\
\text { Accessible }\end{array}$ & $\begin{array}{l}\text { Not at all } \\
\text { Accessible }\end{array}$ & & & $\begin{array}{c}\text { Very } \\
\text { Accessible }\end{array}$ & $\begin{array}{l}\text { Somewhat } \\
\text { Accessible }\end{array}$ & $\begin{array}{l}\text { Not at all } \\
\text { Accessible }\end{array}$ & \\
\hline School & & & & & School & & & & \\
\hline Street & & & & & Street & & & & \\
\hline Radio & & & & & Radio & & & & \\
\hline $\begin{array}{l}\text { Formal peer } \\
\text { network }\end{array}$ & & & & & $\begin{array}{l}\text { Formal peer } \\
\text { network }\end{array}$ & & & & \\
\hline Word of mouth & & & & & Word of mouth & & & & \\
\hline Religious venue & & & & & Religious venue & & & & \\
\hline \begin{tabular}{|l|} 
Television \\
advertisement
\end{tabular} & & & & & $\begin{array}{l}\text { Television } \\
\text { advertisement }\end{array}$ & & & & \\
\hline \begin{tabular}{|l|} 
Community \\
leader/chief \\
recruitment
\end{tabular} & & & & & $\begin{array}{l}\text { Community } \\
\text { leader/chief } \\
\text { recruitment }\end{array}$ & & & & \\
\hline $\begin{array}{l}\text { House-to-house } \\
\text { recruitment by } \\
\text { field staff or } \\
\text { mentors } \\
\end{array}$ & & & & & $\begin{array}{l}\text { House-to-house } \\
\text { recruitment by } \\
\text { field staff or } \\
\text { mentors }\end{array}$ & & & & \\
\hline Workplace & & & & & Workplace & & & & \\
\hline Marketplaces & & & & & Marketplaces & & & & \\
\hline $\begin{array}{l}\text { SMS text/ } \\
\text { WhatsApp }\end{array}$ & & & & & $\begin{array}{l}\text { SMS text/ } \\
\text { WhatsApp }\end{array}$ & & & & \\
\hline Other & & & & & Other & & & & \\
\hline
\end{tabular}




\section{STEP 6: BOX 27. TIMING, FREQUENCY, AND DURATION OF MEETINGS WORKSHEET}

When considering your target segments, there are potential days, times, and frequencies that can facilitate regular and easy access to meetings for long enough to make a difference. Consider the options of timing and frequency, below, and the duration of meetings and determine if they are appropriate for your segment and setting.

\section{SEGMENT:}

SETTING:

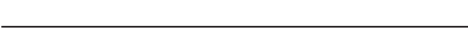

\section{FREQUENCY AND DURATION OF MEETINGS}

Group meetings are more effective with regular attendance over a specific length of time. Meeting plans should consider the risk profile of girls and their daily lives.

\begin{tabular}{|r|}
\hline Once in public space every few months \\
\hline Weekly, in a private session \\
\hline 10-week short course \\
\hline Once a week, at least, for an entire year \\
\hline Only in high-risk seasons \\
\hline Only in low-risk sessions \\
\hline All year, with up to 8-week breaks \\
\hline All year, with maximum 10-week breaks \\
\hline House-to-house recruitment by field staff or mentors \\
\hline Marketplaces \\
\hline SMS text/WhatsApp \\
\hline \begin{tabular}{l} 
Seasonality or yearly patterns should be considered \\
timen organizing meetings for girl segments. Is there a \\
\hline Atheason that is particularly risky for your girls?
\end{tabular} \\
\hline Morning \\
\hline After religious observation \\
\hline Bing observation day \\
\hline
\end{tabular}

\section{APPROPRIATENESS}

Please consider the appropriateness of the following to your particular segment.

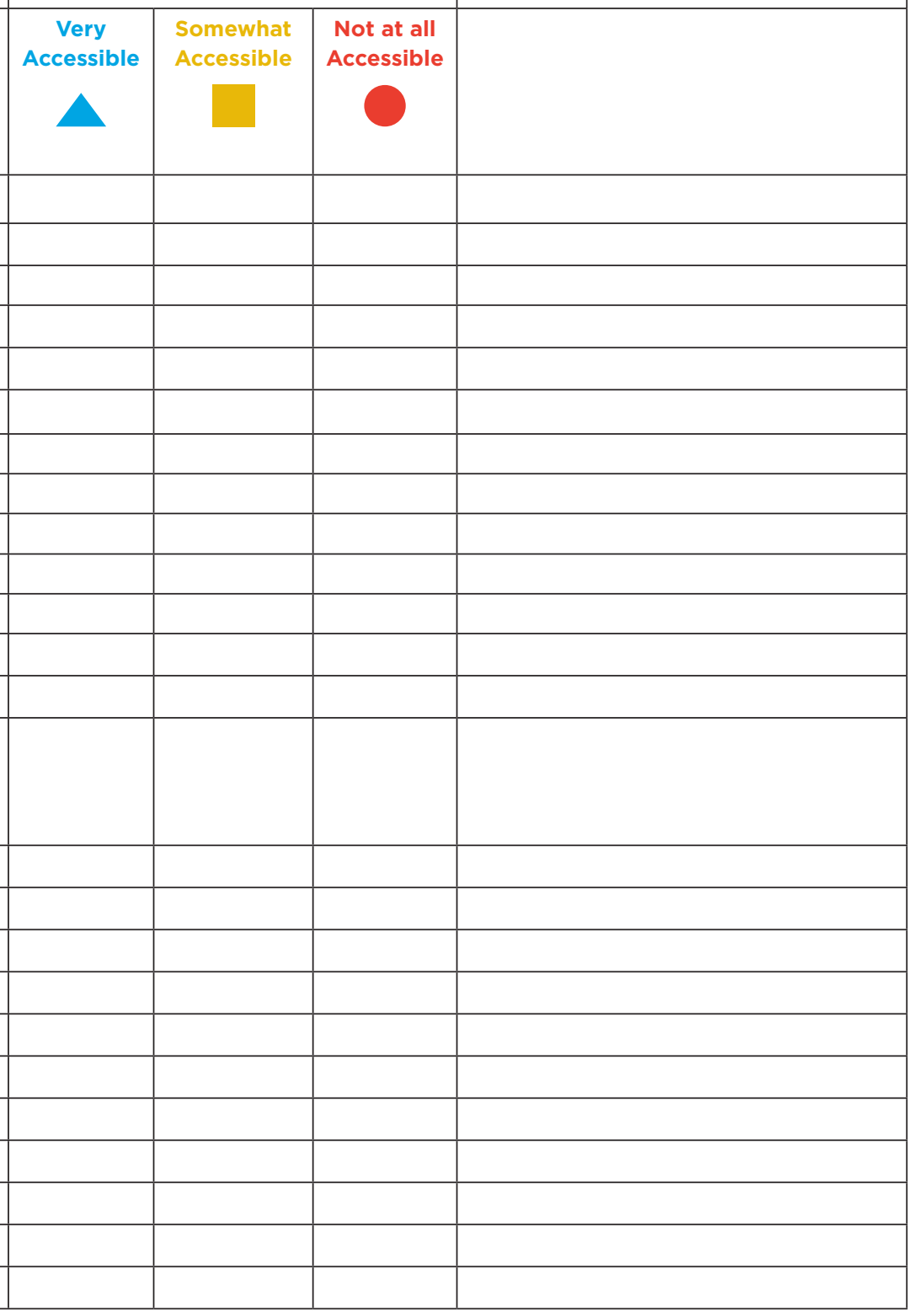


physical and emotional dimensions. What space will allow the segment of girls to feel "private" so they may speak freely-free from being overheard, free from physical harm or stress-as well as provide a respite from their social and emotional isolation? What steps can program staff take to not only keep girls safe but instill confidence in their parents so they will allow girls to attend? Among the Population Council resources is an exercise called the Safety Scan. Program staff can use the Safety Scan to explore different segments of girls' safety regarding safe and unsafe persons, relative safety of meeting at different times of the day, safety across the week, and preferred physical places to meet in the community. In Kenya, a girls' program was originally established in a compound adjacent to bars. Girls' attendance was low, due to feelings of discomfort sharing space with men who were drinking. Falling participation rates alerted the staff and the program venue was changed (Austrian and Ghati 2010).

Program staff's awareness of specific situations or seasons of risk is vital to effective programming and building trust with girls. Those who work to address the issue of FGM might know there is a seasonality to this practice; that is to say, FGM happens in many countries during the stretch from July, August, and September, when girls are on break from school, i.e. "cutting season." Knowing this, program staff might build in special activities or meetings with girls in advance of this risky time to discuss with them explicitly, in a fully private place, the possible evasive and protective actions they might be able to take. This discussion might never take place in the wider community, but it might in a safe place if girls feel they have voice and protection.

The selection of venues must also be informed by segment-specific information about the target girl segments' availability, as decisions must be made about the timing, duration, and frequency of meetings. For instance, single mothers who need to be in the market to earn money for their family will not be able to meet in the middle of the day; domestic workers who need to stay around the household where they work might not be able to meet more than once in the course of a week. To collect information, you could use the Population Council's Timing, Frequency, and Duration of Meetings Worksheet or create your own variation to get the information you require to make the appropriate program venue selection. Box 27 provides an example of this worksheet.

\section{STEP 7: Building Mentoring Structures to Recruit Girls, Deliver Programs, and Provide a Local Safety Net, Resources, Voice, and Support}

\section{Why Mentors Are Important}

Mentors are a central connection between program staff and the girls, their families, and the community. Mentors are the girls' core protectors and core interpreters. As a crucial resource for transformative change, mentors, especially community-based mentors, can:

- Offer girls safe access to programs

- Increase regular participation, especially among the most vulnerable

- $\quad$ Strengthen the learning environment

- Provide a foundation for community engagement

- Deliver sustainability through cascading leadership.

Because community-based mentors are subject to some of the same risks as the girl participants themselves, they are also attuned to girls' risks and can articulate them in a unique way to practitioners. Analyses of safety and cycles of risk are pertinent to understanding the segments of girls and the spaces that would be safe for them, and also to selecting mentors to conduct program activities. Since community-based mentors are subject to the same kinds of risk as the girls they are serving, programs should also address their stressors, their cycles of risk, and their need for adequate livelihoods. Earlier, we discussed the difficulty of younger and most-at-risk girls being "seen" and "actionable," that is, being a population that is deserving of action. The 
same is true of mentors. A seasoned and strong cadre of female mentors, in a sense a female infrastructure, is there to listen to the girls' needs, defend their rights, and communicate with community leaders and service providers. A mentor's recruitment, training, support and supervision must therefore be planned systematically and monitored.

\section{How to Select Mentors}

The Population Council's Basic Model encourages the profile of the mentor to generally match the intended target population-being close in age so that they can relate to their mentees, but slightly older so they can serve as role models and lead program activities responsibly. Another key selection criterion is that mentors come from the same or nearby community as the girl participants so that they understand the participants' lived experience. It's not only vital that they be slightly older and from the same community, but also that they are, in other aspects of their lived experience, representative of the segment they are mentoring. If the participants are mothers, the mentor should be a mother; if the participants are migrants, the mentor should be a migrant herself. The Population Council provides a list of desired criteria-the Mentor Selection Criteria Guide-to assist program staff in thinking this process through, but these criteria are intended to be flexible and adaptable to local situations and contexts.

These criteria can also provide the necessary structure by which you recruit mentors, including how you advertise (e.g., radio announcements, flyers with a job description, peer referrals) and how you interview mentors. The Population Council has available a worksheet on Mentor Advertisement and a guide on Mentor Selection, including a Mentor Interview Score Sheet for these purposes. These resources are from Council programs around the world and can be adapted to fit the reader's context/program.

\section{Training of Mentors}

As mentors deliver program content and provide crucial social connection, their training, ongoing supervision, support, and preparation for leadership are high priority. This can be achieved through monthly meetings, one-onone check-ins, site visits, observations of others running sessions, and more. The documentation of mentors' experiences and insights through any of these mechanisms is the best way to learn about the challenges of dealing with different segments of girls, weighing properly how the different risk factors they face and access points they need must be accounted for by different program elements.

Most program staff have very little experience recruiting and working with young womenpotential mentors-from the program community. Thus, tools such as a Daily Evaluation Form and Monthly Mentor Meeting Agenda can help integrate mentors into the program. Fair compensation is essential because the treatment of mentors becomes a model for how girls in the community are valued. Mentors are not volunteers. They can, however, see many different kinds of support as a type of compensation, such as formal and respectful job descriptions they can use on a resume, compensation that's responsive to the changing commitment, the convenience of working in home communities, the access to additional skills training (e.g., English learning courses), external work opportunities, travel to neighboring communities, internships, and certifications.

Mentor recruitment and training is a vital program link. A useful toolkit that is designed to be practical and user-friendly for program planners, practitioners, mentor trainers, and mentors themselves is: Making the Most of Mentors: Recruitment, Training, and Support of Mentors for Adolescent Girl Programming.

\section{STEP 8: Build Meaningful Content Keyed to Girls' Real Lives-Positive, Achievable Metrics}

Since the beginning of the Population Council's support of programs designed for the most excluded girls in the poorest communities, it's been found that the content of programs for adolescent girls is often overly generalized, not 
STEP 8: BOX 28. AN ILLUSTRATIVE LIST OF PROTECTIVE ASSETS AT THE LEVEL OF THE GIRL, NEEDED BY AGE 12

At least five friends (her team)

adapted to specific populations, misrepresents girls' lives as overly rosy, and "lifts" material originally meant to reach more privileged populations. Some policymakers may think that girls do not face food security risks at young ages or that they should not know the risks of motherhood before they become mothers, nor are they alerted to risks to the girls' physical and sexual integrity in the places where they are supposed to feel safe (home, school, religious establishments, etc.). The Population Council and partners pioneered a process to foster an evidence-anchored and realistic assessment of which specific skills or knowledge (assets) girls should have by a certain age.

Box 28 contains a list of nine assets that are frequently identified by practitioners on the ground as essential, often by age 12 . In Population Council workshops, it has been effective to conduct an "Asset Exercise" early in the agenda as it, like discussions of recruitment strategies, focuses participants on the heavy responsibilities some girls bear at young ages. At the latest stages of puberty, many girls come under intense sexual pressures, which are often closely linked to their economic vulnerability. Their interest in livelihoods, and the need for wealth expansion and financial literacy, are prevalent for girls and parents, and have the additional advantage of being understood as requiring at least weekly activity. Savings and financial literacy, like sports, are sorts of activities that work best when done regularly. Anything that happens with regularity is good for girls, both in terms of layering knowledge and confidence and building community support and acceptance. The Building Assets Toolkit ${ }^{014}$, or the Asset Exercise for short, often fosters productive debates about girls' needs for age-graded financial literacy and livelihoods skills.

As of 2020, the Population Council's Building Assets Toolkit has been translated into Arabic, French, Portuguese, Spanish, and Swahili. It contains 100 assets (each listed on a separate card) that were culled from a core list after many iterations of the exercise were conducted in different settings. In most cases, the assets have substantiation both by an evidence base and by on-the-ground insights about girls' lives.

14 The Building Assets Toolkit introduces practitioners to the asset-building approach, guides them through the exercise, and models the critical thinking needed for effective program design. To access the toolkit, visit: https://www.popcouncil.org/research/building-assets-toolkitdeveloping-positive-benchmarks-for-adolescent-girls. 
There are also blank cards in the toolkit to allow program staff to think creatively about their context, adding assets that are vital to their program participants' well-being and protection. ${ }^{15}$ For example, in the Middle East, there is an ethnic group known for its beautiful dancing. When our implementing partner inquired as to specific protective advice for girls, it was suggested that they not dance in public because dancing had sometimes led to abduction. The asset, in this case, was girls and their families having the knowledge that public dancing, even though meant to be joyous, posed a very strong risk of exploitation to these girls. An outsider would never have understood this, so insider perspective was vital.

Once you have identified key priority assets for your target population, the Turning Protective Assets into Program Content Worksheet-which complements the Building Assets Toolkit-is an invaluable exercise (see Box 29). The exercise, which can be edited and expanded for your specific purposes, asks practitioners to identify core assets, determine if they have program content at their fingertips that builds those assets, and asks who will be responsible for delivering that program content. For each asset, practitioners are asked to brainstorm carefully how they would plan to execute the program in their context, including ways they might engage parents and the larger community. It is important to keep in mind that some assets may create unanticipated risks for girls and plans should be made to enable girls to protect and control them. Therefore, it is not enough to identify which assets are priorities, you must also plan around each of them carefully.

The Safety Scan, mentioned earlier in terms of its ability to help determine the parameters of when and where you meet, can also inform program design through its sensitization of program staff. After segmented girl groups are formed, and primary trust has been built between girls and mentors, there are more in-depth inquiries that can be conducted to understand how increased safety can be built through program content elements, particularly how sexual safety can be protected by building specific assets.

Some program staff seek to ask questions about girls' sexual exposure upfront that are inappropriate (and in some cases inadvertently unethical), and they are likely as a result to receive false information or foster community rejection of the program. Others are reluctant to learn the full dimensions of girls' troubling experiences. In the course of this work, we have observed that organizations often underestimate the level of girls' participation in the economy and how that participation is linked to sexual risk. Thus, as we develop content that will assist girls in navigating their lives it is appropriate to include discussions of sexual risk, and ideally before girls are subject to these risks, which means in most places at an early age.

The Ascertaining Sexual Relationship Types (ASERT ${ }^{\mathrm{TM}}$ ) tool facilitates girls in identifying: a range of sexual partner types with whom "girls like them" have sex; the criteria for making those partner choices; and relationship-specific attributes, ranked in order of importance (see Box 30). To use the ASERT tool (Hallman, Peracca, et al. 2016), social capital and relationships must already have been built between girls and the tool facilitator, who is preferably a mentor. By using the tool, program staff can create a visual representation of girls' sexual risk and safely discuss issues of HIV, social status, and economic survival strategies through an anonymous, group-based reporting method. Because of the sensitive nature of the questions, the tool is intended to be used with a trusted mentor and preexisting group of girls.

The ASERT tool was tested and used in a 2015-16 program in Tanzania, and the results

15 The Building Assets Toolkit is a great example of a steadily improving first draft; from 2015 to 2018 , there was the emergence of additional assets such as those specific to technology, the arts, and the needs of girls in humanitarian settings. In 2018, the Population Council drafted a set of assets specific to the needs of adolescent girls in indigenous communities of North America. In working with indigenous communities, through the Indigenous Adolescent Girls' Empowerment Network (IMAGEN), the Population Council is developing an approach to both defining assets and delivering them that is consistent with the diversity and richness of Native American culture. For more information on how to access or learn more about these additional assets, contact the Council at girlroster@popcouncil.org. 


\section{STEP 8: BOX 29. TURNING PROTECTIVE ASSETS INTO PROGRAM CONTENT WORKSHEET}

This worksheet can be used to determine what material exists to support your program content, what needs to be adapted or developed, and who can deliver the content. It can be used in combination with the Building Assets Toolkit to consider the assets that your program will build for the target segment of girls and young women. The priority assets are listed in the first column; for each asset, assess and record the availability of material and the appropriate delivery strategy.

\section{SEGMENT:}

\section{SETTING:}

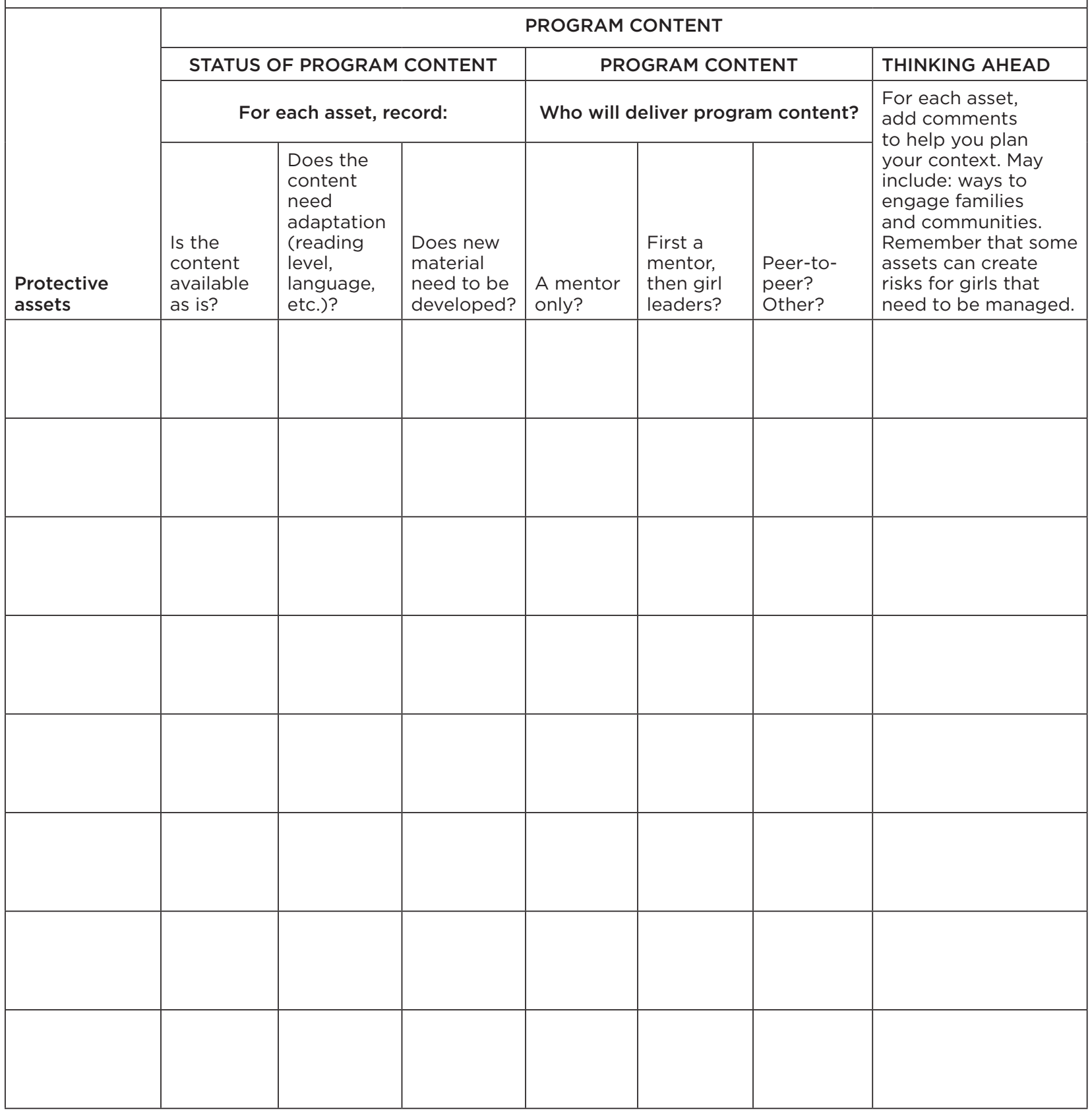

Source: The Asset Toolkit available through the Community of Practice website: https://buildcommunity4girls.org. 
STEP 8: BOX 30. ASERT TOOL IN TANZANIA IDENTIFIES THE ECONOMIC-SOCIOECONOMIC

CONTINUUM OF SEXUAL PARTNER TYPES, FEMALES AGED 15-24

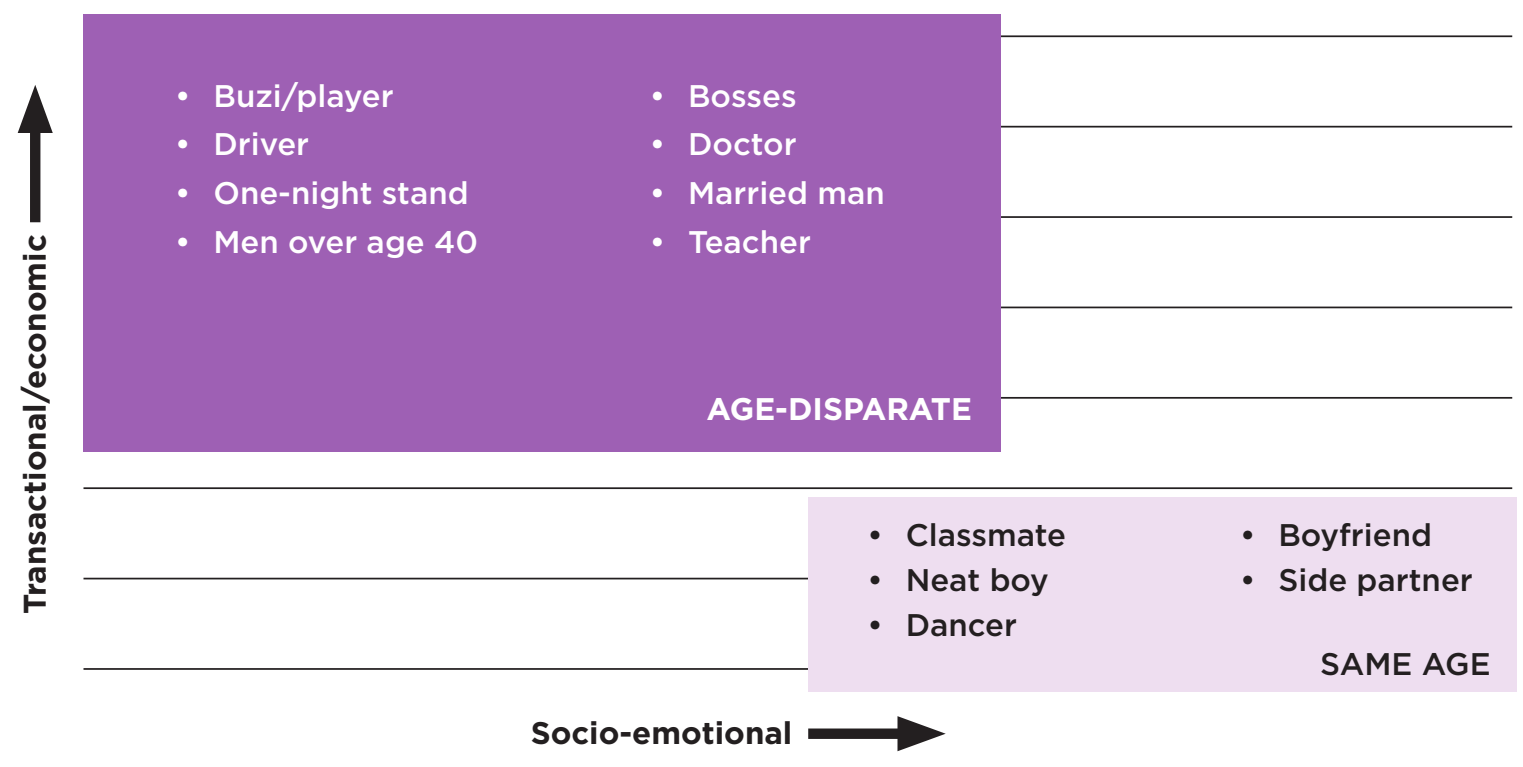

Source: Hallman et al. 2018.

that emerged are shown in Box 30; the girls rank the transactional/economic versus socio/ emotional value of having sex with a variety of sexual contacts (e.g., classmate, dancer, onenight stand, doctor). The typical age of these partners is also considered. For those partners with whom sex was primarily transactional/ economic, there was a large age discrepancy, whereas those relationships that were more socio/emotional were typically with partners of a similar age. Additionally, there seemed to be a greater number of sexual partner types that fell under the transactional/economic sphere.

The information from the ASERT tool had several potential program implications. Asset building had to be tailored to segments of girls (such as those out of school, living outside a supportive family structure, and with young children), with emphasis on financial education, savings, and partner-specific HIV education. Alternative ways for older men to display wealth and masculinity needed to be established, beyond social norm. Sustained female collective action was needed through groups, such as building alternative forms of social insurance. Campaigns that targeted these particular types of men (over age 40, taxi drivers, teachers, doctors) and their unsafe engagement with young girls was also required (Hallman et al. 2018).

\section{STEP 9: Design Programmatic "On- Ramps” Assuring Girls' Access to Public/Private Resources in Their Walkable Communities}

As discussed in Chapters 3 and 4, when the information about the full universe of girls and community resources is brought together, program staff have the basis for a plan to give girls more direct access to existing resources, and to intentional recruitment, creating access for girls to asset-building resources in their community. The identification of the core assets needed leads to a reconsideration of what content and access should be assured through safe spaces (e.g., health workers coming to see groups of girls) and which require building 


\section{STEP 9: FIGURE 13. EXAMPLE OF A "PASSPORT" CREATED FOR GIRLS BY THE COMMUNITY MEDIA TRUST ORGANIZATION IN SOUTH AFRICA}

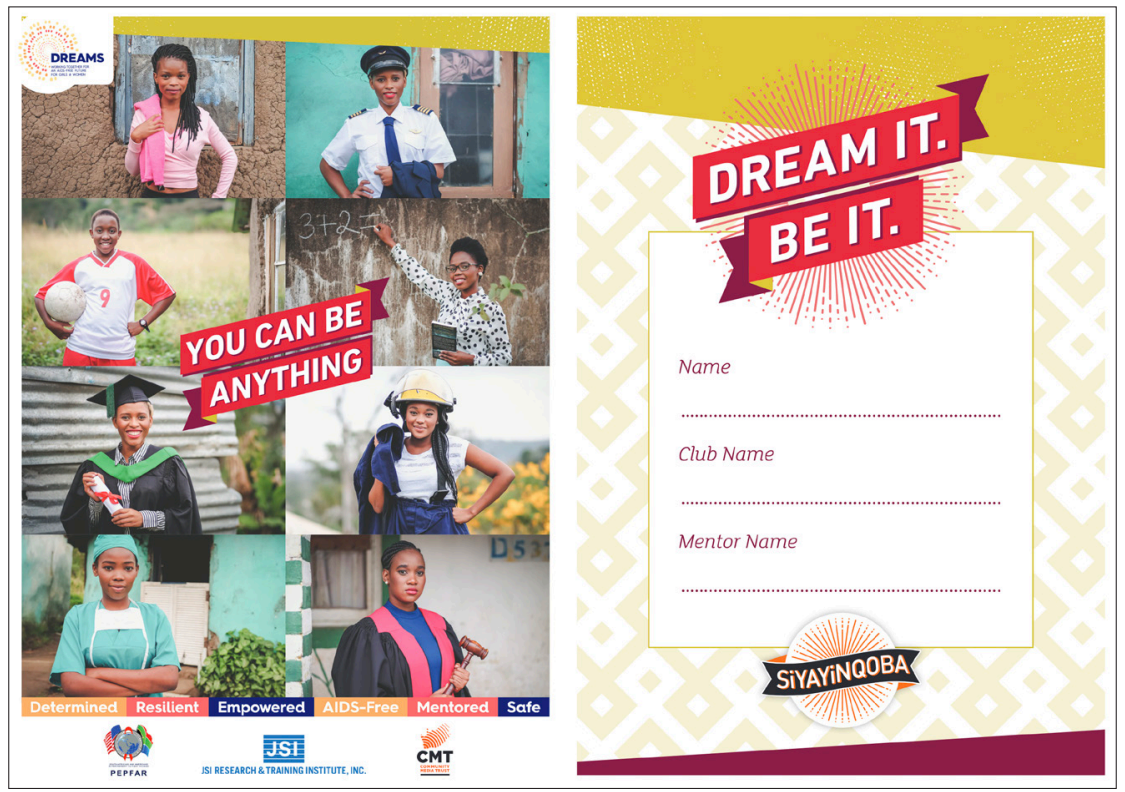

This booklet served as a tool for onboarding girls, allowing them to note services received and also giving them a sense of self (space for photo and brief biography) as they became more accustomed to accessing resources in the community and gaining voice.

on-ramps such as specific referrals and access to "passports" that document girls' receipt of services (see Figure 13).

Figure 14 provides an image of where practitioners should be heading-that is the full vision of their program design. If Steps 1 through 9 of the Basic Model have been properly employed, equitable access to facilities, entitlements, and services have been established for girls, bringing them together in segment-specific, girls-only spaces in which their assets can be built. In most of the settings we work in, that cannot be done without the commitment and buy-in of the community.

Most of this chapter has been devoted to discussing the girls with reference to the social context around them, which must be addressed at different points in program development. The first point is right at the beginning when initial introductions are made to allow the Girl Roster exercise or others like it to be conducted: initial buy-in is a must. In later points of program development and implementation, it is important to determine whether critical actors in the communities will be allies in supporting the girls, potential consumers (e.g., they might also be interested in the financial literacy that girls are receiving), or restrictors of girls' participation and benefit. These individuals might include parents/guardians, teachers/ principals, husbands, village elders, siblings, employers, mothers-in-law, vendors, religious figures, and others. Further, their roles may vary with regard to girl segment-for instance, are they friendly to school-going girls, unsupportive of the rights and opportunities for girls in domestic service.

Girl-Centered Program Design: A Toolkit to Develop, Strengthen, and Expand Adolescent Girls has some exercises to guide practitioners through strategies for engaging adults. In particular, it features instruction on Community Contracts (you will read a real-life example 


\section{STEP 9: FIGURE 14. THE FULL VISION: WORKING AT TWO LEVELS}

- Creating segment-specific girl platforms that build girls' assets

- Crafting segment-specific channels to give girls' equitable access to facilities, entitlements, and priority services

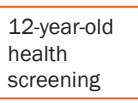

Married girls'

clubs and

SRH classes

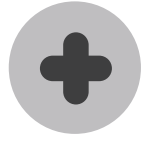

Health Center

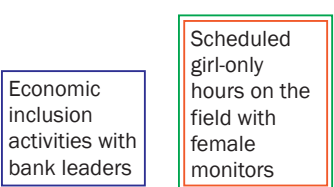

\section{신}

National Savings

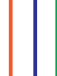

Playing Field
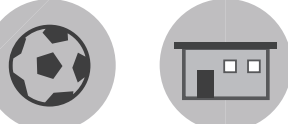

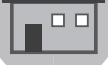

Community Center

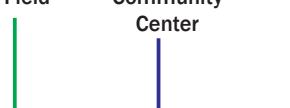

Skills building

in green

technology

including

solar-

powered

charging

stations

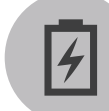

Charging

Station
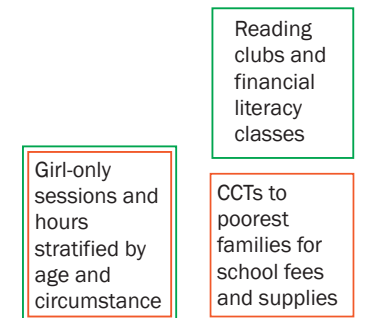

Construction

of safe

washrooms

nearby

marketplace

and supp
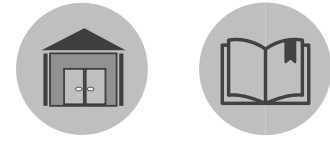

School and

school-based programs

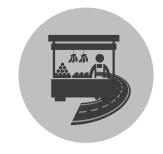

Marketplace

Center

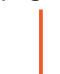

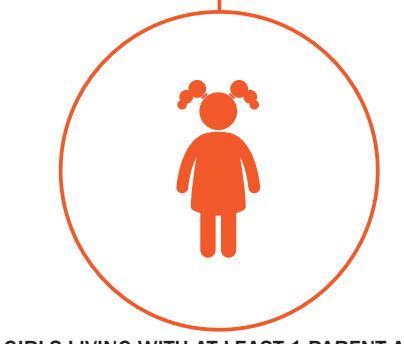

GIRLS LIVING WITH AT LEAST 1 PARENT AND OUT OF SCHOOL OR 2+ SCHOOL LEVELS BEHIND FOR THEIR AGE, AGED 10-14 (AT HIGH RISK OF CHILD MARRIAGE) in Chapter 8). Many programs on the ground have found success when entering into a formal agreement or contract with certain communities, particularly their leaders. The contracts can include what the community is committing to at an emotional/value level, such as agreeing to support girls' financial literacy, and at a logistical level, such as promising the provision of certain girls-only spaces and safety.
When considering on-ramps, gatekeeperstypically male-can influence the success or limitations of a program. Therefore, male engagement is certainly desirable, but it too is subject to the Intentional Design approach, meaning that it must be considered per segment. The Intentional Design approach emphasizes a set of guiding principles, what we call the 5 Ws of male engagement. In planning programs anchored around specific segments, 
it is important to consider for the girl 10-14 years out-of-school as for the girl married to a man 15 years older as for the girl making the transition from primary to secondary school, the following:

- WHETHER there is a crucial male population that will allow the participation of the girl segment. (Is there some male population that is vital to either get onboard or out of the way?)

- WHICH males should be engaged (e.g., younger brothers, fathers, employers, people girls have sex with)

- WHEN males should be introduced (not prematurely, that is, not until the female population is mobilized and has voice)

- $\quad$ WHAT will be the cost (e.g., male populations can be more expensive as their opportunity costs are higher than female populations)

- $\quad$ WHAT will success look like; the female perspective is central here.

STEP 10: Pull it all together in systematic, per-segment planning, and offer a sound basis for future evaluation and measurement of program outcomes

Steps 1 through 9 of the Basic Model comprise a segment-specific plan, guiding program staff and other practitioners through a methodical process that clarifies how essential it is to keep priority segments of girls at the center of every program decision-from identifying the geographic areas in which you will work (where the highest concentrations of priority segments can be found) to designing on-ramps that assure girls' access to available resources in their walkable communities. Step 10 is the summary of these cumulative steps-using the Segment Planning Worksheet (Box 31) and a thought process that encompasses the Basic Model.
Each step of the Basic Model is mirrored in a row of the Segment Planning Worksheet, leading practitioners from segment selection (Step 1 of the Basic Model) to Rows 10 and 11 that capture key considerations when thinking of how to effectively build on-ramps (Step 9). The worksheet prompts users to think about metrics as well. As previously mentioned, the Building Assets Toolkit encourages practitioners to think about measurable, achievable benchmarks; therefore, if you are building content around specific assets, measuring effect should be possible.

Good Monitoring, Evaluation, and Learning (MEL) can help you chart the success of your program, noting what kind of changes are taking place in your priority segments' lives. Before developing the MEL mechanisms you will use, it is important to consider what can be realistically expected as a result of program content around specific assets. Therefore, the Segment Planning Worksheet prompts program staff to consider potential metrics at Time 1 and Time 2, in this case the first year and second year of a program.

It is important to note that these steps are adaptable to specific contexts and scenarios. For example, you might add to or take away from this worksheet. Row $\mathrm{K}$ is an example of a popular addition the Population Council has observed among many partners-will the program build segments' skills and expertise in green productive and/or protective technologies, and if so, what technologies must be accessed (e.g., IT, solar panels, charging stations)?

The Basic Model, though it clearly lists these steps, is also an iterative process-one step can inform another before it and vice versa, and though the steps are sequential, there is always opportunity to go back. This, once again, depends on the practitioner's context. 


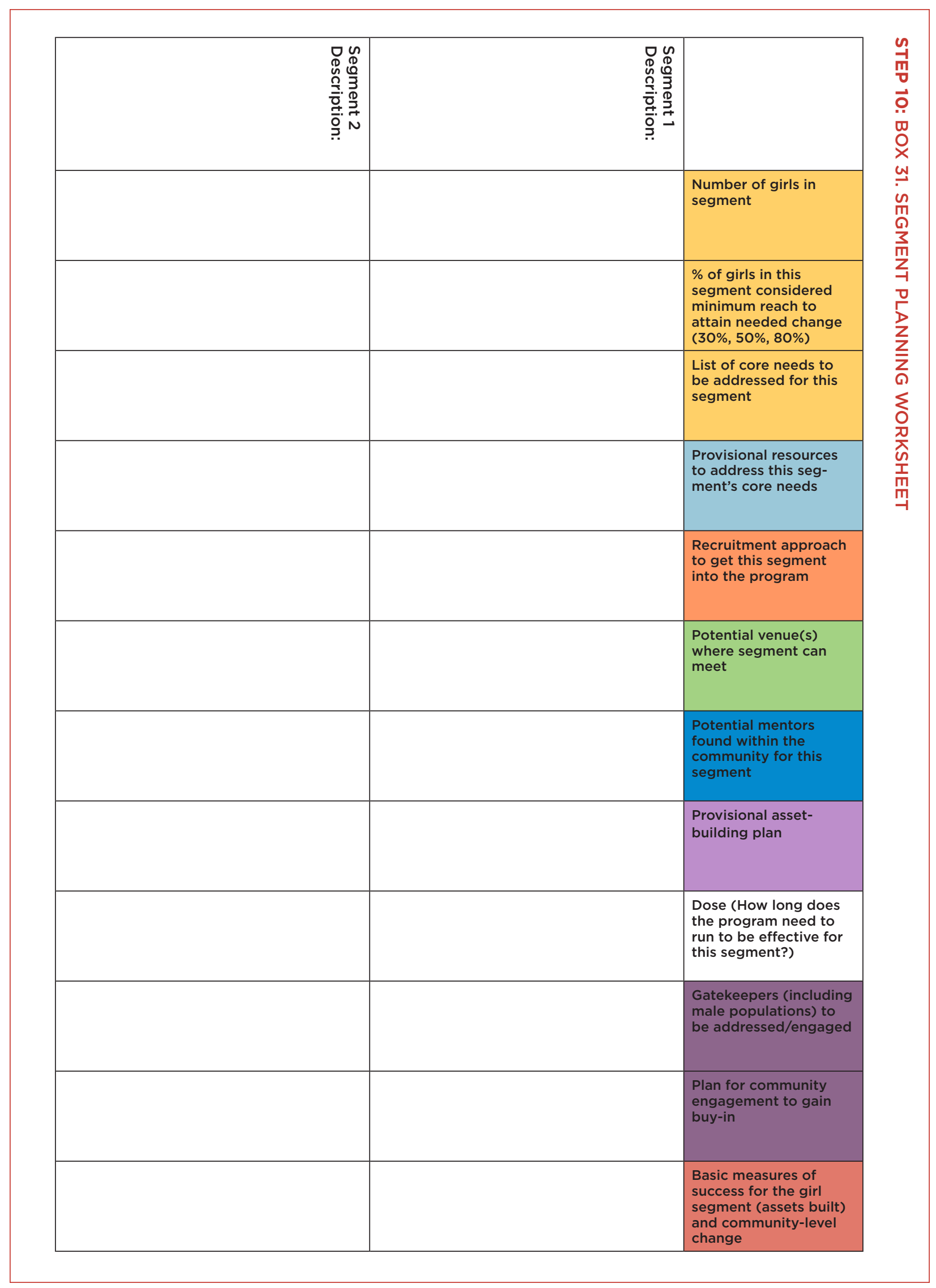




\section{Conclusion}

Throughout this chapter and the guide as a whole, the emphasis has been on using information and careful analysis to craft segment-specific plans for girls with

measurable goals. The tools highlighted

throughout fall under clear steps of this

sequential learning approach, the Basic Model

for Intentional Design, but they are intended to be practitioner-centered and driven. This means, ultimately, that the power is in the hands of local practitioners to keep the experiences of excluded girls at the center, to draw from the communities' key resources, engage early and build insights, and promote more rigorously tested strategies to bring to scale programs that reach those most in need. 


\section{Resources to Support the Intentional Design Approach}

\author{
2020. Adolescent Girls Community of Practice \\ website \\ Visit: https://buildcommunity4girls.org.
}

2019. Making the Most of Mentors: Recruitment, Training, and Support of Mentors for Adolescent Girl Programming

Toolkit. Lessons, tips, and insights that can be adapted and used to find, train, monitor, support, and evaluate mentors. The information is based on materials from programs for adolescent girls implemented by the Population Council. The resources are applicable to program planners, mentor supervisors, and mentors themselves. All resources may and should be adapted to local contexts.

(Step 7)

2019. More Than a Backdrop: Understanding the Role of Communities in Programming for Adolescent Girls Action guide. Focuses on five key questions, offers tips on how to find answers, and provides real-world examples that demonstrate how to use community-level insights for action for adolescent girls. It was written for people who design, manage, and assess community-based programming. In communities, girls' programs often work through "safe spaces" or girls' clubs, which typically include regular meetings led by a local mentor who delivers information to participants. This action guide is also relevant to programs that engage girls through other channels, including schools, and it can be useful for community-based programming with boys and parents.

(Steps 4, 6)

2019. What's the Role of Men and Boys in the Gender Equality Movement?

Video. Skoll World Forum session discussing what role men and boys have in work that seeks to achieve Sustainable Development Goal 5 to attain gender equality. Some advocate for programming that engages men and boys in gender equality efforts. Others worry about diverting limited resources and diluting messaging. Is it a zero-sum equation? Hear leaders discuss-even debatethese questions and more.

(Step 9)
2018. NISITU (Nisikilize Tujengane): Listen to Me, Let's Grow Together

Program documentation. Describes efforts by researchers to test the effects of engaging boys and men alongside girl-centered programming to improve the lives of adolescent girls.

(Step 7)

2017. A Qualitative Analysis of Adolescent Girls' Views on Relationships with Influential Men

Article. Analyzes key segments of males in Kenya that influence adolescent girls lives and how, and describes changes that adolescent girls would like to see in these males.

(Step 9)

2017. Revisiting the Dimensions of Transactional Sex among Adolescent Girls \& Young Women Video. Explores the ways that various types of transactional sex influence the health of countless adolescent girls and young women worldwide, as well as strategies to mitigate their risk. With a special focus on HIV risk in sub-Saharan Africa, presenters describe how power influences AGYW's experience of sex and associated health outcomes, defines the important distinction between transactions in sex and exploitation in the sex industry, and questions the value of "girls engaged in transactional sex" as a useful program category. Using a case study from Mile 6 in Sierra Leone, our presenters illustrate the implications for girlcentered programming, the impact of protectiveasset building with this specific segment of girls, and the positive outcomes that can result.

(Step 8)

2016. Building Girls' Protective Assets: A Collection of Tools for Program Design Toolkit. Practical, user-friendly tools and worksheets intended to help those who are designing and implementing girl-centered programs to integrate a protective asset-building approach to improve their coverage. This collection highlights the Community Resource Scan,

Community Mapping Exercise, and Venn Diagrams for Institutional Access, all of which help you think critically about the walkable community in which the girls live.

(Steps 4, 5, 8) 
2016. Delaying Child Marriage Through Community-Based Skills-Development Programs for Girls: Results from a Randomized Controlled Study in Rural Bangladesh

Program documentation. Describes how the BALIKA program to educate girls, build their skills for modern livelihoods, and engage their communities can reduce the likelihood of child marriage by one-third and produce better health, educational, and social outcomes.

(Step 7)

2015. Adolescent-Friendly Health Services and Health Voucher Mechanisms: Facilitator's Training Manual

Curriculum. From the Adolescent Girls

Empowerment Program (AGEP). Helps facilitators find the best way to improve girls' social, health, and economic resources so that they can stay in school longer, avoid child marriage, delay sexual activity, and prevent unintended pregnancy, HIV, and other STIs.

(Step 8)

2015. Building Assets Toolkit: Developing Positive Benchmarks for Adolescent Girls

Toolkit. Provides program implementers, policymakers, advocates, and adolescents themselves with everything they need to conduct the Building Assets Exercise, grappling with questions like "By what age do girls need to know about sexual coercion?" This exercise includes a series of steps to define commonsense programmatic targets that are grounded in girls' realities, such as what information, skills, or physical assets (like an ID card) girls need in specific settings at specific ages. This information can help build and incorporate tailored content into girl-centered programming. First published in 2015, this toolkit is a living document as it is perfected by users. The Instruction Guide and Resource Manual are available in English and French, and the asset cards are available in Arabic, English, French, Portuguese, Spanish, and Swahili. (Step 8)

\section{Health and Life Skills for Peri-urban Girls/}

\section{Rural Girls}

Curriculum. From the Adolescent Girls InitiativeKenya. Intended for peri-urban or rural adolescent girls. It provides them with knowledge and skills on topics such as water, sanitation and hygiene, nutrition, and HIV and AIDS.

(Step 8)

\section{Financial Education for Peri-urban Girls/} Rural Girls

Curriculum. From the Adolescent Girls InitiativeKenya. Intended for peri-urban or rural adolescent girls. It covers topics such as spending, savings, earning options, and managing stress, to help them transition from economic dependence to independence.

(Step 8)

2014. Building the Assets to Thrive: Addressing the HIV-related Vulnerabilities of Adolescent Girls in Ethiopia

Report. Review of three programs launched by the Population Council and the Ethiopian government. Two of the programs work to reduce Ethiopian girls' HIV risk by providing out-ofschool adolescent girls in urban slums and married adolescent girls in rural areas with adult female mentors, education on HIV and AIDS and related issues, nonformal education, and links to health services. The third program focuses on husbands, promoting care-giving to wives and children and addressing extramarital partnerships, alcohol abuse, and violence. In each, the document carefully summarizes a variety of program designs, tailored to the specific segments, including considerations of safety and program venue. (Steps 6, 7, 8)

2012. Filles Eveillées (Girls Awakened) Program for Migrant Adolescent Girls in Domestic Service in Urban Burkina Faso

Program documentation. Describes the Filles Éveillées program model and the lessons learned from the 2011-12 cohort.

(Step 7)

2012. Girls' Leadership and Mentoring (GIRLS FIRST! Perspectives on Girl-Centered Programming)

Brief. Explores the best ways to cultivate girl leaders and mentors in the communities in which you work. It highlights the basic knowledge and premises of the value of mentorship, and then examines promoted policies and practices for building strong mentorship structures.

Four programs that served as learning labs for mentorship components are discussed. Available in English and French.

(Step 7) 
2012. The Health of Vulnerable Adolescent Girls: A Strategic Return on Investment (GIRLS FIRST! Perspectives on Girl-Centered Programming) Brief. Elaborates on girls' health challenges, and also the promise of investing in these girls. Emphasizes ideas and innovations to help guide the field to better respond to, and maximize, the potential of the poorest girls in the poorest communities.

(Step 9)

2012. Priorities for Adolescent Girls' Education (GIRLS FIRST! Perspectives on Girl-Centered Programming)

Brief. Review of existing programs and policies for adolescent girls. It provides evidence-based recommendations for how the field can quickly and effectively improve girls' lives-by giving them skills, knowledge, meaningful connections to peers and mentors, and a say in their own lives. The brief explores the promising approaches that have been tested and expanded on the ground to incorporate different educational strategies into programs for girls.

(Step 8)

2012. Using Data to See and Select the Most Vulnerable Adolescent Girls

Brief. Explores novel ways to collect and use data on adolescent girls broadly through the review of basic premises and policies, a variety of resources and tools, and the practical field applications of resources in four programs, where the dynamic use of the data revealed places where the highest concentrations of vulnerable girls in need were and how that informed recruitment.

(Step 1, 5)

2011. From Research, to Program Design, to Implementation: Programming for Rural Girls in Ethiopia

Toolkit. Describes a process of developing an evidence-based program, reflecting on the quantitative and qualitative data that can be used to inform several elements of program design. Considerations around recruitment are highlighted. (Step 1)
2011. Young Women, Your Future, Your Money Workbook. Prepared for 10-14-year-old and 15-19-year-old girls in Uganda; can be adapted to build financial literacy skills and put girls on a path to consider savings and financial needs.

(Step 8)

2010. Girl-Centered Program Design: A Toolkit to Develop, Strengthen and Expand Adolescent Girls Programs

Toolkit. Practical, user-friendly tools and guidelines are intended to help strengthen programs for adolescent girls. Chapter 2 highlights the information that is necessary to understand the community and context of the lives of girls in your program and provides the tools to gather this information. Chapter 3 introduces readers to information and tools needed to assess the different dimensions of safety in girls' lives and provides a number of versions of the Safety Scan Tool. This toolkit is available in English, French, and Spanish. Chapter 4 highlights the value of intentional recruitment and explores a variety of recruitment strategies, their pros and cons, and appropriateness for particular segments. The toolkit is available in English, French, and Spanish. (Steps 4, 5, 6, 7, 8, 9)

2009-2015. The Adolescent Experience In-Depth: Using Data to Identify and Reach the Most Vulnerable Young People

Report. Draws principally on data from the Demographic and Health Surveys to provide decision-makers at all levels-from governments, nongovernmental organizations, and advocacy groups-with evidence on the situation of adolescent girls and boys and young women, from 10 to 24 years of age. The data are presented in graphs, tables, and maps, providing multiple formats to make the information accessible to a range of audiences.

(Step 1)

2009. And How Will You Remember Me, My Child? Redefining Fatherhood in Turkey

Case study. Reviews a series of 13-week-long support groups for fathers across Turkey. (Step 9) 
2009. It's All One Curriculum: Guidelines and Activities for a Unified Approach to Sexuality, Gender, HIV, and Human Rights Education Toolkit. Guidelines and activities for educators to provide a unified approach to sexuality, gender, $\mathrm{HIV}$, and human rights education. It is available in Arabic, Bangla, English, French, Mandarin, Portuguese, and Spanish. (Step 8)

2006. Living Up to Their Name: Profamilia Takes on Gender-based Violence

Case study. Describes the evolution of Profamilia through its work on gender-based violence in the Dominican Republic.

(Steps 8, 9)

2006. Tap and Reposition Youth (TRY): Providing Social Support, Savings, and Microcredit Opportunities for Young Women in Areas with High HIV Prevalence

Case study. Tap and Reposition Youth (TRY) was a multiphase initiative to reduce adolescents' vulnerabilities to adverse social and reproductive health outcomes, including HIV infection, by improving their livelihoods options.

(Step 8)

2003. Negotiating Leadership Roles: Young Women's Experience in Rural Egypt

Article. Explores the gendered meanings and processes of venturing into public life in four rural communities in Egypt, and how young women in particular forge new roles and relationships beyond their families.

(Step 7)
1986. The Women's Construction Collective: Building for the Future

Case study. Review of a project developed to integrate low-income women into Jamaica's construction industry. Should be of particular interest to those seeking to identify employment areas where women's participation is feasible and in helping prepare women for entry into nontraditional skill areas.

(Steps 8, 9)

1984. Community Management of Waste Recycling: The SIRDO

Case study. Tells the story of families and a community-based technology, principally managed by women, that improved sanitary conditions and offered possibilities for community-based incomeearning activities.

(Step 8)

1981. Women and Handicrafts: Myth and Reality Case study. Reviews handicrafts as a means of providing income to women. Summarizes a few of the key issues that must be addressed when considering a handicrafts program for women. (Step 8)

1977. Empowering the Next Generation: Girls of the Maqattam Garbage Settlement

Case study. Explores the challenge of extending earning opportunities and access to valued social roles to young women in the garbage settlement of Maqattam, Egypt. This edition furthermore underscores the degree to which livelihood programs must confront the social circumstancessuch as health, marriage, and cultural and family traditions-that play a major role in shaping girls' current and future economic prospects.

(Steps 5, 7, 8, 9) 


\title{
Intentional Design in Action: Reaching Indigenous Adolescent Girls in Guatemala
}

\author{
By Angel del Valle and Elizabeth Vásquez, with contributions from Heather Wehr
}

\section{LEARNING OBJECTIVES}

- Gain an overview of the Intentional Design approach through a review of an evidence-based program.

This case study reviews a successful evidencebased program launched in Guatemala in 2004 called Abriendo Oportunidades (AO), or "Opening Opportunities." The lives of rural indigenous girls have been improved through AO's safe spaces program delivered by young indigenous mentors, which builds human, social, health, economic, and leadership skills, as well as self-esteem. The program was designed to respond to the needs of indigenous girls-the most underserved girls in the country-building on the evidence produced by the Population Council through continuous measurement and evaluation of the program's impact on girls' lives. As of 2018, more than 360 mentors have been trained and close to 12,000 girls and adolescents have been reached in Guatemala's rural indigenous communities. The AO program, based in rural indigenous communities and extending as of 2020 into Belize and Mexico (see Figure 15), is a prime example of the value of Intentional Design.

There are close to a million indigenous girls between the ages of 10 and 19 living in
Guatemala's rural communities. When the AO program was initiated, the quality of life for these girls was notably different from the Ladino (nonindigenous) girls and boys who were receiving the majority of both policy and practical attention (Catino, Colom, and Ruiz 2011). At the national level, the reach of youth programming was poor altogether, and particularly with respect to this population. The AO program engages girls' talents appropriately and increases community accountability for providing girls with a place of their own to meet, a voice in shaping the community, and access to on-the-ground investments.

In 2008, when initial Coverage Exercises were conducted by the Population Council in conjunction with national communitybased organizations, it was found that most programs disproportionately reached urban and often male populations. As a response, the Council launched the AO program to target, intentionally, rural indigenous girls at a greater risk of school dropout and child marriage. 


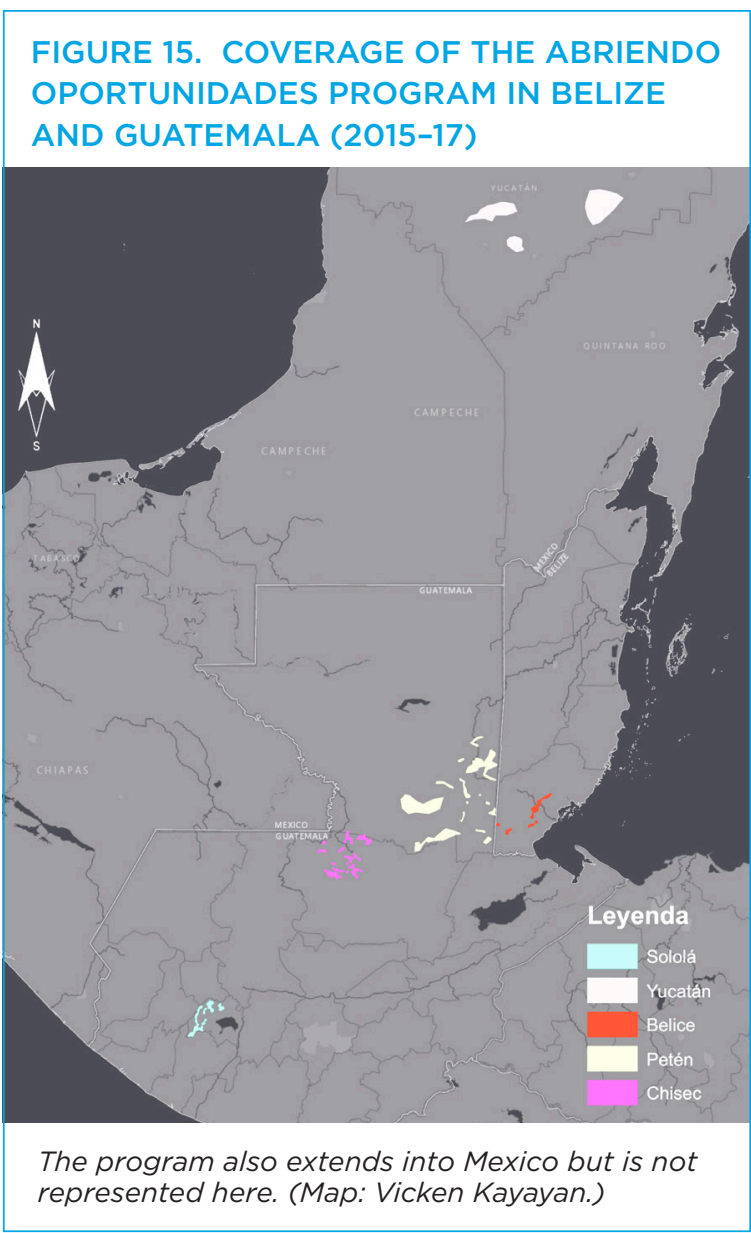

This case study describes the dynamic expansion of the AO program in Guatemala in a scale-up phase supported by UNFPA and the NoVo Foundation between 2013 and 2018. The scale-up phase allowed our team to experiment with approaches that built on the basic $A O$ model, and that was evaluated with a cluster randomized controlled trial conducted in a different indigenous region from the setting described in this chapter. Results from the impact evaluation of the basic AO model showed positive reductions in girls' experiences of child marriage and physical violence (see Box 32 , at the end of the chapter).

Lessons learned from the multiple efforts of experimentation with the AO model are informing work in Costa Rica, El Salvador, Honduras, Nicaragua, Haiti (through HAGN), and in indigenous Native American communities in the United States under the Indigenous Adolescent Girls Empowerment Network

\section{BOX 33. COMMUNITY MAPPING: USING ANDROID} PHONES TO CREATE THE SAFESCAPE BOUNDARIES

Android-phone-based technologies were used to capture information and, eventually, engage the older girls and mentors in mapping their communities. This Community Mapping Exercise had exciting results: a new skill for girls that connected them to technology, and immense efficiency in creating data visualizations that could be used to see girls, see girls in relation to specific community facilities, and also see girls' perceptions of safety in the places they visit on a daily basis.

In 2010, we began collecting the Community Resource Scan information using GPS devices and paper forms to assist in the identification and recruitment of girls. Two years later, we introduced Android phones to collect mapping data. A field supervisor along with three or four girls (usually between the ages of 16 and 24) visited households and asked to speak with the oldest female (the female head of household); they then collected information on the number of people living in the household, the number of girls and their ages, and whether they were in school for grade or how long they had been out of school. The information was kept simple and nonthreatening, and resulted in a clear tabulation of who was in the community (called the "community profile").

Walking the community using the GPS function on the phone allowed us to come up with the shape of the community. The notion of a walkable community is important in the Guatemalan highlands where access to services is difficult if they cannot be reached by walking, given the distances and levels of violence and uncertainty on the roads. Geo-references collected in the field were uploaded to Google Earth, using the offline function, to create maps that serve two purposes: 1) identifying households with girls who face higher risk of exclusion from services, and 2) creating a visual image of the community that was shared at community meetings and often considered a valuable planning resource.

(IMAGEN). In the multiyear case study for the AO scale-up phase detailed in this chapter, you will see how our approach places girls at the center of a strategy that gradually engages parents, community leaders, other stakeholders and government offices in a rural indigenous setting. This case study also details the components of a community-mobilization strategy called safescaping, designed to encourage active participation to reduce experiences of violence that affect women and girls (see Box 33). 


\section{Looking for Partners Committed to Working with Adolescent Girls}

In 2000, the Population Council began looking for the hotspot areas in Central America to begin adolescent girls work. When the pilot of the AO program was launched in 2004, the Population Council office in Guatemala was working in just 24 communities with 24 mentors-one in each community. The communities selected had populations between 500 and 1,500, with the median being around 750. In each of these communities, the focus was on girls aged 10-14. There were a few other criteria to identify the communities where the AO program was likely to have greatest impact, such as having a local board of community leaders (Consejo Comunitario de Desarrollo-COCODE), and young women who expressed interest in becoming mentors. The villages reached in the $A O$ pilot program for the period 2004-06, while extremely poor, were not the ones that were least accessible, as the villages selected had to have a passable road, a school, a health center, and a development committee. The decision not to reach the most marginalized communities was due to logistics challenges, shared by other programs on the ground and linked to the availability of funding, meaning that transportation costs to reach least accessible communities exceeded budget capacities.

Activities delivered to girls through the $A O$ program consist of regular meetings in safe spaces facilitated by local indigenous female mentors 20-29 years of age. Indigenous values and historical cultural knowledge were infused throughout the program's approach and curriculum content from the conception of the model. The program runs in a community for an ideal period of 18 months, and works in parallel with two cohorts of girls: age groups 8-14 and 15-19. Venues for safe spaces usually include school classrooms and community halls.

Ever since the pilot was implemented, the AO program's goal was to make the community a more comfortable and "walkable" place for girls. ${ }^{16}$ The enumeration methods to find and recruit girls were simple: have mentors visit households, take a count of the girls, and invite girls into one of two groups. One group was composed of 8-12-year-olds, based on data collected that showed dropout from school began around age 10 (see Figure 16). The second group was 13-17-year-olds, later broken into 13-15 and 16-17 when demand from "Young Leaders" (participants in the 13-17-yearold age groups who wanted to take part in mentoring activities) was identified as a new component of the AO program. Each set of girls met once a week, and a high proportion (typically more than 70 percent-the level as of 2018) participated every week. There was particularly strong turnout among younger girls. We learned, in the course of the program, that by age 12 the older girls were already under pressure to leave school, contribute to household tasks, and get married (Hallman et al. 2007a).

\section{Engaging the "Whole Girl" in the Whole Village}

After the implementation of the pilot phase of the AO program (2004-06), the team realized that much of the challenge of finding and engaging girls came from adults who resisted the idea of empowering girls-mostly males like fathers, conservative community leaders, school principals, and church leaders. For example, a male adult with decision-making power within the community had the power to impede participation by declining access to the safe spaces where girls could meet, meaning that they would be without a space to attend a program that was attempted to be offered.

In crafting program components that were key to having a great impact on girls' lives, the AO team drew on:

- The commitment to reach change at the level of the girl (measured by acquired health, social, economic, and cognitive assets);

16 For an account of the initial model of AO, visit: http://www.popcouncil.org/research/abriendo-oportunidades-opening-opportunities. 
FIGURE 16. THE IMPACT OF PUBERTY ON THE SOCIAL LANDSCAPE OF RURAL INDIGENOUS GIRLS IN GUATEMALA

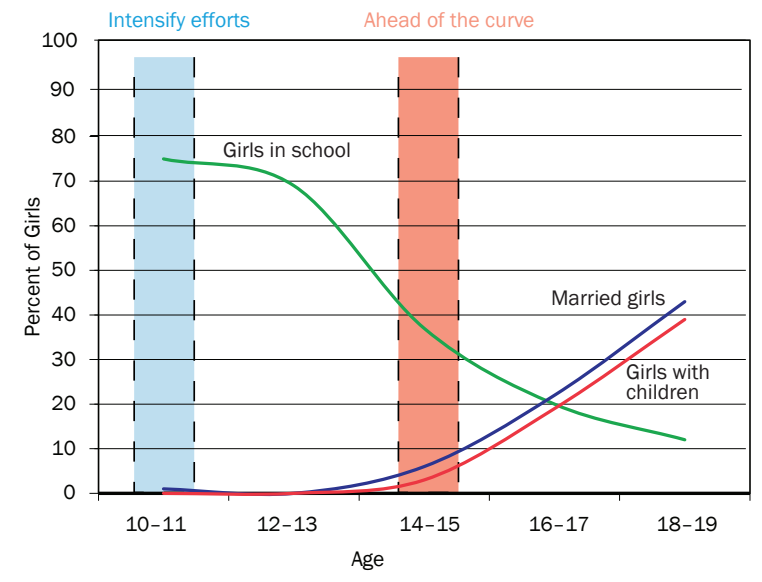

- Community-level commitments to create measurable access to specific community structures for segments of girls;

- Designing for scale: well-tested, observed approaches expanded to territories where indigenous people live;

- Existing literature on successful programs that aimed to engage communities in eliminating violence against women in a participatory way (like the theory of change to foster community mobilization implemented by the SASA! program [Abramsky et al. 2016]).

It became clear from the first days of $A O$ that one of its powers was that a very high proportion-the majority-of girls of eligible age were involved, in particular younger girls who were still enrolled in school. The meetings were almost always held in a school facility that was normally locked at $3 \mathrm{pm}$ (and during holidays) but was provided as a community facility for the girls. Stigma and negative gender roles had both hidden the girls and removed them from access to the most fundamental community services. So, in a number of communities, the COCODE would hand over the school keys to the mentors, and the hours of the club meetings would be posted on public signs. This was
This graphic shows that at age 10-11 years approximately $75 \%$ of girls are in school. Quite swiftly there is an increase in dropout, and not long after a steep rise in rate of marriage and childbearing (around age 14-15).

It is, therefore, important to intensify efforts to reach girls before dropout and ahead of the curve by which child marriage and adolescent pregnancy increases.

Source: Hallman et al. 2007b. possible because of the community contract signed with leaders that established the process of handing over the school keys to the mentors as one of the agreements.

\section{Gradations of Girls' Sense of Safety, Access, and Comfort}

Once mentors started working with girls, it became clear that the girls were more familiar with and felt more comfortable in some areas of the community than others. This included girls who lived near or had to visit places that felt less safe or less familiar. Having girls' perceptions of safety as an initial frame, the strategy was to now add girl-level safety mapping (safescaping) as part of regular club activities for girls aged roughly 15-19, with the intention to represent girls' voice through visuals. To test the strategy, the Population Council conducted a series of activities with small groups of girls (aged 15-19) in five communities located in the highlands and the northern regions of the country covered by the AO program from 2010-13. ${ }^{17}$ These activities were facilitated by $\mathrm{AO}$ mentors, who were aged 19-30. Before conducting the Community Resource Scan with girls, mentors were trained by the Office for the Defense of Indigenous Women (DEMI) on effective approaches to

17 Activities supported by the United Nations Trust Fund to End Violence Against Women (UNTF). 


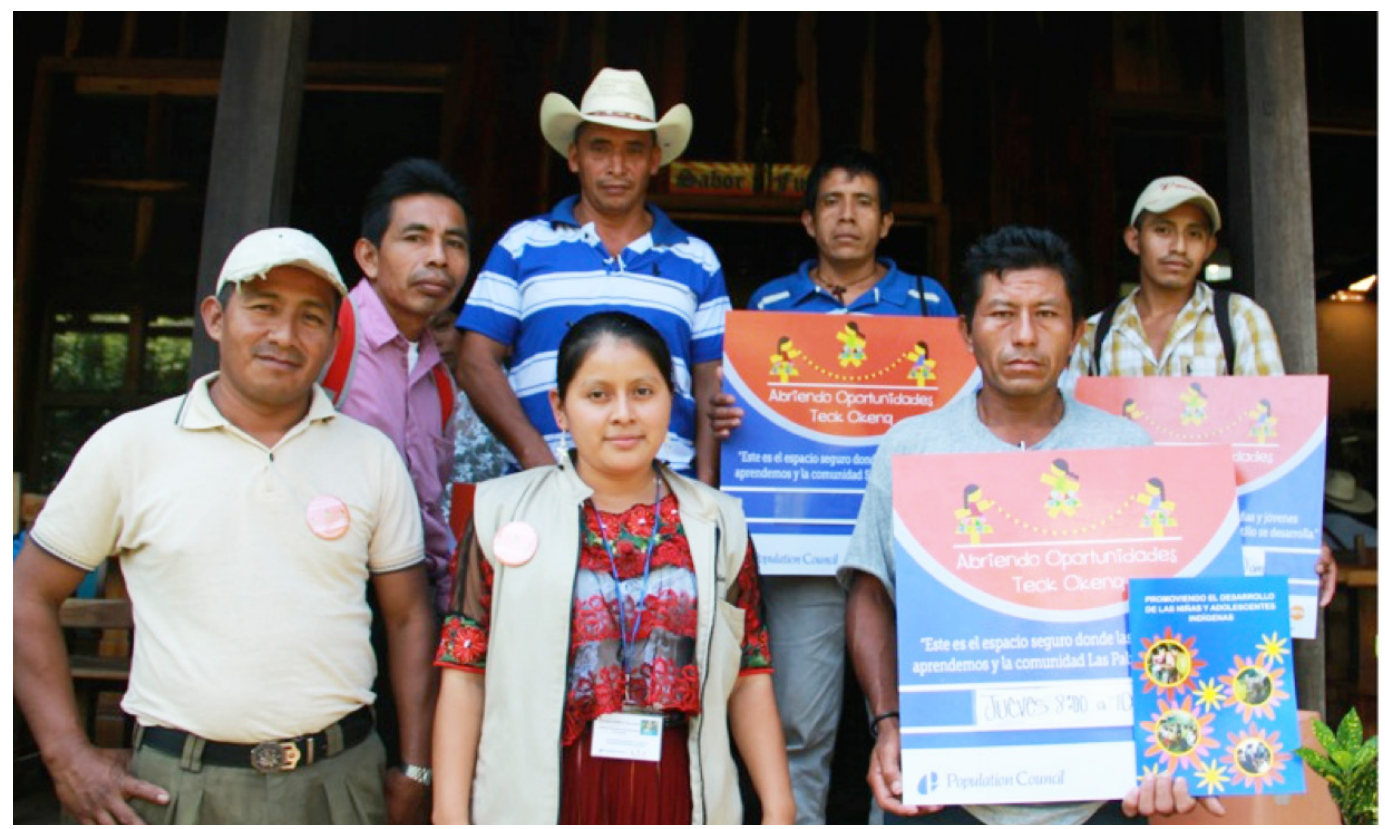

Mentors with community leaders holding signs for the safe space. (Photo: Aiken Chew.)

explore perceptions of violence among girls and women. Mentors were also trained in community mobilization strategies that proved to be effective in the SASA! program (Michau 2007). On average, a mentor received approximately 15 days of training before engaging girls in the safescaping exercises-in addition to the bimonthly trainings they attended as mentors of the AO program. To implement the safescaping strategy around the community, mentors walked along with girls using GPS devices to map public spaces, for example the school, churches, health clinics, and the shops (also called "bars" or "drinking places") where men gather to drink. After walking around the community, GPS information was uploaded to Google Earth and customized using the offline function to create interactive maps of public spaces (see Figure 17).

With visual maps ready to use, AO mentors and Population Council staff engaged girls in participatory exercises to navigate and explore the community using Google Earth. As the visual experience developed, girls were asked to respond to three questions:

1. What time of day would you frequent the space?

2. Who would you find there?
3. How do you feel, in terms of colors (safety levels), when you go there or when you walk by that place (Color 1: I feel completely safe; Color 2: I feel somewhat safe; Color 3: I feel unsafe)?

Each girl had colors to add to a printed version of the map, so that an average of a girl's experience was achieved, as shown in Figure 17. After repeating the same exercise in five rural communities, perceptions of safety were then organized by type of place (community, school, corn-grinding shop, market, playing field, church, drinking place) and a content summary provided a collective sense of girls' perceptions of safety, which was similar across communities for places like the schools, churches, corngrinding shops, and drinking places (see Table 16).

The exercise of walking around the community, combined with real-time community navigation in Google Earth, allowed girls to explore a spatial dimension of the community that was not easy to connect to objective reality (some sites look larger than others and perhaps loom larger), and of course a hand-drawn map cannot compete with a data-anchored computer-driven map. We also learned that girls are aware of 


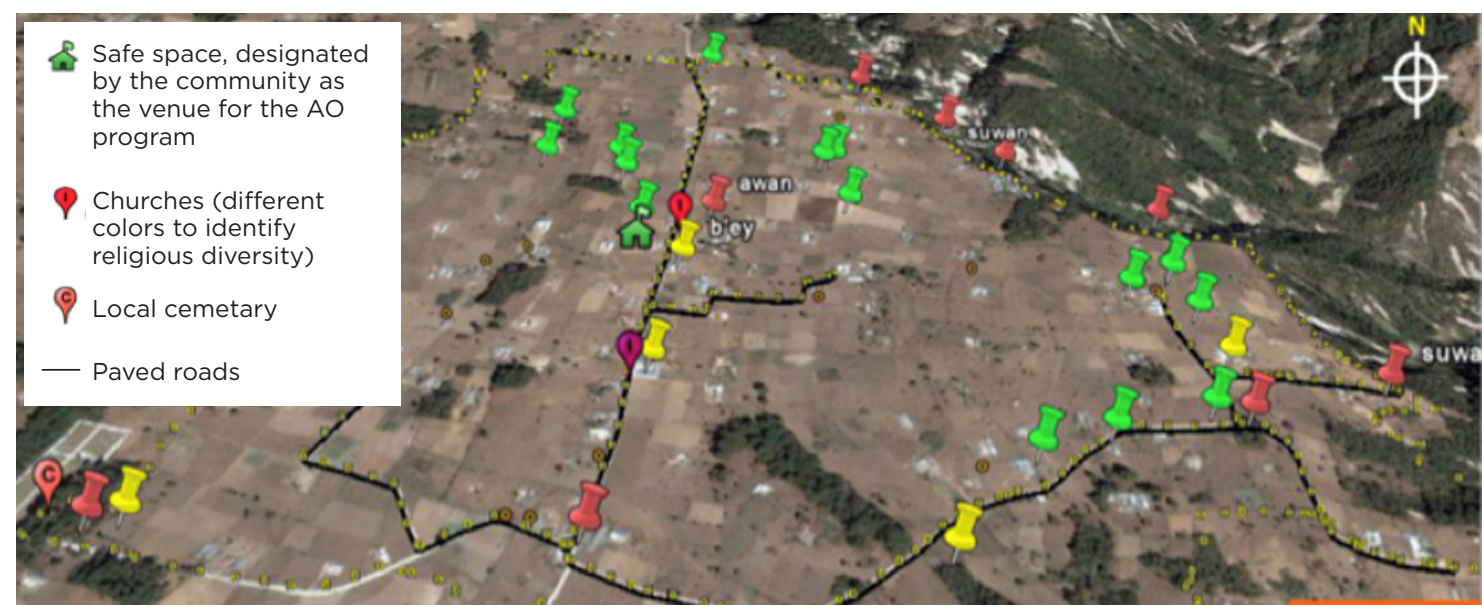

Green, yellow, and red pins identify places deemed "safe" (green), "somewhat safe" (yellow), and "unsafe" (red). respectively, by girls living in the community during a Community Resource Scan.

TABLE 16. GIRLS' (N=12) PERCEPTION OF SAFETY IN DIFFERENT COMMUNITY SPACES IN A SINGLE COMMUNITY FOR A SPECIFIC TIME OF DAY

Safety levels are labeled as "safe" for green, "somewhat safe" for yellow, and "unsafe" for red.

\begin{tabular}{|l|l|l|c|l|}
\hline Space & Time of day & Who is there? & Safety level & Who makes it unsafe? \\
\hline Drinking place & $\begin{array}{l}\text { Afternoon } \\
\text { Night }\end{array}$ & Adult men & $\begin{array}{l}\text { Young and old men who } \\
\text { get drunk and rape/abuse } \\
\text { women }\end{array}$ \\
\hline Corn-grinding shop & Night & Girls; adult men & $\begin{array}{l}\text { Store owners who harass } \\
\text { and touch girls; women } \\
\text { who are mean to girls }\end{array}$ \\
\hline School & Recess & Boys (peers) & & $\begin{array}{l}\text { Boys who bully girls during } \\
\text { recess }\end{array}$ \\
\hline
\end{tabular}

the risks they face when walking around their communities at certain times and days of the week; they have implicit plans to be safe, but paradoxically they are asked to go to unsafe places on a daily basis.

As shown in Table 17, it is striking to note that schools are the only places in which girls feel completely safe at all times across communities. Considering that only four out of ten girls make it to secondary school beyond age 15, girls can expect to become increasingly more isolated as they become older. The Population Council documented these isolation patterns in 2007 (Hallman et al. 2007b), when analysis of national data showed that the vast majority of indigenous girls had only completed three years of schooling by the time they left school. Additionally, we learned that many of these girls start school late, repeat grades, and drop out around pubertal age, when parents expect them to begin taking on adult female responsibilities and roles (Hallman et al. 2007b).

School attendance beyond puberty is perceived by some parents as carrying the risk of exposing girls to danger, including the possibility of adolescent pregnancy, which in the traditional 
TABLE 17. PERCEPTIONS, SAFETY LEVELS, AND RISK IN PUBLIC PLACES DESCRIBED BY GIRLS AGED 15-19 IN FOUR COMMUNITIES $(\mathrm{N}=32)$

\begin{tabular}{|c|c|c|c|c|c|c|c|}
\hline & Community & School & $\begin{array}{l}\text { Corn-grinding } \\
\text { shop }\end{array}$ & Market & Playing field & Church & Drinking place \\
\hline \multirow[t]{4}{*}{ Time of day } & A & Night & Noon & \multirow{4}{*}{$\begin{array}{l}\text { Morning } \\
\text { (usually } \\
\text { weekends) }\end{array}$} & \multirow{4}{*}{$\begin{array}{l}\text { Afternoon } \\
\text { (after school) } \\
\text { on weekdays; } \\
\text { morning } \\
\text { (weekends) }\end{array}$} & \multirow{4}{*}{$\begin{array}{l}\text { Night (when } \\
\text { service is held) }\end{array}$} & \multirow{4}{*}{$\begin{array}{l}\text { All day, } \\
\text { especially nights } \\
\text { and weekends }\end{array}$} \\
\hline & B & Night & Afternoon & & & & \\
\hline & C & School recess & All day & & & & \\
\hline & D & All day & Morning & & & & \\
\hline \multirow{4}{*}{$\begin{array}{l}\text { Frequented } \\
\text { by }\end{array}$} & A & \multirow{4}{*}{\begin{tabular}{|l} 
Girls, \\
adolescent \\
girls, and \\
women
\end{tabular}} & \multirow{4}{*}{$\begin{array}{l}\text { Girls, } \\
\text { adolescent } \\
\text { girls, and } \\
\text { women }\end{array}$} & \multirow{4}{*}{$\begin{array}{l}\text { Girls, } \\
\text { adolescent } \\
\text { girls, and } \\
\text { women } \\
\text { (mothers), } \\
\text { salesmen }\end{array}$} & \multirow{4}{*}{$\begin{array}{l}\text { Boys, young } \\
\text { men, and } \\
\text { adult men }\end{array}$} & \multirow{4}{*}{$\begin{array}{l}\text { All people from } \\
\text { the community }\end{array}$} & \multirow{4}{*}{$\begin{array}{l}\text { Boys, young } \\
\text { men, old men, } \\
\text { and sometimes } \\
\text { young women }\end{array}$} \\
\hline & B & & & & & & \\
\hline & C & & & & & & \\
\hline & D & & & & & & \\
\hline \multirow[t]{4}{*}{ Safety level } & A & & & & & & \\
\hline & $\mathrm{B}$ & & & & & & \\
\hline & C & & & & & & \\
\hline & D & & & & & & \\
\hline \multirow{4}{*}{$\begin{array}{l}\text { Explanation } \\
\text { for safety } \\
\text { level }\end{array}$} & A & \multirow{4}{*}{$\begin{array}{l}\text { Boys can be } \\
\text { aggressive } \\
\text { and mean }\end{array}$} & \multirow{4}{*}{$\begin{array}{l}\text { Men who sell } \\
\text { corn can be } \\
\text { violent } \\
\text { Also boys aged } \\
15 \text { and up who } \\
\text { are in the shop } \\
\text { or nearby }\end{array}$} & \multirow{4}{*}{$\begin{array}{l}\text { Salesmen } \\
\text { and women } \\
\text { who come } \\
\text { from or } \\
\text { live in } \\
\text { neighboring } \\
\text { communities }\end{array}$} & \multirow{4}{*}{$\begin{array}{l}\text { Men from the } \\
\text { community } \\
\text { who play in } \\
\text { the field }\end{array}$} & \multirow{4}{*}{$\begin{array}{l}\text { Men who wander } \\
\text { outside the } \\
\text { venue after } \\
\text { mass/worship }\end{array}$} & \multirow{4}{*}{$\begin{array}{l}\text { Men who "turn } \\
\text { crazy" when } \\
\text { drinking, aged } \\
\text { 15-40, and } \\
\text { outsiders }\end{array}$} \\
\hline & B & & & & & & \\
\hline & C & & & & & & \\
\hline & $D$ & & & & & & \\
\hline
\end{tabular}

\section{FIGURE 18. SATELLITE IMAGE OF COMMUNITY B (CREATED IN GOOGLE EARTH)}

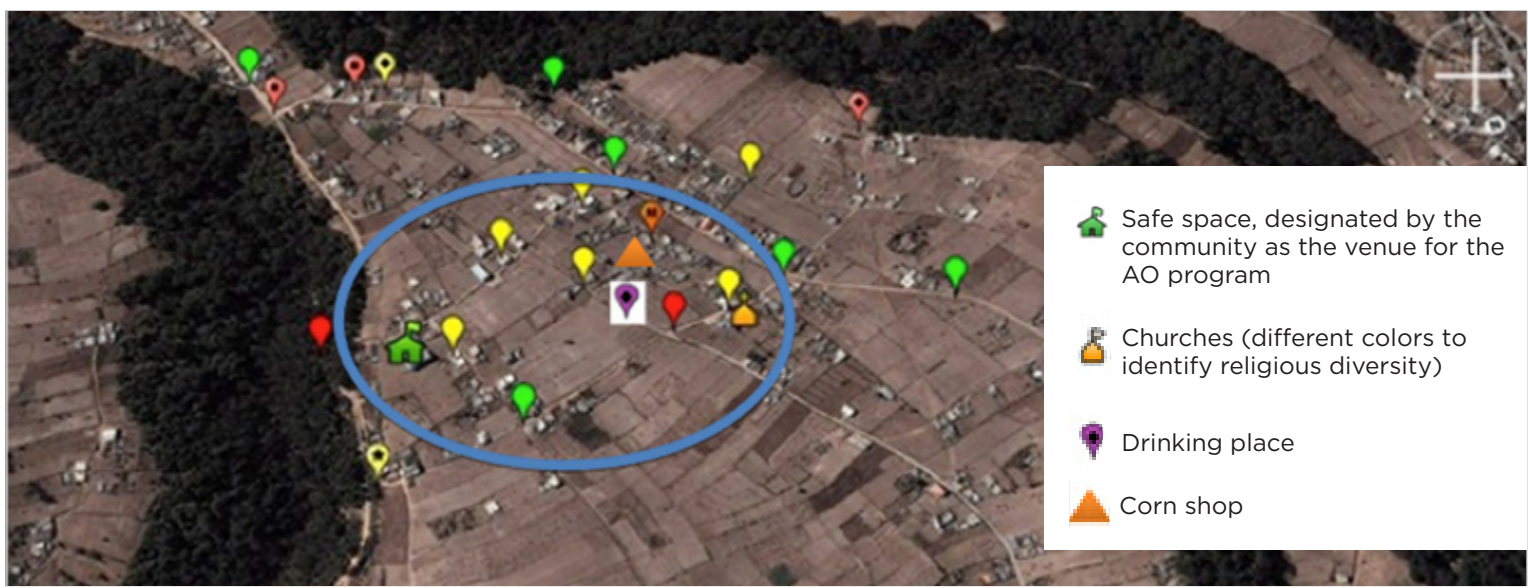

Green, yellow, and red pins identify places deemed "safe" (green), "somewhat safe" (yellow), and "unsafe" (red), respectively. The pins included in the circled area show that the drinking place is located within girls' walkable community. 
setting of the rural Guatemalan highlands would greatly shame the family and ruin a girl's future prospects for marriage. At puberty, girls are also expected to begin working in household-based domestic activities (Hallman et al. 2007a). This means that the most excluded girls, living in already deeply poor communities, are leaving school and staying at home at the onset of puberty, and at the same time are asked to walk past dangerous places without even contemplating the fact that they might be at risk (see Figure 18). In the course of collecting information, multiple experiences of violence were reflected in girls' anecdotes. Girls were aware of places where someone, at some time in the past, had an experience of violence.

\section{Efforts to Engage the Community in Discussing Girls' Safety}

The Population Council, in partnership with DEMI, wanted to include the safescaping data in conversations with communities to increase support for girls' groups and expand access to community facilities, once the AO program was already active. The team decided to replicate safescaping activities with adults, and convened a number of meetings with parents and local leaders to develop plans to reduce violence against girls. The strategy aimed at engaging a diverse group of 20-25 adults (COCODE, parents, teachers, school principals, other relevant leaders, and $\mathrm{AO}$ mentors) in community-based meetings.

\section{Meeting 1: Developing a common definition of violence}

At the first meeting (out of five) there typically was a struggle to agree on a common definition of violence. Men quickly associated violence with crimes like stealing, murder, and break-ins, while women mentioned violent events that happened at home (see Figure 19). Women overall expressed that their voices were rarely heard when issues of violence were discussed in community meetings. The dialogues made it clear that violence had been normalized and was firmly part of the community and, implicitly, women's responsibility. At the end of the first meeting, participants developed a shared idea of what violence meant to them by interpreting it as the suffering that causes pain, bitterness, sadness, depression, and a desire to end one's life.

FIGURE 19. “WORD-CLOUD” (IN SPANISH) OF CENTRAL IDEAS, ATTITUDES, AND BEHAVIORS FROM THE FIRST INDIGENOUS COMMUNITY MEETING

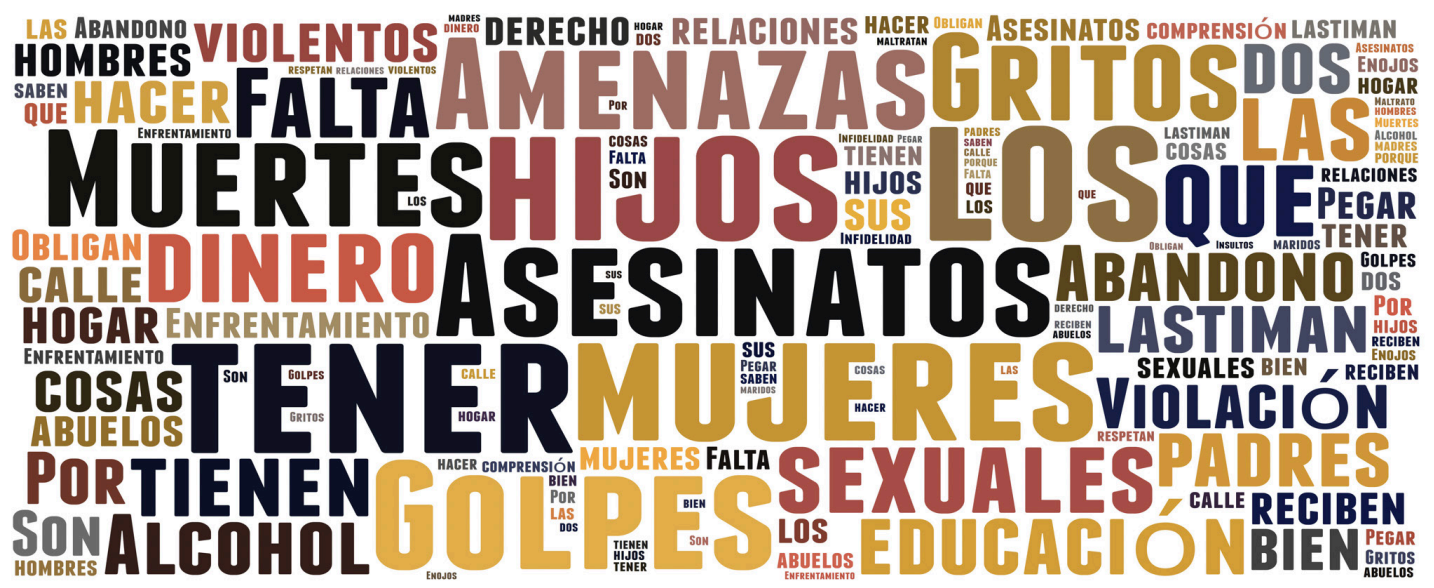

Words mentioned the most are represented in a bigger size, and include: death, murder, children, beating, alcohol, education, sexuality, yelling, threatening, money, rape, and women. 


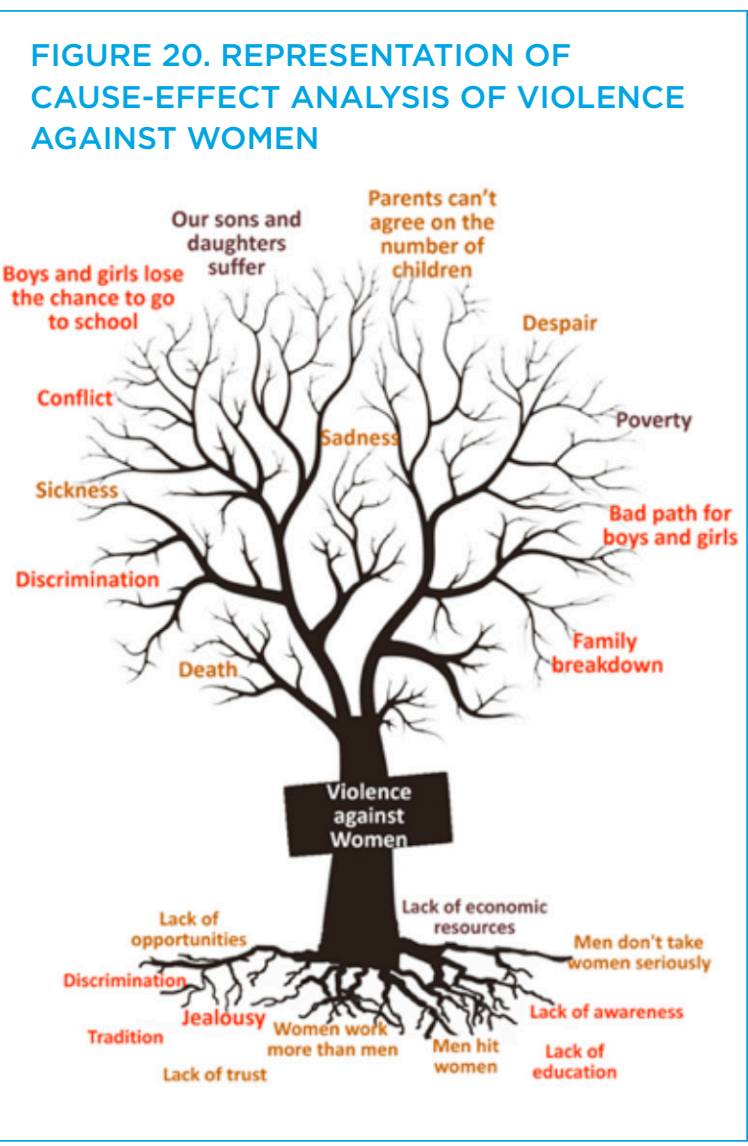

Meeting 2: Building a bridge between the causes and consequences of violence against women

At the second meeting, facilitated by $\mathrm{AO}$ mentors and DEMI's social workers, two or three weeks after the first meeting, participants were asked to link specific forms of violence to their consequences in a diagram labeled the "Tree of Violence against Women" to assist local understanding of violence (see Figure 20). The roots of the tree were associated with the cause of a particular feeling, emotion, or action; the branches represented the consequence of such actions. Men and women were given separate trees. Once the exercise was completed, AO mentors and DEMI's staff facilitated a dialogue to identify similarities between both trees. Meeting 2 revealed that "violent actions/ events" included men beating their wives or parents beating their children-acts of violence that were not mentioned in an explicit way in Meeting 1.
A tree illustrating girls' perceptions-created before Meeting 2 as part of the regular safe spaces meeting-was also presented as a way to initiate the discussion about girls' perceptions of violence. By looking at the cause-effect analysis-illustrated as the roots and branches of the tree-participants could understand that what the girls and women were describing as "effects" or "expressions" of violence reflected their deep suffering.

In seeking some consensual basis to discuss the different forms of violence, AO mentors explained girls' reactions to adults, saying that violent actions made girls feel "sickness, sadness, despair, and a wish to kill oneself." Only in this way-in effect, creating collective empathy-were men and women able to accept the girls' definition.

The discussion then turned to who was causing violence at home and the community. We knew that without discussing the different roles that people play in perpetuating violence, there could be no effective action. Women and girls reported high levels of sexual violence, often perpetuated by their parents, community leaders, and other influential actors, although this was strongly denied by men. These reports were consistent with the findings obtained from the enumeration exercises that we were conducting in AO communities. In 2015 alone, we identified 17 girls under the age of 15 who already had a child (out of a total of 3,500 girls aged 10-15 years old) in the 50 communities where the scale-up phase was implemented. As reported by the National Observatory in Reproductive Health (OSAR 2018), cases of pregnancies among indigenous girls younger than 15 are considered child sexual assault, given that 80 percent of the perpetrators are older men who hold power over girls because of kinship. That is, these are men that live in the same households as girls, and are the result of nonconsensual relationships. At the national level, at least 5,000 cases of child sexual assault are reported every year.

Success in Meeting 2 translated into agreeing on the need to talk about and discuss violence 
among community members, without revictimizing. Furthermore, participants agreed on the need to understand that this "suffering" was not equally shared between men and women, and that although these multiple forms of violence affect the whole family, women and girls are the ones who suffer the most.

Meeting 3: Examining the exclusion of women from decision-making groups in the community

Meeting 3 turned to a less emotional but important structural subject: the exclusion of women from organized groups that underpin violence or grant it impunity. These groups are typically made up of religious pastors, male leaders, and other influential actors who use their influence to manipulate women and families into believing that violence against women should not be acted upon. Historically, indigenous communities have demonstrated strong levels of local organization. For this reason, it is common to find different and diverse types of committees and organized groups within a small community, most of which have little participation from women. The central questions in Meeting 3 were:
1. Do we find females of any age getting information, making decisions, or allocating resources?

2. Where do females (and the female voice) fit in communities and participate in local organized groups and decision-making?

Consistent across communities was the fact that females had no decision-making power over infrastructure, legal issues, financial services, religion, or the use and distribution of natural resources. They had some voice in education, health, and human-rights-related committees (those that may be the least likely to have local resources), but no real control over financial resources. The visuals in Figure 21 gave communities a clear idea of what exclusion from decision-making structures looked like.

Success in Meeting 3 was achieved when the participants acknowledged and validated that there was an imbalance of gender equity and began to proceed equitably (acknowledging participation as a right). The conversation then moved on to how organized groups can use the increasing recognition of violence and suffering, and the role they play in girls' lives, to prevent violence against girls and women.

\section{FIGURE 21. VISUAL REPRESENTATION OF FEMALE PRESENCE IN ORGANIZED GROUPS IN A}

TYPICAL INDIGENOUS COMMUNITY

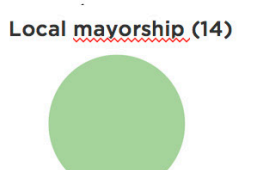

Community security

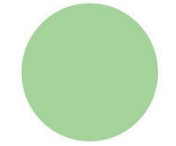

Forest guard (10)

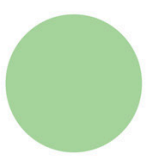

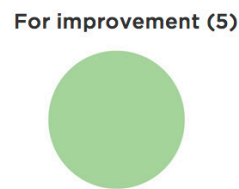

Water committee (40)

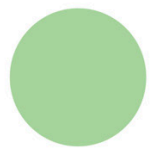

Churches leadership (2)

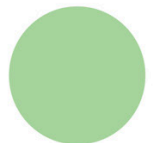

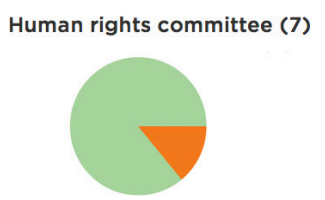

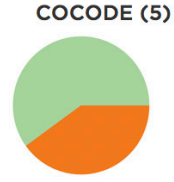

Health committee (5)

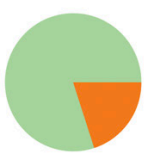

Roads and paving ( 8 )

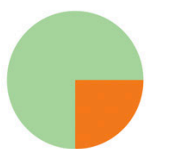

School committee (23)
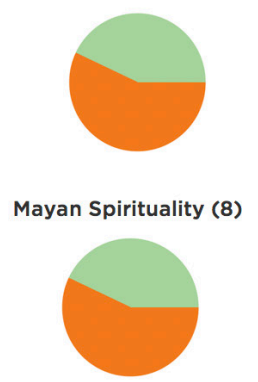

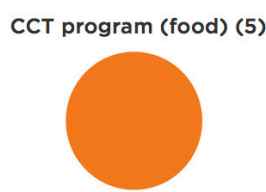

Local women's committee (1) Municipal representative of women (1)

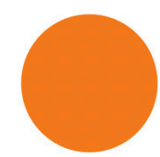

СCT Program (education) (8)

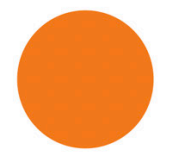

Each circle represents an organized group. Parentheses show the number of people participating in each group or committee. Male representation is shown in green and female representation in orange. 


\section{Meeting 4: Raising visibility of girls' perceptions and need for safety within the community}

Older girls aged 15-19 participating in AO groups were invited to join Meeting 4. Precautions were put into place given that we knew that some girls could be confronting, if not their aggressors, those who had given a free pass to their aggressors (sometimes family members and other influential actors who live in the community). AO mentors and DEMI staff were trained to make sure girls could speak confidently. During this meeting, participants, both adults and girls, navigated through the safety map created by girls (see top map of Figure 22), adding new pins (red, yellow, and green) to represent adults' perceptions of safety (see bottom map of Figure 22). By exposing adults to girls' perceptions, they started to appreciate the time girls' invest in $\mathrm{AO}$ meetings.
As participants navigated through the satellite image of the maps, narratives of past violent events came up. Facilitators asked participants to describe such events with caution, without mentioning names of victims and/or aggressors. As the narratives unfolded, participants started proposing ways to prevent those events from happening again. This time, perceptions of what violence means was not limited to actions perpetrated by outsiders, but by those known personally as well. By the time the exercise concluded, the map became more comprehensive and integrated adults' perceptions, combining both girls' and adults' perceptions of safety in a single map as shown in Figure 22.

Success in Meeting 4 (with more clarity on what violence is and a better understanding of the community's role in ensuring girls' safety) was reflected in participants' ability to identify

FIGURE 22. COMPREHENSIVE MAP INTEGRATING GIRLS' PERCEPTIONS OF SAFETY AND ADULTS' INPUTS
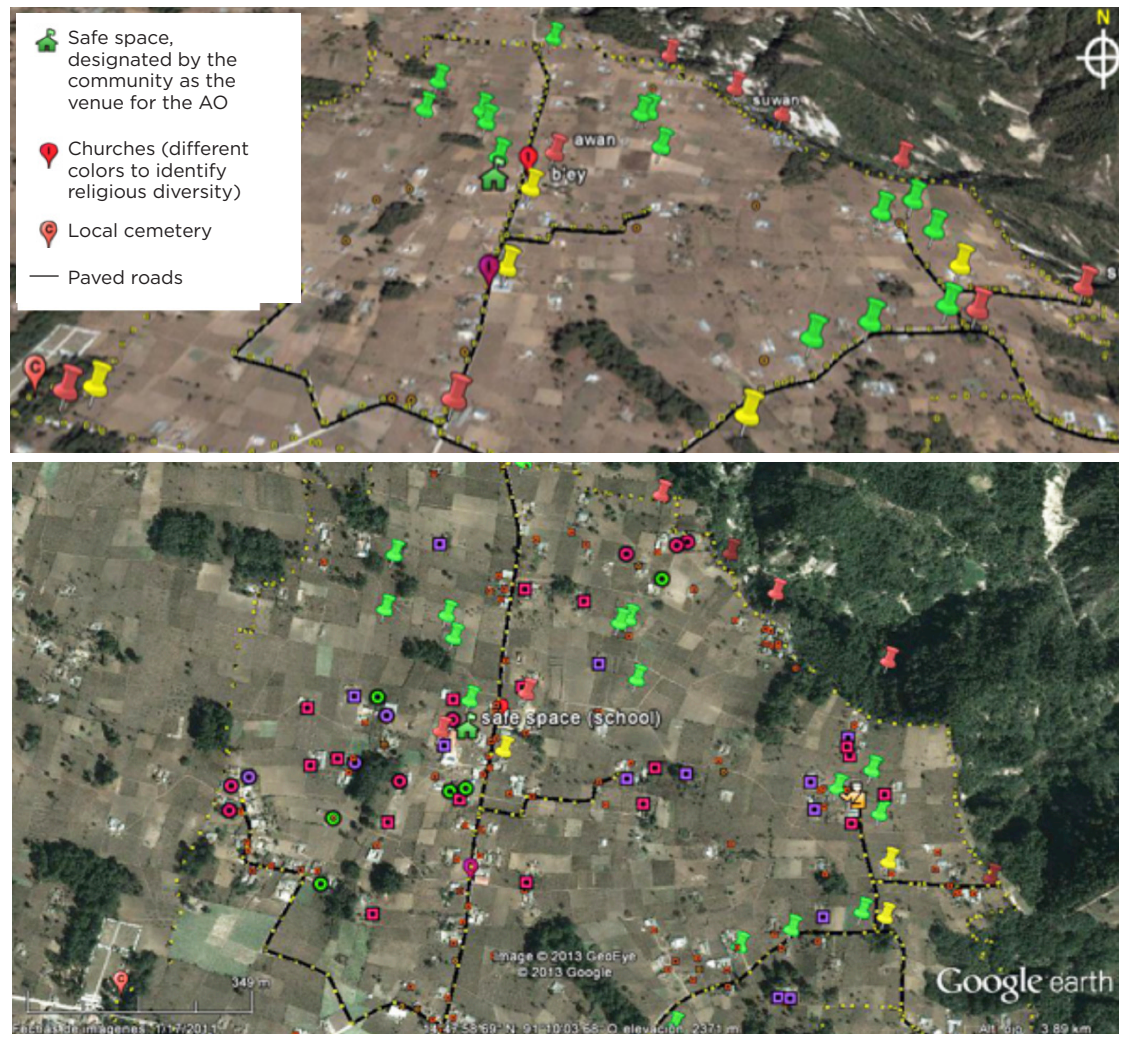

Girls' initial Community Resource Scan (top) and adults' input (bottom) in Community A. 


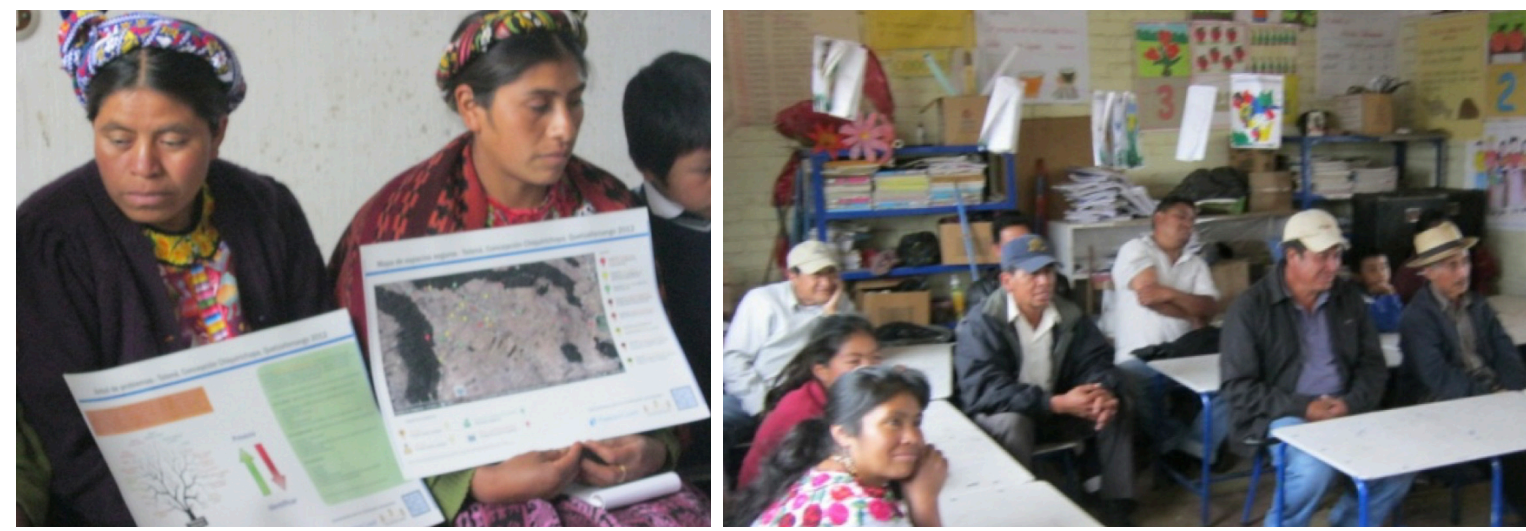

(Left) Mothers holding a copy of the "Tree of Violence against Women." (Right) Participants proposing ideas to implement safescaping plans. (Photo: Angel del Valle.)

women's experience of violence, naming real events that had occurred in the past and that should not be allowed to happen again (rape, harassment, intimidation). By the end of the meeting, key stakeholders (parents, mothers, community leaders, COCODE) had a better understanding of the need to support safe spaces for girls, and started associating girls' safety with the AO program.

\section{Meeting 5: Developing community-based plans to support girls in their desire for a safer community (safescaping)}

In Meeting 5, participants agreed on basic actions they could take to prevent violence from happening in public spaces (action plans). This was the first time leaders and adults realized that taking collective action to make the community safer for girls and women-and every person in the long run-is a desirable outcome.

It is important to point out that all visual resources were shared with communities after each session. By Meeting 5, communities had a toolbox of visual materials, which they used to think of possible actions to implement safescaping ideas. In schools, teachers used maps to help children develop safety plans for getting to school and walking in groups. In some communities there was a long distance to school from one side of town (and perhaps an argument for a satellite school), or drinking places might be located on the way to school. The maps began to be a reference point for making decisions to promote girls' safety.

As communities started discussing effective ways to send the message of reducing and eliminating violence, some participants thought it was a good idea to create videos. The Population Council had recently experimented with participatory approaches using video, in particular, using participatory video techniques. ${ }^{18}$ These videos were dramatized by participants (mothers, leaders, girls, teachers) and filmed in the community. They were edited by the Population Council and screened back in communities as part of the program's closing event. ${ }^{19}$

As participants created safescaping plans, we observed that challenges emerged when turning ideas into actions. Having an ample budget to implement the ideas outlined in the safescaping plans was the major obstacle. Communities could not afford more lighting on the street or hiring a mentor for a playing field, but coordinated to cut down the corn along the road where potentially dangerous individuals could hide. After Meeting 5, the importance of meeting regularly to talk about a communitybased safe space for girls was understood, and the need to sustain the AO clubs into the far

18 With support from the Nike Foundation and InsightShare (http://insightshare.org), AO staff were trained in the creation of participatory videos, using the "Most Significant Change" technique in a project called "Video Girls for Change": https://www.comminit.com/africa/content/ video-girls-change-participatory-video-monitoring-and-evaluation-initiative-final-projec.

19 Participatory videos created by communities: https://vimeo.com/45216851. 
future was agreed upon. Participants laid out a basic set of actions that would be desirable and within their realm of possibility (see Table 18).

\section{Community Report Card}

In all communities where the safescaping activities were implemented, there was a sense of collective action after the meetings. Although some of the actions included in the prevention plans designed by participants were not implemented because of financial limitations discussed earlier, here are some actions communities could implement within six months after the implementation of the five meetings:

- Support household surveys (conducted to evaluate the AO program).

- Collaborate in the process of finding and recruiting girls to $\mathrm{AO}$ groups.

- Conduct Mapping/Girl Roster information collection in every household in an effort to bring girls of school age back to school.

- Ensure access to safe spaces and contribute to the transformation of community public spaces into safe environments.

- Reinforce girls' protection by labeling spaces as "safe" and posting meeting hours for girls' groups.

- Participate in community events organized by mentors in coordination with local leaders.

- Provide girls with a photo ID, even if it is not an official government ID.

- Create safety zones, and develop specific security and protection procedures.

- Enforce protective laws more systematically.

- Organize service provisions and entitlements at days and times of the week that make them more accessible to girls.

- Support the cascading leadership approach promoted by the AO program, whereby mentors keep the safe spaces open after the Population Council phases out of the community.

- Coordinate with central/local government offices once a clear plan with safescaping actions has been developed.

\section{Sustainability of Safescaping Plans}

A year after safescaping actions were implemented, we assessed how effective they had been. To some extent, the girls continued to meet in the AO safe spaces, but they were constrained by the male-dominated decisionmaking groups that declined access to safe spaces once the community leadership was handed over to new boards. Although local women's committees and schoolteachers were still using the tools produced as part of safescaping activities, community mobilization activities that had been organized to implement action plans were not as frequent as they were months after the final safescaping meeting. Community dialogues that had created a temporary space for women to speak were not taking place as frequently. The AO program continued to be the only safe place for girls to meet with their friends, but the parents lacked financial means to buy the basic materials that girls need to learn and play.

It became evident that safescaping actions and plans to mobilize communities to prevent violence against girls and women should be designed so that stakeholders can implement simple tasks without cost on a daily basis. We are confident that reaching a significant number of participants in a significant number of neighboring communities-almost in a clustered approach-will translate into a higher number of safescaping plans for girls that can be sustained over time. By using a clustered approach, we facilitate the role that mentors can play for girls as they are now able to move easily between communities, instead of working in a single community in isolation.

This approach also made it easier to work with community leaders because the AO program became well known and that increased community leaders' confidence in coming to our safescaping sessions. The group of 24 mentors were visible and hard to miss, so the local government invited them to have a seat in the District Council and delegated activities that implied coordination with the Office of DEMI and entities of a similar nature. Girls' mothers, who are crucial to engage to sustain 
TABLE 18. SAFESCAPING ACTION PLANS DESIGNED BY COMMUNITY A IN MEETING 5

\begin{tabular}{|c|c|c|c|}
\hline Community & $\begin{array}{l}\text { Criteria for inclusion in } \\
\text { safescaping pilot }\end{array}$ & Participants & Proposed safescaping actions \\
\hline $\begin{array}{l}\text { - Community A } \\
\text { - Ethnic group: } \\
\text { Kaqchikel } \\
\text { - Total of households: } \\
145 \text { (approximately) } \\
\text { - AO groups started } \\
\text { in } 2011\end{array}$ & $\begin{array}{l}\text { - Community leaders } \\
\text { requested a } \\
\text { workshop to build } \\
\text { capacity in violence } \\
\text { prevention. } \\
\text { - DEMI targeted } \\
\text { this community as } \\
\text { a "pilot" for their } \\
\text { community outreach } \\
\text { intervention as a } \\
\text { result of the strategic } \\
\text { alliance with AO. }\end{array}$ & $\begin{array}{l}\text { - } 12 \text { male leaders who } \\
\text { were members of the } \\
\text { COCODE } \\
\text { - } 1 \text { principal of the } \\
\text { local school (woman) } \\
\text { - } 1 \text { AO mentor } \\
\text { - } 3 \text { adolescent girls } \\
\text { from AO clubs (aged } \\
15-18 \text { ) } \\
\text { - } 5 \text { women from the } \\
\text { local "women's } \\
\text { committee" } \\
\text { - } 8 \text { mothers of AO girls }\end{array}$ & $\begin{array}{l}\text { - The "women's committee" was selected by } \\
\text { community members to coordinate with DEMI } \\
\text { on future prevention of violence against women } \\
\text { strategies and campaigns. } \\
\text { - The local school integrated the "Tree of } \\
\text { Violence against Women" as a tool to identify } \\
\text { "safe routes" to school. } \\
\text { - Safety maps were distributed among organized } \\
\text { groups in the community (COCODEs, } \\
\text { committees, schools). To date, maps are being } \\
\text { used to promote and discuss girls' safety in } \\
\text { public spaces. } \\
\text { - Signs promoting safescaping plans were } \\
\text { posted on school walls. } \\
\text { - Male community leaders have less decision- } \\
\text { making power over cases of violence reported } \\
\text { in the community. Instead, cases are being } \\
\text { referred to DEMI. According to DEMl's records, } \\
\text { two cases that came from the community (one } \\
\text { of sexual violence and the other of economic } \\
\text { violence) were successfully resolved with } \\
\text { support from the local leaders (COCODE). } \\
\text { - AO groups experienced a considerable } \\
\text { increase in attendance as the process unfolded. } \\
\text { AO groups were recognized as a formal } \\
\text { organization of and for girls in the community. }\end{array}$ \\
\hline
\end{tabular}

\section{BOX 32. IMPACT FINDINGS FROM A CLUSTER RANDOMIZED CONTROLLED TRIAL IN GUATEMALA: HOW COMMUNITY-BASED GROUP MENTORING PROMOTES INDIGENOUS ADOLESCENT GIRLS' WELL-BEING}

Although this chapter details the implementation of Abriendo Oportunidades (AO) at the scale-up phase, the impact of the basic model to deliver $\mathrm{AO}$ was assessed through a cluster randomized controlled trial (RCT) conducted in an indigenous region similar to the context described in this chapter. The details of the RCT's findings can be found on the Population Council website and a few are highlighted here.

- The Council evaluated the impact of the program using a cluster randomized controlled trial with two arms: control and AO. Seven domains were assessed using standardized indices. Primary domains were current school enrollment, ever married, experienced physical violence in past 12 months. Secondary domains were financial literacy, SRH knowledge, social capital, and gender norms. For this evaluation, the AO model did not include a safescaping component, due to funding limitations.

- In the context of the AO impact evaluation, conducted in the region of Solola, among eligible girls, 49 percent participated in the program and 26 percent attended half or more of 31 offered sessions. At 12 months, compared with controls, we found successful but small standardized program effects on delaying marriage $(-0.034 \mathrm{SDs}, \mathrm{p}<0.10)$ and reducing physical violence experienced in past 12 months $(-0.056$ SDs, $p<0.10)$. Standardized effects on school enrollment, financial literacy, SRH knowledge, social capital, and gender norms were small ( $\beta, \leq 0.10$ standard deviations [SDs]) and not statistically significant at the 90 percent confidence level.

- Results from the trial demonstrated the promise of $\mathrm{AO}$, which led to reductions of girls experiencing marriage and physical violence. The impacts were not achieved through increased school enrollment but may have been through developing critical reflection skills honed via discussions of Mayan values and worldviews against those of the dominant culture within each curriculum module. Interventions dealing with identity and emotions have proven effective in reducing interpersonal violence. Most important, the findings confirm the value of the clustered approach detailed in this chapter, considering the value of tapping into community-mobilization efforts to maximize the opportunity for impact. 
FIGURE 23. ARENA OF ABRIENDO OPORTUNIDADES SCALE-UP EXPERIMENTATION, GUATEMALA, 2013-15

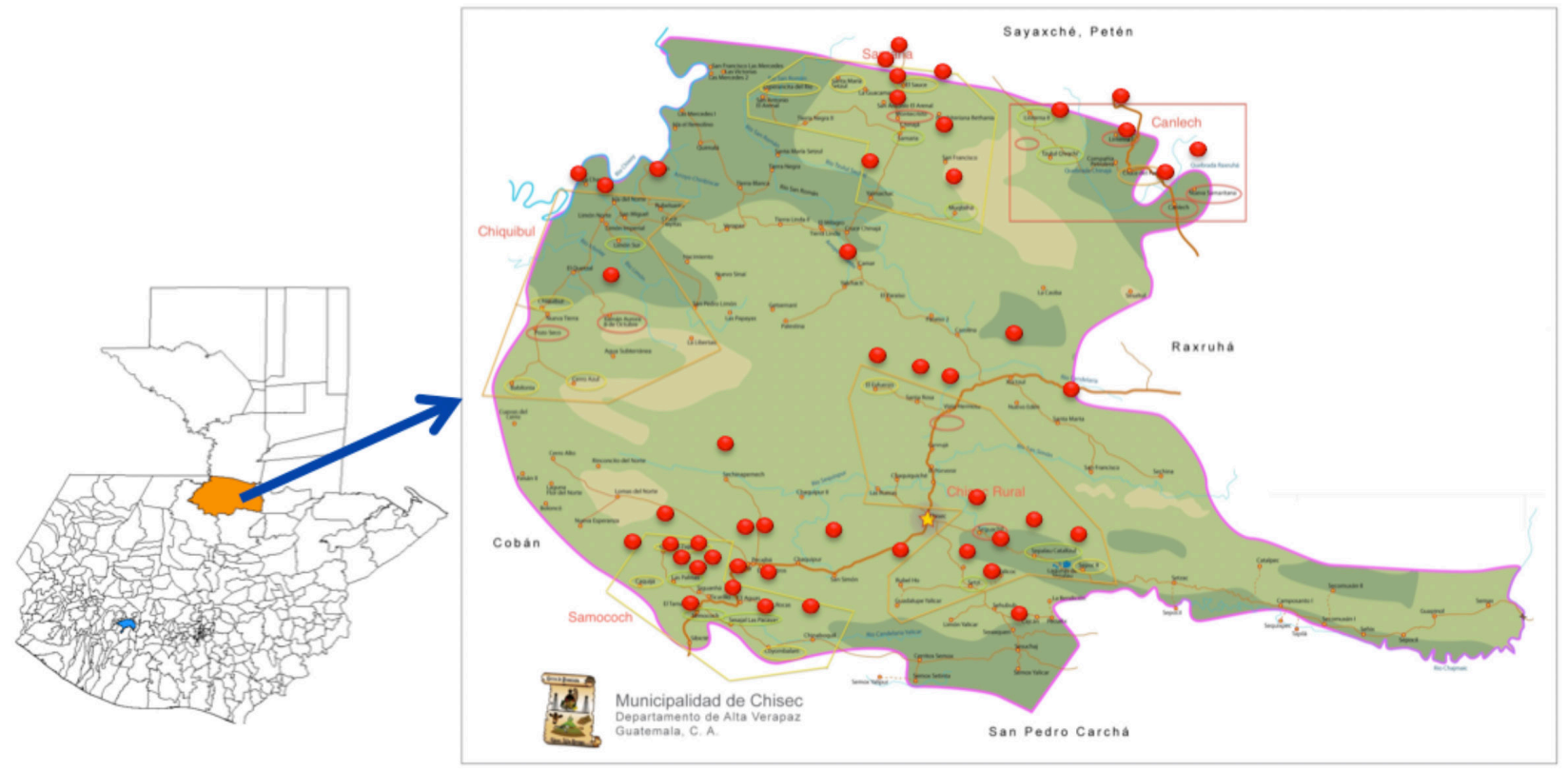

Scale-up experimentation supported by UNFPA and the NoVo Foundation.

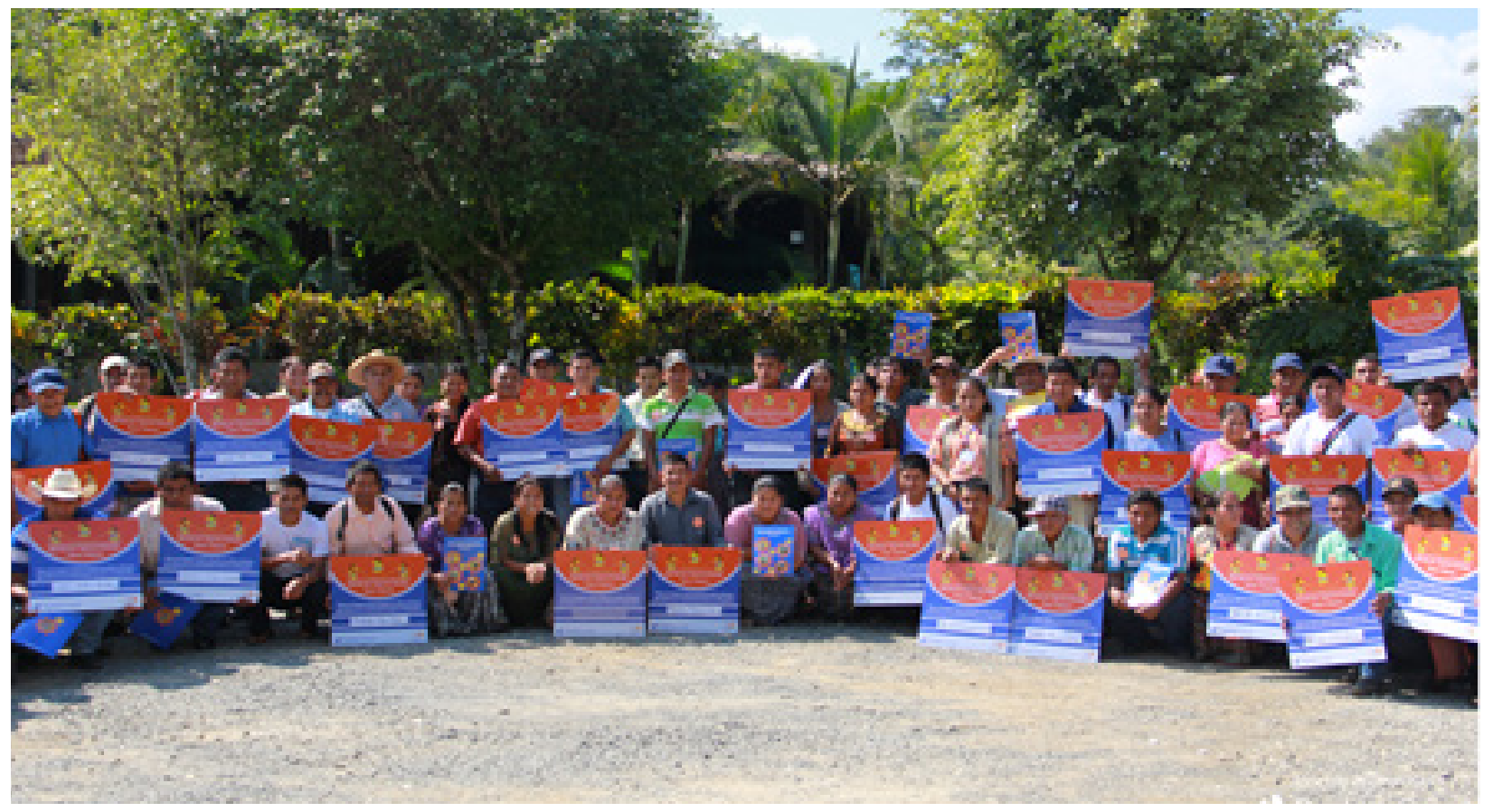

Leaders from 50 communities during the collective signature of the community contract in Chisec, Guatemala. (Photo: Aiken Chew.) 
girls' participation in $\mathrm{AO}$, also trusted the group of mentors because of their knowledge of reproductive health, agriculture, and women's rights.

\section{A Strategy for Community Clusters}

Based on what we learned from the safescaping experience, we moved into a much more intentional program design, where at least 40 percent of the communities in a single district were invited to participate in the AO program. By clustering communities, the $\mathrm{AO}$ team was able reach more girls (2,000 girls aged 8-19 in 50 communities), and made the case for targeted investments from government entities like DEMI, the office of the local mayor, and the Ministry of Education (See Figure 23).

\section{Conclusion}

The systematic approaches that encourage and equip communities to prevent violence against girls and women, implemented through the AO program, have worked because of the involvement of gatekeepers at key stages of program design and implementation. In every AO community, explicit agreements to promote girls' safety are included in a community contract signed by local leaders, mentors, and other relevant stakeholders. Signs announcing days and time for the AO meetings are placed in visible parts of the community, and adults participating in the COCODE commit to ensuring access to safe spaces. Most of the stakeholders are men, often fathers of the girls who participate in $\mathrm{AO}$ meetings. Since few women participate in the COCODE, we have few female "guardians" of the safe spaces. To combat this, women (often girls' mothers), are invited by our mentors to visit $A O$ meetings and participate in activities such as the safescaping meetings.

The programmatic design should contemplate from the beginning how best to use communitybased strategies to mobilize the community and the local resources more effectively in countries where national and municipal budgets allocate little or no resources to eliminating violence against girls and women. The Community Oval, the Girl Roster, safescaping, community contracts, participatory design, and local skillbuilding provide valuable lessons on how to build sustainable programs in low- and middleincome countries. 


\section{The Practitioner Experience: Intentional Design on the Ground}

The Intentional Design approach has been foundational to the Council's work since 2000 when on-the-ground activities greatly expanded. This chapter contains 20 practitioner reports from 2000 to 2020 , reflecting work in all regions of the world. At these $\mathbf{2 0}$ sites the Intentional Design approach was implemented, with nongovernmental and governmental partners, and the Council explored the first prominent " $W$ " question: Why invest in girls? Once that was well understood by partners, the Council offered learning tools to navigate the remaining "Ws," those sequential programmatic and contextspecific questions: Where do we work? With whom do we work? When, chronologically, in the girls' life cycles are the most crucial moments? Which content is meaningful and realistic and builds girls' protective assets? What does success look like for different segments of girls?

In 2013, the Girl Roster was added as a tool when it was clear that many partners lacked the technical and scientific resources to establish the "universe" of girls in the places they had selected to work. The Council has shared and co-created learning strategies with partners in technical workshops. The first large-scale workshop was held in 2000-a weeklong program co-sponsored with UNICEF and UNFPA, in Dakar-and focused on the then-andnow neglected girls of francophone West Africa. Momentum continued to build and in 2007 the Council began more formal capacity-building and training workshops (originally called "boot camps") in East and Southern Africa (Austrian, Bruce, and Maternowska 2017).
The Intentional Design tools-with the Roster being the most known and catalytic learning aid-have been utilized in South and East Asia; the Middle East; Central, East, and West Africa; North America; Latin America; and the Caribbean. (See Table 19 for a complete list of countries.) The Roster has been adapted for use in an array of sociodemographic contexts including dispersed rural villages (e.g., El Salvador, Ethiopia, Guatemala, Indonesia, Nigeria, and Uganda), poor urban neighborhoods (e.g., Egypt and South Africa), conflict zones (e.g., Iraq, Lebanon, and Turkey), refugee camps (e.g., Rwanda and Sudan), densely packed informal/migrant-receiving settlements (e.g., Belize, Indonesia, and the United States), high-risk HIV zones (e.g., Kenya, Mozambique, South Africa, and Tanzania), before and after a ravaging epidemic (Sierra Leone post-Ebola), as a rebuilding tool (in post-Earthquake Haiti), and in Native American reservation communities (as of 2020, Montana, Oklahoma, and South Dakota, in the United States).

These tools have been culturally adapted and translated into many languages-the Roster into 21 languages (see Table 20), the Building Assets Toolkit into 5, and most materials into at least 3, typically English, French, Arabic, and/or Spanish.

In every context, the Roster provided a transformative opportunity to see girls' lives more systematically, drawing both quantitative and qualitative information. The efforts to estimate and segment the universe of girls has challenged initial assumptions about girls, families, safe and unsafe zones in communities, 
TABLE 19. COUNTRIES IN WHICH THE GIRL ROSTER HAS BEEN IMPLEMENTED, AS OF 2020

\begin{tabular}{ll} 
Bangladesh* & Malawi \\
Belize & Mali* \\
Benin & Mexico \\
Botswana & Mozambique \\
Burkina Faso & Namibia \\
Cambodia & Niger \\
Cote d'Ivoire & Nigeria* \\
Egypt* & Philippines* \\
El Salvador & Rwanda \\
Ethiopia & Sierra Leone \\
Ghana & South Africa \\
Guatemala & South Sudan* \\
Haiti & Tajikistan \\
Honduras & Tanzania \\
India & The Gambia \\
Indonesia & Turkey* \\
Iraq* & Uganda \\
Jordan* & United States \\
Kenya & Vietnam \\
Laos & Yemen* \\
Lebanon* & Zambia \\
Liberia & \\
\hline
\end{tabular}

Note: Asterisks indicate countries in which the Roster was implemented by the Women's Refugee Commission, in a humanitarian context, and/or by the Population Council.

and the accessibility and relevance of services, even among those who felt they knew their community, including longstanding program staff. Across the board, practitioners report that on-the-ground application of the learning tools generates surprising and useful qualitative and quantitative knowledge vital to shaping their work, assessing its reach, and articulating plans for expansion.

This chapter is dedicated to and authored by our valued partners who have shared their experiences applying Intentional Design tools and principles. Practitioners range from small tent committees set up after the Haiti earthquake, to established local, nongovernmental organizations working in a handful of communities, to large umbrella
TABLE 20. LANGUAGES IN WHICH THE GIRL ROSTER IS AVAILABLE, AS OF 2020

$\begin{array}{ll}\text { Amharic } & \text { Hindi } \\ \text { Arabic (various } & \text { Kinyarwanda } \\ \text { dialects) } & \text { Kurdish } \\ \text { Bahasa (Indonesian) } & \text { Lao } \\ \text { Bangla } & \text { Luganda } \\ \text { Chewa } & \text { Portuguese } \\ \text { Dagbani } & \text { Rohingya } \\ \text { Dinka } & \text { Spanish } \\ \text { English } & \text { Swahili } \\ \text { French } & \text { Tajik } \\ \text { Haitian Creole } & \text { Turkish }\end{array}$

INGOs implementing service delivery across large subnational districts with millions in population. Though each practitioner report is unique, they commonly highlight how the tools allowed them to:

- Confront false assumptions about the age at which girls began to go off-track;

- $\quad$ See the community through girls' eyes;

- Estimate how many girls by age and social category live in their program communities;

- $\quad$ Divide the girls into meaningful programmable segments to achieve greater fairness, inclusion, and, over the longerterm, impact;

- Contrast the experience of girls and boys of the same age in the same place;

- $\quad$ Project per-segment coverage of generic youth programming (e.g., the proportion of girls 10-14 years old who are participating relative to in-school 15-19-year-old males);

- Identify excluded subpopulations of girls, even within programs nominally devoted to reaching vulnerable girls in disadvantaged communities;

- Gauge access of conventionally configured health, poverty alleviation, livelihoods, creative, and recreational programming to 
important community resources, services, and entitlements;

- Discover previously unseen local-including human-resources (e.g., girls 18-24 years old who could serve as potential mentors);

- Make adjustments in recruitment, staffing, program venues, program content (e.g., adapting financial literacy curricula, introducing new technologies) and mentor selection, among other program elements;

- Reveal often substantial heterogeneity among communities within the same district;

- Develop alliances with parents and sympathetic, but often underinformed, community members, religious leaders, and development colleagues.

\section{Rethinking Basic "Cultural" Assumptions about Girls}

Practitioners may enter communities with preconceived assumptions about girls' lives which, without on-the-ground inquiry, may be reinforced by the ill-founded opinions of community elders or elites, for whom the girls are invisible.

The process of adapting even the brief nonsensitive questions that make up the Girl Roster's questionnaire can elucidate a community's cultural assumptions about girls (such as the stages of marriage and the local understanding of sufficient education for girls) while also reinforcing local ownership. For example, in Nigeria (Practitioner Report 6), during piloting of the Roster, the questionnaire was adapted to distinguish between girls schooled in academic subjects and those with religious schooling; both are common and accepted forms of schooling but are quite different. The organization decided to group girls having had only religious schooling-which usually featured little academic content-with girls who had little or no schooling.
Marital customs are culturally specific, as was the case in one urban community in Egypt (Practitioner Report 16). Girls in urban settings are often engaged a very long time until the couple can afford a separate home. "Engaged" is a different status than "single" in terms of mobility and the nature of family oversight. The Roster questionnaire was amended to include "engaged" as a category under "marital status." After more qualitative interviewing, girls who reported they were "engaged" were found to be living under conditions and cultural prescriptions more similar to married girls than to single girls, thus the married and engaged girls were programmatically grouped together.

The Roster findings can reveal the surprisingly early age at which a significant proportion of girls go off-track-the number of girls out of school, living apart from both parents, or bearing children as adolescents. The findings create a space for dialogue to confront cultural taboos such as denial that premarital sex is widespread. Such was the case in Sierra Leone (Practitioner Report 7), as Roster findings in even small villages revealed an unexpectedly high number of unmarried girls and young women with children.

In Nigeria (Practitioner Report 6), the results helped shift the focus to early childbearing, as before the focus of maternal child health had been on very early childhood health. The partner found that many young and firsttime mothers received little attention beyond maternity care. In both of these examples, from Sierra Leone and Nigeria, segment-specific groups were created. In Sierra Leone, a group was formed for single mothers, with femalecentered rather than only child-focused content. In Nigeria, two segments were added, one for married young mothers (eager for education alongside health support), and a preschool program so that girls 4-7 years old-sometimes the oldest child of young mothers-were prepared both cognitively and socially for schooling. 
Moving Beyond Standard

"Vulnerability" Labels to more Evidence-based and Responsive Programming

Vulnerability-focused programs may employ fairly elaborate criteria (such as distinguishing HIV-affected children from other excluded children) but narrow definitions of disadvantage may overlook other populations that, though not currently affected, are also at high risk. Recruitment techniques suitable for better-off groups may miss some of the target groups because those same programs may have relied on passive forms of promotion, peer communication, and proximity to services to find their clientele. Furthermore, a limited focus on the worst-off (such as HIV-affected children) may result in overlooking relatively high achievers and survivors living among the "vulnerable population." The Roster helped adjust the lens so the mentoring potential of those young women already in the community could be observed, and provided an alternative to the conventional impulse to recruit mentors from outside the community. Using Intentional Design tools, COVida in Mozambique (Practitioner Report 10) identified over 40 better-educated girls 18-24 years old, some of whom had graduated from secondary school, providing a solid starting point for communitybased mentor selection.

In Tanzania (Practitioner Report 13), a girls' school seeking to recruit a few of "the most vulnerable" girls from marginal villages noted a surprisingly high number of school-aged and sometimes school-going girls (28 percent) were not living with parents; this lack of visibility or adult sponsorship affected their chances of selection for the school. They decided rather than recruit a few girls from many places, they would concentrate recruitment in fewer places each year (ten girls per community in each of three communities) and later craft a returning graduate program (what became their Modern Girls Program) to create girl groups with a special mission to incorporate these parentless girls.

\section{Assessments of Existing Program}

Partner organizations are overstretched; in such circumstances it is easy to default to conventional operating procedures. It is notable that partners were willing to step away from their exhaustion to find out who they were reaching, even without a ready way to fund additional activity.

In the context of a persistent HIV epidemic, a HAGN partner operating in an HIV-and cholera-affected neighborhood found that the nearly 200 girls they were serving were disproportionately in school and living with both parents (Practitioner Report 4). Strikingly, no girls with children were reached by the HIV/ reproductive health program. Given the strength of the program and the short distances in the neighborhood, program managers considered the possibility of multiplying by several-fold the number of girls they reach (including those at arguably much higher risk than current participants at the time), using intentional recruitment strategies. It was posited that the same program efforts would therefore yield a higher value for money.

Roster results from South Sudan triggered a fundamental change in the program's primary venue (Practitioner Report 12). Prior to adopting the Women's Refugee Commission's I'm Here approach, which was created collaboratively with the Council's Intentional Design team, a refugee camp committee used schools as recruitment and entitlement distribution venues on the assumption that a very high proportion of girls were in school; with parallel logic, they had identified schoolteachers as program managers. Program staff had assumed that at most 10 percent of the girls in their program community would be excluded by this strategy and found it convenient to deliver resources through the school platform. Roster results revealed that not 10 percent but rather 45 percent of the community's girls were out of school. Exclusion of out-of-school children translated into the exclusion of their families from health and food security initiatives causing program staff to reconsider the school-delivery venue. 
The I'm Here approach, like the Intentional Design approach, fostered new conversations among the program staff: Why are almost half of the girls in this community out of school? How can we recruit them and tailor program content to meet their specific needs? What activities or livelihoods are these girls engaged in? What threats to safety do girls encounter while seeking decent livelihoods in beleaguered circumstances? What social skills and facilities do girls need for self-protection while they gather resources for themselves and their families? Are the out-of-school girls living with parents, partners, or unmarried?

Mindful that in many humanitarian crises what is temporary becomes permanent, Mercy Corps in Gaziantep, Turkey, deployed a range of Intentional Design tools to discern the reach of a community center established expressly to serve Syrian refugees (Practitioner Report 18). Mercy Corps defined its own clientele as both the longer-term resident Turkish adolescents and the newer, very recently arrived Syrian adolescents, especially girls. They located concentrations of at-risk adolescents and broke the information down by neighborhood, age, gender, and ethnicity. These findings assisted them in maximizing access for both poor Turkish and Syrian adolescents and determining whether there needed to be satellite and more intensive outreach activities for some.

Further, they explored the content and program timing desired by different youth clientele. Guided by focus groups and the Asset Exercise, Mercy Corps found a contrast between the ways in which boys and girls expressed their needs for psychosocial support. The boys prioritize sports activities while the girls were looking for safe and supportive spaces and an end to their sense of isolation. Mothers and girls were asked expressly when in the week girls would be most available to participate. This story exemplifies how Intentional Design promotes sequential learning and program revision.

\section{Generating Engagement and Immediate "Service" While Learning}

The application of Intentional Design tools can itself result in the provision of tangible services and the improvement of community cohesion.

Just Like My Child's (JLMC's) field team, using the Girl Roster (Practitioner Report 15), identified a number of girls in extremity whose needs required immediate attention, and very creatively shortly after the exercise generated resource maps in the form of a handy flier that noted underutilized and perhaps lesser known resources, such as where there are livestock services, pro-poor banking outlets, and health insurance facilities, as well as hazards, such as unrepaired bridges and water that was apparently contaminated. As the Intentional Design tools are meant for programmatic engagement, not research, this responsiveness consolidated the partnership between JLMC and the local community, reinforcing their shared desire to make visible the condition of the girls and their families, generating goodwill, and creating a mutual pride of place.

\section{Intentional Design Assisting Scale Planning and Negotiating Realistic Goals}

Whether beginning small or revising large projects, partners provide commentary on the utility of the learning tools as a "can opener." At the cusp of the Ebola epidemic the, at the time, nascent Sierra Leone Adolescent Girls Network, with nine original members, conducted an initial collaborative Roster visit to a small village (Practitioner Report 7). That visit has influenced the shape of the now formally established Network of 150-plus members. The Network promotes Intentional Design principles throughout; as of 2020 , there is current engagement in three multidistrictlevel interventions, covering differing scenarios of exclusion (from remote small islands to neglected urban neighborhoods). 
In the application of the Roster, partners must implicitly address scaling strategy in defining practical/program areas. This sometimes requires aggregating a number of small geographic areas into one program unit. In other cases, it means carving out catchment areas in larger population concentrations. Presentation of the Roster and Asset Exercise results shared in collaborative learning activities builds local NGO capacity to approach scaled programming with both confidence and from a girl-centered perspective as we have seen in the Sierra Leone (Practitioner Report 7), Haiti (Practitioner Report 4), and Tanzania (Practitioner Report 13) reports.

Medium-sized NGOs with ambition to expand, such as JLMC (Practitioner Report 15), the Batonga Foundation in Benin (Practitioner Report 5), Toledo Maya Women's Council in Belize (Practitioner Report 2), and the Centre for Girls' Education (CGE) (Practitioner Report 6) used the Intentional Design tools to assess current performance and plan their growth. These organizations are local, well regarded, and, at the time, wanted to move beyond their foundational assumptions and operating modes.

Notable in this category is the experience of CGE operating in Northern Nigeria (Practitioner Report 6). CGE centered its initial attention on supporting school-going girls in making a transition from primary to secondary school. About five years into the program, a closer assessment of the full universe of girls led them to expand their focus from the 10-14-year-old in-school girls to other vital segments-those girls 4-7 years old in preschool (as support to them and their young mothers), and girls 10-14 years old who are out of school in very high proportion in the most rural communities. Program staff retained their in-school focus but shifted the program's intention to girls 15-18 years old, both helping them consolidate their learning and also preparing a subset of them to work as mentors in their expanding program. The program over the last four years has scaled dramatically, serving 50,000 girls who each receive two years of programming.
Intentional Design was the core of the DREAMS Capacity Strengthening project, a Council-sponsored and Girl Effect-funded technical assistance effort in support of PEPFAR's ambitious DREAMS Partnership (operating first in ten heavily HIV-affected sub-Saharan countries and later in another six DREAMS-like countries). A \$1 million initial investment leveraged a long list of DREAMS activities, including building the capacity of its implementing partners (IPS) to use an assetbuilding approach in their programs (a task the Council was asked to support). Global Communities of Kenya (Practitioner Report 9), and the COVida Project of Mozambique (Practitioner Report 10) document how Intentional Design was deployed to revise recruitment, mentoring, and content to reach the girls left behind by conventional HIV-prevention, mitigation, and treatment approaches. In the context of a multinational scaled program, Intentional Design catalyzed enthusiasm to "see" girls and improved practitioners' ability to target effectively, which meant sometimes revising targets up, sometimes down.

In Kenya (Practitioner Report 9) and Mozambique (Practitioner Report 10), for example, the Roster information enabled a large implementing organization working with numerous community-based groups to reset given targets. In Homa Bay, Kenya (Practitioner Report 8), the organization was given an initial target of 25,000 high-risk girls aged 10-24. This figure had been set using standard census information, which does not consider the mobility of adolescent girls, especially the least advantaged. The Girl Roster results (rapidly obtained in a few weeks) revealed that the district contained only about 23,000 girls in total in that age cohort. The Roster identified that about half of these, or 11,500, would be priority for DREAMS interventions. The reasonable target was, logically, substantially below the one given (12,000-13,000 versus 25,000). This information propelled conversation with partners and donors about resetting goals and led to redirecting what 
would have been excess investments to underserved communities.

Intentional Design further refined the DREAMS hotpot approach by providing guidance and tools on where, within hotspots, to concentrate resources. In Kenya, the same DREAMS IP rostered thousands of households (Practitioner Report 8) aggregated across several wards, but when the information was broken down among adjacent program communities, significant variations in girls' education level emerged. In a comparison of two communities of similar size, Community A gave no reports of girls not attending school and estimated only 10 percent of the 15-17-year-olds were out of school. In nearby Community B, 18 percent of 20-24-year-olds had never been to school and 25 percent of 15-17-year-old girls were currently out of school-two and half times higher than Community $A$ at a key age for HIV risk; the ward-level "average" masked the internal variation, the very finding required to successfully prioritize program location and segments.

The following stories are just a few from the ground, but most of our partners report that the Intentional Design approach has taken root. We honor our partners for their honesty and dedication. They inspire us.

1. IMAGEN: Shifting Native American Youth Programming to a Gender Focus through Intentional Design Methods

2. Intentional Design as a Catalyst for Change in Belize Migration Zones and Later Yucatán, Mexico

3. An Assessment of Plan International El Salvador's GAD (Gender and Development) Programming-Using Evidence for Redirection after the Initial Implementation

4. A Network of Intentional Design Adopters Working for Adolescent Girls' Futures in Post-Earthquake Haiti and Beyond

5. Fine-Tuning the Batonga Foundation's Approach to Reaching Girls: Mapping,
Targeting, and Training Benin's Future Leaders

6. Implementing Intentional Design Tools in CSAGE (Community Spaces for Adolescent Girls Empowerment), Northern Nigeria, to Build a New Program and Assess Coverage of an Ongoing Program

7. Implementing the Girl Roster and Community Resource Scan in Sierra Leone: The Foundation of the Sierra Leone Adolescent Girls Network

8. Intentional Design in Homa Bay, Kenya, in the Context of the DREAMS Partnership

9. Global Communities' Use of Intentional Design to Implement the DREAMS Program: Getting the Correct Value for Money in Highly HIV-Affected Settings in Kenya

10. Lessons from DREAMS Interventions in Matutuíne and Namaacha, Mozambique

11. Investing in Girls' in Northern Mozambique

12. Implementing the Girl Roster in South Sudan

13. Turning a School into the Center of a Movement Using Intentional Design Tools: The SEGA Girls School, Tanzania

14. Intentional Design Builds Up and Coordinates an Existing Community of Practice in Mwanza, Tanzania

15. The Girl Power Project (Just Like My Child Foundation) Moves Forward with Intentional Design to Intensify Regional Impact, Central Uganda

16. Implementation of the Girl Roster in Ezbet Khairallah, Egypt

17. Beginning with the Girl Roster Results from West Bekaa, Lebanon, to Reach the Unreached Girls

18. Proactive Engagement with the Intentional Design and I'm Here Approaches to Ensure Programming Responds to the Needs of the 
Most Vulnerable Adolescents in Gaziantep,

Turkey

19. Implementation of the Girl Roster in Dompu

and Sikka, Indonesia

20. The Influence of an Intentional Design

Approach on WomenStrong International's

Work with Women and Girls in Haiti and

Washington, DC

You may also visit the Population

Council Girl Roster webpage (https://

buildcommunity4girls.org/the-girl-

roster/) where we will continue to post

new Girl Roster practitioner reports from

partner organizations for our learning

community.

Note: The following practitioner reports flow in a geographical pattern, moving from North America, to Central and South America, further east through West, Central, and East Africa, all the way to South East Asia. Each report opens with a summary that presents key findings and observations. "Findings and Decisions" summarizes the major results of using the Girl Roster and other Intentional Design tools during the program design and information-collection process, and the resulting decisions. "Implementation Observations and Adaptations" speaks to unique experiences of the organization in using an Intentional Design approach and tools in its specific context and any adaptations required. Both columns are intended to support practitioners in anticipating what their own experience using an Intentional Design approach and its respective tools might be when working in similar situations. Each report also contains a list of resources. 


\title{
Practitioner Report 1
}

\section{IMAGEN: Shifting Native American Youth Programming to a Gender Focus through Intentional Design Methods}

\author{
By Kelly Hallman, Stephanie Martinez, Janet Routzen, LeToy Lunderman, and Lisa Polen
}

Contributions from Angel del Valle, Eva Roca, Victoria Star Boy, Cheryl Whirlwind Soldier, Sunrise Black Bull, Malorie Arrow, Tasheanna Running, Tristan Two Eagle, Jenny Greaves, Norman Running, Amanda

Roblez, Mariah LaPointe, Ashley Sarracino, Shayla Yellowhair, and Kassel Franco-Garibay

\section{Findings and Decisions \\ - $\quad$ A high proportion of 10-14-year-olds (males and females) live apart from parents and grandparents. \\ - $\quad$ Gender-pooled mentoring structures exist in some larger communities to support positive cultural continuity; nothing exists in smaller communities. People still believe a dedicated physical building is needed to conduct any program. \\ - To increase access to a place for girls to de-stress and discuss sensitive topics, mentorship platforms must be: 1) denser geographically and repurpose existing physical structures, 2) gender-specific (now programs are for "Native Youth," not Native Girls or Boys), and 3) co-led by younger and elder women to strengthen social access and encourage transfer of cultural knowledge between generations.}

- Economic literacy is vital given the extraordinarily high economic burden carried by females-women heading $40 \%$ of Native households in Great Plains communities, often large and multigenerational; great need for gender- and age-specific financialliteracy materials.

- Tools developed in other settings need careful review to be adapted, keeping in mind local risk factors while honoring equally vital loca possibilities and assets, which increase local valuation of maintaining cultural identity and practices.
Implementation Observations and Adaptations

- In light of over-regulation, often to a punitive degree, of American Indian families residing in tribal housing, questions in the Girl Roster asking number of people living in the household were removed.

- The Girl Roster was renamed the Youth Roster; while asking questions about male or female adolescents, it expresses the high value placed on community cohesion even as it reveals important distinctions by gender and age.

- It is vital to alert communities about Roster activity beforehand because they are so often invaded by punitive government activity (forced removal of children during boarding-school era; current Child Protective Services removal of children at disproportionately high rates; law enforcement sweeps of tribal neighborhoods for suspected drug activity).

- Each team collaboratively scripted an introduction on how to clarify the Roster's intent at the beginning of each interview.

- Better to contact household members in the afternoon than in the morning, as unemployment is high and daily schedules are shifted later.

- $\quad$ Safety needs were addressed by creating triples of Roster teams, rather than pairs, comprising two females and one male; being mindful of complex kinship structures within communities (not being assigned a house where a strained family relationship may exist), and using vehicle transportation between houses (because of distance and danger in some places of roaming feral dogs).

- Most of those involved in rostering were already trained mandated reporters, meaning that when faced with issues such as domestic violence, they were equipped and readied to report to the proper authorities, as well as provide resources for services.

In the communities in the Council's Guatemala work it was not mandated to report cases of abuse, but the team came across situations that required immediate case management and reported them to authorities. 


\section{Introduction}

\section{The Issue}

Adolescent Native American girls are distinct from every other segment of young people in the United States, from the assets their ancestors have passed down to them, to the unique challenges they currently face. Native women and girls carry immense responsibilities within the family, and school alone cannot prepare them for the challenges many will face as they transition to womanhood. IMAGEN provides Intentional Design, strategic planning tools, and training to Native families, communities, and schools to create, operate, and maintain a geographically dense network of social platforms where collectives of girls ("Girl Societies") can gather every week.

Native young people in the United States are at high risk for school dropout (Musu-Gillette et al. 2016). Nearly one in five Native high school students were threatened by a weapon at school in the past year (versus $7 \%$ nationally) (Musu-Gillette et al. 2016); 28\% of American Indian/Alaska Native women report being raped and 55\% have experienced sexual violence other than rape in their lifetime (Breiding et al. 2014). Although lifetime fertility rates are no higher for Native females than the national average, and are declining like all other race groups, Native girls still have the highest rate of teen births in the US (Martin et al. 2018). Suicide rates among girls in the US are highest among those in the American Indian/Alaska Native race group (CDC WISQARS 2018). There is also growing evidence that suggests that Native girls face high risks of trafficking (NCAI 2016).

Many current programmatic initiatives and donors serving Native young people often regard Native youths as a monolithic, homogeneous group and do not account in their program designs for the many life transitions that take place between the ages of 10 and 24 years. They also rarely distinguish the needs of girls versus boys. A gap remains in understanding and addressing the gender and age-segment-specific needs and experiences of adolescent Native American girls.
Identifying and working with segments of adolescent girls is a touchstone of the Intentional Design approach, making it a fitting approach for examining the lives of Native adolescent girls and designing programs to better serve their needs.

\section{The Indigenous Adolescent Girls' Empowerment Network (IMAGEN)}

IMAGEN-with its initial brainstorming meeting in March 2017-was conceived as a means of bringing together Native American serving organizations that have the willingness and ability to design, document, and share evidence from programs that build on Native girls' innate talents, while addressing the factors that put them at risk. The Network provides strategic planning tools and training, based on Intentional Design principles, that enable Native families, communities, and schools to create, control, and maintain a geographically dense set of social platforms where collectives of girls ("Girl Societies") can gather every week.

The Network's inaugural workshop was attended by six participating organizations, covering a cross-section of Indian Country's challenges and geographies, including:

- White Buffalo Calf Women's Society (WBCWS)

- Union Pacific Railroad's Council of Native American Heritage (CONAH)

- Anpo Wicahpi/Pine Ridge Girls' School

- Indigenous Peoples Task Force

- National Indigenous Women's Resource Center (NIWRC)

- American Indian Science and Engineering Society (AISES)

Since then, IMAGEN-in addition to its affiliation with the Population Council's Community of Practice-has been designated as a key innovation experiment within the Council's Girl Innovation, Research, and Learning (GIRL) Center where it seeks to provide Native families, 
FIGURE 1. ADAPTING THE GIRL ROSTER

TO WORK LOCALLY

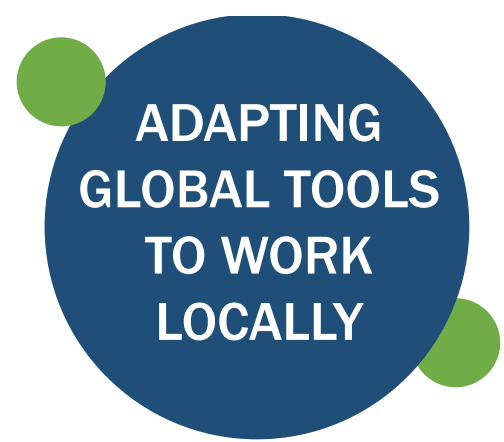

Prior to and during the field exercise, modifications were made to build a Girl Roster that would be responsive to the context of the Rosebud community and WBCWS' work. These changes included:

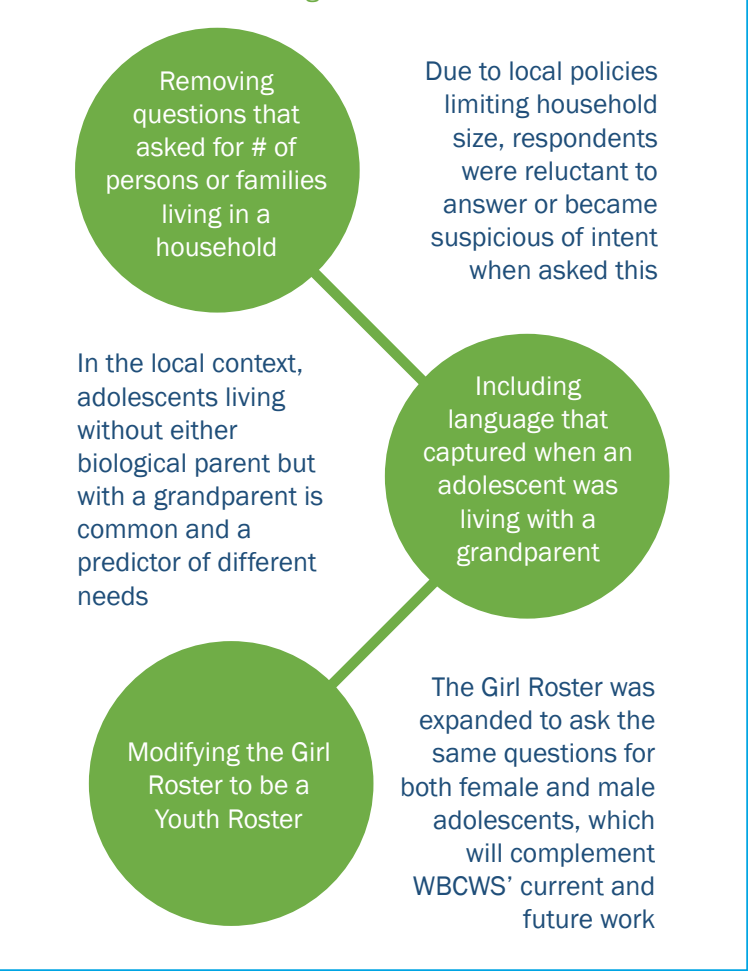

communities, and schools with tools to establish social platforms that increase the protection, safety, and resilience of girls. It does so by using Intentional Design's evidence-based tools to reclaim/repurpose neighborhood spaces where Native matrilineal traditions can be preserved and rekindled by Native girls with mentorship from Native adult women and elders. As of 2020, the Network and its member organizations are active in Minnesota, Montana,
Oklahoma, and South Dakota. IMAGEN's efforts have resulted in girl-centered programming being piloted in eight distinct geographic areas, serving both rural tribal communities and urban Indian neighborhoods.

1. Thunder Valley Community Development Corporation (TVCDC) serves the Oglala Sioux Tribe (OST) on the Pine Ridge Reservation in southwest South Dakota. TVCDC, which has a wide and influential reach within and beyond its communities, is starting Girl Society groups in each of OST's nine administrative districts.

2. 100 Horses Society is based in Eagle Butte, South Dakota, on the Cheyenne River Reservation. It has been a leader in preserving one of the seven rites of womanhood within Lakota culture, the coming of age ceremony for girls. With IMAGEN they are planning more consistent and frequent outreach to local girls instead of just the yearly ceremonial four-day camp held each June in the Black Hills.

3. WBCWS serves Rosebud Sioux Tribal communities in south central South Dakota and hosts weekly community-based girl groups-known as Girl Societies-in three of their most underserved communities, as well as two innovative adaptations to the juvenile justice center and to schoolgirls serving school suspensions.

4. The Mille Lacs Band of Ojibwe in Minnesota are working with local schools in their communities to enable Girl Society mentors to earn high school credit for their leadership activities. High school mentors are being paired with local elder mentors to begin Girl Society groups in three communities.

5. The American Indian Family Center (AIFC), serving the St. Paul, Minnesota, metro area, is establishing a Girls' Talking Circle as part of the outreach efforts to the urban Indian population there.

6. Oklahoma City Indian Clinic serves a large Native metro population and is now 
implementing a weekly program for girls aged 10-16 years; participants hail from eight distinct tribal nations.

7. The Fort Belknap Indian Community's Commercial Tobacco Prevention Initiative has organized a weekly girl group on Sunday afternoons at their local community center in northern Montana.

8. The Little Shell Chippewa Tribe's Commercial Tobacco Prevention Initiative is launching a monthly girl group meeting at their tribal culture building in Great Falls, Montana.

\section{The Adaptation and Application of the Girl Roster}

\section{The Use of the Roster}

An early step in the process was to examine whether the Girl Roster, a benchmarking tool created by the Population Council's Community of Practice, would be useful to support programs that aim to engage girls in their programming but may have reached fewer than they could. The following report details the application of the Roster with the White Buffalo Calf Women's Society (WBCWS) in the northern plains. See Figure 1 for the process of adaptations made to the Roster to contextualize it to a rural tribal setting.

\section{Community Challenges and Adaptations for Roster Application}

Challenge: Immediately after the pilot rostering took place in summer 2017, WBCWS shared negative reactions they received both during and after the exercise. Despite the community knowing WBCWS's 40 years of service locally, WBCWS had never before gone house-tohouse in the community, so people did not know what was happening. Staff implementing the tool expressed that they were met at times with suspicion or rejection from potential respondents. The reasons varied from general suspicion to a belief that the survey was tied to federal government activity.
Adaptation: To resolve this moving forward, WBCWS informed the tribal police, who accompanied them during subsequent Roster activities. WBCWS also created a series of public service announcements (PSAs) that were read over the widely accessed tribal radio stations. These PSAs clarified the purpose of the rostering as a step toward creating programs for young people in the community, and explicitly stated the dates on which the team would be in certain communities. Additionally, the team collaboratively created a script to be read at the beginning of each survey that clarified the intent of the rostering and explained how the information would or would not be used.

Challenge: Another initial challenge faced during the field exercise was the time at which the rostering took place. The WBCWS team went out to roster at approximately 10:45 a.m. in one of the communities hardest hit by unemployment. Many households did not answer their door. Additionally, the staff expressed concern in approaching some residences that were likely to have household members who use alcohol or drugs.

Adaptation: To resolve this moving forward, the team planned to carry out roster activities later in the day and to have the tribal police informed of their location and ready to respond if necessary.

Challenge: The rostering team from WBCWS was comprised of the organization's fulltime staff who had varying experiences with out-of-office outreach and training. As a result, there were some members who felt less prepared to go door-to-door. Some staff members had previous encounters through their work on violence mitigation at WBCWS that necessitated avoiding contact with specific members of the community. Additionally, there was significant concern about the dangers presented by feral dogs known to roam around the area.

Adaptation: To mitigate these concerns, the pairs were reconfigured to match newer employees with those who had more experience dealing with potentially inflammatory situations. 
BOX 1. WHO GIRLS LIVE WITH, BY AGE GROUP, IN RESULTS OF ROSTERING EXERCISE WITH WBCWS

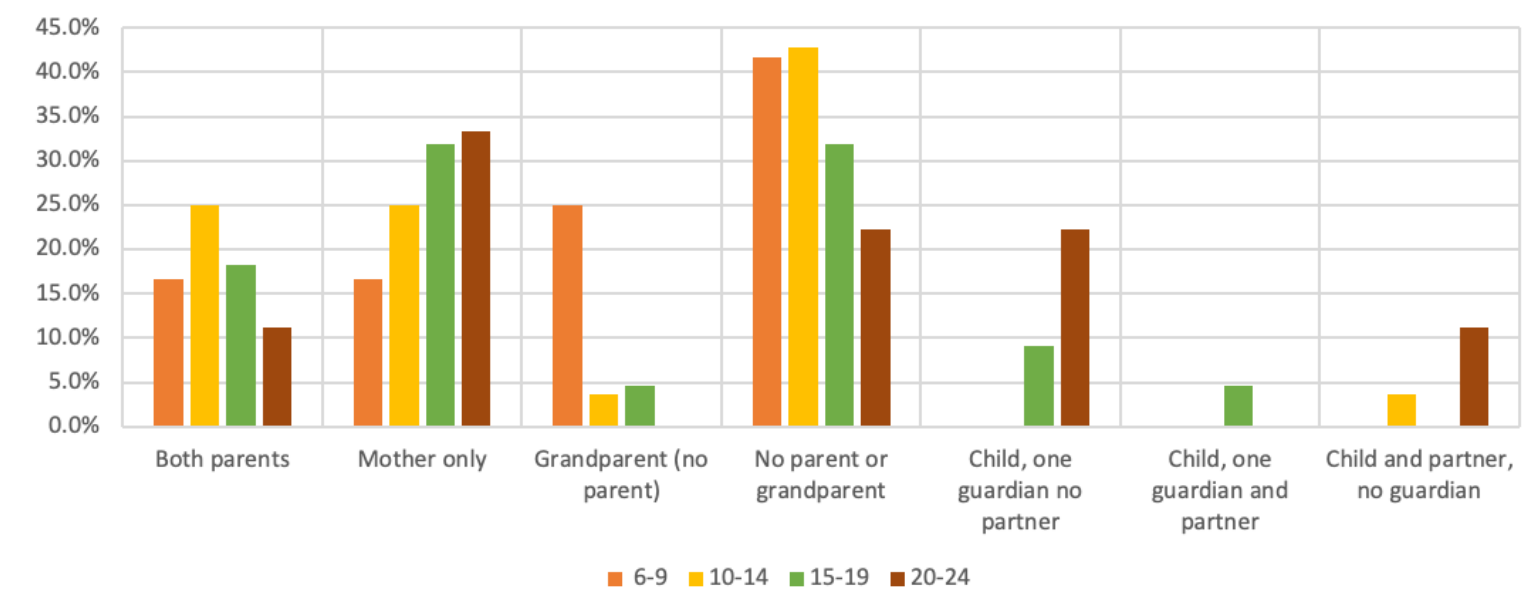

Additionally, WBCWS opted to adopt trios, consisting of two females and one male, rather than pairs of females for extra protection. Prior to rostering, the team also confirmed the assigned houses to ensure that certain households would not be assigned to certain staff members. The concern about the dogs was addressed by using vehicles for transport between households (vehicular support is necessary anyway in this context as homes can be quite remote, and communities often cover large, isolated areas.)

Challenge: A later development for rostering in a tribal community, which has not been faced as often in the tool's previous global applications, is the understanding that the door-to-door process may reveal scenarios in which rosterers might have to fulfill their duties as mandated reporters. That is, WBCWS is, at its core, a provider to victims of domestic and sexual violence, so all staff serve this role and might be confronted by these scenarios when rostering.

Resolution: Leadership in WBCWS, during the briefing after the initial field exercise, reiterated the team's responsibility to serve dual roles-not only as rosterers but as mandated reportersand to alert authorities to problematic situations they witness. They were also reminded to bring violence services support materials from WBCWS to distribute as needed.

\section{Illustrative Findings and Their Unique Revelations about Indigenous Girls' Experience}

Results from the rostering exercise reveal a wide variety of household demographic situations for girls.

- A large percentage of girls did not reside with either a parent or grandparent: $40 \%$ among girls aged 6-9 and 10-14 years old; $30 \%$ among girls aged 15-19 (see Box 1).

- Girls experienced early childbearing: 3\% of 10-14-year-olds and $12 \%$ of $15-19$-year-olds had a child.

- While Native American communities embrace a broader definition of "relatives" than do Western ones, the absence of key guardians in households of young adolescent girls raises questions about their safety and whether they are residing with protective relatives or in potentially exploitative situations, in jeopardy, and out of reach of resources like social-emotional and educational support. 
BOX 2. LOCAL VULNERABILITIES

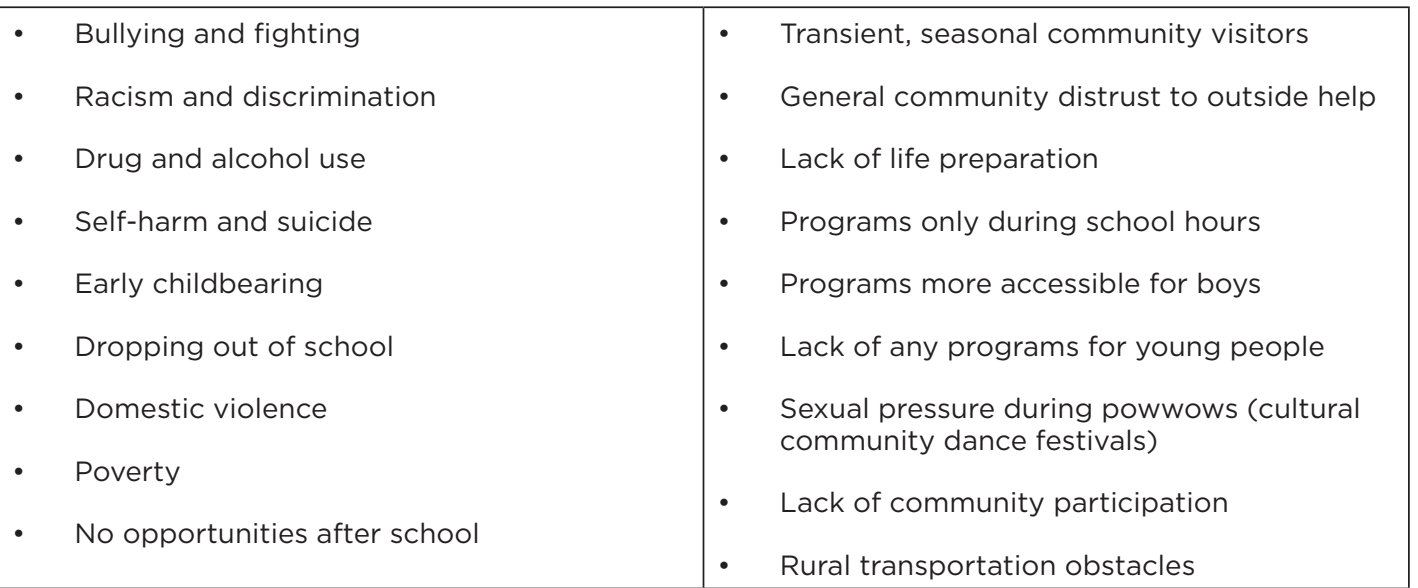

BOX 3. LOCAL POSSIBILITIES AND ASSETS

- Local valuation in maintaining cultural identity

- Existing enthusiasm among young people to participate in cultural activities

- Social media to better understand local "universe" of girls
- Traditional games as a vehicle for culturally relevant programming in partnership with asset-focused curricula

- Powwows

- Mentorship from Native women at local universities

\section{Shaping Program Premises, Learning Methods, and Content to Excluded Native Girls and Communities}

\section{Finding Protective Assets Responsive to Local Vulnerabilities}

In another setting for this work-MontanaIMAGEN staff facilitated a two-day discussion on the girl-centered, Intentional Design approach to program design, which covered, among other subjects, initial reactions to Girl Roster results. We explored, as a group, what a culturally appropriate local rollout could look like. Through activities centered around topics such as asset building, programmatic segmentation, and community mapping, participants identified several regionally specific vulnerabilities (see Box 2) and opportunities (see Box 3) that existed for adolescent girls throughout tribal areas in the state.

\section{Highlights from Adapting Intentional Design in} Native American Contexts

- Because many people in small tribal communities are distantly related, we do not speak of participants, subjects, or clients, but instead as serving "relatives."

- Local girl groups are referred to as "girl societies" (referencing long-established cultural traditions of women's societies and warrior societies) and weekly meetings as "talking circles." Use of these labels reflects the consistency of IMAGEN's approach with those of historical tribal cultures and lifeways.

- The process of recruiting mentors from among females aged 18-29 is common in many parts of the world; IMAGEN has found, however, that this is not fully appropriate for the Native context, because of the strong tie between the generations 


\section{FIGURE 2. EXAMPLES OF NATIVE AND GIRL-FOCUSED RESILIENCE SKILLS CARDS BASED ON THE COMMUNITY OF PRACTICE'S ASSET EXERCISE}

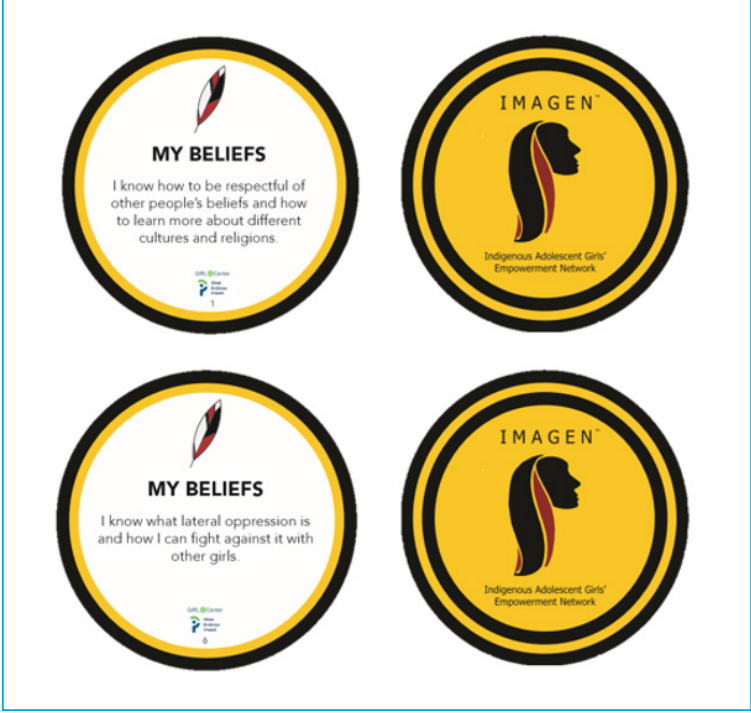

and the need to involve tribal elders in order to preserve tribal knowledge and lifeways before they are forever lost. Research with Native teens in the US consistently shows that due to lack of resources, services, and opportunities, young people are eager to gain knowledge of their cultural traditions as a source of healing and wellness. Some struggle, however, to gain access to elders who can impart such information. Community-based mentored girl societies that utilize a combination of young women and elder women as mentors can begin to strengthen social ties and encourage transfer of knowledge between generations.

- The tremendous pressures and burdens of historical and contemporary trauma and grief in tribal communities, daily occurrences of illness, death, and violence, combined with a lack of even basic services and the immense caregiving responsibilities of Native females all result in regular absences of meeting participants and project team members. This must be planned and budgeted for and requires using trauma-informed practices. Duplicate and back-up team members are required so that plans can go forward, and program knowledge is preserved and built upon over time.

- Inspired by the Community of Practice's Asset Exercise, an original set of Native and girl-focused resilience skills cards were created that featured Native Americanfocused capabilities and skills that girls should have by particular ages (see examples in Figure 2). Realities of modern Native American life and matrilineal cultural traditions feature heavily in the card set. These were created based on a series of workshops and key informant interviews that IMAGEN led with Native women and girls.

- Native adolescent and girl-focused economic literacy curriculum has been drafted to fill a glaring gap we found in this sector. Despite women heading $40 \%$ of Native households in the Great Plains (often large and multigenerational), they have lower financial literacy and financial-service access than males. Existing Native assetbuilding programs (such as the First Nations Development Institute) do not currently have age- and gender-specific materials for Native American girls.

- Working in a trauma-informed manner with this population also means knowing about Native history. This, in turn, informs whether and how global tools could and should be adapted for use. For example, in Native American communities, anyone going house-to-house knocking on doors was traditionally there to take one's children away (to boarding school), to evict you from your house and land (forced removals by the US government), or to arrest someone. One must be extremely careful in considering whether tools that seem innocuous to outsiders can, in fact, be deeply trauma-inducing and inappropriate.

\section{Conclusion}

With our Native American partners, IMAGEN is utilizing Intentional Design tools, gathering 
resources, and drafting girl-centered programplanning tools and a curriculum for use in Native American communities. We are also developing, as of 2020, a Native community-focused "how-to" guide for implementing girl-centered programming in rural tribal communities and urban Indian neighborhoods.

For more information on IMAGEN Network, please visit:

https://www.imagen-network.org/

Journey to Wellness in Indian Country: Tough but Necessary Conversations for Children of Color. Duluth Public Radio, Minnesota. September 24, 2018. http:// www.kumd.org/post/journey-wellnessindian-country-tough-necessaryconversations-children-color\#stream/O

Building Girls' Protective Assets in Indian Country: Intentional Girl-Centered Program Design. September 18, 2018. National Indigenous Women's Resource Center. http://www.niwrc.org/resources/buildinggirls\%E2\%80\%99-protective-assets-indiancountry-intentional-girl-centered-programdesign

Little Shell Tribe hosts workshop to identify issues facing Indigenous girls. KRTV.com Great Falls, Montana News. March 27, 2019. https://krtv.com/news/ great-falls-news/2019/03/27/little-shelltribe-hosts-workshop-to-identify-issuesfacing-indigenous-girls/ 


\section{Practitioner Report 2}

\section{Intentional Design as a Catalyst for Change in Belize Migration Zones and Later Yucatán, Mexico}

By Angel del Valle

Contributions from María José Aldana, Ludivine Cicolella, Ale Colom, Fabiola Romero, Amira Teul, Pulcheria Teul, Claudia Tut, and Isabel Vieitez

\begin{tabular}{|c|c|}
\hline Findings and Decisions & Implementation Observations and Adaptations \\
\hline $\begin{array}{l}\text { - Though there is some variation across communities } \\
\text { in percentage of girls out of school up to age 14, } \\
\text { across all communities it was found that girls from } \\
15 \text { on are highly likely to be out of school. } \\
\text { - Even-and perhaps especially - those girls who } \\
\text { have completed all the available schooling in home } \\
\text { communities are likely to leave unless they can find } \\
\text { acceptable livelihoods and social life at home; both } \\
\text { girls and mothers confirmed this. } \\
\text { Financial literacy, vocational training, and } \\
\text { entrepreneurial skills are vital to engage and sustain } \\
\text { the participation of girls over age } 15 \text { and generate } \\
\text { community support. It is not sufficient to tailor } \\
\text { vocational training to the safety and skills of girls; } \\
\text { must also assure they have female instructors and } \\
\text { mentors. }\end{array}$ & $\begin{array}{l}\text { - It was essential that the team, once formed, } \\
\text { remained constant and, in the context of relatively } \\
\text { continual support, that locally recruited mentors } \\
\text { learned the technology to administer the Roster } \\
\text { and collect information at the household level. } \\
\text { Roster and community mapping results could not } \\
\text { be interpreted locally because of intermittent Wi-Fi } \\
\text { and also because the skills required to interpret the } \\
\text { results of the Output Tables had not yet been built; } \\
\text { the technology has since improved, which should } \\
\text { allow for local generation and greater readability of } \\
\text { Output Tables. } \\
\text { We stress that though it would have been ideal to } \\
\text { have had immediate turnaround from rostering to } \\
\text { results, the delay of two weeks in getting results } \\
\text { back to the communities did not disrupt the } \\
\text { momentum of the program. } \\
\text { Local female mentors (aged 18-30) were the } \\
\text { principal collectors of information and designers } \\
\text { of programs with girls in Mexico, and the same } \\
\text { principles that applied in Belize were adopted } \\
\text { here-that is, taking a team and giving them } \\
\text { consistent support to generate intergenerational } \\
\text { capacity. It is suggested that it takes about two } \\
\text { years of support for mentors to have roles that go } \\
\text { beyond managing safe spaces and offering insights } \\
\text { to becoming program leaders and designers. }\end{array}$ \\
\hline
\end{tabular}

\section{The Toledo (Belize) Context}

In 2015, the Population Council began collaborating with the Toledo Maya Women's Council (TMWC) in the district of Toledo in Belize, a migration zone adjacent to Guatemala, to implement a pilot of the first girl-centered program in the region.

Following the Abriendo Oportunidades ( $A O$ ) evidence-based approach in Guatemala, a secondary analysis was conducted (using the 2011 MICS Survey) and the key findings were (Population Council and UNICEF Belize 2015):
- Rural girls' school attendance drops steadily starting at age 12, while urban girls tend to stay in school until at least 16; Mayan and Mestizo girls have the fewest educational opportunities, with only 55\% of Mayan and $65 \%$ of Mestizo girls aged $10-17$ enrolled in school;

- $\quad 17.3 \%$ of Mayan and $9.7 \%$ of Mestizo girls 15-17 years old reported being ever married, and one in five had given birth to a child before age 18 . 
Toledo was a hotspot of these poor indicators. Half of the population is Mayan, only $38 \%$ of girls aged 15-17 had completed any level of primary education, and $11 \%$ of girls became mothers during their adolescence. Based on these findings, the Council and TMWC sought to initiate a safe spaces program for rural indigenous girls in four communities located near the Guatemala-Belize border and migration zone (Figures 1 and 2).

\section{Action Steps}

As a first step to root the program at the community level, the Council and TMWC collected information on the profile of girls in the community using the Roster. The process and description of outputs are shown in Box 1.

\section{FIGURE 1. OVERVIEW OF THE IMPLEMENTATION OF COUNCIL AND TOLEDO MAYA WOMEN'S COUNCIL (TMWC) SAFE SPACES}

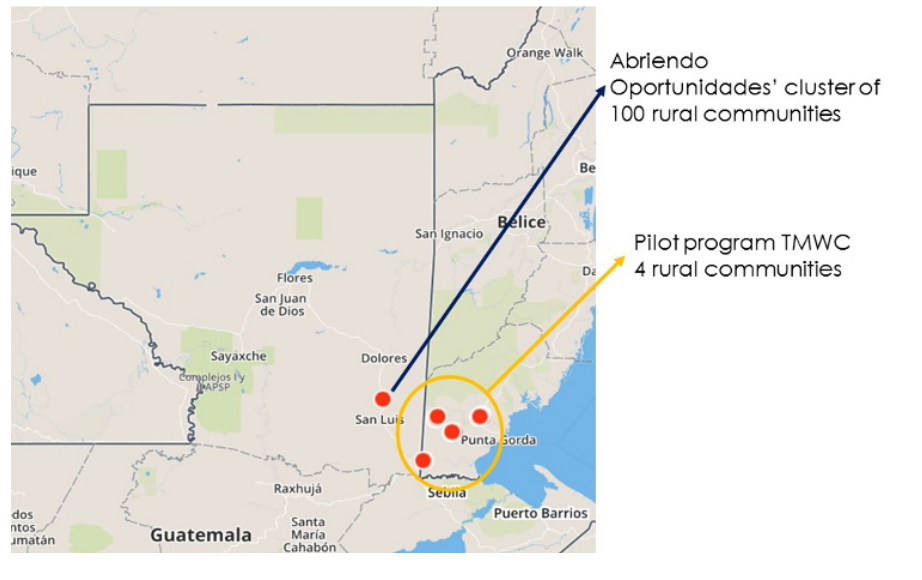

\section{FIGURE 2. LOCATION OF THE FOUR COMMUNITIES WHERE TOLEDO MAYA WOMEN'S COUNCIL (TMWC) WILL IMPLEMENT THE SAFE SPACES PROGRAM}

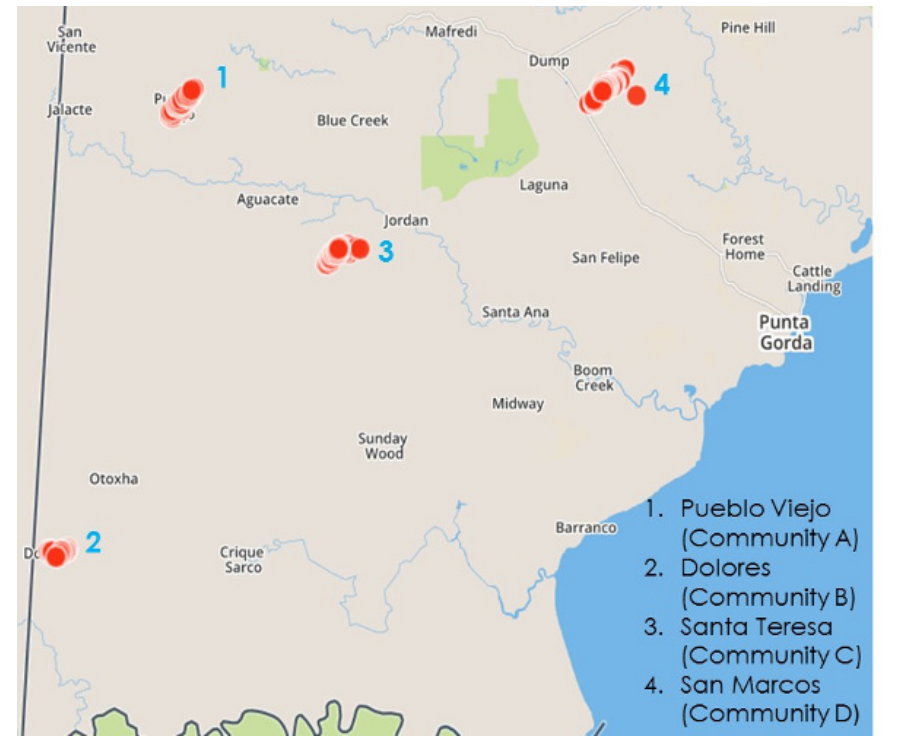


BOX 1. DESCRIPTION OF ROSTER OUTPUTS FROM ROSTER IMPLEMENTATION WITH TOLEDO MAYA WOMEN'S COUNCIL

\begin{tabular}{|c|c|}
\hline Where & 4 rural communities in the District of Toledo, Belize (border with Guatemala) \\
\hline When & January 10-15, 2015 \\
\hline $\begin{array}{l}\text { Process } \\
\text { 1) Training } \\
\text { 2) Engagement with } \\
\text { community leaders } \\
\text { 3) Information collection }\end{array}$ & $\begin{array}{l}\text { The AO/Council staff trained a team of one supervisor and two mentors (all } \\
\text { local, female mentors who spoke the local language-English in Belize) of } \\
\text { TMWC in the use of the Roster. The AO/Council team stayed connected to the } \\
\text { field team during this time. The technical training was fairly simple. Five mobile } \\
\text { phones were provided to the organization for information collection, and the } \\
\text { technical training in the Girl Roster app in the field was accomplished in two } \\
\text { days. } \\
\text { Before the Roster was conducted, TMWC had already presented the idea of a } \\
\text { safe spaces program to community leaders. } \\
\text { TMWC's supervisor organized the team to map all households in the community. } \\
\text { The Council supervised and accompanied information collection in all } \\
\text { communities. Community leaders led the AO/Council and TMWC teams to } \\
\text { show them the boundaries of their walkable community. Given the density of } \\
\text { local languages, their participation helped greatly with translation and further } \\
\text { engaged them; support from these leaders and school principal was crucial in all } \\
\text { communities. } \\
\text { During the rostering, although weather conditions were not ideal because of } \\
\text { the mud and rain, the team made the effort to include all households in the } \\
\text { community. } \\
\text { Each young female mentor, in teams of two, simultaneously identified public } \\
\text { spaces, facilities, and features-a resource mapping exercise-while the Roster } \\
\text { was being conducted. Photos of resources were collected in the course of this } \\
\text { dual rostering and resource mapping exercise. } \\
\text { Once completed, phones were sent to the Council's office in Guatemala, as there } \\
\text { had been intermittent Wi-Fi in the Belize area and the staff still did not feel they } \\
\text { had the skills to interpret the Output Tables. (This was a more onerous process } \\
\text { than it would be today, where the generation of Output Tables is near-automatic; } \\
\text { two weeks later, the outputs were transmitted back to the Belizean partner.) }\end{array}$ \\
\hline
\end{tabular}

\section{Findings and Implementation in Toledo}

Roster results revealed information about girls' numbers and schooling status. Mapping analysis shows the following information (see Table 1) about girls' schooling:

TABLE 1. SUMMARY OF ROSTERING

\begin{tabular}{|l|l|l|l|l|}
\hline Community & $\begin{array}{l}\text { Number of households } \\
(\mathrm{HH}) \text { and population }\end{array}$ & $\begin{array}{l}\text { Number of girls aged } \\
6-17\end{array}$ & $\begin{array}{l}\text { Number of girls aged } \\
\text { 12-17 out of school as a } \\
\text { proportion of total girls in } \\
\text { the age range }\end{array}$ \\
\hline Community A & $\begin{array}{l}75 \mathrm{HH} \\
429 \text { inhabitants }\end{array}$ & $\begin{array}{l}77(18 \% \text { of total } \\
\text { population) }\end{array}$ & $12-14$ & $2 / 20$ \\
\hline Community B & $\begin{array}{l}79 \mathrm{HH} \\
450 \text { inhabitants }\end{array}$ & $81(18 \%)$ & $15-17$ & $13 / 16$ \\
\hline Community C & $\begin{array}{l}52 \mathrm{HH} \\
299 \text { inhabitants }\end{array}$ & $46(15 \%)$ & $15-17$ & $3 / 13$ \\
\hline Community D & $\begin{array}{l}99 \mathrm{HH} \\
599 \text { inhabitants }\end{array}$ & $103(17 \%)$ & $12-14$ & $4 / 14$ \\
\cline { 4 - 5 } & & & $15-17$ & $4 / 10$ \\
\hline
\end{tabular}


Strikingly, across four communities, at minimum $40 \%$ and more typically closer to $85 \%$ of girls 15-17 were out of school. Given the important shift that takes place at 15 to an increasing proportion of out-of-school girls, girl-only groups were organized by age: one group for girls 8-13 years and one for girls 14-17 years.

The emphasis for girls 8-13 years was to build girls' schools and to increase commitment to future schooling and families' willingness to invest in their schooling past age 13. For girls 14-17 years, in-school girls were supported to stay in school while for those out of school a high priority was accorded to program content, which assisted them in navigating sexual and violence risks and preparing for decent livelihoods.

Fact sheets were prepared for community leaders to sensitize them to the severe situation of girls; community contracts specified the promise of space for at least two groups, the support and protection of the mentors, and affirmations of support of girls' rights and skillbuilding. The contracts were signed with each community the day the program was launched.

The pilot program was to run 12 months initially (it is, as of 2020, 24 months) across all seasons of risk, including the heavy rains and the school break in June and July; the content emphasized financial literacy, sexual and reproductive health, and prevention of violence. After the pilot, the safe spaces and girl-only groups expanded to reach new communities. There were not sufficient resources for a full-on assessment, but the Roster was completed after 12 months and it was seen that a longer dose of the program and higher saturation was needed. The teams aimed for $80 \%$ of girls $10-17$ to participate.

An assessment in 2019 on the status of girls who participated in the program shows that at least 30 girls migrated from their communities before age 18. Heads of household cite work and marriage as the main reasons for girls' migration. These girls had 9 years of education on average by the time they migrated, which coincides with the level of schooling girls were able to complete in home communities by age 16 before going to vocational training.
A study of the content and assumptions of vocational training led the team to make some changes. Aware of the power hierarchies in the communities and their desire to create a richer, safer environment for girls in home communities and prepare them better should they migrate, TMWC enhanced the curriculum to include content on financial literacy and combined learning sessions with entrepreneurial activities led by local females as tutors. Given the high levels of migration in the community, and rising levels of migration across central America, it is disheartening to see that girls who were fully educated, to the extent they could be in the community, still had to leave to find meaningful work and perhaps an enriched social life. Thus, one of the goals of the girls' groups was to create a stronger basis for social participation, civil society, and economic inclusion.

Implementation ended in October 2019 and reached close to 800 girls aged 10-18 in ten communities. As of 2019, TMWC continues to work with girls in four communities with support from the CAMY Fund. It is the lack of resources that can constrain a program's expansion; the value of the program to the girls in these communities is clear, and as migration continues to rise, the local community organizations and the governments must understand the value of expansion subject to resources.

\section{Lessons from the Toledo Impact Program in Mexico}

Lessons from Belize also informed the Council's approach in Mexico, where a program for the rural and indigenous setting in Yucatán, Mexico, was set to expand; there, $40 \%$ of the population is indigenous and $60 \%$ live under the poverty line. In Yucatán, the team followed a similar approach to set up the program as in Belize:

- Local female mentors (aged 18-30) were the primary collectors of information and designers of programs with girls, and the same principles that applied in Belize were adopted here-that is, taking a team and giving them consistent support to generate 
intergenerational capacity. It is suggested that it takes about two years of support for the mentors to have roles beyond managing safe spaces and offering insights to becoming program leaders and designers;

- $\quad$ Roster information collectively analyzed by the Roster team and the local community leaders helped identify the priority segments of girls and the development of an intentional recruitment plan per segment;

- Among the priority content-given the economic pressures that create scarcity and drive migration-basic financial skills in preparation for entrepreneurial activities were core;

- Age-graded, girl-only groups were established;

- Mentors led weekly meetings for younger and older girls for a period of 24 months.

Throughout the process, as in Belize, community leaders of Yucatán were engaged in initial discussions, in defining the walkable community, in interpreting Roster and resource mapping results, and providing both contractual and more informal support to the program.

An assessment conducted at the end of the implementation showed that about 30\% of girls aged 12-17 were very regular participants (attending at least half the sessions); those who participated were more likely to have savings and have better knowledge on sexual and reproductive health, and reported having a stronger network of female friends compared to girls with a similar profile who had not accessed the program at all.

As of 2019, Abriendo Futuros was reaching close to 300 girls aged 10-19 in indigenous communities in Yucatán (supported by the Kellogg Foundation). As with the Belize program, the limitation on the Mexico program was simply financial. This program was ready to scale at the time.
For more information on Abriendo Oportunidades in Belize or Abriendo Futuros in Mexico, please visit: https:// www.popcouncil.org/research/abriendooportunidades-opening-opportunities 


\section{Practitioner Report 3}

\section{An Assessment of Plan International El Salvador's GAD (Gender and Development) Programming-Using Evidence for Redirection after the Initial Implementation}

By Alexia Abrego, Audrey Anderson, Maritza Avalos, Laura Brazee, Xenia de Velasco, Angel del Valle, Carlos Ernesto Martinez, Yesenia Segovia, and Gisela Turcios

\begin{tabular}{|c|c|}
\hline Findings and Decisions & Implementation Observations and Adaptations \\
\hline 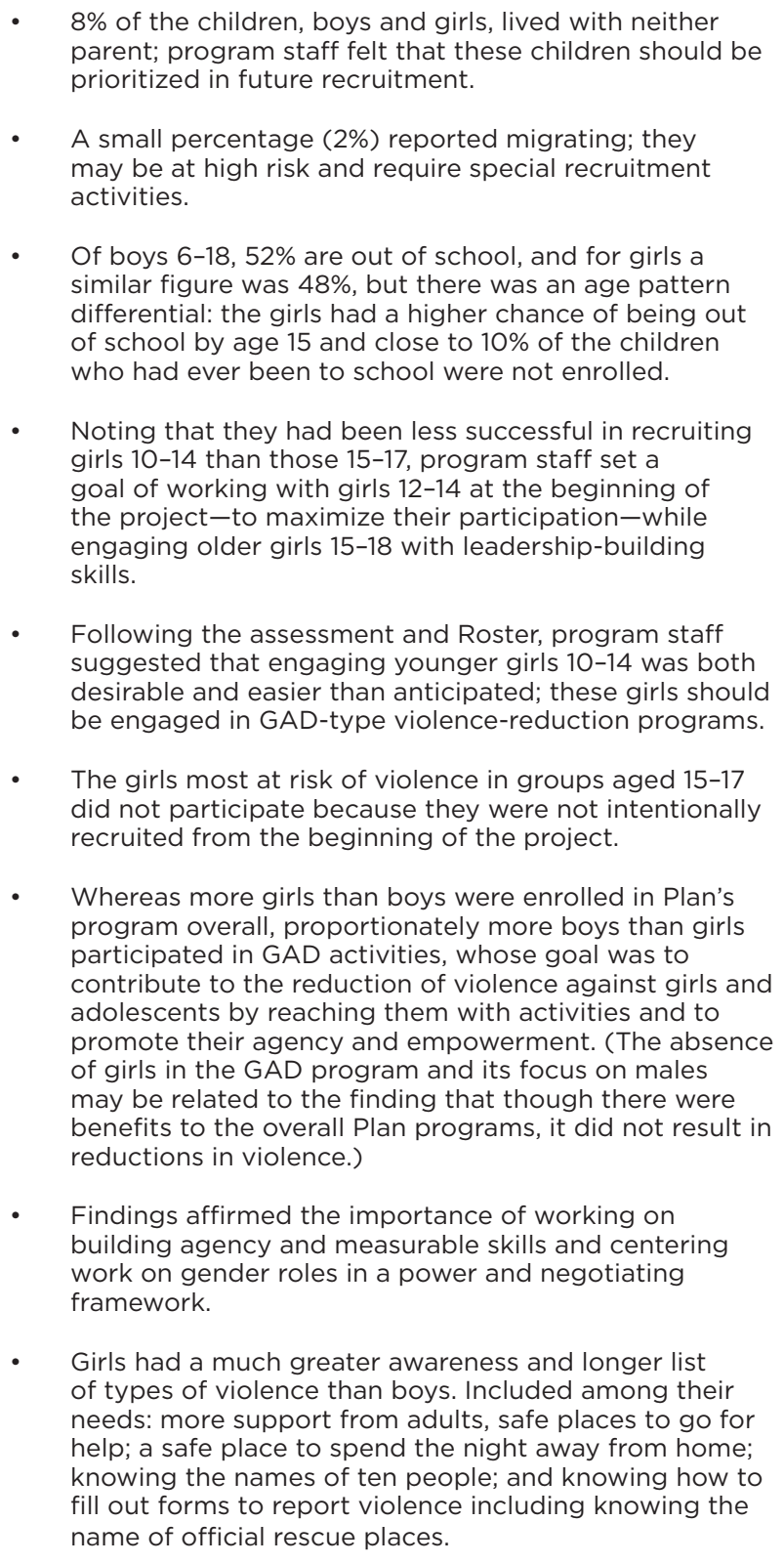 & $\begin{array}{l}\text { - Involvement from Plan El Salvador was key. Everyone } \\
\text { was on board with the assessment, from project } \\
\text { leaders to the finance team, the country director, and } \\
\text { the team based in Washington. Without their honest } \\
\text { engagement, the assessment would not have been } \\
\text { successful. } \\
\text { - The study detailed was comprehensive, going to all the } \\
\text { Plan sites and combining a variety of methods, initial } \\
\text { informal assessments and community conversations, } \\
\text { and the Roster exercise, followed by post-Roster focus } \\
\text { groups. This thoroughness allowed program staff to } \\
\text { identify the participation efforts of different segments } \\
\text { and, going forward, their differential needs. } \\
\text { Roster focus groups gave more depth to the findings } \\
\text { and recruitment. } \\
\text { Program staff across the } 36 \text { sites seemed to have } \\
\text { their ability to "see" girls as well as enumerate them } \\
\text { enhanced, leading Plan El Salvador to adopt these } \\
\text { methods as part of its follow-up to the GAD program, } \\
\text { called Champions of Change. }\end{array}$ \\
\hline
\end{tabular}




\section{Introduction}

This practitioner report documents activities conducted by the Population Council and Plan El Salvador as part of a comprehensive assessment at the close of the girl-centered project Girls Promoting the Reduction of Gender-Based Violence (GAD) implemented between April 2012 and April 2015 in El Salvador. This effort was a conscious exercise in both assessment and future capacity-building and involved three stages of project assessment that combined capacity-building activities at different levels to determine the extent to which Plan International reaches the most marginalized girls in El Salvador.

The three stages of the comprehensive assessment took place between January and October 2015 and were conducted in coordination with key staff based in El Salvador. These stages were: 1) Build capacity among project staff to collect Girl Roster information in 36 communities; 2) Design and supervise focus group discussions (FGDs) to explore the results of the project (based on highlights of the Girl Roster results); and 3) Facilitate workshops with key staff to revise the basic elements of the girlcentered program for El Salvador and present a vision for programmatic sustainability to Plan USA.

\section{GAD 182 Project: Girls Promoting the Reduction of Gender-Based Violence}

The goal of the GAD 182 project was to "contribute to the reduction of violence against girls and adolescents by reaching them with activities that promote their agency and empowerment, with the objective of strengthening their knowledge, skills, and attitudes for the prevention of violence." The project reached 1,396 girls aged 12-18 across 36 communities in 9 municipalities from El Salvador. Activities implemented as part of the project included:

- $\quad$ Asset-building sessions with girls and boys in safe spaces at the community level, delivered by external consultants and complemented by referral services when cases of violence were identified;
- Identification of adolescent girls aged 12-16 with the potential of becoming girl leaders to be trained as "co-listeners" to support other girls who experienced violence;

- Creation of community-based plans for the prevention of violence against women, aimed at sensitizing parents, leaders, and boys in the community;

- Asset-building sessions with a number of boys aged 12-16 aimed at supporting girls in their empowerment process;

- $\quad$ Strengthening local institutions that provide services on violence prevention and attention by building gender-analysis capacities among services providers.

According to Plan El Salvador's records, as of 2019, 436 communities in 62 municipalities across the 5 departments (see Figure 1) have been reached by their projects and activities. Table 1 summarizes the communities covered by each Program Unit Office (PU).

\section{Assessment, Stage 1: Capacity building among project staff to collect Girl Roster information in 36 communities}

The Council initially engaged with Plan El Salvador in early 2011 conducting a workshop with the GAD 182 project team to illustrate the basic elements of girl-centered programming. The workshop was organized by Plan USA's Because I Am a Girl (BIAGG) team and Council staff from New York and Guatemala.

In late 2012, the Council organized a followup workshop with Plan El Salvador to guide them through a set of participatory tools to produce safety maps with girls and boys. Later, in December 2014, the Council invited key staff from Plan El Salvador involved in girl-centered projects to participate in a weeklong workshop where it engaged with different partners from the Central American region to reinforce the elements of the safe spaces model and shared with them lessons learned in recent years of the implementation of the AO program in Guatemala. 


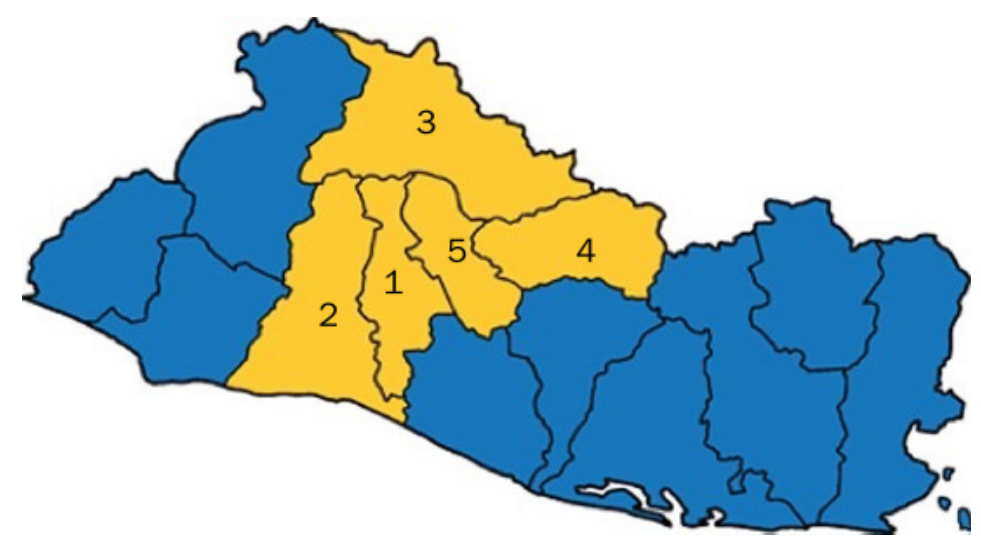

Plan El Salvador works in 5 departments, highlighted in yellow:

San Salvador (1)

La Libertad (2)

Chalatenango (3)

Cabañas (4)

Cuscatlán (5)

TABLE 1. DISTRIBUTION OF MUNICIPALITIES COVERED BY EACH PROGRAM UNIT OFFICE, PLAN EL SALVADOR (2019)

\begin{tabular}{|l|l|l|l|}
\hline & Departments & Municipalities & $\begin{array}{l}\text { Prevalence of Extreme } \\
\text { Poverty }\end{array}$ \\
\hline \multirow{4}{*}{ PU2 } & \multirow{3}{*}{ La Libertad } & Puerto La Libertad & Low \\
\cline { 2 - 4 } & San Salvador & Ciudad Arce & Low \\
\cline { 2 - 4 } & \multirow{3}{*}{ PU3 } & Panchimalco & Moderate \\
\hline \multirow{3}{*}{ PU4 } & Chalatenango & El Carrizal & Low \\
\cline { 2 - 4 } & San Salvador & El Paisnal & High \\
\hline \multirow{2}{*}{ Cabañas } & Ilobasco & Moderate \\
\cline { 2 - 4 } & Sensuntepeque & Hoderate \\
\cline { 2 - 4 } & Cuscatlán & San Rafael Cedros & Low \\
\hline
\end{tabular}

In January 2015, the BIAAG team discussed with the Council's office in Guatemala the need to build capacity at the headquarter and country levels in El Salvador to assess the reach of the GAD 182 project. As a result, a series of workshops were conducted in El Salvador's country office with the participation of all staff involved in the project at different stages. A summary of each workshop is described below, including one key finding from the external programmatic perspective of the Council and one key takeaway from the perspective of the local staff in El Salvador (see Box 1).

To learn more about the specific segments of girls reached by GAD 182 and trace the effects of the program in those segments of girls who were reached, the Council guided the mapping coordinator in the analysis of information once field collection was completed. These are the results. 
BOX 1. WORKSHOP 1. THE IMPORTANCE OF ASSESSING THE COVERAGE, RESULTS, AND EFFECTS OF PROJECTS. LOCATION: PLAN EL SALVADOR'S OFFICE; EL CARRIZAL (RURAL COMMUNITY)

Results:

- After discussing the differences between monitoring and evaluation strategies, participants identified some gaps between the outcomes and indicators included in the original project proposal and current monitoring data available to assess results. However, it is important to point out that outcome indicators often are adjusted after project start-up to adapt to current conditions at the project sites. Because the M\&E plan is a living document, these adjustments are expected to be made.

- Both the BIAAG team and the Council identified the need to conduct a Girl Roster exercise in all communities covered by the project to understand the profile of girls who actually participated in the project.

- The Council introduced participants to the Girl Roster to collect information on girls and guided participants in a field test of the tool in one rural community where the project was implemented.

- A "data center" for the project was created (i.e., an Excel spreadsheet summarizing key information on the project by the community). Prior to the implementation of the workshop there was no centralized information on the project's coverage. Figure 2 illustrates the information included in the data center.

FIGURE 2. MAP SHOWING GPS MARKS IN THE 36 COMMUNITIES INCLUDED IN IMPLEMENTATION OF THE GIRL ROSTER

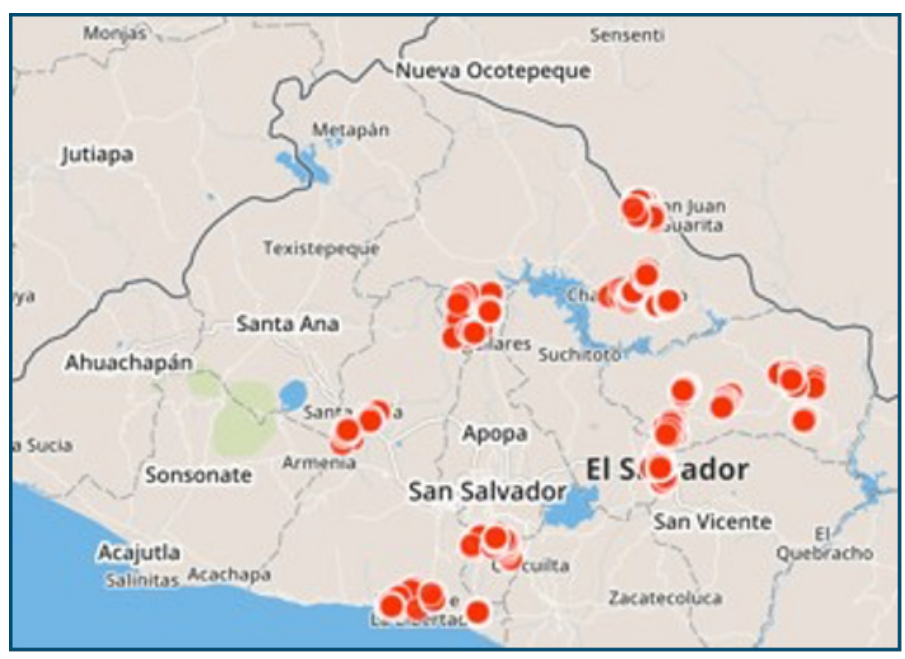

Girl Roster collection in numbers

6 weeks of data collection 556 public spaces identified

$\mathbf{4 , 7 7 5}$ households visited (close to $70 \%$ response rate)

Data collected on 4,144 girls (52\%) and $\mathbf{3 , 8 4 5}$ boys (48\%) between 1 and 17 years of age 
TABLE 2. CHILDREN (BOYS AND GIRLS AGED 1-17) WHO ARE CURRENTLY ENROLLED IN PLAN'S PROJECTS AND GAD 182 PARTICIPANTS

\begin{tabular}{|l|c|c|c|}
\hline \multirow{2}{*}{} & \multicolumn{2}{|c|}{ Girls and Boys Aged 1-17 } \\
\cline { 2 - 4 } & Boys & Girls & Total \\
\hline Girl Roster summary & $48 \%(\mathrm{~N}=3,845)$ & $52 \%(\mathrm{~N}=4,144)$ & 7,989 \\
\hline Enrolled in Plan's programs (all programs) & $39 \%(\mathrm{~N}=735)$ & $60 \%(\mathrm{~N}=1,129)$ & 1,864 \\
\hline Participants in GAD $182^{*}$ & $78 \%(\mathrm{~N}=968)$ & $22 \%(\mathrm{~N}=271)$ & 1,239 \\
\hline
\end{tabular}

Source: Girl Roster information collected by Plan El Salvador.

*Participants of GAD 182 are also eligible to participate in other projects implemented by Plan.

In the 36 communities (see Figure 2), for those households that provided information, findings include:

- Living Status: $8 \%(\mathrm{~N}=626)$ of boys and girls under the age of 18 lived with neither parent. Most of these children lived with their grandmother, a sibling, or uncle.

- Education Status: Close to $10 \%$ of children that have ever been to school (age $>6$ years old) were not enrolled in school. The percentage of out-of-school children and adolescents (aged $6-18$ ) is $52 \%$ for boys $(\mathrm{N}=342)$ and $48 \%$ for girls $(\mathrm{N}=319)$. Compared to the national average, as documented by Plan's mapping analyst, Girl Roster information showed that girls had a higher chance of being out of school by age 15 .

- Birth Certificates: Mapping analysis shows that only 89 children under the age of 18 did not have birth certificates (89/7,989; $1 \%$ ), a much lower figure than expected by the team.

- Tracking Risk-Elevating Conditions-Child Migrants and People with Disabilities: The mapping included a question to determine if any children under the age of 18 had migrated in the last three years. Mapping data showed that there were, indeed, children migrating $(\mathrm{N}=215)$. Although the percentage was not high (2\%), attention needed to be focused on understanding more of the causes that motivated children to move. As reported by key informants, the two main causes for which these $2 \%$ of children left the community were "to reunite with their parents" and to "find a job." The latter explanations may be cause for some concern, considering that these children were exposed to human trafficking and gang violence. A similar level-about $2 \%$ of children-were reported with disabilities $(\mathrm{N}=195)$ across the "universe" of children in the 36 communities.

- Enrollment in Plan's Projects: Since these 36 communities were regularly engaged by Plan El Salvador (including sponsorships and scholarships for boys and girls), the Roster included a question on the participation in Plan's projects, including GAD 182 (see Table 2). Although more girls than boys were found among the general Plan programs, more boys than girls, proportionally and numerically, participated in the GAD program; this was paradoxical, as this project was directed toward reducing violence against girls. (In a later assessment it was seen that though there were many benefits, reduction in violence was not achieved. This suggests the need to look at recruitment processes and assumptions of the GAD program.) 
TABLE 3. RESPONSE RATES OBTAINED IN THE COMMUNITIES COVERED BY EACH PROGRAM UNIT (PU)

\begin{tabular}{|l|c|c|c|}
\hline & PU2 & PU3 & PU4 \\
\hline Households identified & 2,688 & 1,829 & 2,425 \\
\hline Response rate & $80 \%$ & $73 \%$ & $52 \%$ \\
\hline Population in effective households & 10,206 & 5,680 & 6,116 \\
\hline
\end{tabular}

TABLE 4. UNMARRIED GIRLS AGED 10-17 IN SCHOOL AND OUT OF SCHOOL IN EACH PROGRAM UNIT IDENTIFIED IN THE MAPPING

\begin{tabular}{|l|c|c|c|c|c|c|}
\hline Unmarried Girls & \multicolumn{3}{|c|}{$10-14(\mathrm{~N}=1,301)$} & \multicolumn{3}{c|}{$15-17(\mathrm{~N}=894)$} \\
\hline & $\mathrm{PU2}$ & $\mathrm{PU3}$ & $\mathrm{PU4}$ & $\mathrm{PU2}$ & $\mathrm{PU3}$ & $\mathrm{PU4}$ \\
\hline In school (\%) & $95 \%$ & $98 \%$ & $92 \%$ & $81 \%$ & $86 \%$ & $69 \%$ \\
\hline Out of school (\%) & $5 \%$ & $2 \%$ & $8 \%$ & $19 \%$ & $14 \%$ & $31 \%$ \\
\hline Total in segment (N=2,195) & 619 & 323 & 359 & 406 & 259 & 229 \\
\hline
\end{tabular}

Source: Roster information collected by Plan El Salvador.

The analysis of the mapping information for children showed that there were three segments in the 36 communities that needed to be addressed by future projects:

- Children under the age of 18 living without their parents;

- Children who migrated before turning 18 to reunite with their families and/or look for job opportunities;

- Children of school age who are currently out of school.

With the information collected, Plan El Salvador could identify exactly where the most-atrisk children lived. The team had enough information to build a profile for children in each community, municipality, and department. This means they could use the Roster information to inform future decisions concerning investments and project focalization (see Tables 3 and 4). Also, and most important, they now had a tool to identify those girls who are being left behind.
Now, to the key question that motivated the implementation of the Girl Roster: What does the universe of girls look like in the 36 communities where GAD 182 was implemented?

An examination of the universe of girls, with information collected using the Roster, tells the following story for girls in El Salvador. Most girls aged 10-14 are still living in their homes with both parents in those communities covered by the GAD 182 project. Most girls 10-14 are in school (95\%), but as they reach puberty the chances of leaving school increase to the point that close to $25 \%$ of girls 15-17 are out of school (see Figure 3). Most girls aged 10-17 are not married, and $30 \%$ of unmarried girls live only with their mothers. There are 6 girls in age group 10-14 who are already married, and 2 of those have at least one child. Among girls in the age group $15-17,6 \%(N=57)$ are living in unions and/or are married, and almost half of them (47\%) have at least one child. By definition, the current status of 63 adolescent girls in the "universe" fits the expectation of child-marriage rates. 
FIGURE 3. GIRLS IN “UNIVERSE,” BY AGE GROUP AND EDUCATION STATUS $(N=2,258)$

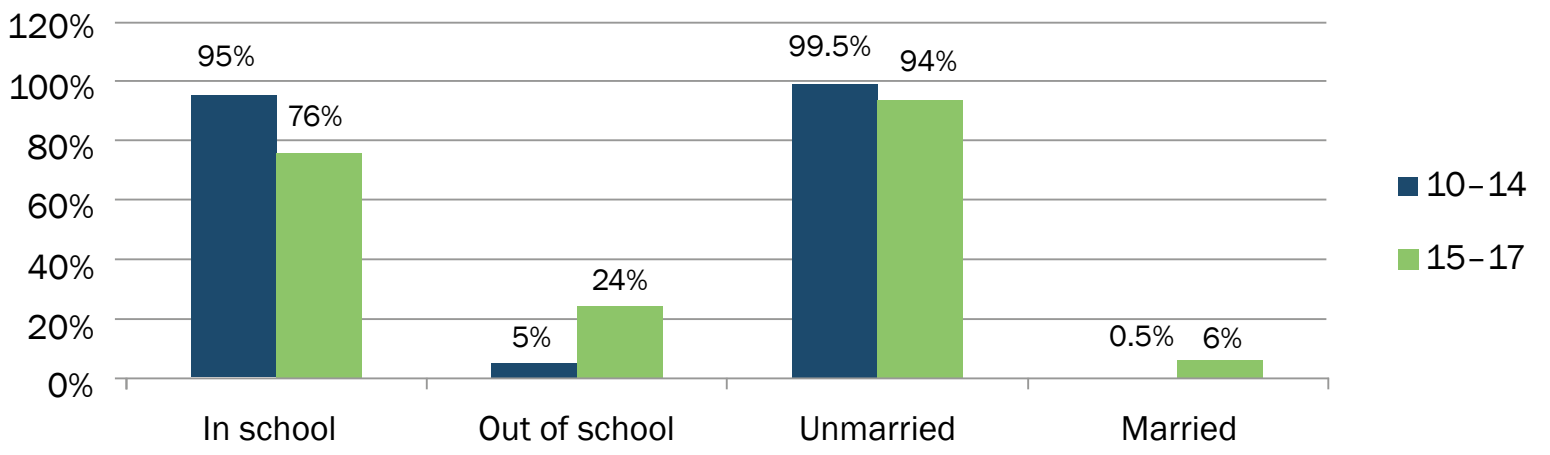

Source: Girl Roster information collected by Plan El Salvador.

\section{Discussion}

Plan El Salvador set the goal of working with girls aged 12-14 at the beginning of the project, while engaging older girls aged 15-18 with leadership-building skills. According to the project's coordinator, this decision was based on the primary prevention rationale of engaging girls who are still in school before they start to drop out.

When looking at the project's reach, within the universe of eligible adolescent girls aged 10-17, Plan was successful in recruiting $36 \%$ of girls aged $10-14$ and $44 \%$ of older girls aged $15-17$. Most of the girls recruited to participate in the project are still in school and living with both parents, and/or just the mother (83\% for girls 10-14 and 73\% for older girls 15-17).

The project was implemented in communities with an important number of unmarried girls 10-14 both in school $(\mathrm{N}=71)$ and out of school $(N=25)$ who are currently living with neither parent who did not participate in GAD 182. As is usually the case, younger girls (10-14) have more time, permission from parents, and interest in attending this type of project. However, it is important to note that girls at most risk in the age group 15-17 did not participate because they were not intentionally recruited from the beginning of the project.
It is also important to bring attention to the fact that the project did recruit older girls aged 15-17 who are already mothers and have at least one child $(\mathrm{N}=8)$ and girls who are already married but have no children ( $N=13)$. According to the project's coordinator, these girls showed interest in the project but faced more challenges than younger or unmarried girls negotiating their participation.

\section{Moving into an Asset-Based, Age- Graded Approach ${ }^{2}$}

The results presented in the previous section are based on focus group discussions with 49 adolescent girls aged 14-18 who participated in the "school for the prevention of genderbased violence," 37 adolescent girls 14-18 who were trained as "co-listeners," and 13 boys who participated in skill-building workshops. FGDs allowed participants' ideas and perceptions on a variety of subjects to be voiced and provided valuable input on the impact that GAD 182 had on participants.

The project had an ambitious goal: "Contribute to the reduction of violence against girls and adolescents by reaching them with activities that promote their agency and empowerment, with the objective of strengthening their

\footnotetext{
${ }^{2}$ The analysis presented in this section refers to the findings from the FGDs, from the external perspective of the Population Council's M\&E specialist based at the Guatemala Office.
} 
knowledge, skills, and attitudes for the prevention of violence." Although Plan El Salvador based the project's theory of change on an asset-building approach, activities designed to engage girls and boys did not fit such an approach. In the context of the prevention of violence, especially when strategies target young girls and adolescents, asset-building activities should have the longitudinal goal of helping girls understand that they are not responsible for the violence around them and provide them with skills to mitigate its effects.

Given the challenges that Plan El Salvador faced to implement and evaluate GAD 182 and considering that this was the first time that the country office implemented a girl-centered project, results reported by participants shed light on important accomplishments at the participant level. Results from FGDs organized after Roster results were collected show that none of the groups mentioned a significant reduction of the forms of violence that they see and/or experience in their houses, schools, or communities. Instead, participants appreciated the knowledge they gained in the domains of self-esteem, life plans, gender and sexuality, reproductive health, and awareness of the risks of violence.

\section{Applying the Asset-based Toolkit to the Roster Results}

By using the Council's Building Assets Toolkit, we were able to identify a number of priorities for girls under specific themes (e.g., economic, social, cognitive, health) that guided the FGDs, and here a brief discussion is presented for the results observed. We frame this discussion using the basic assets that GAD 182 built (or aimed/ should aim to build) for girls.

\section{Self-esteem and Leadership among Older Girls}

It is a fact that girls who were trained as "co-listeners" reported new skills in listening to other girls' problems and experiences of violence. As girls in FGDs mentioned, they felt that their self-esteem increased but also felt that adults in their communities should be more supportive. When fostering a local network of girl leaders, especially when there is an expectation for girls to serve as role models to their peers, organizations should have in mind that girls are not prepared to face the local authorities on their own. Although girls trained as co-listeners reported feeling more confident and capable of supporting other girls who experience violence, a leadership-building component should be designed that aims to train and support these girls in a sustainable manner.

In a context where young girls lack the resources and information to report violence, female leaders trained as mentors should:

- Know what the Community Council does, when it meets, and some of the official leaders;

- Be a female mentor who girls in the community can turn to for advice when faced with challenges;

- Know whom to ask/where to ask for help if she or someone she knows is a survivor of violence.

The increasing context of insecurity in El Salvador demands project staff be more cautious with the visibility they raise for girls when engaging them in activities that promote their leadership within the community. As illustrated by a story shared by one "colistener," without specific interventions by advocates, girls face the risk of being constantly retraumatized. This is something mentors can avoid with proper training and continuous support.

Additionally, most girls in the FGDs mentioned how bad it feels that adults do not appreciate their skills. Designating a person who provides regular aid and oversight to mentors can make the difference in keeping them motivated and reinforcing their self-esteem. 


\section{Gender Roles}

As stated in the focus groups, adolescent girls and boys had a hard time differentiating gender from sex. Knowing that gender roles are socially constructed made a difference for some of the girls who participated in the project and has the potential to set the stage for discussing social norms like "machismo" and girls' constrained mobility within the community.

Evidence shows that sexuality and HIV education programs addressing gender and power in intimate relationships are far more likely to be effective than programs that do not (Haberland 2015). Integrating comprehensive sexuality education into future curriculums designed for girl-centered programs at the country level has the potential of having greater effects on girls' and boys' knowledge of gender and sex, which is one of the topics girls reported they would like to learn in future projects.

When talking about gender in the FGDs, the issues of school dropout and unwanted pregnancies came up frequently. Some responses suggested that girls were responsible for protecting themselves to avoid sexual violence, which could imply that the notion of human rights also needs to be reinforced.

\section{Perceptions of Safety within the Community (Public Spaces) and Safety Plans}

The knowledge gap between boys and girls regarding the forms of violence shows a better engagement with girls through activities like the "school for the prevention of gender-based violence." Girls in all FGDs were able to name a wider list of forms of violence and provided more details on the places and people they can go to in case of an emergency. Although girls reported that it was important to them to have the basic skills to be emotionally supportive to girls who experience violence, these same girls reported challenges in reporting the violence itself, referring to the lack of support or backing from adults.
It is important to remember that there will not always be people in the community who protect girls, unless it is explicitly planned by projects. To respond to this situation, future projects should equip girls to:

- Identify someone to go to for help in case of abuse at school and know where to report abuse;

- Have a safe place to spend the night away from home, if needed;

- Know the names of trained people in the community who can be relied upon to protect girls (the guardians);

- Know how to describe/express a problem to someone in authority, such as a local official;

- Know how to fill out forms to report violence;

- Know what to say and not to say to someone who has been a victim of a violent crime.

All of these are protective assets. When it comes to exercises like safety mapping, the project had the positive result of supporting girls and boys in identifying the risks they face in different public spaces in their communities. These techniques have the potential to increase girls' confidence when reporting cases of violence. However, these plans need to be linked to local actions that engage community leaders in supporting boys and girls in reducing risks of violence to a minimum. To achieve this, projects should aim at building the following assets at different levels (girls, mentors, and guardians):

- Know where the nearest police station is and the kind of help the police can provide;

- Be aware of daily and seasonal demands on her time and know how to budget her time;

- Have a safe place to spend the night away from home, if needed; 
- Know the location of a community center, the activities offered there, and how to participate;

- Know the location and hours of girl-only spaces (or project-related activities);

- Know what to say and not to say to someone who has been a victim of a violent crime;

- Know the time of day/week when she is likely to face more risks at home, at school, in the street.

Finally, the current context of escalating violence in El Salvador is forcing organizations to increase communication with local leaders and strengthen the strategies used to foster and sustain ties with communities. When doing so, future projects should keep in mind that any strategy that aims at preventing violence against girls by building their assets should prioritize girls' awareness about the constraints on their time and mobility as a key step to gain control over their decisions. The shift from the implementation of projects with irregular doses of exposure to asset-building sessions, to a program that includes multilevel modules will have the ability to build the skills girls need as they are growing, allowing them to navigate predictable and often age-specific challenges (Bruce 2015).

\section{Conclusion}

Plan El Salvador continues, as of 2019, to be guided by the Intentional Design approach and tools. Follow-on projects have incorporated as a regular feature a more careful rostering of the different segments and focus on building measurable assets and agency, especially among girls, as well as intentional recruitment within the Champions of Change program.

For more information, please visit Plan El Salvador's website: https://planinternational.org/el-salvador. 


\title{
Practitioner Report 4
}

\section{A Network of Intentional Design Adopters Working for Adolescent Girls' Futures in Post-Earthquake Haiti and Beyond}

\author{
By Myriam Narcisse, Rachelle Fleurimond, Yvenique Bathard, and Sophie Soares
}

Acknowledgment to HAGN's many senior and junior mentors, community members, and HAGN members

\begin{tabular}{|l|l|}
\hline Findings and Decisions & Implementation Observations and Adaptations \\
\hline $\begin{array}{l}\text { Elite capture (attracting better-off girls where there } \\
\text { is no intentional recruitment of the disadvantaged) } \\
\text { is inevitable even in densely settled, very poor } \\
\text { communities; even where high numbers of girls are } \\
\text { participating, these numbers are deceiving as they } \\
\text { may represent less than 10\% of the eligible girls. }\end{array}$ & $\begin{array}{c}\text { The tool was easy to use and especially practical in } \\
\text { a dense, urban setting. }\end{array}$ \\
$\begin{array}{l}\text { Importantly, there is a systematic exclusion of those } \\
\text { at highest risk; educated girls have far more access, } \\
\text { so young and out-of-school girls, and the youngest } \\
\text { married girls or first-time mothers are rarely found } \\
\text { in programs. }\end{array}$ & \\
\hline
\end{tabular}

\section{Background and Lives of Haitian Girls}

Haiti is a Caribbean country, neighbored by the Dominican Republic, that spans 10,714 square miles (World Factbook 2020). The country is comprised of ten departments, and much of the country's infrastructure, industry, and governance is centralized in the capital, Port-au-Prince-which is in the department of Ouest. Although Haiti has large swatches of rural land, over half of the population resides in urban environments (World Factbook 2020)-particularly in Port-au-Prince's major metropolitan area.

Haiti's human development is extremely low, reinforced by the fact that out of 189 countries, Haiti is ranked 168th on the UNDP's GII-placing it in the bottom $15 \%$ of countries for gender inequality. This indicates that the reproductive health, empowerment, and economic status of adolescent girls and young women (AGYW) under the age of 24 are eclipsed by that of their male peers. Access to education is particularly problematic in Haiti where more than $80 \%$ of its primary schools are managed by private organizations, almost all of which charge tuition. Further, the UNDP estimates that Haitians aged 25 years or older have received an average of only 4.9 years of schooling, and only $29 \%$ make it to secondary school. With AGYW making up $15-16 \%{ }^{1}$ of Haiti's population of 10.9 million, this schooling disparity compromises AGYW's safety, education, security, well-being, and-ultimately-their potential. Moreover, this differential prohibits AGYW from becoming active actors and changemakers in the economic, academic, or political sectorscausing their plight to go unspoken and unnoticed often by those within the country.

\section{The 2010 Earthquake}

It is well documented that despite an uptick of violence and restricted access to protective resources-like schooling-adolescent girls are not currently categorized as a high-risk group in

${ }^{1}$ Calculations from DHS (16\%). 
FIGURE 1. MAP OF HAITIAN EARTHQUAKE IMPACT BY REGION, 2010

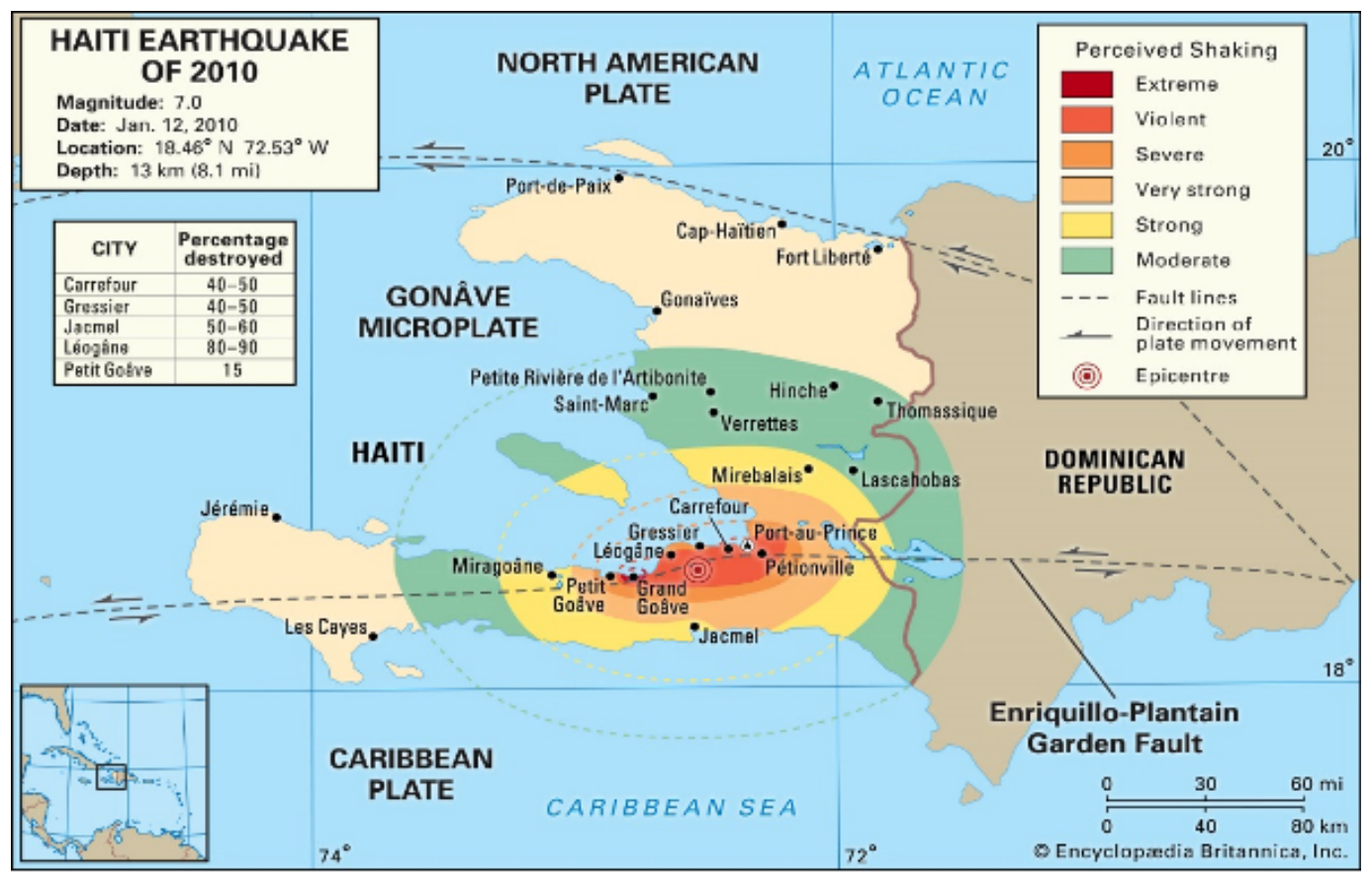

humanitarian efforts (Atkinson and Bruce 2015) exacerbating their risk and vulnerability to a myriad of adverse and dangerous circumstances and outcomes. Haiti was no exception to this observed pattern when faced with its own emergency.

In 2010, Haiti experienced a devastating earthquake creating (as can be seen in Figure 1 a particularly extreme impact in the Ouest and Sud-Est departments of the country, specifically in Port-au-Prince, Leogane (the epicenter of the earthquake), Jacmel, and Arcahaie.

Whereby prior to the earthquake, a portion of girls lived without at least one parent, the earthquake aggravated the problem, leaving an increasing number of very young adolescent girls parentless and responsible for caring for their younger siblings and earning an income. As a result, many girls were at risk for not finishing school-in a country that already has very low rates of school attendance-and being caught up in a cycle of poverty. These girls, now living in slums, IDP camps, and other relocation sites-even several years post-earthquake (and in light of other stressors such as political violence and Hurricane Matthew [2016])remain vulnerable to violence, sexual exchange for food and/or shelter, and innumerable other risk factors.

\section{The Haiti Adolescent Girls Network}

In response to reports of a dearth of humanitarian programming for girls and young women on the ground, a number of national NGOs, INGOs and their Haitian affiliates, camp committees, and local women's groups, led by the Population Council and AmeriCares, formed the Haiti Adolescent Girls Network (HAGN). From the first meeting, in June 2010, the Network sought to increase coverage with quality to the most-in-need girls. HAGN's commitment was to increase awareness among humanitarian responders and service providers about the distinct and critical needs 
TABLE 1. OVERVIEW OUTPUT TABLE WITH PROGRAM PARTICIPATION FOR ONE WALKABLE COMMUNITY OF CARREFOUR

\begin{tabular}{|c|c|c|c|c|c|c|c|c|c|c|}
\hline \multirow{3}{*}{$\begin{array}{l}\text { Age } \\
\text { group }\end{array}$} & \multicolumn{7}{|c|}{ Unmarried } & \multicolumn{2}{|c|}{ Married } & \multirow{3}{*}{ Total } \\
\hline & \multicolumn{3}{|c|}{ In School } & \multicolumn{3}{|c|}{ Out of School } & \multirow[b]{2}{*}{$\begin{array}{l}\text { Has a } \\
\text { child }\end{array}$} & \multirow[b]{2}{*}{$\begin{array}{l}\text { Has a } \\
\text { child }\end{array}$} & \multirow{2}{*}{$\begin{array}{l}\text { Does } \\
\text { not } \\
\text { have a } \\
\text { child }\end{array}$} & \\
\hline & $\begin{array}{l}\text { Living } \\
\text { with } \\
\text { both } \\
\text { parents }\end{array}$ & \begin{tabular}{|l} 
Living \\
with \\
one \\
parent \\
\end{tabular} & $\begin{array}{l}\text { Living } \\
\text { with } \\
\text { neither } \\
\text { parent }\end{array}$ & $\begin{array}{l}\text { Living } \\
\text { with } \\
\text { both } \\
\text { parents }\end{array}$ & $\begin{array}{l}\text { Living } \\
\text { with } \\
\text { one } \\
\text { parent }\end{array}$ & $\begin{array}{l}\text { Living } \\
\text { with } \\
\text { neither } \\
\text { parent }\end{array}$ & & & & \\
\hline $6-9$ & $0 / 270$ & $0 / 98$ & $0 / 27$ & $0 / 30$ & $0 / 19$ & $0 / 5$ & - & - & - & $0 / 449$ \\
\hline $10-12$ & $23 / 206$ & $11 / 87$ & $3 / 36$ & $4 / 15$ & $3 / 13$ & $6 / 9$ & - & - & - & $50 / 366$ \\
\hline $13-14$ & $10 / 80$ & $7 / 28$ & $4 / 11$ & $3 / 11$ & $0 / 3$ & $5 / 9$ & $0 / 0$ & O/O & $0 / 2$ & $29 / 144$ \\
\hline $15-17$ & $36 / 107$ & $13 / 65$ & $9 / 37$ & $4 / 10$ & $1 / 10$ & $3 / 10$ & $0 / 2$ & $0 / 6$ & $0 / 7$ & $66 / 254$ \\
\hline $18-19$ & $24 / 69$ & $5 / 34$ & $7 / 27$ & $5 / 10$ & $3 / 6$ & $2 / 5$ & $0 / 25$ & $0 / 12$ & $0 / 4$ & $46 / 192$ \\
\hline $20-24$ & 0/99 & $0 / 45$ & $0 / 45$ & $0 / 16$ & $0 / 30$ & $0 / 25$ & $0 / 69$ & $0 / 84$ & $0 / 28$ & $0 / 441$ \\
\hline Total & $93 / 831$ & $36 / 357$ & $23 / 183$ & $16 / 92$ & $7 / 81$ & $16 / 63$ & 0/96 & $0 / 102$ & $0 / 41$ & $191 / 1,846$ \\
\hline
\end{tabular}

of adolescent girls in post-earthquake Haiti, leading a movement to bring groups of at-risk girls together at least weekly in dedicated girlsonly safe spaces with mentors to build their protective assets and skills.

The Network was and is, as of 2020 , designed for collaborative learning with 15 local implementing partners and 16 senior mentors supported by dedicated staff to carry out work on the ground inside 5 of Haiti's 10 departments. In commitment to coverage with quality, a first step was taken to facilitate a learning process, including the implementation of the Girl Roster. As of 2020, the Roster was implemented in 15 communes, across 5 departments, and in 75 walkable communities in total; rostering was initially focused on the epicenter of the earthquake, though it was expanded into the West later, due to a focus on low-income or densely populated communities, the worsening economic situation, and geographies where new pressures were being faced as a result of the 2016 hurricane.

\section{The Girl Roster in Action}

At the Network's outset, many participating organizations had preexisting youth programs that engaged mixed groups-boys and girls, or girls and women. In many cases these programs skewed to those who had greater access to them. In Table 1, results from the rostering of one walkable community of the commune Carrefour are shared.

Carrefour is a densely packed urban commune on the edge of Port-au-Prince. The participating organization was implementing an energetic if conventional reproductive health, HIV, and gender-based violence program and was reaching a little under 200 girls, which was within itself an achievement. The Roster was applied to assess the coverage of the existing program and design the next stages of the program in the context of a persistent HIV epidemic affecting young females differentially. ${ }^{2}$

Not only is the overall prevalence of HIV in the country high-160,000 people were living with

\footnotetext{
${ }^{2}$ Haiti was identified as a DREAMS country in the DREAMS Partnership's third year of implementation in 2018. The investment focused in four geographic areas of Haiti: Cap Haitian, Dessalines, Saint Marc, and Port-au-Prince. For more details, visit https://www.state.gov/pepfar/.
} 
HIV in 2018-but the incidence of infection among females is a little less than twice as high as that of men. In 2018, new HIV infections among young women aged 15-24 were 1,600 compared to 1,000 among young men of the same ages (UNAIDS 2020).

Interested in knowing what kind of coverage it was achieving and with whom, HAGN asked the additional question: "Is this girl participating in Organization X's program?"3 In the Key Observations list, below, the denominator indicates the total number of girls in each cell, or segment, of the table, whereas the numerator indicates the number out of that segment who were participating in Organization X's program at the time.

A few key observations:

- $\quad$ Out of the total of 1,846 girls aged 6-24 in the defined walkable community, only 191-as Organization $X$ reported-were participating.

- The target population, by age only, of girls was 6-17 years old; the organization was only reaching $8.7 \%$ of girls in that age range (145 of the total 1,662 girls 6-17 years old).

- $\quad$ Second, of those 191 girls participating, 129 of them-or approximately 68\%-are girls 6-19 years old who were in school and living with one or both parents. That is to say, the majority of girls being reached were the most "well-off," indicating to HAGN and Organization $X$ that the program was facing the challenges of elite capture of participants and proper, more intentional reach was needed to reach most-in-need girls.

- $\quad$ Third, and most important, of the 143 girls under exact age 24 who were married and/ or had children in this commune, none of them were attending the program. Special attention is owed to this cohort; girls carrying the cost of childbearing alone are at especially high risk of poverty- driven sexual exchanges which, in turn, bring elevated risk of HIV and other bad outcomes.

Findings such as these encouraged not only Organization $X$ but also HAGN's other member organizations to rethink many facets of their approach to programming, noting that girlsonly groups have a powerful protective effectigniting friendships, connecting young girls with mentors, fostering a sense of belonging and solidarity, and giving girls a sense of safety in times of trouble. These platforms also, as HAGN and its members learned, served as a place to deliver critical new skills, and because HAGN's members were keen on a coordination of efforts, several of them collaborated to develop an open-source, age-graded financial-literacy program in Creole, with the input of the girls themselves, which was tested in HAGN's first year in 2010 and firmed up in 2011.

Mentors were a key component of the program's driving force. HAGN espoused a model at the time by which a cadre of peer mentors aged 18-35 who are from the same communities as their younger counterparts (the program participants) are engaged and fostered. Peer mentors were and are volunteers under HAGN's approach; they receive a stipend for transportation, communication, and miscellaneous. In 2011, as HAGN continued to grow, mobile payments to mentors were explored to guarantee swift and timely payment, encouraging continued mentor commitment.

\section{Conclusion}

In the last several years, HAGN has continued to grow and establish itself as a leading force of change in girls' lives in Haiti. In 2016, the Network-already independently staffed, overseeing its safe spaces program through each member organization, and in possession of independent funding-became incorporated.

\footnotetext{
${ }^{3}$ The organization's name has been excluded for privacy.
} 
As of 2020, the Network engages 15 active members, with each organization acting as "home" to a field coordinator or senior mentor, typically a contractor of HAGN, who is dedicated to overseeing the implementation of the safe spaces programming with assistance and support from the HAGN staff to whom she reports. The Intentional Design approach has taken hold in a number of ways, from the manner in which the program is implemented and the type of content that is provided. A total of 116 community-based mentors are dispersed in a highly coordinated, organized system to manage at least two safe spaces groups. Mentors range from 18-35 years of age; the mentors who are younger manage the younger girls' groups of 10-14-year-olds because they can relate to these girls and are only slightly older. Those mentors who are older manage both the older and young girls' groups, because they possess enough agency to manage the potentially more energetic older girls but can relate to both the younger and older girls. As of 2020, there were over 230 active girls' groups on the ground, with 5,800 girls enrolled. In every group, the financial literacy and social/emotional learning assets have been adapted to the particular community contexts with, for example, girls in agricultural areas gaining agricultural skills while others in more urban areas learning commercial cooking or cosmetology. All settings benefit from starter savings.

\section{In Our Experience}

The Girl Roster and other Intentional Design tools proved to be effective in helping HAGN determine how to:

- $\quad$ effectively engage community members from the very start of implementation;

- $\quad$ promote girl-centered programming within HAGN intervention communities.

By 2018, the Roster exercise was fully integrated into HAGN's work, specifically in new intervention areas.
The results have also helped prioritize segments of girls and guide door-to-door participant recruitment. As a way to strengthen local engagement and buy-in, and given that communal councils do not have access to population figures at such a sublocal level, the Roster information, in addition to Coverage information, is shared with local authorities, including the communal councils and the representatives of line ministries, such as the Ministry of Public Health and Population at the departmental level.

As HAGN moves forward, in 2020 and beyond, it intends to continue to use the Intentional Design approach to deepen understanding of the lived experience of different girl segments in its intervention areas. It will continue to build internal capacity and it aspires to more strongly document the work being done on the ground.

At a programmatic level, HAGN continues to expand girl programming priority areas, extending capacity building to local organizations that have a desire to utilize the Intentional Design approach (and the resulting HAGN curriculum) for their own girl programs. HAGN seeks to develop cascading leadership and youth networking, engagement, and civic participation at the local, national, and international level.

For more information, please visit HAGN's website at: https://hagn.devhaiti.org/. 


\title{
Practitioner Report 5
}

\section{Fine-Tuning the Batonga Foundation's Approach to Reaching Girls: Mapping, Targeting, and Training Benin's Future Leaders}

\author{
By Emily Bove, Wenceslas Djokpe, Sarah Engebretsen, and Caitlin Hone
}

\begin{tabular}{|c|c|}
\hline Findings and Decisions & Implementation Observations and Adaptations \\
\hline 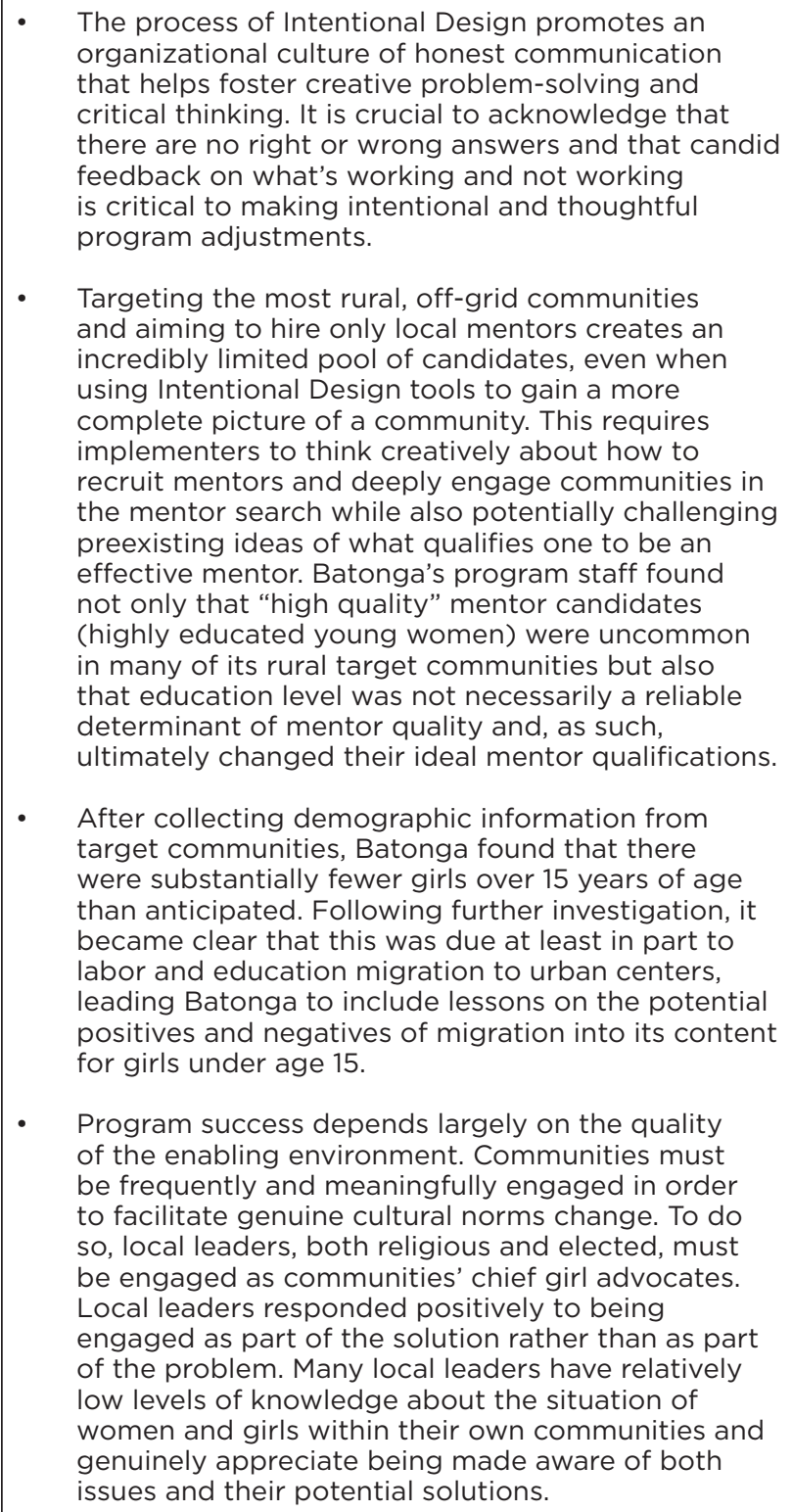 & $\begin{array}{l}\text { - A guiding principle in Batonga's use of the Council's } \\
\text { Intentional Design approach has been to let go } \\
\text { of preconceived notions and assumptions about } \\
\text { girls, their needs, and their communities; instead, it } \\
\text { decided to find ways to learn about girls' lives and } \\
\text { incorporate the findings into actionable program } \\
\text { information. For example, program staff held initial } \\
\text { skepticism about out-of-school girls' motivation } \\
\text { to attend regular club meetings as well as their } \\
\text { capacity to grasp complex content, but they were } \\
\text { quickly proven wrong by the participants' incredible } \\
\text { motivation and voracious desire to gain new } \\
\text { knowledge regardless of education status. } \\
\text { Additionally, program staff were originally reluctant } \\
\text { to introduce sexual and reproductive health content } \\
\text { into the program for young adolescent girls, } \\
\text { anticipating strong pushback from families and } \\
\text { community members. However, the substantial need } \\
\text { observed in adolescent girls through the "pretest" } \\
\text { led program staff to push past this concern; in turn, } \\
\text { program staff found that families and communities } \\
\text { were significantly more supportive than anticipated } \\
\text { because of their collective understanding of the } \\
\text { issues posed by unwanted teen pregnancy in their } \\
\text { communities. } \\
\text { There are significant limitations on how much } \\
\text { can be extrapolated about other communities } \\
\text { from information collected at the local level in } \\
\text { current target communities. Batonga's program } \\
\text { designers recognized the need to acknowledge } \\
\text { heterogeneity between and within communities } \\
\text { in order to effectively and intentionally design } \\
\text { programming that worked for each community. } \\
\text { When planning to scale up in new communities, } \\
\text { Batonga's program staff learned to: } 1 \text { ) Use the } \\
\text { most recent health and maternity state surveys } \\
\text { to gain a general understanding of the regional } \\
\text { populations; } 2 \text { ) Reference information collected in } \\
\text { existing target communities to provide a base of } \\
\text { context understanding; and } 3 \text { ) Collect entirely new } \\
\text { information from the communities in which they } \\
\text { intended to scale. }\end{array}$ \\
\hline
\end{tabular}




\begin{tabular}{|c|c|}
\hline Findings and Decisions & Implementation Observations and Adaptations \\
\hline $\begin{array}{l}\text { - Religious leaders specifically may need to be } \\
\text { sensitized to the content the girls will be taught } \\
\text { to avoid obstacles down the line. Pretest findings } \\
\text { suggested that Batonga needed to deliver sexual } \\
\text { and reproductive health content to significantly } \\
\text { younger adolescents than they were currently } \\
\text { reaching. Although program staff were initially } \\
\text { hesitant about pushback from religious leaders on } \\
\text { the delivery of this content, they found that when it } \\
\text { was presented to religious leaders in an open and } \\
\text { honest way, the majority of leaders were supportive } \\
\text { and appreciated having the content demystified } \\
\text { and transparent. }\end{array}$ & $\begin{array}{l}\text { - Although household-level information collection is } \\
\text { critical to program designers' ability to gain a clear } \\
\text { picture of a given community and target population, } \\
\text { accuracy can be a significant challenge. Information } \\
\text { collection in polygamous households with multiple } \\
\text { wives revealed the challenge of some parents being } \\
\text { unaware of the ages or educational statuses of all } \\
\text { the children living in their household/compound. } \\
\text { In the case of polygamous households, Batonga } \\
\text { chose to have rosterers divide households by } \\
\text { mothers/female family heads, rather than fathers/ } \\
\text { male family heads to facilitate more accurate } \\
\text { information collection, as they found mothers } \\
\text { to have more complete knowledge of their own } \\
\text { children's information than any other caregiver in } \\
\text { the household. }\end{array}$ \\
\hline
\end{tabular}

Starting in 2015, the Batonga Foundation embarked on the process of Intentional Design, beginning with reviewing available evidence and collecting systematic information about girls and their communities. As of 2019, the Batonga Foundation program entitled Mapping, Targeting, and Training Benin's Future Leaders was being implemented with the goal of identifying the most-off-track adolescent girls and young women aged 10-26. Program clubs are broken into segments of 10-11-yearolds, 12-16-year-olds, and 17-26-year-olds in 15 communities surrounding Savalou and Bohicon, in Benin, in which segments of girls are engaged in weekly sessions to acquire social and financial education to increase economic opportunities.

The current program required important shifts from Batonga's previous approach to reaching girls through scholarship provision. With support from the Population Council, Batonga reflected on its approach and realized it was leaving the most-off-track girls behind and began a process of going to new communities to learn about girls living there before offering any services.

Over the past few years, Batonga has conducted systematic information-gathering about girls and their communities to inform program activities and identify potential course corrections in program implementation. Information generated from monitoring activities, observation, training notes, and discussions with country and field staff constituted the basis of this report. Lessons derived from Batonga's experience have been summarized into the following categories:

- Building an efficient team and finding the right mentors, establishing a productive team culture, and collective unlearning;

- Learning about our target population through the Girl Roster and other toolsmaking visible key segments of girls, including migrants and very young adolescents;

- Assuming nothing: The role of a "pretest" and focus group discussions in revealing girls' needs and informing program content;

- Looking beyond Batonga to available services: A landscape of programs in Benin and the Coverage Exercise;

- Looking ahead: Reintroducing key resources on girls and sharing through the learning circle. 
Building an Efficient Team and Finding the Right Mentors, Establishing a Productive Team Culture, and Collective Unlearning

\section{Building an Efficient Team}

Batonga aimed to increase its presence in Benin and refine its programmatic impact through hiring a dynamic and efficient in-country staff. Candidates for Cotonou-based positions were invited to participate in training workshops, including Girl Roster field trainings, to gauge their abilities and willingness to understand the context and conditions of girls' lives. Within those workshops, US-based Batonga staff and global experts working with adolescent girls observed the candidates' willingness to learn, observed their capacity for teamwork and decisionmaking, and listened to their perspectives and assessed suitability while looking out for any prejudices.

Once the in-country staff had been hired and a new Program Officer position had been established in the US, Batonga continued to reflect on its staffing structure to make sure it was as efficient as possible but also deeply rooted in the local realities faced by the girls it served. A process evaluation, conducted in the last quarter of 2017, helped Batonga understand whether staff were implementing the girls' program as planned. One observation was that as the staffing structure became larger, greater clarity was needed on individual roles and ownership of specific pieces of the work. Batonga has also made a concerted effort to recruit more women to the Cotonou-based team.

\section{Finding the Right Mentors}

Knowing that the mentors would be the direct line of contact with program participants, Batonga was thoughtful in its approach to mentor recruitment and selection. Batonga built on the Population Council's global experience with local mentors in order to increase their ability to understand girls' challenges, to gain the trust of parents and guardians for girls' participation, and to increase their accessibility outside of regularly scheduled girls' meetings. Batonga planned for ways to train mentors in new program content but also support their ongoing learning via weekly check-ins with facilitators who oversee program facilitation. Careful thought was also given to support leadership development for exceptional mentors, supporting them in extending their contributions to programmatic strategy and implementation (for example, select mentors were given the opportunity to actively support curriculum development and contextualization).

As Batonga considers expansion and the need to engage more mentors down the line, it also considers increasing the number of training and leadership opportunities offered to mentors to build their skills and actively engage them in their own assessments and in planning activities for scale.

\section{Building a Productive Team Culture}

It was equally important to infuse the program staff and mentors alike with the notion that in girl-centered programming there are no right or wrong answers and that candid feedback on what's working and not working is critical in making tangible program adjustments. A culture of learning and exchange has been a cornerstone of Batonga's work, and the Foundation provided scheduled and needsbased technical and administrative coaching and support in addition to training on specific program content for mentors. Recognizing that the best way to learn is by observing others, Batonga made room for its mentors to observe one another in action and found that this enriched the dialogue at weekly mentor meetings. Batonga launched a formal peerto-peer observation program, where mentors hosted other mentors on site for up to four days at least twice a year, followed by conversations and exchanges animated by the team.

\section{Collective Unlearning}

Parallel to the effort to provide ongoing opportunities for mentor learning, Benin- and 
Cotonou-based staff have also reflected on their own learning-and related "unlearning." Unlearning is often linked to assumptions about effective program delivery structures and stereotypes about the social and economic attributes of the target population.

For example, program staff reflected that the education level or age of a mentor does not reliably determine the quality of mentor that they will be. One of the challenges initially faced by the project was the absence of highly educated candidates for mentor positions. Young women who finish high school tend to move to larger towns, and for many of the targeted villages it was impossible to find young educated women. This was primarily an issue in the small, rural, and off-grid villages without high schools around Savalou. In those villages, Batonga was forced to raise the age limit and lower the minimum education standard for mentor candidates. Initially, Batonga's Beninbased team wondered whether less-educated or older women could effectively take on the teaching role in particular. Team members held the assumption that higher education levels would result in higher quality of teaching and mentorship. But thanks to internal discussions, exchanges with local women, and a recruiting process that was fair and based on consistent criteria, the team rapidly realized that education level was not a reliably effective determinant of mentor quality and that some of the best mentors are dynamic, compassionate, motivated women who may not have even finished middle school.

\section{Learning about Communities and} the Girls Who Live There: The Role of the Girl Roster and Other Tools in Making Visible Key Segments of Girls, Including Migrants and Very Young Adolescents

As Batonga contemplated where to invest its program efforts, the Girl Roster provided a systematic way to learn about the full "universe" of girls living in each community. As program staff experimented with the Roster, they learned about new segments of girls who had not previously been on their radar. For example, the Roster revealed that there are important phenomena affecting older adolescents, including the need to migrate to larger towns and cities for income-generating opportunities. Although the Roster has not proven useful for nomadic populations in other contexts, it was able to alert the team to the prevalence of late adolescent migration and the implications that may have for target communities.

The growing interest in migration led to a thoughtful approach of inquiring about this phenomenon in other information-gathering activities, such as a pretest among program participants and a Coverage Exercise to assess who was being reached by existing youthserving programs in Benin. The Coverage Exercise, conducted in urban centers that often serve as migration destinations for rural young women, found that less than one-third of people attending youth-serving programs had migrated from elsewhere, but almost four out of five of those who had migrated from elsewhere had done so alone, outside the context of family. This finding led Batonga to consider the differential needs of girls choosing to move away from home and include additional curriculum content related to labor migration and the challenges it can pose to young female migrants and their families. Batonga is also choosing to address this subject with young adolescents who may not have decided yet whether or not to migrate.

The team has also learned to turn to data for a more macro picture of girls' lives. Looking at both subnational and community-level data on adolescent girls' lives in Benin revealed that a steep decline in school participation begins around age 13 (see Figure 1). This finding resulted in the team pushing past donor age preferences to insist on inclusion of very young adolescents in Batonga's programming. 
FIGURE 1. SITUATION OF GIRLS IN BENIN BY AGE AND BASIC ROSTER CHARACTERISTICS

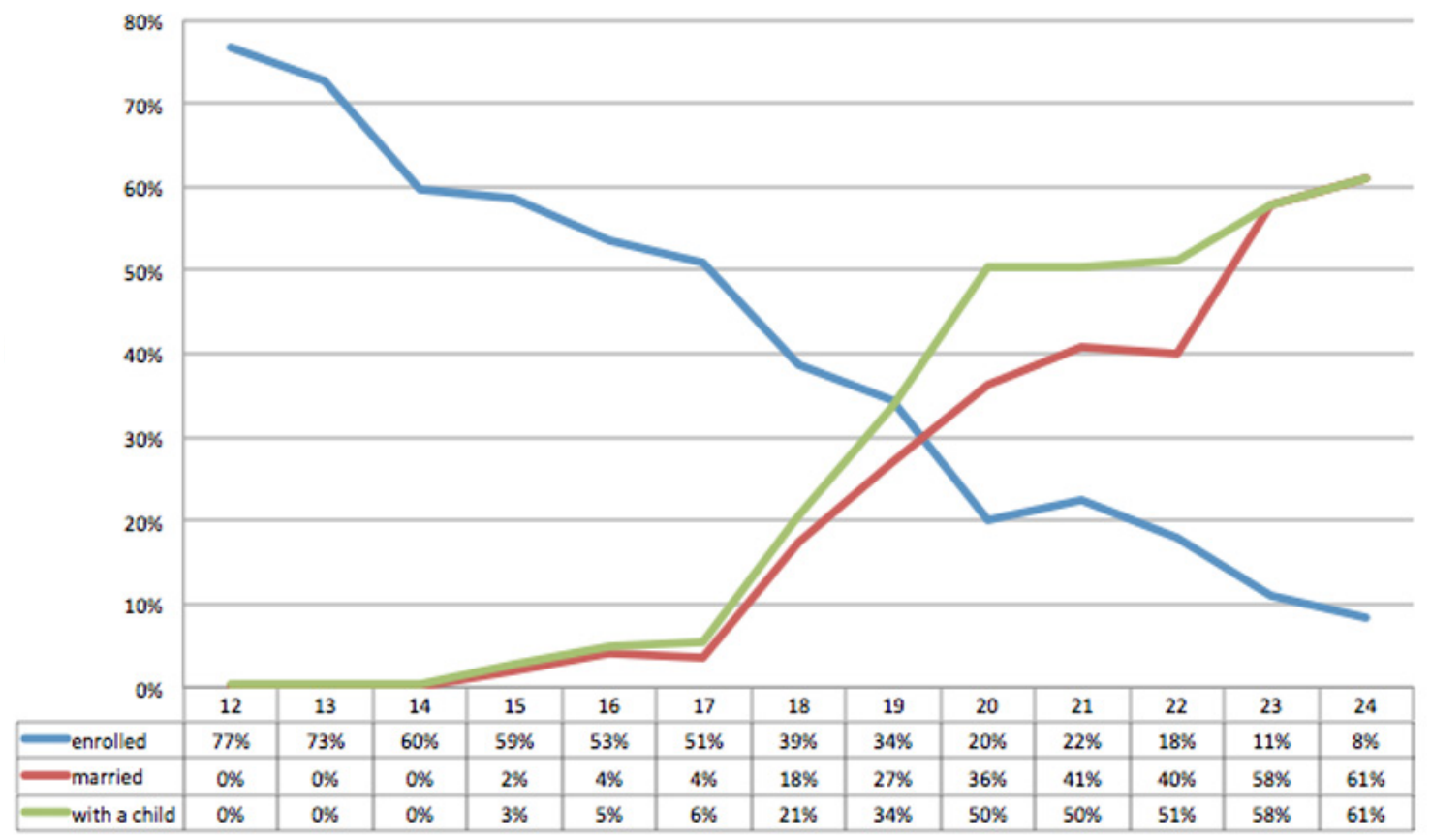

Source: Figure prepared by Angel del Valle using Girl Roster data collected from 1,080 households in Benin, in 2016.

\section{Assuming Nothing: The role of a Pretest and Focus Group Discussions in Revealing Girls' Needs and Informing Program Content}

A guiding principle in Batonga's thoughtful approach to Intentional Design has been to let go of assumptions and find ways to ask about girls' lives and incorporate the findings into actionable program information. Batonga had previously used intake rosters to reveal information about program participants, but there was a desire to broaden the scope of questioning and gain a more comprehensive view of the lives of adolescent girls in Benin to help inform program course corrections. As such, the team engaged in an iterative process of designing a learning plan, generating pretest questions to help inform the learning, and refining questions to be age appropriate.

Some of the pretest questions addressed areas where Batonga would expect to see a change over time (e.g., in knowledge about sexual and reproductive health and attitudes toward savings) and others were exploratory in nature to scratch the surface of Batonga's next phase of learning (e.g., about high interest technologies for girls). Batonga staff members each read the report summarizing the pretest findings and formulated his/her own view on findings that merited: a curriculum adaptation or intensification, a curriculum differentiation for older versus younger adolescents, additional mentor training or support, and additional information gathering. For example, the findings highlighted a stark lack of reproductive health knowledge particularly among young adolescents, which led Batonga's staff to reassess the curriculum content and add additional lessons on sexual and reproductive health for girls aged 12-14 years. The team also grappled with how and what to share with the community, and with mentors, facilitators, in-country girl practitioners, and other stakeholders. 
The pretest answered questions but also raised many more, and Batonga decided to conduct focus group discussions with girls to better understand their needs. Contrary to a common perception among team members, the pretest had shown that more girls had personal identification documents than everyone had thought. Recognizing the relationship between identity documents and access to entitlements, the team devised a series of questions to better understand common types of identity documents and how girls go about getting them. It seemed that girls of voting age had been given a special voting card, but more universal documents like birth certificates were still largely uncommon. On further inquiry, Batonga realized that many girls were counting forms of IDs that were either informal, unofficial, or wouldn't allow them to do certain things like register to vote or open a bank account. Batonga is working with potential donors to develop a program component that would address girls' lack of identification documentation.

\section{Looking Beyond Batonga to Available Services: A landscape of Programs in Benin and the Coverage Exercise}

Batonga is innovating new program approaches while simultaneously trying to understand typical program models for girls and young people in Benin. The Batonga Foundation gathered evidence on current programmatic approaches via a short survey circulated to members of the Adolescent Girls Learning Circle $^{1}$ and via in-depth conversations with key program staff from organizations intervening with girls in the geographic area surrounding Batonga's target communities. Findings from eight surveys and eight in-depth interviews revealed some common approaches to programming for girls in Benin:

- Numbers: There is great variation in the number of girls being reached by current interventions, likely owing to different methods of measuring those who are considered program beneficiaries.

- Intentionality: While there are likely numerous innovative ideas being tested in interventions, the intentionality in approach and geographic selection is not always clear. Thoughtfully designed programs for girls should have geographic specificity (related to data on need) and clear theories of change about how the program's inputs and activities result in desired outcomes.

- Measurement: Changes in the target population are not being measured as often as program outputs (e.g., number of people trained). Measurement at the level of the girl is a topic where practitioners could use additional support.

- Type of activity: Programs for young people tend to focus on sexual and reproductive health and rights, and advocacy far outweighs program monitoring and evaluation.

- $\quad$ Segments of interest: Insufficient attention is paid to designing programs with specific segments of girls in mind, and girls are often seen as "junior women." Adolescent girls are a heterogenous segment, with differences vis-à-vis schooling, marital status, living arrangements, etc.

- Disaggregation: Few organizations disaggregate their activities by gender and granular age segments, and program content is rarely adapted to meet the needs of specific segments.

These findings whetted Batonga's appetite to learn more about programs in Benin through the lens of program beneficiaries rather than providers to see if those coming to programs were those that providers set out to reach. Given the trend toward urbanization and Batonga's interest in learning about available services in urban areas, a Coverage Exercise was conducted to reveal who was being

\footnotetext{
${ }^{1}$ The Batonga Foundation has made important strides in convening an Adolescent Girls Learning Circle in Benin, which was formed following a workshop held in Cotonou in 2017 with 40 participants representing seven countries in francophone Africa.
} 
reached by a large-scale program in a few distinct geographic areas. Over a period of four weeks, the information was gathered on a total of 1,284 individual observations with program beneficiaries in and around two youth centers, one in Bohicon and one in Savalou. The Coverage Exercise revealed that the youngest adolescents (aged 10-14) were minimally reached by the program and a large proportion of program beneficiaries had already aged out of adolescence (definition is 10-19). It also showed that program beneficiaries are largely those who have always lived in these locations, as opposed to in-migrants, and the majority are unmarried and live in a household with both of their parents. These findings leave numerous questions about a potential misalignment between needs of girls in urban Benin and services available to them, and Batonga is weighing the possibility of conducting the Girl Roster and Coverage Exercise in new villages to look at demand and supply in tandem.

\section{Looking Ahead: Reintroducing Key Resources on Girls and Sharing Learnings Via the Adolescent Girls Learning Circle in Benin}

As of 2020, Batonga has made steady progress in systematic information-gathering as part of a long-term process of Intentional Design, but the learning and refinement of targeted, evidencebased programming for girls is far from over. The team is currently refining the organization's strategies for differentiating program content for different age segments. The team will be going back to conduct the Asset Exercise again with an eye toward developing positive benchmarks for girls and working backward from them to meaningful program content. Although the Asset Exercise has been done in years past, the team recognizes that recent information-gathering activities and new staff on board may influence ideas about when girls need to acquire specific health, social, and economic assets. They are also looking to revisit essential resources on girls, such as Investing When It Counts, a publication focusing on the need to invest in very young adolescents and differentiated learning methodologies for them. Batonga is also developing a robust M\&E system that would enable ongoing data collection and support more consistent learning based on feedback mechanisms and evidence. Findings will support the creation of a publication series aimed at diffusing lessons learned and best practices to broader audiences, inside and outside of Benin. Batonga is now thinking about the best way to share its own learning journey and Intentional Design process through the Adolescent Girls Learning Circle and with other practitioners in Benin.

For more information, please visit the Batonga Foundation's website: https:// batongafoundation.org. 


\title{
Practitioner Report 6
}

\section{Implementing Intentional Design Tools in CSAGE (Community Spaces for Adolescent Girls Empowerment), Northern Nigeria, to Build a New Program and Assess Coverage of an Ongoing Program}

\author{
By Habiba Mohammed, Made George, Joy Ochai, David Cao, and Daniel Perlman
}

\begin{tabular}{|l|l|}
\hline Findings and Decisions & $\begin{array}{l}\text { Implementation Observations and Adaptations } \\
\text { - } \begin{array}{l}\text { Meaningful variation of northern Nigerian } \\
\text { communities in the proportion of girls off-track- }\end{array}\end{array}$ \\
$\begin{array}{l}\text { ranging from } 7 \% \text { in one urban community to } 28 \% \text { in } \\
\text { one rural community-indicating more off-track girls } \\
\text { in rural rather than urban communities. }\end{array}$ & $\begin{array}{l}\text { Depending on segment and setting, the program's } \\
\text { contact with participants was never less than } 80 \\
\text { hours and rose to } 400 \text { hours in some cases. }\end{array}$ \\
$\begin{array}{l}\text { Disaggregation sharpens contrasts among girls } \\
\text { 15-19 years; more than 70\% of girls were married } \\
\text { in the rural settings compared to 25\% in the more } \\
\text { years of programming each over the last four years. }\end{array}$ & \\
urban settings. \\
$\begin{array}{l}\text { Numerically, there are more married girls in absolute } \\
\text { numbers in the rural community, even though it is } \\
\text { half the size of the urban community. }\end{array}$ \\
$\begin{array}{l}\text { Two groups stand out as exceptionally underserved: } \\
\text { 10-14-year-old unmarried girls out of school; and } \\
\text { 15-19-year-old married girls. }\end{array}$ \\
$\begin{array}{l}\text { Girls who completed the cSAGE program were able } \\
\text { and eager to serve as mentors to other girls in their } \\
\text { communities. }\end{array}$ \\
$\begin{array}{l}\text { The program grew far more effective, socializing the } \\
\text { community to girls' rights and preparing them for } \\
\text { school; a preschool program was established for a } \\
\text { very young segment of girls 4-7 years old. }\end{array}$
\end{tabular}

\section{Background}

Since 2007, the Centre for Girls Education (CGE) has worked to advance adolescent girls' education and empowerment in northern Nigeria through innovative programming, advocacy, applied research, and strategic partnerships. CGE has been a pioneer in the adaptation of the safe spaces methodology to rural adolescent girls' need for core academic competencies, vocational training, mentored support, and acquisition of crucial life skills. The core components of CGE's programmingcommunity engagement, collaboration with religious leaders, safe spaces (mentored girls' groups), training of female teachers, and the nurturing of girl advocates-have evolved over a decade of community-based research with girls, their parents, and community members.

CGE utilized two Intentional Design toolsthe Girl Roster and the Community Resource Scan-in three communities in Northern Nigeria in January 2014. CGE had been working with adolescent girls in two of the three communities using a safe spaces approach, focused on inschool girls principally, for a number of years, and a project partner was considering working in another community. This report demonstrates using the Girl Roster both to assess the full 
"universe" of girls to inform the planning of a new program and to assess coverage of an ongoing program.

The Community Resource Scan and Girl Roster were implemented with the Population Council, Nigeria, and partners as part of a larger formative research project to identify adolescent girl segments and communities in several focus states for the Community Spaces for Adolescent Girls' Empowerment (CSAGE) project.

CGE-which had developed and implemented safe spaces for school-going adolescent girls in Kaduna State since 2008-partnered with CSAGE as a learning hub to support learning, training, and dissemination for civil society organizations on the safe spaces model and approach. The CSAGE project aimed to improve the sexual and reproductive health of poor and vulnerable adolescent girls in northern Nigerian states using community-based, girl-only safe spaces to enable them to acquire key health, social, cognitive, and economic assets across six northern states. ${ }^{2}$

CSAGE's vision was to bring together all key adolescent girl subpopulations in segmentspecific safe space platforms that would be tailored to the specific needs of that girl segment. However, there was no clear picture of the different segments of girls nor of the community resources that could be designated as safe spaces in the different program catchment areas. CSAGE/CGE used the Girl Roster and Community Resource Scan tools to:

- Roster the universe of adolescent girls in the project communities (by age, schooling, marital and childbearing status, and adult sponsorship status);

- Identify segments of girls for priority targeting and recruitment;

- Conduct an in-depth inventory of community resources including programs that could reach girls but do not currently do so, and assess their reach and accessibility to girls;

- Begin to identify how the project can link different segments of adolescent girl segments with critical human, health, and financial services.

The Roster and Scan would thus allow CSAGE to maximize impact and value for money through enhanced targeting of atrisk subpopulations and efficient delivery of services.

At the same time, CGE and other project partners sought to use these tools to better understand how their own programs have been reaching their intended beneficiaries in their catchment areas. CGE had thus far only focused on working with school-going adolescent girls aged 10-14 years but intended to expand its work to other vulnerable adolescent girl segments, including out-of-school and married girls.

The first part of this practitioner report details the mapping exercise in three communities in Kaduna state in which CGE was involved in its partnership with CSAGE.

\section{Tool Modification}

The Girl Roster was modified in one important way. A question was added to clarify if the school a girl attends or attended teaches "Western"-style or secular education. In Northern Nigeria, almost all Muslim children, including girls, attend some form of religious school (called an Islamiyah or Qur'anic school). While children often attend these schools before or after their formal schooling hours, for others these religious schools may be the only form of education they receive. Recent efforts have been made to introduce secular subjects such as mathematics, social studies, integrated science, and/or English into these religious schools. Thus, by asking if the school teaches "Western"-style or secular subjects,

\footnotetext{
${ }^{1}$ Community Spaces for Adolescent Girls' Empowerment (CSAGE) was formed by the Population Council with funding from the UK Department for International Development in 2013.

2 Jigawa, Kaduna, Kano, Katsina, Yobe, and Zamfara.
} 
TABLE 1. TIME-FRAME SUMMARY

\begin{tabular}{|l|c|c|c|c|}
\hline & Days & Households & HH/EPair/Hr & Minutes/HH \\
\hline Biye & 3.5 & 370 & 3.5 & 17.1 \\
\hline Dakace & 7 & 869 & 4.2 & 14.3 \\
\hline Rafin Guza & 6 & 761 & 4.2 & 14.3 \\
\hline
\end{tabular}

religious schools that included academic subjects were also appropriately classified as "formal" schooling. The initial pilot testing of the unmodified Roster in other communities failed to take this into consideration and led to an incorrect assessment that there were few out-of-school girls in those communities. Based on this previous experience, the Girl Roster was modified for further implementation in Kaduna State.

\section{Training}

CGE staff were trained by CSAGE (with the Population Council's assistance) for two days, which included orientation to the mapping tools and practice using the mobile phones as information-collection tools in a nearby community. All staff members had enumeration experience with pen and paper surveys but were new to the use of mobile phones for this sort of exercise. The two full days allowed the staff members to become fully comfortable administering the tools in the field.

\section{Location}

CSAGE implemented the Roster and Scan in three contrasting communities in Kaduna State. Two of the three communities, Biye and Dakace, surround the town of Zaria and are rural and peri-urban communities, respectively, in which CGE has created safe spaces programming since 2008. The third community, Rafin Guza, is located within Kaduna City and is an urban community where a CSAGE partner organization was planning to but had not yet worked.

\section{Fieldwork}

Using maps from the Population Census of the Federal Republic of Nigeria and provided by the National Population Commission, a pair of rosterers was assigned to map specific census enumeration areas (EAs). Nigerian localities are subdivided into census EAs. These geographic units are demarcated by easily identifiable features such as streets as well as administrative boundaries such as city and municipal limits. The EAs are nonoverlapping, cover the entirety of a given locality, and are small with an average of 48 households. These maps greatly aided in ensuring that rosterer pairs did not visit the same household twice.

The five rosterer pairs mapped the three communities in 16.5 days at 5 hours a day of active information collection (see Table 1). On average, each pair took 17 minutes to locate and list each household in the first community, but this decreased to 14 minutes per household after the rosterers became more comfortable administering the tools.

In each community, each pair initially interviewed three to four households and then regrouped to review the information collected, share experiences, and receive feedback.

Pairs then returned to check in with the field supervisor two to three times each day to have their information reviewed for any errors. The Roster did not incorporate redundancy error checks, so rosterers had to ensure that: 1) the stated number of girls was consistent with the stated number of household members minus adults and boys; and 2) that the number of girls for which information was collected matched the stated number of girls in the household. 
TABLE 2. UNIVERSE OF GIRLS AGED 6-25 YEARS IN BIYE (RURAL) LOCALITY, GIWA LOCAL GOVERNMENT AREA, KADUNA STATE

\begin{tabular}{|c|c|c|c|c|c|c|c|c|c|}
\hline \multirow{3}{*}{$\begin{array}{l}\text { Age } \\
\text { group }\end{array}$} & \multicolumn{6}{|c|}{ Unmarried } & \multicolumn{2}{|c|}{ Married } & \multirow{3}{*}{ Total } \\
\hline & \multicolumn{3}{|c|}{ In School } & \multicolumn{3}{|c|}{ Out of School } & \multirow[b]{2}{*}{$\begin{array}{l}\text { Has a } \\
\text { child }\end{array}$} & \multirow{2}{*}{$\begin{array}{l}\text { Does } \\
\text { not } \\
\text { have a } \\
\text { child }\end{array}$} & \\
\hline & $\begin{array}{l}\text { Living } \\
\text { with } \\
\text { both } \\
\text { parents }\end{array}$ & $\begin{array}{l}\text { Living } \\
\text { with } \\
\text { one } \\
\text { parent }\end{array}$ & $\begin{array}{c}\text { Living } \\
\text { with } \\
\text { neither } \\
\text { parent }\end{array}$ & $\begin{array}{l}\text { Living } \\
\text { with } \\
\text { both } \\
\text { parents }\end{array}$ & $\begin{array}{l}\text { Living } \\
\text { with } \\
\text { one } \\
\text { parent }\end{array}$ & $\begin{array}{l}\text { Living } \\
\text { with } \\
\text { neither } \\
\text { parent }\end{array}$ & & & \\
\hline $6-9$ & 157 & 8 & 5 & 39 & 4 & 3 & - & - & 216 \\
\hline $10-11$ & 59 & 4 & 4 & 18 & 0 & 1 & - & - & 86 \\
\hline $12-14$ & 83 & 6 & 0 & 38 & 1 & 0 & 1 & 4 & 133 \\
\hline $15-17$ & 16 & 1 & 0 & 10 & 0 & 1 & 26 & 32 & 86 \\
\hline 18-19 & 8 & 1 & 0 & 1 & 0 & 0 & 31 & 5 & 46 \\
\hline $20-25$ & $\mathrm{O}$ & 0 & $\mathrm{O}$ & 3 & 0 & 0 & 75 & 9 & 87 \\
\hline Total & 323 & 20 & 9 & 109 & 5 & 5 & 133 & 50 & 654 \\
\hline
\end{tabular}

Such errors were common during the two-day training but were minimized during the actual fieldwork, particularly due to constant check-ins with the field supervisor.

Rosterers spent the majority of time in pairs. However, some pairs ended up, once confident, continuing to roster individually; this was especially helpful as it accelerated rostering. Two field officers conducted the Community Resource Scan in 3 to 5 hours for each community.

Rosterers were well received by the communities and reported strong positive reception. Few households refused to take part in the listing; in the majority of these cases the reason stated was that no appropriate adult was present. CGE has worked in Biye and Dakace since 2007 and has forged strong relationships with community leaders and members. For communities in which CGE has not worked, an additional two days is recommended for community engagement. CGE would also advise adding several minutes at each household to provide families more time to answer any questions they may have about the potential or existing program and/or the mapping process.
The key here, especially in communities in which you do not currently work, is to not overpromise what will happen as a result of the rostering, but rather frame it as a step to learn more to help design programs.

\section{Results}

See Tables 2 and 3 for illustrative results. (For Rafin Guza, illustrative results are not shown.) Because CSAGE's stated aim was to improve the sexual and reproductive health of adolescent girls aged 10-19 years, the following summary only focuses on this group.

\section{Brief Summary of Adolescent Girls Aged 10-19 Years (2014 Findings)}

Across all three communities we see important variation among girls 10-19 years old: In Biye, $52 \%$ of all girls are unmarried and school-going; in Dakace, it is $74 \%$; and in Rafin Guza, it is $65 \%$.

Tightening the age range in analyses from 10-19 to 15-19 reveals more important contrasts in percentages and numbers of different segments and across rural, peri-urban, and urban settings. 
TABLE 3. UNIVERSE OF GIRLS AGED 10-19 YEARS IN DAKACE (PERI-URBAN) LOCALITY, ZARIA LOCAL GOVERNMENT AREA, KADUNA STATE

\begin{tabular}{|c|c|c|c|c|c|c|c|c|c|}
\hline \multirow{3}{*}{$\begin{array}{l}\text { Age } \\
\text { group }\end{array}$} & \multicolumn{6}{|c|}{ Unmarried } & \multicolumn{2}{|c|}{ Married } & \multirow{3}{*}{ Total } \\
\hline & \multicolumn{3}{|c|}{ In School } & \multicolumn{3}{|c|}{ Out of School } & \multirow[b]{2}{*}{$\begin{array}{l}\text { Has a } \\
\text { child }\end{array}$} & \multirow{2}{*}{$\begin{array}{l}\text { Does } \\
\text { not } \\
\text { have a } \\
\text { child }\end{array}$} & \\
\hline & $\begin{array}{l}\text { Living } \\
\text { with } \\
\text { both } \\
\text { parents }\end{array}$ & $\begin{array}{l}\text { Living } \\
\text { with } \\
\text { one } \\
\text { parent }\end{array}$ & $\begin{array}{l}\text { Living } \\
\text { with } \\
\text { neither } \\
\text { parent }\end{array}$ & $\begin{array}{l}\text { Living } \\
\text { with } \\
\text { both } \\
\text { parents }\end{array}$ & $\begin{array}{l}\text { Living } \\
\text { with } \\
\text { one } \\
\text { parent }\end{array}$ & $\begin{array}{l}\text { Living } \\
\text { with } \\
\text { neither } \\
\text { parent }\end{array}$ & & & \\
\hline $10-14$ & 346 & 31 & 14 & 47 & 3 & 3 & 0 & 3 & 447 \\
\hline $15-19$ & 156 & 16 & 15 & 46 & 5 & 3 & 58 & 32 & 331 \\
\hline $20-25$ & 42 & 6 & 5 & 22 & 7 & 5 & 136 & 27 & 250 \\
\hline Total & 544 & 53 & 34 & 115 & 15 & 11 & 194 & 62 & 1,028 \\
\hline
\end{tabular}

- For all adolescent girls 15-19 years old, we see that only $29 \%$ of girls are unmarried in Biye, as compared to Dakace's $73 \%$ and Rafin Guza's 75\%.

- The unmarried school-going segment only comprises $20 \%$ of all girls in Biye, as compared to $57 \%$ in Dakace and $45 \%$ in Rafin Guza. This is not surprising as Biye is a primarily rural community, and poverty is acute and widespread.

- Though Biye is just half the size of Dakace and Rafin Guza, Biye has more married adolescent girls in absolute numbers than the other communities.

- Furthermore, it appears that the smallest segments in Biye and Dakace are the outof-school unmarried girls, whereas in Rafin Guza this segment is slightly larger in size than the married group.

- For adolescent girls aged 10-14, girls were more likely to be out of school in Biye (71\%) than Dakace (88\%) and Rafin Guza (65\%).

- Also in Biye, we find that $2.3 \%$ of girls were married compared to $0.7 \%$ in Dakace and none in Rafin Guza.
Using the Findings (2014 Onward) to Reorient the General Direction of the Program

Having completed the mapping exercises, CGE had an updated view of the universe of girls in its project communities. The findings helped to reinforce CGE's priority to target in-school adolescent girls aged 10-14 years in rural walkable communities like Biye. CGE will continue to work with this segment as it has found that increasing demand for, access to, and retention in secondary schooling may be the most effective strategy in delaying marriage and reducing related adverse maternal and child-health outcomes in the region.

CGE staff were struck by the relatively high numbers of unmarried out-of-school adolescent girls aged 10-14 years as well as married adolescent girls aged 15-19 years in Biye and began thinking more seriously about targeting these sizable and neglected segments through new interventions. This new Intentional Design focus was reflected in CGE's subsequent proposal submitted to the John D. and Catherine T. MacArthur Foundation requesting support for expanding the safe spaces program to unmarried out-of-school adolescent girls aged 10-14 years in rural communities like 
Biye. The Roster results gave substance to the request. Similarly, CGE developed a safe spaces program for married adolescent girls aged 15-19 years.

\section{Technical Insights and Observations}

Although CGE had an updated view of the universe of girls in its project communities, it missed an opportunity to identify which services (including its own programs) adolescent girls were already accessing through an inquiry into program participation. Future mapping exercises will have staff members conduct the in-depth inventory of community resources and participation in the days prior to the Girl Roster exercise. If it were to use the Roster again, CGE would adapt the tool to include a question on access to community assets and services (including existing programs aimed at girls) to better assess the reach and accessibility of these assets and resources.

\section{Conclusion (CGE Work from 2015 to 2019)}

Since this initial rostering, CGE continues to use the Roster when engaging with new communities. Combining the Roster with community-based research, participant observation, and in-depth interviewing has given CGE thorough assessment of girls' lives and risk scenarios in their communities, not only telling us how many girls there are per segment facing specific risk factors (such as how many girls are not in school) but why this is likely the case. Today, the segments served are:

- Preschool girls from the poorest rural families (based on the Montessori method ${ }^{3}$ that undergirds CGE's work)-effectively girls 4-7 years old-to prepare the girls and acclimate their families early to the value of an education;
- Out-of-school girls aged 10-14 years;

- In-school girls aged 10-14 years;

- Out-of-school girls aged 15-18 years;

- In-school girls aged 15-18 years;

The graduates of the program, having completed school and being above the age of 18 , now serve as our mentors in a model of cascading leadership. They participate in many aspects of information collection from the beginning as well as program implementation.

Depending on the context, the dose of the program ranges from 80 to 400 hours per year. Over the last four years of the program, CGE has served 50,000 girls who received two years of the program each.

For more information:

Please view a short introductory video for the CGE program at: https:// centreforgirlseducation.org.

Here you can also find highlights from our seven programs, which include written and radio productions done by the girls themselves.

Please visit our publications on this site as well.

Finally, please see a story featured in Sierra, the Sierra Club's magazine, about the Center: https://www.sierraclub.org/ sierra/2019-6-november-december/ feature/educating-girls-may-be-nigeriasbest-defense-against-climate

${ }^{3}$ The Montessori method was developed by a physician in the first half of the 20th century. The educational method stemmed from close observation of children in relatively free environments. It provides a complex and interrelated set of hands-on materials and lessons across major topic areas and is designed for children aged 0-12+ years. There are no grades or extrinsic rewards, and learning is situated in real or simulative contexts. Montessori education is aimed at development of the whole child, integrating social and cognitive growth for healthy independent functioning (Lillard et al. 2017). 


\title{
Practitioner Report 7
}

\section{Implementing the Girl Roster and Community Resource Scan in Sierra Leone: The Foundation of the Sierra Leone Adolescent Girls Network}

\author{
By Audrey Anderson
}

Contributions from Chernor Bah, Vira David, Salma Babu, Fiona Kaikai, Mamusu Williams, Arnold Williams, and Aminata Kamara

\begin{tabular}{|c|c|}
\hline Findings and Decisions & Implementation Observations and Adaptations \\
\hline $\begin{array}{l}\text { - Girls, particularly around age 15, increasingly are } \\
\text { off-track because they drop out of school, there are } \\
\text { no continuing schooling options, and/or they are } \\
\text { married and have a child. } \\
\text { - The vast proportion of girls are living with just one } \\
\text { or neither parent, plausibly for the reason that some } \\
\text { have moved close by the secondary school some } \\
\text { distance away (this would have to be explored more } \\
\text { in focus groups or individual interviews). } \\
\text { There are significant findings for the Because I } \\
\text { Am a Girl project-the age range is far too broad, } \\
\text { reaching participants } 18-25 \text {, although it was only } \\
\text { intended to reach 7-14-year-olds. Any program for } \\
\text { females in a resource-poor area will likely draw a } \\
\text { broader than anticipated range of participants. } \\
\text { The participants may not be the most-at-risk. For } \\
\text { example, in the case of Songo, 78\% of those living } \\
\text { with both parents were participating, but just 36\% } \\
\text { of the large number of girls living with just one or } \\
\text { neither parent were participating. }\end{array}$ & $\begin{array}{l}\text { - Originally, Songo was thought to be one community } \\
\text { in Sierra Leone. However, through implementing the } \\
\text { Community Resource Scan, it became apparent that } \\
\text { it was, in practice, two communities: Songo Colony } \\
\text { and Songo Koya. } \\
\text { - In Sierra Leone, Plan often had to repeat the } \\
\text { questionnaire because families would miscount } \\
\text { the number of people in the household or forget } \\
\text { to include someone. Because of this, it is essential } \\
\text { that the survey include the questions on the total } \\
\text { number of individuals in the household to ensure } \\
\text { that no one is excluded. } \\
\text { The wording regarding age should read "age } 25 \text { and } \\
\text { older" and "age } 24 \text { and younger" rather than "over/ } \\
\text { under age } 25 \text {," to ensure that individuals who are } \\
\text { exactly } 25 \text { years old are not excluded. } \\
\text { Many individuals in Sierra Leone did not know their } \\
\text { exact age, so they stated certain historical events } \\
\text { that occurred around the time of birth, and Plan } \\
\text { recorded an estimate. } \\
\text { We suspected that many families exaggerated their } \\
\text { daughters' educational achievement. For example, } \\
\text { Plan received reports that three-year-olds were } \\
\text { already in second grade. } \\
\text { It is important to make the questions neutral, } \\
\text { otherwise households may overstate or understate } \\
\text { the situation of their daughters if they think their } \\
\text { answers affect inclusion in a new program. It is } \\
\text { also important to train rosterers to stay neutral and } \\
\text { not criticize the families if their daughters are, for } \\
\text { example, out of school. } \\
\text { The Community Resource Scan was conducted in } \\
\text { partnership with the local village leader, but it can } \\
\text { also be conducted as a participatory exercise with } \\
\text { adolescent girls in the community as appropriate. }\end{array}$ \\
\hline
\end{tabular}




\section{Introduction}

\section{Overview}

This document outlines practitioner experiences in the implementation of mapping tools developed by the Population Council: the Girl Roster and the Community Resource Scan. ${ }^{1}$ Plan International USA, through a formal partnership with the Council, is working to cascade these mapping tools and methodology through its Because I Am a Girl (BIAAG) programs around the world. It is doing so to improve targeted recruitment of the most marginalized girls through a better understanding of the universe of girls in the community of intervention, as well as to learn which specific girls are benefiting from ongoing programming.

This practitioner report takes place in target communities in Plan's BIAAG program in Sierra Leone, which targeted girls 7-14 years old with a focus on reproductive health and financial literacy.

The mapping process is part of a broader effort to promote coordination among organizations working for adolescent girls globally. This effort includes the establishment of an Adolescent Girls Network in select countries/regions to foster collaboration and sharing of resourcesincluding mapping information-among girlfocused organizations. Members of the Sierra Leone Adolescent Girls Network include Save the Children (StC), BRAC, the International Rescue Committee (IRC), and Plan International, along with many local NGOs. In the first case study on Sierra Leone, the mapping was made possible by collaboration among members of the Network. The full vision of the mapping process is to collect targeted information using the Girl Roster and the Community Resource Scan on target communities and share among the Network members to strategically prioritize and plan interventions.

\section{Why Map?}

The mapping tools outlined in this report are used to translate subjective knowledge of adolescent girls to make tangible and actionable plans for these excluded populations at critical life stages. The process and methodology are in response to information that overwhelmingly points to a severe need for targeted programming for specific segments of adolescent girls:

- At puberty, adolescent girls experience a dramatic decrease in their mobility and an increase in school dropout rates, and they are at risk of early pregnancy, which in turn contributes to these risks (Hallman, Kenworthy, et al. 2013; Hallman and Peracca 2005);

- Adolescent girls, particularly younger and poorer girls, have little or no access to existing community resources such as schools, youth centers, and financial institutions (Bruce 2011b);

- Adolescent girls, particularly younger girls, are systematically excluded from programs that aim to reach "youth" or "adolescents" (Population Council 2011);

- Recruitment for youth and adolescent programs is often demand-led, resulting in elite capture of participants (Bruce 2011a).

Before a program is designed, the mapping process is used to enhance intentional recruitment, to do the following:

- Identify off-track girls who have special needs;

- Identify on-track older girls as potential mentors;

- Identify community resources that may be designated as safe spaces for girls;

- Create like segments of girls to benefit from potential programs.

\footnotetext{
${ }^{1}$ This was one of the foundational field exercises undertaken just pre-Ebola, engaging the initial SALONE Network members. The Network had been founded by the Population Council, BRAC, Plan, Save the Children, and nine local NGOs.
} 
During or after a program, the mapping process shows which girls benefited from the program. Using mapping is an efficient and cost-effective way to deliver services for greater impact on targeted populations. The mapping tools complement Plan's development approach of Child-Centered Community Development (CCCD) to efficiently implement more effective programs and maximize overall impact.

\section{Implementing the Girl Roster and Community Resource Scan in Sierra Leone}

\section{Overview}

In May 2014, Plan Sierra Leone hosted a training session on the methodology and an on-theground mapping exercise in three communities: two where Plan had active girl-focused programs and one where Plan might potentially work in the future.

Members of the Adolescent Girls Network, including Plan, BRAC, the World Food Programme (WFP), and Metcorps, participated in the training and on-the-ground mapping, and donated organizational resources to the effort. The training was led by a representative from the Population Council, with additional facilitation by representatives from UNFPA and Plan USA.

\section{Process and Timeframe}

A one-day training was held prior to conducting the fieldwork, on the methodology and the case for mapping, hands-on training with the mobile phones and information collection tools, and the contextualization of the Girl Roster questionnaire.

Within one week, three communities in Sierra Leone were mapped:

- $\quad$ Songo Koya community, Western Rural Area, Sierra Leone;

- Songo Colony community, Western Rural Area, Sierra Leone;
- Yoyema community in Moyamba district, Sierra Leone.

- The total time commitment for the mapping process in Sierra Leone was as follows:

- $\quad$ One day of training on the tools;

- One day per community to implement the Girl Roster and Community Resource Scan;

- $\quad$ Eight rosterers implemented the Girl Roster in less than four hours for a community of 90 households. Note: The rosterers started out collecting information in pairs, but once they became comfortable with the tools, they split up to work faster;

- Two rosterers implemented the Community Resource Scan in less than three hours for a walkable community;

- One day of information analysis and review.

- $\quad$ Several members of the group in Sierra Leone had already conducted this mapping process in the past. If it is the first time for a group to implement the tools, taking one day for revision after first day of implementation is recommended.

\section{Results}

The following are illustrative results from the girls in Songo Colony, a BIAAG community (see Table 1).

Note: White cells indicate on-track girls (those girls age 6-17 of school-going age who are in school, unmarried, and living with one or both parents). Light-grey cells indicate off-track girls (those of school-going age who are out of school, living with no parents, and girls who are married and/or had a child under exact age 18.) In reading the Output Table, risk increases as you move to the right. Darker grey cells indicate girls who may be potential mentors, older girls with higher levels of education relative to community averages; both may have the talent, and the unmarried may have more time available to serve as mentors. 
TABLE 1. WITHIN THE “UNIVERSE” OF GIRLS IN SONGO COLONY, IDENTIFYING THE GIRLS PARTICIPATING IN THE "BECAUSE I AM A GIRL” PROGRAM

\begin{tabular}{|c|c|c|c|c|c|c|c|}
\hline \multirow{3}{*}{$\begin{array}{l}\text { Age } \\
\text { group }\end{array}$} & \multicolumn{4}{|c|}{ Unmarried } & \multicolumn{2}{|c|}{ Married } & \multirow{3}{*}{ Total } \\
\hline & \multicolumn{2}{|c|}{ In School } & \multicolumn{2}{|c|}{ Out of School } & \multirow[b]{2}{*}{ Has a child } & \multirow{2}{*}{$\begin{array}{l}\text { Does not } \\
\text { have a } \\
\text { child }\end{array}$} & \\
\hline & $\begin{array}{l}\text { Living } \\
\text { with both } \\
\text { parents }\end{array}$ & $\begin{array}{l}\text { Living with } \\
\text { just one or } \\
\text { neither parent }\end{array}$ & $\begin{array}{l}\text { Living } \\
\text { with both } \\
\text { parents }\end{array}$ & $\begin{array}{l}\text { Living with } \\
\text { just one or } \\
\text { neither parent }\end{array}$ & & & \\
\hline $6-9$ & $2 / 9(22 \%)$ & $2 / 13(15 \%)$ & $0 / 1(0 \%)$ & $0 / 0$ & - & - & $4 / 23$ \\
\hline $10-14$ & $7 / 9(78 \%)$ & $13 / 36(36 \%)$ & $0 / 0$ & $0 / 0$ & $1 / 1(100 \%)$ & $0 / 0$ & $21 / 46$ \\
\hline $15-17$ & $4 / 5(80 \%)$ & $1 / 9(11 \%)$ & $\mathrm{O} / \mathrm{O}$ & $1 / 3(33 \%)$ & $1 / 7(14 \%)$ & $0 / 3(0 \%)$ & $7 / 27$ \\
\hline $18-24$ & $3 / 5$ & $1 / 4$ & $\mathrm{O} / 2$ & $\mathrm{O} / \mathrm{O}$ & $4 / 13$ & $0 / 1$ & $8 / 25$ \\
\hline & & & & & & & $40 / 121$ \\
\hline
\end{tabular}

Numerator $=$ Girls in Program

Denominator $=$ Girls in Segment

*Either status-bearing a child or being married under 18-indicates a violation of child rights.

Note: At the time of this Roster fielding, the Output Tables combined girls with one parent and neither parent; this has since been changed. Further, the age range 10-14 has now been broken into 10-12 and 13-14 because of the intensity of transitions in this age group. It is often the age at which girls who have completed primary school transition to secondary school, but as secondary school is often a distance from households and girls' labor is needed by the family, many do not make this transition.

\section{Analysis and Programmatic Learning}

Implementing the Girl Roster at this stage of the program (midline) allowed for learning which girls were benefiting from the program:

- As seen in Figures 1 and 2, the BIAAG project was reaching nearly twice as many on-track girls as off-track girls.

- Of girls in school, the project was reaching $78 \%$ of those living with both parents but just $36 \%$ of the large number of girls living with just one or neither parent.
- It is not uncommon for girls in Sierra Leone to have children by age 15-17 (see Figure 3). In Songo Colony, in fact, one girl under 15 had a child.

- There are many girls in school in Songo, more than would be expected compared with secondary information for the region. However, many girls are living with just one or neither parent (see Figure 4). One possible explanation is that Songo is a destination community for schooling, having two secondary schools, and many girls travel from more remote communities and stay with distant relatives to attend school in Songo.

- The Plan program in Sierra Leone is reaching a very broad range of ages (including 8 girls in the 18-25 age range), although the program was intended to reach only 7-14-year-olds.

- Although reaching a broad range of ages, the program is disproportionately reaching girls with more advantage (those in school and living with both parents). In the 10-14year age range, the program reaches $78 \%$ of girls who are living with both parents and only $36 \%$ of girls who are living with just one or neither parent. 


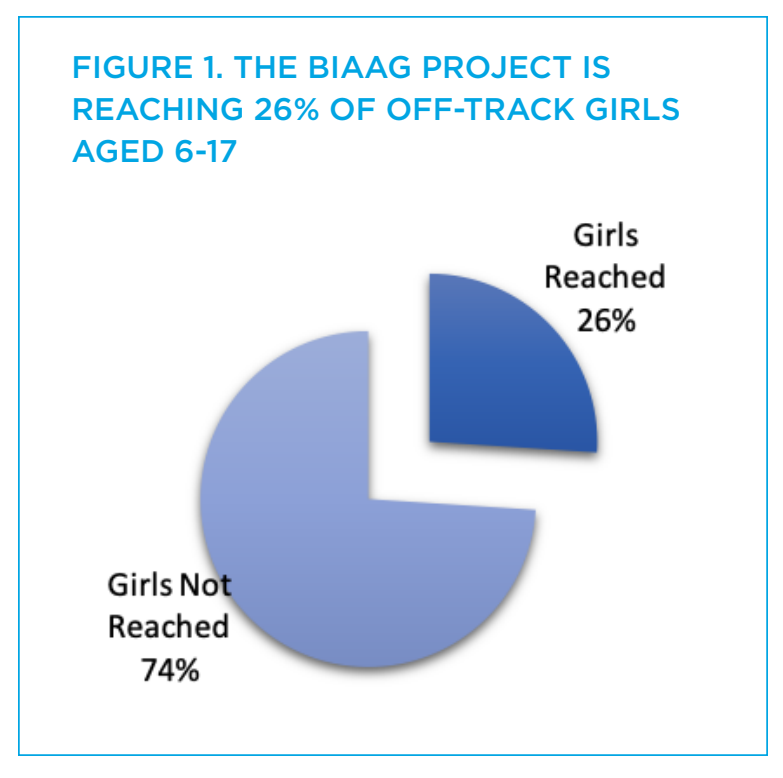

FIGURE 3. 37\% OF GIRLS AGED 15-17 ARE ALREADY MARRIED AND/OR HAVE A CHILD

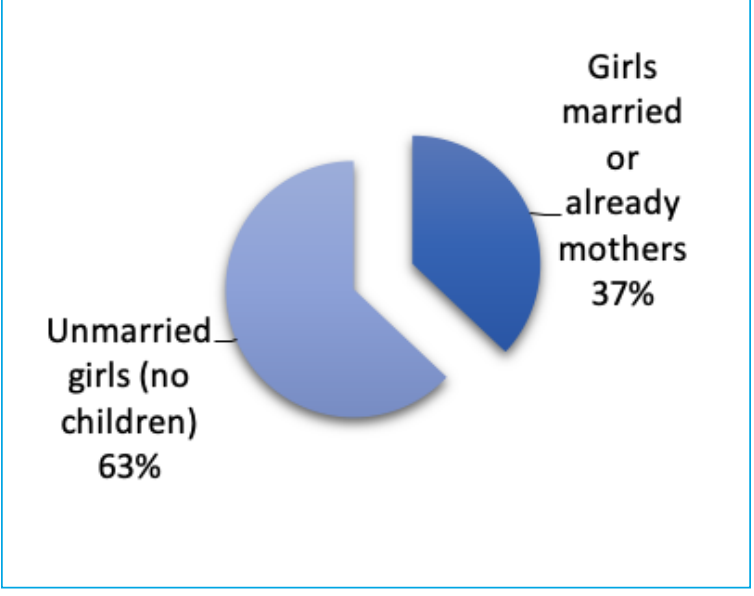

\section{Conclusion}

As of 2019, Purposeful Productions ${ }^{2}$ serves as the Secretariat of the Network, providing a full-time program manager as coordinator of the Network and taking the lead in the Steering Committee that sets the agenda of the group. The Network's membership increased from 80 to over 150 members by 2018. It continues to be a platform for collaboration, capacity building,
FIGURE 2. THE BIAAG PROJECT IS REACHING DOUBLE THE PERCENTAGE OF ON-TRACK GIRLS AGED 6-17
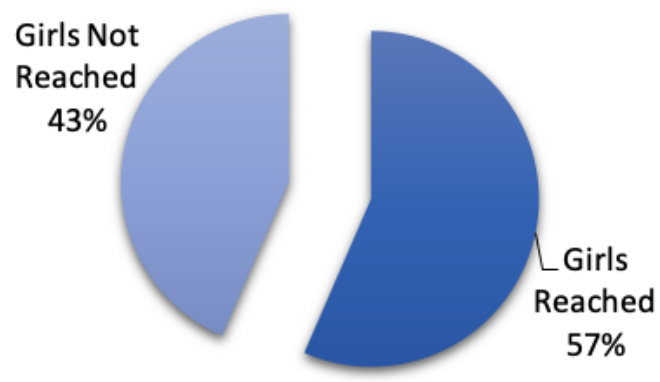

FIGURE 4. 72\% OF GIRLS AGED 6-17 LIVE WITH JUST ONE OR NEITHER PARENT

\section{Girls}

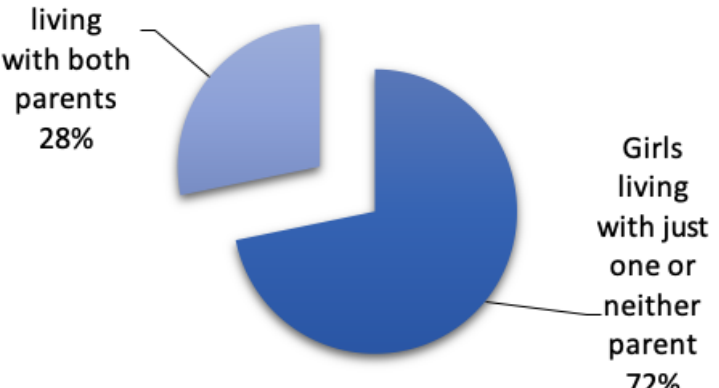

$72 \%$

information exchange, joint advocacy, and a building of evidence-based programs for girls in Sierra Leone.

In 2019, the Network for the first time brought together all 150 members and 400 girls to commemorate the International Day of the Girl by taking over the national well of parliament with a parliamentary debate session on the newly amended sexual offences law, which was

\footnotetext{
${ }^{2}$ For more information about Purposeful Productions, please visit: https://www.wearepurposeful.org/.
} 
topped off with other social activities for the enjoyment and socialization of the girls.

The Network recognizes that among its members there are different levels of expertise and that capacity gaps need to be addressed. On that note, members continually deliver capacity-building trainings and coaching to increase partners' ability to deliver quality interventions for girls.

The Network recognizes that among its members there are different levels of expertise and that capacity gaps need to be addressed. Members continually deliver capacity-building trainings and coaching to increase partners' ability to deliver quality interventions for girls.

Due to constraints, members from the provinces are not always able to attend general meetings in Freetown, the capital city. Therefore, Network members agreed to form four district chapters in four district headquarter towns and hold regular meetings there. Updates from one member/district coordinator are provided during general bimonthly Network meetings.

The coordinator liaises with government bodies to understand their structure, explore collaboration opportunities, and link members to services and resources of the state that will be useful for the work they do.

The Network, overall, has proved the potential of learning circles, if utilized fully.

For more information, please visit the Salone Adolescent Girls Network website: https://www.friendsofsalone.org/thenetwork. 


\title{
Practitioner Report 8
}

\section{Intentional Design in Homa Bay, Kenya, in the Context of the DREAMS Partnership}

\author{
By Judith Bruce \\ Population Council-supported analyses conducted by Audrey Anderson
}

\begin{tabular}{|c|c|}
\hline Findings and Decisions & Implementation Observations and Adaptations \\
\hline $\begin{array}{l}\text { - Across the wards, among the } 25,000+\text { girls } \\
\text { rostered, about } 10 \% \text { were off-track by age } 9 \text {, rising } \\
\text { to } 28 \% \text { by age } 17 . \\
\text { - These findings were far more valuable for } \\
\text { programming purposes when the information was } \\
\text { disaggregated from district to ward ("walkable } \\
\text { community") level; this disaggregation (or break } \\
\text { down) revealed great intra-ward variation, including } \\
\text { in the same subnational district, where one ward } \\
\text { had } 25 \% \text { of girls aged } 15-17 \text { out of school, compared } \\
\text { to another where it was only } 10 \% \text {. These findings } \\
\text { suggest that beginning work in the ward that has } \\
\text { the worse indicators should be a priority. } \\
\text { Across the various wards-including the most } \\
\text { disadvantaged-there were also populations of girls } \\
\text { aged } 18-24 \text { with eight years or more of schooling; } \\
\text { these girls were identified as potential mentors. } \\
\text { One of the participating communities added a } \\
\text { query to their questionnaire asking whether a } \\
\text { specific girl was part of the HIV program that was } \\
\text { being implemented at the time. Findings suggested } \\
\text { that many more off-track girls aged 15-17 (of which } \\
\text { there were } 212 \text { ) were not participating (only } 83 \text { in } \\
\text { total were in the program) than on-track girls. When } \\
\text { the information was combined it was evident that } \\
\text { on-track girls aged } 15-17 \text { were } 18 \text { times more likely } \\
\text { to participate in the program than off-track girls, } \\
\text { hence the rationale of the DREAMs Partnership } \\
\text { to find the girls "left behind" (Bruce and Hallman } \\
2008 \text { ). }\end{array}$ & $\begin{array}{l}\text { - This exercise was extremely instructive to the } \\
\text { Population Council's Intentional Design and } \\
\text { DREAMS Capacity Building team in that it revealed } \\
\text { that without special measures partners might roster } \\
\text { in too broad an area without identifying the priority } \\
\text { communities, thereby losing important community- } \\
\text { specific variation. Thus the instructions and the } \\
\text { questionnaire itself were changed to always prompt } \\
\text { rosterers to identify the name of the walkable } \\
\text { community, so that findings could be appropriately } \\
\text { attributed to the right level and programming area. } \\
\text { The "fix" in analysis, when the walkable } \\
\text { communities had not been disaggregated, was to } \\
\text { use the date of rostering and the rosterers' IDs to } \\
\text { work backward to identify which information about } \\
\text { girls and households belonged to which walkable } \\
\text { community. }\end{array}$ \\
\hline
\end{tabular}

\section{Introduction}

In 2015, the Population Council held a training with a number of DREAMS implementing partners in Kenya operating within preset targets and procedures. One of the partners, AIDS, Population and Health Integrated Assistance (APHIA), produced Girl Roster information for an extraordinary 25,000 girls aged 6-24 years in the course of several weeks.
When the Output Tables were generated, it became clear that the rostering team had rostered over a very large district, which combined several large but distinct program catchment areas. The averages across this large area hid potentially important heterogeneity among wards when compared to each other.

The Council and consultant Audrey Anderson, who had worked closely both in training 
TABLE 1. OVERVIEW OUTPUT TABLE WITH RESULTS ACROSS ALL WARDS IN THE DISTRICT

\begin{tabular}{|c|c|c|c|c|c|c|c|c|c|}
\hline \multirow{3}{*}{$\begin{array}{l}\text { Age } \\
\text { group }\end{array}$} & \multicolumn{5}{|c|}{ Unmarried } & & \multicolumn{2}{|c|}{ Married } & \multirow{3}{*}{ Total } \\
\hline & \multicolumn{3}{|c|}{ In School } & \multicolumn{3}{|c|}{ Out of School } & \multirow[b]{2}{*}{$\begin{array}{c}\text { No } \\
\text { children }\end{array}$} & \multirow[b]{2}{*}{$\begin{array}{l}\text { Has a } \\
\text { child }\end{array}$} & \\
\hline & $\begin{array}{l}\text { Living } \\
\text { with } \\
\text { both } \\
\text { parents }\end{array}$ & $\begin{array}{l}\text { Living } \\
\text { with one } \\
\text { parent }\end{array}$ & $\begin{array}{l}\text { Living } \\
\text { with } \\
\text { neither } \\
\text { parent }\end{array}$ & $\begin{array}{l}\text { Living } \\
\text { with } \\
\text { both } \\
\text { parents }\end{array}$ & $\begin{array}{l}\text { Living } \\
\text { with one } \\
\text { parent }\end{array}$ & $\begin{array}{l}\text { Living } \\
\text { with } \\
\text { neither } \\
\text { parent }\end{array}$ & & & \\
\hline $6-9$ & 4,102 & 910 & 420 & 76 & 29 & 6 & 0 & 0 & 5,543 \\
\hline $10-12$ & 3,260 & 926 & 509 & 32 & 11 & 10 & 0 & 0 & 4,748 \\
\hline $13-14$ & 1,871 & 618 & 431 & 43 & 18 & 19 & 10 & 33 & 3,043 \\
\hline $15-17$ & 2,207 & 826 & 584 & 131 & 81 & 69 & 34 & 286 & 4,218 \\
\hline $18-19$ & 792 & 315 & 186 & 189 & 123 & 108 & 111 & 669 & 2,493 \\
\hline $20-24$ & 642 & 223 & 231 & 319 & 171 & 226 & 406 & 3,276 & 5,494 \\
\hline Total & 12,874 & 3,818 & 2,361 & 790 & 433 & 438 & 561 & 4,264 & 25,539 \\
\hline
\end{tabular}

TABLE 2. ANALYSIS OF OFF-TRACK GIRLS FROM ALL WARDS IN THE DISTRICT

\begin{tabular}{|c|c|c|c|c|c|c|c|}
\hline Age cohort & $\begin{array}{c}\text { \% out of } \\
\text { school } \\
\text { (including } \\
\text { married } \\
\text { girls/ } \\
\text { mothers) }\end{array}$ & $\begin{array}{c}\% \text { married } \\
\text { or has a } \\
\text { child }\end{array}$ & $\begin{array}{c}\text { \% living } \\
\text { with no } \\
\text { parent } \\
\text { and out } \\
\text { of school } \\
\text { (unmarried } \\
\text { only) }\end{array}$ & $\begin{array}{c}\text { \% living } \\
\text { with one or } \\
\text { no parent } \\
\text { (unmarried } \\
\text { only) }\end{array}$ & $\%$ on-track & \% off-track ${ }^{2}$ & $\begin{array}{c}\text { \% off-track } \\
\text { girls and } \\
\text { those with } \\
\text { just one } \\
\text { parent }\end{array}$ \\
\hline $6-9$ & 1 & 0 & 0.1 & 25 & 90 & 10 & 26 \\
\hline $10-12$ & 0 & 0 & 0.2 & 31 & 88 & 12 & 31 \\
\hline $13-14$ & 3 & 1 & 1 & 36 & 82 & 18 & 39 \\
\hline $15-17$ & 11 & 8 & 2 & 37 & 72 & 28 & 48 \\
\hline
\end{tabular}

TABLE 3. ANALYSIS OF OFF-TRACK GIRLS IN WARD 1-DAGO COMMUNITY

\begin{tabular}{|c|c|c|c|c|}
\hline Age cohort & $\begin{array}{c}\text { \% out of } \\
\text { school }\end{array}$ & $\begin{array}{c}\text { \% never } \\
\text { went to } \\
\text { school }\end{array}$ & $\begin{array}{c}\text { \% married } \\
\text { or has a } \\
\text { child }\end{array}$ & $\begin{array}{c}\text { \% living } \\
\text { with } \\
\text { neither } \\
\text { parent }\end{array}$ \\
\hline $6-9$ & 1 & 0 & 0 & 10 \\
\hline $10-12$ & 25 & 4 & 8 & 17 \\
\hline $13-14$ & $\mathrm{n} / \mathrm{a}$ & 11 & 44 & $\mathrm{n} / \mathrm{a}$ \\
\hline $15-17$ & $\mathrm{n} / \mathrm{a}$ & 18 & 81 & $\mathrm{n} / \mathrm{a}$ \\
\hline
\end{tabular}

${ }^{1}$ Here "on-track" is defined as girls who are in school and living with one or both parents. There are three layers of "off-track" definitions we use as recently as 2019 that make up our On/Off-Track Output Tables. This analysis done in 2016 differs slightly.

${ }^{2}$ Here "off-track" is defined as girls who are out of school or living with neither parent or married or have children, or any combination of these. 
TABLE 4. ANALYSIS OF OFF-TRACK GIRLS IN WARD 3-RUPIA COMMUNITY

\begin{tabular}{|c|c|c|c|c|}
\hline Age cohort & $\begin{array}{c}\text { \% out of } \\
\text { school }\end{array}$ & $\begin{array}{c}\text { \% never } \\
\text { went to } \\
\text { school }\end{array}$ & $\begin{array}{c}\text { \% married } \\
\text { or has a } \\
\text { child }\end{array}$ & $\begin{array}{c}\text { \% living } \\
\text { with } \\
\text { neither } \\
\text { parent }\end{array}$ \\
\hline $6-9$ & 2 & 0 & 0 & 14 \\
\hline $10-12$ & 10 & 0 & 10 & 14 \\
\hline $13-14$ & $\mathrm{n} / \mathrm{a}$ & 0 & 42 & $\mathrm{n} / \mathrm{a}$ \\
\hline $15-17$ & $\mathrm{n} / \mathrm{a}$ & 0 & 85 & $\mathrm{n} / \mathrm{a}$ \\
\hline
\end{tabular}

and in a number of initial tests of the Roster, disaggregated the information using the dates of rostering and IDs of rosterers to guide the process. The analysis compared Ward 1 (the Dago Community) to Ward 3 (the Rupia Community); analyses broken out this way demonstrates the importance of identifying within the rostering process specific walkable communities so that community-level differences can be seen. This information can also be aggregated up to a larger geographic area, in this case to reflect district-level averages, but it is immensely important to those planning programs and targeting scarce resources. In this way, the most affected communities with the highest proportion of offtrack girls can receive priority.

This was an important learning experience for the Council, which had noted that it had likely not sufficiently established an understanding among its partners and trainees of why it was important to generate information at a walkable community level or supported them enough with technical procedures to reinforce that. Through this experience, the Roster's sequence of questions was revised to prompt the rosterer to always select a location (in this instance the district) and its sublocations (in this instance the ward) to allow for an aggregation but, more important, a disaggregation of information.
The Output Tables here (Tables 1 and 2) show the results across all rostered wards in the district.

The analysis of on-track and off-track girls in Tables 1 and 2-all wards rostered-would suggest that the percent of off-track girls rose from $10 \%$ in the age cohort of $6-9$ to $28 \%$ by 17 . That detail is substantially deepened by teasing out each ward's rostering information from one another, in this case the Dago Community from the Rupia Community (see Tables 3 and 4).

Another interesting analysis was undertaken to discern who was being reached by the existing program within a community of 1,332 girls aged 6-24 years (see Table 5). The intent of the DREAMS Partnership was to reach adolescent girls and young women aged 10-24 with the understanding that current program approaches were biased to older, somewhat lower-risk in-school and unmarried populations and with recognition that the girls left behind by conventional programs are often those at the highest risk. The highest proportion of off-track girls are among those aged 15-17 ( $32 \%$ on-track, $68 \%$ off-track) (see Figure 1). Yet additional analysis of just this age cohort showed that this program was skewed to 15-17-year-olds on-track: in school, unmarried, without children, and/or living with one or both parents. (The numerator of the 15-17-year-olds 
TABLE 5. PROGRAM PARTICIPATION ACROSS A SAMPLE OF 1,332 GIRLS IN THE SAME WALKABLE COMMUNITY

\begin{tabular}{|c|c|c|c|c|c|c|c|c|c|}
\hline \multirow{3}{*}{$\begin{array}{l}\text { Age } \\
\text { cohort }\end{array}$} & \multicolumn{6}{|c|}{ Unmarried } & \multicolumn{2}{|c|}{ Married } & \multirow{3}{*}{ Total } \\
\hline & \multicolumn{3}{|c|}{ In School } & \multicolumn{3}{|c|}{ Out of School } & \multirow[b]{2}{*}{$\begin{array}{c}\text { No } \\
\text { children }\end{array}$} & \multirow[b]{2}{*}{$\begin{array}{l}\text { Has a } \\
\text { child }\end{array}$} & \\
\hline & $\begin{array}{l}\text { Living } \\
\text { with } \\
\text { both } \\
\text { parents }\end{array}$ & $\begin{array}{l}\text { Living } \\
\text { with one } \\
\text { parent }\end{array}$ & $\begin{array}{l}\text { Living } \\
\text { with } \\
\text { neither } \\
\text { parent }\end{array}$ & $\begin{array}{l}\text { Living } \\
\text { with } \\
\text { both } \\
\text { parents }\end{array}$ & $\begin{array}{l}\text { Living } \\
\text { with one } \\
\text { parent }\end{array}$ & $\begin{array}{l}\text { Living } \\
\text { with } \\
\text { neither } \\
\text { parent }\end{array}$ & & & \\
\hline $6-9$ & 160 & 100 & 0 & 20 & 40 & 8 & $\mathrm{n} / \mathrm{a}$ & $\mathrm{n} / \mathrm{a}$ & 328 \\
\hline $10-12$ & 84 & 55 & 14 & 35 & 30 & 10 & 0 & 10 & 238 \\
\hline $13-14$ & 76 & 45 & 10 & 37 & 34 & 14 & 8 & 10 & 234 \\
\hline $15-17$ & $32 / 40$ & $42 / 60$ & $0 / 16$ & $0 / 40$ & $5 / 56$ & $3 / 40$ & $1 / 40$ & $0 / 20$ & $83 / 312$ \\
\hline $18-24$ & 16 & 32 & 0 & 20 & 16 & 32 & 64 & 40 & 220 \\
\hline Total & 376 & 292 & 40 & 152 & 176 & 104 & 112 & 80 & 1,332 \\
\hline
\end{tabular}

$\mathrm{n} / \mathrm{a}=$ Not applicable

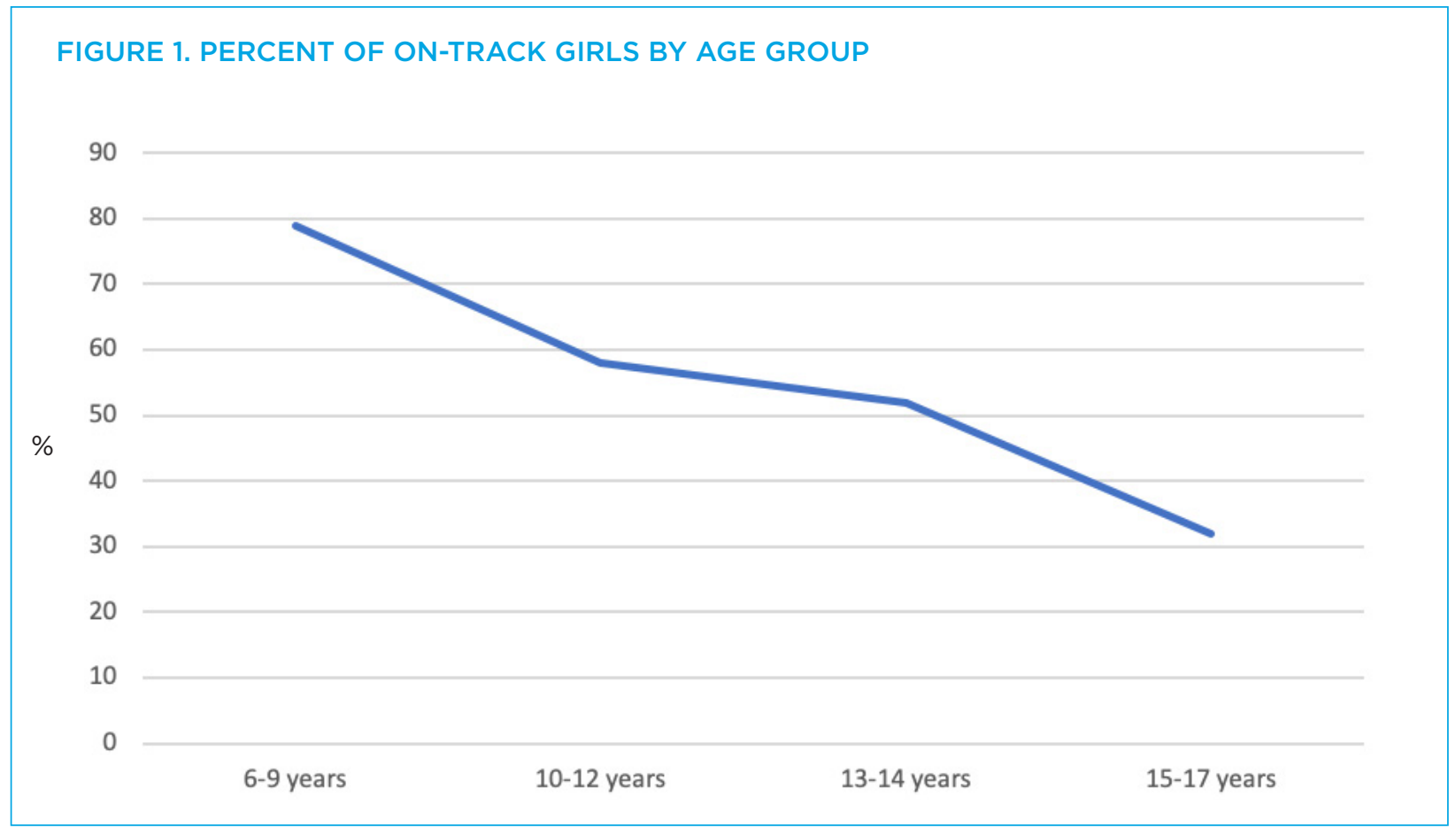


is those participating in the program out of the total number in that segment, the denominator; $74 \%$ of on-track girls were program participants, while only $4 \%$ of off-track girls were participating. An on-track girl, therefore, was over 18 times more likely to participate than an off-track girl.)

\section{Conclusion}

In this instance, the implementation of the Girl Roster was just as much a learning experience for the on-the-ground partner as it was for the Population Council's Community of Practice. It became evident that the concept of a walkable community and its value in designing tailored programming for girls was not taking hold enough. This analysis was formative in revising Roster training, and required formal revisions to the Roster questionnaire itself. We had to reexamine how difficult and pivotal it was to communicate to partners the meaning of a walkable community and how it anchors programming. We had to improve our training to ensure partners had found their footing in this concept in the paired process of identifying walkable communities and within them the segmentation of the universe of girls. Not only were formal revisions to the Roster questionnaire itself required, but we had to reexamine some elements of the way in which we trained, ensuring that partners had found their footing in the main problem statements of the Roster before ever going to implement it.

For more information, please visit: https:// www.popcouncil.org/research/DREAMScapacity-strengthening. 


\title{
Practitioner Report 9
}

\section{Global Communities' Use of Intentional Design to Implement the DREAMS Program-Getting the Correct Value for Money in Highly HIV-Affected Settings in Kenya}

\author{
By Ann Wahinya and Sophie Soares \\ Field Team: Betty Adera, Luciana Koske, and Fredrick Nyagah
}

\begin{tabular}{|c|c|}
\hline Findings and Decisions & Implementation Observations and Adaptations \\
\hline $\begin{array}{l}\text { - Girl Roster findings and subnational-level data } \\
\text { guided staff to a selection of two additional wards } \\
\text { to reach designated target numbers. } \\
\text { - Findings showed a diversity of off-track girls who } \\
\text { were not being captured in the program, so further } \\
\text { segmentation was done, resulting in } 12 \text { separate } \\
\text { segments reached. } \\
\text { Observing pitfalls in a peer-to-peer model, program } \\
\text { staff shifted to a mentorship model, using a list of } \\
\text { criteria to select mentors and create a cascading } \\
\text { model of leadership. } \\
\text { Conventional reproductive-health curriculum was } \\
\text { tailored to each segment's specific needs and age. }\end{array}$ & $\begin{array}{l}\text { - In using the Community Mapping exercise, staff } \\
\text { added additional details that were pertinent to } \\
\text { their implementation including who the target } \\
\text { beneficiaries of the resource were, to note gaps. } \\
\text { - The Girl Roster process served as an entry point } \\
\text { into community sensitization and orientation to } \\
\text { Global Communities. }\end{array}$ \\
\hline
\end{tabular}

\section{Introduction}

Global Communities was funded as an implementing partner of PEPFAR's DREAMS Initiative in Kenya. The initiative aimed to prevent and mitigate the risks of HIV to adolescent girls and young women in hotspot communities of Nairobi County, where HIV and its consequences have taken hold.

The DREAMS Initiative was funded by PEPFAR/USAID, originally in 2015-16. In Kenya, the initiative was implemented by Global Communities in partnership with St. John's Community Centre (SJCC) and the Kenya Girl Guides Association (KGGA) in Kamukunji subcounty. The goal of the DREAMS program was to reduce new HIV infections among adolescent girls and young women (AGYW) aged 10-24 years. The core package of DREAMS programming includes community mobilization and norms change, school-based interventions, parent/caregiver programs, social protection, and the integration of a protective assetbuilding approach into implementation, the latter of which is where the Population Council's input was vital.'

In Kenya, despite remarkable gains in the epidemic (such as reducing national HIV prevalence from $7.2 \%$ in 2007 to $5.7 \%$ in 2018), there were an estimated 46,000 new HIV infections in 2018 alone and a total of 1.6

\footnotetext{
${ }^{1}$ In 2015, the Council received funding from Girl Effect, one of the organizational partners of DREAMS, to support capacity-building activities in the first ten countries of the DREAMS partnership. Led by Miriam Temin, Council researchers shared best practices and resources, and provided mentorship, technical support, and hands-on workshops to strengthen the capacity of partners involved in DREAMS to develop and implement new approaches to reach girls and young women at highest risk of HIV infection, link them with essential resources, and empower them with the social and protective assets they need for a safe and healthy entry into adulthood. To learn more about this project, visit: https://www. popcouncil.org/research/DREAMS-capacity-strengthening.
} 
million people living with HIV/AIDS (UNAIDS Data 2019). More than half (51\%) of all new HIV infections in Kenya in 2015 occurred among adolescents and young people 15-24 years old; females were almost twice as likely to acquire HIV as their male age-mates, accounting for $33 \%$ of the new infections in 2015 (Kenyan Ministry of Health and National AIDS Control Council 2016). At the time, Kenya experienced the third-largest epidemic in the world, alongside Mozambique and Uganda.

The DREAMS Partnership was initiated because despite a multiyear investment through PEPFAR in the years prior, the most at-risk girls and young women had not been appropriately reached. Global Communities was identified as an implementing partner in DREAMS and was one of several Kenya-based organizations implementing the Girl Roster and overall Intentional Design approach. Through a series of workshops and follow-on support, Global Communities was led through a capacitybuilding process by the Population Council. The result was a shift in programming to be segment-specific and girl-centered, which led to the application of quantitative and qualitative information about girls' lives to identify specific segments of girls and their locations, social capital and connections, and vulnerabilities, and to identify those that would be prioritized in the program.

\section{Girl Roster Implementation and Community Resource Mapping}

\section{Girl Roster Findings}

Committed staff and volunteers working for a long time in these communities realized that they had to take a step back and needed new tools to identify and serve the hardest-to-reach girls.

In 2016, Global Communities implemented the Girl Roster in Pumwani, California, and Airbase Wards (informal settlements) of Kamukunji subcounty. Information from over 16,000 households was collected in approximately a month using a saturated approach; a little over
100 rosterers working in pairs implemented the tool in two wards. The rosterers were accompanied by community health volunteers who were known and trusted in the various villages within the wards. They helped map out the geographic boundaries of the villages, which were the "walkable" communities in this context and introduced the rosterers to the households.

Community leaders and members were introduced to the Intentional Design approach, including the Roster, through stakeholder forums that, among other things, stressed the importance of reaching girls and the degree to which they had been neglected by current programming. Thus, the Roster was not merely a tool for information collection but also was a pathway to deeper community engagement and commitment. In addition, the information collected provided a foundation for the redesign of the Global Communities DREAMS project.

Among the Roster Results:

- More than half of the girls were out of school with very low transition levels from primary to secondary school. Results showed that $95 \%$ of girls aged $10-14$ were in primary school but only $45 \%$ of them transitioned to secondary school;

- Some of the in-school girls were actually extremely behind in school for their age, including 20-24-year-olds who were only in primary school;

- The majority of females aged 20-24 were either married with children or living alone with children.

Table 1 shows summaries of the information found for Pumwani Ward.

\section{Community Resource Mapping}

Another key activity in our informationgathering was Community Resource Mapping. In the course of this exercise, we identified and located on a map existing services and intended beneficiaries, as well as other community resources that had previously gone unnoticed 
TABLE 1. OVERVIEW OUTPUT TABLE WITH RESULTS ACROSS ALL WARDS IN THE DISTRICT

\begin{tabular}{|c|c|}
\hline Girls 10-14 Years Old $(n=772)$ & Girls 15-19 Years Old $(n=849)$ \\
\hline $\begin{array}{l}\text { - } 95 \% \text { in school but } 43 \% \text { behind grade for age } \\
\text { (only completed } 1 \text { st or } 2 \text { nd grade) } \\
\text { - } 108 \text { living with neither parent } \\
\text { - } \quad 243 \text { living with only mothers } \\
\text { - } 15 \text { living with only fathers } \\
\text { - } \quad 13 \% \text { in school and have children } \\
\text { - } \quad 2 \text { engaged in paid labor } \\
\text { - } 2 \text { in school and married }\end{array}$ & $\begin{array}{l}\text { - } 468 \text { ( } 55 \% \text { ) out of school, showing low transition } \\
\text { from primary to secondary school } \\
\text { - } \quad 322 \text { living with neither parent } \\
\text { - } \quad 236 \text { living with only mothers } \\
\text { - } \quad 20 \text { living with only fathers } \\
\text { - } \quad 121 \text { out of school and have children } \\
\text { - } \quad 80 \text { engaged in paid labor } \\
\text { - } \quad 13 \text { in school and have children } \\
\text { - } \quad 13 \text { in 1st or } 2 \text { nd grade only }\end{array}$ \\
\hline \multicolumn{2}{|c|}{ Girls $20-24$ Years Old $(n=1,336)$} \\
\hline 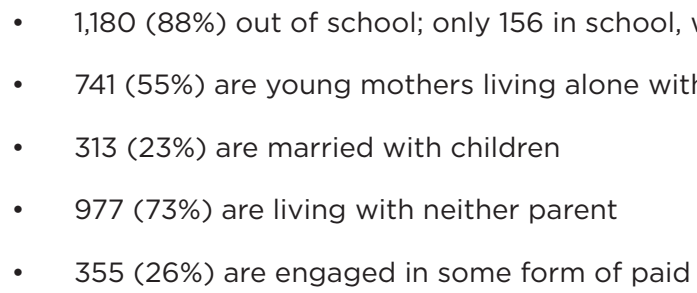 & $\begin{array}{l}45 \% \text { severely behind grade for age } \\
\text { dren, due mainly to absentee fathers }\end{array}$ \\
\hline
\end{tabular}

by us. Community resources mapped included financial institutions, schools, polytechnics, rescue shelters, police posts, health centers, churches/mosques, and potential meeting venues, among others.

Community Mapping results enabled the program to link girls to existing community resources and structures that had been there, but girls had either not been previously aware of or were unable to access. These include government services, such as birth registrations, national identification banks, microfinance institutions, vocational training centers, and health centers, among others. Table 2 details the findings of that mapping process.

\section{Lessons from the Intentional Design Approach That Improved Our Design and Implementation}

Prior to Roster analyses, Community Mapping, and other Intentional Design exercises, many of our conventional program elements had gone unquestioned or unrevised. This process illuminated the need for a number of shifts in our programmatic design. The following sections detail the central lessons-and shifts to the program's design as a result-that were made.

\section{Using Subnational-Level Data to Make Thoughtful Selections about Geographies of Focus, Girls to Reach, and How to Reach Them}

PROBLEM: The program design relied on outdated, overly aggregated national-level data to make selections of where to work, using datasets that were combining demographic and other information across overly large geographic areas, potentially hiding the heterogeneity of girls' experiences and grouping girls together regardless of age or other socioeconomic characteristics. 
TABLE 2. ILLUSTRATIVE COMMUNITY RESOURCE MAPPING EXERCISE RESULTS

\begin{tabular}{|c|c|c|c|}
\hline $\begin{array}{l}\text { Community Service/ } \\
\text { Stakeholder Type }\end{array}$ & $\begin{array}{c}\text { Service/Stakeholder } \\
\text { Name }\end{array}$ & Services Offered & Target Beneficiaries \\
\hline \multirow[b]{2}{*}{ Health Service Provider } & Health Service Example A & 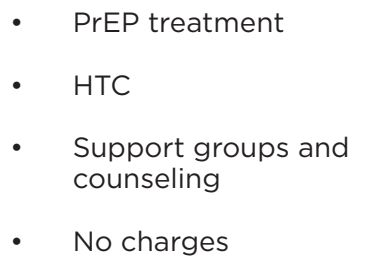 & - $\quad$ Entire community \\
\hline & Health Service Example B & $\begin{array}{ll}\text { - } & \text { Adolescent clinic } \\
\text { - } & \text { Family planning } \\
\text { - } & \begin{array}{l}\text { Antenatal/postnatal } \\
\text { follow-up }\end{array} \\
\text { - } & \text { PMTCT } \\
\text { - } & \begin{array}{l}\text { Charges depending } \\
\text { on service }\end{array} \\
\end{array}$ & $\begin{array}{l}\text { - Young mothers aged } \\
15-24 \text { years }\end{array}$ \\
\hline GBV Service Provider & GBV Service Example A & 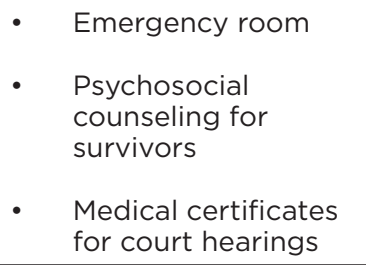 & - General population \\
\hline \multirow[t]{2}{*}{ CBOs } & CBO Example A & $\begin{array}{l}\text { - } \begin{array}{l}\text { Rescue abandoned } \\
\text { children, orphans, } \\
\text { street children }\end{array} \\
\text { - Counseling } \\
\text { - Safe house }\end{array}$ & $\begin{array}{ll}\text { - } & \text { Orphans } \\
\text { - } & \text { Destitute street } \\
\text { children }\end{array}$ \\
\hline & CBO Example B & 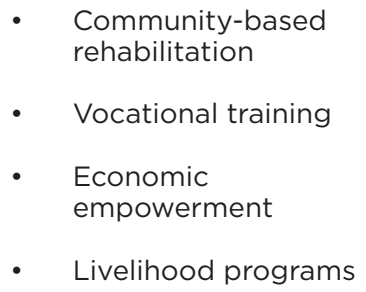 & $\begin{array}{l}\text { - People with } \\
\text { disabilities }\end{array}$ \\
\hline \multirow[t]{2}{*}{ Religious Institutions } & $\begin{array}{l}\text { Religious Institution, } \\
\text { Example A }\end{array}$ & $\begin{array}{ll}\text { - } & \text { Free hall uses for } \\
\text { community meeting } \\
\text { - } & \text { Guidance counseling } \\
\text { - } & \text { Mentorship classes }\end{array}$ & - General population \\
\hline & $\begin{array}{l}\text { Religious Institution, } \\
\text { Example B }\end{array}$ & $\begin{array}{l}\text { - } \begin{array}{l}\text { Support groups for } \\
\text { children aged 5-18 } \\
\text { years }\end{array} \\
\text { - Spiritual } \\
\text { nourishment } \\
\text { - Encouragement and } \\
\text { mentorship }\end{array}$ & $\begin{array}{l}\text { Weekdays, } \\
\text { schoolboys only } \\
\text { - Fridays open to all }\end{array}$ \\
\hline
\end{tabular}


SOLUTION: By applying an Intentional Design approach, we looked at subcounty and ward-specific data that enabled us to prioritize geographic areas having the highest concentrations of off-track girls. We specifically based our selection of areas to work in on data regarding the worst reproductive health outcomes, high HIV incidence, and high incidences of gender-based violence among the youngest cohorts of girls, distinguishing by age and other characteristics. Because of this exercise we were able to see significant variations at the subcounty and ward level, allowing us to make more intentional selections of where to work.

PROBLEM: The program was initially designed to reach 7,000 AGYW in Pumwani Ward. After implementing the Roster, we realized we could not meet our allocated targets in only the geographic ward that had been predetermined by the donor.

SOLUTION: We used the Girl Roster results from Pumwani Ward, complemented by our analysis of subcounty and ward-specific data, to renegotiate geographic coverage with our donors and make a case for expansion to two other geographic wards to meet our target of girls. Knowing now where to work, our program staff applied the Girl Roster again in the two new wards to understand more fully the segments of girls present in these priority geographies. Girl Roster results helped us establish appropriate saturation levels; knowing how many target girls lived in each village within the wards helped us form an estimate of the proportion of girls we would need to reach to make a real difference.

\section{Getting to Know Our Girls and Their Communities through the Girl Roster}

PROBLEM: For many of our program staff, the communities we were entering were new and we were unclear on how best to sensitize them to our intended activities, particularly key gatekeepers to the program's success.
SOLUTION: Beyond the quantitative information collected by the Girl Roster, the act of rostering itself provided an opportunity for important qualitative observation of the communities in which we intended to work. Through rostering, we made first contact with the households, allowing parents/caregivers and the girls themselves to become familiar with us, which facilitated an easier community entry process. As staff now knows, although rostering has intentional and targeted questions, often qualitative insights come to the surface through the inevitable dialogue between the female household member and the rosterer when administering the questionnaire. What we learned from interaction with parents/caregivers during rostering helped inform interventions such as counseling sessions for parents/ caregivers in the program. Indeed, dialogue with parents/caregivers enabled us to learn more about existing gender and social norms in these communities that needed to be addressed by the program. One such example was learning that HIV-positive members of one community were engaging in "revenge sex" where they would intentionally target the people's spouses or children with the aim of infecting them.

Other observations of community interaction and behavior gave us context for further conversations about girls' availability to participate in the program, such as meeting hours and places in which they spent most of their time, giving us a sense of how and where we could reach them. For example, some girls were employed in local brew dens while others, like domestic workers, worked throughout the week and only had one day off, limiting their flexibility to participate. In another example, in a Somali Muslim portion of one community we learned that very clear and stated permission from guardians would be required for girls to participate and that guardians' presence going to, during, and going from the first few meetings would be necessary as well.

The Girl Roster also underpinned social mobilization and recruitment. Girl Roster results 
provided us with geo-locations of target girl households, which enabled us to see where the girls live. This was important in identifying effective recruitment strategies for the girls and knowing which stakeholders and gatekeepers to approach. It also speeded up the journey from rostering to recruitment as we already knew where to find the girls we hoped to reach.

Finally, the rostering helped raise the DREAMS' profile and visibility, thus enhancing acceptability once the program started implementation.

\section{From Broad to Segment-Specific Groups for Intervention}

PROBLEM: Before implementation, our planned groups for intervention were very broad; our only requirement was that they be young people in school aged 9-18 years old. Further, we had created mixed groups of school-going boys and girls, with little consideration for establishing groups with specific characteristics in common beyond age and school attendance.

SOLUTION: Having been oriented to the central concepts of segment-specific program design, and with the Girl Roster results in hand, our staff critically reviewed our existing groups and made revisions. First, we broke up the mixed groups. We used Girl Roster results to segment girl groups based on age and similar characteristics, which enabled us to separate the groups of boys and girls. We realized, through central Intentional Design concepts, that our schoolbased model skewed programming to the girls who have better access and are not as in-need of HIV mitigation, prevention, and treatment programming. We differentiated them into agespecific cohorts, gathering girls of similar ages whose experiences and life transitions are likely shared.

Additionally, the Girl Roster enabled us to identify off-track girls and work with subpopulations of girls that the program otherwise would have never reached. These include street girls, teen mothers, adolescent brides, migrant girls, girls engaged in child labor, domestic workers, and Somali/Oromospeaking girls who did not understand any Kenyan language. The program, therefore, revised its eligibility criteria to include these hard-to-reach girls.

With this information and all these modifications in hand, our staff ultimately identified the following segments for intervention:

- Girls 10-14 years old in school, living with neither parent;

- Girl 10-14 years old in school living with one parent;

- Girls 10-14 years old out of school, migrant girls;

- Girls 10-14 years old out of school, living with relatives/grandparents;

- Girls 15-19 year old out of school, teen mothers;

- Girls 15-19 years old in school, living with neither parent;

- Girls 15-19 years old in school, living with a single parent;

- Girl 15-19 years old, migrant girls;

- Girls 15-19 years old out of school, living with relatives/grandparents;

- Girls 20-24 years old, married and with children;

- Girls 20-24 years old, single mothers;

- Girls 20-24 years old out of school, living alone.

With our specific segments now identified, girls were divided into groups of 25-30 who would meet on a weekly basis at a designated time and location of their choice for two hours with a mentor over a period of two to three years. 
As a result of this segment-specific approach, a number of design and implementation elements similarly changed to be aligned to these specific segments, including how we recruited, where we provided program activities, what sort of activities we did, and more. Here, we focus on two specific elements-the mentorship model and adaptations to program content.

\section{Transitioning from a Peer-to-Peer to Mentorship Model of Support to Participating Girls}

PROBLEM: Prior to adopting an Intentional Design approach, our program used a peerto-peer model to deliver support and some program content to our participants, as well as to help in recruitment of participants. Several flaws in this model were observed. First, peer educators were students and the same age as their peers hence they often lacked the necessary confidence, authority, or technical experience to convey certain program content. Sensitive subjects such as GBV or reproductive health require maturity that, if not properly trained and overseen, peer educators might not possess. Peers from a similar at-risk group may also not be able to model positive behavior for participants consistently. We also foresaw that the hazard of a peer-to-peer model was sustainability; while adult staff or mentors could be retained year by year through payment and opportunities for professional growth, peers would eventually need to move to other classes or to the next level of their education as they aged out of the role, requiring retraining of a new cohort year after year.

SOLUTION: The vital role of mentors in girlcentered programs is well established. Because of our community engagement, as a result of rostering, community mapping, and other exercises, we had naturally begun to build a connection with a group of young women who were already working in the communities in other capacities. Some were trained as facilitators for other community projects, others were young women leaders guiding girls in business initiatives or volunteers in churches/ health facilities; several were young women who had completed university-level education and were offering free tuition classes to younger learners. Observing the qualities that made them potentially good mentors, we developed a basic criterion for mentor selection:

- $\quad$ Slightly older, nonfamily;

- Completed secondary school education;

- $\quad$ Lived in the same community as participants;

- Had the heart and motivation to volunteer;

- Had the ability to serve as a role model.

Once mentors were identified through a thorough application process, their first role was to work with priority segments of girls in the communities to identify safe spaces suitable for meeting. Using the Safety Scan tool from the Council, they guided the girls through identifying the physical locations, days of the week, and hours and times that were safest. Safe meeting venues identified by girls included churches/mosques, community social halls, schools, health facilities, vocational training centers, business premises, and AGYW household compounds, among others. For example, girls aged 20-24 years preferred early morning hours for meeting to allow them the rest of the day to work. Younger girls aged 10-14 years met mainly after school hours from 3:30 to 4:30 p.m. and on weekends, while outof-school girls aged 15-19 years were flexible to meet during the day.

Once safe spaces were established, individual mentors were assigned segment-specific groups to lead, but through immediate feedback after a few weeks of implementation, mentors were paired up to lead groups together. To start, we recruited 50 mentors to mentor other girls in the safe space groups, and after the first year of implementation 34 program participants who 
had completed the program became mentors themselves. This went on year by year, creating a cascading mentorship model.

To support and sustain this model, we learned some key measures through the Intentional Design approach:

- $\quad$ The value of stipends and suppliesmentors were provided a monthly stipend, stationery, training materials, and monitoring tools to facilitate their work;

- The importance of a regular feedback loop-each safe space group identified its own group leader who represented them in the program; these peer leaders, as they were called, worked closely with the mentors to ensure that girls attended meetings, to raise any emerging issues affecting the group, and to propose activities to engage their peers. Program staff would hold monthly meetings with the peer leaders to provide insights into the successes and challenges of the program from the participants' perspective.

\section{Tailoring Program Content to Specific Segments}

PROBLEM: Our program was employing conventional reproductive and sexual health curriculum before being introduced to the Intentional Design approach, giving everyone the same material with little to no adaptation.

SOLUTION: Girl Roster results enabled us to tailor interventions that respond to and address the needs of the girls. An example was that due to the low transition of girls to secondary school, the program put in place strategies to reintegrate girls back to school and help them transition from primary to secondary school. As mentioned before, we had identified some new segments as a result of the use of the Intentional Design approach. In addition to making adaptations to the curriculum to make it more age- and context-specific, we also added new activities to our work to respond to the needs of particularly vulnerable girls (often made transparent through requests by the segment). This included providing:

- A career mentorship program for in-school girls and a workforce readiness program for out-of-school girls to support them in finding safer modes of employment;

- Training in basic child health care, such as hygiene, nutrition, and reading immunization charts for adolescent mothers, as well as childcare during the sessions they attended;

- Menstrual-hygiene education and products (we established public-private partnerships with organizations, such as Ruby Cups, that provided girls with free menstrual cups and education);

- Basic literacy training for the SomaliOromo-speaking girls who were facing risky language barriers (these girls specifically were guided by Somali- and Oromospeaking mentors).

\section{Conclusion}

As of 2019, at the program's close, we had established 400 safe space groups with 12,252 girls both in and out of school meeting on a regular basis. This enabled girls to build social capital, agency, social networks, and trusting relationships, while also encouraging their more consistent engagement in the community through the access of existing resources and civic engagement opportunities. The program had reached 12,252 girls with health education and 10,693 with financial literacy skills, and trained 5,592 girls on entrepreneurship. Out of these girls, 3,171 had been supported to start and/or strengthen existing businesses; 1,050 had completed vocational/apprenticeship training; and 1,931 had been placed in gainful employment. The program had also provided education subsidy support to 4,905 girls, 
which had enabled them to stay in school and/ or transition from one level of education to another and/or complete their schooling.

The Intentional Design approach and complementary tools enabled the program, as well as Global Communities as a whole, to become more thoughtfully girl-centered. As we scale, we take a similar approach to finding the most-at-risk populations to ensure we are reaching them at the right time, with the right things, in the right places.

If you would like to learn more about this project, please visit: https://www. globalcommunities.org/kenya. 


\section{Practitioner Report 10 \\ Lessons from DREAMS Interventions in Matutuíne and Namaacha, Mozambique}

By Belmiro Sousa, Margareth Nhancale, Shirley Eng, and Sophie Soares

\begin{tabular}{|c|c|}
\hline Findings and Decisions & Implementation Observations and Adaptations \\
\hline $\begin{array}{l}\text { - Girl Roster information served as the basis for } \\
\text { redirecting resources, in terms of serving new } \\
\text { communities not previously included in the program } \\
\text { catchment area and redistributing mentors to serve } \\
\text { a proportionate number of girls. } \\
\text { - Information from mapping the communities' girls } \\
\text { and available resources helped convince local } \\
\text { partners to build out more adolescent-friendly } \\
\text { health services and allocate mobile teams to } \\
\text { communities physically far from health facilities but } \\
\text { in the program catchment area. } \\
\text { Girl Roster information illuminated for the project } \\
\text { the potential pool of mentors in the communities, } \\
\text { not only in terms of the denominator (how many } \\
\text { potential mentors in total lived in the program } \\
\text { catchment area), but also in terms of the qualities } \\
\text { of a good mentor. }\end{array}$ & $\begin{array}{l}\text { - The project team became more critical in its } \\
\text { selection of communities to roster after observing } \\
\text { that some of the original communities selected } \\
\text { were not the most in need and therefore not where } \\
\text { the appropriate type of segment and target number } \\
\text { of girls was going to be reached. }\end{array}$ \\
\hline
\end{tabular}

\section{Introduction}

The COVida-Together for Children project of FHI360 Mozambique aims to improve the health, nutritional status, and well-being of orphans and vulnerable children (OVC) in the country. COVida increases community capacity to protect and care for orphans and vulnerable children through the use of existing health and social services. COVida also promotes an environment that fosters the physical health and social and emotional development of children, with the goal of reducing the risk of HIV infection.

In early 2018, the project received funding from the DREAMS Partnership to engage in community- and school-based interventions in new communities of the Maputo Province to reach an increased number of adolescent girls vulnerable to HIV. At that time, approximately three years into the DREAMS Partnership's launch, the Population Council's contributions to the initiative were well noted, with Ambassador Deborah L. Birx, US Global AIDS Coordinator commenting on the value of the Girl Roster in particular. Mozambique's USAID office asked for our coordination with the Council to use the tool in the field.

\section{Implementation of the Girl Roster}

In late 2018, and with extensive training and support from the Council in the selection and mapping of communities, COVida staff implemented the tool in 20 carefully chosen communities of 5 subareas of Matutuíne and Namaacha. Leading this implementation was Belmiro Sousa (Associate Director-Technical), Margareth Nhancale (DREAMS Technical Officer), and Shirley Eng (Deputy Chief of Party), with the support of recruited rosterers (see Table 1). 
TABLE 1. OVERVIEW OUTPUT TABLE WITH RESULTS ACROSS ALL WARDS IN THE DISTRICT

\begin{tabular}{|l|l|}
\hline Namaacha District & Matutuíne District \\
\hline Adelina Mundlovo & Admira Mondlane \\
Senia Fadar & Anania Loombene \\
Aderito Malate & Fausta Cossa \\
Domingos Romão & Eduardo Ndavane \\
Ana Marcela Naftal & \\
\hline
\end{tabular}

Most of these communities are in rural (90\%) areas with limited access to essential resources. Both Namaacha and Matutuíne districts have borders between Maputo and South Africa and Maputo and Eswatini (Swaziland), with high rates of migration from Mozambicans, meaning that in many families, children and adolescent girls live with one or neither parent. Adolescent girls and young women (AGYW) are engaged in commercial activities, selling food at the border or crossing borders to buy products to sell in their communities.

As an example of the new considerations that were made in selecting communities, in our initial training on how to use the Roster the Council accompanied us to implement the tool in Namaacha. The community we chose was on one side of a major road and populated by a number of ex-pats whose domestic workers were likely targets of our programs. In this community, there were also a number of resources, such as a school and health center. On the other side of the road, however, was another community, more isolated from the main resources on the side we found ourselves on. The following day, realizing that the other side of the road was physically far from resources, we decided to roster there instead, thinking this might be where a higher population of girls in need would be found.

As a result, we found other girl segments in the area that would otherwise have been overlooked. This lesson was key for selecting the 20 communities for rostering, as was engaging community leaders in the Community Oval exercise to identify sites with a high volume of AGYW who had limited access to resources and were at risk of suffering the worst consequences at the earliest ages. Table 2 presents the summary of results from one of the 5 subareas.

\section{Lessons Learned from the Roster Results}

\section{Final Selection of Communities}

Of the 20 rostered communities, COVida decided to exclude two sites from actual community-based intervention, namely Mabilibile and Fabrica de Cal, as there were less than 40 eligible girls found in these two communities. Eligibility was defined by girls who were off-track, that is girls under the age of 18 who met at least one of the following conditions: out-of-school, living with neither parent, married, or having children. Instead, it was decided it was a better use of resources to implement only school-based interventions in these two sites, where the majority of girls were in school, as there is secondary boarding school for adolescents coming from other communities across Maputo Province.

The analysis of the information also informed COVida that the number of adolescent girls available in the rostered communities in both districts Namaacha and Matutuíne $(1,780)$ was less than the expected target of 4,800 adolescent girls for that year. This helped COVida negotiate with the donor and implementing partners to expand the program into additional communities that had characteristics similar to the high-volume rostered communities. 
TABLE 2. GIRL ROSTER OVERVIEW OUTPUT TABLE OF BELAVISTA, MAPUTO PROVINCE, MOZAMBIQUE

\begin{tabular}{|c|c|c|c|c|c|c|c|c|c|c|}
\hline \multirow{3}{*}{$\begin{array}{l}\text { Age } \\
\text { cohort }\end{array}$} & \multicolumn{7}{|c|}{ Unmarried } & \multicolumn{2}{|c|}{ Married } & \multirow{3}{*}{ Tota } \\
\hline & \multicolumn{3}{|c|}{ In School } & \multicolumn{3}{|c|}{ Out of School } & \multirow[b]{2}{*}{$\begin{array}{l}\text { Has a } \\
\text { child }\end{array}$} & \multirow[b]{2}{*}{$\begin{array}{l}\text { Has a } \\
\text { child }\end{array}$} & \multirow{2}{*}{$\begin{array}{l}\text { Does } \\
\text { not } \\
\text { have a } \\
\text { child }\end{array}$} & \\
\hline & $\begin{array}{l}\text { Living } \\
\text { with } \\
\text { both } \\
\text { parents }\end{array}$ & $\begin{array}{l}\text { Living } \\
\text { with } \\
\text { one } \\
\text { parent }\end{array}$ & $\begin{array}{l}\text { Living } \\
\text { with } \\
\text { neither } \\
\text { parent }\end{array}$ & $\begin{array}{l}\text { Living } \\
\text { with } \\
\text { both } \\
\text { parents }\end{array}$ & $\begin{array}{l}\text { Living } \\
\text { with } \\
\text { one } \\
\text { parent }\end{array}$ & $\begin{array}{l}\text { Living } \\
\text { with } \\
\text { neither } \\
\text { parent }\end{array}$ & & & & \\
\hline $6-9$ & 78 & 80 & 10 & 1 & 8 & 0 & - & - & - & 177 \\
\hline $10-12$ & 65 & 88 & 16 & 2 & 0 & 0 & - & - & - & 171 \\
\hline $13-14$ & 45 & 47 & 7 & 1 & 2 & 1 & 0 & 0 & 0 & 103 \\
\hline $15-17$ & 36 & 67 & 9 & 5 & 7 & 1 & 5 & 4 & 1 & 135 \\
\hline $18-19$ & 17 & 25 & 2 & 2 & 2 & 0 & 14 & 10 & 7 & 79 \\
\hline $20-24$ & 5 & 11 & 2 & 10 & 10 & 0 & 35 & 38 & 4 & 115 \\
\hline Total & 246 & 318 & 46 & 21 & 29 & 2 & 54 & 52 & 12 & 780 \\
\hline
\end{tabular}

\section{Recruiting Mentors}

The rostering process was an opportunity to identify potential mentors. During information collection, Roster field supervisors had the chance to observe girls and see if they were potential mentors for DREAMS in the selected communities. We defined mentors as on-track girls and young women aged 18-25 years who had completed a minimum of eight years of schooling, were seen as good role models for girls in the community, and displayed positive behavior, assertiveness, and the ability to face challenges head on. Based on the collected information, COVida was able to determine the number of potential mentors-defined by level of schooling and age-and, in comparing it with the number of potential participants, determine the number of mentors needed to adequately cover the adolescent girls in the area. To recruit the mentors, our implementing partners publicized a job description and the recruitment process on local radio. We then organized a meeting with community leaders and other stakeholders (schools, churches, health facilities) to disseminate the information. Table 3 shows the distribution of mentors allocated per community.

\section{Establishment of School-based Interventions}

In the original design for DREAMS, COVida was asked to implement community-based interventions for safe spaces, but analysis of the Girl Roster outputs indicated that the number of girls who are out of school or behind grade for age (2+years) is considerably higher for all ages, ranging from 58\% (10-12 years) to $80 \%$ (15-17 years). To prevent having more girls out of school, COVida advocated with DREAMS stakeholders in Maputo to introduce safe spaces in schools for adolescent girls in early stages (9-14 years old), allocating $40 \%$ of the total target for safe spaces in primary and secondary schools and $60 \%$ for safe spaces in the community.

\section{Advocacy for Mobile Clinical Services}

DREAMS is a multisectoral program providing both community and clinical services for adolescent girls and young women. To avoid creating demand for limited sexual and reproductive and family planning services in the communities, COVida used the collected information from the Roster to convince clinical partners-Ariel Glaser Foundation and the 
TABLE 3. MENTOR ALLOCATION PER COMMUNITY BASED ON NUMBER OF ADOLESCENT GIRLS TO BE REACHED

\begin{tabular}{|c|c|c|c|c|}
\hline Community & Bairro & $\begin{array}{l}\text { Number of } \\
\text { Adolescent Girls }\end{array}$ & $\begin{array}{l}\text { Number of Mentors } \\
\text { Allocated }\end{array}$ & Comments \\
\hline Salamanga & Chidzukuine & 125 & 3 & \\
\hline Salamanga & Ngovoza & 93 & 2 & \\
\hline Salamanga & Fabrica de cal & 35 & 2 & \\
\hline Belavista & A & 178 & 4 & \\
\hline Belavista & B & 132 & 3 & \\
\hline Belavista & C & 230 & 5 & \\
\hline Belavista & D & 111 & 3 & \\
\hline Belavista & Mudada & 48 & 1 & $\begin{array}{l}\text { School-based } \\
\text { interventions only }\end{array}$ \\
\hline Belavista & Mabilibile & 10 & 1 & $\begin{array}{l}\text { School-based } \\
\text { interventions only }\end{array}$ \\
\hline Belavista & Tchelene & 78 & 2 & \\
\hline Belavista & Mudissa & 118 & 2 & \\
\hline Goba & B1 & 178 & 4 & \\
\hline Goba & B2 & 142 & 3 & \\
\hline Goba & B3 & 73 & 2 & \\
\hline Mahelane & B1 & 166 & 4 & \\
\hline Mahelane & B2 & 100 & 2 & \\
\hline Mahelane & B3 & 111 & 2 & \\
\hline Mahelane & B4 & 72 & 1 & \\
\hline Changalane & E. Mondlane & 112 & 3 & \\
\hline Changalane & J. Machel & 208 & 5 & \\
\hline
\end{tabular}

Provincial Directorate of Health-to create Adolescent Friendly Health Services in the health facilities and allocate mobile teams to the schools and communities covered by the programs, but far from the health facilities.

\section{Conclusion}

In conclusion, we were able to map and recognize the full composition, or "universe" of girls in our program catchment area, breaking the girls into segments by age, schooling, marital, childbearing, and living-arrangement status. Of the rostered communities, we decided to exclude two sites for community-based interventions, as the number of adolescent girls found was lower than expected.

Making scaling decisions is not easy. Programs must balance the desire to "reach every last girl" with cost-effectiveness-particularly where there are such high numbers and great need. We established a budget metric that each mentor should reach 100 or more beneficiaries. This meant that we did not include and deferred working with communities that had less than 100 AGYW. Intentional Design Tools were used to assist COVida in identifying additional communities that had high concentrations and numbers of at-risk girls, allowing the project to 
reach 4,533 AGYW (95\% of annual target) and remain within budget.

As of 2019, COVida has been implementing a safe spaces model. Our primary interventions for the 4,533 AGYW includes social asset building, in which girls use the GoGirls curriculum (covering self-esteem, relationships, sexual and reproductive health, HIV prevention, and violence). We have also provided secondary interventions for 431 AGYW by mobilizing beneficiaries to create 21 savings groups and implementing contextual interventions for 380 AGYW with education subsidies to cover school fees, materials, and uniforms for adolescent girls.

The use of Girl Roster methodology was critical for COVida's DREAMS program design and the selection of communities.

If you would like to learn more about this project, please visit:

https://www.fhi360.org/projects/covidatogether-children. 


\title{
Practitioner Report 11
}

\section{Investing in Girls in Northern Mozambique}

\author{
By Cristina Alcada, Kátia Almeida, Ana Avillez, and Alexandra Machado (Girl Move)
}

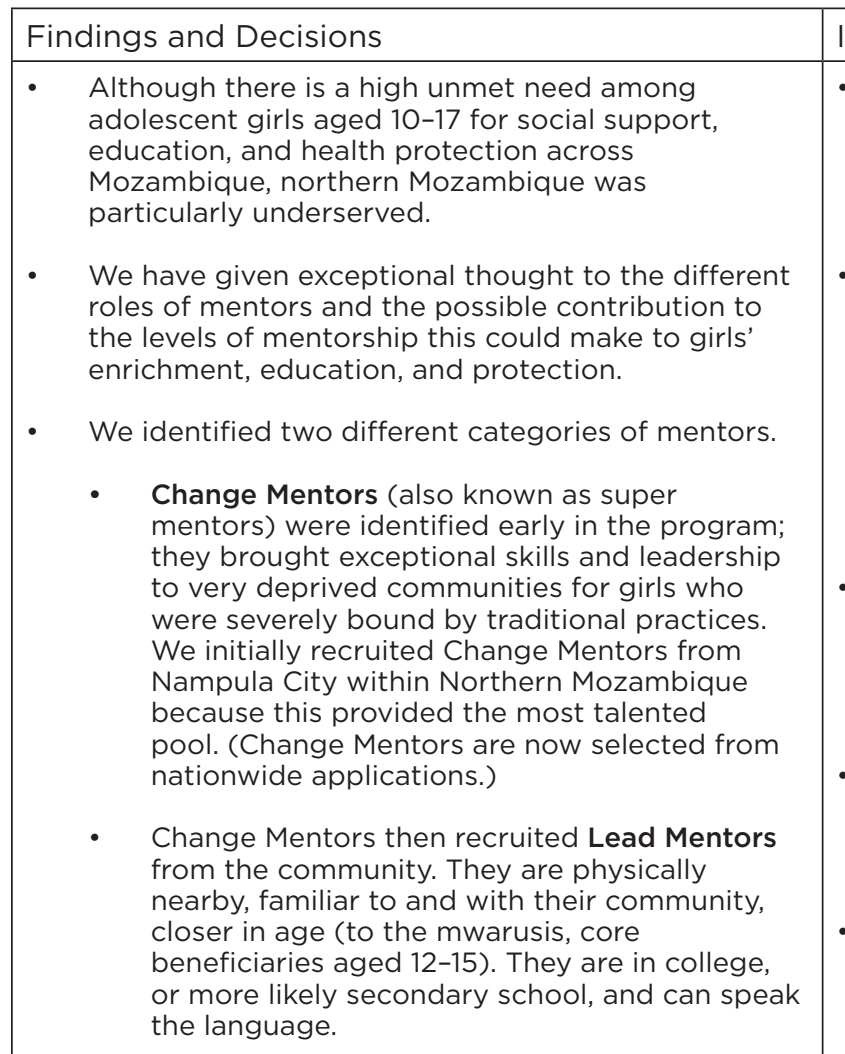

- Even girls (and potential mentors) who attended school for six or seven years had poor academic skills (only $22 \%$ passed an equivalent of a 2 nd- or 3rd-grade literacy test).

- To overcome academic limitations, the training and socialization of mentors required special cognitive support, as well as confidence-building and community-engagement skills.

- With beneficiary girls and Change and Lead mentors, interactive and play-based content are essential to enhanced learning.

- Mentors should engage with local communities as early as possible, laying the foundation for sustainability and trusting relationships vital to their ability to organize responses in emergencies (Beira cyclone, COVID-19 pandemic, etc.).
Implementation Observations and Adaptations

- It was useful to pilot with a variety of segments before settling in on which segment(s) to focus on; while there was some interest in older, in-school girls (over age 15), we found it most fruitful to concentrate our resources on those 12-15 years.

- A shorter program of the same content made more sense because in a one-year versus a two-year program, the same impact could be better achieved by the 7th-grade segment, and aligned with the school year (early February to December). The two-year-long program proved to be repetitive and would require (due to the connection to the other programs) a counterproductive change of mentors mid-process.

- The most accomplished mentors are able to extend the program to other neighborhoods and cities, conducting the necessary technical mapping, engaging with the community, and making program decisions.

- The age cohorts in the Output Tables were adapted to reflect Mozambican schooling systems and cultural patterns, including late entry; girls 8-11, 12-15, and 16-18 were grouped together.

- We continue to be open to innovations tested around the world to unleash the potential of adolescents in vulnerable contexts as they may address weaker aspects of our intervention. We have successfully introduced:

- "Gamebook" technology to address decisionmaking skills;

- Sports as a tool to address the "being a team" element of groups of adolescents;

- Open Space as a tool to engage community members in seeing girls and themselves as partners in finding solutions that benefit the whole community;

- Support replicas of the program led by former Change Mentors (as of 2020, three ongoing);

- We are shaping a new generation of leaders that can envision and work toward a better future for all. 
FIGURE 1. GRAPHICS OF ADOLESCENT GIRLS' EXPERIENCE IN MOZAMBIQUE. (MOZAMBIQUE DHS 2011). ANALYSIS CONDUCTED BY SHELLEY CLARK ON BEHALF OF THE POPULATION COUNCIL USING MOZAMBIQUE DHS DATA. UNITED NATIONS DEVELOPMENT PROGRAMME MOZAMBIQUE.

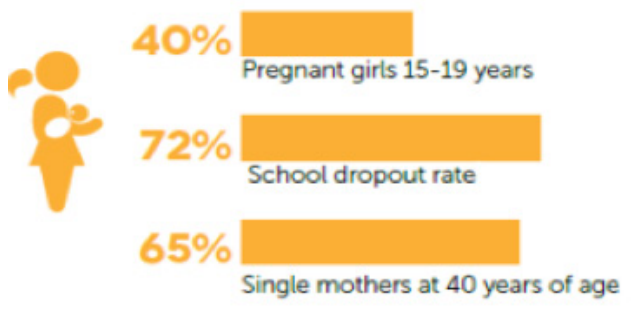

$68,7 \%$

Working population

living with less than $\$ 1,9$

a day

\section{Introduction: Girls' Lived Experience in} Mozambique

In Mozambique, one of the poorest countries in the world (ranking 180 out of 189 countries in the Human Development Index 2017), 58\% of the population is under 19 years of age. Many adolescent girls (mwarusis in the Mozambican language Emacuwa, largely spoken in Nampula, a northeast province of the country) are at a very high-risk stage in life and face challenges associated with the life transitions that occur during adolescence (including puberty) as well as communities' perceptions about their role in society (see Figure 1). Adolescent girls are often kept home for their safety and to do household chores. Furthermore, poverty can force girls into child marriage and exploitative sexual relations for economic security; families cannot support all their children and often see girls making up for resource scarcities.

The dramatic shift in girls' lives during young adolescence is very clear when looking at school attendance. Although 94\% of Mozambican girls complete primary school, there is a steep decline in participation in education after the primary level. Only $24 \%$ of girls continue with secondary school, of whom $10 \%$ finish and $1 \%$ go to university (MISAU, INE, and ICF 2018). In Mozambique, school dropout coincides with key transitions in girls' lives. Almost half of the girls (48\%) get married and have their first child (40\%) before the age of

\section{FIGURE 2. PREDICTIVE IMPROVEMENT IN EDUCATION AND FERTILITY REDUCTION (WORLD BANK 2017)}

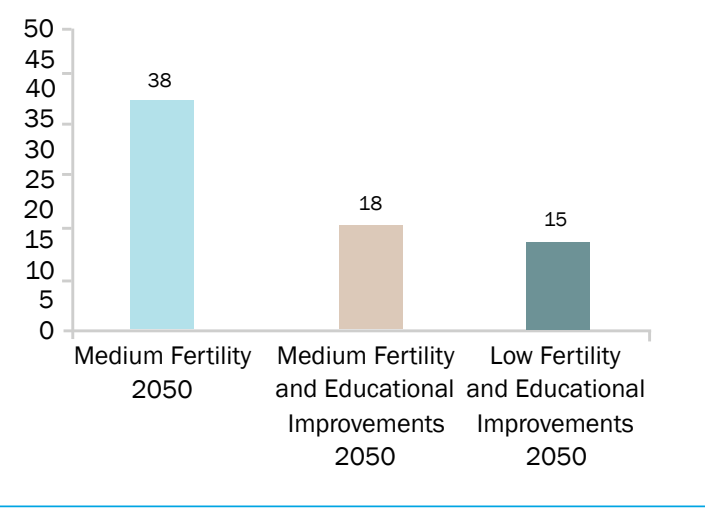

18 (UNICEF 2015). The World Bank reported in 2017 that projections from Mozambique show that "only by improving education and reducing fertility can Mozambique eradicate extreme poverty by 2050" (World Bank 2017) (see Figure 2).

Evidence further shows that even one more year of secondary education can link girls to employment with $10-25 \%$ more income-a resource that can be used to support not only themselves but their families (Psacharopoulos and Patrinos 2004), and that given the work opportunity $90 \%$ of that income is invested back into the family (Fortson 2003). 
SUMMARY OF THE VIRTUOUS CYCLE OF POSITIVE TRANSFORMATION AND VALUE CREATION

Empowerment of a new generation of women changemakers, as disruptive leaders to change the world

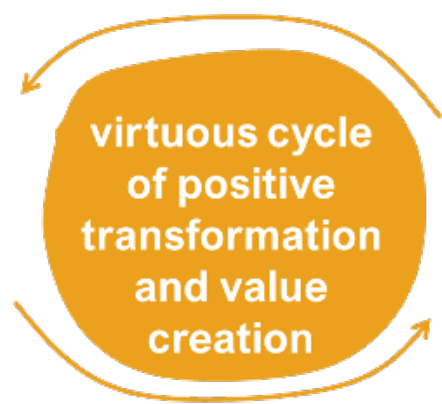

\section{Model of mentorship promoting girls access to positive life rolemodels, thus fighting school drop- out and child pregnancy and marriage}

This evidence frames the premise of the Girl MOVE Academy's work-that investment in girls not only benefits the girls themselves but empowers them to unleash their potential and have a greater impact on their families and home communities.

\section{Girl MOVE Academy's Interlinked Programs and Mentorship Model}

\section{The Program's Premise and Overall Structure}

Girl MOVE aims to lead a new model of female empowerment that boosts the multiplying effect of women and girls' education. We strive for a world where all women have access to opportunities to become leaders and agents of positive change, able to contribute to the political, economic, social, and cultural development of their country.

Girl MOVE'S one-year program is aligned with the Population Council's Intentional Design approach, which focuses on establishing girl-only spaces (Step 6 of the Basic Model) with the support of the community (Step 9 of the Basic Model) in which girls can, with the support and guidance of mentors (Step 7 of the Basic Model), build protective assets (Step 8 of the Basic Model). Girl MOVE was the first organization to pilot this approach and the safe spaces methodology in Mozambique.

\section{Using an Evidence Base to Pilot Intentional Design in Mozambique}

\section{Deciding Where to Work}

Girl MOVE Academy has been implementing its vision for girls (the BELIEVE Program) since 2014; our first challenge was to decide where to work, using data from the 2011 Demographic and Health Survey (DHS) to identify at the provincial level where there were the highest concentrations of off-track, including out-ofschool, girls. This analysis drew attention to Nampula Province, where indicators showed a higher prevalence of school dropout, early pregnancy, and child marriage rates than nearly every other province.

Within Nampula Province, we focused on Nampula City because we were seeking, within a poor place, a density of highly talented potential mentors and knew that university students resided there. Within Nampula City, we looked at peri-urban neighborhoods (to reach the most remote and poorest communities), combining the risks of rural world mentalities from parents and the risks of urban-like youth behaviors and risks (alcoholism, violence, idleness/unemployment, high number of displaced male workers, etc.). From this research we narrowed our priority areas to two possible neighborhoods and finally decided on Marrere, with a population of 8,000 people, indicating a pilot our size would be impactful 
and relevant. Furthermore, Marrere was where we had a partner willing to introduce us to the community.

Marrere is a peri-urban neighborhood 12 kilometers [7 miles] away from Nampula City, strikingly underserved in services and basic facilities. Population data indicated that $60 \%$ of the Marrere population was 18 years or younger (4,144 people), of which 22\% (943) were girls. In the following years, Girl MOVE Academy expanded its intervention to other areas in Nampula and Beira.

\section{"Seeing" the Girls to Learn Whom (Which Segments) and When to Support}

In 2013, Girl MOVE Academy elected to apply the Girl Roster using pen and paper ${ }^{1}$ in the Marrere community to capture a clearer picture of the "universe" of girls. The community was divided into seven subareas, mapped out crudely by locals and then using Google maps by program staff (see Figure 3). A field team comprised of one coordinator and four subteams (two mentors and one community adult) led the rostering. The subteams carried leaflets with them describing the BELIEVE Mwarusi program both in Portuguese and the local language Emacuwa.

Table 1 shows a summary of the information collected. $^{2}$

The results indicated that among girls 8-18:

- $8 \%$ of girls (76/943) are married, and 6\% (53/943) have children; $19 \%$ are under the age of 19 , and a full $34 \%$ of girls aged $16-18$ are married;

- $30 \%$ of girls (287/943) are out of school, $31 \%$ of those are 8-11 years old;
- $38 \%$ of girls (358/943) live with one or neither parent, $40 \%$ of those are as young as 8-11 years old;

- $\quad 35 \%$ of girls in school (8-18 years) are significantly delayed in grade for age. ${ }^{3}$

Post-Rostering Reflection on the More Specific Goals within Our Empowerment StrategySegment Selection

The results reinforced the priority of preventing school dropout on transition to secondary schools (7th to 8th grade) while also preventing early/child marriage and pregnancy (noting that $34 \%$ of girls aged 16-18 were married).

To provide maximum support for continuous education, especially a transition to secondary school, the pilot aimed to reach 220 girls concentrated in these two in-school segments:

- Girls in school 12-15 years old between 5th and 7 th grade (121);

- Girls 8-11 years old and 16-18 years old bordering those grades (61);

In the following year, we developed a pilot for out-of-school girls.

To reach the out-of-school girls age 15 and over, a mentor went house to house identifying outof-school girls who had not been absent from school for longer than two years. We believed this would increase the chance that they would be more successful in a second-chance program. The mentors convinced them to join a program that would build their skills and reconnect them to education in some form. The group started with 5 girls and had 30 after two months. This success was due to a "mouth-tomouth" and "face-to-face" campaign.

\footnotetext{
${ }^{1}$ At the time, the phone app version of the Girl Roster was still being perfected so using pen and paper was the better option for implementing the tool.

2 It is notable that because the Girl Roster was administered by pen and paper, the Output Tables were not generated immediately. Therefore, program staff were able to summarize the tables in the way they saw fit, hence the difference in age breakdown from the standard Overview Output Table.

${ }^{3}$ The Overview Output Table does not display girls behind grade for age; the determination of this value comes from analysis of back-end information not displayed in the table.
} 
FIGURE 3. CRUDE RENDERING AND FORMAL MAPPING OF THE MARRERE COMMUNITY COMPLETED BY LOCALS AND PROGRAM STAFF, RESPECTIVELY
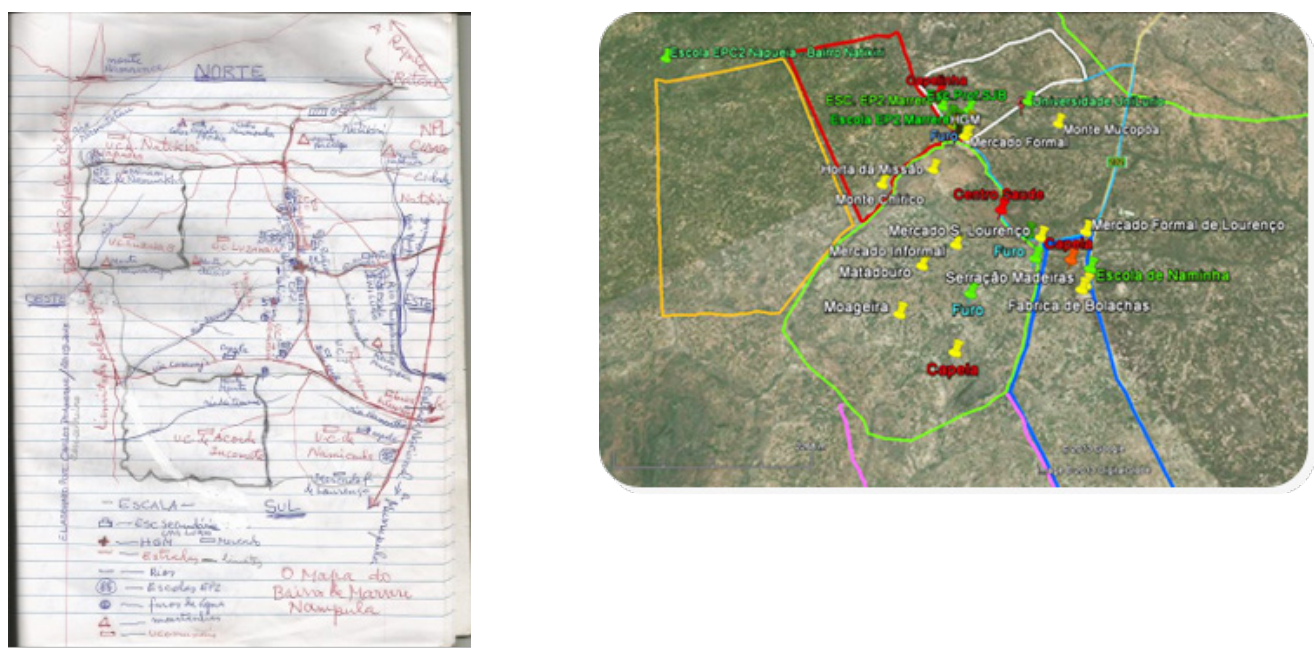

TABLE 1. SUMMARY OF GIRL ROSTER RESULTS FROM MARRERE COMMUNITY, NAMPULA PROVINCE, NOVEMBER 2013

\begin{tabular}{|c|c|c|c|c|c|c|c|c|c|}
\hline \multirow{3}{*}{$\begin{array}{l}\text { Age } \\
\text { cohort }\end{array}$} & \multicolumn{4}{|c|}{ Unmarried } & \multicolumn{4}{|c|}{ Married } & \multirow{3}{*}{ Total } \\
\hline & \multicolumn{2}{|c|}{ In School } & \multicolumn{2}{|c|}{ Out of School } & \multicolumn{2}{|c|}{ In School } & \multicolumn{2}{|c|}{ Out of School } & \\
\hline & $\begin{array}{l}\text { Living } \\
\text { with } \\
\text { both } \\
\text { parents }\end{array}$ & $\begin{array}{c}\text { Living } \\
\text { with just } \\
\text { one or } \\
\text { neither } \\
\text { parent }\end{array}$ & $\begin{array}{l}\text { Living } \\
\text { with } \\
\text { both } \\
\text { parents }\end{array}$ & $\begin{array}{l}\text { Living } \\
\text { with just } \\
\text { one or } \\
\text { neither } \\
\text { parent }\end{array}$ & $\begin{array}{l}\text { Has } \\
\text { children }\end{array}$ & $\begin{array}{l}\text { Has no } \\
\text { children }\end{array}$ & $\begin{array}{l}\text { Has } \\
\text { children }\end{array}$ & $\begin{array}{l}\text { Has no } \\
\text { children }\end{array}$ & \\
\hline 8-11 & 225 & 108 & 51 & 38 & 0 & 1 & 0 & 0 & 423 \\
\hline $12-15$ & 144 & 96 & 40 & 57 & 4 & 4 & 8 & 3 & 356 \\
\hline $16-18$ & 33 & 31 & 16 & 28 & 6 & 4 & 35 & 11 & 164 \\
\hline Total & 402 & 235 & 107 & 123 & 10 & 9 & 43 & 14 & 943 \\
\hline
\end{tabular}




\section{Initial Content}

With respect to in-school girls, the pilot project in Marrere reached a total of 249 adolescent girls, which we refer to as mwarusis, or "butterfly" in Portuguese. The mwarusis were divided into 10 groups of girls in 5th, 6th, and 7 th grades. With the support of 10 mentors and 10 guides, these groups met two times per week for 90 minutes, with the addition of one bimonthly house call, ${ }^{4}$ all over the course of two years.

The curriculum emphasized four key areas:

- "I am," building self-esteem and identitybuild social skills and capital;

- "I know," emphasizing academic skills like reading and math-build cognitive assets;

- “I am healthy," emphasizing understanding basic public health interventions (such as making drinking water safe and homemade oral rehydration solutions-build health capital;

- " "I have," focusing on opportunities (including a job fair)-build economic capital.

\section{Community Engagement}

The community was supportive of the program, with community volunteers building a safe space classroom in which girls could meet and community leaders agreeing to a contract in support of the program. The space was built in Namigonha, a subarea of Marrere, to serve as a safe space and double as a school classroom. It lasted for two years. The contract stated that the school could use the classroom whenever it wasn't being used as a safe space. The space was built by the local community members, who were provided materials and were compensated not only for the construction but for the longterm maintenance of the space. Unfortunately, although the community always respected the space and kept it safe, they breached the contract of maintenance, and we eventually declined to keep doing it on our own, so as not to encourage this behavior. Since the maintenance stopped, heavy rains washed away the room.

\section{Lessons Learned from the Pilots and Program Adaptation: Feeding a Continuous Process of Intentional Design}

As of 2019 , the program is in its fifth round of implementation and has trained and fielded 99 Change Mentors, 170 Lead Mentors, and reached more than 2,200 adolescent girls in six different neighborhoods across not only Nampula Province but also Sofala Province (see Table 2).

In the early phases of the program, we piloted programs with girls aged 8-11 and out-of-school girls 15 and over, and have settled on prioritizing girls 12-15 to assist school retention and transition from primary to secondary school.

The work in Sofala Province provided an unexpected learning experience when a severe cyclone hit the capital, Beira, doing significant damage. Two Senior "Warrior" Mentors and 30 local mentors had sufficient skills to mobilize an emergency response and protect the 325 girls in the program, and craft a community response, including identifying local support, a school building, and university engagement.

After each round of implementation, a quantitative and qualitative evaluation effort allowed us to learn from good practices and mistakes, and subsequently project improvements and aspects we wanted to keep.

\footnotetext{
${ }^{4}$ Mentors went to the mwarusis' family homes to get to know the family, gain their trust, explain what was talked about in the sessions, They checked out the surroundings to look for red flag risks and to gain a better understanding of economic difficulties and the composition of the family (such as whether there was a father present). Mentors always found a way to compliment the girl in front of her parents.
} 
TABLE 2. GIRL MOVE'S MENTORSHIP AND BENEFICIARY STRUCTURE

\begin{tabular}{|c|c|}
\hline Change Mentors & $\begin{array}{l}\text { Young women aged 22-30, university graduates from all over Mozambique, } \\
\text { who mentor Lead Mentors and lead a team of } 3 \text { Lead Mentors in the mentoring } \\
\text { of mwarusis (adolescents) } \\
\text { - Lead team of } 3 \text { mentors in the process of safe spaces project and } \\
\text { methodology } \\
\text { - Be role models and mentor Lead Mentors } \\
\text { - Do house calls for mwarusis and mentors } \\
\text { - Define intervention plans for critical incidents and follow up on them with } \\
\text { the team of Lead Mentors } \\
\text { - Follow up on critical incidents from Lead Mentors themselves } \\
\text { Be positive role models to mwarusis and Lead Mentors } \\
\text { Ensure community engagement }\end{array}$ \\
\hline Lead Mentors & $\begin{array}{l}\text { Girls aged } 16-21 \text { who attend late secondary schools or university in Nampula. In } \\
\text { teams of } 3 \text {, they mentor a group of } 30 \text { mwarusis } \\
\text { - } \quad \text { Recruit mwarusis } \\
\text { - } \quad \text { Facilitate sessions } \\
\text { - } \quad \text { Do house calls } \\
\text { - } \quad \text { Follow up on critical incidents (identification and intervention plan) } \\
\text { - } \quad \text { Be positive role models to mwarusis }\end{array}$ \\
\hline $\begin{array}{l}\text { Mwarusis (adolescent } \\
\text { beneficiaries) }\end{array}$ & $\begin{array}{l}\text { Girls aged } 12-15 \text { who are in their last year of primary school and live in } \\
\text { vulnerable contexts in urban and peri-urban communities } \\
\text { - } \quad \text { Attend tailor-made life-skills programs twice a week in safe spaces } \\
\text { - } \quad \text { Attend reading support sessions } \\
\text { - } \quad \text { Organize and participate in community events } \\
\text { - } \quad \text { Develop projects to benefit families and communities } \\
\text { - } \quad \text { In earlier pilots, included girls } 8-11 \text { and out-of-school girls } 15 \text { and older }\end{array}$ \\
\hline
\end{tabular}

\section{Lessons Learned: Segmentation Priority}

- Recognizing the acute pressures on early adolescent girls, we selected girls aged 12-15 as the priority segment for the development of girl leadership and the group on whom we wanted to concentrate resources;

\section{Lessons Learned: Mentorship Is Core}

- All pilots affirmed priority to the mentorship relationship and its role in risk prevention, improvement of girls' skills, and, when needed, rapid intervention;

- Mentors were able to make quick risk assessments, were given effective guidelines, and were able to act more and more autonomously in most common cases; 
- Mentors' leadership and social entrepreneurship are maximized if they start the process of local community engagement early, laying the foundations for continued commitment to girls beyond the program.

- Lead Mentors' capacities are strengthened by:

- " "O meu projecto de vida com impacto" (Impactful life project) exercise: Mentors design their own life project, focusing on finishing university and on how to use their education to further the development of their community and country.

- Application of the Change My Community Framework: Mentors develop skills such as empathy, selfesteem, and self-control; proactivity and responsibility; and critical thinking, creativity, and problem-solving.

\section{Lessons Learned: Content and Design}

- $\quad$ Shorten the programs (we scaled back gradually from 24 months to 12 months);

- $\quad$ Align the program with the school year to make sure mentors accompany the girls through national exams and enrollment in secondary-school processes.

- Introduce game-based programming to enhance learning, especially for intensive financial literacy and savings programs, and supporting sexual risk and relationship decision-making.

- Assess and reinforce reading skills as a formal part of program content; when we applied the international standardized test for literacy skills in 2nd and 3rd grades to girls attending 6 th and 7 th grades, we realized we needed to shift the school support component, which became a "literacy fast track" program. ${ }^{5}$
Lessons Learned: Adapting to Other Settings and Autonomy

- We piloted in urban and peri-urban settings in both Nampula (North) and Sofala (Beira, center) in different provinces, confirming its utility in relatively high population settings.

- Graduate program participants (mwarusis) were encouraged to start meeting in their own groups, with reduced supervision by Lead Mentors and supported by purposeful connection to local women's groups; we are evaluating this sustainability strategy.

\section{Lessons Learned: The Importance of} Ascertaining Girls' Sexual Exposure

- We implemented the Ascertaining Sexual Relationships Types (ASERT) tool in a focus group style and learned how common transactional sex is among adolescents 12-15 years old and also among the college students mentor segments (Lead Mentors).

\section{New Directions}

We will intensify our core mission to promote a new generation of female leaders for Mozambique. These mentors will shape change through providing relatable, positive role models for girls from their home communities, use their acquired skills to communicate effectively with traditional power structures at local and national levels, generate qualitative and quantitative information, and design evidence-based innovations for the common good.

- We will continue to acknowledge and disseminate success and good practices among partners - to drive coverage with quality while never shrinking from frank assessment of what works and what does not for different groups of girls-making their lives, their education in the broadest terms, and their role as catalytic leaders the central subject.

\footnotetext{
${ }^{5}$ In collaboration with Girl MOVERs, we developed a literacy program based on the Paulo Freire methodology, running once-a-week sessions facilitated by mentors. The program is based on going from the girls' realities to concepts translated in words. Results from the pilot showed incredible results in terms of literacy (66.8\% correct answers by the end of the pilot) but also in terms of girls' self-esteem, and gaining the families trust in the program.
} 
- In the fifth phase of the project (2019), we are piloting Mwarusi in Motion, a sportsbased activity to promote team spirit and improve leadership skills through weekly rugby practices. This component was designed with the technical and financial support of Women Win. Evaluation results are not yet available, but from a qualitative point of view it is quite clear that girls are very engaged.

- We are promoting what we have learned about mentoring (Lead Curriculum; How to Be a Mwarusi Mentor Manual; the Wheel of Life Tool; and the Risk Prevention and Intervention Manual). In partnership with local universities and other civil society organizations (CSOs), we hope the toolkit can benefit the three million girls aged 10-19 in Mozambique.

- Lead Mentors are able to lead and manage the mapping process and give valuable input on segmenting girls (see Figure 4).

\section{Launch of the Mozambican Learning Circle- Movimento $M$}

In partnership with the Population Council, Girl MOVE Academy analyzed national data of population size and age cohort to approximate the size of the constituency to which Girl MOVE's learning might apply; there are 3.3 million girls aged 10-19 living in Mozambique. Even if we only define the condition of being off-track by the percentage who are getting married as children (that is, under the age of 18), $48 \%$ of these 3.3 million are already offtrack (or more than 1.5 million).

We are expanding (while testing) the Girl MOVE Program beyond Nampula to other hotspots for child marriage, school dropout, early pregnancy, and other risks. Partnership and flexibility (offering open-source material, such as the Mentor Toolkit) are vital to bring the program to scale. It is a social entrepreneurship/franchise model.

Movimento M, launched by Girl MOVE, is a
FIGURE 4. EXAMPLE OF THE LEAD MENTORS MAPPING PROCESS

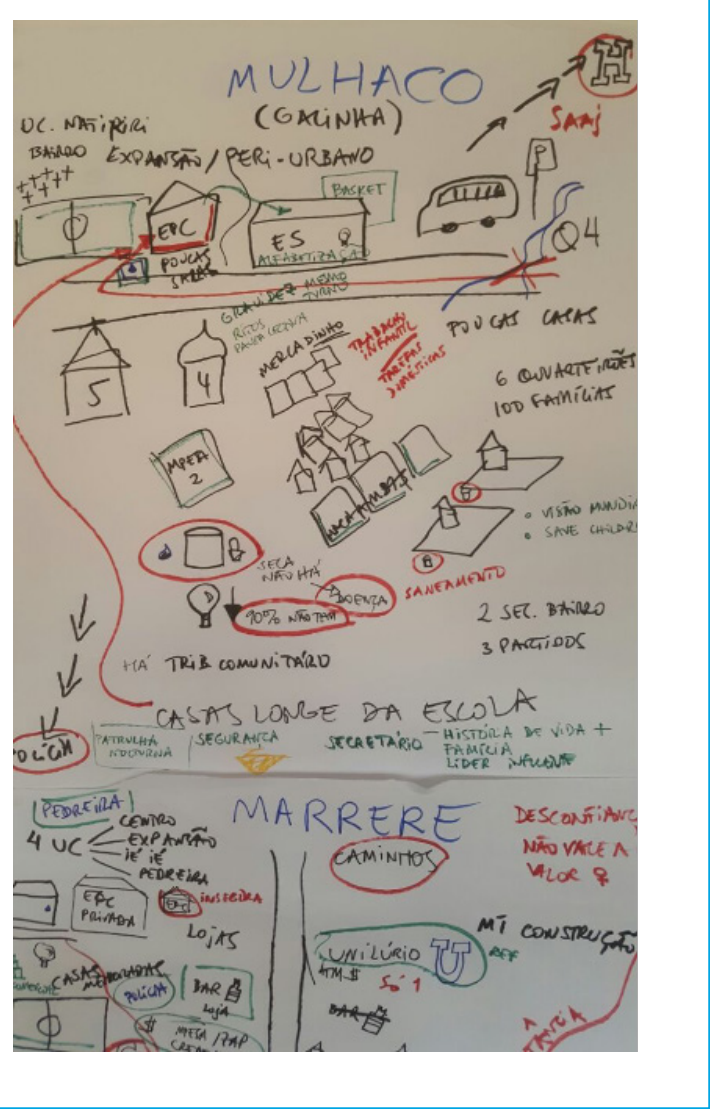

learning circle that aims to strengthen the work that CSOs, universities, and individuals are doing to implement and scale up girl-centered programs across the country. As of 2019, Movimento $M$ has 65 participating organizations and Girl MOVE Academy openly shares all of the program's learnings, best practices, tools, and methodologies.

We are learning about how best to support partners in adaptation and replication. As of 2019, we have actively engaged with one CSO and one university (Zambese University) which has included mentorship in the academic education, accrediting this "work" as part of the academic curriculum and simultaneously building a nationwide cadre of mentors. 
A Wider Reach for Girl Move through Movimento M-A National-level Engagement

Girl MOVE has used on-the-ground learning to inform national policies, such as the National Strategy to Prevent and Reduce Child Marriage (2016) and the Gender Strategy of the Ministry of Education and Human Development (20162019).

Specifically, we have recommended a preventative (acting early and with high saturation in at-risk communities) rather than reactive (after a girl is pregnant, has dropped out of school) line of action. We insist investments are made directly in girls themselves as a priority, rather than engaging all those around them as objects, not subjects, in their own change. We urge that clear and objective indicators for specific segments of girls, with emphasis on hotspot communities, are built into the plans. At the formal presentation of the National Strategy to Prevent and Reduce Child Marriage (2016-2019), Girl MOVE shared its risk-prevention model, which has been made available to all Movimento $M$ members. ${ }^{6}$

Girl MOVE Academy is an active participant of the National Coalition for the Elimination of Child Marriage (CECAP) and a member of the Girls Not Brides Global Network. Furthermore, in 2018 Girl MOVE Academy has been welcomed as an affiliate to the Ashoka Network of changemakers. ${ }^{?}$

For more information, please visit: www.girlmove.org Girl MOVE Academy (video).

\footnotetext{
${ }^{6}$ This report can be found on the Ministry of Gender, Child and Social Action's website: http://www.mgcas.gov.mz/st/FileControl/Site/ Doc/9996estrategia_casamentos_prematuros_2016_2019_002.pdf

${ }^{7}$ ASHOKA is the biggest network of social innovators in the world, reaching 3,500 fellows globally. ASHOKA coined the term "social entrepreneur" and has now evolved to a vision of a world where Everyone is a Changemaker.
} 


\section{Practitioner Report 12 \\ Implementing the Girl Roster in South Sudan'}

By Omar Robles, Dale Buscher, and Aimee Lyons

\begin{tabular}{|c|c|}
\hline Finding & ion Observations and Adaptations \\
\hline $\begin{array}{l}\text { Resettlement camp managers had projected that } \\
\text { about } 10 \% \text { of girls of school-going age would be } \\
\text { out of school, but rostering revealed it was closer to } \\
45 \% \text {. This led to a full evaluation of using the school } \\
\text { as a base through which to deliver vital inputs, } \\
\text { including food security and vaccinations, as a high } \\
\text { proportion of the most vulnerable were not present. } \\
\\
\text { - The program assumed married girls had children, } \\
\text { but about one-third did not. The childless girls may } \\
\text { not have had surviving children because this part } \\
\text { of Sudan has catastrophically high infant mortality, } \\
\text { particularly among very young girls. } \\
\text { The content of the program for married girls } \\
\text { needed review as it had little young-female-focused } \\
\text { content, was child-focused, and did not provide } \\
\text { means to include or support the childless. } \\
\text { This experience was a breakthrough for the } \\
\text { Women's Refugee Commission, as it was in the } \\
\text { context of this field experience that a poor girl } \\
\text { came forward to program organizers. As an out- } \\
\text { of-school girl, she had not been part of the initial } \\
\text { school-based program. She called attention to } \\
\text { herself, saying "l'm here," leading to both the } \\
\text { naming and crafting of the l'm Here approach, } \\
\text { which incorporated the Girl Roster as a key tool. }\end{array}$ & $\begin{array}{l}\text { - Technical aspects of Girl Roster training are } \\
\text { relatively easy, but the rapidity of the Roster } \\
\text { should not supersede productive community } \\
\text { interaction. That is, it is important to advance } \\
\text { through the questionnaire quickly while remaining } \\
\text { respectful. Finding a balance between reaching } \\
\text { all the households in the walkable community and } \\
\text { maintaining a positive relationship with community } \\
\text { members is vital. } \\
\text { - The results at the end of Day } 1 \text { of rostering were } \\
\text { surprising to the rosterers, as they found more girls } \\
\text { of school-going age out of school than they had } \\
\text { anticipated. Results identified young married girls } \\
\text { with and without children. } \\
\text { In working in an Internally Displaced Persons (IDP) } \\
\text { camp, there are important protocols to follow and } \\
\text { political factors to navigate. Key humanitarian } \\
\text { actors and the host population were apprehensive } \\
\text { about activities perceived as assessments or } \\
\text { research. It was important to describe the Girl } \\
\text { Roster in the proper terms for what it actually is-a } \\
\text { rapid response tool that supports effectiveness and } \\
\text { quality. Emphasizing this helped increase the trust } \\
\text { of the host population. } \\
\text { The questionnaire was translated into and applied } \\
\text { in Dinka so that the questions could be articulated } \\
\text { rapidly and the information effectively sourced. }\end{array}$ \\
\hline
\end{tabular}

\section{Introduction}

This practitioner report outlines the Women's

Refugee Commission's (WRC's) pilot implementation of the Girl Roster in South Sudan. In consultation with the Population Council and in partnership with Action Contre Le Faim/Action Against Hunger (ACF) in
South Sudan, Omar Robles, who was a senior program officer at the WRC at the time, coordinated the pilot implementation. On-theground pilot activities took place in April 2014, approximately three months after the WRC initially suggested the partnership to several operational humanitarian organizations.

\footnotetext{
${ }^{1}$ This practitioner report is special because it was foundational in the creation of the Women's Refugee Commission's (WRC's) I'm Here approach, the product of much iteration between the Council's Intentional Design team and WRC. At the time, the WRC took an extraordinary role in bringing to earth the Girl Roster, as part of the broader Intentional Design approach, in extremely challenging circumstances. Because this field experience happened in an earlier phase of the Roster's testing and evolution, this report focuses more on the technical understanding and adaptations of the Roster and includes commentary on how learning tools must be deployed differently in humanitarian settings, not only because of security concerns in those settings but also because of the sensitivities and protocols around research. Not only are implementing organizations sensitive to this but the refugee population has grown distrustful of entities that collect information about them. The Council observed this same sensitivity in the United States paradoxically where our partners used pen and paper, because US authorities with tablets had become threatening. The Council is grateful to the WRC and Mercy Corps for being earlier testers and adapters of and collaborators on the Girl Roster tool and its application.
} 


\section{Experience with Girl Roster Technology}

Rosterers' familiarity with smart phonesincluding the swiping gesture, among other features-varied significantly in South Sudan, and the team consisted of only four people. The concept of (GPS-linked) mobile applications was foreign and took time to get accustomed to through an applied exercise. Overall, the process of using the phones and the mobile apps is accessible and user-friendly. For staff at headquarters who might pitch in and/or provide technical support to their colleagues in the field, the information-collection process and the steps to produce the Output Tables are even more user-friendly.

If ease of use is measured, as well as the operational setup, the experience is positive. Operational setup includes: setting up and modifying the questionnaire, uploading the questionnaire to "Ona," downloading the required applications, setting up the phones, testing the applications, uploading collected information, interpreting the outputs, and managing technical challenges.

\section{Challenges to Implementation}

The main (and only significant) challenges that the team in South Sudan encountered involved: translation to Dinka, and producing the Output Table. The first challenge was overcome by rosterers' patience and willingness to translate every question, and the meaning and language being reviewed during the one-day simulation training. The second challenge was resolved with technical support from the Population Council. Apart from this specific glitch, the information gathering went smoothly.

Another challenge was the impact of the process on rosterers' attentiveness. Given that the Girl Roster is based on a household/tentto-tent approach, which can feel redundant, it was important to keep the rosterers energetic, to maintain a rapid yet respectful pace in asking questions, and to ensure that, collectively, the team made a reasonable and ethical effort to reach all tents. This commitment was also impeded by time-of-day factors, e.g., the dates and time of day when rosterers use the tool impacts both the number of people, and who within the household rosterers could reach to collect information, as some people were simply not home.

Another takeaway from implementation in South Sudan was that when using the I'm Here and Intentional Design approaches, some geographical consideration about where to start is important. That is, do not begin to roster near/around the school or existing childfriendly space (CFS), as this starting point is more likely to result in identifying girls who can access these resources because they are more conveniently located and likely do not reflect the priority segments, which are those girls with restricted mobility/access to public space. It does not mean you do not roster the whole walkable community, merely that your priority should be in low-resource areas.

Last, in South Sudan a considerable number of heads of households did not know girls' exact ages, and in some families, had a number of girls in the same general age cohort (e.g., 6-9). Girls could be fitted loosely into a cohort, but for enumeration purposes they were assigned a letter code within their household to avoid double counting. When the raw information was accessed to better understand into which categories these subsets of girls fell, most of these girls (whose ages were unknown) fell into categories of heightened vulnerability/risk, i.e., off-track girls.

The South Sudan implementation occurred at an internally displaced persons (IDP) camp. This context is different from a refugee camp setting where UNHCR has more protocols and oversight, and where there may be apprehension about activities that are perceived as assessments of management or response.

All of these challenges, though, do not factor in the added security considerations and local context that provide their own challenges. 


\section{Approach to Introducing the Roster and Bridging Community Access}

Several key points are important to pitch WRC's I'm Here approach, of which the Girl Roster is an integral part. In the humanitarian context, it is important to avoid terms that may arouse suspicion, territorial response, or imply that the project involves research. These include "assessment," "research," "information," "questionnaire," "survey," "evaluation," and "accountability." Instead, framing the Girl Roster as a rapid response tool that supports effectiveness and quality taps into colleagues' desires to do their jobs well. One phrase that has been effective is that the "Girl Roster helps to generate actionable information."

The rostering team was comprised of four people: three non-ACF staff members and one ACF program staff person. In this context, rostering is defined as applying the questionnaire and using the mobile phones and applications. The three non-ACF staff were hired consultants; they were individuals who had previously worked for ACF as "hygiene promoters" and who could speak English and Dinka.

For more information, please review our report: https://s33660.pcdn.co/wpcontent/uploads/2020/05/Im-Here_2016Update.pdf. 


\section{Practitioner Report 13}

\section{Turning a School into the Center of a Movement Using Intentional Design Tools: The SEGA Girls School, Tanzania}

By Pauline Dolan, Sarah Hewitt, and Clementina Mwambene

Field Practitioners: Gertrude Bisoleka, Angel Mtale, Salama Ally, Catherine Mamba, Susan Emilian, Pili Abdallah, Jennifer Joseph, and Siwema Jaffary

\begin{tabular}{|c|c|}
\hline Findings and Decisions & Implementation Observations and Adaptations \\
\hline $\begin{array}{l}\text { - The Girl Roster exercise gave SEGA schools a more } \\
\text { in-depth view of the communities from which they } \\
\text { drew their students. } \\
\text { - Girl mentors (who graduated and came from the } \\
\text { communities) found the Roster assisted them } \\
\text { in really seeing their communities and drawing } \\
\text { insights, and offered systematic information for the } \\
\text { design of responsive programs. } \\
\text { - Some of the results from the Rostering process: } \\
\text { A large population of girls aged 10-18 live apart } \\
\text { from one or both parents. } \\
\text { Both seeing and reaching girls in domestic } \\
\text { service is challenging, especially those working } \\
\text { in non-relative households. } \\
\text { Girls living without parental guardianship not } \\
\text { only are less visible but also require more time } \\
\text { and financial resources to participate in the girl } \\
\text { groups (convened by the Modern Girl outreach } \\
\text { program). } \\
\text { Many girls have children but few are married. } \\
\text { Many girls 17 years old or older with minimal } \\
\text { years of schooling have no way of making a } \\
\text { living and need entrepreneurship skills and } \\
\text { financial literacy, career counseling, and skill } \\
\text { development. }\end{array}$ & $\begin{array}{l}\text { - The Girl Roster questionnaire was relevant and was } \\
\text { used unmodified, but implemented using paper and } \\
\text { pen. } \\
\text { - There was some difficulty tracking walking paths } \\
\text { with the maps. } \\
\text { - Rosterers found the information-collection process } \\
\text { easy but needed help with analysis and reading } \\
\text { Output Tables initially. } \\
\text { - Some leaders were skeptical of the program's } \\
\text { value but could be persuaded by females in their } \\
\text { community and trusted teachers. } \\
\text { The Roster is simple enough to deploy that it can } \\
\text { be used as an introduction tool; girl graduates (in } \\
\text { the second phase of the program) conducted the } \\
\text { Roster while developing their ideas for the modern } \\
\text { girl program, which ultimately created girl groups. } \\
\text { Acceptance from some communities requires } \\
\text { extended conversations following the Roster } \\
\text { process with school-based supervisors and } \\
\text { community leaders. }\end{array}$ \\
\hline
\end{tabular}

Secondary Education for Girls Advancement (SEGA) in Morogoro, Tanzania, reaches girls who are extremely poor, orphaned, or unsafe at home during the critical ages of $12-14$ as they approach the transition from primary to secondary school. SEGA works to ensure that these girls' transition to, and complete, secondary school and beyond. The SEGA Girls School, which was boarding 250 students as of 2019, has three main programs: academics as per the national secondary curriculum; an experiential entrepreneurship program; and an in-depth personal development, life, and leadership-skills program to equip girls with a comprehensive set of tools to enable them to earn income and lead self-determined lives.

\section{Moving from the Girl Roster (2015) into the Modern Girl, Graduate-Led Program (2018 and Beyond)}

The Girl Roster was the first tool tested among the Intentional Design tools to: 1) learn how 
it would work in our area (Kihonda Ward of Morogoro Municipality, Tanzania) with our program; 2) see if we could train our own graduates to implement the tool as we prepare to introduce a girls' club program using our own graduates as peer mentors; and 3) lay a foundation for a pilot, now the Modern Girl Program (see below), in which girls within a specific geographic area (in which we had a concentration of existing graduates) would lead their own girls' clubs and mentoring program. This is now operational in two communities.

In 2015, Sarah Hewitt (Population Council consultant at the time) collaborated with the team consisting of the school counselor, two teachers, and three of our recent girl graduates (aged 22), from the immediate community we mapped.

To introduce the exercise to the community, we first approached the mwenyekiti (village chair) in each area to ask permission to conduct the exercise. We explained that we were from the SEGA Girls Secondary School and that we wanted to learn more about the community the school serves. One leader was reluctant at first as he said that he had had too many surveys in the past with no benefit. However, our counselor managed to convince him, explaining that the school is already benefiting the community. The girls being interviewed were very receptive to the exercise as they recognized our graduates as being from the community.

The Girl Roster tool was easy to implement:

- It was applied using pen and paper because people do not feel comfortable around phones, particularly because of the threat of being filmed.

- The questionnaire was user-friendly, and, in our case, there was only one question that presented a challenge-we had difficulty explaining the concept of "female head of household," distinguishing that from "oldest female."

- Our students, and even some staff, had limited familiarity with maps, particularly viewing them on a tablet.
- When the phone batteries died in the afternoon on the day surveys were being conducted, information was collected in notebooks.

- When it came time to upload the information, the Wi-Fi was not working at the school. Finally, using a $3 G$ phone with a Wi-Fi hotspot, the information was uploaded. However, when we tried using a different type of phone, this took over an hour, most likely due to the GPS coordinates or photos and to the low speed internet lines available.

\section{Findings}

We found $28 \%$ of girls $10-18$ years old rostered in the first implementation were living with neither parent. Noting this, we affirmed our decision to cluster participation with selection of those in fewer communities each round, so that more girls-especially these least visible segments-might have a better chance of attending the program. We found very few married girls, though many young girls had children. This was noted and we looked ahead to recruiting them when the Modern Girl Program was initiated. While the team had expected to see many school dropouts, most of the girls aged 17 and above had completed Form 4 and had left school and were now at home with little to do.

We found that the Girl Roster tool is highly applicable for designing girls' clubs and mentoring programs. Specifically, it can assist us in seeing and understanding more about the status of girls within different age groupings in order to target interventions, and more broadly to confirm or establish the level of need for a mentoring program involving our girl graduates. Through piloting the tool, we also affirmed that it can be implemented by young women with a Form 4 education, which in this case is our graduates.

Moreover, the experience of implementing the questionnaire by future mentors was extremely important in building capacity and informing programming; for example, the rosterers 
suggested that SEGA introduce financial literacy and entrepreneurship education opportunities to assist out-of-school girls. The presence of many Form 4 leavers at home reinforces SEGA's rationale for having a robust "career counseling" and continuing education scholarship program for our graduates, and the need for practical, relevant education in addition to academic skills.

\section{The Modern Girl Program at SEGA}

As of 2019, SEGA has worked in over 31 Modern Girl (Msichana Kisasa) centers, whereby 15 have graduated from the core program. We currently have 16 active centers, run by SEGA girl school graduates, located in four districts including:

- Morogoro Municipal (4 centers);

- Mvomero District (5 centers);

- Morogoro Rural District (3 centers);

- Kilolo District (4 centers).

Each club has approximately 25 regular attendees and 2 SEGA mentors. One SEGA field officer supervises every five clubs. Clubs hold sessions for approximately 12 months, twice a week on Saturday and Sunday afternoons, and then a graduation ceremony is held.

After graduating, girls are encouraged to stay in contact, and every year a forum is held for all program graduates, called the Empowered Girls Network Forum, which helps connect all program graduates so that they can share what they have been doing after the program. The event helps encourage all new graduates to use the knowledge they have gained. During the forum, in addition to providing networking activities, we invite one professional of the graduates' choice (the graduates are actually involved in planning the event) as a speaker and facilitator to take them through any new knowledge they want, be it entrepreneurship- or health-based.
The Start Up of a New Center: Laying the Foundation with Intentional Design Tools

The government in Tanzania is highly decentralized with leaders designated per region, district, ward, village, and even street (every ten households). When starting the Modern Girl program in a new geographic area, we must therefore coordinate with government at nearly every level to ensure success, starting with the ward leader. Through a chain of command, mentors (with support from the SEGA field officer) are eventually linked up with Street Leaders, ' with whom we work closely to identify girls from the community who will be in the program. This activity is done houseto-house through interviews with parents and guardians. We wish to underscore that mentors who have helped with the recruitment process come to be trusted and experienced leaders in their communities and play increasingly critical roles as they represent SEGA and learn to cooperate with different government authorities at each level. Figures 1 and 2 show the details of our recruitment pattern over ten years of implementation.

The mentors, together with the SEGA field officer and Street Leader are divided into groups of two to three people who then walk around the community collecting information with the Roster, which is recoded from paper to an Output Table (see Table 1).

With this information in hand, the program staff examine the findings to learn about the girls in that community (i.e., age range, in school versus out of school, young mothers or not, etc.).

We hold a community meeting with local leaders, parents, and other community members and collaboratively decide which segments of girls to prioritize and where the program will be held. These meetings give the community an opportunity to understand the purpose of the program, address their concerns, ${ }^{1}$ Street Leaders oversee all activities and the welfare of the citizens of that street. This includes community meetings, community/family
arguments, and monitoring what organizations/government is doing for development in that particular street/area. 
FIGURE 1. REGIONS WHERE GIRLS WERE RECRUITED (2010-20)

\section{GEOGRAPHIC AREAS OF SEGA SECONDARY SCHOOL RECRUITMENT \& SEGA MK CLUBS} 2010-2020

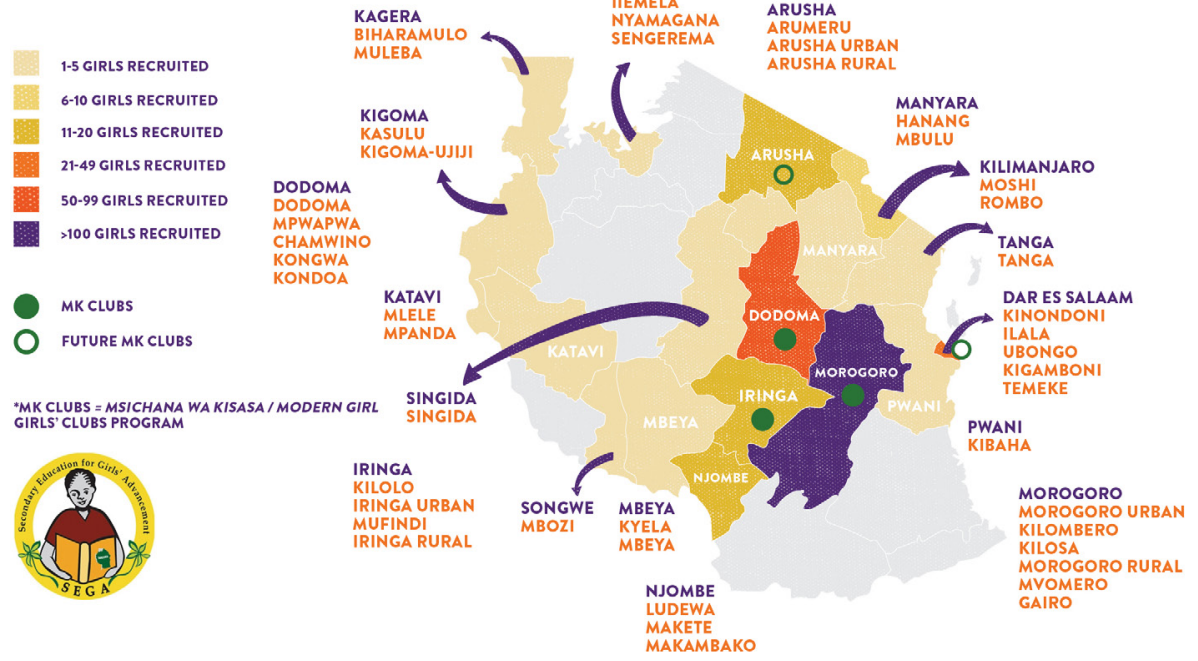

FIGURE 2. DETAILED MAP OF GEOGRAPHIC AREAS WHERE GIRLS WERE RECRUITED (2010-20)

GEOGRAPHIC AREAS OF SEGA SECONDARY SCHOOL RECRUITMENT \& SEGA MK CLUBS- DETAIL 2010-2020

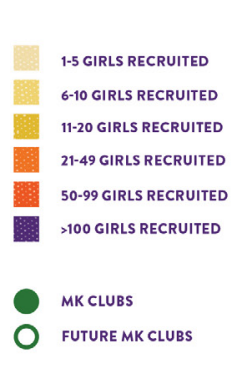

"MK CLUBS = MSICHANA WA KISASA / MODERN GIRL
GIRLS' CLUBS PROGRAM
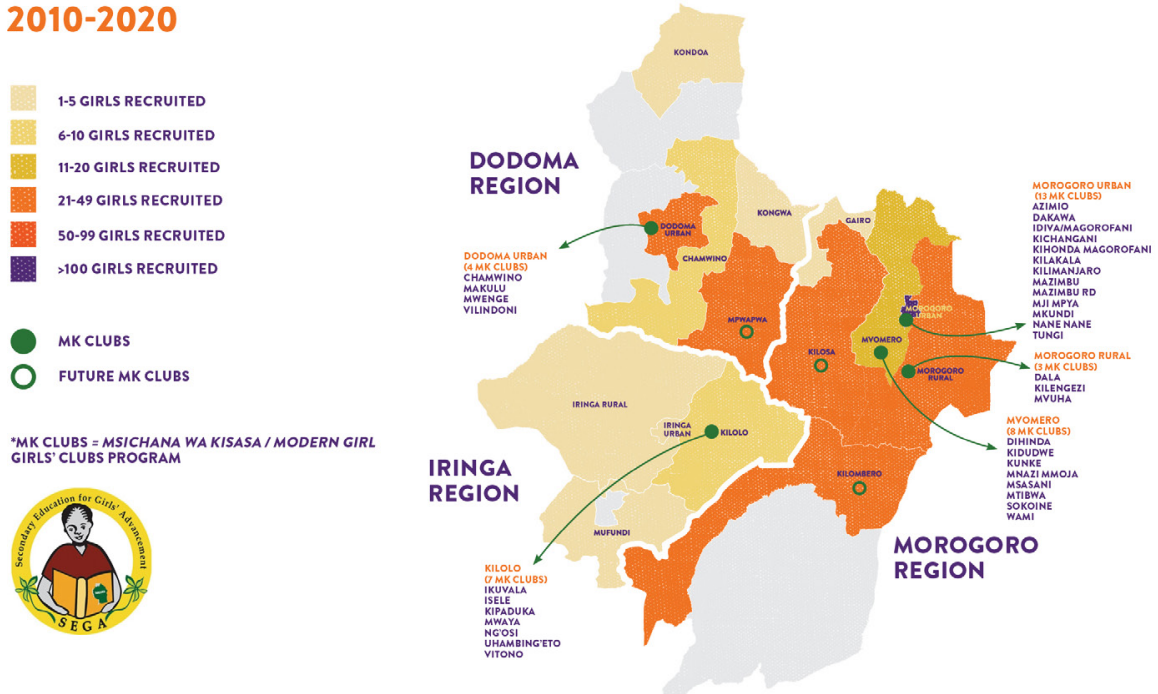
TABLE 1. OVERVIEW OUTPUT TABLE FOR COMMUNITY IN SEGA ROSTERING (EXAMPLE)

\begin{tabular}{|c|c|c|c|c|c|c|c|c|c|}
\hline \multirow{3}{*}{$\begin{array}{l}\text { Age } \\
\text { group }\end{array}$} & \multicolumn{6}{|c|}{ Unmarried } & \multicolumn{2}{|c|}{ Married } & \multirow{3}{*}{ Total } \\
\hline & \multicolumn{3}{|c|}{ In School } & \multicolumn{3}{|c|}{ Out of School } & \multirow[b]{2}{*}{$\begin{array}{l}\text { Has a } \\
\text { child }\end{array}$} & \multirow{2}{*}{$\begin{array}{l}\text { Does } \\
\text { not } \\
\text { have a } \\
\text { child }\end{array}$} & \\
\hline & $\begin{array}{l}\text { Living } \\
\text { with } \\
\text { both } \\
\text { parents }\end{array}$ & $\begin{array}{l}\text { Living } \\
\text { with } \\
\text { one } \\
\text { parent }\end{array}$ & $\begin{array}{l}\text { Living } \\
\text { with } \\
\text { neither } \\
\text { parent }\end{array}$ & $\begin{array}{l}\text { Living } \\
\text { with } \\
\text { both } \\
\text { parents }\end{array}$ & $\begin{array}{l}\text { Living } \\
\text { with } \\
\text { one } \\
\text { parent }\end{array}$ & $\begin{array}{l}\text { Living } \\
\text { with } \\
\text { neither } \\
\text { parent }\end{array}$ & & & \\
\hline $6-9$ & 9 & 1 & 1 & 0 & 0 & 0 & -- & -- & 11 \\
\hline $10-12$ & 50 & 5 & 3 & 0 & 0 & 1 & -- & -- & 59 \\
\hline $13-14$ & 42 & 6 & 5 & 4 & 0 & 3 & 0 & 0 & 60 \\
\hline $15-17$ & 15 & 3 & 2 & 12 & 1 & 2 & 0 & 0 & 35 \\
\hline $18-24$ & 5 & 0 & 0 & 20 & 5 & 1 & 19 & 1 & 51 \\
\hline Total & 121 & 15 & 11 & 36 & 6 & 7 & 19 & 1 & 216 \\
\hline
\end{tabular}

and feel part of the implementation. With the community's input, sessions can begin swiftly, typically the weekend following the community meeting.

\section{Detecting Differences in Geography and Demographics, and Drawing Out the Implications for Programming}

\section{Programming Considerations in Different Geographic Areas}

There are some key differences between the communities of Iringa (rural) and Morogoro (urban). It has been our observation that the more urban and educated parents of Morogoro town and its surrounding areas tend to encourage their girls to join the program, while in rural Iringa some parents are discouraging. This aligns with the fact that in rural Iringa, some parents discourage good performance in primary school among their daughters out of concern that they will then be eligible for secondary school, which is seen as a waste in many communities. This is because many parents view teenage girls as adults, ready to meet financial needs for themselves and their family, therefore they do not want to increase their exposure to transactional sex, other forms of sexual exploitation, and early pregnancy. SEGA staff have considered these contextual challenges in the first phase of implementation and community mobilization of the Modern Girl program, and have identified these as key issues that must be covered during the program's sessions. Therefore, each time the program is implemented, it is tailored to the demographics and cultural context of the community. Further, the act of going house to house through the rostering really has allowed SEGA to gain these specific insights into girls' lives.

\section{Segmenting Groups}

We use the compiled Output Table results to decide what kind of segmentation is needed. This process of Intentional Design is still a work in progress for us, but with support from the Population Council, is has taken root not only among our staff but among our mentors and communities as well. For example, in the community of Turiani (Mvomero District), we found a number of adolescent mothers, so we created a club especially for them, in addition to the 10-14-year-old girl group already intended. Sessions with this group were essentially a pilot, as we had never formed a group for adolescent girls before, and its success reinforced the value of segmentation. 


\section{House Girls-A Hard-to-reach Group}

We have found two types of domestic help, also known as house girls, in both Morogoro and Iringa-those that are serving in an official capacity working for non-relatives and those who are living with distant relatives due to death of, or abandonment by, their own parents and serve as domestic help to pay their way. Getting house girls who are properly employed-rather than those who work for family-to join the program is a challenge because their employers do not want them educated as it might take them away from their work time or because they feel their own children deserve the program more. Girls have frequently been banned by employers from joining us, and our engagement with local leaders to rectify this issue has often failed. That said, there have been two wonderful examples of house girls who came to our program and went on to be mentors, and we continue to persist.

\section{Conclusion}

At SEGA, we do appreciate all the support we receive from the parents/guardians and the community at large in ensuring that the program continues to be a success. This shows that they have accepted the program and that the community benefits from the program.

We opened the program in Dodoma starting January 2020 (before the COVID-19 pandemic). We sought to lay a foundation with the community and government officials for all girls living in vulnerable and marginalized communities. During the pandemic, the value of the Modern Girl Program (and the application of Intentional Design) continued to be affirmed. Along with our founding organization, Nurturing
Minds, we developed tools to monitor and support program participants during the pandemic, and provided additional resources through phone counseling and educational packages.

For more information, please visit: https:// www.nurturingmindsinafrica.org/. 


\section{Practitioner Report 14}

\section{Intentional Design Builds Up and Coordinates an Existing Community of Practice in Mwanza, Tanzania}

By Revocatus Sono, Sophie Soares, and Samantha Berg

\begin{tabular}{|c|c|}
\hline Findings and Decisions & Implementation Observations and Adaptations \\
\hline $\begin{array}{l}\text { - SMASH members learned the importance of using } \\
\text { localized data as a tool for advocacy, the potential } \\
\text { (even in poor districts) of using hotspots, and the } \\
\text { importance of segmenting. } \\
\text { - SMASH members met with local officials to } \\
\text { provide information on the importance of reaching } \\
\text { adolescent girls in the Mwanza district. } \\
\text { - Utilizing the Intentional Design approach allowed } \\
\text { us to identify two key districts with } 37 \text { wards for } \\
\text { recruitment and program implementation. } \\
\text { Most members had previously used demand-led } \\
\text { recruitment. We moved beyond this to identify key } \\
\text { segments of underserved girls, including: } \\
\text { - } \quad \text { 10-year-old out-of-school girls } \\
\text { - 10-year-old in-school girls } \\
\text { - 15-17-year-old girls who are pregnant or have } \\
\quad \text { children } \\
\text { - 15-17-year-old girls who are married } \\
\text { From the initial pilot rostering, we could already } \\
\text { appreciate the heterogeneity even within smaller } \\
\text { geographies. } \\
\text { - For example, in neighboring hamlets of similar } \\
\text { a segmenting strategy that will individually and } \\
\text { collectively be turned into a pilot program. } \\
\text { concentration of young women with babies, } \\
\text { requiring more discovery to understand the } \\
\text { discrepancy. } \\
\text { accelerates, and reaching all girls of that age in } \\
\text { the poorest region as a sort of "social vaccine." }\end{array}$ & $\begin{array}{l}\text { - Rostering was an initial process in the Nyanguge } \\
\text { ward of the Mwanza district. We worked in two } \\
\text { villages and six hamlets (three per village). } \\
\text { - Overall, the rostering process was extremely useful } \\
\text { and relatively easy to implement. } \\
\text { - At least eight participating organizations have plans } \\
\text { to implement the Girl Roster in eight wards once } \\
\text { it is safe to resume activities on hold due to the } \\
\text { COVID-19 pandemic. }\end{array}$ \\
\hline
\end{tabular}




\section{Background}

\section{The Geography of Mwanza}

Mwanza is a predominantly rural region of the Lake Zone in northwest Tanzania, including the southern parts of Lake Victoria, which also borders Uganda and Kenya. It is a site of high migration, with people frequently coming in and out of the region. Comprised of 3.1 million people, the region is divided into seven districts: Ilemela, Kwimba, Magu, Misungwi, Nyamagana, Sengerema, and Ukerewe.

\section{Girls’ Lives in Mwanza}

In addition to its intense poverty $-47 \%$ of its population is defined as very poor and another $27 \%$ vulnerable to poverty-Mwanza has a number of other contextual factors that call the attention of organizations on the ground (Population Council et al. 2015).

School attendance rates show a troubled picture; $19.2 \%$ of girls $10-14$ years old are not in school. While $75.8 \%$ of girls are enrolled in primary school, only $4.4 \%$ enroll in secondary school. Almost one-fifth of school-age girls are not in school and thus gravely off-track, and the dropout rate among rural girls is accelerating, with $10 \%$ out of school at age 10 and $36.3 \%$ by age 14 (Population Council et al. 2015).

In Mwanza, $7.4 \%$ of girls are married before exact age 15 years; this proportion increases by six-fold before exact age 18, when $37.4 \%$ are married. An assessment of sexual exploitation and transactional sex in Tanzania, utilizing the Population Council's Ascertaining Sexual Relationship Types (ASERT ${ }^{\mathrm{TM}}$ ) tool,' revealed high levels of sexual exploitation of adolescent girls as they seek the most basic resources such as food, transportation, medical/health services, and more (Hallman, Peracca, et al. 2016).

In this same assessment, we found that females 20-24 years old in Mwanza report early sexual initiation-9.5\% before age 15 and 51.5\% before age 18. Of females 20-24, almost $7 \%$ gave birth before age 15 and almost half before exact age 18. When offered the statement "wives are justified in being beaten," $67.3 \%$ of girls and women aged 15-24 accept at least one reason and $12 \%$ accept all five. This reflects low selfesteem and self-efficacy among adolescent girls and young women, as well as the expectation and acceptance of physical and sexual control by males from a young age. In Mwanza, levels of violence are shocking: of those aged 15-24 years the following percentages report experiencing sexual or physical violence:

- $\quad 15-17: 27.7 \%$;

- $18-19: 49.6 \%$;

- 20-24: 57\%.

Females face economic burden from supporting themselves as well as their families, heightening sexual exploitation, poor health outcomes, and low schooling levels. If present trends continue, more than $70 \%$ of Tanzanian females will be single mothers in their lifetime, either through partnered childbearing or as divorced, abandoned, or widowed mothers; for most of these women, single motherhood and the associated economic responsibilities and social isolation will occur by age 30 (Clark and Hamplova 2013; Clark and Brauner-Otto 2015).

\section{The HIV Epidemic in Mwanza}

The HIV epidemic has compounded young females' risk in Mwanza, as well. While over half of girls aged 15-17 have been sexually initiated, only $27 \%$ of girls in this age group have knowledge of HIV prevention measures, such as condom use. Of girls 15-24 years old with a current partner, two-thirds (67\%) have a partner four or more years older and $27 \%$ have partners more than ten years older, raising their HIV risk. Young females' ability to bargain for condom use or contraception is limited as

\footnotetext{
${ }^{1}$ The ASERT tool can be used to build girls' social and protective assets. It can be found in the Building Girls' Protective Assets Toolkit Collection: https://www.popcouncil.org/uploads/pdfs/2016PGY_GirlsProtectiveAssetsTools.pdf.
} 


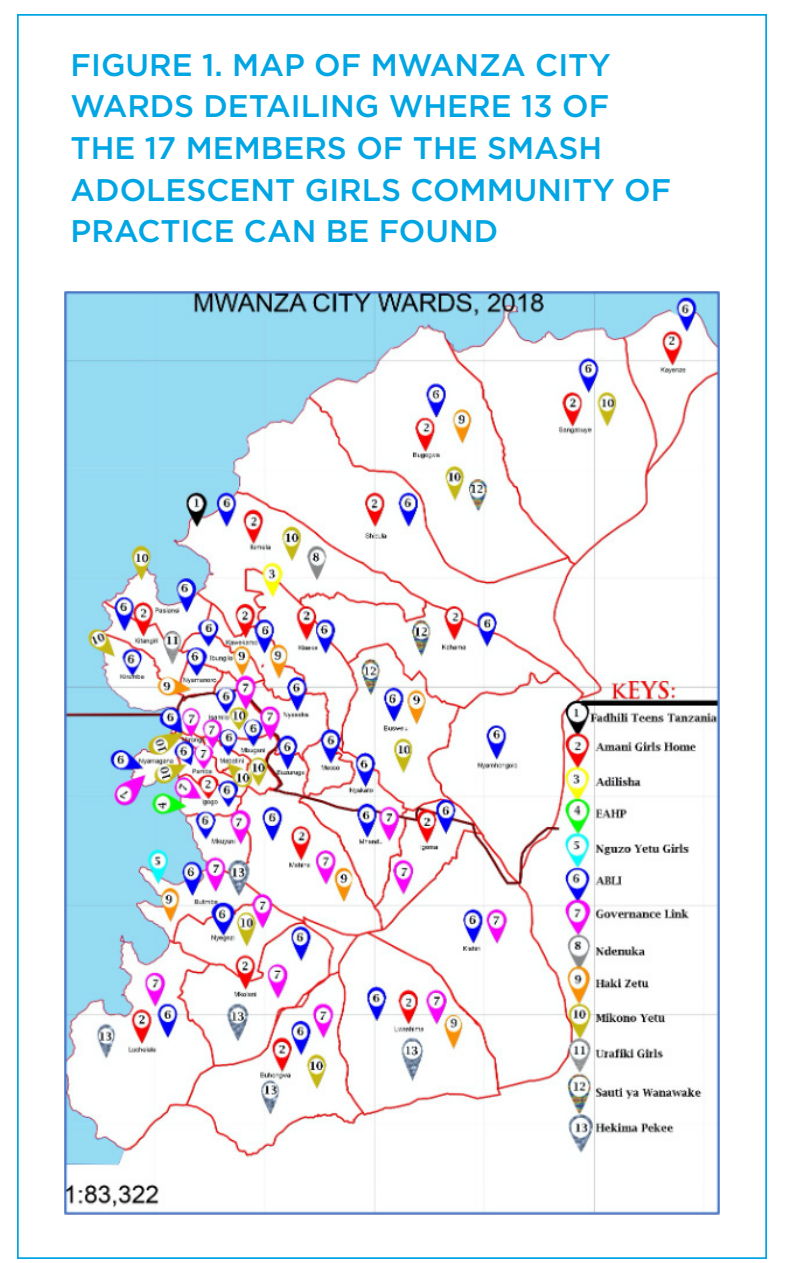

many of these relationships are economically driven. Only 5.2\% of married females 15-24 years are using contraception, compared with $20.7 \%$ of their unmarried sexually active peers. These young married girls have less power in their relationships and greater economic responsibility, increasing their risk for HIV (Population Council et al. 2015).

Thus, without early intervention and increasing access to resources for those at the highest risk of the worst outcomes at the youngest ages, we are in effect tolerating injustice, suffering, and poverty. The SMASH Adolescent Girls Community of Practice (SMASH) commits itself to investing in these excluded girls and their futures. SMASH will collaboratively craft a Business Plan for young girls of Mwanza that is anchored in evidence and shared values. From age 10 and up, girls are invisible and unsupported actors in family economies. Thus, adolescent girls and young women must be taught skills to achieve decent livelihoods, including financial and technical literacy skills, and given access to safe savings opportunities.

\section{The SMASH Adolescent Girls Community of Practice}

The SMASH Adolescent Girls Community of Practice (SMASH) is a group of 17 likeminded local NGOs and community-based organizations (CBOs) with operational offices in the Mwanza region (see Figure 1). These organizations have come together with the goal of understanding and responding to the unique needs of diverse segments of girls and young women in the region. Launched in early 2017 , SMASH is coordinated by a steering committee of representatives from a selection of the member organizations and is supported by two adolescent girl interns. SMASH's main objective is to create a platform where members can share experiences, knowledge, and tools; network; build and strengthen capacity of advocacy services; influence girl-related policy; and support girl-led programming and coordinating for collective action.

SMASH members include a wide range of organizations. Some members are girl- and women-led, working across a spectrum of issues including gender norms, sexual and reproductive health, education, violence, civic engagement, human rights, and financial literacy. SMASH members, led by Amani Girls Home-its anchoring partner-are quite varied not only in terms of focus but also history, levels of funding, human resources, etc. Because of its varying capacity, SMASH reached out to the Population Council's Community of Practice in early 2017 with an interest in utilizing the Girl Roster to better understand adolescent girls and young women and to implement targeted and girl-centered programming using the Intentional Design approach.

In early 2018, the Population Council conducted an introductory workshop in Mwanza City for the 17 SMASH members. The training focused 


\begin{tabular}{|c|c|}
\hline Pre-Intentional Design & Post-Intentional Design \\
\hline $\begin{array}{l}\text { Locations for programming were often based on staffs' } \\
\text { proximity to and/or convenience of communities, } \\
\text { particularly in the central Mwanza City, rather than } \\
\text { on subnational-level data that would indicate girls' } \\
\text { heightened vulnerability. }\end{array}$ & $\begin{array}{l}\text { SMASH used regional data to identify two districts in } \\
\text { the entire Mwanza region containing a total of } 37 \text { wards } \\
\text { they wish to reach. These wards are areas of greater } \\
\text { vulnerability for girls in the whole of Mwanza. }\end{array}$ \\
\hline $\begin{array}{l}\text { Recruitment was a "blanket" demand-led process, and } \\
\text { content and services were the same for all girls. }\end{array}$ & 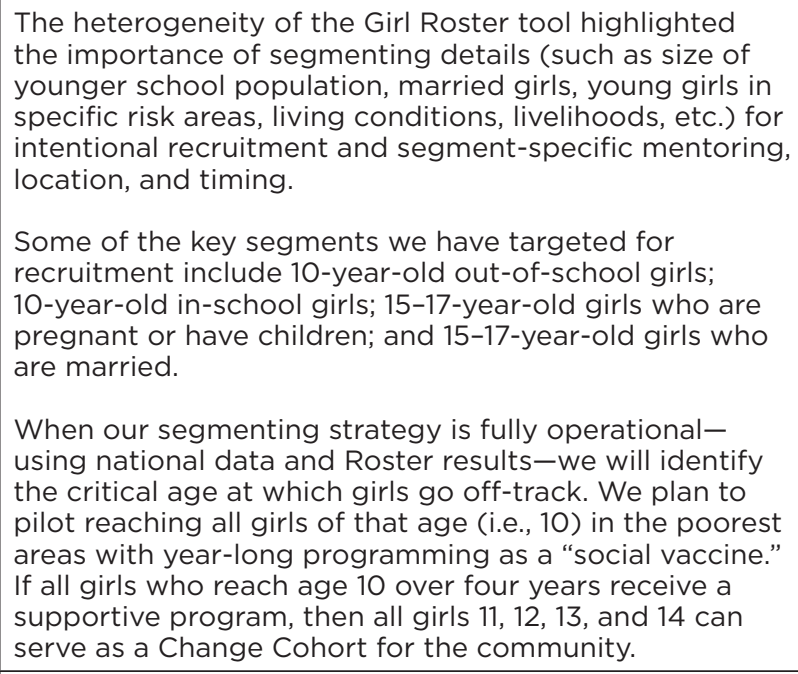 \\
\hline $\begin{array}{l}\text { Members lacked language, knowledge, and learning } \\
\text { tools through which to anchor their arguments and } \\
\text { programs in a wider context to advocate for their work } \\
\text { and create thoughtful proposals for programming. }\end{array}$ & $\begin{array}{l}\text { Members have learned to use vital learning tools-the } \\
\text { Roster, the Asset exercise, per segment planning-and } \\
\text { intentional recruitment. They draw local government } \\
\text { in early in their planning. They are more aware of } \\
\text { Mwanza- and Tanzania-wide data, thus becoming } \\
\text { better advocates for girls, using both qualitative and } \\
\text { quantitative information to set goals and lay the basis } \\
\text { for donor investments. }\end{array}$ \\
\hline $\begin{array}{l}\text { SMASH's presence in the Mwanza region was relatively } \\
\text { unknown, and members had trouble establishing trust } \\
\text { and name recognition. }\end{array}$ & $\begin{array}{l}\text { SMASH increased its visibility by strengthening } \\
\text { members' skills, expanding evidence-based } \\
\text { programming, and with an eye toward shaping } \\
\text { community services and obtaining long-term } \\
\text { support through explicit collaboration with the } \\
\text { Local Government Authorities. We judged schools } \\
\text { as especially vital to sustainability and increased } \\
\text { partnerships with schools ( } 46 \text { primary and } 11 \text { secondary) } \\
\text { and } 17 \text { community wards (an administrative structure } \\
\text { for a town or portion of a city). SMASH is also now } \\
\text { recognized by the Tanzania government as a trusted } \\
\text { development partner after formal approval by the } \\
\text { minister's regional administration. } \\
\end{array}$ \\
\hline $\begin{array}{l}\text { The idea of a Community of Practice was unknown- } \\
\text { organizations not only did not collaborate, but they } \\
\text { sometimes even competed, though the needs far } \\
\text { exceeded the capacity and they were operating in } \\
\text { different geographies. Donors did not always help } \\
\text { this isolation. So, there were few existing and familiar } \\
\text { pathways for collaboration and partnership among } \\
\text { member organizations. }\end{array}$ & $\begin{array}{l}\text { We identify the girls-particularly the most off-track-as } \\
\text { a common core constituency. To underpin this shared } \\
\text { identity of mission, we have increased the flow of } \\
\text { information regarding girls' experiences and rights in } \\
\text { Mwanza Region and across Tanzania. We have mapped } \\
\text { the segments we serve or plan to serve, shared research, } \\
\text { and tested program content-noting where one member } \\
\text { for example has a livelihood component and another has } \\
\text { experience with married girls-and M\&E tools to improve } \\
\text { collaboration and reduce duplication. }\end{array}$ \\
\hline
\end{tabular}


on how to use the Girl Roster and other tools that can help assess the full universe of girls in their communities and coordinate efforts on the ground. Following this workshop, which included a practical application of the Girl Roster, Amani Girls Home led the charge to continue to roster in the region, starting with one ward.

Though our rostering continues as of 2020 , there are a number of findings that have already shifted the way SMASH works (see Box 1).

\section{Conclusion}

After a nearly two-year-long process, SMASH is now in a position to create coordinated programming in multiple geographies of the Mwanza region. We had sufficient trust to mobilize as a group to respond to the COVID-19 pandemic. We recognize that no one organization can possibly meet the unique and varied needs of adolescent girls in Mwanza, therefore we are coordinating and collaborating through the Adolescent Girls' Community of Practice to use our partnership to define a joint investment plan for the girls of Mwanza. SMASH views this mechanism as a strategic opportunity to align local practice with the global evidence base, as well as to scale successful strategies across the Mwanza region.

For more information, please visit: https:// amanigirlshome.or.tz/community-ofpractice-smash/. 


\section{Practitioner Report 15}

\section{The Girl Power Project (Just Like My Child Foundation) Moves Forward with Intentional Design to Intensify Regional Impact, Central Uganda}

By Tessa Davis, Annette McFarland, Audrey Kanyesigye, Agnes Achom, Allen Kakakawa, Janat Nakigudde, Judith Akware, and Sophie Soares

Acknowledgments: Agnes Achom, Anna Akello, Judith Akware, Flavia Alimo, Kizito Benah, Rukia Birungi, Joseph Buguma, Tessa Davis (Program Director), Carol Giibwa, Ivan Kabaale, Livingstone Kanakulkya, Audrey Kanyesigye, Yusuf Kimuli, Hassan Kizito, Tito Lubega, Fred Lwanga, Annette McFarland, Martin Luther Mukalazi, David Muyenja, Nauma Nabakooza, Goretti M. Nabunya, Regina Naiga, Allen Nakakawa, Joyce Nakitende, Aisha Nakito, Rebecca Nalubega, Mariam Nampiima, Rebecca Namugabe, Sarah Nankanja, Florence Nassuna, Ismail Nyanzi, Lovinsa Opyera, Raphael Opyera, Jjuko Ssalongo, Norah Ssekadde, Hammy Ssenkindu

\section{Findings and Decisions \\ - The Intentional Design/Girl Roster process was implemented, in part, to find out why an appreciable number of girls were dropping out of school and marrying early, with the intention of reaching $50-80 \%$ of the girls $10-14$ years old. \\ - It is necessary to focus on the girls living in the catchment areas of the smaller schools (heretofore excluded because of the small number in the classrooms) both because the higher proportions out of school and the lack of other social/health/ other supportive services the Roster revealed double and triple the disadvantage of girls living in the catchment areas around smaller schools.}

- $\quad$ The Roster process helped to engage both community members and JLMC field staff in uncovering underused and valuable resources (ranging from dairy goats to entrepreneurship support services) and also unsafe places (e.g., bars, swamps, boreholes, at certain times of day).

- Maps were terrific follow-up in rostered communities and quickly generated in new communities, serving as an excellent foundation for planning and building trust going forward.

- $\quad$ The Roster process uncovered extreme and invisible situations (e.g., disabled children), which required immediate follow-up care by the field team or community.

- JLMC utilized the Building Assets Toolkit to refine program content and expand the range of skills of JLMC and partners to deliver needed content (livelihoods, better knowledge of community) and strategies to engage socially excluded girls at greater disadvantage.
Implementation Observations and Adaptations

- Implementing a Community Mapping Tool simultaneous to rostering, and improved insights from both, helped JLMC to "see" households that are highly disadvantaged alongside physical conditions and underutilized resources.

- $\quad$ Trained field staff were able to not only collect the quantitative information from the households using the Roster but also make qualitative assessments and offer almost simultaneous care if extreme situations were uncovered.

- The Roster results were used as a basis of calculating projections of off-track girls and confirmation that girls in the catchment areas of small schools were especially likely to be out of school. This information, combined with population data, served to enlarge the geographic areas in which JLMC operated, adding girls in five catchment areas that had smaller schools. 


\section{Girl Power Project Intentions and Target Population}

Just Like My Child Foundation's Girl Power Project $^{\circledR}$ is a transformational program targeting girls in central Uganda as they enter the most vulnerable juncture of their lives: adolescence. This project steps in just as girls in early puberty face the choices that will either lead them to a life of early marriage, pregnancy, and disease, or alternatively, a life of education, economic independence, and delayed marriage. It does so by aiming to reach a high proportion (50-80\%) of girls aged $12-15$ years in a given community with interactive content-covering subjects such as sexual and reproductive health $(\mathrm{SRH})$, financial literacy, self-defense, and civic engagement-delivered through an intensive two-year program. Girls receive 60+ hours of content through two multiday workshops, a weekend overnight camp, and monthly twohour-long club sessions. Moreover, adults and boys in the community receive two multiday workshops focused on similar content with an emphasis on supporting girls.

\section{Selecting Geographies for Implementation of the Girl Roster}

Having worked in Uganda since 2006, Just Like My Child (JLMC) selected places strategically in which to implement the Roster. In the communities in which JLMC had built schools as part of a separate program, the teachers had created strong learning environments with JLMC's support but still reported appreciable levels of girls dropping out and getting married as children.

The Girl Power Project was a response to these gaps, and it was built as a layer on top of the other successful programs JLMC had established. These programs had already grown self-sustainable in the communities where they had fostered a relationship and now wished to reach a new population and ensure the Girl Power Project was additive to what existed on the ground. The Roster was implemented in all key areas in which JLMC programs already existed.

\section{Selection and Engagement of Community Leaders in Rostering}

In November 2015, JLMC selected and trained 19 community leaders in central Uganda (Table 1) to serve as implementers of the Girl Roster, a role they served across three parishes (which make up Uganda's subdivisions) over an eight-day period. While some of the leaders had already engaged with JLMC in the past, the remaining leaders were carefully vetted and selected by longtime JLMC partner Save for Health Uganda (SHU), which was deeply embedded and highly respected in the three parishes in which the Girl Roster was carried

TABLE 1. NOVEMBER 2015 KEY GIRL ROSTER FIELD TEAM AND TRAINERS*

\begin{tabular}{|l|l|l|}
\hline Rebecca Nalubega & David Muyenja & Ismail Nyanzi \\
\hline Carol Giibwa & Kizito Benah & Yusuf Kimuli \\
\hline Flavia Alimo & Joseph Buguma & Goretti M. Nabunya \\
\hline Agnes Achom & Allen Nakakawa & Joyce Nakitende \\
\hline Livingstone Kanakulkya & Regina Naiga & Judith Akware \\
\hline Tito Lubega & Ivan Kabaale Hassan Kizito \\
\hline $\begin{array}{l}\text { Rebecca Namugabe } \\
\text { Tessa Davis } \\
\text { (Program Director) }\end{array}$ & $\begin{array}{l}\text { Annette McFarland } \\
\text { (M\&E Specialist) }\end{array}$ & $\begin{array}{l}\text { Audrey Kanyesigye } \\
\text { (Country Director) }\end{array}$ \\
\hline
\end{tabular}

*The names highlighted in blue served as Girl Roster trainers for others who were in the first phase of rostering. 
FIGURE 1. OFFICIAL GIRL ROSTER

BADGES WERE PROVIDED TO

COMMUNITY LEADERS WHO SERVED

AS ROSTERERS IN NOVEMBER 2015.

BADGES INCLUDED THE ROSTERER'S

PHOTO, AND GIRL POWER PROJECT,

POPULATION COUNCIL, JLMC, AND

LOCAL PARTNER LOGOS

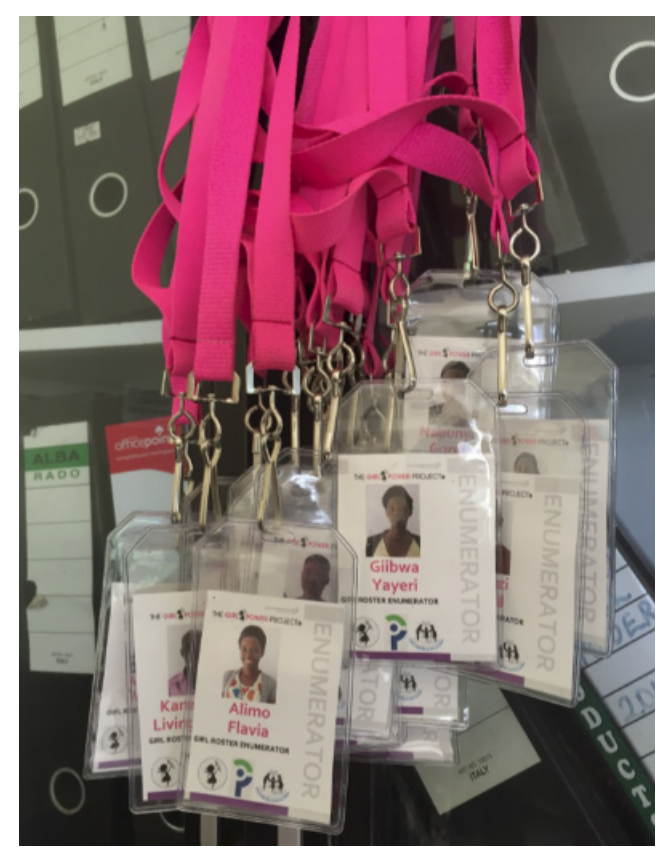

(Photo: JLMC.)

out. SHU knew precisely who could implement the Roster effectively, intensify community engagement, and craft improvement (sometimes immediate, where difficulties were found) on behalf of girls. The leaders, or rosterers, were also incentivized by JLMC to implement the tool through the following culturally appropriate mechanisms:

- A daily per diem, lunch allowance, and transport reimbursement;

- An official Girl Roster badge that provided them credibility as they moved through communities (see Figure 1);
FIGURE 2. A FIELD TEAM MEMBER RECEIVES HER TRAINING CERTIFICATE

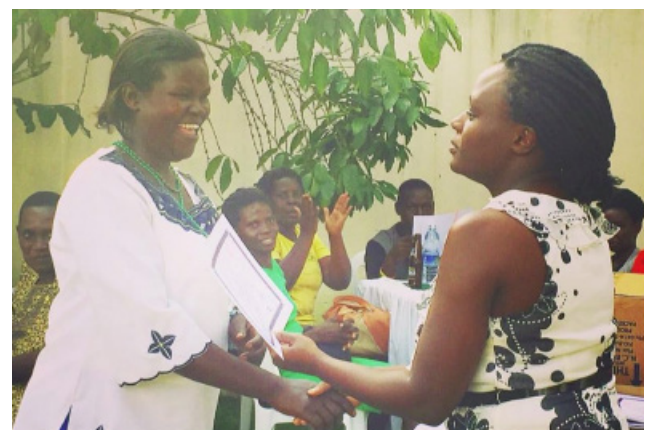

- A certificate confirming their training and experience in carrying out the Roster, to be included in their resume and job search, should they wish (see Figure 2);

Before rostering and to onboard the communities, letters were sent to official community leaders to request permission to conduct the activity. Once more, the selected rosterers proved useful as they were well known and their motives were trusted by the official community leaders.

In the second phase of rostering, which occurred in April 2016, the field team was comprised of 15 rosterers. In a clear demonstration of how capacity had been built, these 15 rosterers were prepared for rostering by "phenomenal" trainers-four individuals from the first rostering experience who stood out for their skill set, including an affinity for teambuilding, familiarity with technology, excellent facilitation and training skills, and keen interest and passion for the implementation process. These trainers are highlighted in Table 2.

In this first phase of rostering, the field team rostered 1,249 households making up $76 \%$ of the population in the three parishes.

\footnotetext{
${ }^{1}$ Note that an ID badge for rosterers is only effective in certain contexts. Some rosterers might need to consider issues of safety. For other rosterers, having an ID badge might actually challenge the work from getting done as it might make the process overly formal or because households may be wary of the organization due to their own safety concerns.
} 
TABLE 2. APRIL 2016 KEY GIRL ROSTER FIELD TEAM AND TRAINERS*

\begin{tabular}{|l|l|l|}
\hline Aisha Nakito & Anna Akello & Norah Ssekadde \\
\hline Nauma Nabakooza & Jjuko Ssalongo & Lovinsa Opyera \\
\hline Sarah Nankanja & Mariam Nampiima & Martin Luther Mukalazi \\
\hline Rukia Birungi & Hammy Ssenkindu & Carol Giibwa \\
\hline Fred Lwanga & Joseph Buguma & \\
\hline Ivan Kabaale & Flavia Alimo & \\
\hline David Muyenja & Florence Nassuna &
\end{tabular}

* Individuals highlighted in blue served as Girl Roster trainers in April 2016 after serving as excellent rosterers in the first rostering in November 2015.

\section{Analyzing and Visualizing the Intentional Design Information}

\section{Learning How to Prioritize Segments and Specific Schools}

Concerned with getting sufficient coverage of the girls 10-14 years old in the three poor parishes rostered, the Roster revealed that approximately 913 girls in this age range lived in these areas, of which JLMC wished to reach 50-80\%, or approximately 457 to 730 girls total, a solid target number within its own geographic confines.

The initial Girl Roster exercise also guided JLMC to change the criteria for selecting parishes. For example, one parish mapped had very few primary schools and all but one had small populations of girls in the target age range. Previously, JLMC had determined not to implement in the catchment areas around schools with fewer than 50 girls in the target age range of 10-14 years, but as a result of the Roster information, JLMC learned that girls in these catchment areas and in places that were generally underserved in the surrounding community (remote areas with longer walking distances to schools, minimal to no local health clinics or community-based organizations [CBOs] providing support around education, health, income generation, etc.) were at higher risk of being out of school and of child marriage. So, in order to reach $50-80 \%$ of the most-off-track girls in that parish, girls in the catchment areas around those smaller schools needed to be reached. This changed JLMC's priority geographies.

The Roster process, in the hands of the field team coming from the communities being rostered, not only provided good numeric visualizations of the "universe" of girls but also immediate, focused observation of the challenges girls were facing and the nature of their communities. The field team noted a higher incidence of child-headed households than anticipated and poor living conditions (such as living in mud homes rather than cement homes, being remote from water sources, having no electricity or land for farming). They also observed a number of girls with disabilities, some requiring immediate follow-up. Due to JLMC's partnerships built over the years and the thoughtful selection and training of the field team, the team was prepared almost immediately to link many households with appropriate resource persons and services.

\section{Visualizing the Information onto Vital Real- Time Community Maps-A Form of Advocacy and Linking of Neglected Off-Track Girls to Services}

Rostering was undertaken simultaneously with the mapping of community resources, including unsafe spaces (such as bars or swamps) and not previously apparent or underused resources (where one could obtain loans, health insurance coverage, livestock, etc.). Within three days of rostering, JLMC saw an opportunity to 
transform a map of unsafe spaces and lesserused resources into a flyer-a service within itself to be distributed to rostered communities, with the names and contact information of helpful resource persons such as local childprotection officers (see Figure 3). Extra flyers were given to community leaders as a realtime resource, and the field team was armed with calling cards as they went door-to-door. This spontaneous innovation reflects the deep service commitment of JLMC and the empathy and strength of their field team, and validates JLMC as a trusted resource.

\section{Mapping Your Community-Generating New Content}

Commitment to innovation included swiftly integrating a mapping exercise into sessions with girls as well. In an early session of our curriculum, girls came together and used phones to create their own maps of the community so that they could articulate times and places in which they felt safe. ${ }^{2}$

\section{Integrating Intentional Design and} the Roster into the JLMC Community Introduction and Program Design Process

In April 2016, in Ssambwe Parish, another cadre of well-trained rosterers implemented the Roster across 808 households in three days and generated a similar map of resources in the parish as had been generated in the previous experience. Table 3 shows the results of that rostering-29 girls aged 10-14 were out of school, which represented $8.7 \%$ of the girls aged 10-14; 77 of 778 girls aged 6-17 were out of school, about $9 \%$, comparable to the national average at the time (the 2011 DHS stated $9 \%$ of children 7-14 were out of school).

Half of the girls aged 10-14 (50.3\%) lived with both parents, while the other half (49.7\%) lived with only one or neither of their parents.
FIGURE 3. EXAMPLE OF A RESOURCE MAP/FLYER PRODUCED TO INCREASE AWARENESS OF RESOURCES AND GIRLS' FEELINGS ABOUT SAFETY

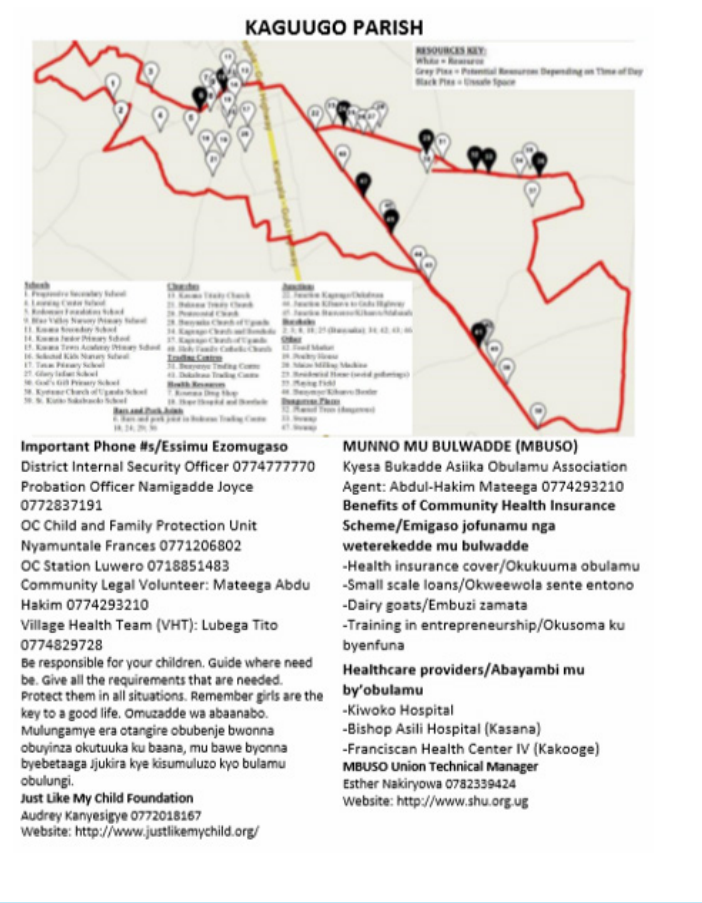

This was slightly more than the national figure reported in the 2011 DHS of $44 \%$ of children under age 18 living with one or neither parent.

\section{Combining Roster Information with National Data}

This exercise was undertaken to identify the most-off-track girls and generate evidenceanchored segment-specific targets (50-80\% saturation) to make these projections. JLMC combined national population data for the parish (a total of 7,835 people were living in Ssambwe parish) with Roster results to generate crude but useful estimates of how many girls 10-14 they needed to reach. As there were about 619 total girls living in Ssambwe in

\footnotetext{
${ }^{2}$ An exercise like this was suggested by the Girls in Emergencies (GiE) Collaborative, but to the Council's knowledge has not been implemented by $\mathrm{GiE}$ partners.
} 
TABLE 3. GIRL ROSTER OVERVIEW OUTPUT TABLE FOR SSAMBWE PARISH, UGANDA (2016)

\begin{tabular}{|c|c|c|c|c|c|c|c|c|c|}
\hline \multirow[b]{2}{*}{$\begin{array}{l}\text { Age } \\
\text { group }\end{array}$} & \multicolumn{3}{|c|}{ In School } & \multicolumn{3}{|c|}{ Out of School } & \multirow[b]{2}{*}{$\begin{array}{l}\text { Has a } \\
\text { child }\end{array}$} & \multirow[b]{2}{*}{$\begin{array}{c}\text { Does not } \\
\text { have a } \\
\text { child }\end{array}$} & \multirow[b]{2}{*}{ Total } \\
\hline & $\begin{array}{l}\text { Living } \\
\text { with both } \\
\text { parents }\end{array}$ & $\begin{array}{c}\text { Living } \\
\text { with one } \\
\text { parent }\end{array}$ & $\begin{array}{l}\text { Living } \\
\text { with } \\
\text { neither } \\
\text { parent }\end{array}$ & $\begin{array}{l}\text { Living } \\
\text { with both } \\
\text { parents }\end{array}$ & $\begin{array}{c}\text { Living } \\
\text { with one } \\
\text { parent }\end{array}$ & $\begin{array}{c}\text { Living } \\
\text { with } \\
\text { neither } \\
\text { parent }\end{array}$ & & & \\
\hline $6-9$ & 157 & 56 & 45 & 6 & 7 & 0 & - & - & 271 \\
\hline $10-12$ & 97 & 43 & 46 & 7 & 4 & 5 & - & - & 202 \\
\hline $13-14$ & 59 & 27 & 31 & 4 & 8 & 1 & 0 & 0 & 130 \\
\hline $15-17$ & 76 & 35 & 23 & 12 & 12 & 11 & 5 & 1 & 175 \\
\hline $18-24$ & 44 & 26 & 28 & 33 & 26 & 35 & 81 & 11 & 284 \\
\hline Total & 433 & 187 & 173 & 62 & 57 & 52 & 86 & 12 & 1,062 \\
\hline
\end{tabular}

2016, this gave them a range of $310(50 \%)$ to 496 (80\%) girls.

In sum, the Roster deepened JLMC's understanding of the community, connected us more closely to the community through the generation of the resource map, and provided an evidence base to identify targets for coverage with quality. It significantly expanded the geographies in which we intensified our work, with the understanding that the girls living in the catchment areas of the smaller schools were often more in need than the girls living in the catchment areas of the larger schools, thus adding five other areas to JLMC's programming.

\section{JLMC as an Emerging Girl Roster Leader in Uganda}

Given this multilevel expertise and commitment, the talents of JLMC staff have been recognized. They were invited by Mercy Corps and Girl Effect University to present their experience with the Roster and community engagement and other intentional design tools in November 2015. Armed with the experience of the Roster implementation and other Intentional Design tools of the Council (including the Building Assets Toolkit), JLMC served as a critical resource during the training, and its experience sparked a great deal of curiosity about the tools and the overall approach.

\section{Conclusion}

Today, Intentional Design is an important aspect of the Girl Power Project, which involves three key steps. The first step is to lay the foundation for girls' empowerment. The second step is to conduct introductory workshops for girls, boys, potential mentors, and adults to introduce community members to the Girl Power Project, develop mentor capacity, and increase advocacy among adults for girls. The third is to hold a camp where in-school girls and teachers are selected, trained, and graduate as peer mentors. In that first step, laying the foundation, the project encourages the implementation of the Girl Roster to gain insight into specific issues faced by girls and to document how many live in each community to be served by the project.

JLMC also encourages the utilization of the Building Assets Toolkit and employing its results to assess what priority girls aged 10-14 years need, but also when JLMC needs to add content to build those required assets (such as giving

\footnotetext{
${ }^{3}$ Note that the contemporary Girl Roster Overview Output Table differs from this one from the JLMC rostering experience. This table does not include girls who are "Unmarried and Have Children" and it also consolidates the age range of 18-19 and 20-24 into one age category.
} 
girls with disabilities or migrant girls specific skills).

Ultimately, Intentional Design underscored and helped build our existing creed and taught us a lot more about what is real and true. As is often experienced on the ground, data provided by the government is not always valid, and so knowing that there were a lot of girls off-track and in precarious situations we used Intentional Design to help identify what in the available national data was real for the populations we were serving and what was missing. For example, the Intentional Design approach revealed that the proportion of girls not going on to secondary school was much higher than what national-level data indicated. Sessions such as our financial literacy club sessions were intended to address this dropout between primary and secondary school by providing girls skills to budget and earn small savings that could then be used on secondary school fees. Intentional Design deepened our commitment to reach as many girls as we could with the Girl Power Project because we learned not only our denominator but where promises-such as the universal primary education that Uganda offers-were being met on the surface but not successfully (e.g., the girls who were in school but severely behind or attending inconsistently).

For more information, please visit: https:// www.justlikemychild.org/. 


\title{
Practitioner Report 16
}

\section{Implementation of the Girl Roster in Ezbet Khairallah, Egypt}

\author{
By Audrey Anderson, Emy Yanni, and Laura Brazee, Plan International USA
}

With thanks to Community Development Associations El Nour (based in Khairallah) and Kheir we Barka (based in Asmarat)

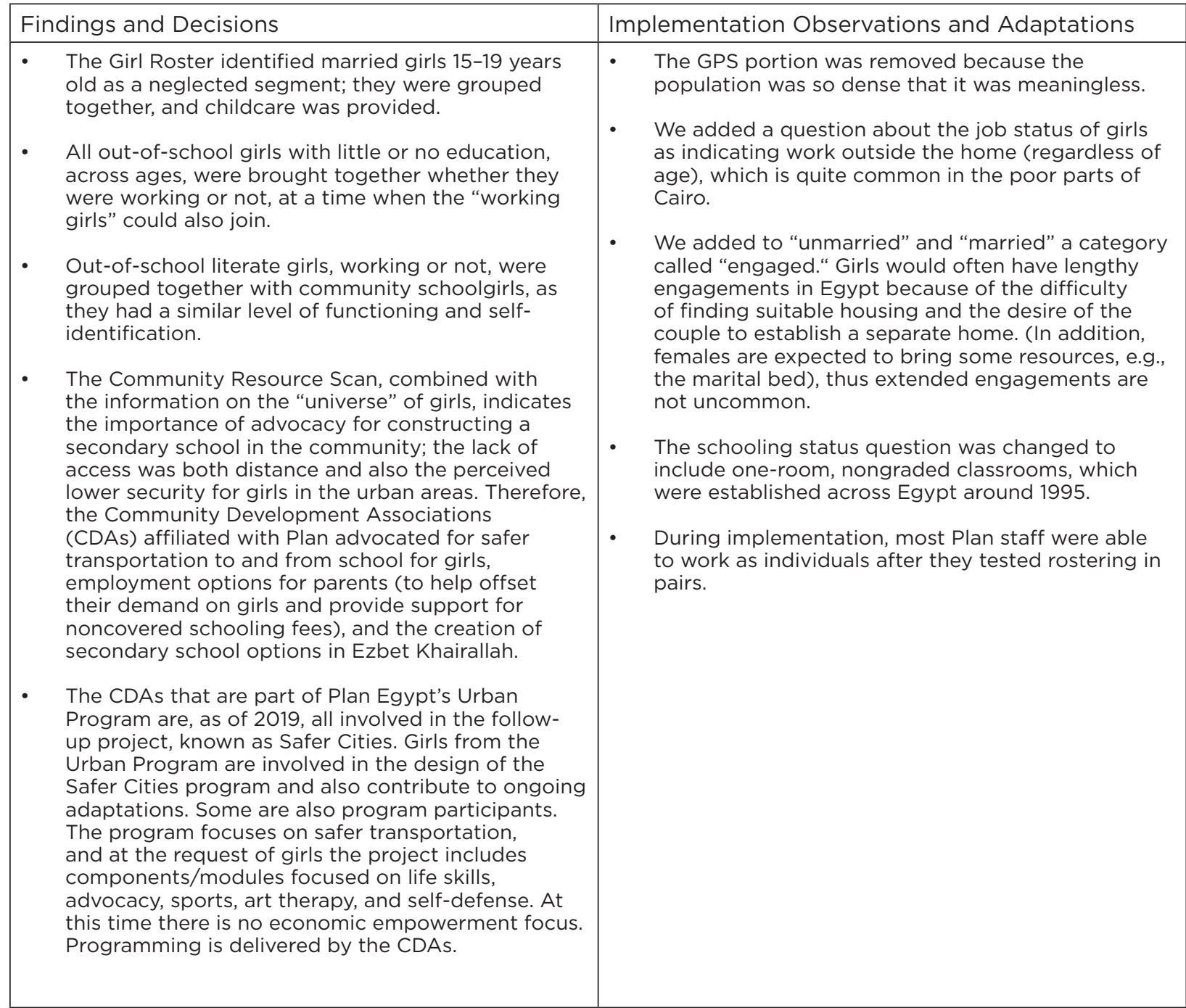




\section{Background}

In August 2014, Plan launched the Because I Am a Girl (BIAGG) Urban Program in Cairo, Egypt. The Urban Program is a global initiative in five cities around the world (Cairo, Egypt; Delhi, India; Lima, Peru; Kampala, Uganda; and Hanoi, Vietnam) that aims to make urban areas safer and more inclusive spaces for girls. This was the first application of the Girl Roster and the experience in Cairo was formative, both regarding our learning approach and the special conditions of urban girls (early exposure to work in the public space and using the question "Does she have a job?)."

The Urban Program aimed to increase girls' active and meaningful participation in urban development and governance, with the following specific outcomes:

- Increase girls' safety and access to public spaces;

- Increase girls' autonomous mobility in the city;

- Improve girls' access to quality city service.

The program worked with transportation systems and authorities, local government, and institutions to make public spaces safer and more inclusive for girls. The program also worked directly with girls aged 13-18 who face particular risk factors, such as being out of school, married, or engaged in child labor.

To learn more about the girls in the community, we collected information on 568 girls in six communities in Ezbet Khairallah using the Girl Roster.

\section{Location: Ezbet Khairallah, Greater Cairo}

Ezbet Khairallah is an informal settlement on the outskirts of Cairo, roughly 12 square kilometers ( 4.5 square miles) in area. This area, which includes six urban communities of

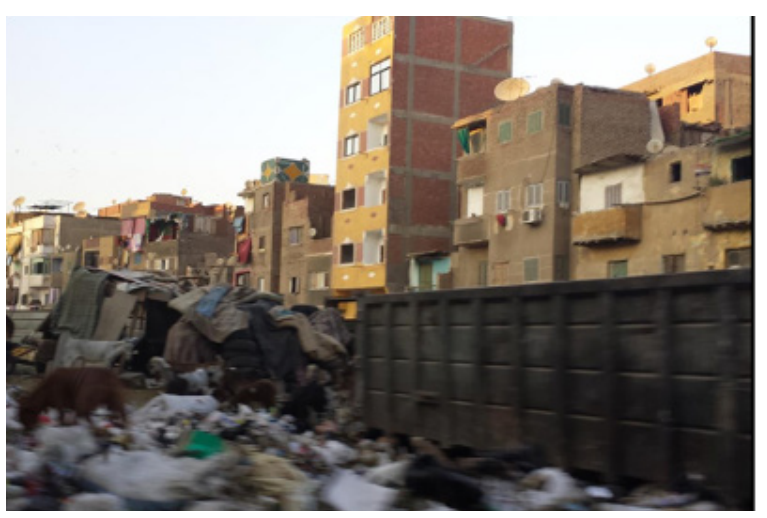

Entrance to Ezbet Khairallah. (Photo: Plan International.)

informal settlements (averaging 140 houses each), was selected because of levels of school dropout and higher-than-average (for urban areas) child marriage and labor outside the household. It is a very densely populated region that had a population of about 650,000 as of 2014. It is bordered by Masr El Kadima to the North, Dar AI Salam to the South, the Nile to the West, and El Basateen to the East.' When the Ring Road was constructed around Cairo, it cut straight through the region of Ezbet Khairallah, creating tunnels underneath the freeway throughout the area. Several other NGOs were already working in the area doing basic programs such as distributing medicine. Plan had the strongest NGO presence in the area.

For logistical purposes, Plan had already organized the region into three CDA areas, each including 8-12 communities.

\section{Rollout of the Girl Roster in Ezbet Khairallah}

Given the densely populated, urban context of Ezbet Khairallah, as well as the security situation in Egypt at the time, several modifications were made to the Girl Roster tool:

- $\quad$ Removed the GPS portion of the survey;

- Clearly introduced the intent of the survey to each household and asked for consent;

${ }^{1}$ Based on data collected by the NGO Peace and Plenty. 
- Added "engaged" to the formal answers about marital status;

- Added a question about work: "Does she have a job?"

- Added a list of options for school grade, including "no school" and "community school"- this was very helpful in analysis to double-check girls who had no schooling as well as to group girls by those who were most likely literate/illiterate.

The Girl Roster was piloted in one community in the Nahdet Khairallah region of Ezbet Khairallah, with the following methodology:

- $\quad$ The rosterers were all Plan field officers who would be community workers throughout the project;

- $\quad$ At the beginning, the field officers went out in pairs, and each pair implemented the tool in five households and then returned to share their experiences. They then decided to continue working as individuals to save time, so for the remainder of the information collection there were ten field officers working at once;

- $\quad$ During the pilot, 144 households were completed in about three hours of active information collection;

- Field officers started collecting information around 10:30 a.m., and many people were still asleep, so it was decided to delay the start time moving forward.

Field officers responded positively to the methodology of the Girl Roster and found that most families were very open to the questionnaire, with a few exceptions:

- "I felt the importance of this before even going out, and I was afraid some families would stop me and wouldn't want to reply. But the families want a better life for their children. I didn't promise anything, like we talked about, but families really wanted the girls to participate."

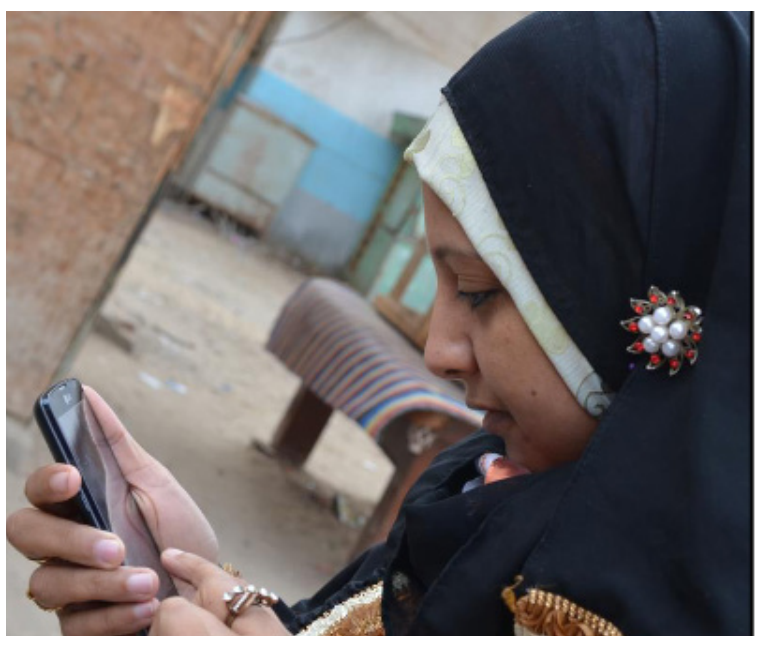

Field officer practicing with mobile survey. (Photo credit: Plan International.)

- "Although Ezbet Khairallah is one community, any time we go to a different subcommunity it's different. So, I'm sure that today we'll have even more surprises."

- $\quad$ "One family refused and said, 'We've heard a lot of promises and haven't seen any results, so we're not interested in answering your questions.",

- "Some Christian families were afraid to let us in."

- "I found the opposite-Christian families let me in, but Muslim families did not."

- 'We've realized the importance of knowing the numbers of girls who were out of school and such. Before the project begins, we now have a better idea of what success will be."

\section{Results Overview}

In six days, the field officers collected information on six communities, with a total of 840 households. Information was recorded on 1,227 girls aged 0-18 years, with 568 girls in the target age range of 13-18 years. The results of the rostering can be found in Table 1. 
TABLE 1. OVERVIEW OUTPUT TABLE OF GIRLS IN NAHDET KHAIRALLAH REGION (SIX COMMUNITIES) OF EZBET KHAIRALLAH*

\begin{tabular}{|c|c|c|c|c|c|c|c|}
\hline \multirow[b]{3}{*}{$\begin{array}{l}\text { Age } \\
\text { group }\end{array}$} & \multicolumn{4}{|c|}{ Unmarried } & \multicolumn{3}{|c|}{ Married } \\
\hline & \multicolumn{2}{|c|}{ In School } & \multicolumn{2}{|c|}{ Out of School } & \multirow[b]{2}{*}{ Has a child } & \multirow[b]{2}{*}{$\begin{array}{c}\text { Does not } \\
\text { have a child }\end{array}$} & \multirow[b]{2}{*}{ Total } \\
\hline & $\begin{array}{l}\text { Living } \\
\text { with both } \\
\text { parents }\end{array}$ & $\begin{array}{l}\text { Living with } \\
\text { just one } \\
\text { or neither } \\
\text { parent }\end{array}$ & $\begin{array}{l}\text { Living } \\
\text { with both } \\
\text { parents }\end{array}$ & $\begin{array}{l}\text { Living with } \\
\text { just one } \\
\text { or neither } \\
\text { parent }\end{array}$ & & & \\
\hline $6-9$ & 217 & 12 & 43 & 6 & 0 & 0 & 278 \\
\hline $10-14$ & 301 & 26 & 48 & 12 & 0 & 0 & 387 \\
\hline $15-17$ & 95 & 18 & 59 & 20 & 3 & 4 & 199 \\
\hline $18-20$ & 19 & 3 & 22 & 8 & 6 & 13 & 71 \\
\hline TOTAL & 632 & 59 & 172 & 46 & 9 & 17 & 935 \\
\hline
\end{tabular}

*Note: The contemporary Overview Output Table has since been modified in a number of ways: 1) it distinguishes "Living with one parent" from "Living with neither parent"; 2) it includes girls who are "Unmarried" and "Have a child"; and 3 ) it distinguishes the age cohorts of 10-12 years and 13-14 years.

"In one case a girl was trying to go take her exams, and the grandfather chased her to stop her because she had to take a bus and walk to get there and it's not safe."

-Field officer observation from field experience

\section{Results: Education}

There is only one primary school in Ezbet Khairallah and no secondary school. To attend a secondary school outside the community, extra fees are required. Upon further analysis, poverty, safety, and early marriage were all given as reasons for the low levels of girls' education in Ezbet Khairallah, which are nearly half that of national data reported for Cairo (Egypt Demographic and Health Survey 2005). A breakdown of education findings based on the Roster can be found in Figure 1.

Community Schools: About 3\% of the girls 13-18 years captured by the Roster information attended community school, a one-classroom nonformal education program under the Ministry of Education for children who had dropped out of school or for children aged 9-12 who had never been to school.
In community schools, children attend school for three days and work for three days. Some NGO-sponsored community schools pay the students for the three days of work they do. This results in an interesting phenomenon of some parents keeping their children out of school until age nine so that they can both go to school and earn money.

Safety and Mobility: Many parents reported that they would not let their daughters go out alone due to safety issues as well as responsibilities at home. Girls as young as seven years old were tasked with looking after younger siblings at home.

\section{Results: Marital Status}

The rate of early marriage among girls in Ezbet Khairallah is nearly twice as high as the rate for Cairo (Egypt Demographic and Health Survey 2005). Several girls as young as 12 were already engaged, and girls as young as 15 were already married. A breakdown of marital status findings based on the Roster can be found in Figure 2.

\section{Results: Employment Status}

Roughly one in four girls in Ezbet Khairallah is involved in paid work, such as factory work. 
FIGURE 1. EDUCATION STATUS OF GIRLS AGED 13-18 YEARS IN THE GIRL ROSTER

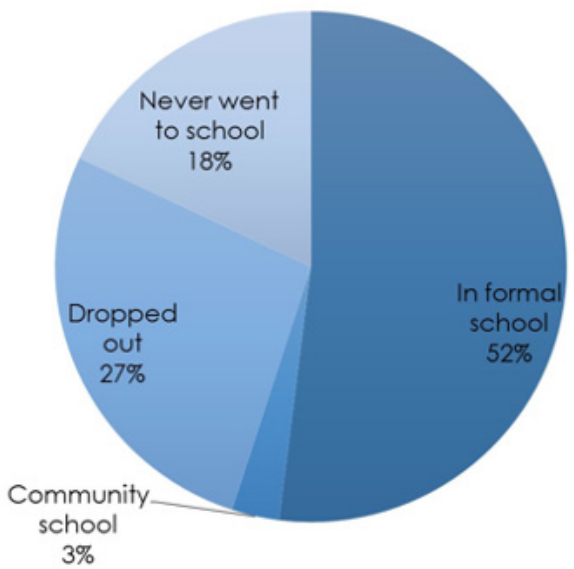

FIGURE 2. MARITAL STATUS OF GIRLS AGED 16-18 YEARS IN THE GIRL ROSTER

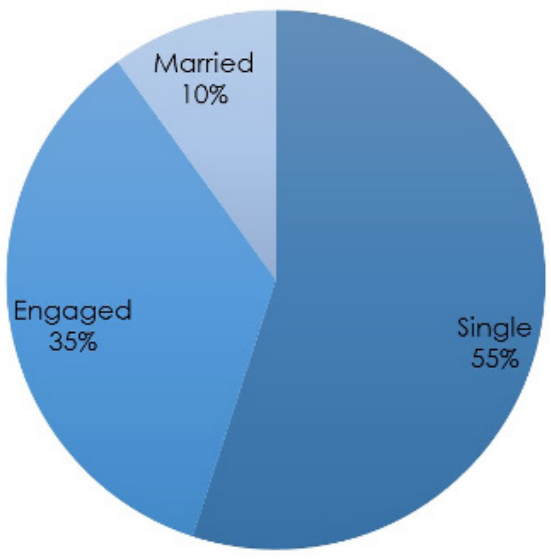

TABLE 2. PROFILE OF WORKING GIRLS IN EZBET KHAIRALLAH

\begin{tabular}{|c|c|c|c|c|c|c|}
\hline $\begin{array}{c}\text { Age group } \\
\text { (years) }\end{array}$ & In school & No school & $\begin{array}{c}\text { Community } \\
\text { school }\end{array}$ & $\begin{array}{c}\text { Dropped out } \\
\text { in primary }\end{array}$ & $\begin{array}{c}\text { Dropped out } \\
\text { (but finished } \\
\text { primary) }\end{array}$ & Total \\
\hline $13-15$ & $11(23 \%)$ & $9(19 \%)$ & $11(23 \%)$ & $6(13 \%)$ & $11(23 \%)$ & 48 \\
\hline $16-18$ & $6(7 \%)$ & $29(34 \%)$ & $4(5 \%)$ & $12(14 \%)$ & $35(41 \%)$ & 86 \\
\hline
\end{tabular}

TABLE 3. EXPECTED SEGMENTS OF GIRLS

\begin{tabular}{|c|c|c|c|}
\hline $\begin{array}{c}\text { Age group } \\
\text { (years) }\end{array}$ & $\begin{array}{c}\text { Out of school and } \\
\text { single/engaged }\end{array}$ & $\begin{array}{c}\text { Married } \\
\text { (in or out of school) }\end{array}$ & Working/ Community school \\
\hline $13-15$ & $11(23 \%)$ & $9(19 \%)$ & $11(23 \%)$ \\
\hline $16-18$ & $6(7 \%)$ & $29(34 \%)$ & $4(5 \%)$ \\
\hline
\end{tabular}

Several girls as young as seven years old were already involved in paid labor. A breakdown of employment status findings based on the Roster can be found in Figure 3.

Most of the girls who were engaged in paid labor were out of school, but not all. Of married girls who were working, the majority had never been to school. The profile of girls who are working can be found in Table 2 .

\section{Results: Living Situation}

Of the $17 \%$ of girls living with just one or neither parent, most live with their mother only. These girls are at much higher risk of school dropout, early marriage, and child labor. A breakdown of living situation findings based on the Roster can be found in Figure 4.

\section{Recommendations for Program Learning and Design}

In a community in Ezbet Khairallah with about 100 girls between the ages of 13 and 18, we would expect roughly the same segments of atrisk girls as found in Table 3.

These segments can be grouped together for girls' clubs as outlined in "Recommendations." 
FIGURE 3. EMPLOYMENT STATUS OF GIRLS AGED 13-18 YEARS IN THE GIRL ROSTER

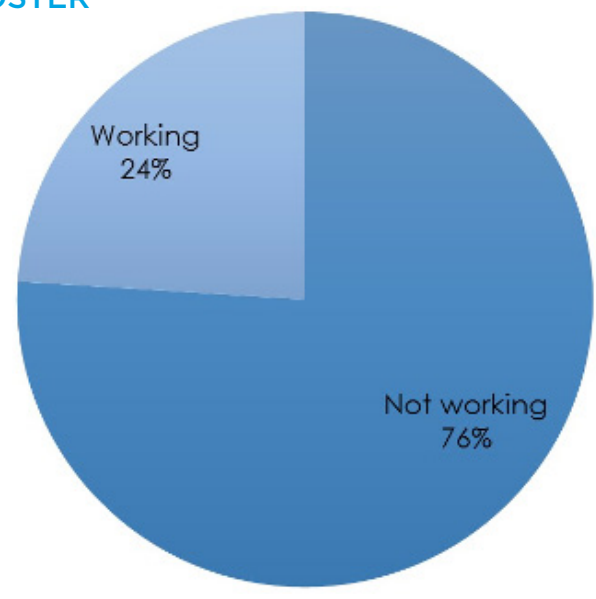

\section{Recommendations}

- Group all married girls aged 15-19 together (perhaps one club for two communities);

- Provide childcare for married girls;

- Group all out-of-school girls with little or no education together (working or not);

- Group all out-of-school, literate girls (working or not) together with community schoolgirls;

- Target advocacy on the following issues:

- Construction of a secondary school in Ezbet Khairallah;

- Safer transportation to and from school for girls;

- More employment options for parents.

\section{Challenges}

- Married girls and working girls living with just one or neither parent will be difficult to mobilize.

- Poverty and low employment opportunities are overarching problems in the region that
FIGURE 4. LIVING SITUATION OF GIRLS AGED 13-18 YEARS BASED ON THE GIRL ROSTER

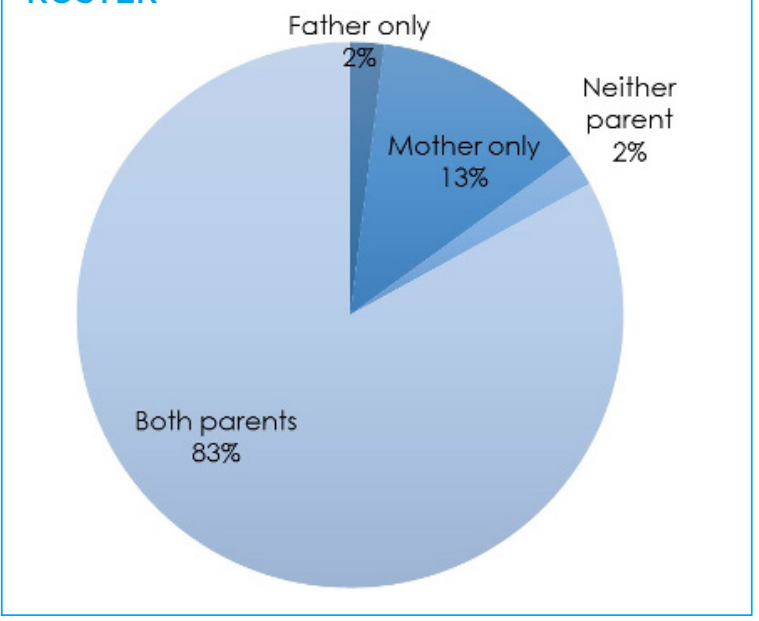

"In one area, many men were involved in drug dealing, and even the children are getting involved. Poverty is also very high here. Many girls are working and out of school, and many mothers are single moms because the husbands are in prison or have left to work in another country or region."

-Field officer observation from field experience

prevent participation in social programs and increase dropout and child labor.

- A culture of early marriage is pervasive, with marriage emphasized as the top priority for a girl's life.

- Only one primary school and no secondary school increases dropout and leads to the use of unsafe transportation for girls going to school.

- Families reported the following reasons for keeping girls out of school:

- Early marriage;

- Poverty and school fees, particularly for secondary school; 


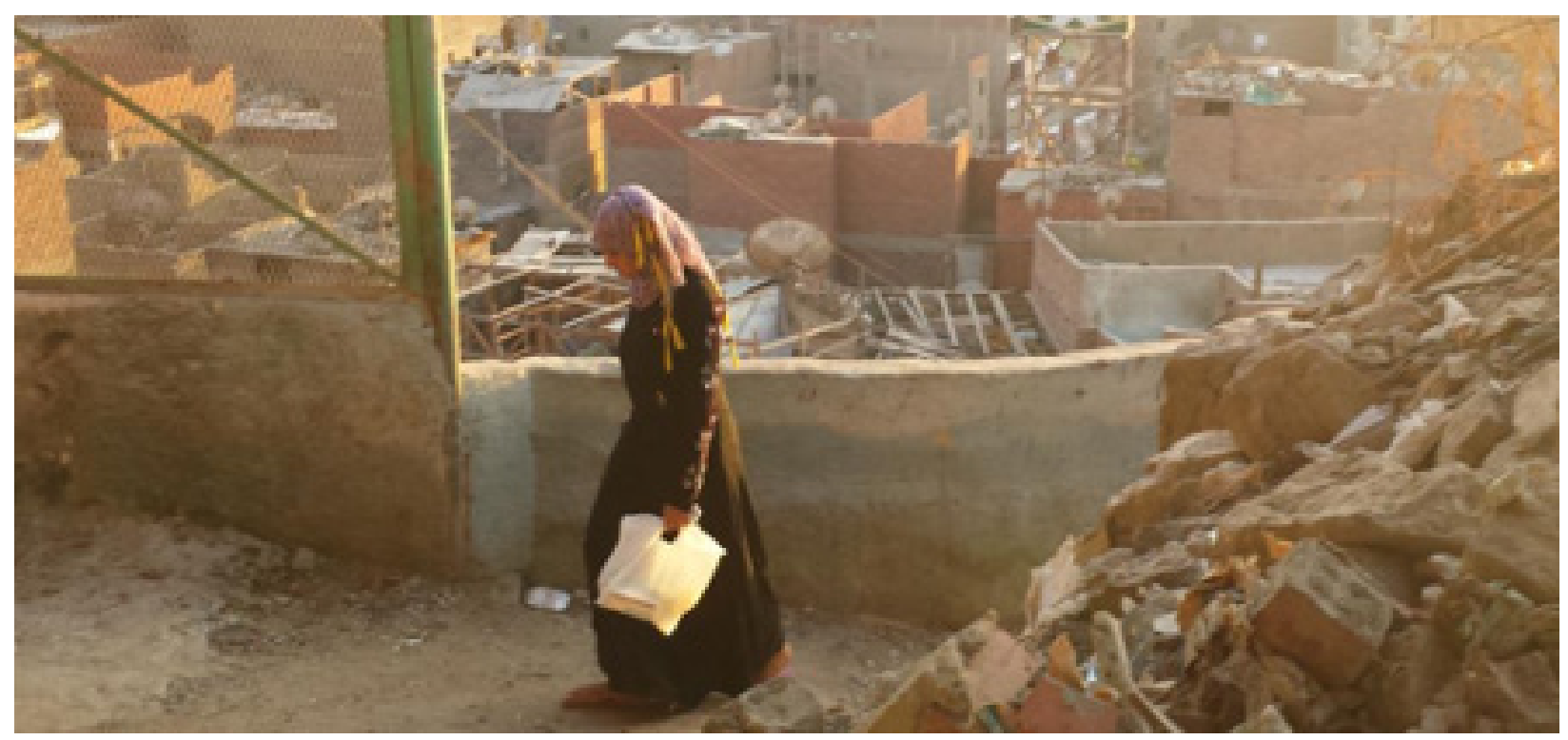

Girl passing a trash heap in Ezbet Khairallah. (Photo: Plan International.)

"Many times, the father isn't there, so the girls have to stay at home while the mom works, or the girl must go out and work. Sometimes the family will have three children and send two to school and keep the other one home to keep house while the mom works."

-Field officer observation from field experience

- $\quad$ Safety going to and from school;

- Low quality of schooling-many girls who go to school are still illiterate;

- $\quad$ Preference for educating boys over girls.

\section{Conclusion}

Plan's global Safer Cities for Girls project is the follow-up to the BIAAG Urban Program, and the Safer Cities for Girls model was designed before Plan conducted the Girl Roster in Egypt. As a result, the Girl Roster was not a tool included in the program model. However, the notions of Intentional Design-centering all program plans
"Girls should insist on their own opinions and not just listen to whatever others say. They should look to what's right and be bold and move forward."

-Mona, age 16, Ezbet Khairallah

on the lived experiences of specific segments of girls-was vital to Plan's process and led to strategic investments to ensure girls were part of the planning process as Safer Cities was adapted in follow-up programs. As a result of careful consultations and input from the girls themselves, Safer Cities, as of 2019, includes program components/modules focused on life skills, advocacy, safety walks, and training of the government transportation agency. At the girls' behest, there are also activities focused on sports, art therapy, and self-defense. The CDAs from the Urban Program are still involved as local partners and are using the evidencebased, girl-informed methods they learned through the first project. As of 2019, there is no economic empowerment component of the project in Cairo.

The rostering done in the first phase helped to inform Plan's programmatic approach in 
terms of reaching Safer Cities participants and

prioritizing certain areas of the catchment zone.

As of 2019, the project is working in Ezbet Khairallah and El Asmarat. The total direct

beneficiaries reached are:

- $\quad 1,693$ girls;

- 588 boys;

- 636 parents;

- 270 drivers;

- 263 community leaders/government

officials/local authorities: 194 female, 69

male.

The project continues to engage girls and boys in Champions of Change clubs and has been working with numerous local NGOs on advocacy campaigns promoting girls' rights and safety. The project has also begun working closely with transportation workers as girls cite transportation as one of the risky areas for their safety in the city. The project is training transportation workers on keeping girls and children safe and setting up a media campaign on public buses.

For more information on this project, please visit: https://www.planusa.org/ egypt-safer-cities-for-girls. 


\title{
Practitioner Report 17
}

\section{Beginning with the Girl Roster Results from West Bekaa, Lebanon, to Reach the Unreached Girls}

\author{
By Rima Mourtada
}

Field Teams:

Women Now for Development in West Bekaa: Khitam Diab, Laila Haraba, Nada Hassan, Joumana Lahham, Jihan Obeid, Jana Seiffeddine, and Women Now leadership (Aisha Dennis, Weam Ghabash, and Roula Roukbi)

Basmeh and Zeitooneh in Beirut: Amina Dawood, Samah Dirawi, Ali Fatayerji, Omar Mansour, Amina Mousa, Basmah Mousa Ousaily, Mohammad al Yassine, Alaa Zakaria, and Basmeh and Zeitooneh leadership (Rabi Ahmad and Amal Al Raai)

\begin{tabular}{|c|c|}
\hline Findings and Decisions & Implementation Observations and Adaptations \\
\hline $\begin{array}{l}\text { - Overall, } 45 \% \text { of } 6-18 \text {-year-old girls who ever } \\
\text { attended school are currently not in school in West } \\
\text { Bekaa and } 20 \% \text { are currently not in school in Beirut. } \\
\text { - There was a dramatic decline in schooling at age } 13 \\
\text { in West Bekaa and at age } 14 \text { in Beirut. } \\
\text { - There was a higher proportion of girls who were } \\
\text { not in school in West Bekaa among those living } \\
\text { inside the ITS (Informal Tented Settlements) (43\%) } \\
\text { than those living outside the ITS (21\%). This is a } \\
\text { significant program challenge. The proportion of } \\
\text { girls who were not in school in Beirut was much } \\
\text { higher for those living in Shatila camp (32\%) than it } \\
\text { was for those living in Burj al Barajneh Camp (13\%), } \\
\text { and it was higher among Syrian refugee girls (21\%) } \\
\text { than it was among Palestinian refugee girls (11\%). } \\
\text { Roster results as well as results of other studies } \\
\text { suggest that residing inside the ITS may impair girls' } \\
\text { access to schooling; there is pressure to remain } \\
\text { inside the ITS due to security concerns, which } \\
\text { increases risk of child labor, child marriage, and } \\
\text { adolescent childbearing. Therefore, future programs } \\
\text { should use outreach activities to increase the } \\
\text { chances of reaching girls living in ITS. } \\
\text { - Around } 10 \% \text { of the rostered 13-17-year-old girls in } \\
\text { both settings (Bekaa [n=480] and Beirut [n=1,105]) } \\
\text { were currently or previously married. } \\
\text { The percent of ever-married girls was higher for } \\
\text { those living inside the ITS (14\%) than for those living } \\
\text { outside the ITS ( } 8 \% \text { ). } \\
\text { Bekaa and } 82 \% \text { of girls in Beirut had at least one } \\
\text { pregnancy. }\end{array}$ & $\begin{array}{l}\text { - Gaining access to most of the settlements in } \\
\text { West Bekaa requires an official approval from } \\
\text { the municipality. This ensures the cooperation of } \\
\text { the Swawishs (camp leaders) thus facilitating the } \\
\text { rostering process inside the settlement, } \\
\text { - Paring Syrian community workers with Lebanese } \\
\text { ones eased the tension the Syrian community } \\
\text { workers felt when approaching Lebanese } \\
\text { households. } \\
\text { Participants who were not familiar with the } \\
\text { collaborating NGO in West Bekaa were sometimes } \\
\text { hesitant to participate; this underscored the } \\
\text { importance of liaising with the community and the } \\
\text { rosterers wearing name tags with the NGO logo on } \\
\text { them as a means of introduction. } \\
\text { Gaining access to some of the neighborhoods in } \\
\text { Beirut was difficult because of security concerns, } \\
\text { so not all households in those neighborhoods were } \\
\text { rostered. } \\
\text { Questions about marriage and pregnancy should } \\
\text { apply to girls starting at } 9 \text { years of age, given the } \\
\text { sometimes extreme child-marriage patterns in those } \\
\text { communities (and not } 12 \text { years of age, as originally } \\
\text { assumed). Additionally, many girls between } 9 \text { and } 12 \\
\text { are engaged, which is one of the danger signs that } \\
\text { those girls will most likely fall off-track (drop out of } \\
\text { school and marry before turning 18). }\end{array}$ \\
\hline
\end{tabular}


Findings and Decisions

- Less than $20 \%$ of the rostered 6-17-yearold girls in both settings participated in health or development programs, confirming that existing programs are not yet sufficiently reaching younger girls.

- Programs in Bekaa are not sufficiently reaching younger girls who are facing many risks. Without intentional reorientation, such programs will continue to disproportionately reach the older age categories.

- There should be outreach programs to recruit (10-17-year-old) Syrian refugee girls from the following locations: Bar Elias, Marj, and Saadnayel (inside and outside the ITS) in West Bekaa; the ITS from all of the rostered locations in West Bekaa; neighborhoods that had the highest percent of off-track girls in each Burj al Barajneh and Shatila camps in Beirut.

- In both settings, programs should give additional attention to: 1) out-of-school 10-14-year-old girls who are at risk of child marriage and early pregnancy, and the associated health risks and poverty, and 2) 13-17-year-old married girls, the majority of whom are also mothers with poor access to health and other vital services.

\section{Background}

\section{Syrian Refugees in Lebanon}

Lebanon is among the countries that have been hosting the highest number of Syrian refugees in the region since the onset of the Syrian conflict. Lebanon has the fourth largest refugee population in the world and the largest concentration of refugees per capita (UNHCR, UNICEF, and WFP 2018).

The latest figures from UNHCR indicate that there are currently 919,578 registered Syrian refugees in Lebanon (UNHCR data portal), however this figure is believed to be much higher reaching 1.5 million refugees if unregistered refugees are included. Among Syrian refugees in Lebanon, 37\% reside in Bekaa, especially West Bekaa, which includes large agricultural areas. Almost $20 \%$ of refugees are 5-17-year-old girls (183,916 girls).
The Lebanese government did not establish official camps for refugees as neighboring countries such as Jordan and Turkey did. In $2018,66 \%$ of Syrian refugees lived in residential buildings, 19\% lived in informal tented settlements, and 15\% lived in nonresidential buildings (e.g., unfinished buildings, factories, warehouses and shops) (UNHCR, UNICEF, and WFP 2018).

Syrian refugee adolescent girls in Lebanon have limited access to education and are at high risk of child marriage and early pregnancy, as demonstrated by a number of studies in West Bekaa as well as in Burj al Barajneh and Shatila camps in Lebanon (UNFPA, AUB, and SAWA 2016; Basmeh and Zeitooneh 2017; Mourtada, Schlecht, and DeJong 2017). A previous study (a cross-sectional survey) conducted by a research team at American University of Beirut in collaboration with UNFPA (United Nations Population Fund) in August 2016 that surveyed 2,400 9-24-year-old Syrian refugee girls in three regions in West Bekaa, Marj, Bar Elias, and Qab Elias, demonstrated that half of the 9-17-year-old girls (1,612 girls) were not attending school and the prevalence of child marriage among sampled girls/ women was $34.6 \%$. Additionally, $61 \%$ of the 15-17-year-old married girls had at least one pregnancy (UNFPA, AUB, and SAWA 2016). This is concerning given the fact that Syrian refugee women, particularly adolescent girls, have limited access to sexual and reproductive health services (UNFPA, AUB, and SAWA 2016; Kabakian-Khasholian et al. 2017; Han et al 2019). Additionally, most Syrian refugees are unable to register their children due to many logistical and financial barriers (UNFPA, AUB, and SAWA 2016). Unregistered children face additional barriers to access major services such as education and health services (UNFPA, AUB, and SAWA 2016).

The 2018 vulnerability assessment (UNHCR, UNICEF, and WFP 2018) (the most recent at the time of this report) revealed that $69 \%$ of Syrian refugees were below the poverty line. The same assessment also showed that despite all the efforts attempting to address school enrollment 
for Syrian refugees in the country, more than half of Syrian refugee children aged 3-17 were still out of school in 2018 (UNHCR, UNICEF, and WFP 2018). Consequently, adolescent girls who are out of school are even at an increased risk of child marriage and child labor.

\section{Gaps of Present Programs on the Ground}

Programs offered by NGOs and UN agencies have largely focused on collective priorities in humanitarian settings unintentionally neglecting the needs of adolescent young females, especially those who are out of school and those who married at an early age. Additionally, the few programs attempting to reach vulnerable adolescent girls were not always successful due to the content of such programs that did not always prioritize their needs or because of implementation mechanisms that were not culturally or contextually appropriate.

For example, most of the programs are provided at the NGOs' centers making it difficult for girls who do not live within close proximity of those centers to participate. Sometimes programs are offered at inconvenient times that clash with school attendance (considering that most Syrian refugee girls attend the afternoon shift at schools). Another factor that may discourage girls' participation is the lack of female-only spaces-which raises reputational and safety concerns for girls and young married women. Moreover, centers offering female programs may have concurrent programs for men and boys, thus effectively seen by the community as mixed-sex. Some of the outreach programs are offered at schools preventing girls who are not attending school (and who are likely to be more vulnerable) from benefiting from such programs. Moreover, many programs are subject to serial interruptions, given the high mobility of refugees in Lebanon.

In the dynamic refugee context, there is high staff turnover within the NGOs, and without intentional efforts, there are few community advocates for girls and women or a sustainable female leadership. The rostering highlighted the repressive leadership in informal tented settlements (ITS), under universally male leadership, which promotes restrictive norms for girls and women, including restricting them from attending schools or NGO-run programs, and the active promotion of child labor and marriage.

Funding gaps also prevent well-intentioned NGOs from establishing long-term evidencebased programs that have sufficient continuity with their constituent households and the girls and women within them to be beneficial and build sustainable capacities.

\section{Aims and Objectives}

The aim of this project is to address the abovementioned gaps that limit the NGOs' ability to reach the most-at-risk Syrian refugee girls in Lebanon, thus magnifying the hazards resulting from war and displacement; this is achieved by building the capacity and resources of local NGOs to:

- Identify the categories and the numbers of adolescent girls and young women who are most at risk (especially those who are not currently reached by existing programs);

- Modify current programs or create new ones so they are more likely to address the social, economic, and reproductive health needs of the most disadvantaged adolescent girls and young women.

In this practitioner report, the most-off-track girls, as defined by the Population Council, include the following segments:

- Girls (6-17 years old) who are not currently attending school or who have missed several years of schooling and thus are at elevated risk of child marriage and adolescent childbearing;

- Girls who are isolated (such as those living in ITS), focusing on 10-14-year-old girls;

- Girls who do not currently live with their parents; 
FIGURE 1. AREAS WHERE THE GIRL ROSTER WAS APPLIED IN WEST BEKAA REGION

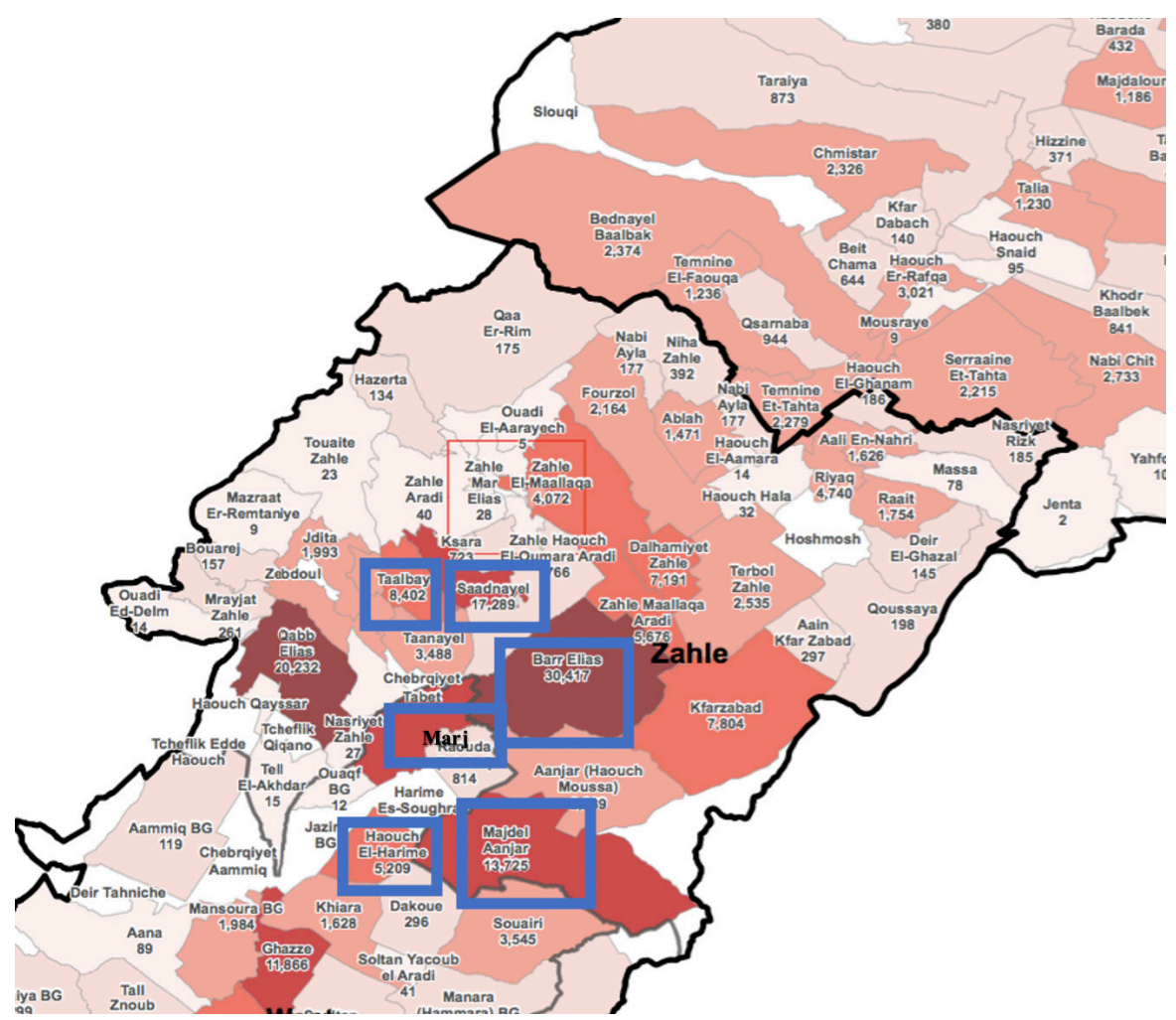

- Girls who are married as children before the age of 18;

- Girls who have had a child before the age of 18 .

The Council, as part of an extended effort by the Girls in Emergencies (GiE) Collaborative, has undertaken a program-coordinated by Dr. Rima Mourtada, collaborating closely as of early 2020 with two NGOs: Women Now for Development (WN) and Basmeh and Zeitooneh (B\&Z), as well as other NGOs and INGOs-to sponsor a learning circle. It is the Council's hope that this will become a sustainable community of practice in Lebanon that, over the next years, will assist those wishing to support the needs of adolescent refugee girls in this dynamic setting resulting from refugees' high mobility and the often severe political challenges.

\section{The Implementation of the Girl Roster}

The project started with an overall introduction to Intentional Design and collective learning, establishing the value of an evidence base across current and prospective programs and communities to plan programs that effectively target at-risk females in humanitarian settings. This entailed the implementation of the Girl Roster tool in several areas of expansion and of special need chosen by the staff at both WN and B\&Z.

\section{Settings: West Bekaa, South Beirut}

\section{WEST BEKAA}

WN chose six cities in West Bekaa: Bar Elias, Houshharimeh, Majdalanjar, Marj, Saadnayel, and Thaalabaya (including areas they are already serving, to identify who they are currently 
reaching, and areas they would like to reach). Because of privacy concerns, we do not list the names of the subcommunities (neighborhoods or ITS within each of those cities).

Rostering was conducted in ITS (which were located in both urban and rural areas) as well as in residential areas such as rented apartments, rooms, or unfinished buildings in the selected communities in each of those cities. The type of accommodation entails different challenges, which are important to consider when designing programs.

Figure 1 highlights the different areas where WN staff applied the Girl Roster survey. Darker colors indicate higher concentrations of Syrian refugees per area.

WN staff recruited six female community workers (five Syrian and one Lebanese, aged 19-45 years) based on their qualifications. Those community workers were already attending programs at a WN center and expressed interest in working with $\mathrm{WN}$. They received a two-day training session in September 2019. The Rostering process started around the end of the same month and was completed within the first week of November 2019.

\section{SOUTH BEIRUT}

Shatila and Bourj al Barajneh refugee camps in south Beirut were established in the late 1940s mainly to accommodate Palestinian refugees.
Since the Syrian conflict and the influx of Syrian refugees in 2011, Shatila camp is estimated to have around 30,000 people and Bourj al Barajneh camp is estimated to have around 50,000 people. The population in the camps includes Palestinian, Syrian, and other refugee and migrant workers from Ethiopia, Bangladesh, and other locations.

The camps do not fall under the authority of the Lebanese government. Services in both camps are provided by host authorities such as the UN Relief and Works Agency for Palestinian Refugees in the Near East (UNRWA) that provides services such as education and health to Palestinian refugees.

Both camps are integrated in the surrounding urban areas and therefore are different from other typical refugee camps that are more rural and isolated. However, both camps are overcrowded, with poor living conditions and limited access to basic services such as clean drinking water and electricity.

B\&Z selected a number of neighborhoods in each camp. Eight Palestinian community workers were recruited (four females and four males). Pairing male and female Palestinian community workers was important for both access and security concerns. Rostering for $B \& Z$ started in the first week of December. It was delayed by one month due to the political turmoil in the country that resulted in demonstrations and road closures.

TABLE 1. THE NUMBER OF HOUSEHOLDS AND GIRLS PER LOCATION AND TYPE OF ACCOMMODATION

\begin{tabular}{|l|c|c|c|c|}
\hline \multicolumn{1}{|c|}{ Location } & $\begin{array}{c}\text { Households } \\
\text { inside ITS } \\
\text { N (\%) }\end{array}$ & $\begin{array}{c}\text { Households } \\
\text { outside ITS } \\
\text { N (\%) }\end{array}$ & $\begin{array}{c}\text { Girls inside ITS } \\
\text { N (\%) }\end{array}$ & $\begin{array}{c}\text { Girls outside ITS } \\
\text { N (\%) }\end{array}$ \\
\hline Bar Elias & $217(60.3)$ & $143(39.7)$ & $520(64.1)$ & $291(35.9)$ \\
\hline Houshharimeh & O(0) & $307(100)$ & 0 & $379(100)$ \\
\hline Majdalanjar & $101(46.1)$ & $118(53.9)$ & $162(48.6)$ & $171(51.4)$ \\
\hline Marj & $152(40.9)$ & $220(59.1)$ & $190(68.4)$ & $299(50.4)$ \\
\hline Saadnayel & $94(64.0)$ & $53(36.0)$ & 0 & $88(31.6)$ \\
\hline Thaalabaya & 0 & $29(100)$ & $1,166(47.6)$ & $1,283(52.4)$ \\
\hline Total & $564(39.3)$ & $870(60.7)$ & $100)$ \\
\hline
\end{tabular}




\section{FIGURE 2. SCHOOL ATTENDANCE BY GIRLS' AGE FOR 6-18-YEAR-OLD GIRLS WHO EVER ATTENDED SCHOOL ( $N=1,010$ GIRLS) IN WEST BEKAA}

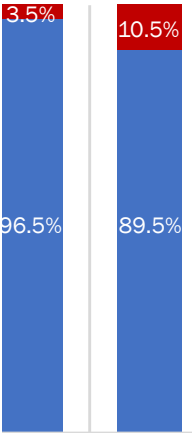

6

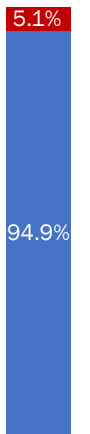

8
In school

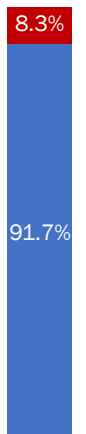

9

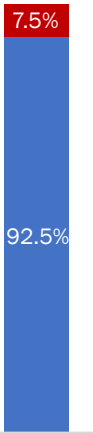

10

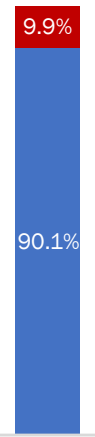

11
Out of school

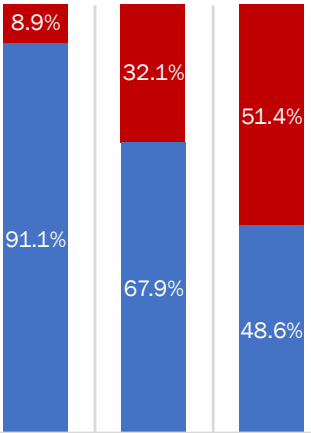

13

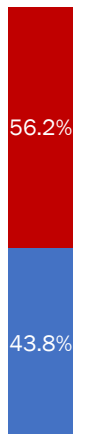

15
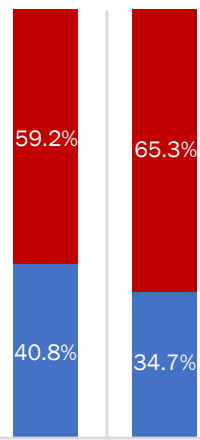

17

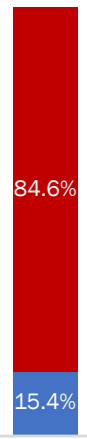

18

TABLE 2. CURRENT SCHOOL ATTENDANCE PER LOCATION (6-18-YEAR-OLD GIRLS WHO EVER ATTENDED SCHOOL, $\mathrm{N}=1,010$ )

\begin{tabular}{|l|c|c|c|}
\hline \multicolumn{1}{|c|}{ Location } & $\begin{array}{c}\text { Attending school } \\
\mathrm{N}(\%)\end{array}$ & $\begin{array}{c}\text { Not attending school } \\
\text { N (\%) }\end{array}$ & Total \\
\hline Bar Elias & $163(55.1)$ & $133(44.9)$ & 296 \\
\hline Houshharimeh & $165(84.2)$ & $31(15.8)$ & 196 \\
\hline Majdalanjar & $141(82.5)$ & $30(17.5)$ & 171 \\
\hline Marj & $136(68.3)$ & $63(31.7)$ & 199 \\
\hline Saadnayel & $83(67.5)$ & $40(32.5)$ & 123 \\
\hline Thaalabaya & $20(80.0)$ & $5(20.0)$ & 25 \\
\hline Total & $708(70.1)$ & $302(29.9)$ & 1,010 \\
\hline
\end{tabular}

Results: Women Now, Basmeh and Zeitooneh

\section{WOMEN NOW}

Sample Overview

The community workers approached 1,741 households in six areas in West Bekaa. A total of 307 households refused to participate ( $18 \%$ of the approached households). A total of 1,434 households were rostered including 2,449 0-24-year-old girls.

Table 1 shows the breakdown of households and girls per community and housing type. Among the rostered households, $92 \%$ are of Syrian origin, $7 \%$ are of Lebanese origin, and the remaining $1 \%$ are of Palestinian origin. Among the rostered girls, $52 \%$ live outside the ITS and $48 \%$ live inside the ITS.

\section{Schooling}

As per the standard Girl Roster questionnaire, schooling questions were only asked for 6-24-year-old females. We present the findings with respect to females who are 6-18 years old.

The proportion of girls who were currently attending school decreased as the girls' age increased (see Figure 2).

- There is a sharp drop in school attendance at age 13, where the proportion of girls who are currently in school drops from $91 \%$ at age 12 to $68 \%$ at age 13 . 
TABLE 3. AGE FOR GRADE PER LOCATION (6-18-YEAR-OLD GIRLS WHO ARE CURRENTLY IN SCHOOL, $\mathrm{N}=708$ )

\begin{tabular}{|l|c|c|c|}
\hline \multicolumn{1}{|c|}{ Location } & $\begin{array}{c}\text { 2y+ behind grade } \\
\text { N (\%) }\end{array}$ & $\begin{array}{c}\text { Less than 2y behind grade } \\
\text { N (\%) }\end{array}$ & Total \\
\hline Bar Elias & $104(63.8)$ & $59(36.2)$ & 163 \\
\hline Houshharimeh & $61(37.0)$ & $104(63.0)$ & 165 \\
\hline Majdalanjar & $51(36.2)$ & $90(63.8)$ & 141 \\
\hline Marj & $47(34.6)$ & $89(65.4)$ & 136 \\
\hline Saadnayel & $42(50.6)$ & $41(49.4)$ & 83 \\
\hline Thaalabaya & $8(40.0)$ & $12(60.0)$ & 708 \\
\hline Total & $313(44.2)$ & $395(55.8)$ & \\
\hline
\end{tabular}

- There are also sharp drops in the proportion of girls who are currently in school at ages 14,17 , and 18 . Of the rostered 15-year-old girls, $56 \%$ are currently out of school.

Table 2 shows the current status of school attendance per location. Bar Elias has the highest percentage of girls who are currently not attending school (45\%).

Almost $43 \%$ of girls residing inside the ITS are currently not in school compared to $21 \%$ of girls residing outside the ITS.

Table 3 shows girls who missed at least two years of school per location. Of 708 girls who are currently attending school, $44 \%$ are at least two years behind their grade. Bar Elias had the highest percentage of girls who missed at least two years of schooling (64\%), followed by Saadnayel (51\%) and Thaalabaya (40\%), though Thaalabaya's sample size was small.

The proportion of girls who missed at least two years of school was much higher among those living inside the ITS (57\%) compared to those living outside the ITS (38\%).

\section{Marriage and Pregnancy}

Questions about marriage, as per the standard questionnaire, were asked for girls above 12 years old only (975 girls). Among 13-24-yearold rostered girls, $34 \%$ were married, while $10 \%$ of 13-17-year-old girls were ever-married. The highest percentage of 13-17-year-old girls who ever married were from Marj (14\%) followed by Bar Elias (11\%). In some of the locations, the total number of girls was very small, indicating more girls would need to be rostered to confirm these patterns.

The proportion of 13-17-year-old girls residing inside the ITS who were ever-married was higher compared to the proportion of evermarried girls residing outside the ITS (14\% versus $8 \%$, respectively).

Out of the 358 ever-married girls, $82 \%$ had at least one child or were pregnant at the time of the survey. Of the 13-17-year-old ever-married girls, $66 \%$ had at least one pregnancy.

The proportion of ever-married girls who were ever-pregnant was roughly similar across the selected locations and among those living inside and outside the ITS.

\section{Participation in Non-school-based Programs}

Overall, $15 \%$ of the 1,264 10-17-year-old girls participated in NGO programs (by WN or other NGOs). We found that older girls are more likely to participate in NGO programs compared to younger ones. For instance, 35\% of 18-24-yearold girls participated in NGO programs compared to $11 \%$ of $10-12$-year-old girls and $24 \%$ of 13-14-year-old girls.

The highest percentage of 6-17-year-old girls who participated in NGO programs came from Saadnayel (27\%) followed by Bar Elias (19\%), Majdalanjar (19\%), and Marj (13\%). 
Only 5.5\% of the rostered 6-17-year-old girls participated in programs by WN. The highest percentage of girls who participated in programs by WN were located in Majdalanjar (16\%), followed by Marj (9\%) and Saadnayel (7\%).

The proportion of 6-17-year-old girls who participated in any NGO program was similar for girls living inside the ITS (15.4\%) and those living outside the ITS (15.2\%). However, the percentage of girls who participated in WN programs was much higher for those living outside the ITS (9\%) than those living inside the ITS (2\%).

\section{On-track Off-track Girls}

We present three categories of "off-track" 6-17-year-old girls based on certain vulnerability criteria (constructed by the Population Council):

- $\quad$ Category 1. The most-at-risk girls: Girls who are out of school OR living with no parent OR married OR have a child.

- $\quad$ Category 2. The next risk level (adding single parent): Girls who are out of school OR living with no parent OR living with one parent OR married OR have a child.

- Category 3. Adding in-school girls who are behind their accrual grade: Girls who are out of school OR behind grade for age (2+ years) OR living with no parent OR living with one parent OR married OR have a child.

Table 4 lists the proportion of girls who are offtrack per housing type, location (highlighting only the results for the locations that had the highest and lowest off-track girls), and per origin. Bar Elias, Marj, and Saadnayel had the highest proportion of girls who were off-track for all three categories.

Overall, $46 \%$ of the 6-17-year-old girls were off-track according to Category 1, 52\% were off-track according to Category 2, and $73 \%$ were off-track according to Category 3. The proportion of girls who are off-track is noticeably higher for the older two age categories (13-14 and 15-17) compared with the younger age categories. For instance, $69 \%$ of 15-17-year-old girls were off-track according to Category 1 compared to $38 \%$ of 6 -9-year-old girls.

The proportion of girls who were off-track was much higher for girls living inside the ITS (64\%) than for those living outside the ITS (29\%).

The proportion of girls who were off-track was noticeably higher for Syrian refugee girls compared with the local Lebanese girls. For instance, and according to Category 1, 49\% of Syrian refugee girls were off-track compared to only $4 \%$ of local Lebanese girls. The sample size for Palestinian refugee girls was too small to draw strong conclusions (19 girls), although they were clearly more vulnerable than the local Lebanese girls.

\section{BASMEH AND ZEITOONEH}

\section{Sample Overview}

Rostering was conducted in selected neighborhoods in two camps; Burj al Barajneh camp and Shatila camp. A total of 4,533 households were approached by the community workers, out of which, 3,905 households were rostered. A total of 628 households were excluded, $39 \%$ of which were empty, $32 \%$ declined to participate, and $29 \%$ had no adult at home. Out of the 3,905 rostered households, 2,262 (58\%) were from Burj al Barajneh and 1,643 (42\%) were from Shatila.

Among the households, 839 did not have any girls. Out of the 6,232 rostered girls, 3,506 (56\%) were of Syrian origin, 2,550 (41\%) were of Palestinian origin, and 176 (3\%) were of other origins. Among girls in Burj al Barajneh, 50\% were Palestinians, 49\% were Syrians, and 1\% were of other origins. Among girls in Shatila, $67 \%$ were Syrians, 29\% were Palestinians, and $4 \%$ were of other origins.

\section{Schooling}

Almost $80 \%$ of the 3,111 6-18-year-old girls who ever attended school were currently attending 
TABLE 4. PROPORTION OF OFF-TRACK 6-17 YEAR-OLD-GIRLS $(N=1,264)$ PER LOCATION, HOUSING TYPE, AND ORIGIN

\begin{tabular}{|c|c|c|c|}
\hline Category & Type & On-track (\%) & Off-track (\%) \\
\hline \multirow[t]{11}{*}{ Category 1} & A-All locations & 54.4 & 45.6 \\
\hline & B-Housing type & & \\
\hline & Inside ITS & 36.4 & 63.6 \\
\hline & Outside ITS & 70.7 & 29.3 \\
\hline & C-Location & & \\
\hline & Bar Elias & 37.0 & 63.0 \\
\hline & Majdalanjar & 78.5 & 21.5 \\
\hline & D-Origin & & \\
\hline & Syrian & 51.4 & 48.6 \\
\hline & Lebanese & 95.7 & 4.3 \\
\hline & Palestinian & 36.8 & 63.2 \\
\hline \multirow[t]{11}{*}{ Category 2} & A-All locations & 48.3 & 51.7 \\
\hline & B-Housing type & & \\
\hline & Inside ITS & 33.2 & 66.7 \\
\hline & Outside ITS & 62.0 & 38.0 \\
\hline & C-Location & & \\
\hline & Bar Elias & 31.4 & 68.6 \\
\hline & Majdalanjar & 71.4 & 28.6 \\
\hline & D-Origin & & \\
\hline & Syrian & 45.0 & 55.0 \\
\hline & Lebanese & 92.5 & 7.5 \\
\hline & Palestinian & 36.8 & 63.2 \\
\hline \multirow[t]{11}{*}{ Category 3} & A-All locations & 27.5 & 72.5 \\
\hline & B-Housing type & & \\
\hline & Inside ITS & 14.4 & 85.6 \\
\hline & Outside ITS & 39.3 & 60.7 \\
\hline & C-Location & & \\
\hline & Bar Elias & 11.4 & 88.6 \\
\hline & Majdalanjar & 46.9 & 53.1 \\
\hline & D-Origin & & \\
\hline & Syrian & 23.4 & 76.6 \\
\hline & Lebanese & 76.3 & 23.4 \\
\hline & Palestinian & 31.6 & 68.4 \\
\hline
\end{tabular}




\section{FIGURE 3. SCHOOL ATTENDANCE BY GIRLS' AGE FOR 6-18-YEAR-OLD GIRLS WHO EVER \\ ATTENDED SCHOOL IN BURJ AL BARAJNEH AND SHATILA $(N=3,111)$}

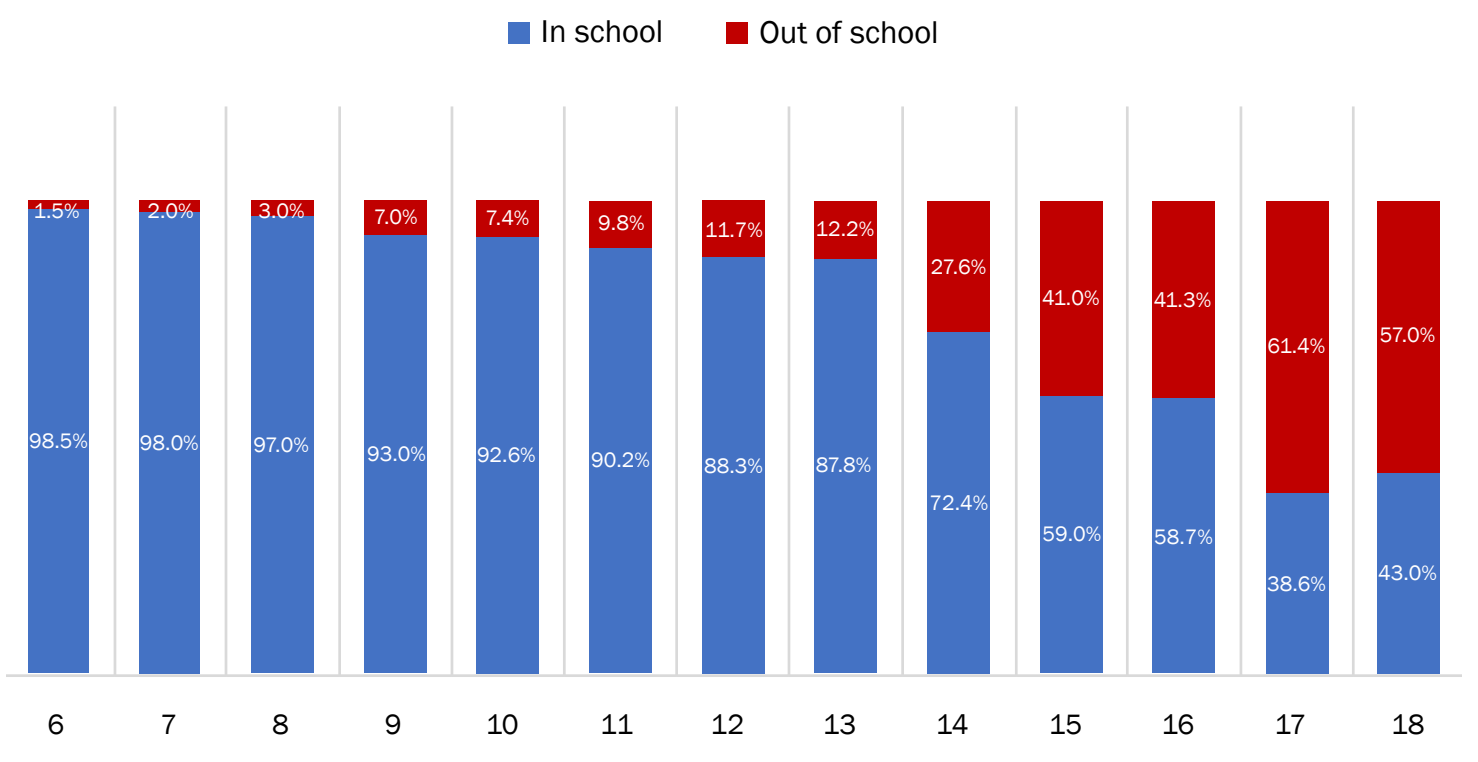

TABLE 5. CURRENT SCHOOL ATTENDANCE PER CAMP (6-18-YEAR-OLD GIRLS WHO EVER ATTENDED SCHOOL, $\mathrm{N}=3,111$ )

\begin{tabular}{|l|c|c|c|}
\hline \multicolumn{1}{|c|}{ Camp } & $\begin{array}{c}\text { Attending school } \\
\mathrm{N}(\%)\end{array}$ & $\begin{array}{c}\text { Not attending school } \\
\mathrm{N}(\%)\end{array}$ & Total \\
\hline Burj al Barajneh & $1,675(87.1)$ & $248(12.9)$ & 1,923 \\
\hline Shatila & $810(68.2)$ & $378(31.8)$ & 1,188 \\
\hline Total & $2,485(79.9)$ & $626(20.1)$ & 3,111 \\
\hline
\end{tabular}

school. The proportion of girls who were currently attending school decreased as the girls' age increased (see Figure 3).

- There is a sharp drop in school attendance at age 14: the proportion of girls in school dropped from $88 \%$ at age 13 to $72 \%$ at 14 .

- There are sharp drops in the proportion of girls who were in school at ages 15 and 17. At least $40 \%$ of girls who were 15 and above were not in school.

The proportion of girls who were not in school was much higher among girls living in Shatila (32\%) than girls living in Burj al Barajneh (13\%) (see Table 5). A possible explanation is that Shatila regularly receives new Syrian refugees who tend to be more vulnerable. The proportion of girls who were not in school was much higher among Syrian refugees than it was among Palestinian refugees (20.6\% vs. $11 \%$, respectively).

Among 6-18-year-old girls who are currently attending school, $32 \%$ were at least two years behind their actual grade: $29 \%$ in Burj al Barajneh and 38\% in Shatila (see Table 6).

The proportion of girls who were at least two years behind their grade was much higher for Syrian girls (58\%) than it was for Palestinian girls (12\%). We will learn more about these dynamics using focus group discussions. 
TABLE 6. AGE FOR GRADE PER CAMP AND NEIGHBORHOOD (6-18-YEAR-OLD GIRLS WHO ARE CURRENTLY IN SCHOOL, $\mathrm{N}=\mathbf{2 , 4 8 5}$ )

\begin{tabular}{|l|c|c|c|}
\hline \multicolumn{1}{|c|}{ Camp } & $\begin{array}{c}2 \mathrm{y}+\text { behind grade } \\
\mathrm{N}(\%)\end{array}$ & $\begin{array}{c}\text { Less than } 2 \mathrm{y} \text { behind grade } \\
\mathrm{N}(\%)\end{array}$ & Total \\
\hline Burj al Barajneh & $481(28.7)$ & $1,194(71.3)$ & 1,675 \\
\hline Shatila & $305(37.5)$ & $505(62.4)$ & 810 \\
\hline Total & $786(31.6)$ & $1,699(68.4)$ & 2,485 \\
\hline
\end{tabular}

TABLE 7. MARITAL STATUS PER CAMP (13-17-YEAR-OLD GIRLS, N=1,105)

\begin{tabular}{|l|c|c|c|}
\hline \multicolumn{1}{|c|}{ Camp } & $\begin{array}{c}\text { Ever-married } \\
\text { N (\%) }\end{array}$ & $\begin{array}{c}\text { Never-married } \\
\text { N (\%) }\end{array}$ & Total \\
\hline Burj al Barajneh & $29(4.3)$ & $650(95.7)$ & 679 \\
\hline Shatila & $73(17.1)$ & $353(82.9)$ & 426 \\
\hline Total & $102(9.2)$ & $1,003(90.8)$ & 1,105 \\
\hline
\end{tabular}

\section{Marriage and Pregnancy}

There were 2,572 girls above 12 years of age who were asked questions about marriage and pregnancy, as per the standard questionnaire. Of the rostered girls aged 13-24, 31\% were currently married. Of the 1,105 13-17-year-old girls aged $13-17$, 9\% were married and $2.9 \%$ were engaged.

The proportion of ever-married girls aged 13-17 was much higher for girls living in Shatila than for girls living in Burj al Barajneh (17\% vs. $4 \%$, respectively) (see Table 7 ). The proportion of 13-17-year-old ever-married girls was also much higher among Syrian girls than it was for Palestinian girls (18\% vs. $1 \%$, respectively).

Out of the 822 ever-married girls, 91\% had at least one child or were pregnant at the time of the survey. Of the 13-17-year-old ever-married girls, $82 \%$ had at least one pregnancy.

The proportion of ever-married girls who were ever-pregnant was higher for women living in Burj al Barajneh (95\%) compared to women living in Shalita (84\%) and was roughly similar between Palestinian and Syrian refugee girls.

\section{Participation in Non-school-based Programs}

Overall, 41\% of the 3,199 6-17-year-old girls participated in NGO programs (B\&Z or other NGOs). Burj al Barajneh had a higher proportion of girls who participated in NGO programs than Shatila (44\% vs. $36 \%$, respectively). The percentage of girls who participated in NGO programs was roughly similar among Palestinian and Syrian refugee girls.

Only $18.6 \%$ of $6-17$-year-old girls participated in programs by B\&Z; $22 \%$ in Shatila and $16 \%$ in Burj. However, a higher percentage of Syrian girls participated in programs by B\&Z (28\%) than Palestinian girls (8\%).

\section{On-track Off-track Girls}

The proportion of off-track girls was higher for girls living in Shatila than it was for girls living in Burj al Barajneh for the three categories defined in this study: $40.5 \%$ vs. $18 \%$ (Category 1), $47 \%$ vs. $22 \%$ (Category 2), and $67.5 \%$ vs. $44 \%$ (Category 3 ). The proportion of off-track girls was also higher among Syrian girls as compared to Palestinian girls (see Table 8). 


\begin{tabular}{|c|c|c|c|}
\hline Category & Type & On-track (\%) & Off-track (\%) \\
\hline \multirow[t]{6}{*}{ Category 1} & Burj al Barajneh & 81.8 & 18.2 \\
\hline & Shatila & 59.5 & 40.5 \\
\hline & Origin & & \\
\hline & Palestinian & 89.1 & 10.9 \\
\hline & Syrian & 59.6 & 40.4 \\
\hline & Other & 76.3 & 23.7 \\
\hline \multirow[t]{6}{*}{ Category 2} & Burj al Barajneh & 78.3 & 21.7 \\
\hline & Shatila & 53.4 & 46.6 \\
\hline & Origin & & \\
\hline & Palestinian & 82.3 & 17.7 \\
\hline & Syrian & 57.0 & 43.0 \\
\hline & Other & 71.0 & 29.0 \\
\hline \multirow[t]{6}{*}{ Category 3} & Burj al Barajneh & 55.7 & 44.3 \\
\hline & Shatila & 32.5 & 67.5 \\
\hline & Origin & & \\
\hline & Palestinian & 73.7 & 26.3 \\
\hline & Syrian & 23.3 & 76.7 \\
\hline & Other & 64.5 & 35.5 \\
\hline
\end{tabular}

\section{Challenges}

Some of the challenges encountered by WN staff included not being able to gain access to some of the ITS due to restrictions imposed by the camp leader, "the Shawish," who prevented the community workers from entering the settlements without official permission from the municipality, which was also very difficult to obtain in some of the areas. There were a few kidnapping incidents in Bekaa that contributed to increasing the anxiety of Syrian refugees living outside the ITS, in rented apartments, and consequently some refugees refused to participate.

The households that refused to answer the Roster questions-a stark minority-were either Lebanese who were not interested in programs for adolescent girls or households who were not interested in participating simply because there were no financial incentives. Occasionally, Syrian community workers faced harassment from some of the Lebanese residents in those communities due to the increased tension between the local Lebanese residents and Syrian refugees induced by competing over limited resources. Finally, the recent political turmoil in the country, which resulted in road closures and increased insecurity caused additional delays in the implementation of the Girl Roster in those areas as well as delays in paying the salaries of the community workers. Despite the above-mentioned challenges, community workers were able to complete the work in the Bekaa region.

The challenges encountered by B\&Z staff included not being able to complete rostering in two neighborhoods because of security concerns, encountering many empty households (as many Syrian refugees go back and forth to Syria), and not being able to work when it was raining, particularly in Shatila camp due to the exposed electricity wires. Despite these obstacles, the community workers collected information vital to program decisions on more than 6,000 girls. 


\section{The Learning Circle}

The current humanitarian system in Lebanon has become overstretched as a result of cuts in funding, limited resources, the dynamic setting, and political turmoil. All of these factors have implications on the humanitarian system's efficiency in addressing the refugees' needs. Many NGOs and UN agencies work on similar programs targeting the same populations, but the lack of transparency results in wasting resources and decreasing the efficacy of such programs.

The first meeting for the Learning Circle, convened by the Council, was held in October 2019 and included the following NGOs/ agencies: Women Now NGO; Basmeh and Zeitooneh NGO; Jusoor NGO; Mercy Corps; and the Arab Institute for Women (The Lebanese American University).

Each of those NGOs/agencies was approached individually by the Population Council to discuss their willingness to take part in this Learning Circle initiative and discuss ways to collaborate with other actors on the ground and improve the efficiency of their programs targeting adolescent girls.

At this first meeting, the main topics of discussion were: 1) the main areas of work for each of these actors, particularly programs for adolescent girls; 2) challenges faced on the ground; 3 ) the promise/potential of a Learning Circle; and 4) the aims and aspirations for future meetings, particularly addressing the competitive inefficiency and wasteful competition as described in a Guardian article discussing ways to fix the aid system (Chonghaile and Rankin 2016).

All participants mentioned that one of the main challenges is the recent cut in funds, which resulted in a discussion on finding innovative ways that NGOs can complement each other's work and ways to collaborate. Some participants discussed potential initiatives to raise joint funding. Other challenges raised by some of the participants were the difficulty in accessing some communities and dealing with the swawishs.
In April 2020, a second meeting was held remotely due to the COVID-19 pandemic. The main purpose of the meeting was to discuss potential and successful adaptations of existing programs for adolescent girls given the political, economic, and health/COVID challenges.

The third meeting was also held remotely in June 2020. The main purpose of the meeting was to identify the best strategies to involve men and boys for gender equality in Lebanon. We hosted a guest speaker from ABAAD NGO who highlighted the NGO's current programs and the best strategies of involving men and boys.

As of August 2020, Lebanon is contending with the conjoint impact of the increase in COVID-19 cases and the devastating aftermath of the August 4 explosion. Both NGOs (WN and B\&Z) have amended some of their activities and are currently focusing on the following:

- Providing online awareness sessions on COVID-19;

- Gender-based violence (GBV) online counseling (given the increase in GBV cases since the lockdown due to COVID-19 as well as a consequence of the economic crisis);

- Participating in relief efforts in their communities as well as in other communities, such as cleaning the rubble in the affected communities and providing basic needs such as food and water.

\section{The Design and Implementation of a Pilot Program for 11-14-year-old Out-of-school Girls and 13-17-year-old Married Girls in West Bekaa and South Beirut}

- Based on the roster results, we are currently designing a pilot program targeting the most-at-risk girls in the rostered locations (11-14-year-old out-of-school girls and 13-17-year-old married young women).

- The content of the program will incorporate elements that will be adapted from existing programs developed by the Population Council as well as additional elements/ 
activities based on the needs of those girls/ women; 20 focus group discussions have been carried out (to date) to identify the needs of the most-at-risk girls/women in those communities to elicit their opinions regarding the content of the sessions and the preferred implementation mechanism, especially given the current political and health challenges in the country that limited their mobility.

- The majority of girls/young women expressed a great interest in participating in such programs.

- $\quad$ The majority were illiterate. Many expressed interest in incorporating literacy programs and vocational training sessions.

- The majority of married young women expressed interest in limiting the number of their children given all the challenges in the country (health, political, and economic), but they have poor access to health services and modern contraception methods. They all expressed interest in a program that will facilitate their interaction with health services.

- $\quad$ Both NGOs are currently in the process of recruiting the mentors who will implement the sessions. The recruitment of the girls will soon follow.

- Given the restrictions/concerns related to the COVID-19 pandemic, the following activities/precautions will be applied once the program starts:

- $\quad$ There will be ongoing weekly online training sessions for the mentors.

- $\quad$ For girls living inside the ITS in West Bekaa, the sessions will take place outside the farming season (as most of those girls work in agriculture) and inside the ITS to maximize attendance and decrease the risks of COVID-19 transmission.
- The sessions for girls living outside the settlements will be carried out at the WN community center in a large room with fewer girls to maintain social distancing.

- Similar approaches will be followed for mentors and girls in South Beirut.

- Male authority figures in the girls'/ women's lives will not prevent their participation as long as the sessions are carried out in female-only spaces for all girls, inside the ITS (for girls living in the ITS), and as long as transportation (bus with a female mentor on board) is provided for girls living outside the ITS.

To read the full report, contact: rima. mourtada@yahoo.co.uk.

To learn more about Women Now for Development, visit: https://women-now. org/.

To learn more about Basmeh \& Zeitooneh, visit: https://www.basmeh-zeitooneh.org/.

To learn more about this project, visit: https://www.popcouncil.org/research/ expanding-capacity-to-serve-at-riskadolescent-girls-and-young-women-in-the. 


\section{Practitioner Report 18}

\section{Proactive Engagement with the Intentional Design and I'm Here Approaches to Ensure Programming Responds to the Needs of the Most Vulnerable Adolescents in Gaziantep, Turkey}

By Amy Ibold, Altunay Özatay, Omar Robles, Karen Scriven, Matt Streng, and Amie Wells

\begin{tabular}{|c|c|}
\hline Findings and Decisions & Implementation Observations and Adaptations \\
\hline $\begin{array}{l}\text { Among Syrian (largely refugees within the last } \\
24 \text { months) and Turkish (native-born) girls living } \\
\text { within the catchment area around the Mercy } \\
\text { Corps Community Information center, there were } \\
\text { significant variations between each ethnic group's } \\
\text { school-going status and language abilities. The vast } \\
\text { majority of out-of-school girls in the community } \\
\text { were Syrian, and virtually all were married or } \\
\text { engaged (15-17-year-olds). None of the } 53 \text { very } \\
\text { young married girls or married young women (on } \\
\text { which information was available) were in school. } \\
\text { There was an ample supply of potential mentors, } \\
\text { young women aged 18-24 years with the likely skills } \\
\text { to become mentors. } \\
\text { Boys and girls both expressed psychosocial } \\
\text { concerns but they identify them differently vis-à- } \\
\text { vis context. Girls spoke much more about feeling } \\
\text { isolated and shy and wanting more social contact, } \\
\text { whereas boys solely referenced social activities and } \\
\text { opportunities to play sports. } \\
\text { While including and honoring both Turkish and } \\
\text { Arabic speakers, CBOs/civil society created more } \\
\text { social cohesion among the refugee and host } \\
\text { populations and encouraged access by both to the } \\
\text { refugee service center. } \\
\text { Adolescent Syrian boys, like girls, needed more } \\
\text { informal education including financial literacy, and } \\
\text { boys needed dedicated content to foster "gender- } \\
\text { equitable masculinities"-notions of masculinity that } \\
\text { promote norms, attitudes, and patterns of behavior } \\
\text { for boys and young men that help them develop } \\
\text { more equitable attitudes that benefit girls and } \\
\text { young women. }\end{array}$ & $\begin{array}{l}\text { The Girl Roster laid the foundation for segment- } \\
\text { specific focus groups with adults, especially } \\
\text { mothers, and boys and girls (segmented by age, } \\
\text { ethnicity, and scholarship). } \\
\text { In focus group discussions (knowing that access } \\
\text { issues were both geographic and social), adolescent } \\
\text { girls and mothers were asked when girls would } \\
\text { be most able to access the youth center. They } \\
\text { responded: weekends, especially Saturdays. }\end{array}$ \\
\hline
\end{tabular}


FIGURE 1. I'M HERE APPROACH AND TOOLS TO FACILITATE IMPLEMENTATION

\section{I’m Here Approach}

\author{
Identify the crisis-affected \\ community
}

Make visible the context-specific

profile of adolescent girls

Hold group meetings with girls of similar vulnerabilities or capacities

Elaborate plans responsive to girls' needs, risks and capacities

Rally support across humanitarian sectors and local communities

Engage the capacities of adolescent girls

\section{... and Tools \\ to facilitate implementation!}

Service-area mapping

Girl Roster

Focus groups Participatory

Ranking Methodology

Outputs + Emergency Girl

Analysis Matrix (eGAIM)

\section{Background | Why the Intentional Focus on Adolescents?}

Mercy Corps opened a community information center in Gaziantep, Turkey, in 2015 that aimed to serve both the refugee and host communities. Its mission was to provide a safe and inclusive space to give credible information about services and to offer trainings, workshops, coordination meetings, and community-centered activities for the diverse population of vulnerable people in Gaziantep.

Mercy Corps was committed to ensuring that the center was responsive to the needs and protection risks of the diverse populations it served, including adolescent girls and boys. However, we knew from experience that opening a center or offering services in a designated location does not mean the intended population will ever use them. For example, adolescents from more advantaged households are more likely to learn of and access the services. Traditional outreach efforts miss the most vulnerable adolescents and youth who would most benefit from the services, as well as the social cohesion that it can provide. Many adolescents, varying by age, gender, ethnicity, and marital status, have additional status-specific access barriers that must be considered, such as the day and time when services are offered, or the need to ensure an acceptable staff profile (e.g., female staff are present for girl-focused activities). Too often, well-intentioned efforts fail to provide the mostneeded services to those most in need.

Mercy Corps and partners were and are committed to changing the status quo. Reaching "the most vulnerable" requires giving this term context-specific meaning:

- Who lives in our community? How many adolescents?

- What ages and what sex?

- Within the community, where is the center situated?

- What adjunct resources are available to adolescents? What portion of adolescents is in school versus out of school? 
- How many adolescents work?

- Does vulnerability differ based on citizenship or sex? Additionally, how do adolescents with different challenges and capacities use different words to express their concerns and needs?

Answers to these questions matter. This report outlines key steps that Mercy Corps has taken to identify the adolescents in the Gaziantep community and to learn about their biggest vulnerabilities, needs, and capacities. The report reviews key outputs and findings for each step and then notes the key implications for programming gathered at the time.

\section{The Intentional Design "I'm Here" Approach: What Mercy Corps Did To Be More Responsive to the Internal Heterogeneity of Adolescents in a Refugee Zone}

In February 2015, Mercy Corps, with support from the Women's Refugee Commission (WRC) within the broad framework of the Girls in Emergencies Collaborative, implemented in Gaziantep the first door-to-door application of the I'm Here approach in an urban refugee setting (see Figure 1). Implementation included piloting the Population Council's Girl Roster in this context. Implementation took place within an estimated half-mile radius of the Mercy Corps Community Information center.

Within this area, the team completed a servicearea mapping of facilities, while also mapping adolescent girls in the catchment area by their status-schooling, social, family, marital, childbearing situations. Subsequent to this rostering, the team conducted targeted focus group discussions. The team applied the approach and generated key outputs to program design within four weeks. The three-step process is summarized as follows.
STEP 1 | Identifying the community: What resources already exist within the community?

During this step, the implementation team used the My Tracks mobile application ${ }^{1}$ to visually represent the local population in service-area mapping. The rationale for this action was to define with some specificity the community where the center is situated, with an emphasis on key services and public spaces within the community that exist within walking distance of where adolescent girls and boys live.

\section{STEP 2 | Mapping the context-specific profile of girls: Who are the girls living in the catchment area near the center?}

Tailoring the Girl Roster to the context of Syrians and Turks in Gaziantep, additional questions recorded included: 1) the day of the week girls would mostly likely visit the center; 2) the respondents' citizenship; 3) boys' and young men's school enrollment and employment status; 4) if females older than 12 years were not only married or single, but also if they were engaged; and 5) the work status of girls and young women. In an effort to keep the questionnaire brief, the criterion for adding questions to the Roster was whether responses would yield significant actionable information and remain "nonsensitive."

\section{STEP 3 | Holding targeted focus groups: What do girls and parents with similar experiences have to say?}

Based on results from the Girl Roster, the implementation team facilitated targeted focus group discussions with specific segments (e.g., Syrian girls aged 10-14 out of school), using the Participatory Ranking Methodology (PRM) developed by Columbia University's Program on Forced Migration and Health for use in emergency contexts.

${ }^{1}$ MyTracks no longer exists, but any fully functional GPS tracking application could supplant MyTracks. 
FIGURE 2. COMMUNITY RESOURCE SCAN

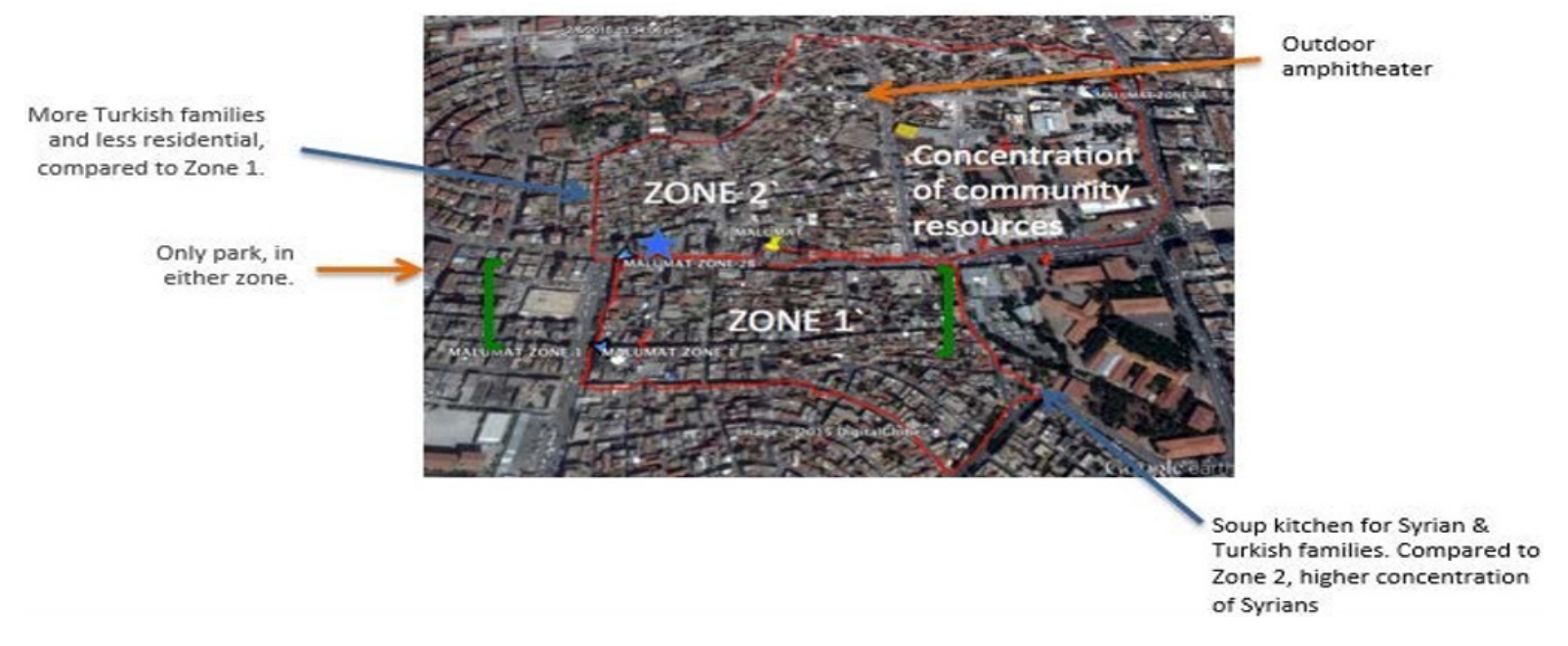

Key Findings and Outputs | What Kind of Information Came Out of This Approach?

This section outlines the key outputs and findings-many of which were unexpectedfrom the tools used in these three steps.

\section{STEP 1 | Key findings while identifying the community}

The Community Resource Scan (see Figure 2) visually captured the center's location in relation to two elements: the institutions that Mercy Corps might partner with and girls' locations. This information was used for the identification of where to refer program participants and how to strengthen content. The information gathered using the mobile My Tracks application was helpful in determining where there were unused or underutilized facilities and services to which adolescents-girls in particular-may have rights, but not access. The main output from this activity was a visual representation of the catchment area, including key service points and public spaces within it.

Key findings from this step include:

- The limited number of public spaces where children and adolescents can safely gather.
- The distance between where a majority of Syrians live (Zone 1) and where community resources are concentrated (Zone 2 ), across a high-traffic avenue along which the center is located.

- The high concentration of mechanic shops in Zone 1 that could become potential partnership opportunities that introduce adolescent girls and boys to the automotive industry (but could be unsafe-pending further study for girls).

\section{STEP 2 | Key findings from mapping the context-specific profile of girls}

In Stage 4, 1,317 households within an estimated half-mile radius of the center were interviewed (between 250 and 350 a day) (see Figure 3). The implementation team that systematically went through each community zone varied daily, ranging from three to five two-person groups. Within mixed-sex rostering pairs, one member spoke Arabic and one spoke Turkish.

During implementation, the team occasionally relied on three-person groups to provide additional security (e.g., when two individuals entered a narrow alley or an apartment building, one team member remained attentive to people entering and leaving the area). 
TABLE 1. GIRL ROSTER RESULTS FOR TURKISH POPULATION ONLY

\begin{tabular}{|c|c|c|c|c|c|c|c|}
\hline \multirow[b]{3}{*}{$\begin{array}{l}\text { Age } \\
\text { group }\end{array}$} & \multicolumn{4}{|c|}{ Unmarried } & \multicolumn{3}{|c|}{ Married/Or has a child } \\
\hline & \multicolumn{2}{|c|}{ In School } & \multicolumn{2}{|c|}{ Out of School } & \multirow[b]{2}{*}{ Has a child } & \multirow[b]{2}{*}{$\begin{array}{c}\text { Does not } \\
\text { have a child }\end{array}$} & \multirow[b]{2}{*}{ Total } \\
\hline & $\begin{array}{l}\text { Living } \\
\text { with both } \\
\text { parents }\end{array}$ & $\begin{array}{l}\text { Living with } \\
\text { just one } \\
\text { or neither } \\
\text { parent }\end{array}$ & $\begin{array}{l}\text { Living } \\
\text { with both } \\
\text { parents }\end{array}$ & $\begin{array}{l}\text { Living with } \\
\text { just one } \\
\text { or neither } \\
\text { parent }\end{array}$ & & & \\
\hline $6-9$ & 37 & 0 & 1 & 0 & & & 38 \\
\hline $10-14$ & 48 & 4 & 1 & 0 & 0 & 0 & 53 \\
\hline $15-17$ & 29 & 2 & 3 & 0 & 0 & 1 & 35 \\
\hline $18-20$ & 19 & 2 & 3 & 0 & 6 & 2 & 32 \\
\hline TOTAL & 133 & 8 & 8 & 0 & 6 & 3 & 158 \\
\hline
\end{tabular}

TABLE 2. GIRL ROSTER RESULTS FOR SYRIAN POPULATION

\begin{tabular}{|c|c|c|c|c|c|c|c|}
\hline \multirow[b]{3}{*}{$\begin{array}{l}\text { Age } \\
\text { group }\end{array}$} & \multicolumn{4}{|c|}{ Unmarried } & \multicolumn{3}{|c|}{ Married/Or has a child } \\
\hline & \multicolumn{2}{|c|}{ In School } & \multicolumn{2}{|c|}{ Out of School } & \multirow[b]{2}{*}{ Has a child } & \multirow[b]{2}{*}{$\begin{array}{l}\text { Does not } \\
\text { have a child }\end{array}$} & \multirow[b]{2}{*}{ Total } \\
\hline & $\begin{array}{l}\text { Living } \\
\text { with both } \\
\text { parents }\end{array}$ & $\begin{array}{l}\text { Living with } \\
\text { just one } \\
\text { or neither } \\
\text { parent }\end{array}$ & $\begin{array}{c}\text { Living } \\
\text { with both } \\
\text { parents }\end{array}$ & $\begin{array}{l}\text { Living with } \\
\text { just one } \\
\text { or neither } \\
\text { parent }\end{array}$ & & & \\
\hline $6-9$ & 20 & 2 & 58 & 7 & & & 87 \\
\hline $10-14$ & 50 & 9 & 35 & 8 & $\mathrm{O}$ & $\mathrm{O}$ & 102 \\
\hline $15-17$ & 26 & 11 & 13 & 3 & 5 & 10 & 68 \\
\hline $18-20$ & 12 & 1 & 11 & 1 & 22 & 7 & 54 \\
\hline TOTAL & 108 & 23 & 117 & 19 & 27 & 17 & 311 \\
\hline
\end{tabular}

\section{FIGURE 3. STAGE 4 ROSTER PARTICIPATION OVERVIEW}

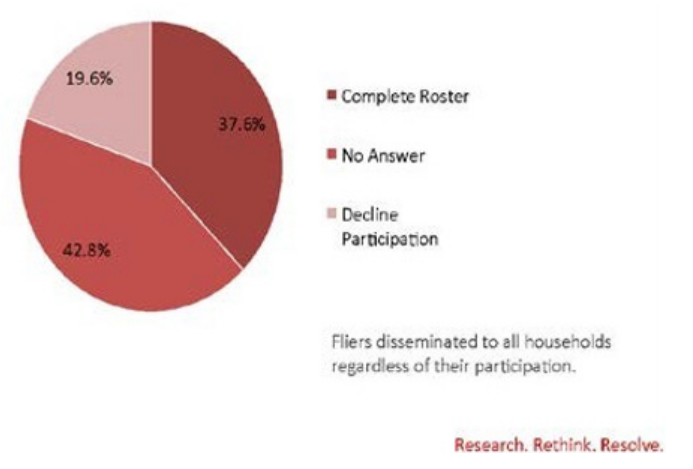

After producing one table that collapsed results from Syrian and Turkish families, the implementation team chose to generate two tables, sorting adolescent girls' top-line vulnerabilities, needs, and capacities based upon their household nationality (see Tables 1 and 2).

Key findings from this step include:

- Significant differences between the profiles of Syrian and Turkish girls (6-17 years).

- For example:

- Syrian girls accounted for $96.1 \%$ of out-of-school girls in the community. Among in-school girls, Syrians accounted for nearly half (49.6\%). 
FIGURE 4. PRIORITIZATION OF ADOLESCENT GIRLS' CONCERNS AS IDENTIFIED BY

OUT-OF-SCHOOL SYRIAN ADOLESCENT GIRLS (10-14), SYRIAN MOTHERS, AND TURKISH

MOTHERS. GAZIANTEP, TURKEY, FEBRUARY 2015

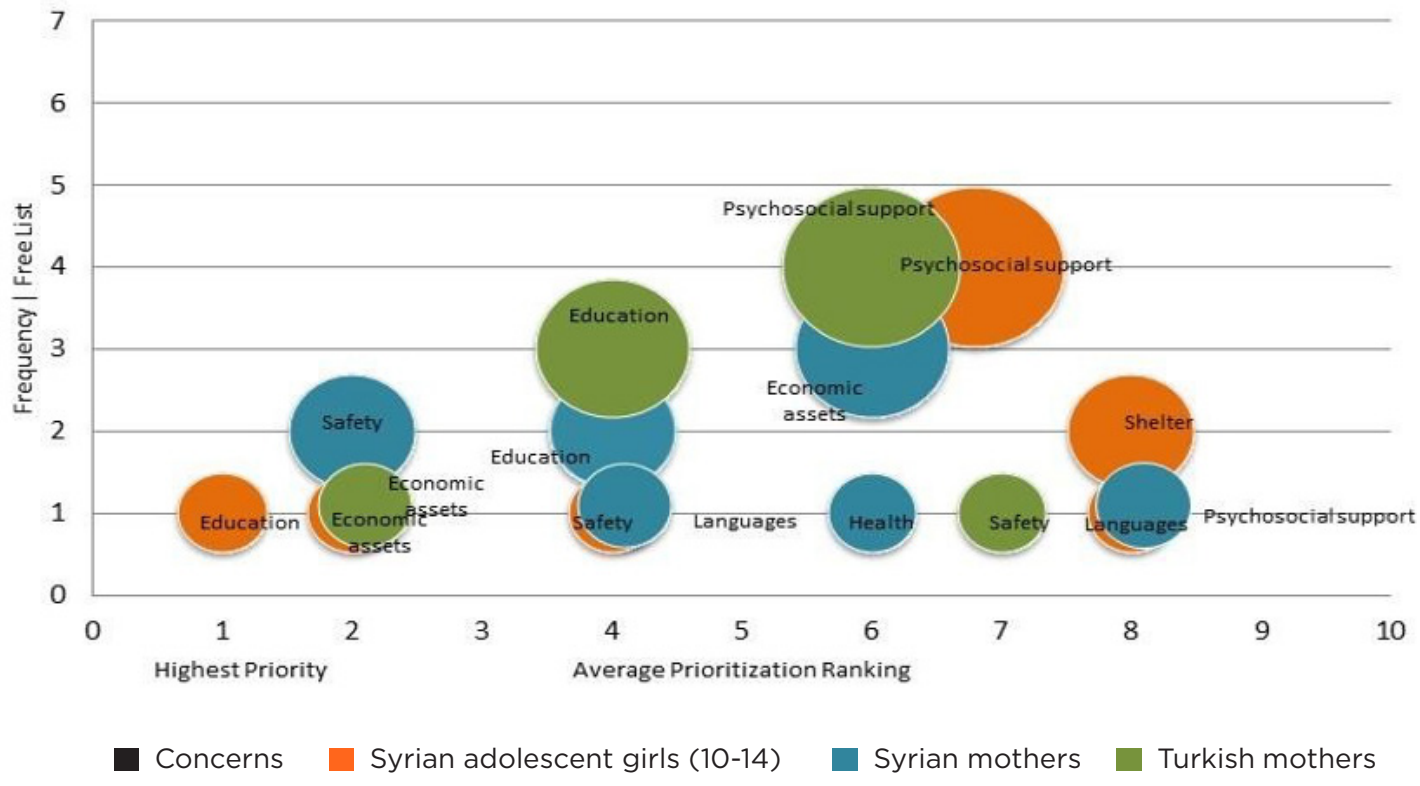

- 16 girls (15-17 years old) in the community were married or engaged -15 of these girls are Syrian and 11 of them (including the Turkish girl) did not yet have children.

- The number of married women (18-20 years old) was larger among Syrians as compared to Turkish girls -29 and 8 , respectively.

- None of the married girls were attending school at the time they were rostered:

- Of the 53 girls and young women who were married, available information on 40 of them revealed that none were in school and 31 were not adults.

- More Syrian boys at every age category (6-17 years old) were out of school than attending school.

- The ratio of boys who did not attend school but worked was higher in late adolescence (15-17 years old) as compared to childhood (6-9 years old) or early/mid adolescence (10-14 years old).

- Adult respondents stated that girls in their households would access the center on weekends rather than weekdays, with a preference for Saturday over Sunday.

- Average number of entries was more than double for Saturday and Sunday, over weekdays.

STEP 3 | Key findings from the targeted focus groups with adolescents by gender and age, and mothers by ethnicity, to assist program design

Based on results from the Girl Roster, the implementation team facilitated targeted focus group discussions. In one day, the field team facilitated Participatory Ranking Methodology discussions with: Syrian out-of-school 
adolescent girls (10-14 years old, $n=10$ ); Syrian mothers ( $n=11)$; out-of-school Syrian adolescent boys (10-14 years, $n=7$ ); and Turkish mothers $(n=7)$ (see Figure 4).

Key findings from this step include:

- Out-of-school Syrian adolescent girls and boys asserted that education and economic support were priorities.

- While adolescent girls and boys both frequently referenced the need for psychosocial support, girls and boys selfexpressed their concerns differently, e.g., girls referenced feeling isolated and shy and expressed a desire for more social activities with other girls and their parents, while boys solely referenced social activities, specifically opportunities to play sports.

- Girls' and boys' distinctive prioritizations, however, were not the only takeaway. Syrian girls and Turkish mothers, for example, referenced psychosocial support the greatest number of times. Girls expressed feeling isolated, wanting opportunities to interact with friends and parents away from the home, lacking an area to play, and feeling shy. Mothers-Turkish and Syrianreferenced their daughters "introversion."

- $\quad$ Syrian and Turkish mothers noted the limited number of safe public spaces in the community.

Program considerations | How is Mercy Corps acting on these findings?

The service map, the Girl Roster results, and the information generated from the focus group discussions enabled Mercy Corps to:

1. Modify outreach initiatives;

2. Build community partnerships;

3. Create or strengthen adolescent-friendly referrals;

4. Develop complementary programming to be more responsive to the profile of adolescent girls and boys in the community, with an emphasis on the tailored programs that take into account the area-specific (in a high-density area) vulnerabilities of the population by age, gender, and ethnicity.

As the Mercy Corps team developed its operations and services, some program quantitative and qualitative information gathered during rostering in the follow-up focus groups suggested the following options. (Also see Box 1 for steps to create a safe space for girls.)

\section{For adolescent girls:}

- Design and modify asset-building programming to the unique profile of Syrian and Turkish adolescent girls who live around the center. No population of adolescent girls is homogenous. However, a more useful profile of adolescent girls who live near the center is revealed when information is sorted by citizenship.

Specifically, Syrians accounted for a larger proportion of out-of-school girls. Turkish girls certainly had school-related concerns and needs; however, there were differences in baseline needs and capacities between Syrian and Turkish girls. Parents and girls themselves-Syrian and Turkish-also referenced a need for psychosocial support and opportunities to interact with others. Mercy Corps should modify activities accordingly, e.g., focusing on participatory ways to build the more often out-ofschool Syrian girls' life skills and literacy competencies (in Arabic and Turkish), while addressing Turkish girls' school-related curricula through similar methods. As the center works with Syrian and Turkish girls, the youth team can identify and build upon their common experiences, challenges, and aspirations, and then identify/frame services around common challenges and concerns expressed by Syrian and Turkish families. This also includes creating a feedback mechanism that engages and involves the Syrian and Turkish adolescent girls on programming. 


\section{BOX 1. CREATING A SAFE SPACE FOR} GIRLS

Mercy Corps has taken several steps to make its community center safe for girls, including:

- Opening on Saturdays

- Creating girl-only activities and classes for adolescents

- $\quad$ Scheduling girls' activities/classes at specific times or ensuring they are on separate floors from adults/boys when times overlap

- $\quad$ Ensuring the presence of female staff and volunteers with girls whenever they are present

- Offering transportation for girls under the age of 14

- $\quad$ Creating a female-only prayer room and breastfeeding/relaxation room.

- Young women-Syrian and Turkishcould serve as mentors for girl-centered programming. There were 86 Syrian and Turkish young women 18-24 (54 Syrian, 32 Turkish) in the half-mile radius of the center who could serve as mentors, volunteers, or staff, and several women who lived near the center who had completed secondary school. Additionally, some already-married women could also support programs and outreach efforts.

- Partner with both Turkish and Syrian identified civil society organizations (CSOs) so the center becomes a liaison and valued resource for all ethnicities and avoids being labeled a resource for Syrians only. The implementation team was previously familiar with several service-based organizations. The community mapping, however, brought several communitybased organizations to staff's attention.
Mercy Corps could partner with select CSOs to coordinate community outreach or joint activities for adolescents. Since Turkish families were less engaged during activity implementation and these CSOs likely have built up capital and trust with the community, particularly with Turkish families, strategic partnerships could enable the center to recruit Turkish mentors and promote social cohesion between Syrian and Turkish adolescents.

- Verify that referral partners have the capacity to provide adolescent-friendly information and services to Syrians and Turks. Central to the center's mission was its ability to link community members to health and social services. In keeping with its commitment to safely serve adolescent girls, Mercy Corps should research partners' capacity to deliver adolescent-friendly services that are void of stigma and discrimination. This action may require additional time and resources, including building key partners' capacity to deliver such services, e.g., health clinics.

For adolescent boys:

- $\quad$ Create time and space for Syrian adolescent boys to convene in settings that: 1) offer nonformal education; 2) promote genderequitable masculinities; and 3) build their financial literacy. Girl Roster results find that most boys are not attending school, and one-third of adolescent boys (10-17) are working and not attending school.

\section{Conclusion}

The I'm Here and similar Intentional Design approach aligned with Mercy Corps' commitment to find and reach the most marginalized adolescents. In Gaziantep, the approach provided valuable insights into the diverse needs of Syrian and Turkish adolescent girls and their caregivers. In response, Mercy Corps expanded the offerings of its youth center to meet needs identified by girls and their caregivers, such as class offerings and open hours at the center. Following this initial 
implementation, Mercy Corps conducted a second I'm Here approach implementation in Gaziantep that was inclusive of adolescent boys (using the Boy Matrix that was developed in Iraq with WRC and Mercy Corps in June 2015), and sought to illuminate the specific needs of married adolescent girls. Globally, Mercy Corps piloted the approach in Guatemala, Haiti, Iraq, Lebanon, Mali, Nigeria, Syria, and Yemen between 2016 and 2019. Mercy Corps also conducted a qualitative analysis of the strengths and weaknesses of I'm Here through semistructured interviews with teams that implemented the approach. Piloting the I'm Here approach illuminated the overall importance and effort it takes to find and reach adolescents in fragile settings. It was also documented that the I'm Here approach required a substantial amount of time and resources, making it difficult to employ in the first weeks or even months of an emergency. Mercy Corps continues to examine how to best implement the approach (i.e., integrate it into existing assessments, and create criteria for when it should be undertaken).

To learn more, please visit: https://www.mercycorps.org/. 


\title{
Practitioner Report 19
}

\section{Implementation of the Girl Roster in Dompu and Sikka, Indonesia}

\author{
By Audrey Anderson, Marzalena Zaini, Plan International USA, and Plan International Indonesia
}

\begin{tabular}{|c|c|}
\hline Findings and Decisions & Implementation Observations and Adaptations \\
\hline $\begin{array}{l}\text { - Across the villages, which had similar rates of } \\
\text { adolescent pregnancy (through age 19), significant } \\
\text { differences were found in the rate of school-going } \\
\text { and family living arrangements. } \\
\text { - } \quad \text { In one migrant village, } 29 \% \text { of girls aged 10-18 were } \\
\text { living with neither parent owing to their parents' } \\
\text { migration for work. } \\
\text { - The rates of adolescent pregnancy (through age } \\
\text { 19) were similar, but the sources seem to contrast. } \\
\text { In one village, unexpected pregnancy led to school } \\
\text { drop-out and child marriage almost simultaneously. } \\
\text { In Sikka, there was very low school attendance, } \\
\text { but sources were more economically driven than } \\
\text { unexpected pregnancy. } \\
\text { - Married girls in Sikka were more than six times more } \\
\text { likely to have dropped out of school after ninth } \\
\text { grade than those in Dompu. } \\
\text { This information about schooling and the impact } \\
\text { of migration status assisted advocacy with local } \\
\text { governments in, among other things, improving } \\
\text { schooling access in one town and bringing to local } \\
\text { officials the unseen conditions of girls. } \\
\text { In sum, the Girl Roster was most useful in discerning } \\
\text { differences by villages and questions for further } \\
\text { inquiry, and laying the foundation for village- } \\
\text { specific program design and advocacy. }\end{array}$ & $\begin{array}{l}\text { - The application of the Girl Roster followed a } \\
\text { qualitative assessment identifying adolescent } \\
\text { childbearing as a critical issue. The villages are small } \\
\text { but the results (four villages with between } 156 \text { and } \\
377 \text { households, average 267) allowed the team to } \\
\text { discern important differences. } \\
\text { - The local Plan staff easily learned rostering skills. } \\
\text { - The rosterers initially went out in pairs, collecting } \\
\text { information from five pilot houses, then after that } \\
\text { continued on their own effectively. } \\
\text { - The rostering approach took } 17 \text { field officers in one } \\
\text { site, } 15 \text { in another; this process took approximately } \\
\text { one full day to get information on 1,066 households } \\
\text { across four villages. } \\
\text { Program staff and prospective mentors saw the } \\
\text { Roster exercise as an important "viewing" exercise- } \\
\text { that is, an opportunity to really try to "see" the girls' } \\
\text { lives, appreciating differences in villages they had } \\
\text { viewed as homogeneous and adapting their plans. }\end{array}$ \\
\hline
\end{tabular}

\section{Background}

Following a situation assessment conducted in April 2014, adolescent early pregnancy was identified as a critical issue in Dompu and Sikka districts in Indonesia (see Figure 1). Before embarking on a pilot program in adolescent reproductive health (as part of the Community Action to Improve Maternal and Child Nutrition program, connected at that time to Plan's Because I am a Girl-BIAGG campaign), the Girl Roster exercise was implemented in April 2015 to provide more up-close information about the condition of girls in these villages. Given the remote and small geography of the communities, though it generated useful numbers for targeting, the Roster was principally helpful in generating insights
FIGURE 1. MAP OF INDONESIA WITH DOMPU AND SIKKA DISTRICTS HIGHLIGHTED

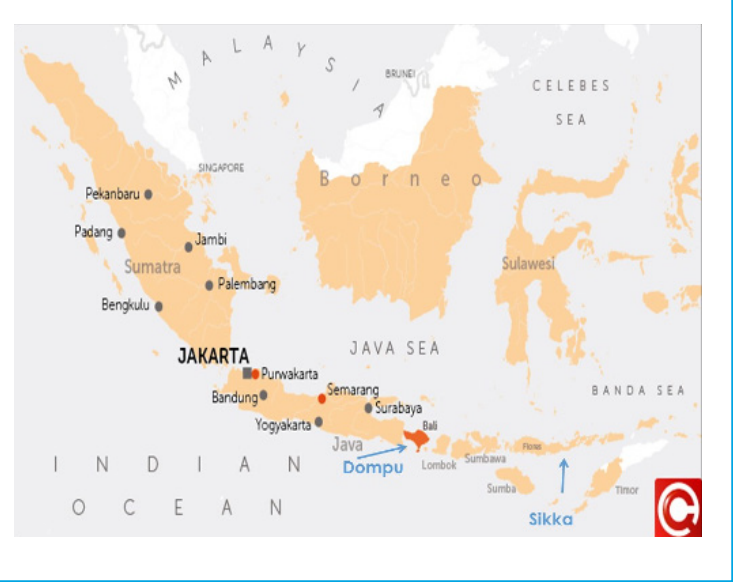




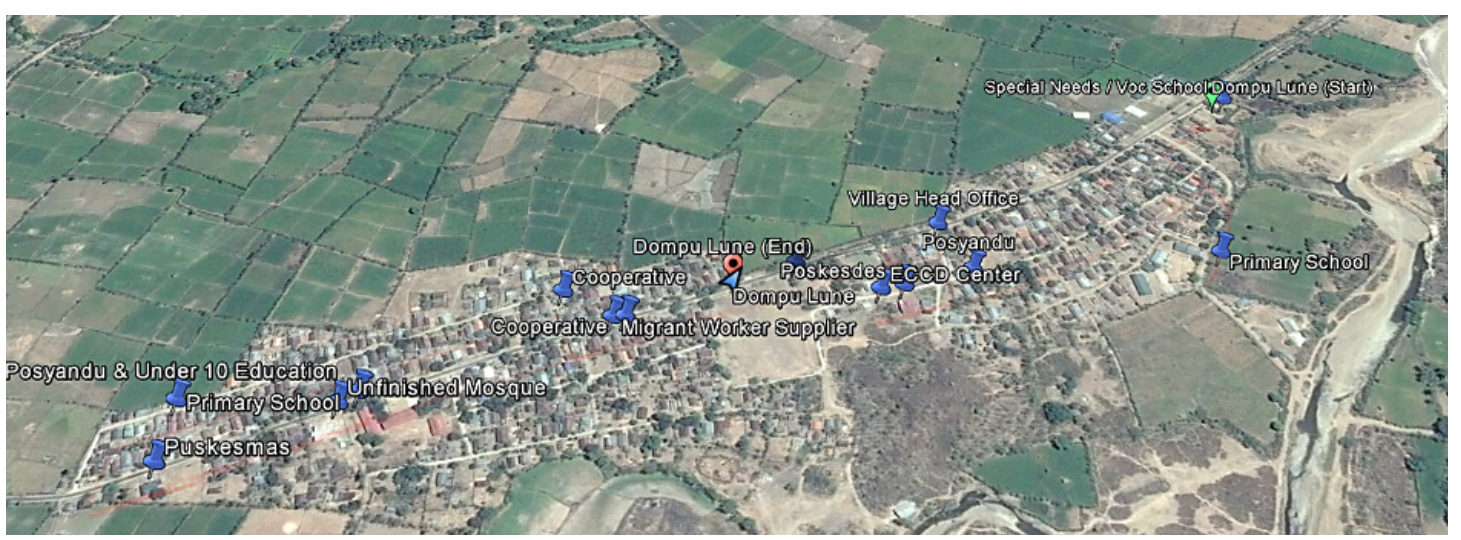

FIGURE 3. THE COMMUNITY RESOURCE SCAN OUTPUT IN ADU VILLAGE, DOMPU

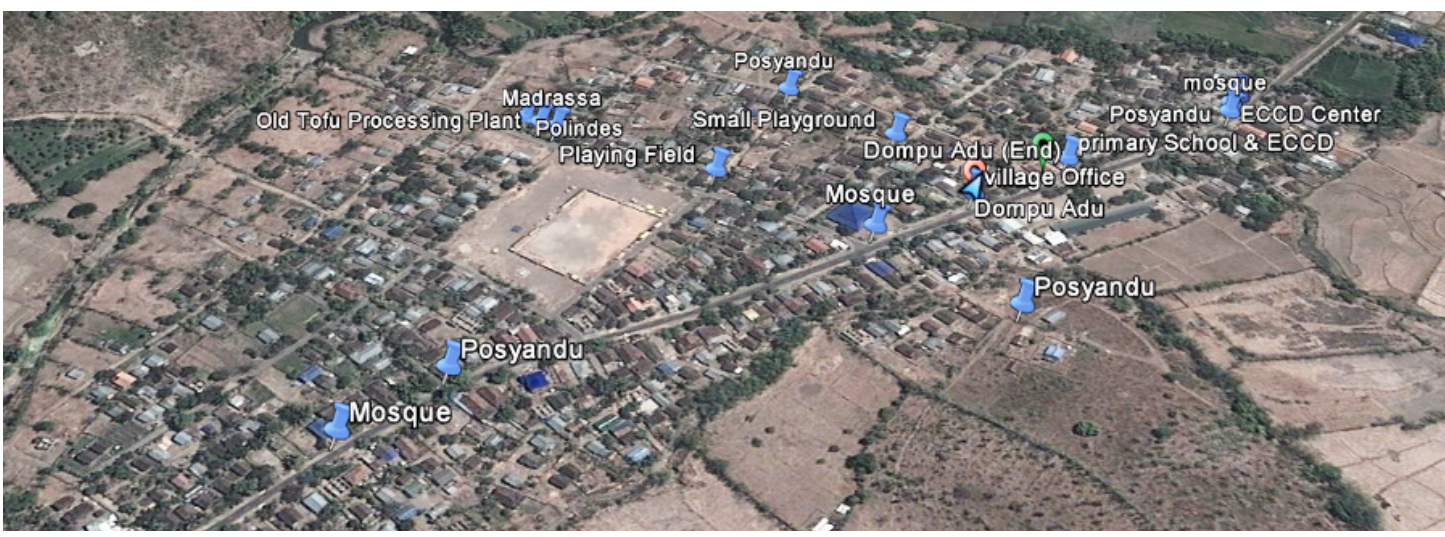

among practitioners who had not focused on the possibility of contrast between villages that, at a glance, seem similarly challenged in terms of sufficient resources. Through the Roster exercise, practitioners became attuned to the differences among girls and the hidden economic burden they were coping with. The Population Council's Girl Roster and Community Resource Scan were deployed using mobile phones in four villages in two districts:

- Lune village, Dompu district

- Adu village, Dompu district

- Wolodesa village, Sikka district

- Loke village, Sikka district

\section{Results of the Community Resource Scan in Dompu and Sikka}

In Dompu district in West Nusa Tenggara, the population is primarily Muslim. Terrain is flat, and most adults are farmers or migrate for work. Even if a village does not have a secondary school, neighboring villages are close by.

In Lune village (see Figure 2), there are two primary schools and one special needs/ vocational school. The junior and senior high schools are in neighboring villages. There are a number of posyandu, or health centers, and girls often gather there. In the center of the village 
FIGURE 4. THE COMMUNITY RESOURCE SCAN OUTPUT IN WOLODESA VILLAGE, SIKKA

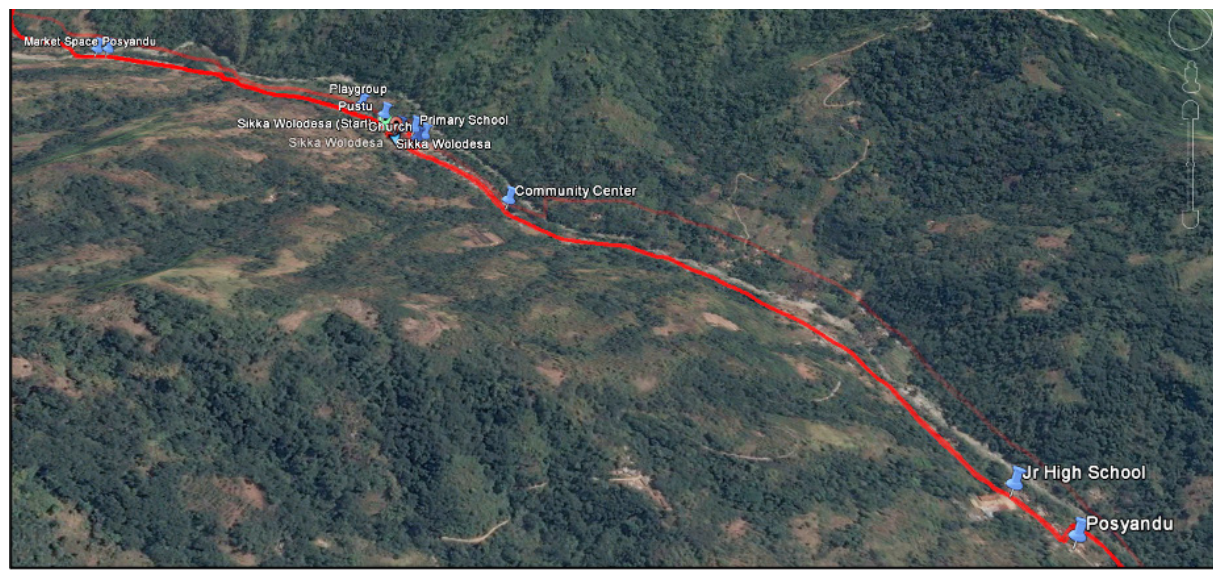

is an office to assist workers in migrating to Malaysia or the Middle East.

In Adu village in Dompu (see Figure 3), there are two Early Childhood Care and Development (ECCD) centers, one primary school and a madrassa (religious school). The junior and senior high schools are in neighboring villages. There are several posyandu where young people gather.

In Sikka district in East Nusa Tenggara, the population is primarily Catholic. Terrain is mountainous, and the villages are remote. Farming and migration are both common in Sikka, and economic opportunities are generally limited.

In both Wolodesa (see Figure 4) and Sikka villages, there is no senior high school. Thus, to attend a boarding school after age 15, girls and boys must move to Maumere town, three to four hours away. This discourages schooling participation, requiring much cost and time.

In Wolodesa village, there is one primary school and one junior high school. Several posyandu and pustu (health posts) exist where young people gather.
Loke village is extremely remote, with mountainous terrain (see Figure 5). There is only one primary school, located at the top of the mountain, and no junior high or high school. Each neighborhood has a posyandu where young people gather.

\section{Rollout of the Girl Roster, Dompu and Sikka}

To contextualize the Roster, the following changes were made:

- Standardized a drop-down menu for the school grades with added options for no school and nonformal school, to ensure consistency in information reporting and to facilitate analysis';

- Asked questions about the age of a girl's oldest child, to calculate her age at first pregnancy;

- Included other options for contact besides a phone number. Many villages were uncomfortable giving a phone number but wanted to be contacted for the program. ${ }^{2}$

\footnotetext{
${ }^{1}$ The standard Girl Roster questionnaire has a drop-down menu option and includes other forms of nonformal schooling that can be contextualized to each context.

${ }^{2}$ To maintain the Girl Roster's use as a programming, not research, tool and particularly to sustain its nonsensitivity, the Population Council no longer permits inquiry about contact information in the questionnaire. Should partners elect to collect these sorts of details, they must do so in tandem but not within the Roster itself.
} 
FIGURE 5. THE COMMUNITY RESOURCE SCAN OUTPUT IN LOKE VILLAGE, SIKKA

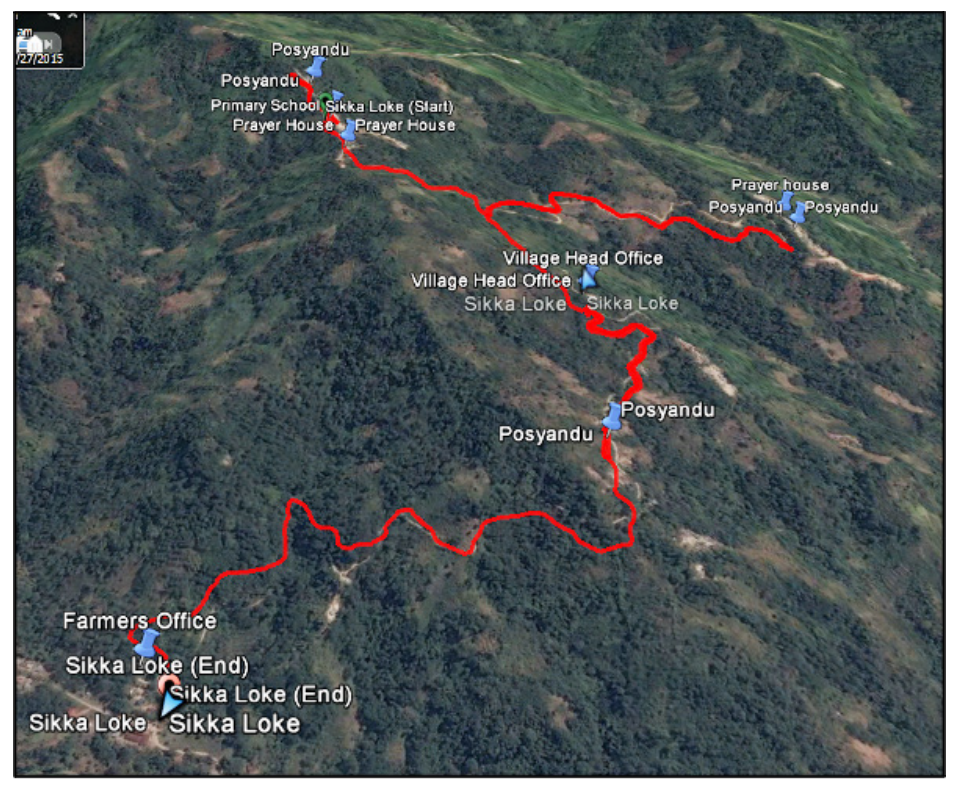

The Roster was piloted in Lune village. The rosterers were all Plan staff from the country office and the Dompu and Sikka Program Units. At first, rosterers went out in pairs and collected information from five houses each. They then decided to continue on their own. Rosterers continued to travel in pairs, but they collected information individually to be more efficient.

\section{Girl Roster Results Overview}

Seventeen field officers collected information in Dompu, and 15 in Sikka. Each village took approximately one full day, with one day reserved after the pilot to adjust as needed. In total, information was collected on 1,066 households across the four villages, with 759 girls and 700 boys in the target age range of 10-24 years (see Box 1).

Field officers responded positively to the process of rostering and gave feedback:

- "A woman leader from the village accompanied me. It some ways it was very helpful, since she knows the layout of the village and the people. But she was reluctant to say that a young girl had children. I met one girl who looked about 19 or 20 and had two children, but the woman from the village insisted that she was 27 or 28."

- "A major challenge was the age. Many people don't know their age."

- "Now that we have the information from the Girl Roster, we know how to plan for the next phases."

- "We can use this information for advocacy with the local government to make a change."

\section{Girl Roster Results: Education}

In general, education levels were high in Dompu and low in Sikka. Of girls aged 18-24 in Dompu, nearly all (86\%) had attended at least one grade of high school, compared to only a third of girls in Sikka.

The villages of Dompu and Sikka were different from each other with respect to educational 


\section{BOX 1. GIRL ROSTER ROLLOUT OVERVIEW}

Lune village, Dompu district: 358 households with 259 girls and 262 boys aged 10-24.

Adu village, Dompu district: 377 households with 198 girls and 179 boys aged 10-24.

Wolodesa village, Sikka district: 175 households with 186 girls and 128 boys aged 10-24.

Loke village, Sikka district: 156 households with 116 girls and 131 boys aged 10-24.

attainment; young women aged 18-24 were four times more likely to drop out of school (68\%) in Sikka than in Dompu (see Figure 6). In both sites, boys and girls had similar dropout rates; that is, it varied more by location than gender. The implications of school dropout were different for girls than boys-becoming pregnant while still a child and being married, and, in many cases, carrying heavy economic responsibility for children at a young age.

In both villages in Sikka district, education was limited. Loke village had the lowest levels of education, with many girls and boys dropping out even in primary school, and about half of girls 15-17 years old already having dropped out of school (see Figure 7). There was only one primary school in Loke, located at the top of a mountain more than an hour's hike for some girls in the village. For junior high school, girls had to travel to a different village, and for senior high school, they needed to move to a boarding school in Maumere town, at least three hours away by public transportation.

Informal feedback from the rostering participants indicated that, although school was technically free, there was no teacher available in the area. To send their children to school, the villagers had to pay to bring in a teacher
"Parents think that education isn't good for children; it just keeps them from making money."

-Plan staff in Sikka district

"The problem is that girls get pregnant before they get married. There's nothing we can do about that."

-Village leader in Adu, Dompu, where $100 \%$ of married girls already have children or are pregnant

from an outside area. Since there were few employment opportunities outside of farming, parents were not highly motivated to send their children to school.

\section{Girl Roster Results: Marital Status}

The rates of early marriage were similar between Dompu and Sikka, at $26 \%$ and $20 \%$ of girl school dropouts aged 18-20 years. In both districts, there were a few cases of marriage/ pregnancy at age 16 or 17, although this was not common. Several 20-year-old girls already had two or more children, however. In Dompu, there were several girls who had been previously married and were either divorced or widowed.

There were no cases of boys married before age 20 in either Dompu or Sikka.

In Dompu district, it is more common for married girls to have children than in Sikka. In Adu village in Dompu, all married girls already had children or were pregnant. This information suggests that girls in Adu village, and Dompu in general, were only getting married in the case of unexpected pregnancy. In Sikka however, only $67 \%$ of married girls aged $18-20$ had children.

The disparity in education status between Dompu and Sikka is even more pronounced among married girls, who are six times more 
FIGURE 6. GIRLS AGED 18-24 WHO

DROPPED OUT BEFORE HIGH SCHOOL

ACCORDING TO ROSTER RESULTS

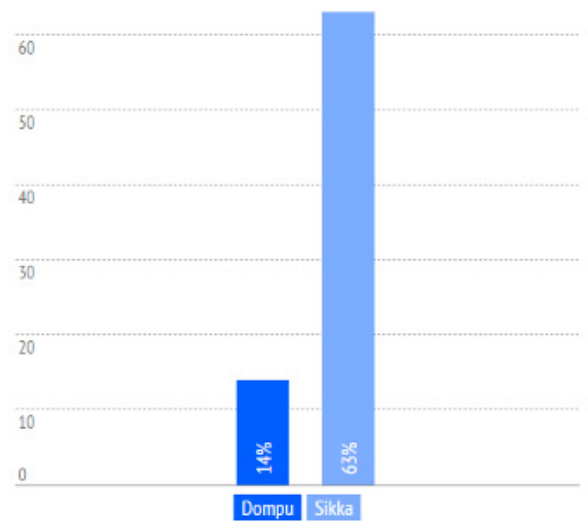

FIGURE 8. MARRIED GIRLS AGED 18-20 WHO HAD DROPPED OUT BEFORE HIGH SCHOOL

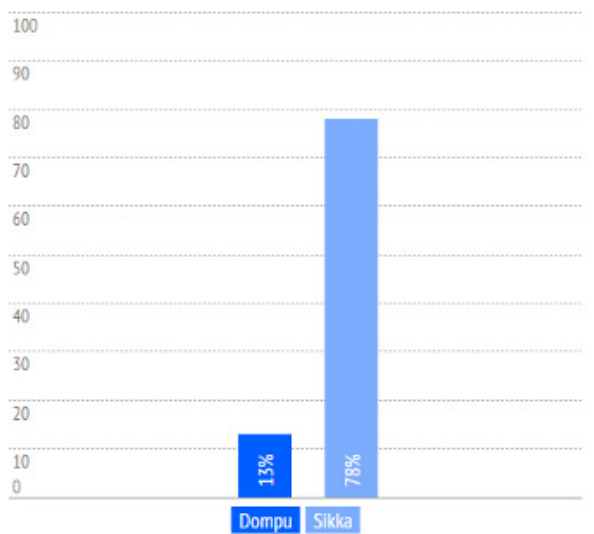

likely to drop out of school after the ninth grade in Sikka than in Dompu (Figure 8).

Although the rates of early marriage in Dompu and Sikka were fairly similar, the root causes appeared to be different. In Dompu it appeared that unexpected adolescent pregnancy led to forced early marriage and school dropout. In Sikka, the sources appeared more complex, a combination of limited access to school and
FIGURE 7. EDUCATION STATUS OF GIRLS AGED 15-17 IN LOKE VILLAGE

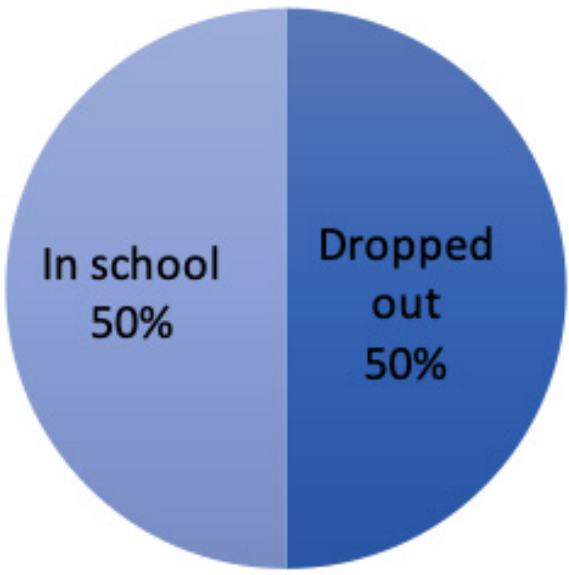

FIGURE 9. LIVING SITUATION OF GIRLS AGED 10-18 IN WOLODESA VILLAGE, SIKKA

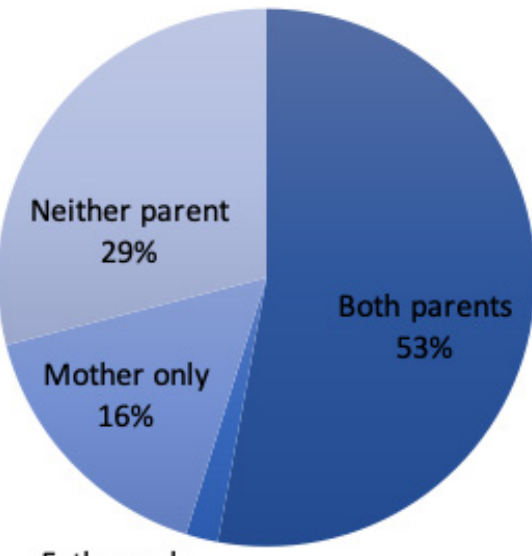

Father only

$2 \%$

limited employment options connected to higher education, along with a lack of sexual/ reproductive health information and services.

\section{Girl Roster Results: Living Situation}

In three villages, roughly three out of four girls lived with both parents. Most of the remaining girls lived with just their mother or neither parent. However, in Wolodesa village in Sikka, 
"Migration is very common. Parents think a local job isn't 'real work,' if you haven't migrated."

-Plan staff in Wolodesa village, Sikka

only a little over half of all girls were living in two-parent households, and $29 \%$ of girls were living with neither parent (Figure 9).

Migration was listed as the main reason for parental absence. With limited employment options, one or both parents were likely to migrate to Malaysia or the Middle East for work.

Respondents reported girls as young as 16 living by themselves and looking after their younger siblings, while their parents lived abroad for work.

\section{Recommendations for Program Learning and Design}

Implementation of the Community Resource Scan and the Girl Roster in Dompu and Sikka revealed the following:

- The location of key physical assets that girls could access as potential safe spaces;

- The location and quantity of girls who were off-track (e.g., married, out of school, living without parents) to recruit for the program;

- The likely root causes of early pregnancy/ marriage in Dompu and Sikka to tailor programming.

The Better Life Options and Opportunities Model (BLOOM) was the core content to be delivered through the program. BLOOM covers reproductive health, access to services, assertive communication, financial literacy, and the importance of an education. In Sikka, mentors emphasized the financial literacy and education modules, while in Dompu, mentors emphasized reproductive health and access to services.
"Girls should learn about the dangers of early marriage, because it makes them drop out of school."

-Rathi, age 16, Dompu district

Potential challenges and future directions:

- $\quad$ Dompu and Sikka districts are quite conservative and may resist reproductive health programs for adolescents. The information provided from the Girl Roster can be used as an advocacy tool for reproductive health and education with local governments to strengthen commitment to the program.

- Families in Sikka reported the following reasons for keeping girls out of school: poverty and school fees, distance of school, and low quality of school with no connection to improved livelihoods.

- To address the extreme problems in Sikka, the Roster supported advocacy for scholarships for junior and senior high school, and for transportation to schools, incentives for teachers, and entrepreneurship/livelihood training for youth.

For more information, please visit:

https://plan-international.org/indonesia

https://www.plan.ie/biaag-page/

https://www.planusa.org/bloom-model 


\section{Practitioner Report 20}

\section{The Influence of an Intentional Design Approach on WomenStrong International's Work with Women and Girls in Haiti and Washington, DC}

By Rose-Marie Chierici, Executive Director, and Dr. Thony Voltaire, Medical Director, Haiti Outreach Pwoje Espwa (H.O.P.E.); Lynda Brown, Director, and Donnie Hampton, Supervisor, WomenStrong DC, Bread for the City, SE; Audrey Anderson, trainer; Dr. Susan M. Blaustein, WomenStrong International

\begin{tabular}{|l|l|}
\hline Findings and Decisions & Implementation Observations and Adaptations \\
\hline $\begin{array}{l}\text { The most economically and socially excluded girls } \\
\text { do not come forward to participate in supportive } \\
\text { programs; they have to be recruited intentionally } \\
\text { through household visits. }\end{array}$ & $\begin{array}{c}\text { In the US, door-to-door rostering was challenging } \\
\text { given the fear that local communities had of being } \\
\text { monitored and the prevailing levels of violence. }\end{array}$ \\
$\begin{array}{l}\text { Family and community members need to be } \\
\text { brought onboard to work against attitudes that } \\
\text { pity poor or poorly dressed girls and reject more } \\
\text { progressive content due to fear of girls' gaining } \\
\text { more power or freedom. }\end{array}$ & \\
Mentors are vital and their own pathway-as young \\
women who are getting married and so forth- \\
needs to be considered to ensure that they too have \\
support and resources. \\
In the Us setting, community mapping is helpful \\
in creating an awareness of rights and increasing \\
advocacy for vital services (in this case, basic \\
community infrastructure and affordable, healthier \\
food options).
\end{tabular}

\section{Introduction}

WomenStrong International is a global nonprofit organization that finds, funds, nurtures, and shares women-driven solutions that transform lives in urban communities. Our member organizations start by listening to women, who know best what they need in order to thrive. Then we bring our members together with other women-led and womendriven organizations into a Learning Lab, to develop, test, sharpen, and share solutions. Through our collective learning and sharing, WomenStrong is building a global community of organizations empowering urban women and girls to leave poverty behind. Womenstrong has benefited tremendously from its association and partnership with the Population Council, especially with regard to the Girl Roster.

\section{HAITI: Haiti Outreach Pwoje Espwa (H.O.P.E.)}

The Council trained all WomenStrong staff and the leading staff members from our five WomenStrong founding members-Ghana, Haiti, India, Kenya, and Washington, DC. All project staff appreciated the training, which they found clear, concise, collegial in spirit, and practical. They found the Girl Roster tool well designed in its minimalism, discretion, and utility, and readily applicable in the field where they work.

In Haiti, the Girl Roster was conducted in the urban and close-in areas of Borgne, a commune in the region of the country where we were focused. The girls' clubs were established on the basis of Roster findings, and programming was enabled and mentored through the Haitian Adolescent Girls Network (HAGN), the implementing partner of the Council and an expert in the Roster. 
Our initial assumption was that the program would address the needs of the girls at risk in Borgne. The girls we wanted to reach came from poor families or were orphans living with relatives. Life is hard for these girls and their invisibility is heightened by household chores, affecting their ability to attend school; thus, finding them in school is unlikely. They are often victims of physical and sexual violence, either at home or in their environment. Without intentional recruitment, they are unlikely to know about or join programs; also, their relatives are often controlling, so the intercession of an organization like H.O.P.E. is essential to smooth the way for acceptance of their joining a girls' group.

Using the Girl Roster, a team of census workers trained in the use of the tool canvassed the three poorest neighborhoods of town to identify girls aged 10-19 and get an idea of the severity of the problems they faced. Then H.O.P.E. worked with HAGN to select and train the program director and two mentors who would lead girls' groups and put in place a program that would meet their needs.

The coordinator and mentors were supervised by both H.O.P.E. and HAGN. H.O.P.E. staff traveled to Port-au-Prince regularly to attend training meetings with coordinators and mentors in the HAGN network, to whom they submitted their weekly reports.

A total of 135 otherwise-invisible girls were selected and organized into five groups. The program was named Espas Pa'm (My Own Space), which was the moniker adopted by the members of HAGN who collaborated closely in framing this work. This title reflects the girls' need for a space of their own, away from the prying eyes of the community and parents. The program started well, weekly meetings were well attended, and the girls enthusiastically participated in lessons and exercises, but local issues interfered in its functioning.

\section{Findings}

Challenges quickly surfaced and strained the program's efforts to meet the girls' needs:

1. Securing safe meeting places was difficult. Originally, the group met in a Protestant church ideally located in reach of three neighborhoods. Soon, however, the pastor objected to the girls' poverty, reflected in their attire; he also found the curriculum too progressive and refused to continue hosting the program. Another location was secured briefly, and then we moved on to the ultimate site-H.O.P.E.'s ASB hospital campus, where there was more security, space, and flexibility.

2. Espas Pa'm was isolated from HAGN's other partner groups, which were in Port-auPrince or areas close to Port-au-Princerather far for attending meetings and training.

3. Attendance started going down, prompting the coordinator and mentors to try to understand the reasons why. They visited families to speak with the girls and parents about the reasons for their absence and learned that parents or guardians were often reluctant to let the girls attend meetings because they didn't understand the program. Their assumption was that the program was to teach girls work skills and get them jobs. Some girls didn't have shoes or proper clothes, while others claimed to be sick.

4. Finally, we had staffing issues. The program coordinator was also a nurse in our women's health program. She was passionate about her role in the program and had the right qualifications and skills to lead it. The mentors were willing to work, but it was difficult to keep them motivated. The coordinator left when she got married, and we had a void to fill.

5. We used a similar model with mixed adolescent groups in the rural communities, with a lot more success. Several reasons explain the difference: the rural 
communities in the commune of Borgne are more cohesive, and adolescents were engaged in projects that benefited their communities. These communities wanted their teens in the program and were willing to lend a hand, and the teens themselves were eager to learn. Groups of girls and boys met to discuss issues of concern for both sexes and learned to behave appropriately with adolescents of the opposite sex. In this setting, this has proved a good model so far. What we have not yet discerned is whether mixed-sex groups serve girls fully; this may be something to explore.

Given the constraints listed above, we did not have capacity to take the program further as had been designed.

\section{Southeast Washington, DC: Bread for the City SE}

In southeast Washington, DC, where WomenStrong worked only with an adult population of women, our participants made creative use of the Community Resource Scan to map the safety and health assets (e.g., ample street lighting, social service agencies, healthy food stores) and deficits (e.g., broken curbs, payday lenders, countless liquor stores) for girls and women in their community. These were distinct from the health and safety assets and deficits in a higher-income part of town, so the intent was to advocate before the relevant local public officials on behalf of their own unjustly neglected neighborhood.

Although the women, who had other priorities, including lack of access to safe and affordable housing and health care, for example, were at that point unable to advocate on their own behalf, their awareness of the inequity in the delivery by their local government of functioning public infrastructure and services marked an important moment in building their sense that: 1) they have a right to these public goods and services, and
2) they are not only entitled, but obliged, and also able to speak up and fight for that right. This sense of empowerment gained by our women participants, particularly after gaining greater knowledge about their own community's risks and deficits as compared to those in a higher-income community, was unanticipated and illustrates the promise of the Community Resource Scan in helping women and other community members deepen their understanding of their own local contexts and their own rights.

The women in our program did feel strongly that there were innumerable invisible girls in their community who deserved and needed targeted programming (they could each name a niece, grandchild, or neighbor who fit that description), but they simply felt too vulnerable in their neighborhoods-even in their own buildings - to carry out the Girl Roster, which would entail asking basic questions of neighbors and acquaintances to identify those girls. ${ }^{1}$ This caution should be considered not only for the use of the tool in unsafe impoverished urban settings, but also in acute crisis zones; whether due to conflict, post-conflict, chaos, a natural disaster, or a climate emergency, girls may find themselves in hastily assembled shelters or displaced persons camps.

\section{Summary, Outcomes, and Conclusion}

In sum, we can see that the Intentional Design approach's commitment to reaching, serving, and empowering the "last girl," along with practitioner-friendly learning tools, has expanded the thinking, awareness, and sense of mission of our entire WomenStrong staff, as well as of those among our member organizations' program officers who were trained in the use of the Girl Roster.

WomenStrong's model has now expanded to enable the learning and cross-learning of those on the ground: those smaller, womendriven grassroots organizations identifying and working with each "last woman and girl," to

\footnotetext{
${ }^{1}$ Another partner-Safe Hands for Girls, operating in both The Gambia and Clarkston, Georgia (the most diverse square mile in the US)-found that paper and pen was more acceptable than Android phones when deploying the Roster in the US, as individuals associated these devices with Immigration and Customs Enforcement (ICE).
} 
ensure their safety, improve their health, and help them gain access to the educational and employment opportunities that will enable them to thrive. This broad content, including livelihoods, is reflected in our Girls' Club handbook, Strong Girls Make Strong Women, ${ }^{2}$ and is based on the work with girls of our founding members in Ghana, Haiti, India, and Kenya. The content has been deeply informed by what we have learned from the Girl Roster and the Population Council-particularly about building girls' protective assets, which we speak about often, and which we have shared with our new Girls' Education and Empowerment Lab ${ }^{3}$ members as the Council's own invaluable guide.

For more information:

Haiti

WomenStrong's partnership with the Haiti Outreach Pwoje Espwa (H.O.P.E.)-S.E.E.Famn project, which includes stories about the people and progress there: https://www.womenstrong.org/projects/ haiti-outreach-pwoje-espwa-hope-seefanm;

Haiti Outreach Pwoje Espwa (H.O.P.E.): http://www.hopehaiti.org/

Washington, DC

WomenStrong DC, WomenStrong's project in partnership with Bread for the City SE, which includes stories about the women and the progress there: https://www.womenstrong.org/projects/ bread-for-the-city

Bread for the City: https://breadforthecity.org/

\footnotetext{
${ }^{2}$ For more information visit: https://www.womenstrong.org/publications/stronggirls.
}

${ }^{3}$ For more information visit: https://www.womenstrong.org/news/womenstrong-launches-new-learning-lab/. 


\section{REFERENCES}

Abramsky, Tanya et al. 2016. "Ecological pathways to prevention: How does the SASA! Community mobilisation model work to prevent physical intimate partner violence against women?" BMC Public Health 16: 339.

Amin, S., K. Austrian, M. Chau, K. Glazer, E. Green, D. Stewart, and M. Stoner. 2013. The Adolescent Girls Vulnerability Index: Guiding Strategic Investment in Uganda. New York: Population Council.

Amin, Sajeda, Ian Diamond, Ruchira T. Naved, and Margaret Newby. 1998. "Transition to adulthood of female garment-factory workers in Bangladesh," Studies in Family Planning 29(2): 185-200.

Amin, Sajeda and Lopita Huq. 2008. "Marriage considerations in sending girls to school in Bangladesh: Some qualitative evidence." Working Paper No. 12. New York: Population Council.

Atkinson, Holly G. and Judith Bruce. 2015. "Adolescent girls, human rights and the expanding climate emergency," CUNY Academic Works.

Austrian, K., J. Bruce, J. Catino, S. Engebretsen, and C.B. Lloyd. 2012. "GIRLS FIRST! Perspectives on girl-centered programming: A series of briefs." New York: Population Council.

Austrian, Karen, Judith Bruce, and M. Catherine Maternowska. 2017. "Early Empowerment: The Evolution and Practice of Girls' 'Boot Camps' in Kenya and Haiti." In Shari Dworkin, Monica Gandhi, and Paige Passano (eds.), Women's Empowerment and Global Health: A Twenty-First-Century Agenda, pp. 93-116. Oakland, CA: University of California Press.

Austrian, Karen and Dennitah Ghati. 2010. "Girl-centered program design: A toolkit to strengthen and expand adolescent girls programs." Population Council.

Austrian, Karen and Eunice Muthengi. 2014. "Can economic assets increase girls' risk of sexual harassment? Evaluation results from a social, health and economic asset-building intervention for vulnerable adolescent girls in Uganda," Children and Youth Services Review 47(2): 168-175.

Baldwin, Wendy. 2011. "Creating 'safe spaces' for adolescent girls," Promoting Healthy, Safe, and Productive Transitions to Adulthood. Brief No. 39. Population Council.

Bandiera, Oriana, Niklas Buehren, Robin Burgess, Markus Goldstein, Selim Gulesci, Imran Rasul, Munshi Sulaiman. 2013. "Empowering adolescent girls: Evidence from a randomized control trial in Uganda (English)." enGender Impact: The World Bank's Gender Impact Evaluation Database. Washington, DC: World Bank.

Basmeh and Zeitooneh. 2017. "Barriers to Education for Female and Male Syrian Youth in Shatila and Bourj al Barajneh."
Breiding, Matthew J., Sharon G. Smith, Kathleen C. Basile, Mikel L. Walters, Jieru Chen, and Melissa T. Merrick. 2014. "Prevalence and characteristics of sexual violence, stalking, and intimate partner violence victimizationNational Intimate Partner and Sexual Violence Survey, United States, 2011. Surveillance Summaries," Morbidity and Mortality Weekly Report 63(SS08): 1-18. Division of Violence Prevention, National Center for Injury Prevention and Control, CDC. https://www.cdc.gov/mmwr/preview/ mmwrhtml/ss6308a1.htm.

Bruce, Judith. 2011a. "Violence Against Adolescent Girls: A Fundamental Challenge to Meaningful Equality." New York: Population Council.

_. 2011b. "Scaling for Change: Strategic Investment in the Poorest Girls in the Poorest Communities." Presentation at the Clinton Global Initiative, New York.

2014. "The Adolescent Girl Moment: Passion Is Our Fuel but Not Our Plan.” Blog post. Girls' Globe.

2015. "Commentary: Investing in the poorest girls in the poorest communities early enough to make a difference," Global Public Health: An International Journal for Research, Policy and Practice 10(2): 225-227.

2016. "The difficulties of 'living while girl,"' Journal of Virus Eradication 2(3): 177-182.

Bruce, Judith and Kelly Hallman. 2008. "Reaching the girls left behind," Gender and Development 16: 227-245.

Bruce, Judith, Miriam Temin, and Kelly Hallman. 2012. "Evidence-based approaches to protecting adolescent girls at risk of HIV." AIDSTAR-One Spotlight on Gender.

Catino, Jennifer, Alejandra Colom, and Marta Julia Ruiz. 2011. "Equipping Mayan girls to improve their lives." Brief No. 5. Transitions to Adulthood. Population Council.

CDC Web-based Injury Statistics Query and Reporting System (WISQARS). 2018. Fatal Injury Mapping Data, 2014-18. https://www.cdc.gov/injury/wisqars/index.html.

Chong, Erica, Kelly Hallman, and Martha Brady. 2006. Investing When It Counts: Generating the Evidence Base for Policies and Programmes for Very Young Adolescents-Guide and Tool Kit. New York: Population Council.

Chonghaile, Clár Ní and Jennifer Rankin. 2016. "Fix the aid system or you will fail the poor, experts warn world leaders," The Guardian. January 17, 2016. https://www. theguardian.com/global-development/2016/jan/17/fixthe-aid-system-or-you-will-fail-the-poor-experts-warnworld-leaders.

Clark, Shelley and Sarah Brauner-Otto. 2015. "Divorce in sub-Saharan Africa: Are unions becoming less stable?" Population and Development Review 41(4): 583-605. 
Clark, Shelley, Judith Bruce, and Annie Dude. 2006. "Protecting young women from HIV/AIDS: The case against child and adolescent marriage," International Family Planning Perspectives 32(2): 79-88.

Clark, Shelley and Dana Hamplová. 2013. "Single motherhood and child mortality in sub-Saharan Africa: A life course perspective," Demography 50(5): 1521-1549.

Engebretsen, Sarah. 2013. "Designing, implementing, and evaluating a targeted, evidence-based intervention for a vulnerable subgroup of girls: A case study of the Filles Éveillées (Girls Awakened) pilot program for migrant adolescent girls in domestic service in urban Burkina Faso." New York: Population Council.

Erulkar, Annabel. 2011. "From research, to program design, to implementation: Programming for rural girls in Ethiopia-a toolkit for practitioners." Addis Ababa: Population Council.

_. 2013. "Early marriage, marital relations and intimate partner violence in Ethiopia," International Perspectives on Sexual and Reproductive Health 39(1): 6-13.

2014. "Building assets to thrive: Addressing the HIV-related vulnerabilities of adolescent girls in Ethiopia." New York: Population Council.

2018. "Child domestic work and transitions to commercial sexual exploitation: Evidence from Ethiopia." Brief. New York: Population Council.

Erulkar, Annabel, Abebaw Ferede, Woldemariam Girma, and Worku Ambelu. 2013. "Evaluation of "Biruh Tesfa" (Bright Future) program for vulnerable girls in Ethiopia," Vulnerable Children and Youth Studies 8: 182-192.

Erulkar, Annabel S. and James K. Matheka. 2007. "Adolescence in the Kibera slums of Nairobi, Kenya." Nairobi, Kenya, and New York: Population Council.

Erulkar, Annabel and Barbara Mensch. 1997. "Youth centres in Kenya: Evaluation of the Family Planning Association of Kenya Programme." Nairobi, Kenya: Population Council.

Erulkar, Annabel S. and Eunice Muthengi. 2009. "Evaluation of Berhane Hewan: A program to delay child marriage in rural Ethiopia," International Perspectives on Sexual and Reproductive Health 35(1): 6-14. doi:10.1363/3500609.

Erulkar, Annabel and Eunice Muthengi-Karei. 2012. "Berhane Hewan ('Light for Eve'): Increasing opportunities to delay marriage and promote schooling." New York: Population Council.

Erulkar, Annabel and Tigest Tamrat. 2014. "Evaluation of reproductive health programs to support married adolescent girls in rural Ethiopia," African Journal of Reproductive Health 18: 68-76.

Fortson, Chris. 2003. "Women's rights vital for developing world," Yale Daily News. https://yaledailynews.com/ blog/2003/02/14/womens-rights-vital-for-developingworld/.
Haberland, Nicole. 2015. "The case for addressing gender and power in sexuality and HIV education: A comprehensive review of evaluation studies," International Perspectives on Sexual and Reproductive Health 41(1): 31-42.

Hallman, Kelly K., Elizabeth Kelvin, Berk Ozler, Juliette Seban, Erica Kuhlik, Cooper Alton, Joseph Kamara, and Sarah Goodman. 2016. "Combining mentoring programs with cash transfers for adolescent girls in Liberia: Baseline report." Policy Research Working Paper No. WPS 7797. Washington, DC: World Bank Group.

Hallman, Kelly K., Nora J. Kenworthy, Judith Diers, Nick Swan, and Bashi Devnarain. 2013. "The contracting world of girls at puberty." Poverty, Gender and Youth Working Paper No. 25. New York: Population Council.

2015. "The shrinking world of girls at puberty: Violence and gender-divergent access to the public sphere among adolescents in South Africa," Global Public Health: An International Journal for Research, Policy and Practice 10(3): 279-295.

Hallman, Kelly and Sara Peracca. 2005. "Causes of low educational achievement and an early transition to adulthood in Guatemala: Ethnicity, gender, or poverty?" New York: Population Council.

Hallman, Kelly, Sara Peracca, Jennifer Catino, and Marta Julia Ruiz. 2007a. "Assessing the multiple disadvantages of Mayan girls: The effects of gender, ethnicity, poverty, and residence on education in Guatemala." Brief No. 16. Promoting Healthy, Safe, and Productive Transitions to Adulthood. Population Council.

_ 2007b. "Indigenous Girls in Guatemala: Poverty and Location." In Maureen A. Lewis and Marlaine E. Lockheed (eds.), Exclusion, Gender and Schooling: Case Studies from the Developing World, pp. 145-176. Washington, DC: Center for Global Development.

Hallman, Kelly, Sara Peracca, Alison Jenkins, Neema Matee, Fatma Mrisho, Phillipo Paul, and I. CernaTuroff. 2018. "Beyond boyfriends and sugar daddies: Ascertaining Sexual Relationship Types (ASERT) qualitatively among adolescent girls and young women in Tanzania." Paper prepared for the Annual Meeting of the Population Association of America, April 26-28, 2018, Denver, CO.

Hallman, Kelly, Sara Peracca, Alison Jenkins, Neema Matee, Phillipo Paul, Ilan Cerna-Turoff, Fatma Mrisho, and Judith Bruce. 2016. The ASERT method reveals a transactional-socio-emotional continuum of 13 sexual partner types among adolescent girls and young women in Tanzania. New York: Population Council.

Hallman, Kelly, Marie Stoner, Michelle Chau, and A.J. Melnikas. 2013. "A review of control-comparison interventions on girls and health in low- and middleincome countries." London: Girl Hub, Nike Foundation, UK Department for International Development. 
Han, A., S. Michael, S. Helal, N. Bakhache, A. Bunting, C. Davison, and S.A. Bartels. 2019. "A pilot study of family planning perspectives and practices among Syrian child brides in Lebanon," Current Opinion in Gynecology and Obstetrics 2(1): 208-215.

Hermes, Rachel. 2009. "Girls will be girls-Even in Darfur." New York: Huffington Post. https://www. huffingtonpost.com/catholic-relief-services/girls-will-begirls8212ev_b_394592.html.

Joint UN Programme of Adolescent Girls. 2012. "Belize coverage exercise study: Assessing the status to build a portfolio of targeted interventions for vulnerable girls." Report.

Kabakian-Khasholian, T., R. Mourtada, H. Bashour, F.E. Kak, and H. Zurayk. 2017. "Perspectives of displaced Syrian women and service providers on fertility behaviour and available services in West Bekaa, Lebanon," Reproductive Health Matters 25(Supp. 1): 75-86.

Kalibala, Samuel and Lynne Elson. 2010 "Protecting hope: Situation analysis of vulnerable children in Uganda." Final report. New York: Population Council.

Kohl, Richard and Lawrence Cooley. 2005. "Scaling up: A conceptual and operational framework." Preliminary Report to the MacArthur Foundation's Program on Population and Reproductive Health. Washington, DC: Management Systems International.

Lardoux, Solène, Mohamed Aly Ekeibed, and Yao Gaspard Bossou. 2006. "Exercice de couverture sur les activités et la fréquentation des centres de jeunes en Mauritanie: Rapport final." New York: Population Council and UNFPA.

Lardoux, Solène and Afiwa N'Bouke. 2013. "Reaching adolescents and youth in Burkina Faso, Guinea-Bissau and Mauritania," African Journal of Reproductive Health 17(1): 73-84.

Lillard, Angeline S., Megan J. Heise, Eva M. Richey, Xin Tong, Alyssa Hart, and Paige M. Bray. 2017. "Montessori preschool elevates and equalizes child outcomes: A longitudinal study," Frontiers in Psychology.

Lloyd, Cynthia B. 2009. "New lessons: The power of educating adolescent girls." New York: Population Council.

Martin, Joyce A., Brady E. Hamilton, Michelle J.K. Osterman, Anne K. Driscoll, and Patrick Drake. 2018. Births: Final data for 2016. National Vital Statistics Reports 67(1). Table 2. Hyattsville, MD: National Center for Health Statistics. https://www.cdc.gov/nchs/data/nvsr/nvsr67/ nvsr67_01.pdf,

McCarthy, Katharine, Martha Brady, and Kelly Hallman. 2016. "Investing When It Counts: Reviewing the Evidence and Charting a Course of Research and Action for Very Young Adolescents." New York: Population Council.

Mekbib, Tekle-Ab, Annabel Erulkar, and Fekerte Belete. 2005. "Who are the targets of youth programs: Results of a capacity building exercise in Ethiopia," Ethiopian Journal of Health Development 19(1): 60-62.
Mensch, Barbara S., Judith Bruce, and Margaret E. Greene. 1998. The Uncharted Passage: Girls' Adolescence in the Developing World. New York: Population Council. http://www.popcouncil.org/ uploads/pdfs/passage/passage.pdf.

Mensch, Barbara S., Monica J. Grant, Erica SolerHampejsek, Christine A. Kelly, Satvika Chalasani, and Paul C. Hewett. 2019. "Does schooling protect sexual health? The association between three measures of education and STIs among adolescents in Malawi," Population Studies 74(2): 241-261. doi: 10.1080/00324728.2019.1656282.

Michau, Lori. 2007. "Approaching old problems in new ways: Community mobilization as a primary prevention strategy to combat violence against women," Gender \& Development 15(1).

Ministério da Saúde (MISAU), Instituto Nacional de Estatística (INE), and ICF. 2018. Inquérito de Indicadores de Imunização, Malária e HIV/SIDA em Moçambique (IMASIDA) 2015. Maputo, Moçambique: MISAU/ Moçambique, INE, and ICF.

Mourtada, R., J. Schlecht, and J. DeJong. 2017. "A qualitative study exploring child marriage practices among Syrian conflict-affected populations in Lebanon," Conflict and Health 11(1): 27.

Musu-Gillette, Lauren, Jennifer Robinson, Joel McFarland, Angelina KewalRamani, Anlan Zhang, and Sidney Wilkinson-Flicker. 2016. Status and Trends in the Education of Racial and Ethnic Groups 2016 (NCES 2016007). Washington, DC: U.S. Department of Education, National Center for Education Statistics.

National Congress of American Indians (NCAI). 2016. Human \& Sex Trafficking: Trends and Responses across Indian Country. Tribal Insights Brief. Washington, DC. NCAI Policy Research Center.

National Youth Council of Malawi and UNFPA. 2010. "The Malawi coverage exercise report: Evidence for youth services coverage." Malawi.

Observatorio en Salud Reproductiva (OSAR). 2018. Embarazos, partos y registro de nacimientos de madres adolescentes entre 10 y 19 años-año 2018. https:// osarguatemala.org/embarazos-y-partos-de-madres-entre$10-y-19-2018 /$.

Population Council. 2005. "Building assets for safe, productive lives: A report on a workshop on adolescent girls' livelihoods." https://knowledgecommons.popcouncil. org/departments_sbsr-pgy/141/. New York.

2009. The Adolescent Experience In-Depth: Using Data to Identify and Reach the Most Vulnerable Young People: Haiti 2005/06. New York.

. 2011. "Promoting healthy, safe, and productive transitions to adulthood: A series of briefs." New York.

2013. The Adolescent Experience In-depth: Using Data to Identify and Reach the Most Vulnerable Young People. New York. 
Population Council, Tanzania Commission for AIDS (TACAIDS), Zanzibar AIDS Commission (ZAC), and UNICEF-Tanzania. 2015. The Adolescent Experience In-Depth: Using Data to Identify and Reach the Most Vulnerable Young People, Tanzania 2009-2012. Dar es Salaam: Population Council, TACAIDS, ZAC, and UNICEFTanzania.

Population Council and UNICEF Belize. 2015. The Adolescent Experience In-Depth: Using Data to Identify and Reach the Most Vulnerable Young People, Belize 2011. New York: Population Council.

Psacharopoulos, George and Harry Anthony Patrinos. 2004. "Returns to investment in education: A further update," Education Economics 12(2).

Psaki, Stephanie. 2016. "Addressing child marriage and adolescent pregnancy as barriers to gender parity and equality in education," Prospects 46(1): 109-129. doi: 10.1007/s11125-016-9379-0.

Psaki, Stephanie R., Barbara S. Mensch, Erica K. Chuang, and Andrea J. Melnikas. 2019. "Does education improve health in low- and middle income countries? Results from a systematic review." GIRL Center Research Brief No. 5. New York: Population Council.

Robles, Omar et al. 2015. "I'm here: Steps \& tools to reach adolescent girls in crisis-Updates \& learning from implementation in 6 countries, 25+ communities." New York: Women's Refugee Commission.

Selim, Mona, Nahla Abdel-Tawab, Khaled Elsayed, Asmaa El Badawy, and Heba El Kalaawy. 2013. "The Ishraq Program for Out-of-School Girls: From pilot to scale-up." Cairo: Population Council.

Sen, Amartya. 2000. Development As Freedom. New York: Anchor Books.

Soler-Hampejsek, Erica, Barbara S. Mensch, Stephanie R. Psaki, Monica J. Grant, Christine A. Kelly, and Paul C. Hewett. 2018. "Reading and numeracy skills after school leaving in southern Malawi: A longitudinal analysis," International Journal of Educational Development 59: 86-99.

Temin, Miriam and Ruth Levine (eds). 2009. Start with a Girl: A New Agenda for Global Health. Washington, DC: Center for Global Development.

Temin, Miriam, Mark R. Montgomery, Sarah Engebretsen, and Kathryn M. Barker. 2013. "Girls on the move: Adolescent girls \& migration in the developing world." New York: Population Council.

UNAIDS. 2014. "Kenya AIDS response progress report: Progress towards zero."
—. 2017. "Ending AIDS: Progress towards the 90-90-90 targets."

2020. Country Overview: Haiti. https://www.unaids. org/en/regionscountries/countries/haiti.

UNHCR, UNICEF, and WFP. 2018. "VASYR 2018:

Vulnerability Assessment of Syrian Refugees in Lebanon." Beirut, Lebanon. https://www.unhcr.org/lb/wp-content/ uploads/sites/16/2018/12/VASyR-2018.pdf.

UNICEF. 2015. Child Marriage and Adolescent Pregnancy in Mozambique: Causes and Impact. Maputo, Mozambique.

United Nations. 2017. World Population Prospects: The 2017 Revision. New York: Department of Social Affairs, Population Division, United Nations.

United Nations Population Fund (UNFPA), American University of Beirut (AUB), and Sawa for Development and Aid (SAWA). 2016. The Prevalence of Early Marriage and Its Key Determinants among Syrian Refugee Girls/ Women: The 2016 Bekaa study, Lebanon.

Vaitla, Bapu et al. 2017. "Social Norms and Girls' WellBeing: Linking Theory and Practice." Washington, DC: Data2x.

Wamoyi, Joyce. 2011. "Parental control and monitoring of young people's sexual behaviour in rural North-Western Tanzania: Implications for sexual and reproductive health interventions," BMC Public Health 11(1): 106.

Weiner, Adam. 2011. "Assessing equity of access in programs for young people." Transitions to Adulthood Brief No. 28. New York: Population Council.

Women's Refugee Commission. 2014. 'I'm here: Adolescent girls in emergencies-Approach and tools for improved response." Report. New York.

World Bank. 2017. "Mozambique Economic Update: Making the Most of Demographic Change." World Bank: Washington, DC.

World Factbook. 2020. Washington, DC: Central Intelligence Agency, 2020. https://www.cia.gov/theworld-factbook/. 


\section{APPENDICES}

APPENDIX I: Glossary

APPENDIX II: How to Conduct the Community Resource Scan

APPENDIX III: DHS Estimates of the Proportion of the Population in Rural and Urban Areas in 54 Countries, Boys and Girls Aged 6-19 


\section{APPENDIX I: GLOSSARY}

\begin{tabular}{|c|c|}
\hline $\begin{array}{l}\text { Ascertaining Sexual } \\
\text { Relationship Types } \\
\text { (ASERT) }\end{array}$ & $\begin{array}{l}\text { A tool that facilitates a method by which practitioners can understand } \\
\text { how girls describe and rank people in their community with whom } \\
\text { they have sex and the reasons for having sex with each type of } \\
\text { person. Allows for analysis of different social and economic risk } \\
\text { factors that influence sexual behavior among target populations. }\end{array}$ \\
\hline At-risk Girls & $\begin{array}{l}\text { A category of girls who are less likely to transition safely and } \\
\text { healthfully into adulthood. }\end{array}$ \\
\hline Catchment Area & $\begin{array}{l}\text { An area from which a city, service, or institute attracts a population } \\
\text { that uses its services; in this context, it is the area in which a program } \\
\text { is focused on providing activities or services. }\end{array}$ \\
\hline Community Contract & $\begin{array}{l}\text { A commitment from community leaders to support girls and } \\
\text { adolescents in specific ways agreed upon by program staff, } \\
\text { community members, parents, and the girls themselves. }\end{array}$ \\
\hline Community Oval & $\begin{array}{l}\text { A Population Council graphic that represents segments and } \\
\text { community resources; used when conducting informal community } \\
\text { mapping or the formal Community Resource Scan. }\end{array}$ \\
\hline Community Resource Scan & $\begin{array}{l}\text { Program tool that provides a rapid picture of the geographic and } \\
\text { social features, including key resources, of girls' communities. }\end{array}$ \\
\hline Coverage & The extent to which a program reaches a segment of participants. \\
\hline Coverage Exercise & $\begin{array}{l}\text { Simple and low-cost exercise used by program staff to understand } \\
\text { how well a program is being accessed in the community. }\end{array}$ \\
\hline Demand-led Recruitment & $\begin{array}{l}\text { An ineffective method of recruitment that is based on recruiting } \\
\text { program participants who ask for, or have easier access to, a service, } \\
\text { rather than those who need it most-those with poorer access. }\end{array}$ \\
\hline Elite Capture & $\begin{array}{l}\text { A misstep of programs whereby those who are better off are more } \\
\text { easily reached, rather than those more in need of a program, causing } \\
\text { a skew. }\end{array}$ \\
\hline Food Insecurity & $\begin{array}{l}\text { The state of being without reliable access to a sufficient quantity of } \\
\text { affordable, nutritious food. }\end{array}$ \\
\hline Gatekeepers & $\begin{array}{l}\text { Community leaders, husbands, and others, typically male, who exert } \\
\text { power over girls and dictate their access to a variety of services and } \\
\text { entitlements. }\end{array}$ \\
\hline Girl Roster & $\begin{array}{l}\text { A practical tool designed to help practitioners understand their } \\
\text { community and elicit foundational information to intentionally link } \\
\text { girls-especially the most marginalized adolescent girls-to the vital } \\
\text { resources, facilities, and services to which they are entitled but often } \\
\text { have limited or no access. }\end{array}$ \\
\hline Hotspot & $\begin{array}{l}\text { Geographic area or location with evidence of a high prevalence of } \\
\text { different risks, depending on program staff's areas of focus (e.g., HIV, } \\
\text { child marriage, polygamy, gender-based violence) }\end{array}$ \\
\hline Human Stock & Health, social, economic, and cognitive assets of individuals. \\
\hline Intentional Design & $\begin{array}{l}\text { A sequential learning approach to designing programs that focuses } \\
\text { on and facilitates seeing and reaching the most-at-risk girls. }\end{array}$ \\
\hline
\end{tabular}




\begin{tabular}{|c|c|}
\hline Off-track & $\begin{array}{l}\text { Denotes girls who are missing out on appropriate entitlements and } \\
\text { services. }\end{array}$ \\
\hline On-ramps & A method of accessing a service or facility. \\
\hline On-track & $\begin{array}{l}\text { Denotes girls who have received age-graded and appropriate } \\
\text { entitlements and services. }\end{array}$ \\
\hline Open-source & $\begin{array}{l}\text { Denotes software for which the original source code is made freely } \\
\text { available and may be redistributed or adapted. }\end{array}$ \\
\hline Opportunity Visit & Visits by girls to previously unfamiliar or unsafe facilities or programs. \\
\hline Output Table & $\begin{array}{l}\text { Any auto-generated table that displays collected information from the } \\
\text { Girl Roster. }\end{array}$ \\
\hline Rosterer & A word that denotes an individual who implements the Girl Roster. \\
\hline Safescaping & $\begin{array}{l}\text { The exercise of determining what constitutes a "safe community" with } \\
\text { regard to gender-based violence and identifying local threats to girls' } \\
\text { safety. }\end{array}$ \\
\hline Safe Spaces & $\begin{array}{l}\text { A safe space generally means a dedicated program space, for girls } \\
\text { in particular. This is an important component since public spaces are } \\
\text { often inhabited largely by men. Examples of locations that can be } \\
\text { used are community halls, schools, and youth centers. A safe spaces } \\
\text { program model incorporates the establishment of girls-only spaces } \\
\text { into program activities. }\end{array}$ \\
\hline Saturation & $\begin{array}{l}\text { The level at which a program has reached enough of its target } \\
\text { beneficiaries to make a difference in the lives of those beneficiaries } \\
\text { and the secondary beneficiaries around them not participating in the } \\
\text { program. }\end{array}$ \\
\hline Segment (of Girls) & $\begin{array}{l}\text { A specific group-in this case girls-sorted by multiple demographic } \\
\text { and other characteristics including age, schooling, religion, } \\
\text { childbearing status, marital status, living arrangements, migration } \\
\text { status. }\end{array}$ \\
\hline Skewing & $\begin{array}{l}\text { Occurs when the participants you have in your program are favored or } \\
\text { have better access than those you intended to reach. }\end{array}$ \\
\hline Spider-scaling & $\begin{array}{l}\text { A way of building and scaling up your program, by which you focus } \\
\text { on one geographic area and then build out to new communities in the } \\
\text { vicinity, and continue this way, creating an almost weblike pattern. }\end{array}$ \\
\hline Stakeholder & $\begin{array}{l}\text { In the development field, this refers to anyone who has an interest } \\
\text { in a project and can influence its success; this includes community } \\
\text { members, government agencies, parents, girl advocates. }\end{array}$ \\
\hline Theory of Change & $\begin{array}{l}\text { Specific type of methodology for planning, participation, and } \\
\text { evaluation that is used in the philanthropy, nonprofit, and government } \\
\text { sectors to promote social change. }\end{array}$ \\
\hline Value for Money & $\begin{array}{l}\text { The most advantageous combination of cost, quality, and } \\
\text { sustainability for a program to meet its deliverables. }\end{array}$ \\
\hline Walkable Community & $\begin{array}{l}\text { The geographic area where typical girls feel socially and physically } \\
\text { comfortable moving around; the area that they consider their } \\
\text { neighborhood or home. }\end{array}$ \\
\hline
\end{tabular}




\section{APPENDIX II: HOW TO CONDUCT THE COMMUNITY RESOURCE SCAN}

The Community Resource Scan is a program tool that provides a rapid description of the geographic and social features of girls' communities, detailing potential programmatic assets for girls and ranking them according to their accessibility. With this tool, program staff can systematically explore the program's catchment area by intentionally covering the area by foot while recording basic features and key resources using either pen and paper or a mobile phone app. The Scan can be used in combination with the Girl Roster to provide informative mapping of where girls live in relation to the resources around them and assessing their accessibility and safety as a result. The value of the Community Resource Scan is that it can inform program staff on decisions about where to locate girl platforms, what community resources exist, and how to connect girls with the resources they need.

The following steps describe how to use the Community Resource Scan on a mobile phone or tablet using a GPS tracking application. The app is not unique to the Population Council but we have chosen to use it in a unique way to assist program staff in getting a thorough picture of its program catchment area. Given the constant evolution of technology, the following steps will continue to change. If you want to verify the appropriate steps to conduct a Community Resource Scan, please contact girlroster@popcouncil.org.

\section{HOW TO USE THE TOOL}

You will need an Android Phone with GPS capabilities, an internet connection, and a Google $^{\odot}$ account.

\section{PREPARATION}

Step 1. Before beginning your scan, you will need to identify the (3-4 kilometer; 2.0-2.5 mile) walkable community of interest that you wish to scan for resources. Note: This should be a community to which you are accustomed, will be or are doing programming, and in which you can gain support and the assistance of a community leader. This may correspond with administrative boundaries such as villages, but you may need to divide larger communities into two or more program catchment areas.

Step 2. Download the GPS tracking application Geo Tracker $^{\odot}$ to your Android phone.

Step 3. Make sure the application can be eventually linked with your Google account by ensuring the Android phone has a Google account linked to it. Note: If you intend to use the Community Resource Scan alongside the
Girl Roster, the Google account linked should be the same for both this and the Girl Roster application.

Step 4. Open Geo Tracker. There should be an immediate display of a map, either on the scale of a country or region. Note: If a map does not appear, there might be an issue with your GPS services. Please ensure your phone is completely updated in Google Play Services while still in WiFi, and try again.

\section{COMMUNITY SCANNING}

Step 5. Identify a knowledgeable community leader or member who can show you around. Explain to the leader the purposes of doing the Community Resource Scan. Though you might personally be identifying limitations, that is hazards to girls' safe spaces in the community, we advise that you do not inform the community leader of this part as it might offend them. You can use your personal judgment here.

Step 6. In the community, and preferably with the guidance of a knowledgeable community leader or member, you will begin to "scan" or map the community's resources. You will start by mapping the perimeter.

Note: GPS tracking applications are constantly changing; it is possible that Geo Tracker will no longer be available at the time of your review of this section. If so, please choose a comparable GPS tracking application or contact the Population Council at girlroster@popcouncil.org for suggestions. 
Step 7. While outside in the community, press the GPS button ( $\phi$ ) so "Track My Trip" will determine your location by displaying a more specific map of the area on your screen. You can zoom in or out on this map by expanding two fingers outward or making a pinching gesture, respectively. Note: If a more specific map does not appear, this is not an issue. Sometimes using this application takes some experimentation and you can test scanning resources briefly to see that it worked. To double check that there are no challenges to your GPS services, you can hit the Three-bar button at the bottom-center of your screen and see if it says "Waiting for GPS signal." You might need to exit and enter the application a few times to get it working.

Step 8. Once you have hit the GPS button ( $\phi)$, ensure you are at the start of your community perimeter. Hit the Play button to begin your "track."

Step 9. Walk the perimeter of the community. As you walk along, you might identify different facilities or resources. These may include the following:

\begin{tabular}{|c|c|}
\hline Social & $\begin{array}{l}\text { Community centers, social clubs, } \\
\text { youth centers, playing fields }\end{array}$ \\
\hline Educational & Schools or other learning locations \\
\hline Religious & Churches, mosques, temples \\
\hline Service & $\begin{array}{l}\text { Hospitals, clinics, charging stations, } \\
\text { taxi or motorcycle stands, salons, } \\
\text { water-collection points }\end{array}$ \\
\hline Retail & Markets, kiosks, bars \\
\hline Financial & Banks, credit unions, ATMs \\
\hline Other & Male hangouts \\
\hline
\end{tabular}

Step 10. At the resource, drop a "pin" by hitting the "Pin" button. You will be prompted by a window to complete: "Create Point of Interest?"

- On the first line, leave the note "Point of Interest...." as is.

- On the second line-"Maintain description"enter the name of the resource or hazard.
For example, you might identify a "Primary School" or "Playhouse for Young Children." You can elaborate on other observations you have about the resource or hazard. For example, you might be pinning a market area and notice it is surrounded by a lot of older men. This might be worth noting. Though it does not immediately mean this is an unsafe space for girls and young women, it could potentially be. You could write that "a lot of men gather here." Note: It is important to be brief on "Maintain description" to save yourself time and for readability later. It is more important that you get the type of resource/hazard than the description.

Step 11. You can also note basic information about the resource in the description section of your tracking application, particularly conditions that are relevant to girls. For instance, if you visit a market, it is important to note what time of day you are visiting, the hours of operation of banks or health clinics, and whether there are groups of men or women and girls present. Locating community resources allows partners to identify the range of resources already available in the community, which resources to link to which segments of girls, and how to effectively link girls to the appropriate resources. This exercise also allows program staff to identify gaps in resources, where additional programming is needed, unsafe spaces for girls, and potential girl platforms.

Step 12. Once you have returned to the office, you can use the Community Oval (see Community Oval Worksheet) to involve program staff in analyzing information about the resources you mapped. Steps are as follows:

- Fill in the name of your various girl segments of focus; use the space below each segment name to provide as much detail as possible about that segment;

- Fill in the name of the various resources you marked during the Community Resource Scan using blank resource circles to name additional resources not already included in the worksheet; 
- Using a scale of 1-5 (1 signifying the lowest access and 5 signifying the highest access), identify where the resource falls per segment. For example, a girl 10-14 years old and in school might not have highest access to HIV testing.

1. Due to cultural and/or social restrictions, girls are likely not found here.

2. This place could serve girls but is unlikely to be currently doing so.

3. This facility is female-centered, but mostly utilized by adult males and females, or adult married females.

4. There is some age criteria-youth, adolescents, children-but there is no dedicated, age-graded, girls-only time.

5. Girls are definitely found here and have a safe space and time at this location.

- Draw a line from the segment to each of the resources. Next to the line, write a number from the above scale (1-5) to denote the "accessibility" of this resource. You can even use a dashed or a solid line to signify the difference in access (dashed being low, solid being high). 


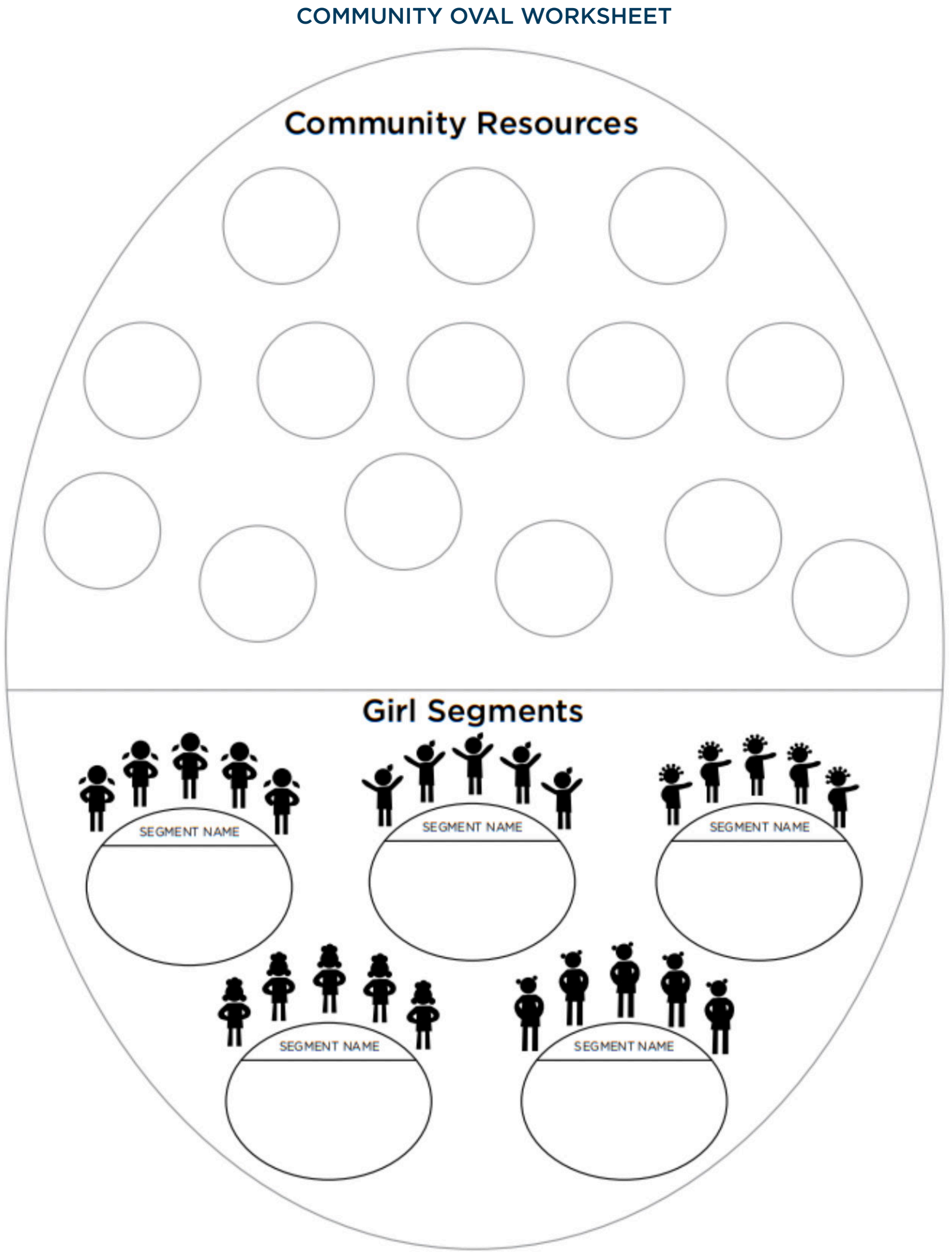


APPENDIX III: DHS ESTIMATES OF THE PROPORTION OF THE POPULATION IN RURAL AND URBAN AREAS IN 54 COUNTRIES, BOYS AND GIRLS AGED 6-19

Estimates are calculated using the latest DHS data from each country, as of 2018.

Analysis by Craig Heck and Kate McCarthy. 
DHS Survey

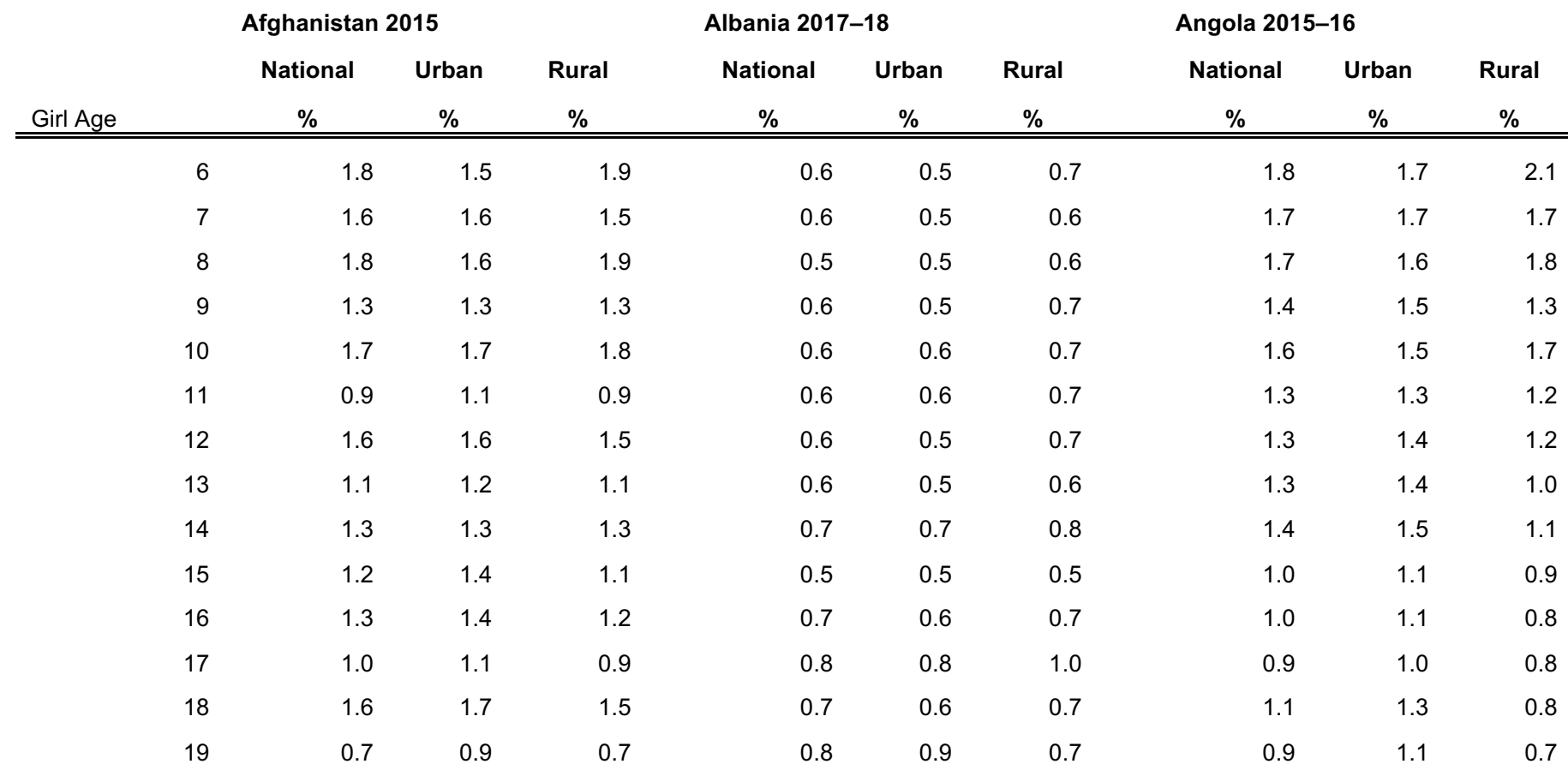

N Total

Population

(weighted)

$203,702 \quad 52,383 \quad 151,319$

$53,898 \quad 25,417 \quad 28,481$

$74,003 \quad 42,876 \quad 31,127$

\begin{tabular}{|c|c|c|c|c|c|c|c|c|c|c|}
\hline & \multicolumn{3}{|c|}{ Armenia 2015-16 } & \multicolumn{3}{|c|}{ Azerbaijan 2006} & \multicolumn{4}{|c|}{ Bangladesh 2014} \\
\hline Girl Age & & $\begin{array}{c}\text { National } \\
\% \\
\end{array}$ & $\begin{array}{c}\text { Urban } \\
\% \\
\end{array}$ & $\begin{array}{c}\text { Rural } \\
\% \\
\end{array}$ & $\begin{array}{c}\text { National } \\
\% \\
\end{array}$ & $\begin{array}{c}\text { Urban } \\
\% \\
\end{array}$ & $\begin{array}{c}\text { Rural } \\
\% \\
\end{array}$ & $\begin{array}{c}\text { National } \\
\% \\
\end{array}$ & $\begin{array}{c}\text { Urban } \\
\% \\
\end{array}$ & $\begin{array}{c}\text { Rural } \\
\% \\
\end{array}$ \\
\hline & 6 & 0.7 & 0.7 & 0.8 & 0.8 & 0.8 & 0.8 & 1.1 & 1.0 & 1.2 \\
\hline & 7 & 0.6 & 0.7 & 0.6 & 0.7 & 0.6 & 0.7 & 1.2 & 1.1 & 1.3 \\
\hline & 8 & 0.6 & 0.6 & 0.7 & 0.7 & 0.6 & 0.8 & 1.2 & 1.0 & 1.2 \\
\hline & 9 & 0.5 & 0.5 & 0.5 & 0.7 & 0.7 & 0.8 & 0.9 & 0.9 & 0.9 \\
\hline & 10 & 0.6 & 0.6 & 0.7 & 0.8 & 0.8 & 0.8 & 1.3 & 1.2 & 1.4 \\
\hline & 11 & 0.6 & 0.7 & 0.5 & 0.9 & 0.7 & 1.0 & 1.1 & 1.1 & 1.1 \\
\hline & 12 & 0.5 & 0.6 & 0.5 & 1.1 & 1.0 & 1.2 & 1.2 & 1.1 & 1.2 \\
\hline & 13 & 0.5 & 0.5 & 0.6 & 1.0 & 1.0 & 1.1 & 1.1 & 1.1 & 1.1 \\
\hline & 14 & 0.6 & 0.5 & 0.6 & 1.2 & 1.2 & 1.2 & 1.1 & 1.0 & 1.1 \\
\hline & 15 & 0.5 & 0.6 & 0.5 & 0.9 & 0.9 & 0.8 & 1.2 & 1.1 & 1.2 \\
\hline & 16 & 0.6 & 0.6 & 0.6 & 1.1 & 1.2 & 1.0 & 1.2 & 1.2 & 1.2 \\
\hline & 17 & 0.6 & 0.5 & 0.7 & 1.2 & 1.2 & 1.0 & 1.1 & 1.2 & 1.1 \\
\hline & 18 & 0.5 & 0.4 & 0.7 & 1.2 & 1.1 & 1.4 & 1.4 & 1.5 & 1.4 \\
\hline & 19 & 0.5 & 0.5 & 0.6 & 1.0 & 1.0 & 0.9 & 1.1 & 1.1 & 1.0 \\
\hline
\end{tabular}

N Total

Population

(weighted) 


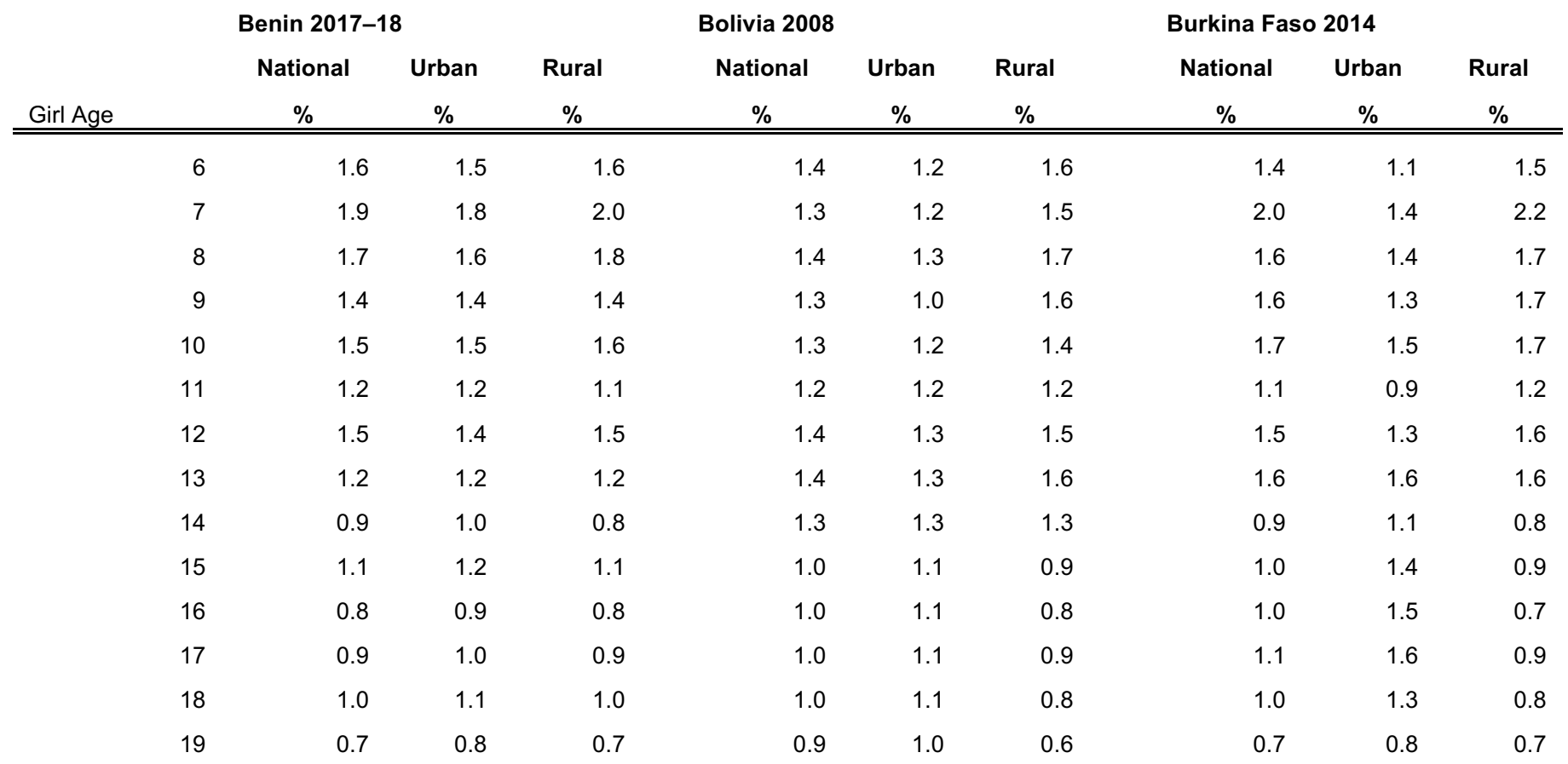

N Total

Population

(weighted)

$74,673 \quad 31,271 \quad 43,402$

$77,637 \quad 45,951 \quad 31,686$

$39,524 \quad 7,054 \quad 32,470$

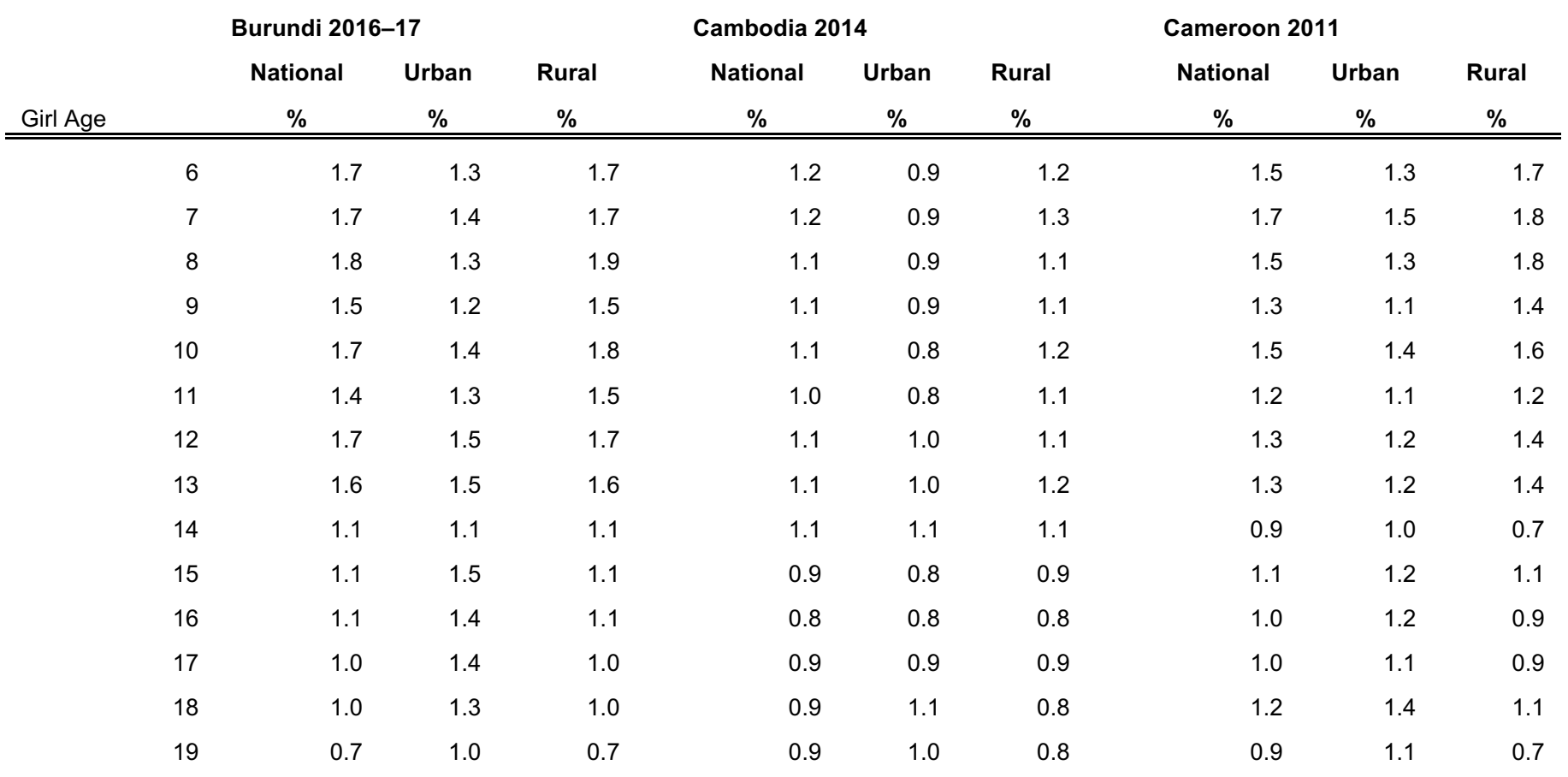

N Total

Population

(weighted)

$78,359 \quad 14,820 \quad 63,539$

$74,119 \quad 21,532 \quad 52,587$

72,869

$34,631 \quad 38,238$ 


\begin{tabular}{|c|c|c|c|c|c|c|c|c|c|c|}
\hline \multicolumn{5}{|c|}{ Chad 2014-15 } & \multicolumn{3}{|c|}{ Colombia 2015} & \multicolumn{3}{|c|}{ Comoros 2012} \\
\hline & & National & Urban & Rural & National & Urban & Rural & National & Urban & Rural \\
\hline Girl Age & & $\%$ & $\%$ & $\%$ & $\%$ & $\%$ & $\%$ & $\%$ & $\%$ & $\%$ \\
\hline & 6 & 2.3 & 1.9 & 2.4 & 0.8 & 0.8 & 1.0 & 1.6 & 1.4 & 1.7 \\
\hline & 7 & 2.0 & 1.7 & 2.1 & 0.8 & 0.8 & 1.0 & 1.4 & 1.4 & 1.4 \\
\hline & 8 & 2.3 & 1.9 & 2.4 & 0.9 & 0.8 & 1.0 & 1.4 & 1.3 & 1.4 \\
\hline & 9 & 1.4 & 1.2 & 1.4 & 0.8 & 0.8 & 1.0 & 1.4 & 1.1 & 1.6 \\
\hline & 10 & 2.1 & 1.7 & 2.2 & 0.8 & 0.7 & 1.1 & 1.4 & 1.2 & 1.5 \\
\hline & 11 & 1.0 & 1.1 & 1.0 & 0.9 & 0.8 & 1.0 & 1.1 & 0.9 & 1.1 \\
\hline & 12 & 1.8 & 1.8 & 1.8 & 0.9 & 0.8 & 0.9 & 1.2 & 1.4 & 1.1 \\
\hline & 13 & 1.4 & 1.5 & 1.4 & 0.8 & 0.8 & 1.0 & 1.1 & 1.2 & 1.1 \\
\hline & 14 & 1.3 & 1.4 & 1.3 & 1.0 & 0.9 & 1.1 & 1.2 & 1.3 & 1.2 \\
\hline & 15 & 1.1 & 1.2 & 1.0 & 0.9 & 0.9 & 1.0 & 1.1 & 1.1 & 1.1 \\
\hline & 16 & 0.8 & 0.9 & 0.8 & 0.9 & 0.9 & 1.0 & 1.2 & 1.2 & 1.2 \\
\hline & 17 & 0.8 & 0.9 & 0.7 & 1.0 & 1.0 & 0.9 & 1.1 & 1.2 & 1.0 \\
\hline & 18 & 1.1 & 1.3 & 1.1 & 1.0 & 1.0 & 0.8 & 1.3 & 1.2 & 1.4 \\
\hline & 19 & 0.6 & 0.7 & 0.5 & 0.9 & 1.0 & 0.8 & 1.0 & 1.0 & 1.1 \\
\hline
\end{tabular}

N Total

Population

(weighted)

$99,603 \quad 23,722 \quad 75,881$

$162,390 \quad 117,800$

44,590

$24,323 \quad 7,624$

16,699

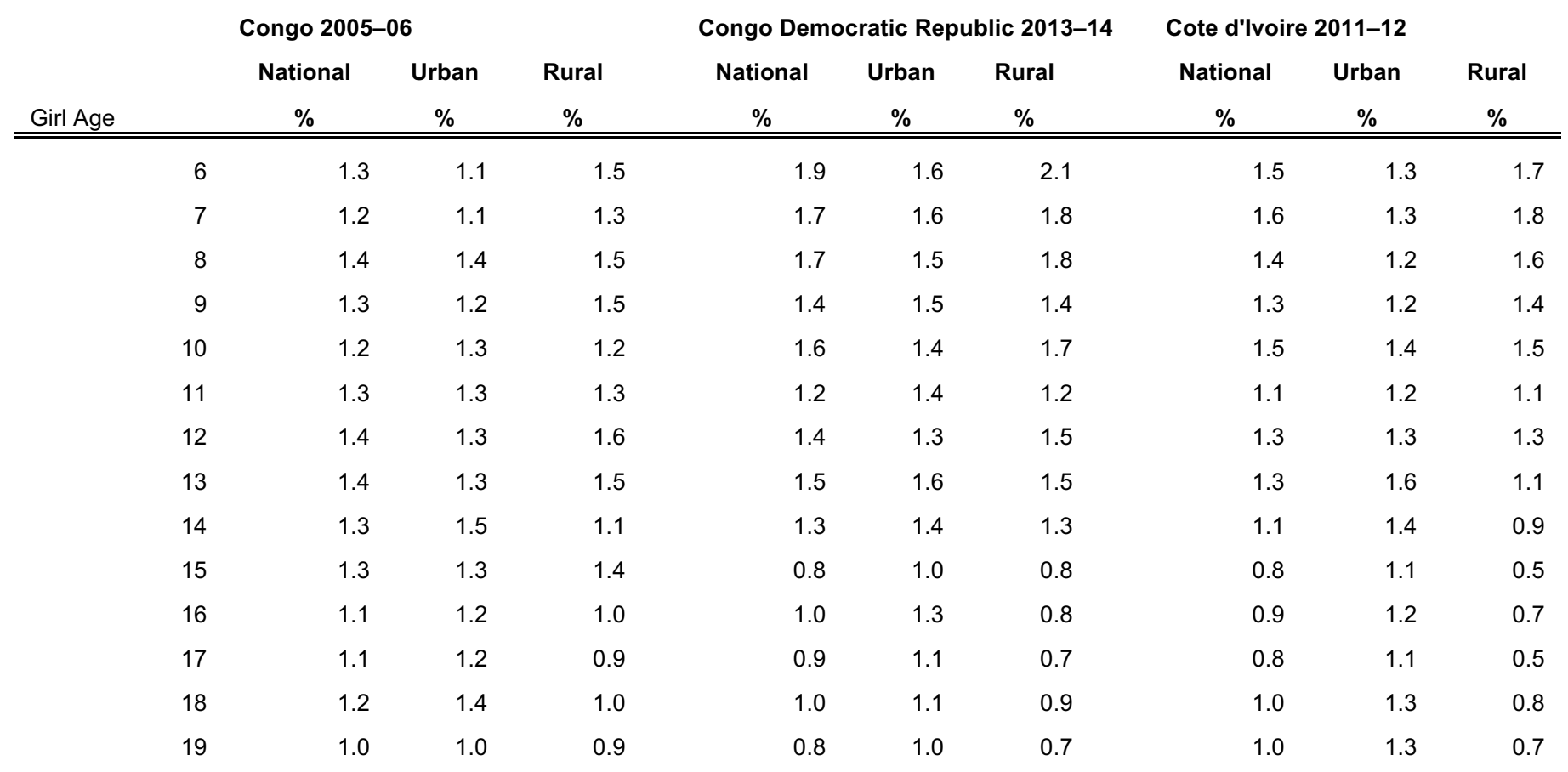

N Total

Population

(weighted) 


\begin{tabular}{|c|c|c|c|c|c|c|c|c|c|c|}
\hline & & Dominican $\mathrm{R}$ & public 20 & & Egypt 2008 & & & Eswatini 20 & & \\
\hline & & National & Urban & Rural & National & Urban & Rural & National & Urban & Rural \\
\hline Girl Age & & $\%$ & $\%$ & $\%$ & $\%$ & $\%$ & $\%$ & $\%$ & $\%$ & $\%$ \\
\hline & 6 & 0.9 & 0.9 & 0.7 & 1.1 & 1.0 & 1.2 & 1.3 & 1.2 & 1.4 \\
\hline & 7 & 0.9 & 0.9 & 0.8 & 1.0 & 0.9 & 1.1 & 1.4 & 0.9 & 1.5 \\
\hline & 8 & 1.0 & 1.1 & 0.9 & 1.0 & 0.9 & 1.1 & 1.5 & 1.3 & 1.6 \\
\hline & 9 & 0.9 & 0.9 & 0.8 & 1.1 & 1.0 & 1.2 & 1.3 & 0.8 & 1.5 \\
\hline & 10 & 1.0 & 1.0 & 1.0 & 1.0 & 0.9 & 1.1 & 1.6 & 1.2 & 1.7 \\
\hline & 11 & 1.1 & 1.1 & 1.3 & 1.1 & 0.9 & 1.1 & 1.5 & 1.1 & 1.6 \\
\hline & 12 & 1.1 & 1.2 & 1.0 & 1.1 & 1.0 & 1.1 & 1.4 & 0.9 & 1.5 \\
\hline & 13 & 1.2 & 1.1 & 1.2 & 1.0 & 0.9 & 1.0 & 1.4 & 1.0 & 1.6 \\
\hline & 14 & 1.1 & 1.1 & 1.0 & 1.0 & 1.0 & 1.0 & 1.8 & 1.1 & 2.0 \\
\hline & 15 & 1.0 & 1.1 & 0.8 & 0.9 & 0.9 & 1.0 & 1.2 & 0.7 & 1.3 \\
\hline & 16 & 1.0 & 1.0 & 0.9 & 1.0 & 0.8 & 1.1 & 1.4 & 1.1 & 1.4 \\
\hline & 17 & 1.0 & 1.0 & 1.0 & 1.0 & 1.0 & 1.1 & 1.2 & 1.1 & 1.3 \\
\hline & 18 & 1.0 & 1.0 & 0.9 & 1.1 & 1.1 & 1.1 & 1.2 & 1.5 & 1.2 \\
\hline & 19 & 1.1 & 1.0 & 1.3 & 1.1 & 1.1 & 1.1 & 1.2 & 1.2 & 1.1 \\
\hline
\end{tabular}

N Total

Population

(weighted)

$\begin{array}{lll}41,019 & 30,217 & 10,802\end{array}$

$89,396 \quad 38,246 \quad 51,151$

$22,138 \quad 5,679$

16,459

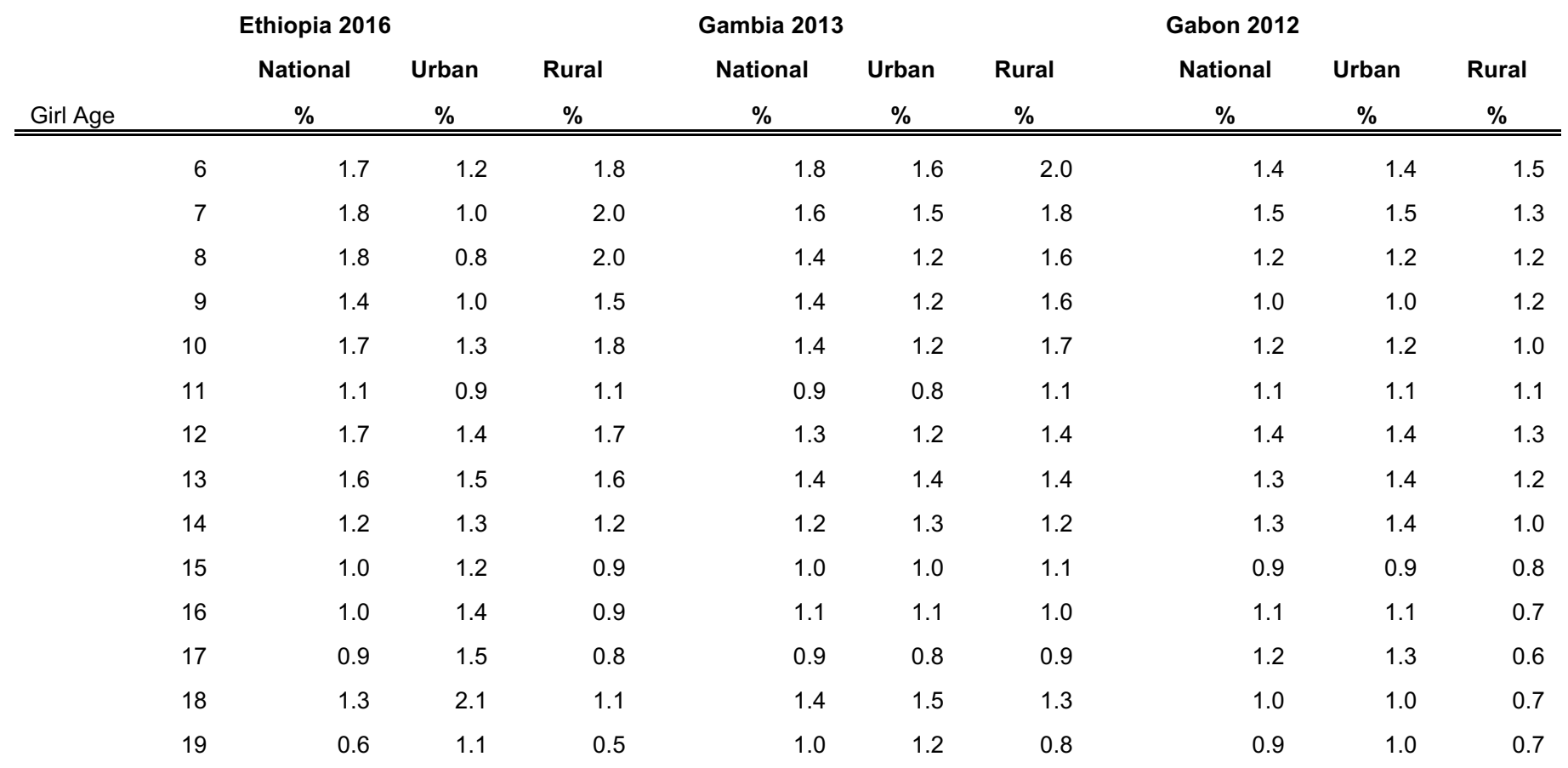

N Total

Population

(weighted) 


\begin{tabular}{|c|c|c|c|c|c|c|c|c|c|c|}
\hline & & \multicolumn{3}{|l|}{ Ghana 2016} & \multicolumn{3}{|c|}{ Guatemala 2014-15 } & \multicolumn{3}{|c|}{ Guinea 2012} \\
\hline & & National & Urban & Rural & National & Urban & Rural & National & Urban & Rural \\
\hline Girl Age & & $\%$ & $\%$ & $\%$ & $\%$ & $\%$ & $\%$ & $\%$ & $\%$ & $\%$ \\
\hline & 6 & 1.1 & 1.1 & 1.1 & 1.3 & 1.1 & 1.4 & 1.9 & 1.6 & 2.0 \\
\hline & 7 & 1.3 & 1.2 & 1.5 & 1.2 & 1.1 & 1.3 & 1.8 & 1.4 & 1.9 \\
\hline & 8 & 1.3 & 1.4 & 1.2 & 1.2 & 1.0 & 1.4 & 1.7 & 1.5 & 1.9 \\
\hline & 9 & 1.3 & 1.1 & 1.4 & 1.3 & 1.1 & 1.4 & 1.4 & 1.1 & 1.6 \\
\hline & 10 & 1.3 & 1.5 & 1.2 & 1.3 & 1.2 & 1.4 & 1.8 & 1.4 & 2.0 \\
\hline & 11 & 1.0 & 0.8 & 1.2 & 1.2 & 1.0 & 1.3 & 1.1 & 1.0 & 1.1 \\
\hline & 12 & 1.4 & 1.4 & 1.3 & 1.3 & 1.1 & 1.4 & 1.8 & 1.9 & 1.8 \\
\hline & 13 & 1.2 & 1.1 & 1.2 & 1.3 & 1.2 & 1.3 & 1.6 & 1.5 & 1.6 \\
\hline & 14 & 1.3 & 1.3 & 1.3 & 1.2 & 1.1 & 1.3 & 1.3 & 1.9 & 1.0 \\
\hline & 15 & 0.8 & 0.6 & 1.0 & 1.3 & 1.2 & 1.3 & 0.9 & 1.0 & 0.9 \\
\hline & 16 & 1.1 & 1.1 & 1.0 & 1.3 & 1.2 & 1.3 & 0.9 & 1.1 & 0.8 \\
\hline & 17 & 0.6 & 0.7 & 0.6 & 1.2 & 1.2 & 1.2 & 0.9 & 1.2 & 0.7 \\
\hline & 18 & 0.8 & 0.8 & 0.9 & 1.1 & 1.2 & 1.1 & 1.3 & 1.5 & 1.1 \\
\hline & 19 & 0.6 & 0.7 & 0.6 & 1.1 & 1.1 & 1.1 & 0.8 & 1.1 & 0.6 \\
\hline
\end{tabular}

N Total

Population

(weighted)

$23,008 \quad 9,576 \quad 13,432$

$102,510 \quad 42,371 \quad 60,139$

$\begin{array}{lll}45,021 & 14,672 \quad 30,348\end{array}$

\begin{tabular}{|c|c|c|c|c|c|c|c|c|c|c|}
\hline & \multicolumn{3}{|c|}{ Guyana 2009} & \multicolumn{3}{|c|}{ Haiti 2016-17 } & \multicolumn{4}{|c|}{ Honduras 2011-12 } \\
\hline Girl Age & & $\begin{array}{c}\text { National } \\
\% \\
\end{array}$ & $\begin{array}{c}\text { Urban } \\
\% \\
\end{array}$ & $\begin{array}{c}\text { Rural } \\
\% \\
\end{array}$ & $\begin{array}{c}\text { National } \\
\% \\
\end{array}$ & $\begin{array}{c}\text { Urban } \\
\% \\
\end{array}$ & $\begin{array}{c}\text { Rural } \\
\% \\
\end{array}$ & $\begin{array}{c}\text { National } \\
\% \\
\end{array}$ & $\begin{array}{c}\text { Urban } \\
\% \\
\end{array}$ & $\begin{array}{c}\text { Rural } \\
\% \\
\end{array}$ \\
\hline & 6 & 1.0 & 0.9 & 1.0 & 1.2 & 1.0 & 1.4 & 1.1 & 1.1 & 1.2 \\
\hline & 7 & 1.0 & 1.1 & 1.0 & 1.2 & 1.1 & 1.3 & 1.1 & 1.0 & 1.2 \\
\hline & 8 & 1.2 & 1.0 & 1.3 & 1.3 & 1.3 & 1.3 & 1.0 & 1.0 & 1.1 \\
\hline & 9 & 1.4 & 1.2 & 1.5 & 1.2 & 1.1 & 1.2 & 1.1 & 1.0 & 1.2 \\
\hline & 10 & 1.2 & 1.1 & 1.2 & 1.1 & 0.9 & 1.2 & 1.1 & 1.0 & 1.3 \\
\hline & 11 & 1.3 & 1.0 & 1.4 & 1.1 & 1.1 & 1.1 & 1.3 & 1.2 & 1.4 \\
\hline & 12 & 1.1 & 1.1 & 1.1 & 1.1 & 1.0 & 1.1 & 1.4 & 1.2 & 1.5 \\
\hline & 13 & 1.2 & 1.0 & 1.3 & 1.1 & 1.1 & 1.0 & 1.3 & 1.2 & 1.4 \\
\hline & 14 & 1.2 & 1.2 & 1.2 & 0.9 & 0.9 & 0.9 & 1.2 & 1.1 & 1.3 \\
\hline & 15 & 1.1 & 1.3 & 1.1 & 1.2 & 1.3 & 1.1 & 1.2 & 1.1 & 1.2 \\
\hline & 16 & 1.1 & 1.2 & 1.1 & 1.2 & 1.4 & 1.1 & 1.3 & 1.3 & 1.3 \\
\hline & 17 & 0.9 & 0.9 & 0.9 & 1.2 & 1.3 & 1.1 & 1.2 & 1.2 & 1.1 \\
\hline & 18 & 1.0 & 1.3 & 0.8 & 1.2 & 1.3 & 1.1 & 1.2 & 1.3 & 1.1 \\
\hline & 19 & 1.2 & 1.0 & 1.3 & 1.0 & 1.1 & 0.9 & 1.1 & 1.2 & 0.9 \\
\hline
\end{tabular}

N Total

Population

(weighted) 


\begin{tabular}{|c|c|c|c|c|c|c|c|c|c|c|}
\hline \multicolumn{5}{|c|}{ India 2015-16 } & \multicolumn{3}{|c|}{ Indonesia 2012} & \multicolumn{3}{|c|}{ Jordan 2017-18 } \\
\hline & & National & Urban & Rural & National & Urban & Rural & National & Urban & Rural \\
\hline Girl Age & & $\%$ & $\%$ & $\%$ & $\%$ & $\%$ & $\%$ & $\%$ & $\%$ & $\%$ \\
\hline & 6 & 0.9 & 0.8 & 1.0 & 1.0 & 0.9 & 1.1 & 1.1 & 1.1 & 1.0 \\
\hline & 7 & 0.9 & 0.8 & 1.0 & 0.9 & 0.9 & 1.0 & 1.2 & 1.2 & 1.2 \\
\hline & 8 & 1.0 & 0.8 & 1.1 & 1.0 & 0.9 & 1.0 & 1.1 & 1.1 & 1.3 \\
\hline & 9 & 0.8 & 0.8 & 0.9 & 1.0 & 1.0 & 1.1 & 1.2 & 1.2 & 1.2 \\
\hline & 10 & 1.0 & 0.8 & 1.1 & 0.9 & 0.8 & 1.0 & 1.2 & 1.2 & 1.3 \\
\hline & 11 & 0.8 & 0.8 & 0.9 & 1.0 & 0.9 & 1.0 & 1.1 & 1.1 & 1.1 \\
\hline & 12 & 1.0 & 0.9 & 1.1 & 1.0 & 0.9 & 1.1 & 1.0 & 0.9 & 1.2 \\
\hline & 13 & 1.0 & 0.9 & 1.1 & 0.9 & 0.8 & 1.0 & 1.1 & 1.1 & 1.1 \\
\hline & 14 & 0.9 & 0.9 & 0.9 & 0.9 & 0.9 & 1.0 & 1.0 & 1.0 & 1.3 \\
\hline & 15 & 0.9 & 0.8 & 1.0 & 0.9 & 0.8 & 0.9 & 1.0 & 1.0 & 1.1 \\
\hline & 16 & 0.9 & 0.8 & 1.0 & 0.9 & 0.9 & 0.9 & 1.0 & 1.0 & 1.0 \\
\hline & 17 & 0.9 & 0.8 & 0.9 & 0.8 & 0.9 & 0.8 & 1.1 & 1.1 & 1.2 \\
\hline & 18 & 1.1 & 0.9 & 1.1 & 0.7 & 0.9 & 0.6 & 1.0 & 1.0 & 1.0 \\
\hline & 19 & 0.8 & 0.8 & 0.8 & 0.8 & 0.9 & 0.6 & 0.9 & 0.9 & 1.0 \\
\hline
\end{tabular}

N Total

Population

(weighted)

$2,868,588 \quad 804,575 \quad 2,064,013$

$177,598 \quad 88,387 \quad 89,211$

$93,347 \quad 73,614$

19,733

\begin{tabular}{|c|c|c|c|c|c|c|c|c|c|c|}
\hline & & \multicolumn{3}{|l|}{ Kenya 2015} & \multicolumn{3}{|c|}{ Kyrgyz Republic 2012} & \multicolumn{2}{|c|}{ Lesotho 2014} & \multirow[b]{2}{*}{$\begin{array}{c}\text { Rural } \\
\% \\
\end{array}$} \\
\hline Girl Age & & $\begin{array}{c}\text { National } \\
\% \\
\end{array}$ & $\begin{array}{c}\text { Urban } \\
\% \\
\end{array}$ & $\begin{array}{c}\text { Rural } \\
\% \\
\end{array}$ & $\begin{array}{c}\text { National } \\
\% \\
\end{array}$ & $\begin{array}{c}\text { Urban } \\
\% \\
\end{array}$ & $\begin{array}{c}\text { Rural } \\
\% \\
\end{array}$ & $\begin{array}{c}\text { National } \\
\% \\
\end{array}$ & $\begin{array}{c}\text { Urban } \\
\% \\
\end{array}$ & \\
\hline & 6 & 1.5 & 1.3 & 1.6 & 1.1 & 1.1 & 1.1 & 1.2 & 1.1 & 1.3 \\
\hline & 7 & 1.6 & 1.2 & 1.8 & 1.0 & 0.9 & 1.0 & 1.2 & 1.0 & 1.3 \\
\hline & 8 & 1.4 & 1.1 & 1.6 & 1.0 & 0.9 & 1.0 & 1.2 & 1.1 & 1.2 \\
\hline & 9 & 1.4 & 1.2 & 1.5 & 0.7 & 0.7 & 0.8 & 1.3 & 1.1 & 1.4 \\
\hline & 10 & 1.5 & 1.4 & 1.6 & 1.0 & 0.9 & 1.1 & 1.2 & 1.0 & 1.2 \\
\hline & 11 & 0.9 & 0.8 & 1.0 & 0.8 & 0.7 & 0.9 & 1.2 & 0.9 & 1.3 \\
\hline & 12 & 1.4 & 1.2 & 1.5 & 1.1 & 0.8 & 1.2 & 1.2 & 1.1 & 1.2 \\
\hline & 13 & 1.2 & 0.9 & 1.3 & 1.0 & 0.8 & 1.2 & 1.2 & 0.9 & 1.3 \\
\hline & 14 & 1.1 & 0.6 & 1.3 & 1.1 & 1.0 & 1.1 & 1.3 & 1.3 & 1.3 \\
\hline & 15 & 0.9 & 0.6 & 1.1 & 1.1 & 0.9 & 1.1 & 1.0 & 1.0 & 1.0 \\
\hline & 16 & 1.0 & 0.8 & 1.0 & 1.1 & 1.2 & 1.1 & 1.1 & 1.2 & 1.1 \\
\hline & 17 & 0.7 & 0.6 & 0.8 & 1.0 & 1.2 & 0.9 & 1.0 & 1.0 & 1.1 \\
\hline & 18 & 0.8 & 0.8 & 0.8 & 0.9 & 1.2 & 0.8 & 1.1 & 1.1 & 1.1 \\
\hline & 19 & 0.9 & 1.2 & 0.7 & 0.8 & 1.1 & 0.7 & 1.0 & 1.3 & 0.9 \\
\hline
\end{tabular}

N Total

Population

(weighted) 


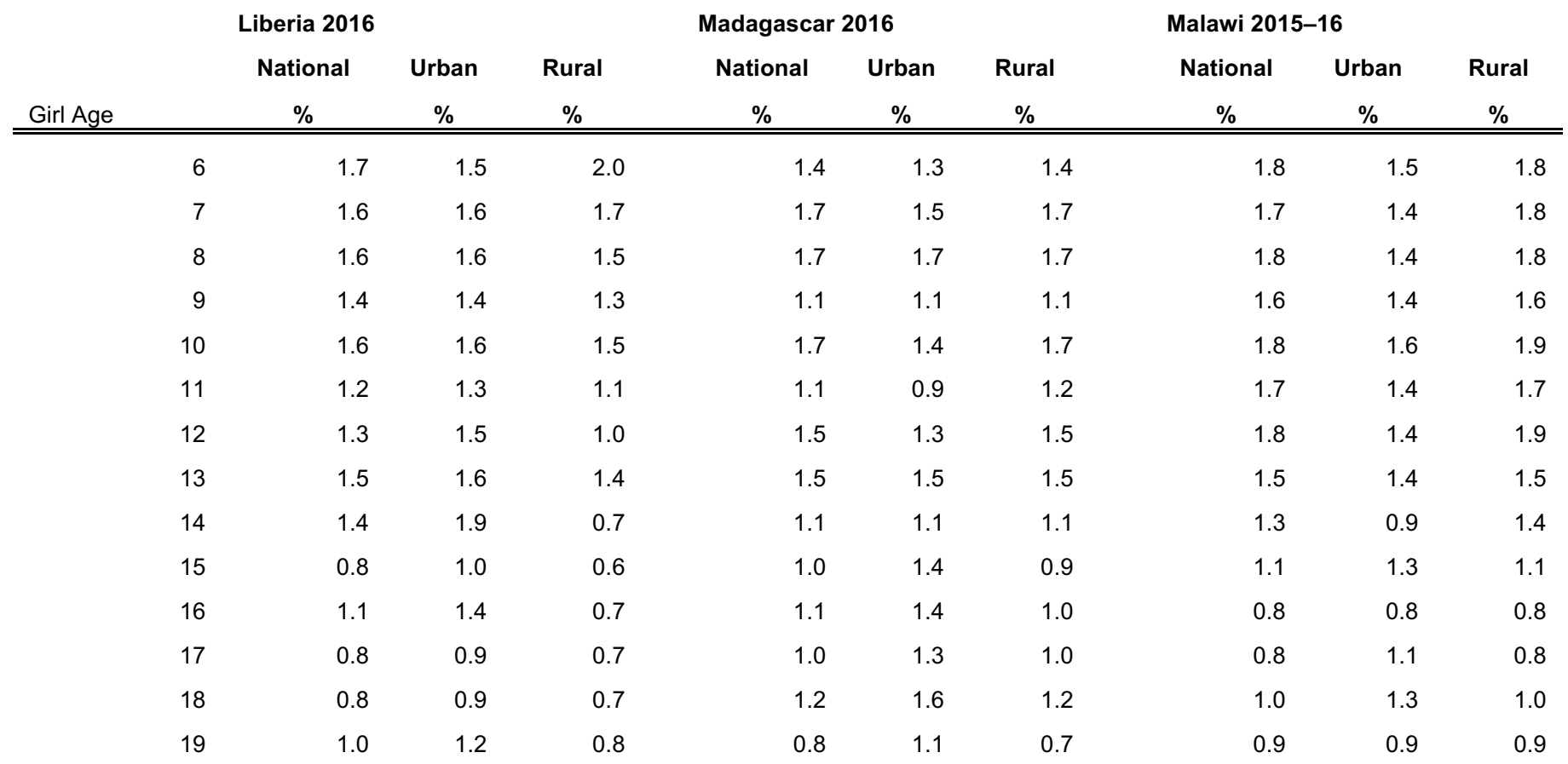

N Total

Population

(weighted)

$22,010 \quad 10,805 \quad 11,205$

$49,108 \quad 8,084 \quad 41,024$

$120,360 \quad 21,538 \quad 98,822$

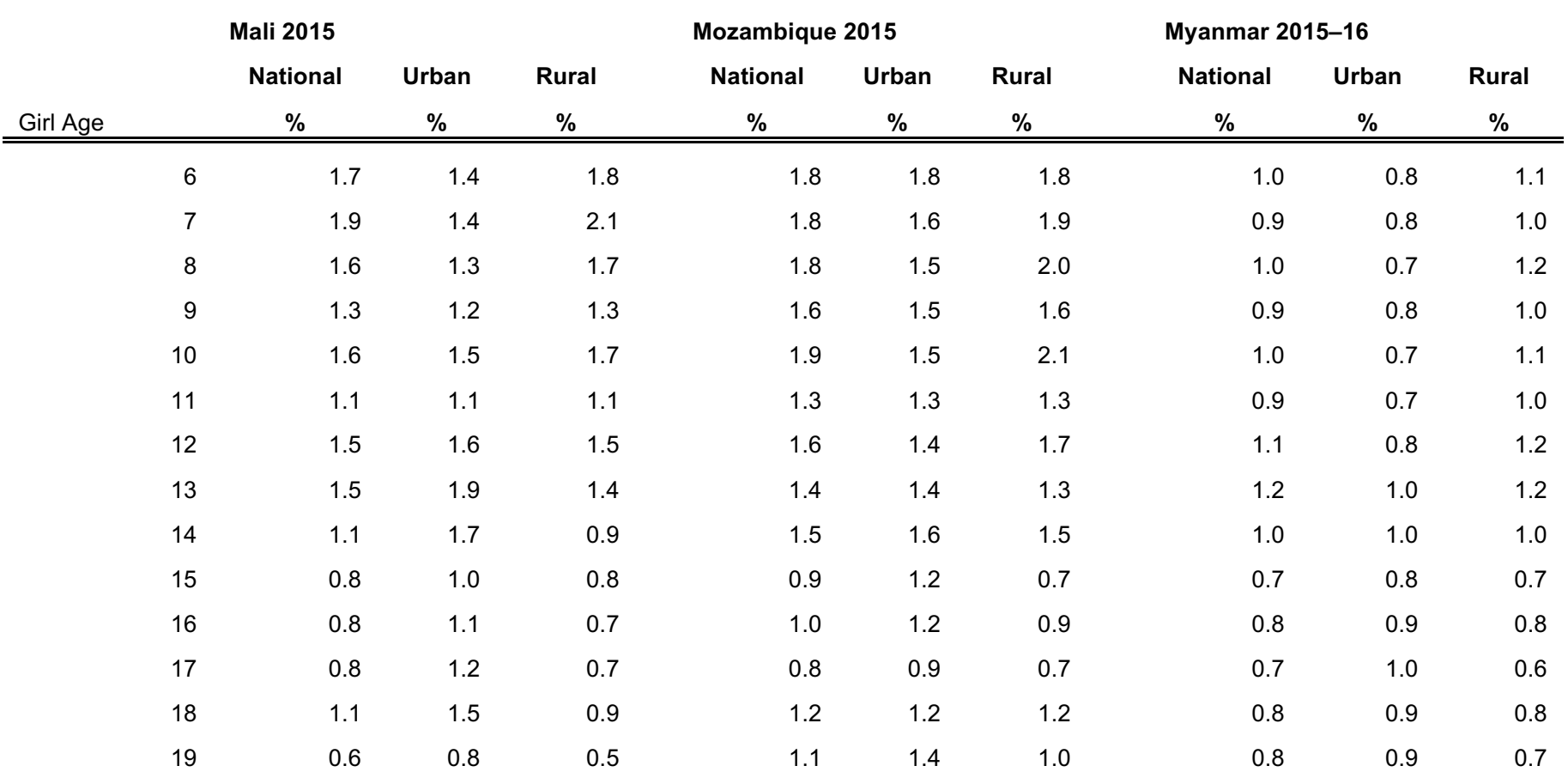

N Total

Population

(weighted) 


\begin{tabular}{|c|c|c|c|c|c|c|c|c|c|c|}
\hline & \multicolumn{3}{|c|}{ Namibia 2013} & \multicolumn{3}{|c|}{ Nepal 2016} & \multicolumn{4}{|c|}{ Nicaragua 2001} \\
\hline & & National & Urban & Rural & National & Urban & Rural & National & Urban & Rural \\
\hline Girl Age & & $\%$ & $\%$ & $\%$ & $\%$ & $\%$ & $\%$ & $\%$ & $\%$ & $\%$ \\
\hline & 6 & 1.3 & 1.1 & 1.4 & 1.0 & 0.9 & 1.2 & 1.4 & 1.3 & 1.6 \\
\hline & 7 & 1.3 & 1.2 & 1.5 & 1.2 & 1.1 & 1.3 & 1.4 & 1.1 & 1.7 \\
\hline & 8 & 1.2 & 1.1 & 1.4 & 1.1 & 1.0 & 1.2 & 1.4 & 1.2 & 1.6 \\
\hline & 9 & 1.2 & 1.0 & 1.3 & 1.1 & 1.0 & 1.1 & 1.5 & 1.4 & 1.5 \\
\hline & 10 & 1.1 & 1.0 & 1.3 & 1.2 & 1.1 & 1.4 & 1.4 & 1.3 & 1.5 \\
\hline & 11 & 1.1 & 0.9 & 1.3 & 1.1 & 1.1 & 1.2 & 1.3 & 1.2 & 1.5 \\
\hline & 12 & 1.1 & 0.8 & 1.3 & 1.3 & 1.2 & 1.4 & 1.4 & 1.4 & 1.4 \\
\hline & 13 & 1.2 & 0.9 & 1.4 & 1.3 & 1.2 & 1.5 & 1.3 & 1.2 & 1.4 \\
\hline & 14 & 1.4 & 1.1 & 1.7 & 1.1 & 1.0 & 1.2 & 1.3 & 1.4 & 1.3 \\
\hline & 15 & 0.9 & 0.8 & 1.1 & 1.1 & 1.0 & 1.2 & 1.2 & 1.3 & 1.1 \\
\hline & 16 & 1.0 & 0.9 & 1.1 & 1.2 & 1.2 & 1.2 & 1.2 & 1.3 & 1.2 \\
\hline & 17 & 0.9 & 0.9 & 1.0 & 1.1 & 1.2 & 1.0 & 1.2 & 1.4 & 1.1 \\
\hline & 18 & 1.1 & 1.2 & 1.0 & 1.1 & 1.2 & 1.0 & 1.2 & 1.3 & 1.2 \\
\hline & 19 & 1.2 & 1.3 & 1.0 & 1.1 & 1.2 & 1.0 & 1.2 & 1.2 & 1.1 \\
\hline
\end{tabular}

N Total

Population

(weighted)

$41,612 \quad 18,680 \quad 22,932$

$49,064 \quad 30,365 \quad 18,699$

$60,327 \quad 34,239 \quad 26,088$

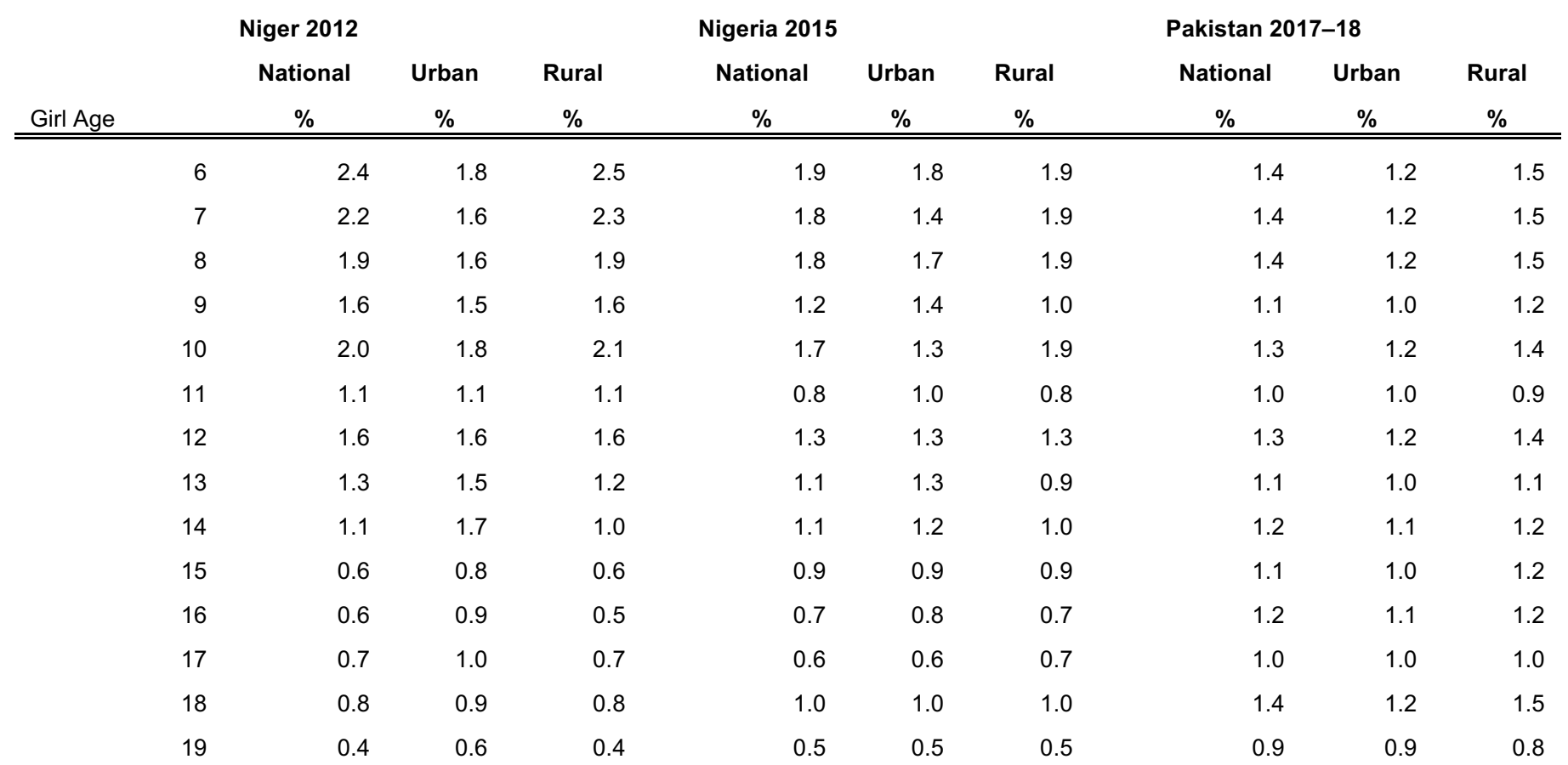

N Total

Population

(weighted) 


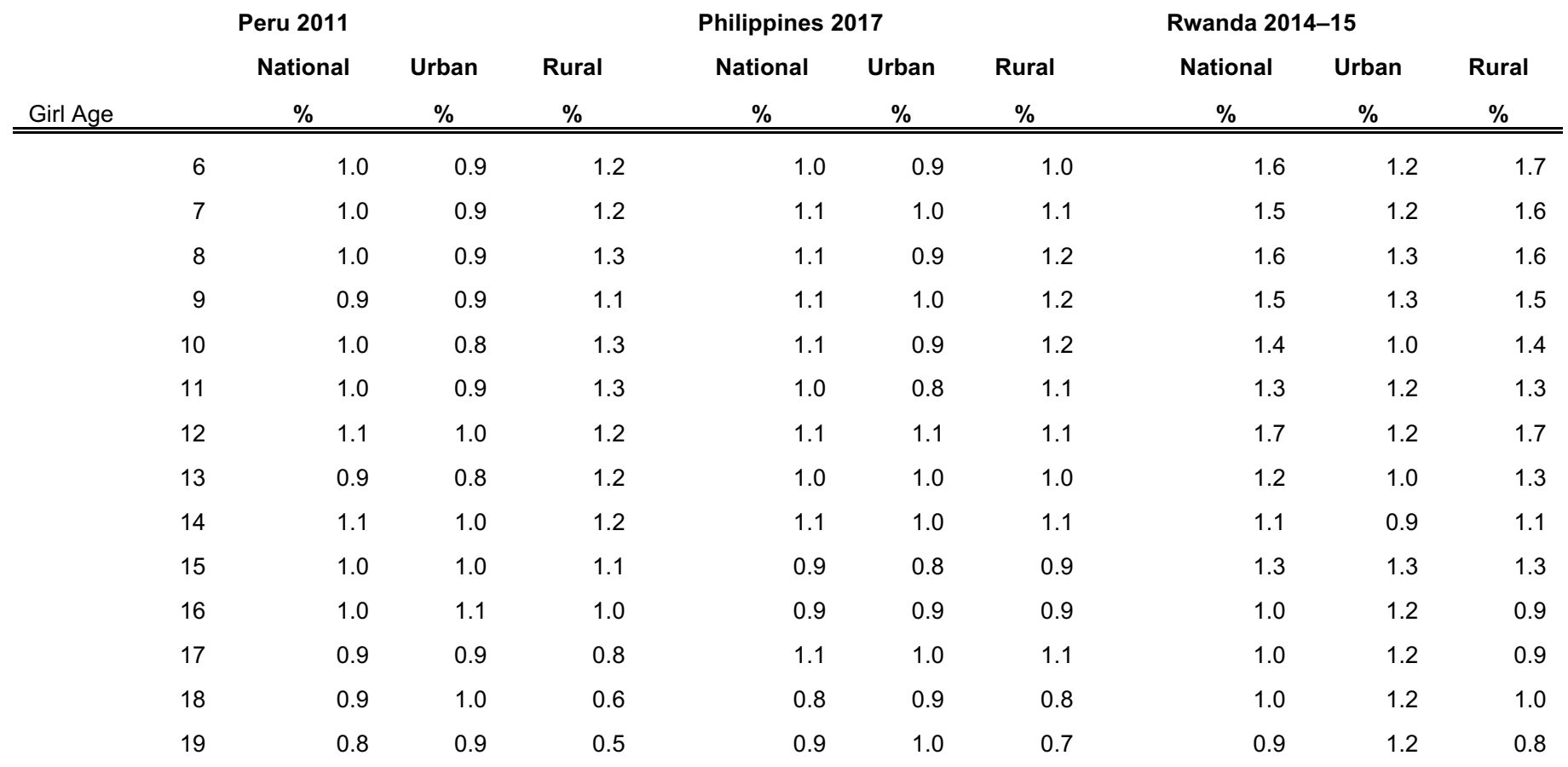

N Total

Population

(weighted)

$98,661 \quad 58,183 \quad 40,478$

$120,230 \quad 38,576 \quad 81,654$

$54,901 \quad 12,254 \quad 42,648$

\begin{tabular}{|c|c|c|c|c|c|c|c|c|c|}
\hline \multicolumn{4}{|c|}{ Senegal 2017} & \multicolumn{3}{|c|}{ Sierra Leone 2013} & \multicolumn{3}{|c|}{ South Africa 2016} \\
\hline Girl Age & $\begin{array}{c}\text { National } \\
\% \\
\end{array}$ & $\begin{array}{c}\text { Urban } \\
\% \\
\end{array}$ & $\begin{array}{c}\text { Rural } \\
\% \\
\end{array}$ & $\begin{array}{c}\text { National } \\
\% \\
\end{array}$ & $\begin{array}{c}\text { Urban } \\
\% \\
\end{array}$ & $\begin{array}{c}\text { Rural } \\
\% \\
\end{array}$ & $\begin{array}{c}\text { National } \\
\% \\
\end{array}$ & $\begin{array}{c}\text { Urban } \\
\% \\
\end{array}$ & $\begin{array}{c}\text { Rural } \\
\% \\
\end{array}$ \\
\hline 6 & 1.8 & 1.5 & 2.0 & 1.6 & 1.2 & 1.8 & 1.1 & 1.0 & 1.2 \\
\hline 7 & 1.6 & 1.3 & 1.9 & 1.7 & 1.4 & 1.8 & 0.9 & 0.8 & 1.1 \\
\hline 8 & 1.5 & 1.2 & 1.8 & 1.8 & 1.6 & 1.8 & 1.0 & 0.7 & 1.4 \\
\hline 9 & 1.4 & 1.4 & 1.4 & 1.3 & 1.3 & 1.3 & 1.0 & 0.9 & 1.2 \\
\hline 10 & 1.6 & 1.3 & 1.8 & 1.7 & 1.7 & 1.7 & 0.9 & 0.8 & 1.2 \\
\hline 11 & 1.4 & 1.3 & 1.4 & 0.8 & 0.9 & 0.8 & 1.0 & 0.8 & 1.2 \\
\hline 12 & 1.2 & 1.0 & 1.4 & 1.4 & 1.7 & 1.3 & 1.0 & 0.9 & 1.1 \\
\hline 13 & 1.4 & 1.1 & 1.7 & 1.2 & 1.4 & 1.1 & 0.9 & 0.8 & 1.2 \\
\hline 14 & 1.2 & 1.2 & 1.2 & 0.8 & 1.0 & 0.8 & 0.9 & 0.9 & 0.9 \\
\hline 15 & 1.0 & 1.0 & 1.0 & 1.4 & 1.6 & 1.2 & 0.8 & 0.8 & 0.8 \\
\hline 16 & 1.1 & 1.1 & 1.1 & 0.9 & 1.2 & 0.8 & 1.0 & 0.8 & 1.2 \\
\hline 17 & 1.0 & 1.0 & 1.0 & 0.9 & 1.2 & 0.7 & 0.9 & 0.9 & 0.9 \\
\hline 18 & 1.3 & 1.3 & 1.4 & 1.2 & 1.6 & 1.1 & 0.9 & 0.9 & 0.9 \\
\hline 19 & 0.9 & 1.0 & 0.8 & 0.9 & 1.2 & 0.7 & 0.9 & 1.0 & 0.9 \\
\hline
\end{tabular}

N Total

Population

(weighted) 


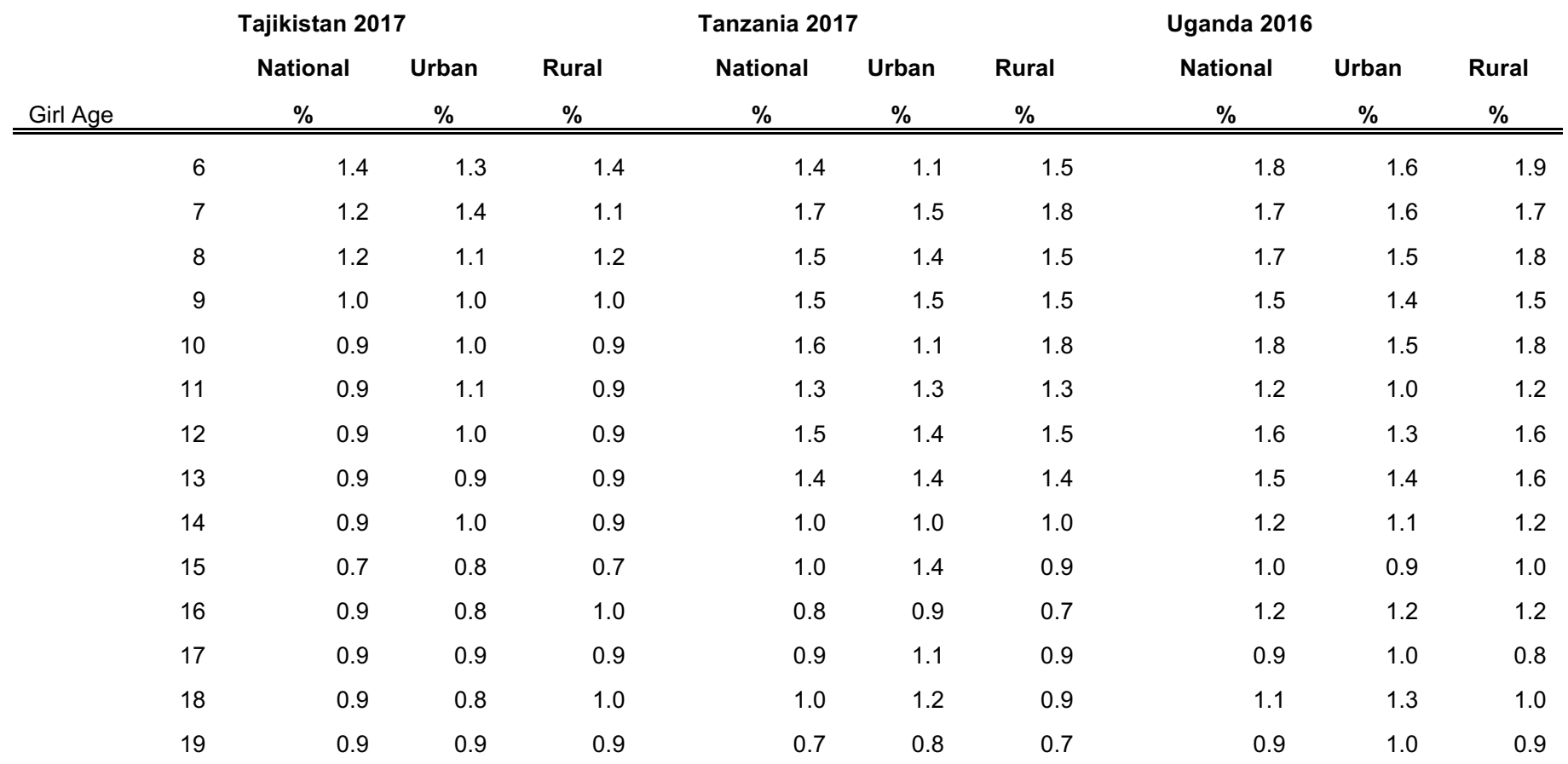

N Total

Population

(weighted)

$44,913 \quad 17,184 \quad 27,729$

$47,644 \quad 11,692 \quad 35,952$

$91,108 \quad 17,929$

73,179

\begin{tabular}{|c|c|c|c|c|c|c|c|c|c|c|}
\hline & \multicolumn{3}{|c|}{ Vietnam 2005} & \multicolumn{3}{|c|}{ Yemen 2013} & \multicolumn{4}{|c|}{ Zambia 2013-14 } \\
\hline Girl Age & & $\begin{array}{c}\text { National } \\
\% \\
\end{array}$ & $\begin{array}{c}\text { Urban } \\
\% \\
\end{array}$ & $\begin{array}{c}\text { Rural } \\
\% \\
\end{array}$ & $\begin{array}{c}\text { National } \\
\% \\
\end{array}$ & $\begin{array}{c}\text { Urban } \\
\% \\
\end{array}$ & $\begin{array}{c}\text { Rural } \\
\% \\
\end{array}$ & $\begin{array}{c}\text { National } \\
\% \\
\end{array}$ & $\begin{array}{c}\text { Urban } \\
\% \\
\end{array}$ & $\begin{array}{c}\text { Rural } \\
\% \\
\end{array}$ \\
\hline & 6 & 0.8 & 0.7 & 0.8 & 1.6 & 1.5 & 1.6 & 1.8 & 1.5 & 2.0 \\
\hline & 7 & 0.8 & 0.7 & 0.8 & 1.5 & 1.2 & 1.7 & 1.8 & 1.6 & 1.9 \\
\hline & 8 & 0.8 & 0.6 & 0.8 & 1.6 & 1.5 & 1.7 & 1.8 & 1.6 & 1.9 \\
\hline & 9 & 0.8 & 0.5 & 0.9 & 1.3 & 1.3 & 1.3 & 1.6 & 1.4 & 1.7 \\
\hline & 10 & 0.9 & 0.6 & 1.0 & 1.6 & 1.3 & 1.6 & 1.7 & 1.5 & 1.8 \\
\hline & 11 & 1.0 & 0.8 & 1.1 & 1.1 & 1.1 & 1.1 & 1.3 & 1.2 & 1.3 \\
\hline & 12 & 1.3 & 1.1 & 1.3 & 1.5 & 1.3 & 1.5 & 1.5 & 1.5 & 1.5 \\
\hline & 13 & 1.3 & 0.8 & 1.4 & 1.5 & 1.4 & 1.5 & 1.8 & 1.7 & 1.9 \\
\hline & 14 & 1.2 & 0.9 & 1.3 & 1.3 & 1.2 & 1.4 & 1.4 & 1.4 & 1.4 \\
\hline & 15 & 1.2 & 1.1 & 1.2 & 1.2 & 1.1 & 1.3 & 1.0 & 1.2 & 0.9 \\
\hline & 16 & 1.1 & 1.0 & 1.1 & 1.1 & 1.1 & 1.2 & 1.0 & 1.1 & 1.0 \\
\hline & 17 & 1.0 & 1.0 & 1.0 & 1.1 & 1.3 & 1.0 & 0.9 & 1.1 & 0.8 \\
\hline & 18 & 1.0 & 1.2 & 1.0 & 1.4 & 1.3 & 1.4 & 1.1 & 1.3 & 0.9 \\
\hline & 19 & 0.9 & 0.9 & 0.9 & 1.0 & 1.1 & 1.0 & 1.0 & 1.2 & 0.8 \\
\hline
\end{tabular}

N Total

Population

(weighted) 


\begin{tabular}{|c|c|c|c|c|}
\hline \multicolumn{5}{|c|}{ Zimbabwe 2015} \\
\hline \multirow[b]{2}{*}{ Girl Age } & & National & Urban & Rural \\
\hline & & $\%$ & $\%$ & $\%$ \\
\hline & 6 & 1.3 & 1.0 & 1.4 \\
\hline & 7 & 1.4 & 1.1 & 1.5 \\
\hline & 8 & 1.3 & 1.1 & 1.4 \\
\hline & 9 & 1.3 & 1.1 & 1.4 \\
\hline & 10 & 1.3 & 1.1 & 1.4 \\
\hline & 11 & 1.2 & 1.1 & 1.3 \\
\hline & 12 & 1.3 & 1.0 & 1.5 \\
\hline & 13 & 1.3 & 0.9 & 1.5 \\
\hline & 14 & 1.3 & 1.2 & 1.4 \\
\hline & 15 & 1.2 & 0.9 & 1.2 \\
\hline & 16 & 1.2 & 1.2 & 1.1 \\
\hline & 17 & 1.0 & 1.0 & 1.0 \\
\hline & 18 & 1.0 & 1.2 & 1.0 \\
\hline & 19 & 0.9 & 1.2 & 0.7 \\
\hline
\end{tabular}

N Total

Population

(weighted)

$43,706 \quad 16,301 \quad 27,405$

